\title{
Towards a theory of innovation in handloom weaving in India
}

Citation for published version (APA):

Mamidipudi, A. (2016). Towards a theory of innovation in handloom weaving in India. [Doctoral Thesis, Maastricht University]. Maastricht University. https://doi.org/10.26481/dis.20160414am

Document status and date:

Published: 01/01/2016

DOI:

10.26481/dis.20160414am

Document Version:

Publisher's PDF, also known as Version of record

\section{Please check the document version of this publication:}

- A submitted manuscript is the version of the article upon submission and before peer-review. There can be important differences between the submitted version and the official published version of record.

People interested in the research are advised to contact the author for the final version of the publication, or visit the DOI to the publisher's website.

- The final author version and the galley proof are versions of the publication after peer review.

- The final published version features the final layout of the paper including the volume, issue and page numbers.

Link to publication

\footnotetext{
General rights rights.

- You may freely distribute the URL identifying the publication in the public portal. please follow below link for the End User Agreement:

www.umlib.nl/taverne-license

Take down policy

If you believe that this document breaches copyright please contact us at:

repository@maastrichtuniversity.nl

providing details and we will investigate your claim.
}

Copyright and moral rights for the publications made accessible in the public portal are retained by the authors and/or other copyright owners and it is a condition of accessing publications that users recognise and abide by the legal requirements associated with these

- Users may download and print one copy of any publication from the public portal for the purpose of private study or research.

- You may not further distribute the material or use it for any profit-making activity or commercial gain

If the publication is distributed under the terms of Article $25 \mathrm{fa}$ of the Dutch Copyright Act, indicated by the "Taverne" license above, 


\section{TOWARDS A THEORY OF INNOVATION IN HANDLOOM WEAVING IN INDIA}

ANNAPURNA MAMIDIPUDI 
(c) 2016, Annapurna Mamidipudi, Maastricht, the Netherlands All rights reserved.

M amidipudi, A nnapurna

Towards a theory of innovation for handloom weaving in India

ISBN

Design \& Layout : A rth M edia Solutions

Cover : Natural Dye colored fabric woven at $M$ alkha, Jamdani fabric woven by K rishna Rao

Printed at $\quad:$ Kalajyoti Printers, Hyderabad, India

Production of this thesis has been supported by:

The Faculty of A rts and Social Sciences, M aastricht U niversity The Graduate School of Science Technology and M odern Culture (WTMC) 


\title{
TOWARDS A THEORY OF INNOVATION IN HANDLOOM WEAVING IN INDIA
}

\author{
DisSERTATION \\ to obtain the degree of Doctor at Maastricht University, \\ on the authority of the Rector Magnificus Prof. Dr. L.L.G. Soete \\ in accordance with the decision of the Board of Deans, \\ to be defended in public on Thursday, 14th April, 2016 at 12:00 hrs.
}

ANNAPURNA MAMIDIPUDI 
Supervisor

Prof Dr. ir. W.E. Bijker

Co-supervisor

Prof Dr. Louk Delarive Box

Assessment Committee

Prof. Dr. Sally Wyatt (Chair)

Dr. Anique Hommels

Prof. Dr. ir. Harro van Lente

Prof. Dr. Shiv Viswanathan

J indal Global University, New Delhi, India 
FOR MY GRANDMOTHERS

Alladi Annapurnamma, Alladi Rajyalakshmi and Vedula Satyavati 



\section{TABLE OF CONTENTS}

1 INTRODUCTION

$\begin{array}{lll}1.1 & \text { Relevance of craft in contemporary society } & 01\end{array}$

$\begin{array}{lll}1.2 & \text { Vulnerability in livelihoods of handloom weavers } & 04\end{array}$

1.3 Conceptual building blocks: Handloom as sustainable and innovative socio-technology 06

2 BRIEF REVIEW OF LITERATURE AND DESCRIPTION OF THE HANDLOOM STE

2.1 Handloom Weaving in India: Mapping Stories, Scholars, and Sources 13

2.2 STS and Its Heuristics: Reflexivity, Symmetry, and Interaction 20

2.3 Handloom as Socio-technology: Elevating Technique or Diminishing Artisanry? 24

2.4 Both Cultural Tradition and Technological History: The SCOT gharaana 28

2.5 Describing the Sociotechnical Ensemble of Handloom 31

3 LIVELIHOOD TRAJ ECTORIESIN HANDLOOM

3.1. Supporting handloom livelihoods: A complex framework 40

3.2. Interpretative flexibility of handloom's unsustainability 46

3.2.1. Business groups: Consumers, retailers and textile industry actors 47

3.2.2. Public sector groups: Policy planners, state institutions and weaver co-operatives $\quad 52$

3.2.3 Civil society groups: Cultural conservation groups, activists groups, and NGOs 56

3.2.4 Producer groups: Weavers, allied workers and master weavers $\quad 60$

$\begin{array}{lll}3.3 & \text { Conceptualizing vulnerability in handloom weaver livelihoods } & 68\end{array}$

3.3.1 Emergent nature of vulnerability in weaver livelihoods $\quad 69$

3.3.2 Multiplicity of vulnerabilities in the handloom sociotechnical ensemble $\quad 72$

$\begin{array}{lll}\text { 3.3.3 The argumentative approach as generative } & 74\end{array}$

3.3.4 Anaganagaa oka nethagadu: Once upon a time, a weaver... 80

$\begin{array}{ll}3.4 & \text { Sustainability: Somewhere between suicide and success }\end{array}$

4 FROM INTERVENTION TO MEDIATION: DESIGNING FOR SOCIAL CHANGE 87

4.1. Curtain Raiser $\quad 88$

4.2. Design Intervention in Craft livelihoods $\quad 89$

4.3. Narratives of Designers $\quad 91$

4.4. From Design Methodology to Cultures of Design 94

4.5. Conceptualizing Intervention, Interaction, and Mediation 96

4.5.1. Design as intervention $\quad 97$

4.5.2. Design as Interaction: Combining technical, material and aesthetic expertise in
the craft ensemble

4.5.3. Methodological intermezzo: The work of the designer from a
constructivist viewpoint

4.5.4. Design as mediation $\quad 101$

$\begin{array}{ll}\text { 4.5.5. Kala [artistry] and design } & 102\end{array}$

4.6. Designing for Social Change 105

$\begin{array}{lr}\text { 4.7. Conclusion } & 107\end{array}$ 
5.1 A routine case of technology transfer: Reactive dyes 112

5.1.1. Technological frame and sociotechnical change in handloom $\quad 114$

$\begin{array}{ll}\text { 5.1.2. Social groups and their technological frames } & 115\end{array}$

5.1.3. Stabilization of the artefact reactive dye in the respective technological frames 117

5.1.4. The stabilization of reactive dye technology in the handloom technological frame 123

5.2. Catalyzing Sociotechnical Change: Role of Interactional Experts 126

5.3. Recipe for Reinventing Technology: The Natural Dyes Monologue 128

5.3.1. Recipe 1: Naga Red Rubia Sikkimensis $\quad 129$

5.3.2. Recipe 2: Katha; Acasia Catechu 132

5.3.3. Recipe 3: Danima, Punica Granatum 134

5.3.4. Recipe 4: Chevalikudi, Rubia tinctoria 137

5.3.5. Recipe 5: Kasimi, Continuous fermentation vat 138

5.4. Stabilizing sociotechnical change: Vocabularies, recipes, and standards 139

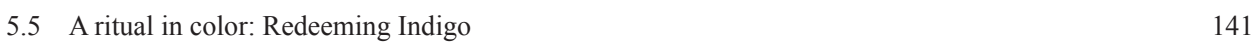

$\begin{array}{lll}\text { 5.5.1 Indigo past } & 143\end{array}$

$\begin{array}{lll}5.5 .2 & \text { Indigo present } & 144\end{array}$

$\begin{array}{lll}5.5 .3 & \text { Indigo lost } & 145\end{array}$

$\begin{array}{lll}5.5 .4 & \text { Indigo relearned } & 145\end{array}$

$\begin{array}{ll}\text { 5.5.5 Indigo visioned } & 146\end{array}$

$\begin{array}{lll}\text { 5.5.6 Indigo tales } & 147\end{array}$

$\begin{array}{lll}\text { 5.5.7 Standardizing Indigo } & 148\end{array}$

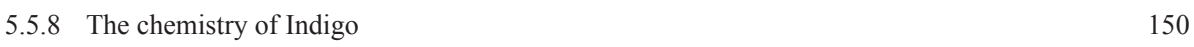

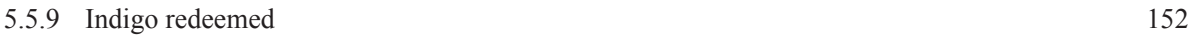

5.6 Mobilizing Knowledge Through Time: Memory Practices in the Handloom STE 152

5.7 Intermezzo in Scale: Compatibility Standards in the Heterogeneous Ensemble 154

$\begin{array}{llr}5.8 \text { Conclusion } & 156\end{array}$

6 CULTURES OF INNOVATION IN HANDLOOM: THE CASE OF J AMDANI 161

6.1 Interlude: Flashback to $1995 \quad 162$

6.2 Flash Forward: The 2013 Crisis 164

6.3 Framing a J amdani s Solution to Yarn Price Rise: Innovation, Not Revival 167

6.4 J amdani as Product Innovation: Combining Skills within the Kinship Network 174

6.5 Jamdani as Market Innovation: Aunties, Ladies, and Mobile phones 178

6.6 Jamdani as Process Innovation in the Sociotechnical Ensemble: The Digital Loom 181

6.7 Cultures of Innovation in Handloom: The Need for Continuity in Cultural
Production and Market

6.7.1 Innovation that permits change to maintain tradition: Valuing continuity 190

6.7.2 Transgressing the dilemma between regressive and progressive: Innovating tradition $\quad 191$

6.7.3 Transcending the gap between tradition and modernity: Effacing innovation 193

6.8 A Constructivist View of Handloom Innovation: Tacit in Expertise and Tacit by Design 195 
7 TOWARDSA THEORY OF INNOVATION FOR HANDLOOM WEAVING IN INDIA

7.1 Practicing sustainability in the handloom ensemble: Yama-Niyama

7.2 Towards a Theory of Innovation: Saadhana-M anodharma

7.2.1 Acquisition of expertise: M eruguparachadam

7.2.2 M apping creativity in innovation: M anodharma

7.2.3 Innovating tradition in handloom weaving: A tradition of innovation

7.2.4 Theorizing handloom as innovative socio-technology: What do weavers gain?

7.3 Creating an ethos of sustainable development: Satyam Sivam Sundaram

7.3.1 Combining knowledge, equity and beauty

7.3.2 Crafting sustainable development: Living within our means

$\begin{array}{ll}\text { APPENDICES } & 219\end{array}$

Glossary

List of figures

List of tables

List of interviews 



\section{1 | INTRODUCTION}

\subsection{RELEVANCE OF CRAFT IN CONTEMPORARY SOCIETY}

For the $4.33^{1}$ million craftspeople who make a livelihood out of handloom weaving in India, around half of whom live below the poverty line, the difference between hope and despair lies in the affirming of the relevance of craft in contemporary society. Crafts, or handicrafts, as the Development Commissioner of Handicrafts, Government of India, refers to them, are "both objects of utility and objects of decoration" and are defined as "items made by hand, often with the use of simple tools and are generally artistic and/or traditional in nature." 2 The definition differentiates handicraftstraditional crafts that provide livelihoods for poor artisans - from hobby crafts that are the leisurely pursuit of the better-off. The number of people engaged in traditional crafts for sustaining their livelihoods changes depending on which definition of handicraft one uses, but may be as high as 31 million (Viswanathan 2013). Handloom weavers and textile workers, who are the focus of this thesis, constitute one of the largest groups amongst Indian craftspeople.

It is generally accepted that the decreasing number of weavers in succeeding government censuses is evidence of unsustainability of

1 http://handlooms.nic.in/W ritereaddata/H andloom\%20report.pdf last retrieved on $15^{\text {th }}$ J une 2015

$2 \mathrm{http}: / /$ handlooms.nic.in last retrieved on $15^{\text {th }}$ J une 2015 handloom livelihoods, ${ }^{3}$ raising questions about its relevance in the future. Why do weavers leave weaving? How can their handmade products stand up to competition from mechanized production? How can an old technology of production be considered relevant in a modern, industrialized world? Tradition is thought to be unchanging and modernity constantly innovating-with tradition inevitably giving way to modernity. How can traditional handloom craft be relevant, when it does not innovate?

A dvocates of handloom weaving maintain that these questions themselves bear examination, particularly in the light of the hand-operated loom's persistence in the face of all predictions of its imminent death. Traditional craftspeople are labelled as not being innovative as they face challenges in understanding the contradictions between the old and the "viable, new" markets (Liebl and R oy 2004, 5373), yet handloom weaving could not have survived for over two millennia if weavers did not innovate. Handloom weavers all over India have evidenced, and I shall give several examples in this thesis, that under enabling circumstances, their work is sustainable. They are resilient through bad times and persist to good

3 http://businesstoday.intoday.in/story/w eavers-seeking-othersources-of-livelihood/1/13225.html last retrieved J une $10^{\text {th }} 2015$ 
times. Handloom products have proven themselves consistently in changing markets, most recently selling successfully in urban retail chains that use handloom weavers' customization and flexibility as strengths.

It is true, one of the challenges handloom products face in the domestic market is competition from lower-priced products made using mechanized technologies. However, as handloom and weaver activists show, the problem is not just that products from the mechanized power loom sector are priced lower, but also that they are illegal imitations of the handloom products. ${ }^{4}$ The power loom sector, which consists of decentralized, mechanized weaving factories, buys yarn from mills and out sources the processing of the fabric they produce into finished textiles (Roy 1998a). Since the mechanized textile industry is driven by the imperative to keep prices low, conditions of labor are frequently worse in the power loom sector than in handloom weaving, indicated by the increased number of power loom operator suicides. ${ }^{5}$

Rather than going along with the assumption that mechanization made for better lives for those engaged in craft production and better value for customers, thinker and pioneer of the craft sector Laila Tyabji has, over three decades of non-governmental organization (NGO) work, disproved the idea of craft as "ornamental irrelevance," instead characterizing it as "a paradigm for development." In the words of Uzra Bilgrami (Uzramma), visionary and handloom activist, "behind the cloudy present, the past reminds us of the possibility of another future." ${ }^{, 7}$ Uramma offers handloom weaving and the community-based social organization that it supports as an equitable and sustainable solution for the energy-stressed future.

4 http://www.newindianexpress.com/cities/hyderabad/TragedyLooms/2015/04/15/article2764311.ece last retrieved August 12015

5 http://www.newindianexpress.com/cities/hyderabad/Power loom-weavers'-suicides-give-officials-the-jitters/2013/08/11/ article1729094.ece last retrieved June 30th 2015

6 http://www.craftrevival.org/voiceDetails.asp?Code=178.Last retrieved on $5^{\text {th }}$ April 2013.

7 http://www.lilafoundation.in/2014/10/21/uzramma-cotton-clothcontinuity/
Such leaders inspired development workers through the 80 s and 90 s to work to alleviate poverty in craft livelihoods by intervening in markets and state policy. ${ }^{8}$ They built credible business models that were carefully balanced between ameliorating vulnerability and pursuing sustainability, and this propelled a generation of craftspeople out of poverty. ${ }^{9}$ Yet, despite the unquestionable success of these efforts, the association of handloom and craft livelihoods with unsustainability endures. No sooner is the word handloom uttered, as a senior handloom activist succinctly said, than people bring out the violins and start playing funereal tunes in anticipation of its demise. I have argued elsewhere that this is inevitably linked to the narratives of technological progress, modernization, and development that characterizes handloom as unproductive, pre-modern, and unsustainable manual labor (Mamidipudi, Syamasundari, and Bijker 2012). These narratives have themselves been systematically debunked within various disciplines by credible and committed scholarship (Pfaffenberger 1992). However, they continue to influence discourses around traditional crafts and hold power in Indian policymaking.

As an alternative to the modernization narrative, in this thesis, I offer an analysis of handloom weaving as sustainable and innovative socio-technology rather than pre-modern, unproductive, manual labor. I argue that describing the situated nature of craft knowledge (in this case handloom weaving) as traditional, embodied practices of marginalized communities at the periphery of development-in opposition to universal science and technology that is the prerogative of developed societies - is unproductive for both craft and science. Illuminating the sociotechnical nature of handloom weaving is not to valorize craft as valid scientific knowledge, it is an attempt to be symmetric in the study of craft by using the concepts that scholarship in science, technology and society studies (STS) have

\footnotetext{
I was one such development worker, from 1991-2010, working with Uzra Bilgrami in the NGO Dastkar Andhra.

9 Dastkar and Dastkar Andhra, amongst others, also worked with such business models.
} 
developed to unpack science and technology. In order to do so, I analyze the hand-operated loom as part of a sociotechnical ensemble: handloom is a collection of heterogeneous elements of technologies (Charkhas [spinning wheels], looms, warping drums and computers), practices (designing, sizing, and computer programming), formal institutions (cooperatives, civil society organizations [CSOs], NGOs, and government institutions), informal institutions (households, extended families, village communities, and castes) and social groups (weavers, dyers, designers, and customers) that together constitute a sociotechnical ensemble (Bijker 1995). Henceforth in this thesis I shall refer to this ensemble as the handloom sociotechnical ensemble (STE).

The rich repertoires of weaving skills that Indian weavers possess; their sensibilities regarding ethics and consumer aesthetics of handloom production and products; the expertise of village handloom cooperatives in collaboration and their historical engagement of servicing weaver members; the understanding of scaling processes in a dispersed industry as enacted by policy makers; the capability of activists to understand both policy and implementation in high-risk livelihoods; and the general importance of clothes in ritual; in this thesis all these are looked at as elements of handloom knowledge that the handloom STE carries. I propose that it is from this societal base of knowledge that new trajectories for handloom do and will emerge, as old alliances fade and new ones respond to emerging opportunities and threats. This thesis is about what people-weavers, customers, policy makers, activists, and academics, to name a few-tacitly know about handloom craft, based on what they say, do and stand for. It seeks to explain the paradox that a labor-intensive traditional craft like handloom has survived after two centuries of mechanization and government-induced industrialization in the market-economy of India. Thus, in explicating this knowledge, the key question that I will answer in the rest of this thesis is, "What is the relevance of craft in contemporary society?"

I trace trajectories of handloom weavers from vulnerability to sustainability. Starting from the acute vulnerability of the isolated suicidal weaver that ends in pessimism and despair, I narrate stories of hope of those weavers who have proven to be sustainable. Tracing trajectories that form a continuum from unsustainability to sustainability makes it possible to broaden our understanding of what constitutes success and failure in framing sustainable outcomes - for craftspeople, for STEs, for development paradigms and for technological cultures. The handloom STE as a unit to be analyzed is one in which we can study how different actors facilitate, contest, and selectively frame handloom as livelihood, as design, as technology and as culture. As an analytical concept, I propose the handloom STE as an integrative move - one that is inclusive of the multiplicity in the handloom ensemble and that includes the vulnerable handloom weaver yet doesn't isolate him or her in unsustainability.

Panini, the $4^{\text {th }}$ century grammarian ${ }^{10}$ of Gandhaara, now in Pakistan, is known particularly for his formulation of the 3,959 rules of Sanskrit grammar that make up the Astadhyaayi, or the "eight chapters". While it is generally understood that Panini knew writing as a form of ordering knowledge, the text of Astadhyayi does not make for ease of reading. Rather, it is conjectured that Panini had a group of students who each memorized a complex section of interlinked rules and ideas. These students served as a living database from which the rules could be retrieved and transmitted to others at will. In seven and half of the eight chapters, Panini detailed out his understanding of the principles of grammar, referring to his detractors only in one half-chapter at the end (or beginning, depending on where one starts). Taking a page from the form of his book, this thesis is made up of seven chapters of interlinked analyses and ideas, where each chapter can be independently retrieved for use and read at will. My endeavor here is to reinterpret the very idea of handloom, through a study that treats handloom as a sociotechnical ensemble with different kinds of expertise and a knowledge system. This, I hope, will produce ways of understanding the relevance of handloom craft that will in turn render valuable the lives and livelihoods of its vulnerable practitioners.

10 I will bring back the example of grammar again in the concluding section of the thesis to explain the vocabulary of skill 


\subsection{VULNERABILITY IN LIVELIHOODS OF HANDLOOM WEAVERS}

Journalist Asha Krishnakumar ${ }^{11}$ details the poignant stories in handloom weaving when weaver suicides had reached a peak in 2001 in post-liberalized India. She outlines a series of policy decisions as well as ground realities of handloom weaving by documenting the emergence of the competition from the power loom sector; the dumping of cheap products by China and Thailand which led to a distressing loss of income for Indian weavers; inadequate alternative work; mounting debt; family distress; and, finally, a decision to end life. This well-informed discussion about the causal factors that lead a tiny minority of affected individuals to choose death (Mayer 2010), points effectively to the vulnerability of the vast majority that did not choose death but whose livelihoods and lives were equally precarious. Suicide becomes a form of resistance, a last recourse to hold an uncaring society accountable to the injustice that its victims experience. In the case of farming, the other major rural livelihood in India, the numbers are much worse. Suicide amongst cotton farmers in the neighboring state of Maharashtra, who provide a large part of the inputs for handloom weavers is referred to as "history's largest socio-economic tragedy," 12 and has reached epic proportions today. On average, at least ten farmers killed themselves every day for the last ten years. In Maharashtra, the number has exceeded 60,000; nationwide, 300,000. In a bid to wake up policy makers and mobilize civil society, journalist Sainath crunches these mind-numbing numbers. ${ }^{13}$ Here, too, are the stories of the issues of debt, hyper-commercialization, exploding input costs, water-use patterns, severe price shocks and price volatility - all factors driven by state policies.

11 http://www.frontline.in/static/html/fl1808/18080050.htmlast retrieved $27^{\text {th }}$ june 2015

12 http://www.lilafoundation.in/2014/10/21/uzramma-cotton-clothcontinuity/

13 http://psainath.org/maharashtra-crosses-60000-farm-suicides/last retrieved $27^{\text {th }}$ June 2015
What caused some weavers to give up, and others to carry on? What could be learned from more resilient weavers about how this acute vulnerability can be ameliorated? What assurances could be made to those who felt their lives to be meaningless, sunk deep in the fallacy that the only thing left was to give up, in the hope that this final act would move society to action? Pragmatic naysayers dismissed the suicides as senseless acts of frustrated individuals; activists took the questions the suicides raised as a wake-up call for the sector, and lobbied all the more for political change. CSOs that dissented with dominant paradigms of development were spurred to work for the provision of alternatives. Their efforts towards dealing with vulnerability of practitioners of traditional knowledge systems provided evidence that the multiplicity in knowledge systems as well as presence of dissenting imaginations could provision innovative alternatives on the ground (Prasad 2014, Quartz 2014). The interventions of these activists resulted in the acute vulnerability of livelihoods being transformed to sustainability for a generation of weavers. Such stories of hope lay the foundation for narratives of resilience in handloom livelihoods.

Where such enabling circumstances do not exist, weavers are forced out of weaving by financial conditions that do not give them or their children the opportunity for upward mobility, and they end up as footloose migrant laborers (Breman 1996). If they do stay back in weaving, handloom weavers become vulnerable not just financially but also socially in contemporary society. Lack of acceptance in a modern world compels those who stay in their caste occupation (kulavritti) ${ }^{14}$ to accept the social identity of being backward, of practicing a traditional and static profession that

14 I will explain the purpose of giving vernacular words in section 1.3. 
persists due to the poverty of its practitioners, of being caste-bound, with no promising futures. Weavers experience this particular vulnerability acutely; in ways that others in the handloom ensemble who are not born into weaving castes do not share.

Yet the conundrum of being socially vulnerable whether leaving or staying in one's caste occupation plays out in the lives of weaver youth. Drought (karuvu) portends financial hard times in the handloom industry, and weaver households become financially vulnerable, and young weavers migrate to the city in search of livelihoods. There they face the workforce individuation typical of modern occupations and fragmentation of family lives of urban contexts. Yet, since these are socially accepted realities of contemporary society, in contrast, the close-knit weaver households that practice hereditary caste occupations become further boxed into a social identity of being backward. Youth from weaver households respond by migrating out of their hereditary occupations, while striving to retain kinship networks that afford some security in an anonymous urban landscape.

When the vulnerable weaver is isolated and cannot break out of his or her own narrative of hopelessness, he or she is most at risk. An important step in understanding vulnerability, then, is to accept the reality of the suicidal weaver, the migrant weaver and the successful weaver and accept him or her equally as part of the sociotechnical ensemble where civil society actors, activists, markets and state are more powerful actors. Thus we enlarge the focus from the vulnerable personal story of the weaver in the village, beyond the micro-focus on the techniques and products of craftspeople, to the sociotechnical ensemble of handloom weaving and the knowledge it carries in order to reflect on science in our society and the conscience in our (social) science.

The handloom ensemble can be perceived to have a distinctive technological culture-its own knowledge-craft, politics, and values that govern continuity and technological change. Visvanathan (Visvanathan 2006) argues for recognizing different peoples' fundamental right to maintain their own belief systems encompassing different kinds of knowledge - from scientific to religious, and from technical to social-as a matter of "cognitive justice." Feminist philosopher, Sandra Harding, argues that such plurality makes for more robust knowledge systems by making them strongly objective (Harding 1998). In the sociotechnical analysis of handloom weaving, what connects the different groups in society to a weaver is not just empathy during a crisis, or a voluntary social obligation to a vulnerable population, but the sociotechnical relations of being part of a common (technological) culture that cognitively sustains a plurality of knowledge systems.

This analysis allows us to go beyond the development "gap" between weavers and the rest of society, between craft and universal science; to the interactive ensemble of social groups, technologies, institutions, and knowledge practices that constitute handloom technological culture. It becomes in turn possible for handloom craft to understand its relevance to contemporary society and science and to claim its place as having one of the longest traditions of innovation in technological history. Sustainability is then the outcome of a responsibly innovating technological culture, rather than unsustainability being inherent to the vulnerable weaver or the loom. This is my main argument, towards which each succeeding chapter lays a building block. 


\subsection{CONCEPTUAL BUILDING BLOCKS: HANDLOOM AS SUSTAINABLE AND INNOVATIVE SOCIO-TECHNOLOGY}

In style, this book is first and foremost an academic treatise, which demands some succinctness and leanness of argument. But it is more; it also attempts to immerse readers who are not familiar with handloom weaving communities into that culture. This requires more ethnographic detail and even storytelling. The stories in this thesis focus on particular aspects that I would like to highlight in making my academic argument. For example, I write stories of technological change that focus on reducing weaver vulnerability and increasing sustainability at a community level.

Each chapter then presents a metaphorical combination of abstract theory and storytelling (nritta [pure dance] and abhinaya [expressive storytelling]) that can be compared in form to a particular dance composition in the Bharatanatyam style of classical dance. In anticipation of the Indian art theme that I will elaborate on later, for those familiar with the Margam - the established "way" of ordering repertory in a dance performance- $-\mathrm{I}$ introduce the chapters of this thesis in a similar order. Here I give first the name of the composition in dance, followed by the name of the chapter: Alarippu-Introduction, Mallari-Brief Literature Review, J athiswaram-Livelihood Trajectories in Handloom Weaving, Shabdam-Designing for Social change, Varnam-Handloom as Adaptive Socio-Technology, Padam-Cultures of Innovation in Handloom, and Tillana-Conclusion.

Methodologically, this dissertation stands on two separate streams of qualitative empirical material. I have used my field notes and annual reports from the period of 1991-2008, when I was an NGO worker and trustee in Dastkar Andhra, a CSO which works to support livelihoods of handloom weavers in Andhra Pradesh in South India. Secondly, as participant-observer in Dastkar Andhra between 2010 and 2013, I attended public meetings and expert seminars that the organization conducted where I was able to make audio recordings and take notes. Although it was not always possible to identify the speakers by name, I have specified their affiliations- particularly in large public meetings. I also conducted individual interviews with weavers in the villages of Andhra Pradesh and Telangana.

A challenge in my research as I switched my location from being an actor working in the handloom field into an STS analyst is the issue of language and translation in a multilingual world. All the interviews with weavers, dyers, and cooperative members in Andhra Pradesh and Telangana were in Telugu, their and my native language. Some interviews crossed two languages: English along with either Telugu, Hindi or even partly Tamil, in the case of non-Telugu respondents. These are all languages that I am fluent in. All the interviews were directly translated into English as I transcribed them. Where I have quoted the words in Telugu, I have indicated the meaning in English that I have attributed to it. ${ }^{15}$ The thesis is peppered with bilingual interjections coming from the language practices of the population that I study and that I am part of. While purists may find the switching between languages disconcerting, it serves two purposes. The first one is that in general English translations of the weavers' languages do not completely capture the essence of what is being communicated. In this particular case, the English equivalent of Telugu terms has been workshopped with the weavers and dyers themselves to best express the meaning of what they wanted to say. The second reason has to do with readership. When

15 In order to guard against errors, the translations I ascribe to particular terms in the manuscript have been cross-checked with other native speakers and, in the case of Sanskrit, a scholar. I have had help from Alladi Venkatesh and M. R. Vikram for Telugu, Sushruti Santanam for Tamil, and Sumithra Vasudev for Sanskrit. 
read together, these combined, multilingual words become a vocabulary that is especially useful to communicate contested concepts such as innovation and tradition across bilingual readerships from the handloom world: policy makers, practitioners, and scholars.

I interject a methodological reflection at this point that is relevant for a large part of my research. Trying to identify an engaged position with respect to laboring craftspeople is potentially difficult for a researcher, however observant she may be. Standpoint methodology (Harding and Norberg 2005) argues that dominant groups are especially poorly equipped to identify oppressive features of their own beliefs and practices. Being well-intentioned is not enough. Not being sensitive to the lack of democratic social relations between the vulnerable weaver and the knowledge-seeking researcher can result in theory that distorts the lived reality of others. Additionally, a relevant question asked of outsiders who have no lived experience of a phenomenon is whether they have the right to theorize it at all (Sarukkai 2007).

For example, the social concern of "untouchability" historically oppressed whole groups of people by assigning a status of being "impure" by birth, which inevitably resulted in an inescapable low-caste identity for them as well as their progeny. This concern has been better addressed in literature and poetry than in social sciences. This is attributed to the notion that "untouchability, as a dynamic reality tends to produce experience" (Guru 2009, 49). The notion of experience in untouchability is equally valid with respect to the experience of livelihood vulnerability. While handloom weavers in my area of study do not themselves squarely belong to the untouchable castes, what is relevant here is their experience of vulnerability and their anger about the systematic devaluation of their kulavritti, or hereditary caste occupation. When this experience is invoked, caste solidifies into a boundary of what constitutes the vulnerable inside of being a handloom weaver - and researchers such as myself are squarely outside it.
In this thesis, I will be referring to other boundaries which actors in the handloom ensemble maintain - those between different technological cultures (Section 5.1), between theory and practice (Section 5.3), between science and art (6.7), between modernity and tradition (6.7), and between mind and body (7.2.4). Yet I will attempt to relate these domains to each other in order to encompass a comprehensive perspective of handloom craft. While not reducing handloom to a trade nor a technology, I contextualize change in terms of cultural preferences as well as in terms of changing socio-economic and labor conditions. I therefore follow a trans-disciplinary methodology that borrows from art history, cultural anthropology, cultural studies, sociology of science, and social studies of technology. The main heuristic I use is to focus on multiplicity in trajectories of livelihoods, in associated discourses of technological adaptation, in aesthetics, and in related market conditions. I then attempt to find concepts that can relate these multiplicities to each other, in order to understand how these multiple realities, discourses, and trajectories interact. For example, in my analysis the concept of cognitive justice is a relational dynamic between the multiple domains of knowledge that I have detailed. I endeavor to build a set of concepts that are generative rather than divisive in their analysis of multiplicity.

A final disclaimer before leaving this introduction: The research and the work it builds on pertain to a distinct craft community in a specific time and in a particular geography. It concerns the Devangula, Padmasali, Pattusali, and Netagani castes engaged in handloom weaving in the districts of East Godavari and Vijayanagaram and Adilabad in the states of Andhra Pradesh and Telangana in South India in the last three decades. Even within this specific focus, my analysis of framing handloom as sociotechnology will only briefly touch on complex issues of identity, labor, caste, social organization, and gender that effect lives of handloom weavers; each deserves much more study than I have attempted to do here. 


\begin{tabular}{|c|l|l|l|}
\hline No & \multicolumn{1}{|c|}{ Chapter Title } & \multicolumn{1}{|c|}{ Technological Concept } & Proposed Socio-Technical Concept \\
\hline 1 & Introduction & & \\
\hline 2 & Review of Literature & & \\
\hline 3 & Livelihood Trajectories in Handloom Weaving & Unsustainability & Vulnerability \\
\hline 4 & Designing for Social Change & Intervention & Mediation \\
\hline 5 & Handloom as Adaptive Socio-Technology & Technology transfer & Interactional expertise \\
\hline 6 & Cultures of Innovation in Handloom & \begin{tabular}{l} 
Innovation \\
- Practicing sustainability in the handloom STE \\
\hline 7
\end{tabular} & $\begin{array}{l}\text { Conclusion } \\
\text { - Theory of innovation for handloom weaving }\end{array}$ \\
\hline
\end{tabular}

Table 1.1: List of chapters with their proposed socio-technical concept

In the four empirical chapters of the thesis (Chapters 3,4,5, and 6), I address vulnerability in livelihoods, social change agents, sociotechnical change, and innovation in handloom weaving. Setting aside the assumption that handloom weavers are averse to change because they continue to engage the hand-operated loom, in these four empirical chapters I seek to understand the relevance of craft knowledge. Instead of assuming that handloom weaving must be unsustainable because the children of some successful weavers become doctors, engineers, and teachers instead of choosing to take up their hereditary caste occupation of weaving, I reframe the assumption. Thus in the first empirical chapter, instead, I ask, "Under what conditions do livelihoods of handloom weavers who chose to stay in weaving become unsustainable and how can they become sustainable?" The questions I frame for the following three empirical chapters are, how do craftspeople and designers work together for social change? How does handloom-weaving technology succeed in persisting in the changing world? Where has craft survived and even thrived in the market, and how has it done so? I also make a conceptual shift in each of these chapters, from Unsustainability to Vulnerability, from Intervention to Mediation, from Technology transfer to Interactional expertise and from Innovation to Creativity [Table 1.1]. The aim of this conceptual shift is to embed the project of the social analysis of handloom technology to the particular contexts of traditional Indian craftspeople and their vocabulary for technological change ${ }^{16}$, using STS scholarship. In doing so, we are able to foreground the social in the analysis of technology - from technological concept to a sociotechnical concept.

Before I start with the empirical Chapters $3,4,5$ and 6 , in chapter 2, I offer a brief review of literature and a description of the sociotechnical ensemble of handloom weaving. Scholarship about handloom weaving pursues three different approaches: first, it creates counter narratives to the master narrative of handloom's inevitable demise as a mode of production, second, it creates narratives of loss-descriptions of the losses that handloom communities bear as a result of these master narrative frames of viewing and (re) presenting handloomand last, it interrogates policy understandings that ride on these deterministic frames. I structure this literature into narratives of what Breman calls "aborted transformations" (Breman 2009) transformations to industrialization, to development, and to modernity.

A kind of engagement with scholarship that is particular to the civil society of India is activist-

16 The omission of the reference to this table in the originally submitted draft of the thesis is now rectified, thanks to Sally Wyatt. 
scholarship that examines choices in technology in the past in order to intervene and change the future. ${ }^{17}$ Activist-scholarship engages with academic accounts and actively creates counter narratives in order to effect social change through the adage of the road not taken. It is an approach that looks confidently at the idea that reality could have been otherwise, in order to make a difference through intervention. Particularly in the field of craft and handloom, activists and experts who are from science and technology backgrounds as well as academics from diverse disciplines (social anthropology, sociology, history of technology, economic history, heterodox economics, development studies, gender studies, culture studies, subaltern studies, postcolonial studies, and so on), have borrowed from each other in the service of advocacy for vulnerable populations.

In choosing a constructivist STS approach to study handloom weaving, I foreground the heuristics of reflexivity, symmetry, and interaction to engage the empirical, which I will show to overlap with the methods of development practice. I trace STS scholarship on knowledge-building practices that do not operate on the assumption that the mind is intelligent, that the body is an instrument of labor, and that labor and intelligence are mutually exclusive. I will also introduce the social construction of technology [SCOT] concepts that I will use in this thesis.

Chapter 3 is the first empirical chapter, in which I describe the different trajectories in handloom livelihoods as discourses of different groups in the handloom STE and demonstrate the interpretative flexibility of unsustainability in livelihoods. Here I answer the question, "Under what conditions do livelihoods of handloom weavers become unsustainable, and when can they become sustainable?" I propose the notion of vulnerability for understanding both sustainability and unsustainability in handloom livelihoods.

\footnotetext{
17 For example, see the Malkha Project http://malkha.in/about-malkha/.
}

Employing this lens, rather than starting with the assumption of unsustainability, vulnerability is treated as a condition of openness that has the potential to lead to positive change and sustainability. I look at the generative aspect of argumentation and dissent that characterizes debates around handloom vulnerability and argue that rather than leading to dissonance, these differences have found overlap in their discourses of handloom vulnerability, leading to collective action. These different actions in turn lead to possible options for weavers to chose trajectories for better outcomes. I relate discourse analysis and collective action in order to explain how coherence is built in an argumentative culture, asserting argumentation can be generative rather than divisive.

Chapter 4 discusses designer interventions in supporting craft livelihoods. From a linear technological progress point of view, the nine million people engaged in traditional craft livelihoods in India are underdeveloped and static. Within cultural identity projects those same craftspeople and traditions are transformed into a heritage that needs to be preserved without change. Is there an escape from these discourses of poverty or museumization when thinking about weavers? This chapter investigates how design can be the key to growth and a paradigm for development, using the market for craft and handloom. I propose that designers intending to mitigate vulnerability in livelihoods of craftspeople have to look beyond the economic into social and cultural outcomes of design interventions. The purpose of this chapter is to broaden understanding of design interventions in craft livelihoods through empirical examination of designer narratives. This chapter extends the STS concept of "cultures of technology" to "cultures of design" in order to understand complex relationships around skills, tools, materials, markets, identities, aesthetics, and rituals in contemporary craft and handloom networks. 
In dialogue with 20 independent design practitioners and development organizations working with craft livelihoods through individual interviews, group meetings, and presentations, I explore the work of a designer as intervention in an economic frame, as interaction in a social frame, and as mediation in a cultural frame. Chapter 4 explicates the multiple ways of knowing and doing design in the sociotechnical networks of craft and handloom weavers and in doing so it seeks to understand how designers can bring about social change in vulnerable craft livelihoods. This social change is brought about not by turning craft into standardized production that can compete with mechanized production, but by trying to understand craft's role in materializing notions of beauty in society into products. These products bring satiety in consumption to the users and at the same time sustain the producer's development. I argue that designers are able to leverage social and cultural aspirations of both the producers and the consumers; designers both connect market segments and maintain barriers between them. Through the concept of Kala, artistry that is a combination of technical, aesthetic, and creative aspects of production that are imagined as the artisan's forte, I discuss how artisans themselves can take up the function of design in craft production. Design I define as a combinatory and entrepreneurial activity that spans aesthetic, economic, social, and cultural functions with the goal of increasing the value of the product.

The question that Chapter 5 seeks to address is this: "How does handloom weaving technology succeed in persisting in the changing world, even as the loom itself looks unchanging?" In order to answer this question, I relate three stories of technological change in the handloom ensemble, using the case of dyeing. The handloom ensemble coexists with the mechanized power loom and the mill ensembles of technologies. Change in demand may require the handloom ensemble to acquire new technologies that meet new market standards. In the first story in this chapter, I relate how reactive dyeing, a technology from the mechanized sector, makes its way into the handloom ensemble as handloom weaver cooperatives adopt and adapt the technology for their contexts. In doing so, reactive dyeing itself is adapted as skill rather than as mechanized technology. But in the handloom ensemble, it is not only new and futuristic technologies that are added; in an interesting movement, we see that the ensemble can go back in time and add older forgotten technologies, such as natural dyeing, by recalling and reintroducing them into contemporary practices. This process creates multiple technological variants in the handloom ensemble, which are made operational through meeting compatibility standards that allow them to couple with the other technologies in the ensemble. The only criterion is that the new or old technology has to work in the service of maintaining value for the loom and the deep craft attached to the loom.

The three stories in Chapter 5 are narratives from the work of communities of dyers and NGO workers from 1991-2010, where I, too, was a participant and are recalled through the study of the reports, field notes, and interviews with other actors involved. I use the concepts of technological frame, interactional expertise, and memory practices to elucidate adaptive change, as well as its stabilization, in the handloom STE. This helps to understand how cultures of technology that have persisted while adapting to meet market demands as well as societal aspirations and needs acquire cultural meaning for every new generation of producers and users. This acquisition of cultural meaning adds to our understanding of change and stability, balancing productivity and sustainability.

In Chapter 6, I seek to address two related issues. The first is to deepen the theoretical understanding of innovation by exploring it in supposedly non-innovating traditional contexts. The second is to explore how this improved understanding of innovation in handloom can renovate the socio-cultural and technological 
imagination around the relevance of craft knowledge. I show how innovations are shaped by interactions between individuals across different user groups and communities and identify product, market, and process innovations in handloom. These innovations include the use of mobile phones to explore new markets and the use of computers to speed up calculative functions. These innovations allow weavers to engage in slower and more skilled work while keeping the product cost-effective.

In order to build a vocabulary of innovation in tradition, I borrow the language of the practitioners of South Indian classical music, a traditional genre known for its jazz-likeimprovisation and creativity that is close to the vocabulary of innovating handloom weavers. I follow the innovations of weavers responding to the yarn crisis of 2010 as they recall and re-invent the technique of Jamdani, recasting innovation as tradition, renaming it the traditional Uppada J amdani, a newly invented tradition.
The concluding Chapter 7 has three sections: in the first section, I summarize sustainability in handloom weavers' livelihoods. In the second section, I attempt to explicate a vocabulary for innovation in handloom practice, moving towards a theory of innovation. In a final brief section, I point towards an ethos for sustainable development that we can learn from weavers, as living within one's means, combining knowledge, equity and beauty. Based on weavers' innovative sociotechnical practices, I highlight and foreground craft as an instance of embodied knowledge, which is indispensable to notions of democratic science, robust knowledge-building, and innovation. I conclude by arguing that craft embodies various forms of knowledge (material, historical, and collective) of often-vulnerable communities, providing them forms of resilience against destabilizing paradigms (colonialist expansion, industrialization, and oppressive caste identities) and needs to be understood holistically (including the relation to ethical, spiritual and aesthetic values). 


\section{2 | BRIEF REVIEW OF LITERATURE AND DESCRIPTION OF THE HANDLOOM STE}

This chapter has five distinct sections. The first four sections each review one set of literature relevant for the forthcoming chapters. In the first section of this chapter, I briefly review the present scholarship on handloom weaving and craft in India. In the second section, I describe three key heuristics of STS, which facilitated my shift from actor to analyst and from development practice to STS. In the third section in this chapter, I review literature from History of Technology, Sociology of Knowledge, and STS, in the context of a broader sociotechnical system thinking to situate craft as knowledge. The fourth section of this chapter is a short introduction to key concepts of a sub-disciplinethe social construction of technology [SCOT] approach-wherein I locate my apprenticeship in STS and which forms the theoretical foundation for this thesis. These four sections are structured independent of each other, but together they present a survey of literature that the next chapters are based on. In the final fifth section, I describe handloom as a sociotechnical ensemble.

\subsection{HandlOOM WEAVING IN INDiA: MAPPING StORIES, SCHOlARS, AND SOURCES}

Activist and community worker Bablu Ganguly is the initiator of one of India's most successful food security programs. This program transformed the lives and livelihoods of millions of the poorest farmers of Andhra Pradesh, India. With the support of the "Timbaktu Collective," women and men in drought-prone district of Anantapur shifted back to growing organic millets that used to be their staple diet. The opening words on their blog, "Our recipes are our memories" introduce a promotional film on how to make spicy onion, chilli, and tomato chutney along with information on how to grow them organically. They have to teach people how to cook and eat millets, both unfamiliar to the present generation of consumers. Bablu and his fiery wife Mary were Marxist ideologues. A little perplexed himself at their 25-year-old journey from organizing resistance to the capitalist market and state, to becoming a land owning farmer of organic millets, he tries to explain the detour- "We thought the people's revolution was coming tomorrow! It was just round the corner! Farming and nurturing the land is what we did while we waited." Today the farmers of the Timbaktu Collective offer concrete resistance to the commodification of agricultural land, and offer support to fellow vulnerable farmers in times where these two problems threaten the lives and livelihoods of farmers across India.

There is a similar sense of incompleteness in the great rhetorical stories of Industrialization, Development, and Modernization in independent India-setting out with the conviction that the 
destination was just round the corner, that today has become increasingly distant. Life and livelihoods of craftspeople carry on under the weight of these aborted transformations. Karl Polanyi (Polanyi 1944) refers to the process of industrialization, in tandem with urbanization in Europe and Great Britain in particular, as the great transformation. "Before the process had advanced very far, the laboring people had been crowded together in new places of desolation, the so-called industrial towns of England; the country folk had been dehumanized into slum dwellers; the family was on the road to perdition; and large parts of the country were rapidly disappearing under the slack and scrap heaps vomited forth from the 'satanic mills" (Polanyi 1944, 39). Eventually, in Europe, this catastrophe turned out to be the beginning of economic improvement. In South Asia, on the other hand, from his study of rural-urban transition and the social identity and dynamics of poverty, Jan Breman suggests that the pace of urbanization outstripped expansion in industrial employment, giving rise to a huge reserve army of footloose migrant labor. Rather than functioning as a waiting room for migrants, the informal sector offered them casual work, rotated them around as temporary rather than regular hands, causing them to leave again, only to come back in search of work- "A large number of people who leave the village, do not 'arrive' in the cities" (Breman 2009, 5).

Instead, Breman refers to this process as labor circulation driven by distress rather than voluntary migration out of agrarian work. Like Polanyi, who was scathing in his description of what the selfregulating market meant for the people pushed out of their rural habitat, in Great Britain, Breman does not mince words regarding the deregulation of the Indian economy and its impact on migrant workers in the hands of the state and the influential locals who operate at the interface between informal and formal sector institutions. He reports in 2004 that "About 836 million or 77 per cent of the population had to make do with less than 20 rupees per day, i.e. less than half a dollar per capita. These people are the backbone of India's informal economy and their life in abject poverty was conditioned by the lack of any legal protection of their jobs and the absence of decent standards of employment and social security" (Breman 2009, 23).

A major feature of Breman's analysis is focused on circulation in combination with informalization, which he interprets "as ways to organize economic activity with a high return to capital and an excessively low return to labour" (Breman 2009, 27). Unlike Polanyi, who ended his treatise on a hopeful note when he illustrated the triumph of society over the market, Breman is less hopeful regarding the capacity of Asia's migrant labor to "withstand the onslaught of free market, let alone come together on a common platform" (Breman 2009, 27). Referring to this as the "transformation aborted" (Breman 2009, 26 ), he suggests that society is inadequate to the task of collective action necessary to reverse this pauperization of migrants.

Scholarship about handloom weaving can be ordered around these three important and interlinked aborted transformations: Industrialization and the colonial rulers, Development and its subjects [the craftspeople], and Modernization agendas enshrined in the policies of a nationalist state toward its citizens.

As Britain consolidated her control over the political economy of the Indian subcontinent in the early 19th century, one of the key colonial projects became the centralization and systematization of knowledge by the state (McGowan 2009, 24). Where previously the knowledge had been personal, practical, and local, now in the words of British observer John Forbes Watson in 1872, it took the form of "trigonometrical, topographical, revenue, and geological surveys", with the further plan of including surveys of the industrial, "with productions of country, agricultural, forestall, pastoral and mineral, of manufactures, of the localities of production, of the varieties, qualities and values of the produce, its supply and mode of distribution and consumption" [quoted in (McGowan 2009)]. 
George Birdwood - a medical doctor, the curator of Victoria and Albert [V\&A] museum, and eventually registrar of the University of Bombay - compiled "The Industrial Arts of India" (Birdwood 1880), a comprehensive textual survey of all crafts, in all media, from all parts of the Indian subcontinent as the handbook for the Indian Court at the Paris Universal Exhibition of 1878. As he was then based in London, he called on the officials of the Government of India to conduct systematic and thorough investigations into traditional methods. This demand was met first by the 1880 s series of government gazetteers, as well as craft monographs commissioned in 1893 to 1909.

Each province, for example, prepared a monograph on the same craft in a given year. Along with this effort, craft goods were collected as material for exhibitions through the late 19th century. The Great Exhibition of 1851, in Crystal Palace in London constituted one of the first attempts to systematize knowledge about trading goods as well as design in Indian crafts. These efforts attempted to "render production into the language of science, but by identifying crafts as embodied labor they also marked the fundamental impossibility of such a project" (McGowan 2009). Yet these accounts form an important source of information regarding crafts and producers of the time, thereby, providing a base for contemporary scholarship on crafts.

Contemporary scholars have studied the history of the handloom industry both before and during the industrial revolution, starting from the medieval period to the 17 th-18th centuries; giving detailed accounts of the trading relationships and role of European companies (Ramaswamy 1985b, Hossain 1979, Arasaratnam 1980, Parthasarathi 2001, Subrahmanyam 1990, Subramanian 1998, Brennig 1986). Some have paid particular attention to production of artisanal goods with relation to changing markets and consumption patterns (Yanagisawa 1993, Haynes 1986, Specker 1989, Guha 1989b, Haynes et al. 2010, Tarlo 1996). These studies form the scholarly narrative of how handloom communities and their technologies declined, changed, and developed over this time.
Discussion about artisans in India is dominated by the "de-industrialization" debate under colonialism, and its "revisionist" detractors who counter this narrative from a market perspective. According to scholars of de-industrialization, the rise of the industrial textile industry in Britain brought about a massive decline in handloom weaving in India (Bagchi 1976, Simmons 1985). Rajnarayan Chandavarkar points out that historians influenced by the modernization school and Marxist approaches saw industrialization as a "technologically determined choice beyond the realm of social choice, [...] it was inevitably and inexorably progressive...flowing form the West, it constitutes the only dynamic force acting upon the passive indigenous economy" (Chandavarkar 1985, 30-73). This view positioned artisans as powerless figures who inevitably succumbed to western colonialism. Revisionist Douglas Haynes suggests that the nationalistic perception of the artisan; particularly, the handloom weaver as a powerful symbol of India's fate under colonialism encouraged this framing (Haynes 2012, 217).

Swarnalatha (Potukuchi 2005), Ian Wendt (Wendt 2005b), and Prasannan Parthasarathi (Parthasarathi 2001) examine production relations in the period prior to Industrialisation, during the 17th-18th centuries across India. They suggest that weavers' position vis-à-vis the market was fairly strong during this period, even as the handloom industry underwent substantive commercialization during the same time (Sivasubramonian 2000). David Washbrook (Washbrook 1990), Karuna DW (Miryam 2014, 189), and Parthasarathi (Parthasarathi 2001, 59) counter the imperialist narrative of a benevolent and paternalistic Empire, and argue that for instance laborers were not always impoverished. In 18th century India, laboring "paraiahs" [untouchable castes] were a large part of the handloom industry and possessed secure claims to incomes and were in a strong position in the social and economic order. It has been argued that the competitiveness of textiles in the world market rested equally on the shoulders of 
the agriculturists who grew, harvested, cleaned, prepared, and spun the yarn for the cotton textile industry (Parthasarathi 2001, 105). A loom in the 17 th century required labor by "producers and merchants involved in commercial agriculture, cotton cleaning, spinning, weaving, washing and commerce" (Wendt 2005b, 31) —which I shall now analyze as the sociotechnical ensemble of weaving.

The artisanal tradition survived the initial shock of the onslaught of industrialization in the 19th century, to eventually supply labor and capital to small scale industry causing a resurgence of small scale industry in the late 19th and 20th century (Roy 2000, 17). In the context of this resurgence, poverty in South Asia did not originate with deindustrialization, but with the profound political reordering that accompanied foreign rule (Parthasarathi 2001, 100). This analysis points to the indigenous source for colonialism; the cloth merchants and dominant classes who joined hands with colonial authority to discipline weavers and agrarian producers (Parthasarathi 2001, 118).

Generally, scholars concur that any single unitary account of decline or progress, or singularity in agency, whether of colonial state, or international markets, or weavers themselves, cannot be sustained-the trend varies with geography, temporality, and sector. Historical studies of handloom, thus, pay attention to kings, merchants, weavers caste groups - high and low, mobile transport operators, traders, literate elite, state, markets; to practices such as spinning, cotton production, dyeing, carding, sizing, and trading.

The larger debate regarding craft, within which handloom is subsumed, was dominated by 19th century arts and crafts movement thinkers such as John Ruskin and William Morris. They presented three issues of concern regarding craftsthe vernacular, the decorative arts, and the politics of work (Greenhalgh 1997). There was unease with industrialization in the West, which led to the valorization of the vernacular: village life, work of country craftsmen, and the authenticity of tradition. India became an important site for this movement through the work of George Birdwood, Ananda Coomaraswamy, and E. B. Havell (Venkatesan 2009b), craft activists of the 19th century, in relation to the preservation and protection of Indian artisans from industrialization. The importance of craft in both cultural and economic debates created a particular duality in the discourse around its future. As national culture, it had to be preserved; as part of national economy, it had to be modernized. Attention to crafts, therefore, brought together "markets and tradition, heritage and progress" (McGowan 2009,6).

The orientalist vision was of timeless village craftsmanship, which had to be protected from the evils of modernization by a paternalistic British government. This gave rise to a convergence between British officials and Indian elite in their agreement to put "crafts development at the heart of the state's duty to promote the welfare of its people" that framed artisans as subjects, not agents of this development (McGowan 2009, 7). At the same time, using examples from the late 19th century, Abigail McGowan shows how in these accounts fault for the lack of progress in Indian crafts lay squarely on artisan's shoulders.

"If artisans had been more independent of their castes, they could have embraced new technologies and applied their skills to new occupations. If artisans had been more open to outsider leadership, they could have benefitted from the new knowledge elites were bringing from the west. If artisans had been less lazy and more trustworthy, they could have raised standards of work rather than cutting corners at every opportunity. And finally, if artisans had been properly oriented towards material consumption, they would have expanded and improved production to earn more money for their families. Passive in the face of modern changes, content with the past, secure in the work they had done for generations, timeless and unchanging, Indian artisans appeared as the polar opposite of the striving, competitive, rational, efficient, industrial men of western capital enterprise" (McGowan 2009, 89). 
In her reading craft as being forever counter poised to the perceived opposite, modern industry was a central idea in this vision. Government officials, local and provincial government bodies, missionaries, artisans, reformers, nationalists, and industrialists - all participated in reifying the category of craft in opposition to modern industry. Therefore, the type of modernization that those who sought to protect crafts advocated would at once preserve the best elements of artisanal practices and at the same time adapt those practices also to new contexts. However, while defining weavers as being too tradition-bound to handle change on their own, these social groups legitimized outside intervention for managing this change (McGowan 2009, 203).

Craftspeople who sought to keep knowledge private within kin or caste network, as compared to a European strategy of dense information networks of artisan guilds, were perceived to lack initiative in sharing knowledge. Yet, in an era with no protection for intellectual property rights, this urge to retain a competitive advantage seems a logical response (Roy 1998b). As such the shift of the colonial state in making private knowledge public represented an exercise not just in access but also of power (McGowan 2009, 65); control of knowledge shifted as colonial authors of surveys, gazetteers and monographs put into public hands what had been personal heritage of craft groups.

Lack of formal education was another explanation offered for lack of progress among craftspeople. Alfred Chatterton in 1904 found "the ordinary artisan... unacquainted with principles and is therefore quite unable to explain why one way of doing a thing is better than another" (Chatterton 1904, 37) Yet, an "inspired tinkerer" with no particular education in science and technology could hit upon a good solution to a problem in weaving (McGowan 2009, 170). Artisans launched their own changes in this period by reorganizing production and new technologies (Roy 2007). By the early 1900s, as a result of experiments on new looms, weavers could choose among an indigenous loom working with a fly shuttle sley, the European fly shuttle, the Hattersley, Jesop's Japanese loom manufactured in India, The Sayaji Cottage, the Salvation Army Triumph, and the Serampore and the Ahmednagar loom (Chatterton 1908).

However, craftspeople rarely played an active role in public debates about crafts. They were objects rather than agents of the conversation. They provided the ground on which arguments about development took place (McGowan 2009, 20). Abigail McGowan suggests that emphasizing the difference and not similarity between traditional crafts and modern industry was an interpretative choice and made in spite of much evidence to the contrary. Craft became a site of active negotiation about what the future of the Indian economy should be, and how modernization should be pursued (McGowan 2009, $69)$. By the $1880 \mathrm{~s}$, public leaders increasingly ignored the possibility of an easy transition from crafts to modern industry highlighting instead the essential difference of crafts from western style factory production. For those who valued the western style, this contrast had negative connotations. On the other hand, craft idealists sought to protect craft and society from change. Therefore, upheavals of a society in transition cemented rather than erased the difference between crafts and modern industry (McGowan 2009, 73).

Most specifically, we can see the difference played out in the fact that none of these initiatives tried to help the artisans make the transition into mechanized industry, even when that might have represented the most viable economic path (McGowan 2009, 201). McGowan relates the politicization of crafts to the struggles of Indian elites and British officials to establish authority over the lower classes as well as the newly emerging state itself. At the same time, artisanal leadership and authority was replaced with that of outsiders who "claimed public authority over Indian crafts [that were then deemed to be] in the hands of uneducated, conservative lower class artisans" (McGowan 2009, 203). It did so in part because of the absence of artisans from such conversations. While the state 
was to provide support for artisans that relief was to be temporary. As early as 1905 , the demise of craft was being foretold: the key was to ease the transition from one state to the other [replace craftwork with modern machinery, factories, and companies]. Acknowledging the needs of artisans who were unprepared for modern factories while slowly paving the way for the ultimate obsolescence of their way of life, H.J. Tozer, a speaker at the 1905 industrial conference, stressed a thought that "the process of decay should be gradual"18 (McGowan 2009, 186). Therefore, it would be the benevolent state that had to save artisans from the depredations of global capitalism. Yet, these efforts were themselves divided in a manner akin to the division of the idea of crafts in this period.

Crafts, which the British used to demonstrate the backwardness of India, had come to be the heart of the nationalist movement. At the point, there was an intense competition to catch up with the industrial achievements of the West, Indian nationalists thoroughly espoused the ideal of crafts - the very opposite of modern industry. In the words of Saloni Mathur, "The actual physical body of the craftsman-ruined, disfigured and enslaved by colonialism-became a powerful metaphor [..] for the state of the national body itself" (Mathur 2007, 46). Viewing the practice of craft or creativity as spiritual revelation embodied in oral and religious texts, Ananda Coomaraswamy (Coomaraswamy 1909), Kramrisch (Kramrisch 1994), and Yanagi Soetsu (Soetsu 1972) attempted to provide a basis for unity of culture as national heritage, ${ }^{19}$ and thereby, creating a conceptual opposition to the Occident-constructing the scholarly discourse about the traditional craftsman (Kawlra 2001).

The creation of artisans as objects of development emerges from the debates on the place of tradition in modernity, which is articulated

18 Quoted in Report of the first Industrial Conference held at Banaras in 1905.

19 For discussion on links between India and Japanese understanding of "tradition" in craft see (Kawlra 2001) as a place of friction (Venkatesan 2009a, 6, Tsing 2005). Michael Herzfeld too focuses on the relationship between the universal and particular in craft knowledge to create a global hierarchy of value, so that "diversity can become a homogenous product. So too can tradition and heritage: the particular itself is universalized" (Herzfeld 2004, 2). Gandhi stressed the moral value of crafts-by virtue of its thread being spun by hand - as a part of national service; handspun cloth represented a larger cultural alternative of distinctively Indian national development, compared with the modern, industrial West. Thus, craft initiatives continued to structure their response to vulnerability in craft livelihoods around the idea of crafts' difference. Design concerns became development agendas, rejecting mechanization and insisting on individual autonomy within the limits of larger co-operative structures, and attempting to circumvent the market (McGowan 2009).

Development discourses in the second half of the 20th century around crafts continued to construct the craftsperson as the object, rather than agent of development. A society at odds with the world it lived in - of industries, alienated labors, and lifestyles that left no time for the simple joys of making - sought to resolve this disquiet by consuming objects made by "traditional craft producers" (Venkatesan 2009a, 7). In this process, development and its projects became a way to protect and create value for the craft objects - an organizing paradigm that generated "competition and strategizing" for craftspeople (Venkatesan 2009a, 17).

The state agenda of developing craftspeople has historical roots within nationalistic framings of traditional handloom as cultural identity. There were no clear state policies to develop handloom weaving in the pre-independence period. The second world war shortage of yarn created a crisis in the handloom industry, and a fact finding committee for Mills and Handloom was set up in 1942 (GOI 1942), which found changes in tariff policy, shift in consumer taste, competition from 
mill sector and power loom sector, and the strong dependency relationship between weavers and middlemen as the causal factors for this crisis. The All India Handloom Board was set up to support weavers with raw material supply and marketing. LC Jain, a member of the planning commission on multiple occasions assisted the promoter of the Indian Co-operative Union, Kamaladevi Chattopadhyay, and was secretary to the All India Handicrafts Development Board. In his review of handloom policy in the Economic and Political Weekly, he echoes the sentiment of handloom activists "It is time for the policy maker to lift his little finger in their [craftspeople's] favor. We have a heritage to keep" (Jain 1986).

Co-operativization of weavers was emphasized in the Five-year Plans postindependence, along with control of power loom growth by the Textile Commissioner. These were key thrusts of the 1948 Cotton textile control order passed by the Government of India. This prevented mills from producing varieties of cloth that had been traditionally the domain of handlooms, as well as some items reserved for small power loom units (Eapen 1984, 583). In 1949, excise duty was imposed on mill products. In 1953, additional excise was levied on mill made cloth and the amount was used for growth of handlooms, through the Khadi and Other Handloom Industries Act, and introduction of the handloom rebate scheme.

The Kanungo Committee set up in 1952 was of the view that handloom had no future, and recommended a progressive conversion of handlooms to power looms over a period of 15 to 20 years (GOI 1954, para 75, 81). In contrast, the Karve committee of 1955 [on Village and Small scale Industries, Second Five year Plan] (GOI 1955, 89) recommended freezing not just the mill but also the power loom output at existing levels. The Textile policy of 1956 extended working capital for co-operatives through the RBI scheme for handloom finance in 1952, and a guaranteed cover to co-operative banks for non-recovery of loans to handloom weavers' societies in 1956.
Subsequently, the Ashok Mehta Committee in 1964 (GOI 1964, 164-172) swung back on these resolutions questioning handloom's long term viability and suggested that power looms be given support. This resulted in the official recognition and expansion of power looms in India. By 1974, as the Sivaraman committee of Handlooms pointed out, the handloom industry had taken a further beating from the expansion of power looms (GOI 1974, Srinivasulu 1996, 3202). In 1978, the new Janata government announced a textile policy that would freeze power loom and mill capacity to those of handloom and Khadi, yet this could not be implemented successfully. The 1981 policy reduced this limit, and also emphasized the need for modernization of handlooms. The National Handloom Development Corporation was set up for procuring and supplying yarn at reasonable prices, and the infrastructure of the Indian Institute of Handloom technologies and Weavers' Service Centres were strengthened.

The New Textile policy of 1985 was the most comprehensive one to date and made a critical shift in emphasis from employment potential to enhancing productivity (GOI 1985, 4). It also split the textile sector in terms of processes: spinning, weaving, and processing, rather than the sectors of Mill, Power loom, Handloom, and Khadi. In 1990, the Abid Hussain Committee reviewed the policy and suggested splitting weavers into three tiers based on skill and earning, and an added focus on improving weavers' earnings (GOI 1990). LC Jain's denouncement of what he saw as the "liquidation of the handloom industry" (Jain 1985) was caustic. In view of the unprecedented suicides in weavers, the Mira Seth committee was set up in the 1990s to examine the impact of the policy, ending up with recommendations for an export-oriented strategy for the survival of handloom. This was criticized for its short-sightedness regarding demand in the local markets (Srinivasulu 1997).

The Satyam commission, set up in 1999 , recommended that the lowest tier of weavers be converted to power loom, a removal of the handloom 
reservation act, and a switch of 50 percent of the handloom weavers into export production, amongst other perceived anti-handloom recommendations. There was a huge furor against this report from handloom activists. Considering that less than 1.3 percent of looms currently produced for export, the suggestion was seen as being impractical (Mukund and Sundari 2001, 36). Handloom constituted not only luxury items but also wage goods, for which there were different kinds of national and local markets (Chandrasekhar 2001). The planning commission commissioned an independent report on the Growth and Prospects of Handloom, under the aegis of handloom scholars Seemanthini Niranjana and Soumya Vinayan. They produced a substantive review of handloom policies and their effects on handloom weavers (Niranjana and Vinayan 2001). This report recommended that apart from support for credit, inputs, and marketing, development of implementation strategies for policies that protected handloom is necessary. Patent protection as a way of protecting handloom designs was suggested for the very first time in this report.

In 2006, the Development Commissioner of Handloom introduced the Integrated Handloom Cluster Development Scheme (IHCDP), generally addressed as the Cluster scheme, as a policy to develop handloom using an approach that was based on geographic areas and focused on the market. In spite of wide criticism from handloom activists, this scheme gained further importance in the succeeding five-year plan of 2012. The polarized battle between those who perceived handloom as unproductive in the Western neo-liberalist capitalist paradigm, and those who perceive its value in non-monetary ideas of cultural preservation and tradition has continued even in the recent move to change the definition of handloom to include mechanized processes. This was extensively denounced using media-both print and social media-by handloom activists. As a result, the Ministry of Textiles withdrew the suggestion in 2014.

A particular characteristic of scholarship on handloom and crafts in the last two decades in India has been the collaboration between erudite activists, activist scholars and interventionist NGOs. One example is the collaboration between Uzra Bilgrami and C. Shambu Prasad on the history of cotton in India that simultaneously formed the basis of technological research into new forms of spinning as the Malkha Project, as well as scholarly work (Prasad 1999). Activists and scholars across India contributed to a special issue on marketing of handlooms (Niranjana et al. 2006). Another significant collaboration on development practice was between Radhika Gajjala, Seemanthini Niranjana, and B. Shyamasundari across academia and NGO locations (Gajjala 2013). In all of these contexts, this genre of scholarship seeks to interrogate policy understandings that are embedded in a deterministic frame of modernization-to hold the state as well as society accountable for the consequences of its past actions and of its neglect.

\subsection{STS AND ITS HeURISTICS: ReFLEXIVITY, SyMmETRY, AND INTERACTION}

My shift from intervening in vulnerable livelihoods as a development practitioner to a researcher within the discipline of Science Technology and Society Studies [STS] was facilitated by methodological overlaps in the domains of acting and analyzing. At the core of this overlap is the premise that "realities could have been different"-in this case, it seems, following Bablu Ganguly's journey, development practice suggests that we must recognize that "realities are different." STS scholarship, specifically the social constructivist approach, too approaches its object of study on the premise of investigating how people construct their realities. In order to recognize and understand how these new realities portend new destinations, and study the trajectories that lead to them, STS scholarship offers us the heuristics of reflexivity, symmetry, and interaction. 


\section{Reflexivity}

Reflexivity in research requires awareness on the part of the researcher of his or her own effect on the process and outcomes of research, as it is based on the premise that "knowledge cannot be separated from the knower" (Steedman 1991). David Bloor argues, "In principle [Sociology of Scientific Knowledge's [SSK]] patterns of explanation would have to be applicable to sociology itself," with respect to reflexivity in academic practice (Bloor 1976, 7). Within the hierarchy of positivist understandings of the researcher and practitioner, the development practitioner supplies the researcher with problems for study and receives research results whose utility she tests. This hierarchic notion is overturned with the introduction of reflexivity in practice, whether the practitioner is a social worker or an STS scholar. When someone reflects in action, he becomes a researcher in the context of practice (Schön 1983). Reflexivity allows STS scholars to deconstruct biases in understanding technological change such as debunking a technological determinist ideology (Bijker 1993) the assumption that technological development proceeds via an autonomous internal logic and that it determines social organization of a society. In the practice of urban NGO workers intervening in traditional handloom weaving production, reflexivity allows them to problematize their own identity, as coming in from the outside, to provide solutions to livelihood problems as if the context of the specific problem can somehow be ignored (Hajer 1995, 40).

Below is an excerpt from field notes of Uzra Bilgrami, founder of the NGO Dastkar Andhra, about her early travels to visit handloom weavers, and the reflexivity the role of the social worker demanded in intervening in the lives of others.

"In 1990, a small group of us began visiting producer communities in these villages. As we walk from village to village the travellers we pass ask us "Which caste? [kulam] ${ }^{20}$ ?"

20 Kulam: local word for "caste" and we would reply, for want of a better selfdescription: "wanderers" [tirrigin orlu]. We are a new jati ${ }^{21}$ here, outsiders, interventionists, would-be community workers. There have been and continue to be the outsiders who come to exploit, the contractors and businessmen: recently cotton farmers who have exhausted their own lands in coastal Andhra are now exploiting the near-virgin soil of the recently cleared forest lands. However, the outsider tradition to which I refer is that of the itinerant community worker, a tradition that in some ways, though not all, derives from the part played by the sanyasi ${ }^{22} .{ }^{23}$

Unidirectional development is a form of institutionalized global governmentality rather than an exchange of economic and cultural ideas and creates the notion of being underdeveloped as "a form of identity" for the receiver (Gupta 1995, 11). My dual identity, as an STS researcher immersed in the empirical (my analyst self) and a community worker negotiating with the lived reality of my engagement with weavers (my actor self), resists the idea that technological change brought from the outside is by definition progress. Technological change can only be transferred through translations of social, cultural situations, and contexts across individuals and collectives (Nauta 2006). Rather than privileging the outside, individuals engaged with development practice as well as with research have to instead acquire the capacity to reflexively approach the field with the sensibility of meeting the "other," the insider.

Symmetry

Scholars of SSK are adjured to be impartial to whether a knowledge claim is true or false (Bloor 1976). Within Social Construction of Technology [SCOT], scholars are impartial to whether a technology is a success or a failure (Pinch and Bijker 1984). Scholars from the Actor

\footnotetext{
21 Jati: local word for category, or "sub-caste"

22 Sanyasi: ascetic

23 Field notes Uzramma, field worker Dastkar Andhra 1993
} 
Network Theory are impartial to whether actors or human or non-human (Latour 1988). All three are instances of interpreting the symmetry principle.

An international funding agency from the North asked a community worker from a Southern NGO to enumerate how many of the beneficiaries, whose livelihoods they supported, were Dalits ${ }^{24}$. Seemanthini Niranjana and B. Syamasundari, core team members of the NGO were alarmed by this request, as it would be an asymmetrically intimate intrusion into the private worlds of weavers who were in a market relationship of dependence with the NGO. For the field worker and progressive Telugu intellectual Ravindra who was lower down in the social hierarchy of the caste system than the [Padmasaali] weaver, asking for this information would displace his own position with respect to the weaver. The response below led to the NGO refusal to meet the request for enumeration, at the risk of losing funding.

"I cannot honorably ask a weaver for his or her caste, without revealing my own; where as a production field worker of an NGO, I can enter their homes, once I reveal my caste, the social norms of the village will ensure the opposite, and my own livelihood will be at stake ${ }^{25}$."

Symmetry has been a key concept in STS methodology: for example between the social and technical, between narratives of success and failure, between western scientific and southern indigenous expertise, between producers and users or consumers, even between people and things. This symmetry is by design utopian, particularly in situations of power inequality (Russell 1986). Its utility is in navigating a path away from polarized narratives that may inadvertently reify current

24 "Dalit" refers to one's caste rather than class; it applies to members of those menial castes which have borne the stigma of "untouchability" because of the extreme "impurity and pollution" connected with their traditional occupations. It is the term that they adopt as a name for themselves over harijans, schedule castes, and untouchables.http:// www.ncdhr.org.in/dalits-untouchability/

25 Personal conversation between Ravindra and Annapurna, Dastkar Andhra 2004 categories and their tacit power structures. At its most effective, it offers a way to bring together categories without taking away difference.

For both the development worker and the researcher, symmetry helps to reduce the distance of knowledge production between "desk and field" (Lewis and Mosse 2006). It is a beacon that signals them away from the sharp rocks of hubris; toward the humility that is required for joint framings of problems in situations where one may have more agency than the other, or where one is in a dissenting position with regard to the other. Scholars writing about South-South cooperation from the South, for example, come up with different commitments and stances toward these inequalities. This results in building capacity for symmetric engagement between North-South in knowledge production (Cesarino 2012, 533). It could be argued similarly, facilitating symmetric negotiation of standards between powerful marketing agencies and vulnerable producers can itself be an important political commitment [Chapter 5].

One way of thinking about strategic political action that bypasses dichotomies of inside/outside, policy analysis/class struggle, and developmentalism/revolution is to draw an initial distinction between entitlement and empowerment (Gupta 1995, 394). Entitlement is the discourse of development; empowerment allows people the possibility of political action and freedom. Both are needed, whether we are to explore in a Gandhian sense "the democratic potential of technological options" (Ninan 2009, 190), or we pursue the ideal of development as freedom. NGO actors explicate through their practices that the term "capacity building" underdetermines what craftspeople know. STS scholars explicate the same about the concept, and offer the concept of "expertise" (Wynne 1989, Collins and Evans 2007) as a way of understanding the continuum from indigenous knowledge to universal science. The aim in both locations is to achieve "the freedom to envision both problems and solutions in local ways without the imposition 
of categories used in the sciences or technologies [and policies] of the North" (Cozzens et al. 2008, 790). We move then from a paradigm of capacity building to one of capability: "the substantive freedoms that include elementary capabilities" (Sen $1999,3)$ to avoid deprivations such as starvation, morbidity, as well as freedoms associated with being literate, numerate, knowledgeable, and so on. In an understanding of a symmetric engagement between the field worker and the weaver producer, the benefits of capacity building are not presumed to be unidirectional. The field worker can be open about his own vulnerability, for example in the case of the field worker who is of a lower caste, even as he works toward the sustainability of the vulnerable weaver livelihoods; the weaver is not a disempowered beneficiary of charity, but a citizen of a democratic state with the freedom to make substantive choices that include epistemic ones.

\section{Interaction}

The underlying assumption of technology in social constructivist studies of technology is relativistic (Bijker 2010) and thus relational. This methodological relativism predicates that units of analysis - artefacts, technological systems, sociotechnical ensembles, and technological cultures - are always studied in relation to each other. Interaction moves us from coexistence to coproduction; it requires socialization between groups. I take the concept of interaction from the work of Collins and Evans in describing interactional expertise - expertise acquired through socialization into the practices of an expert group (Collins and Evans 2007, 35). The principles of reflexivity and symmetry allow us, for example, to see that different social groups have their own interpretations of what technology works best and why. Through the interaction of such actors and their positions, meanings converge to coproduce society and technology (Jasanoff 2004), facts and values (Ravetz 1999). In order to understand how technological cultures develop, it becomes critical to understand interaction.
The successful introduction in the 1980s and 1990s of neo-liberal and growth theories into development practice brought a new avatarthat of the techno-manager (Srinivas 2008) into a sector that was predominantly driven by volunteers. Financial sustainability measured by parameters such as increase in wage of producers, return on capital investments, increase in scale of operations, and efficiencies of intervening organizations, became the norm. The resulting financial stability in the livelihoods of handloom weavers as they accessed new markets seemed to validate the success of the NGO interventions, yet it brought a new puzzle. Merely showing that weaving was economically viable was not enough to create value for handloom technologies. Even as middle class India turned toward consumerism, with disposable double incomes and a social conscience, weavers educated their children into modern professions, as a way out of their caste-based traditional identity (Mamidipudi, Syamasundari, and Bijker 2012). When the economic bubble burst, by 2010, the weaving industry lost three million jobs. ${ }^{26}$ Some weavers became migrant laborers. At the same time, as in the case of J amdani weaving [Chapter 6], resilient weavers innovated upon and incorporated new information and communication technologies (ICT) in their work to interact with consumers in emerging markets. In all these cases, weavers did not act alone, but interacted with others in the handloom STE, with both positive as well as negative outcomes to livelihoods.

When we recognize interaction as a site of study, we move from isolating the loom as unit of analysis to the Handloom STE, a complex interactive system that includes various technologies, social groups, institutions, and the interactions of their technological cultures. In this understanding of the handloom ensemble,

26 http://www.scribd.com/doc/214684301/Handloom-Census-Reportin-India\#scribd,

http://planningcommission.gov.in/aboutus/committee/strgrp12/ str_handloom0305.pdf,

http://planningcommission.gov.in/reports/genrep/drft_ cosulpapr_1410.pdf 
the development worker, the academic, the weaver, and the consumer are all implicated in the framing of handloom weaving [in terms of the sustainability, development, vulnerability, and so on]. The development worker and the NGO are no more "outside" but present and interacting with others such as the dyer, warper, designer, weaver, and consumer in the financial value chain, and in the social and cultural fabric of the handloom ensemble. In such an arrangement, no single person creates the product, nor is one actor al one financially unsustainable or underdeveloped. Equally, the techno-manager operating on economies of scale is not any more in control; different actors, institutions, and social groups interact to innovate production and consumption ensembles that optimize the scale for survival in conditions of vulnerability. This allows us to go beyond coexistence of traditional handloom knowledge in the periphery of the mechanized and modern center, to cognitive justice (Visvanathan 2006) for craft knowledge that allows handloom weavers to make legitimate knowledge claims.

\subsection{HANDLOOM AS SOCIO-TECHNOLOGY: DIMINISHING ARTISANRY?}

The purpose of this section is to review some of the STS and history of technology concepts used in deconstructing standard views of science and technology. In studying handloom as socio-technology, I make it clear that I am using an analytical tool to open the black box of craft. It is not to elevate bare technique to the status of technology, nor is it an attempt to diminish aesthetic artisanal work and reduce it to its technical base. Instead, I use the analysis to understand craft as knowledge, using perspectives ranging from Sociology of Scientific Knowledge [SSK] and Science, Technology and Society studies [STS] to History of Technology and Art History.

The "standard view" of science and technology divides the domain of natural science into sciences or knowledge itself and its applied form in associated technologies (Pfaffenberger 1992). In this understanding, knowledge is produced by scientists and flows from science to technology, from laboratory to factory. Technology takes the universal knowledge generated by science and applies it systematically to specific transformations of matter and materials. Characteristic knowledge of preindustrial production that was referred to as "craft," embodied in technique, generally does not feature in this view. The production of scientific knowledge was seen essentially as a disembodied process, "the mind was crucial, the hand only incidental" (Bray 2008, 323); science and its theories were thought to exist within a realm of ideas; written texts become the carriers of these across time and space (Smith 2015). Yet, as scholars, Pfaffenberger, Bray, and Smith point out, these are evolving definitions as Science itself is interrogated by theory and practice.

Scholarship in Sociology of Scientific Knowledge (Bloor 1976), History of Technology (Staudenmaier 1985, Hughes 1983), and Science Technology and Society studies (Latour 1987, KnorrCetina 1999) has challenged this "standard view" of science and the perceived dichotomy between science and technology by treating technology as applied science. With the development of concepts such as sociotechnical systems (Bijker et al. 1987 (2012)) that takes into account the materiality, sociality and [cultural] contexts of human science and technological activity, the underlying theoretical argument is situated in an understanding of science as being thoroughly infused with technology, as made possible (even in its formulation as knowledge) by technology.

Rather than inherently being objective, universal and accumulative, scientific knowledge is standardized and homogenized to exhibit such characteristics. In order to mobilize scientific knowledge, scientists "deploy a variety of social strategies and technical devices for creating the 
equivalences and connections" (Turnbull 2012, 275) between peoples, places, contexts, and materials. Science can now be defined as "knowledge about natural, material processes expressed in declarative transmissible form, as text or graphically inscribed knowledge that is further encoded by translation into a specialist technical vocabulary, verbal or visual" (Bray 2008, 324). When we think of science as human engagement with nature, with a long past in human history (Smith 2015, 272), then we can see that modern science is in essence not so different from other so-called traditional knowledge (Turnbull 2012, 276).

Knowledge and society both are "complex and messy." In this context, coherence is achieved through our story-telling and making meaning. The resultant knowledge claims, in turn, become accumulative and are rendered into truth-statements (Turnbull 2012, 276). In the case of science, theory becomes a standardizing practice of meaningmaking (Star 1995). When science as universal global theory encounters the local in its travels, the global systematizes, and the local resists in a dialectic that connects and circulates local as global scientific knowledge (Watson-Veran and Turnbull 1994, 137). The totalizing discourses of Science are challenged in local sites as cultural contradictionsin fact it is when local knowledge traditions are set against global that the power differentials become explicit. The collective resistance of the marginalized against hegemonic distributions of power then becomes feasible and can lead to increased freedoms for practitioners of local knowledge traditions (Watson-Veran and Turnbull 1994). This approach to knowledge attempts to contextualize modern science and at the same time, elevate local knowledge traditions [for example pre-industrial craft knowledge] to a valid way of knowing, thereby situating itself in the pursuit of cognitive justice (Visvanathan 2006).

The story that we tell of Science is one of universality in knowledge, rationality in method, objectivity in view, pursued by individual scientists driven by the pure quest for knowledge-where the coherence in narrative comes from the idea of its universal good. In the words of Robert Merton, its values are of communalism, universalism, disinterestedness, and organized skepticism [CUDOS] (Merton 1973). This universality has another aspect — science is designated as knowledge that is universally accessible, born as it is of modern egalitarian ideals - all men are equal before science, and science belongs to all men, rather than the purview of a few. While there is disagreement on whether science is indeed egalitarian in practice; traditional knowledge is less (Watson-Veran and Turnbull 1994), embodied practice is less (Smith 2004), women are less (Cowan 1983, Harding 2009), poor and marginalized people are less (Visvanathan 1998), there can be no disagreement on the intent - that all men and women should be equal before science. However, in order to make this claim meaningful, it requires society to recognize that "analysis and critique of scientific knowledge, whether from the point of contesting knowledge systems, or any other point, is part of science" (Watson-Veran and Turnbull 1994, 138).

When scholars, activists, and scientists talk of democratizing science, they are implicitly answering the question about the sort of politics that they want to characterize their knowledge systems with. Some scholars of STS have interrogated science precisely from this normative position that science and technology could be better than they are (Watson-Veran and Turnbull 1994), considering that general acceptance of knowledge, in this case science as universal good-where "good" is normative as well as material-facilitates its construction and mobility.

In its travels, science encounters the social, the [physical] context, and the material. The turn to the social anchors knowledge back into social processes that validate knowledge (Bloor 1983) as well as construct sociotechnical systems (Pinch and Bijker 1984). Context and location reappears: knowledge transfer requires learning how and why things are done in certain ways in particular sociotechnical locations (Ribeiro 2007, 15). The 
turn to material brings back technique into the discourse of science. Technique, derived from the Greek "Techne" is defined as skilled practice that goes into material production of knowledge as well as production of artefacts (Bray 2008). ${ }^{27}$ This approach suggests that ideas and theories, rather than being abstract, emerge from the interaction of the human hand with the material world (Smith 2015). "Socio-technology" can now denote social-material networks or systems, which include sets of techniques and equipment, but also trained personnel, raw materials, ideas, and institutions (Bray 2008).

How sociotechnical systems emerge, stabilize, and (sometimes) dissociate has been a prominent area of inquiry for STS scholarship (Hughes 1983, Latour 1988, Law 1987). Therefore, for example, as Thomas Hughes (Hughes 1983) demonstrates in a now classic example: in order to popularize the electric bulb, Edison invented not only the electric bulb but engineered instead an entire sociotechnical system within which the bulb could successfully function. In another example, that examines how technological artefacts are implicated in social change, Ruth Cowan studies how "labor-saving" technologies such as vacuum cleaners, irons, washers, dryers, and dishwashers might in fact make "more work for mother" as an "unintended consequence" of sociotechnical change (Cowan 1983, Cowan 1987). Centering the gendered consumer of technology as the focus of study, she suggests that the change from the laundry tub to the washing machine is "no less profound than the change from the hand loom to the power loom" (Cowan 1976, 9).$^{28}$ Stated more generally, technology is inextricably bound up in a

27 Rather than technique, I will use the term craft, as a transformative process of production that requires knowledge of and interaction with the material world, but is not limited to that knowledge.

28 Thus rather than the positive effect of liberating women from the drudgery of household tasks, or the negative effect of propelling them to divorce, she finds that industrialization in the home has "unintended consequences" such as investing household tasks such as baking and waxing the kitchen floor with emotional weight far out of proportion to its previous own inherent value. wide-ranging ensemble of heterogeneous entities, and is hence irreducibly social; in contrast to standard narratives of technological development that often reify deterministic ideologies (Wyatt 2008). A sociotechnical systems approach makes visible the idea behind developing technologies (Pfaffenberger1992):

"Against the Standard View's exaggerated picture of technological evolution from simple tools to complex machines, the sociotechnical system concept puts forward a universal conception of human technological activity, in which complex social structures, nonverbal activity systems, advanced linguistic communication, the ritual coordination of labor, advanced artefact manufacture, the linkage of phenomenally diverse social and non-social actors, and the social use of diverse artefacts are all recognized as parts of a single complex that is simultaneously adaptive and expressive" (Pfaffenberger 1992, 513).

Such system building is inevitably sociogenic: system builders have to draw on existing resources in particular local contexts, even as they modify them in order to make the system work. Social choice, tactics, alternative techniques, and the social redefinition of needs and aspirations play a role in the rise of sociotechnical systems"the plethora of made things are a product of human minds replete with fantasies, longings, wants and desires" (Basalla 1988). This perspective illustrates how the adoption of artefacts does not necessarily require the adoption of the system of logic that produced the technology. This implies that introduced technology does lead to change, but that the change is not preordained by the technology adopted (Schaniel 1988, 496) but is located in a particular place, time, and context. Yet, when sociotechnical systems come into direct competition [under conditions of unequal power], as is the case of the imposition of advanced technological diffusion, "spectacular disintegrations" of local systems may occur (Pfaffenberger 1992, 512). 
Expanding the study of technological change in sociotechnical systems, scholars have replaced the standard linear understanding of technological evolution with the concept of innovation (Nowotny 2006a). Shifting from social processes of production of sociotechnical knowledge, a focus on innovation allows for thestudy of how value is constructed through the mechanism of the market for sociotechnical inventions. Innovation is always conceptualized in terms of newness. As Schumpeter mentions, it is "new products, new methods of production, new sources of supply, exploitation of new markets and new ways to organize business" (Fagerberg 2004, 18) that drive innovation and growth.

Yet, this very newness brings uncertainties; which affect the way we conceptualize the future. The idea of risk is introduced, "because of the way we think about [the future]" (Nowotny 2006b, 3). In response to this uncertainty, we plan and model our futures. We devise road maps, create visions in order to negotiate the forces of chaos, flexibility, and creativity. As our cultures become increasingly technological, innovation bridges the gap between risky uncertainty and the promise of positive change-both of which are characteristics of modern technological advances (Nowotny 2006b, 13). The "now habitual" pairing of technology and innovation implies that the goal is change in and of itself, detached from human ends (Williams 2006).

Innovation culture was not always a positive aspect of change, it became so as part of the movement in the mid-19th century in Europe that was concerned with the quest for freedom (Godin 2015, loc 381). After the French revolution, for instance, radical changes were perceived with positive connotations, and changes made by humans became innovation (Godin 2015, loc 518). Later, when the quest for innovation became the quest for profitability in a capitalist economy, technological progress became linked with the process of endless innovation. The idea of innovation now linked the mechanism of the market to the quest for freedom. Citizenship along with consumerism became constitutive of democratic plurality (Nowotny 2006b, 3). In this sense, the concept of innovation linked notions of freedom, technological progress, and profitability in capitalistic markets. This, in turn, legitimized the anxiety that the sources of creativity would dry up and halt the technological progress. In order that this endless social process continued, it required a "culture"-thus, we identify cultures of technology, to uncover their common characteristics (Williams 2006) - so that they may reliably foster success in the quest, in a manner that manages both the vulnerability and the sustainability that technological change can bring about.

To study craft as part of technological culture without diminishing its artisanal roots, it becomes necessary to soften the boundaries between art and science. Craft as traditional cultural activity has been inextricably bound up with the work of artisans. Therefore, up until the 18th century, works of art as well as utility were still subsumed in the human act of making (Smith 2004) or technique. In the contemporary domain of art, the values that prevail are of the pursuit of the particular. The method, if there is one, is of intuitive creativity facilitating subjective taste that has to evolve through association with a particular cultural [even elitist] collective. ${ }^{29}$ In this framework, craft as technique has to embrace the creative exercise of imagination if it is to make the grade to lofty art, otherwise it is diminished to the merely technical or the mechanical execution of predetermined sequences (Ingold 2001, 18).

Therefore, we can place craft at the intersection of the rhetorical oppositions of technology and art, mental and material, knowing and doing, theory and practice. All of these are representative of a general tendency to distinguish between intellectual and manual labor that came about in late $18^{\text {th }}$ century Europe, that arose from more fundamental oppositions between mind and body, creativity and repetition, freedom and determination (Ingold 2001, 18). It is the same opposition that is at the heart of the oppression of the social organization of caste in India. It is this opposition that I will endeavor to resolve, in analyzing handloom craft as knowledge.

29 For a discussion of status of craft with respect to fine art see (Risatti 2009) 


\subsection{BOTh CUltural Tradition AND TECHNOlOgiCAl History: The SCOT GHARAANA ${ }^{30}$}

"What appealed to me in SCOT was that it provided a set of tools for structuring the telling of complex stories."

Larry Cohen, quoted in the introduction to the new edition of the "The Social Construction of Technological Systems. New Directions in the Sociology and History of Technology" (Bijker et al. 1987 (2012))

Distinguishing technology at three levels, as physical objects and artefacts, as activities or processes as well as what people know (MacKenzie and Wajcman 1985), I propose to lay the foundation for one of the central themes of this thesis, that there is much to be gained in our understanding of handloom ${ }^{31}$ by studying it as technology. The weaver sits at his loom set in the mud or stone floor; he is bare-chested, working with his hands and feet, in his home in a thatched hut, usually in a rural setting. Such weavers, dyers, and sizers, usually described as part of India's cultural traditions and technological history, will be studied as contemporary technologists constructing an artefact, as part of a sociotechnical ensemble. In the tradition of a "research program that aims to contributing to a greater understanding of the social process involved in technological development while respecting the seamless web character of technology and society" (Bijker et al. 1987 (2012), 4), I will provide, in the next chapters, the evidence of handloom's sociotechnical nature, using the core concepts from the Social Construction of Technology [SCOT] gharaana [school] of thought that I summarize below.

\section{Against technological determinism}

Technological determinism comprises of two complementary ideas: first, technology develops

30 The word gharaana comes from the Urdu/Hindi word "ghar," which means "family" or "house." It typically refers to the place where a particular musical ideology originated, its iconic teachers [gurus] and is associated with a particular style and genealogy of performance. autonomously following its own internal logic and independent of its societal contexts, and second, technological change drives ("soft determinism") or determines ("hard determinism") social changes (Cherlet 2014, Wyatt 2008). In Bijker's summary, technological determinism encompasses both the idea that technological development proceeds via an autonomous, internal logic (a logic determined only by a unidirectional calculus of engineering considerations, rather than a dense weave of contradictory aims that are both "social" and "technical" in nature), and the idea that technology determines the social organization of a society (and therefore pushes rather than pulls societal change) (Mody 2004). The social-constructivist [SCOT] approach in STS does not accept any a priori claims that aim to "produce universalistic claims of either approbation or blame which can be attributed to technologies" (Bijker et al. 1987 (2012), xxi). Therefore, it questions both kinds of deterministic claims of science and technology. Arguing against technological determinism makes it possible to disrupt deterministic trajectories for handloom weaving that would seek to modernize and mechanize the hand operated loom, as the natural trajectory of any manual production process, a trajectory that disappears any promise of future for the millions who make up India's innovative and resilient craft communities.

The heuristics of Social C onstruction of Technology [SCOT]

The strong program of Bloor in the 1970s recommended to the sociologist "knowledge for the sociologist is whatever people take to be knowledge. [...] in particular the sociologist is concerned with beliefs which are taken for granted or institutionalized or invested with authority by groups of people" (Bloor 1976, 5). Taking this idea to the domain of technology, Pinch and Bijker argue that SCOT's primary point of focus is, thus, the perception of problems and solutions by members 
of relevant social groups. ${ }^{32}$ Key concepts are "relevant social group," "interpretative flexibility," and "stabilization" that are used as heuristics to study technological change. The technological artefact is described from the point of view of relevant social groups, where a social group can be taken as relevant by the analyst when they attribute explicitly the same meaning to the artefact under study - a social group is a group of actors who talk about and in this sense, interpret the artefact in the same way. This heuristic generates a multiplicity of descriptions around the same technology, allowing the analyst to examine in Staudenmeier's words the assumptive statements around the relationship between science, technology [and society], through an analysis of the contextualist history and characteristics of technological knowledge and skill (Staudenmaier 1985). The different descriptions around the technology do not just evidence the different ways that social groups think and describe a technology, but also show how such differences influence its design. Instead of looking for an elusive "best" way, the analyst examines the flexibility in the way artefacts are designed to demonstrate the interpretative flexibility of the artefact- "there is not one artefact, but many" (Bijker 2010, 69). Technological change can then be studied by tracing changing modalities of interpreting technological design.

A critical heuristic at this point that speaks to the metaphor of "construction" in SCOT is stabilization: having socio-historically deconstructed the artefact's unified meaning, stabilization is the mechanism of achieving a stable meaning of technology or closure. It is here that the analyst has to pay attention to the power relations between the social groups - stemming from financial, social, cultural, gendered positions, and so on - in the design and use of an artefact, and the strategies and negotiations that different groups employ to further one interpretation of the technology, rather than another.

"Closure" stemming from SSK is the

32 The first formulation of the SCOT program was done by Trevor Pinch and Wiebe Bijker in 1984 (Pinch and Bijker 1984) irreversible point of a discordant process in which several facts existed next to each other-usually in the early stage before publication, or when a scientific controversy arises. "Stabilization" stresses the process character of stabilizing the meaning of an artefact, and its use, and turns the momentous closure into a longer drawn-out process of social construction (Bijker 2010, 69). However, in laying stress on process, that tends toward closure, yet does not fully complete this journey, the analyst attends to the possibility that social groups can reopen the black box of a stabilized technology. Reality could have been different, we understand, in this approach to technology, and thus allows for the possibility that it can always be made different.

So how then does the process of stabilization take place at all? The social construction of technology [SCOT], thus, comprises a three-step research heuristic. The first step in SCOT is to identify "relevant social groups" [RSG] by looking for actors who refer to the technological artefact in the same way. Social groups are defined in SCOT by the group's members having shared attributes; for example common interests, shared problems, shared belief systems, and shared knowledge and methods. The shared meanings of a technology held by a social group, which structure their interactions with the technology is referred to as the technological frame. Looking at the artefact through the eyes of different relevant social groups produces different descriptions of the artefact. This is the "interpretative flexibility" of the artefact. In a second step, the researcher traces how some artefacts gain dominance over the others, how meanings slowly converge, and the interpretative flexibility diminishes. Finally, only one meaning and one artefact stabilize through the process of social construction. "Stabilization" is a concept that stresses on the process of social construction through which the process reaches a moment of closure. "Closure" is the irreversible point at which conflict around the different variants of the artefact is laid to rest and broad agreement over meaning is reached among the social groups (Pinch and Bijker 1984). 
In the final step, the processes of stabilization described in the previous step are analyzed and explained by interpreting them in a broader theoretical framework: SCOT uses the concept of technological frame to explain why a social construction process would follow one course, rather than another, as a way to order interactions among the members of a relevant social group toward closure. It also explains obduracy or resistance to change, the opposite of interpretative flexibility in the process of technological change. The first form - closed in hardness - occurs when actors have a high inclusion in the associated technological frame; that is they have a high level of involvement in the technological frame. The second is closed out obduracy, when the actors are not able to access the technology for whatever reasons. In both cases the technology has an impact on these people, but in completely different ways. In this way, existing practice does guide future of practice, but it is in turn equally shaped by past practices, without giving into logical determination as an explanation for technological phenomenon (Bijker 2010, 70).

The technological frame of handloom, thus, binds the different social groups engaged with it in a common set of "theories, goals, problem solving strategies, and practices of use" (Bijker 1987 (2012), 167). The technological frame includes but is not limited to the technologist's frame; it would take into cognizance the other social groups interacting with the technology. Conceptualizing social groups' technological frames also helps to highlight the struggle for dominance among actors with diverging views and opinions on how technological change should be adopted by the handloom ensemble; as an interactionist conception that explains obduracy during the design and use stages (Hommels 2005, 331). I use this concept to include the other social groups and technologies of the Handloom ensemble in the analysis, rather than the handloom weavers alone.

\section{Sociotechnical ensemble as unit of analysis}

Bijker's work on a theory for sociotechnical change extends SCOT from artefacts to systems, ensembles, and cultures (Bijker 1995). This implies the development of concepts and research questions regarding sociotechnical change within complex units, derived from concepts used to describe simpler units (Bijker 2010).

\begin{tabular}{|c|c|c|c|}
\hline Unit of Analysis & Research Q uestions in SC OT & Handloom Q uestions & SCOT's Key Concepts \\
\hline $\begin{array}{l}\text { Singular artefact } \\
\text { (which could be treated as } \\
\text { technical system) }\end{array}$ & $\begin{array}{l}\text { How can we describeand } \\
\text { understand the development } \\
\text { and use of technology in non- } \\
\text { internalis }{ }^{33} \text { terms? }\end{array}$ & $\begin{array}{l}\text { How can we understand } \\
\text { technological change in traditional } \\
\text { crafts? }\end{array}$ & $\begin{array}{l}\text { Relevant social group [RSG] } \\
\text { Interpretative flexibility } \\
\text { Stabilization and closure } \\
\text { Technological frame }\end{array}$ \\
\hline Sociotechnical ensemble & $\begin{array}{l}\text { How to understand social } \\
\text { order? } \\
\text { How to understand the relation } \\
\text { between the social shaping } \\
\text { of technology and technical } \\
\text { building of society? }\end{array}$ & $\begin{array}{l}\text { How to understand tradition in } \\
\text { technology? } \\
\text { How to understand the relation } \\
\text { between cultural shaping of } \\
\text { innovation and innovation } \\
\text { cultures in traditional societies? }\end{array}$ & $\begin{array}{l}\text { Closed-in hardness } \\
\text { Closing-out obduracy }\end{array}$ \\
\hline Technological culture & $\begin{array}{l}\text { How to understand normative } \\
\text { and political issues in } \\
\text { technological societies? }\end{array}$ & $\begin{array}{l}\text { How to understand change and } \\
\text { continuity in traditional societies? } \\
\text { How can we innovate, yet be } \\
\text { responsible to vulnerable people, } \\
\text { to society and to the planet? }\end{array}$ & Co-production \\
\hline
\end{tabular}

Table 2.1: Units of analysis with associated research questions and key concepts. [Parts of this table have been borrowed from Table 2: Units of analysis with associated key concepts (Bijker 2010, 69)and from Table 3: Units of analysis with associated research questions (Bijker 2010, 70). I have also added new questions based on application of SCOT approach to the study of the handloom sociotechnical ensemble.

33 The definition of internalist is one who believes that scientific/technological change can be explained in its own terms, without reference to the social context. 
With this widening of the unit of analysis from the single artefact to the sociotechnical ensemble, it is possible to bring the interactional component into focus. Technological cultures are made of sociotechnical ensembles that interact with each other, social groups interact within sociotechnical ensembles, and actors have to acquire the expertise to interact with each other in order to facilitate technological change. In the case of technological change in vulnerable populations, innovation has to be constrained to be responsible.
Within this context the questions that I will engage with, with respect to handloom are: How can we understand technological change in traditional crafts [Chapter 5]? How does contemporary social order renew [livelihood] technology that is perceived to be traditional [Chapter 3]? How to understand the relation between cultural shaping of innovation and innovation cultures in traditional societies [Chapter 7]? How to understand change and continuity in traditional societies [Chapter 8]?

\subsection{Describing THE SOCIOTECHNiCAL EnSEMble OF HANDLOOM ${ }^{34}$}

"How many people does your household support with handloom weaving?" Srinivas, a young engineer and management graduate, in his role as the assistant project director in the District Rural Development Agency of Adilabad in Telengana, asked Odellu, a weaver who wove for the weavers' co-operative in Chinnur, Adilabad in 1990. "Other than myself, my wife, my mother-in-law, two children and my washer-man [chaakali]" he answered. "Chaakali!", Srinivas was purported to have exclaimed. "Here is a luxury! I don't propose to support one, how can you!" It was in Odellu's home that the conversation took place, when a group of urban development workers were first encountering what I call the handloom ensemble. It was only later that it became evident that the luxury of personal laundry service in the weaver's household was also linked to the loom, to wash and bleach the fabric that the family wove, before they put it up for sale. This served for them as the first introduction to the weaving ensemble beyond the loom: the technologies that are integral to handloom weaving, which are referred to as pre-loom, of getting the yarn ready for the loom, coloring it, and applying starch for ease of weaving, and post-loom activities such as washing for controlling shrinkage as well as bleaching and color fixing. To add another layer to the technological culture of the handloom sociotechnical ensemble that I will describe, I make one more observation. The washerman [chaakali] caste played an important role in the handloom ensemble, the members of this group could transform and "purify" the product of lower down castes, the fabric woven by the Netagani caste that Odellu belonged to, for the consumption and use of upper castes, through the act of washing. Therefore, through the intervention of the washer man, higher castes in the same village could become part of the production consumption ensemble of the Netagani weaver.

In order to convert yarn to fabric in the handloom ensemble many groups work together, each with a specific expertise and function. The ensemble is not just one of production but also consumption. I start with the cotton yarn, and follow it as it passes from hand to hand as cotton is transformed into fabric. I then follow the fabric to its journey through the hands of the trader, the co-operative, the retailer to the user, where fabric is exchanged for money by the consumer that goes back to the trader to be exchanged for yarn. The intention is to describe the often different RSGs who perform these techniques and not just different techniques used by one group, the handloom weavers.

34 Visual representation of handloom weavers is a contentious issue, since the identity of the weaver as represented by media, and NGOs as objects of charity are in contradiction to the self-image that the weavers would chose for themselves. The choice to represent processes as hand drawings, rather than photographs, is a result of many discussions and careful negotiations between the artist, designer, and me. All the hand-drawn illustrations in this section are by Chari, supervised by Satish, inspired by the drawings in the website, http://www.dacottonhandlooms.in/short-story/ 


\section{Cotton}

India occupies the second position in cotton production in the world. ${ }^{35}$ Many more varieties of cotton were produced in the past than today, the majority being the short staple variety, which was ideal for hand spinning (Prasad 1999). Today most production has shifted to long staple, suitable for mechanized spinning at high speeds without breakage. Cotton was the first global commodity "whoever says Industrial Revolution says cotton" (Hobsbawm 1999, 34) cited in (Riello and Parthasarathi 2011). It linked the most modern industries of the day, the factories in Manchester, to the most underdeveloped institutions like the slave plantations of the West Indies that provided the labor to grow cotton, and the colonized natives that consumed the product. The commodification of cotton continues to have consequences for poor producers, as in the fortunes of cotton growers and cotton weavers whose livelihoods fluctuate with global cotton prices.

\section{Spinning}

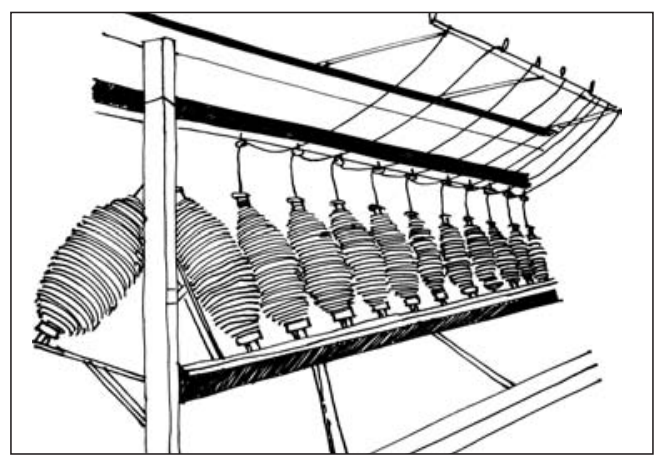

[Fig. 2.1 Mill spinning]

Yarn is a continuous length of interlocked fibers. Staple length of cotton also determines the thickness of yarn spun and this is referred to as yarn count. Hank yarn is typically used in handloom production as opposed to cone yarn, which is used in mill production. Yarn is sold in "pettelu" or boxes by yarn traders in the city, or wholesale from the mills by master weaver-traders who supply yarn and buy the cloth woven by weavers, at a pre-agreed rate. Each box is of 4.5 kilograms, or 10 imperial pounds.

The process of converting cotton fiber to yarn [spinning] is complex and the strength and fineness of yarn is dependent on the staple length of the fiber and the skill of the spinner. The technical problem that determined the nature of mechanization in the cotton industry was the imbalance between the efficiencies of hand spinning and hand weaving. The inventions that tipped the balance were the "spinning jenny" of the 1760s, where one cottage spinner could spin several threads at once, the "water frame" of 1768 which combined the original idea of spinning with the use of rollers and spindles, and the fusion of the two "the mule" of the 1780 s, to which steam power was soon applied (Hobsbawm 1999, 36). Spinning shifted from the home to factories, and mill spun yarn quickly penetrated the hand-weaving ensemble across India. Today most handloom weavers across the country have shifted to using mill spun yarn. Srikakulam in Andhra Pradesh is one of the few places where handspinning still continues.

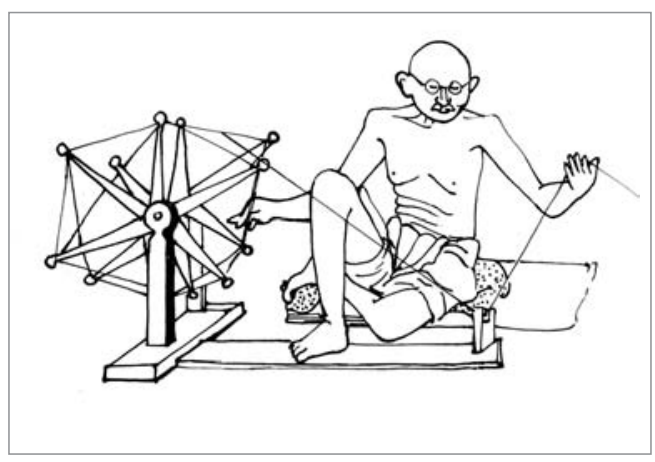

[Fig. 2.2 Hand spinning]

35 http://cotcorp.gov.in/shares.aspx Last retrieved on 25th July 2015 


\section{Dyeing}

Textiles can be dyed in the yarn form or at the fabric and garment stages. Hank yarn dyeing is a predominant practice in South India, unlike in the North where fabric is dyed or printed on. Dyes extracted from natural materials such as Indigo, Al, are known as natural dyes. Local experts in and around weaving villages provide dyeing services to handloom weavers using technologies of vat dyes and naphthol dyes using manual as well as mechanized dyeing practices.

Colors have historically held different meanings for different communities, "Muhammadans generally patronise the shades of green or purple, the latter being often used as

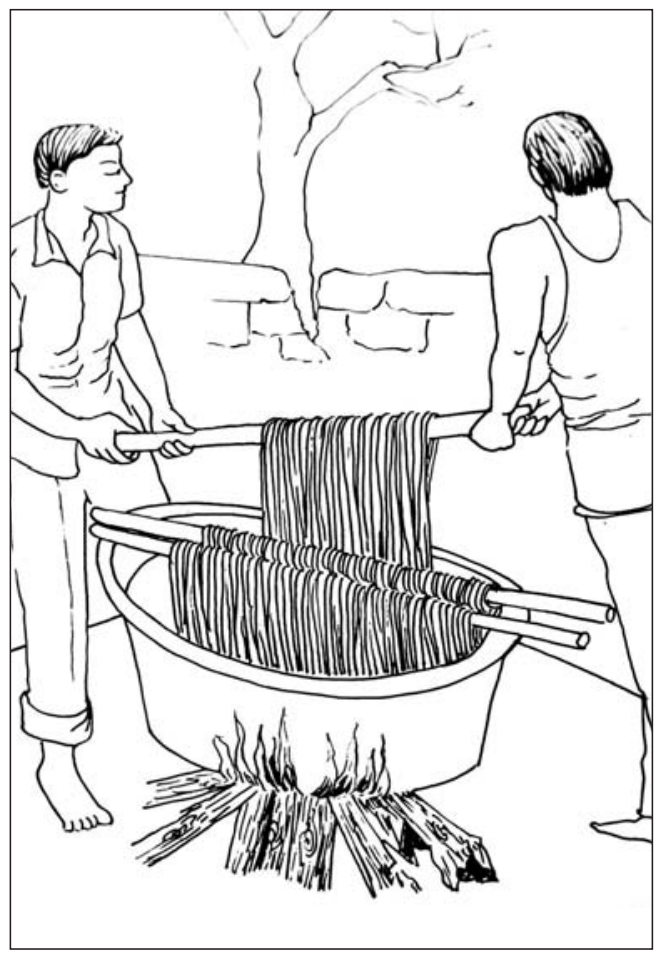

[Fig. 2.3: Dyeing of the yarn] a lining for white coats. Fakīrs or Muhammadan beggars wear light green. Mārwāri Banias and others from Rājputāna like the light yellow, pink or orange shades. A green or black head-cloth is with them a sign of mourning. Cloths dyed in yellow or scarlet are bought by Brāhmans and other castes of Hindus for their marriages. Blue is not a lucky colour among the Hindus and is considered as on a level with black", as outlined by RV Russell ${ }^{36}$ in 1916 to capture the colorful practices of the Muslim dyers of the Central Provinces, the rangrez, whose name is derived from rang, color, and rez, rekhtān, to pour. As much as for cotton and weaving, India was known for her master dyers and their colors (Gittinger 1982).

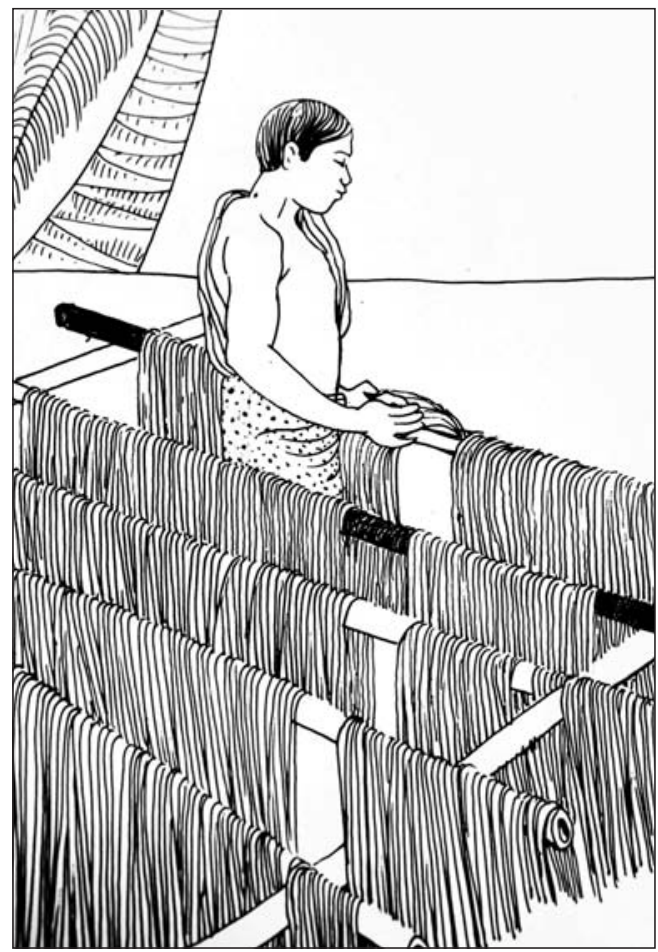

[Fig. 2.4: Drying of the washed yarn] 


\section{Bobbin winding for the warp and winding for the wet}

Yarn in the form of hank has to be wound onto bobbins, in this process. This transforms hank to a linear form, the warp or the many threads aligned lengthwise for weaving on the loom. Dyed hank yarn is first wound on to bobbins with the help of charkhas or spinning wheels. The bobbins are used to load yarn into the warping drum. Typically, 19 to 20 bobbins are required for a five-saree warp length of 34 meters. Hank yarn for weft, the horizontal weaving thread, is wound onto a pirn, a small bobbin. The weft yarn is then inserted into a shuttle, a device used in weaving to carry the weft thread back and forth between the warp threads. Women of the weaver household normally perform both these operations.

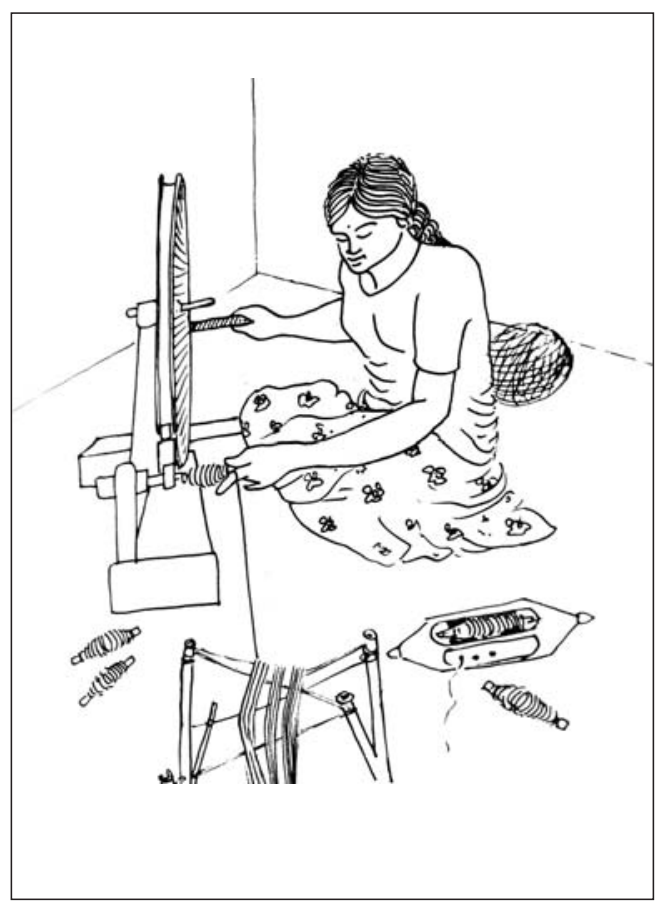

[Fig. 2.5: Bobbin winding for the weft]

\section{Warping}

The warp is a set of threads ordered and attached to the loom lengthwise before the weaving begins. These threads form the base for the weft. For a 46 inch wide fabric, over 3200 individual yarns run along the warp of the fabric. Typically, 1,96,550 yards of yarn are ordered by wrapping them around the circular warping drum. Warp lengths and widths vary according to the draping styles of the sarees of a particular region. Each weaving village generally has a warping drum, and a warper who is able to service the entire village. Warping and sizing are the two processes that, like hand weaving, are unique to the handloom ensemble.

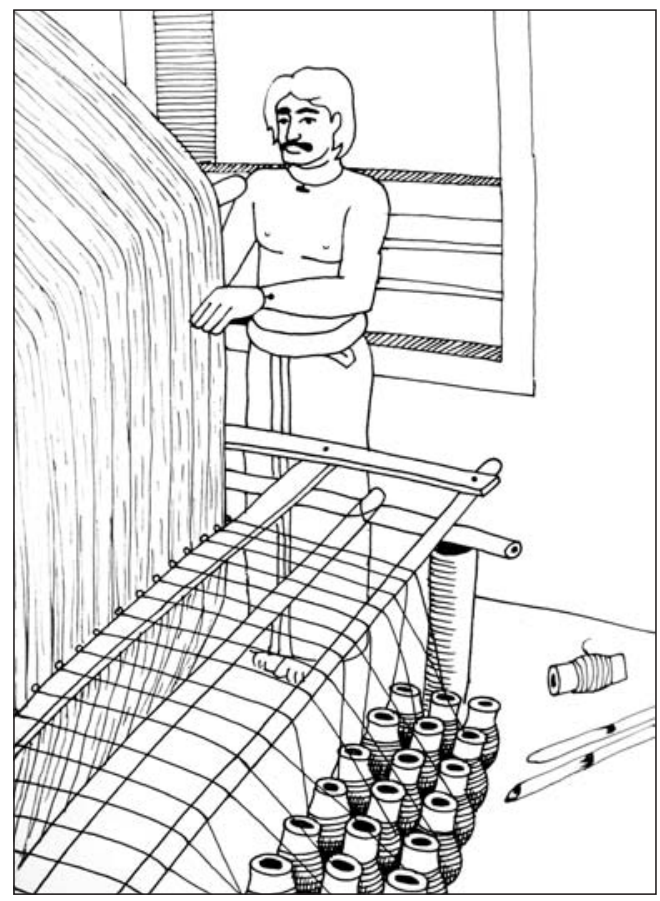

[Fig. 2.6 Warping drum] 
Sizing

A most common sight when walking in the weaving village early in the morning is of street sizing. The warps are stretched out with leases to keep the yarn disentangled and natural adhesives are applied by spraying. This process of adding starch or "size" on the yarn is called sizing — it adds strength to the yarn and lubricates it to withstand the rigors of weaving. In most handloom centers, rice starch/gruel is mixed with coconut/ground nut oil and sprayed and brushed on as "size." Since this activity is done on the street it is called street sizing. Compared to weaving, it is less visible, but technically it is the backbone of the weaving process. It is here and in dyeing that labor from agricultural castes is generally employed.

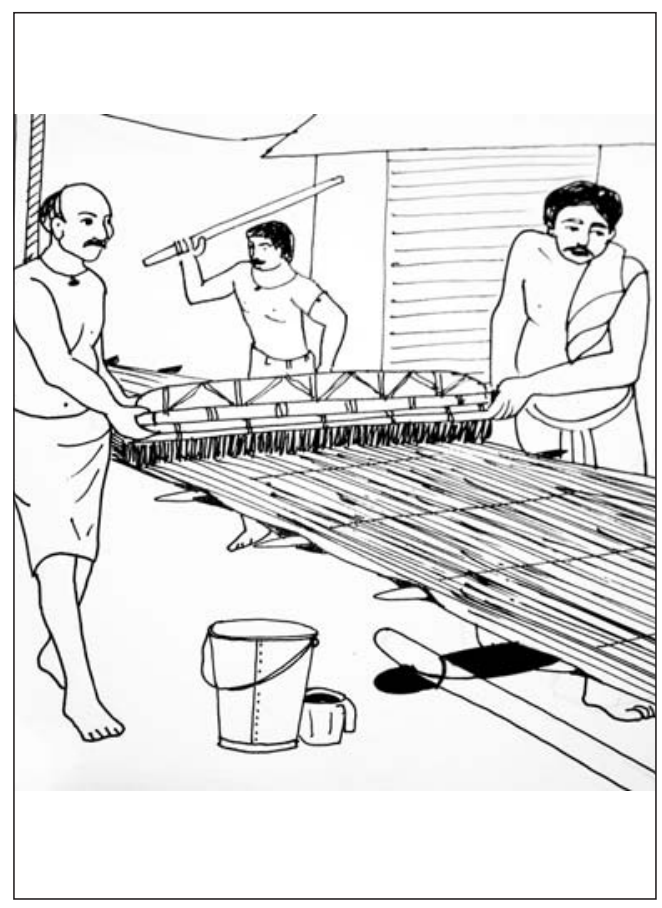

[Fig. 2.7: Street sizing]

\section{Attaching the warp onto the loom}

Individual warp threads are drawn through heddles taken through a set of reeds and tied onto beams located on both ends of the loom. The heddles separate the warp into two sections, which allows the weft threads to pass between them easily. Heddles are made out of rods or cords each with an eye through which the warp thread is drawn. Reed is a comb like frame that pushes the weft yarn firmly against the finished cloth after each insertion. The weavers' households perform this part of the process. It requires using the dexterous weaver's knot, a smooth action attaching two threads to each other, which is the first step for students learning weaving.

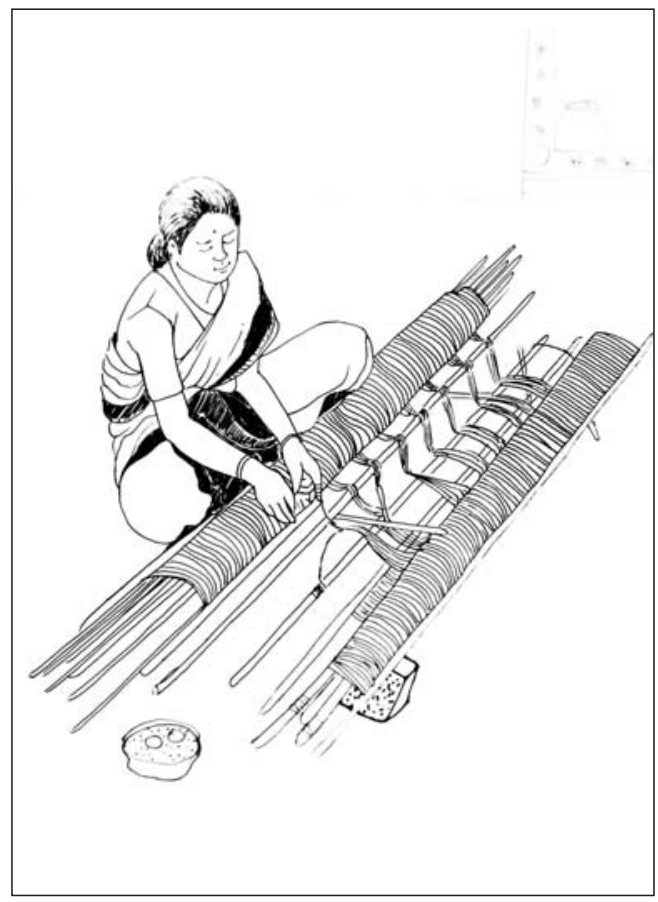

[Fig. 2.8 Attaching threads of the warp] 


\section{Weaving}

The basic action of weaving stays unchanged, whether performed by hand or by a machine; it is the interlacing of two sets of yarnthe warp [the longitudinal threads] and the weft [the horizontal threads]. The equipment that facilitates this interlacement is the loom. A handloom is a loom that is used to weave fabrics using the hand and feet, distinguishing it from other looms that use electricity. It is the oldest kind of loom known to mankind, and weavers in Andhra Pradesh and Telengana are known masters of this kind of loom. The basic action of weaving requires the weaver to manipulate the foot pedals to lift the warp in sync with the throwing of the shuttle which carries the weft yarn from side to side, from one hand to the other and back. A perfect weave demands coordination between mind and body. The weaver achieves a harmony of motion and rhythm when he or she weaves. Depending on the complexity of design, a weaver weaves between half a meter to five meters of fabric in a day. Looms are classified by the weaving arrangement, horizontally close to the ground, set on a frame at table level, anchored on the back, or vertical, as in the case of carpet looms; by the number of shuttles, one, two, or three; the action of the throwing of the shuttle, whether by hand or through an arrangement on the loom referred to as fly shuttle and on whether there are other attachments in order to add patterns: dobby, jacquard, and jala [extra weft setting]. Weavers will tell you though that no loom, even if it has identical characteristics on all these dimensions, is truly like the other. The local carpenter and weaver work together to customize the loom to the dimensions and ease of the weaver's body, and fit it to its place in the front room of the home. This is usually the verandah, the inside-outside room that is well lit and ventilated, and open to the road.

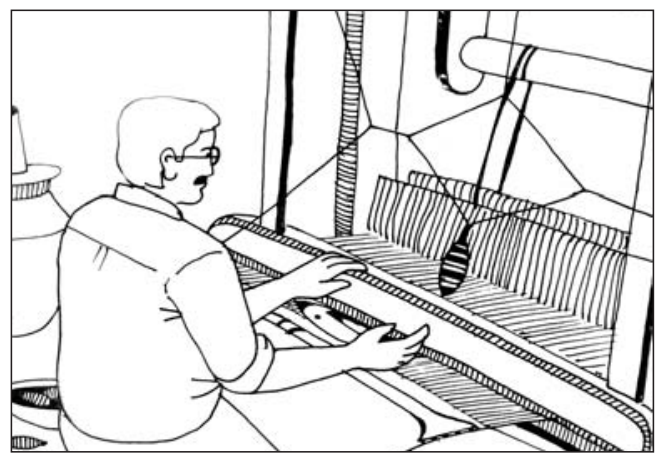

[Fig. 2.9 Weaving]

\section{Designing and Trading}

Seventy-five percent of handloom product at the village level is traded by master-weavers, who act as intermediaries between weavers and markets. They provide working capital in the form of inputs such as yarn, or extra attachments for the loom. In some cases, master weavers also trade in yarn. Master weavers are usually from the same caste as the weavers themselves. It is generally believed that master weavers, while generating large profits for themselves, pay low wages to the weavers. Master weavers recover the loans that they advance to the weaver on first hiring him, out of the earned wage, for which it is presumed that usurious rates of interests are charged. Recent studies have shown that this is not uniformly true - new master weaver firms have been established by weavers who were careful not to get trapped in debt (Bhagavatula 2009). Since they are generally agents of the market, they are also key in supporting design and innovation in handloom.

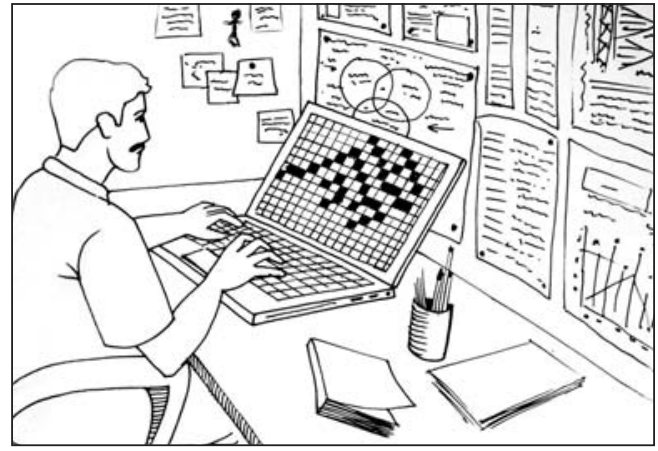

[Fig. 2.10 Designing] 
The handloom co-operative is the other trading institution in the handloom ensemble. It was set up with the objective of easing poverty through economic collaboration. The 1915 Government of India Committee on Co-operation in India started co-operatives as the basic principle that "an isolated and powerless person can by association with others and by moral development and mutual support obtain in his own degree the material advantages available to wealthy or powerful persons, and thereby develop himself to the fullest extent of his natural abilities." (GOI 1915, 2) Co-operatives were set up in opposition to financial exploitation of master-weavers, as well as individualistic striving by members. W here there are well working entrepreneurial co-operatives, weavers weave steadily for them, and benefit from the stable livelihoods they provide. Post-independence, they were sponsored partly by the government, which invests heavily in working capital, and has set up public sector marketing institutions to support them. In many weaving villages in A ndhra Pradesh, they form the backbone of the weaving communities.

In recent times, civil society organizations and non-governmental organizations have taken up the role of designing and trading, with the view to alleviate poverty or conserve craft traditions, frequently supported by state funding. Designers have played important roles in bringing about successful outcomes in these interventions.

Retailing, consuming, and using

Even up to the late 19th century, the system by which weavers received yarn from cultivators and wove cloth for them was still functional (Havell 1909 , 19). Therefore, when weavers shifted to weaving mill yarn along with increased dependence on the trader for inputs, the direct transaction and market information between the user and the producer also broke down. M aster-weavers instead transacted with the users, and as urban markets grew, with the retailers. In some instances, master weavers themselves set up handloom retail, in others they supplied the small boutiques and designer led retail that formed the backbone of the urban retail. Today, increasingly retail store owners across the country buy from master weavers, who visit them regularly, both to gauge market demand as well as to show them new developments in the production. In India, clothing matters- to identity, to behavior, to propriety (Tarlo 1996). Customers generally indicate to the sal espersons their preferences while interacting with them. This forms an informal channel of market feedback that ensures that production and demand match each other (B hagavatula 2009, 65) - a practice that continues from a time when consumers and producers belonged to the same village.

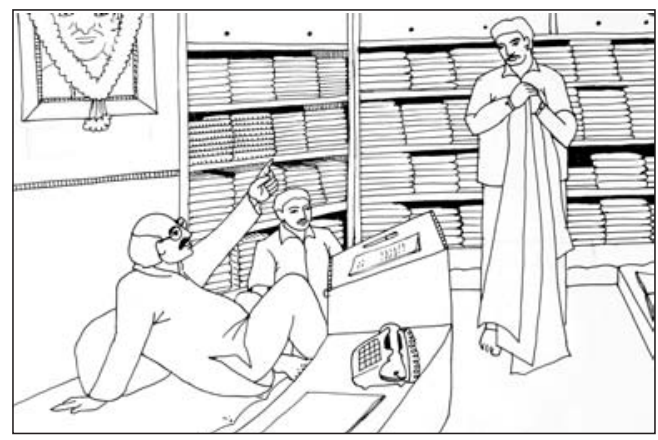

[Fig. 2.11 Retailing]
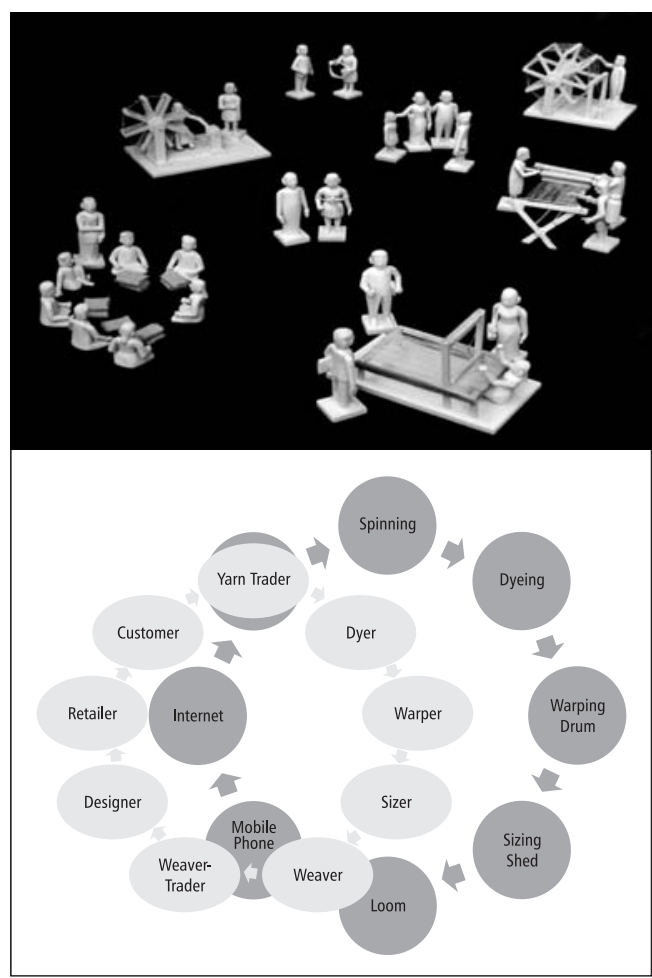

[Fig. 2.12: The social groups and technologies in the handloom ensemble] 
The sociotechnical ensemble of handloom weaving [the Handloom STE] [Fig 2.3], which is our focus, exists alongside the $\mathrm{Khadi}^{37}$ ensemble, the power loom ensemble and the mill ensemble, the other components of the textile industry that together make up its whole.

\begin{tabular}{|c|c|}
\hline Segment & $\begin{array}{c}\text { Contribution to Total C loth } \\
\text { Production (\%) }\end{array}$ \\
\hline Mill & 3.34 \\
\hline Handlooms & 11.28 \\
\hline Power loom & 61.32 \\
\hline Hosiery & 22.71 \\
\hline Others (Khadi, wool and silk) & 1.35 \\
\hline
\end{tabular}

Table 2.2: Production for the year 2011: Textile Commissioner Mumbai $^{38}$

The Khadi ensemble has its own set of technologies and institutional arrangements, as do the mill and power loom ensembles. Each ensemble has a different level of mechanization. The Khadi ensemble is least mechanized, spinning too in this ensemble is by hand, unlike the handloom ensemble which uses mill made yarn. The integrated mills are completely mechanized. This makes difference in social as well as financial organization within each ensemble. Therefore, within Khadi, co-operatives are also in charge of the spinning activity as well as marketing, and sponsored almost totally by the government. Handloom, power loom, and mill ensembles share yarn spinning, dyeing, and retail institutions. More NGOs work with handloom and Khadi than in the power looms or mill sectors. The handloom weavers' institutions included the temple and kingly patronage in the past. The caste and community networks continue to the present, coexistent with the new institutions of cooperatives and in some geographies, the handloom factories [karkhanas], and unions (Miryam 2014).

Handloom weaving is listed as one of the handicrafts of India, by the Development Commissioner of India, below is a table of the other

37 Khadi refers to hand spun yarn. The essential difference between handloom fabric and Khadi fabric, which is also hand woven, is that handloom weavers use mill spun yarn, whereas Khadi weavers continue to use hand spun yarn.

38 http://texmin.nic.in/aboutus/rfd/strategic_plan_2011_2016.pdf crafts that are practiced. In total, the number of working craftspeople is considered to be at least 16 million (Viswanathan 2013).

\begin{tabular}{|c|c|}
\hline & Name of the C raft \\
\hline 1. & Bidri \\
\hline 2. & Cane \& Bamboo \\
\hline 3. & Carpet \\
\hline 4. & Conch-Shell \\
\hline 5. & Doll \& Toys \\
\hline 6. & Filigree \& Silverware \\
\hline 7. & Folk Painting \\
\hline 8. & Furniture \\
\hline 9. & Grass, leaf, read \& fiber \\
\hline 10. & Horn \& Bone \\
\hline 11. & Jewellery \\
\hline 12. & Leather (footwear) \\
\hline 13. & Leather (other articles) \\
\hline 14. & Metal ware \\
\hline 15. & Metal images (classical) \\
\hline 16. & Metal images (folk) \\
\hline 17. & Musical instrument \\
\hline 18. & Pottery and clay objects \\
\hline 19. & Rugs \& durries \\
\hline 20. & Stone (carving) \\
\hline 21. & Stone (inlay) \\
\hline 22. & Terracotta \\
\hline 23. & Theatre, Costumes \& Puppet \\
\hline 24. & Textile (handloom) \\
\hline 25. & Textile (Hand embroidery) \\
\hline 26. & Textile (Hand printed) \\
\hline 27. & Wood (carving) \\
\hline 28. & Wood (inlay) \\
\hline 29. & Wood (turning and lacquer ware) \\
\hline 30. & Zari \\
\hline 31. & Coir twisting \\
\hline 32. & Miscellaneous crafts and Paintings \\
\hline
\end{tabular}

Table 2.3: Table of handicrafts, including handloom weaving in India from (Viswanathan 2013)

Therefore, we have the handloom ensemble, whose focus is the hand operated loom, expanding to include the different kinds of social groups, their expertise, technologies, and institutions that I have described. This in turn is part of a larger textile industry, which ranges from the village level homespun Khadi ensemble to the large mills of modern India. Rather than isolating the loom, it is the handloom ensemble that is the unit of analysis for this study. 


\section{3 | LIVELIHOOD TRAJECTORIES IN HANDLOOM}

Indian society's historical relationship with cloth and its makers can be evidenced by the wide usage of the term "handloom" in common parlance, irrespective of the native language of the speaker. At first glance, customers, weavers, even nonusers generally seem to understand precisely what it refers to. "It's handloom" acknowledges the savvy shop owner in the busy market street in Secunderabad, significantly raising an eyebrow to the upper class customer in appreciation of her good taste; "it's handloom" apologizes the salesgirl when the critical customer points to the bands of inconsistent color. "It's handloom" warns the tailor, of shrinkage, when his young client wants to make a tightly fitted kurtha (tunic) out of a length of cloth she purchased in a bazaar. "It's handloom!" sniffs the supercilious designer to the urban fashion aspirant who is not sufficiently appreciative of the home-spun effect of the new "green" collection; "it's handloom" dismisses the marketing executive of an export firm to the foreign buyer who would like five thousand replicas of a beautiful sample she found in a local boutique; "it's handloom" admires the museum goer to her friend, awestruck by theexquisitely beautiful piece of textile art, "it's handloom" approves the gray-haired aunty at her niece's wedding, reaching out and running the saree the bride is wearing between experienced fingertips. In all these different usages of the term, people seem to exhibit a deep and intimate knowledge of what it means. Yet, the meaning does not hold together in any endeavor that would seek to integrate these different uses of the term. Then it quickly becomes fuzzy - does it mean the product of the hand loom? Or the process of hand weaving? Is it the weaving apparatus itself? A kind of ethnic Indian aesthetic? Or does it refer to rural livelihood?

This struggle over meaning presents even more sharply when we try to define the problem of handloom livelihoods in order to solve it. Around 4.3 million handloom weavers continue to weave and clothe Indian society till date-practitioners of a traditional technology in a modern world. This challenge has no easy solutions, sustaining traditional livelihoods in a modern world is a complex issue. However, I define, for this chapter, a question that underpins endeavors to understand and intervene in supporting weavers' livelihoods: under what conditions does the vulnerable livelihood of a handloomweaverbecomesustainable, and when does it become unsustainable? Using social constructivist methodologies, I examine discourses of relevant social groups (Pinch and Bijker 1984) around "handloom," to see how perspectives regarding handloom's unsustainability and its paradoxical persistence emerge and cohere. The handloom ensemble abounds with an almost cacophonic array of claims, disclaimers, and concerns ranging across handloom weavers, market, state, and civil society groups. We find that even as handloom weavers' own narratives loom large, the problem of handloom livelihoods is differently represented in 
different social groups' discourses. In the presence of such a multiplicity of discourses, consensus in the sociotechnical ensemble of handloom regarding the right intervention to alleviate vulnerability and the right model of sustaining livelihoods is a shifting goal post. Within which domain -economic, social, political, cultural- is the problem of handloom livelihoods defined? What roles do different groups in society play in defining the problem? Does a collective definition of the problem of handlooms emerge among the different actors? What sort of consequences does this have for handloom weavers themselves?

From my analysis, we begin to see how different actors make shared sense of problems, and work toward coherence amidst the noisy argumentation around handloom. Rather than a clear consensus, a sense of coherence is gained through discourse coalitions that form between the different groups (Hajer 1995). When these groups intervene to solve the problems of handloom weavers, they generate a multiplicity of livelihood outcomes for weavers. Contradicting the notion of an all-encompassing consensus on handloom's unsustainability, these coalitions' interventions evidence responses to alleviate handloom's vulnerabilities. We find that weavers weave a multiplicity of trajectories while charting a pathway through these possibilities, ranging from vulnerability to sustainability in livelihoods, thereby refuting the idea that any one existing trajectory of technology can be taken for granted (Williams 1996, 872). Where this journey is made successfully, the weaver has hope, where not, it ends in despair. In this chapter, I explore a strengths-based approach to weaver livelihoods: explicating sustainable and resilient practices of weavers in order to understand conditions under which handloom weavers can move from vulnerability to sustainability and hope, rather than just to unsustainability and despair.

The argumentative tradition with its roots in skepticism and the use of dialectics is well and alive in handloom discourses as we will see, and plays an important role in generating sustainable outcomes in handloom livelihoods. In this chapter, I present argumentation as a socially accepted cultural practice that comes from a dialogic tradition and an acceptance of heterodoxy (Sen 2005, xiii). This approach allows me to study the large and diverse body of existing knowledge that my CSO and NGO colleagues and fellow actors have gained from their deep engagement with the problems that handloom weavers face, as well as handloom weavers' own reflexive narratives and practices of dealing with them. It follows, I submit, that not much new conceptual work needs to be done to answer the questions I have set out. Established methodologies from Science Technology and Society Studies will suffice to make the point. As I will demonstrate, there is already a treasure of insights, ideas, and interventions from different actors in the handloom ensemble, as well as an array of concepts from disciplines such as sociology of science, sociology of vulnerability and risk, discourse analysis, and social construction of technology that can be used. What emerges in this chapter is the study of handloom livelihoods as a socio-cultural idea, rather than just an economic one.

\subsection{SUPPORTING HANDLOOM LIVELIHOODS: A COMPLEX FRAMEWORK}

According to the handloom census of $2010,{ }^{39}$ 4.3 million weaver and allied worker households are engaged in weaving in India. Of the 2.8 million weaver households, 70 percent engage in handloom

$39 \mathrm{http}: / /$ economictimes.indiatimes.com/opinion/view-point/censusweaves-rich-handloom-data/articleshow/440632.cms as the sole livelihood activity. 87 percent live in rural India and 22 percent are women. Around half of the handloom weaver households are below the poverty line as defined by the Government of India, earning less than 32 rupees a day. This industry produced 6.9 billion square meters of fabric in 2012-2013, up from 6.6 billion the previous year. 
95 percent of world demand of hand woven fabric is met by production from India. Market share of handloom is a little more than 11 percent of the textile markets ${ }^{40}$ in India. According to the ministry of textiles, the domestic textile and apparel industry in India is estimated around 58 billion dollars in 2011 , with an expectation to almost triple in ten years, handloom's share of this market is around 10 percent. On an average, a handloom product can cost anywhere from one hundred rupees [less than two euros], a simple towel woven by a single weaver, to 65,000 euros, ${ }^{41}$ a work of art woven into a saree by 36 weavers.

The number of handloom weaver households declined from 6.5 million in 19951996 to 4.3 million in 2010 , the decline has been attributed to competition from the mechanized mill and powerloom Sectors, decline of public sector handloom corporations and ApexCooperative Societies, high cost of credit and low disbursement of credit for the handloom weavers, choking of co-operative credit lines due to debt over-dues and marketing problems. ${ }^{42}$ The minister of textiles in response to criticism of government apathy to handloom weavers attempts to moderate this view: "the number of handloom weavers and allied workers has declined, yet improvement in various other parameters has also been reported in the 2009-2010 Census over the 1995-1996 Census" ${ }^{33}$ in particular focus areas. The parameters used were increased days of employment, which had gone up from 194 to 237, and the percentage of weaver households who now depended solely on handloom weaving for livelihood had gone up from 44 percent to 64 percent. In the same period, weaver suicides have been reported in the press, conservative official estimates suggest more than

40 http://www.citiindia.com/uploads/CITI_Annual_Report_2012-13.pdf

41 Vivaha patu sari, where the embroidery is made from real gold threads and uses precious gem stones like diamond, emerald, ruby, yellow sapphire, sapphire, topaz, pearl, cat's eye, and coral. The sari was hand woven using double warp by 36 handloom workers at Chennai Silks mill in Kancheepuram. It weighs $8 \mathrm{~kg}$ and was completed in 12 months.

42 Reply of minister panabaka Lakshmi http://pib.nic.in/newsite/ erelease.aspx?relid $=70550$

43 http://pib.nic.in/newsite/erelease. aspx?relid $=70550$ thousand weavers have taken their own life under the "burden of unbearable debt" in the last ten years. ${ }^{44}$

Declining numbers of weavers from the Census statistics naturally lead one to assume unsustainability of weaving livelihoods. Yet, when the state accepts migration numbers as irrefutable evidence of handloom's unsustainability, it consigns an industry that 4.3 million rural poor people are engaged in to obsolescence..$^{45}$ Instead, in this chapter, I choose a strengths-based perspective (Saleebey 2008): if we take the evidence of the 53 percent who are making a livelihood for themselves in handloom seriously, rather than the 47 percent whose livelihoods are precarious, it might provide us evidence for handloom's sustainability, as well as lessons for alleviating the vulnerability of the most invisible among its practitioners. This view makes it possible to differentiate between environments and conditions where vulnerable livelihoods of handloom weavers are sustainable, and those where they become unsustainable.From this perspective, it becomes important to study interaction between vulnerability and sustainability in handloom livelihoods, where vulnerability does not lead only to unsustainability.

Viewing the extinction of handloom weaving as imminent in the future tars the handloom weavers' present with the label of a "sunset" industry, which becomes a self-fulfilling prophecy. Within policy, this has historic roots in three interlinked frames of technological determinism: Industrialization backed by Colonization, Modernization imposed by the state (previously colonial, now the nation state), and International Development. Each of these discourses still carries power in policy circles, even though their credibility has become questionable over time.

Economic historian Roy (Roy 1988), an

44 http://www.thehindu.com/todays-paper/tp-opinion/weft-and-warpof-a-crisis/article4182782.ece

45 This lack of confidence in handloom weaving is evidenced in succeeding budget allocations, the latest government's further slashing the money allocated to the sector http://theotherside.org. in/index.php/issue/march_2015/talk_and_walk_not_together_ handloom_sector_in_union_budget_2015-16__d._narasimha_ reddy last retrieved August 12015 
authority on the effects of industrialization on the textile industry in colonial India is one of those who questioned the view of unsustainability of handloom livelihoods by arguing that it is based on assumptions rather than data. According to him, such characterizations are often accompanied by implicit or explicit assumptions that these sectors are typically composed of subsistence households, simple commodity producers, surviving by dint of super-exploitation of family labor and undergoing continuous immiseration (Roy 1988). Instead, Roy provides an alternate reading of artisanal livelihood through studying technological change historically in textile production during the late 19th and early 20th century. He suggests that "technological change in handlooms cannot be seen as a simple response to competition from powerlooms based in the mills, since the new tools and processes came nowhere near to bridging the productivity gap between these alternatives. Specific markets and the need to become more efficient in supplying these markets, therefore, are as relevant to the experience of traditional industry as the comparison of laborintensive and capital-intensive alternatives" (Roy 2002, 508). However, he cautions that such changes "remained limited in scale and confined to certain places, products, and groups of weavers" (Roy 2002, 509).

Small, whilst beautiful, still does not portend growth, defined as it is by a linear, accumulative, and infinitely expanding scale. Yet, the smallness of the industry is belied by its production capabilities: 7.1 Billion square meters in 2013-2014. ${ }^{46}$ Haynes adds to a nuanced understanding of weaver sustainability through his in-depth historical studies of the interactions between handloom and mechanized textile production. He suggests that handloom weavers' ability to customize products to suit small regionally focused markets, even if these were distant, allowed them to survive in the face of competition from mechanized production (Haynes 2001).

In India, indigenous knowledge systems

46 Annual Report of the Textile Ministry of India 2014-2015 http:// texmin.nic.in/annualrep/ar_14_15_english.pdf first faced technological determinism during British colonization. The assumption that Indian technology would inevitably follow the Western technological trajectories, for example, from craft production to mechanization presumed that traditional knowledge should give way to scientific advances of the West. This destructive agency of British colonialism disrupted indigenous political, legal, and ritual systems effecting disastrous social change. In doing so, it seriously degraded the inherent capacity of local system builders to deal with the consequences of technological change (Pfaffenberger 1992). Vijaya Ramaswamy (Ramaswamy 2006) traces the steadily growing fortunes of handloom weavers in South India from the 10th century up until the 16th, the period of the Vijayanagara Empire, with growth in both domestic and foreign trade. She quotes from the personal account of French navigator Francois Pyreard (1578-1623) writing around 1600: "everyone from the Cape of Good Hope to China, man and woman is clothed from head to foot in the products of the Indian looms" (Ramaswamy 2006, 70).

Contrast this to the statement attributed to Lord Bentinck of weavers in colonized India in the 18th century: "The bones of the cotton weavers are bleaching the plains of India" (Ramaswamy 2006, 4). However, as India fought for freedom from colonial rule during the first half of the 20th century, the political philosophy and practices of Mohandas Karamchand Gandhi (1869-1948) provided a strong counter point to the discourse and effects of western technological determinism. Closely integrated into the political program of Gandhian critique of colonial imperialist subjugation and the proposal for a possible model of democratic independent nationhood of India was the formulation that the technological process is inherently a social process that is integrated into political, social, and economic contexts (Ninan 2009).

This discourse informed social movements, environmental activism, and civil society organizations who adopted Gandhian modes of resistance (Linkenbach 1994, Swain 1997, 
Bandopadhyay and Shiva 1987) and Gandhi figured as a central theme (Saravanamuthu 2006) in the wide-ranging discussions on sustainable development (Hopwood, Mellor, and O'Brien 2005, Redclift 2005) throwing insightson the "apparent tensions" (Stirling 2007) in the social choice of sustainable technology (Ninan 2009). Handloom activists were quick to see the opportunity for positioning handloom within this debate; from being framed as manual and obsolete technology, its non use of electrical power afforded it new relevance that of being sustainable technology: "The handloom is a low carbon footprint technology for the energy-stressed future. ${ }^{" 47}$ Rather than give into the deterministic ideal of powering looms in order to increasing productivity, this influential activist in 2014 evocatively calls for the recognition of "the power of handloom" for sustainability across times: "behind the cloudy present, the past reminds us of the possibility of another future." 48 Such framings allow her to make other linkages, to other vulnerable rural livelihoods, and to the loss of other knowledge systems, for example, the calamity engendered by forcing farmers to grow risky American cotton varieties that are alien to the soil and climate of India: “one of history's largest socio-economic tragedy: the long thread of farmer suicides in the Indian sub-continent." ${ }^{49}$

Another key descriptor of unsustainability in traditional communities such as handloom weaving is the discourse of development that "results in concrete practices of thinking and acting through which the Third World is produced" (Escobar 1995, 11). Development is broadly seen as an economic model, a functional concept of transformation of a "traditional" society into a "modern" one devoid of any cultural considerations. Subsumed in this understanding of development is a deterministic understanding of the good that western science and technology can do for

47 http://www.lilafoundation.in/2014/10/21/uzramma-cotton-clothcontinuity/

48 http://www.lilafoundation.in/2014/10/21/uzramma-cotton-clothcontinuity/

49 http:/www.lilafoundation.in/2014/10/21/uzramma-cotton-clothcontinuity/ the "underdeveloped" third world.

In 1949, Truman had called to the western science and technology establishment for "a bold new program for making the benefits of our scientific advances and industrial progress available for the improvement and growth of underdeveloped areas" a statement that displayed a high degree of technological determinism that remains very present in public discourse that constructs handloom as unsustainable and outdated technology (Cherlet 2014, 774).The term Technological Assistance (TA) was first coined in 1947-1948 to indicate the official help of the UN economic affairs department to the underdeveloped world. It referred to a program of unidirectional knowledge transfer in the hands of Western experts and was colored by evolutionist thinking (Cherlet 2014, 780). Oppositional movements, inspired in part by various environmental and civil rights movements of the 1960s, championing "alternative technology" models also came to the forefront prominently during this period (Schumacher 2011). By the end of the 1960s, the concept of appropriate technology and some sensibility of local knowledge were gradually adopted in the World Bank models of technology transfer (Visvanathan 2001) but still technology transfer itself was not questioned. Emerging as opposition to the ideology of TA, "capacity building" did try to harness local expertise in order to build up local capacities, but as Wilson (Wilson 2007) remarks, capacity building-like TA - still focused on learning things that are already known by one of the actors. While International funders acknowledged now that knowledge was embedded in social and cultural contexts, capacity building was still suspected by civil society actors and NGOs as being a way of disciplining local ways of knowing into universal knowledge, rather than grasp or support genuinely different perspectives as the basis for culturally variant alternatives to development (Escobar 2012)(Mosse 2013, 232).

For example "sustainable development" was introduced in the Bruntland Report as development that meets the needs of the present without 
compromising the ability of future generations to meet their own needs (WCED 1987), with the goal of "maximizing goal achievement across these three systems (economic, social, and environmental) at one and the same time through an adaptive process of trade-offs" (Mebratu 1998, 505). However, academic work from disciplines such as anthropology and development studies rooted in a tradition of dissent is critica ${ }^{50}$ : in this example, Pestre, suggests that "in bringing the different domains of political consensus, rural development and business interests together, the term has come to replace the tension that used to pit the discourse of unlimited technological development in the service of resource-intensive growth against those who advocated a different idea of development" (Pestre 2008, 110). In fact, he warns, over the last two decades, the overarching acceptance of the term has resulted in the vanishing of the opposition:

"Even if the expression of 'sustainable development' forced recalcitrant people to take the environment seriously into account, which is a good thing, overly positive views concerning sustainable development might assist an overly facile fusion of fish and fowl, reassuring everyone of their own environmental and economic good sense. They might allow us to lead a comfortable existence in a happy and reasonable world, since we now know how to progress in a healthy manner-how to think about development and sustainability, (rather than) be aware of the profound uncertainties generated by technological development and (be) able to reflexively assign both this uncertainty and our ignorance to their appropriate places" (Pestre 2008, 110).

The turn to neoliberal development in the $1980 \mathrm{~s}$ and $1990 \mathrm{~s}$ brought in deregulatory adjustment and economic liberalization that turned national development into a matter of creating the conditions for attracting mobilecapital to enclaves

50 "STS for Development" -Chapter in forthcoming Handbook of Science and Technology Studies $4^{\text {th }}$ Edition of production of labor-intensive goods for global markets (Mosse 2013).Within policy, measurable economic and financial outcomes became the primary goals for evidencing development. Again, critics were scathing in their descriptions of the consequences to the "bottom billion," who live under the curse of ungoverned resource extraction (Collier 2007).They observed the demobilizing effect of development through marketization as the "appropriation and co-option of pre-existing cultural and social achievements" (Harvey 2003, 146) that depleted numerous livelihood systems. Development projects and bureaucratic power were no longer the focus of critique.

Scholarship and activism highlighted instead the loss of state power in the government of development. In the age of neoliberal reform, the terms following of official state, collapsed state became descriptors of government, as NGOs, donors, social entrepreneurs, and private sector providers (Li 2005) gained power. As a result, the idea of governance made its appearance, but with continuity in the key effect of bureaucratic arbitrariness and neglect on either side of a major ideological policy shift from state welfare to "empowerment" in Indian projects targeting rural women and children (Gupta 1995). From this location, critics of development saw this as a modernization agenda of the west; in framing it as catch up and given it paternalistically as a good thing, there was a lack of freedom of choice for its beneficiaries. The South's encounter with modernity was described in contrast to that of the west, rather than being unequivocally positive, the technological change it brought became a place of conflict, rather than a way to achieve "the freedom to envision both problems and solutions in local ways without the imposition of categories used in the sciences or technologies of the North" (Cozzens et al. 2008, 790).

Against this background, handloom sustainability vs. its unsustainability is a debate over which there is no clear consensus between different actors engaged with sustaining handloom livelihoods, as well as its detractors. As an example 
of such a debate, I present different problem definitions of handloom that emerged in a meeting convened by a group of civil society actors in response to an on-going crisis in handloom livelihoods. The public meeting was organized in Hyderabad, Telangana, India, in February 2014; to draw public support against a policy move by the Government of India to alter the definition of handlooms, to include mechanized production ostensibly for modernizing and improving weaver livelihoods. Civil society actors felt that this was a backdoor invitation to the powerloom sector, to legitimize its position vis-a-vis the handloom market, and protested it vociferously. One influential activist explained that such a redefinition would "blur the differences between power loom and handloom to claim benefits limited to handlooms" and muscle on the huge demand for handmade, while wearing a mask of pity for the "poor" handloom weaver. Invited to the meeting were actors from NGOs, civil society institutions with links to weaver communities, and consumers. The press note issued prior this meeting was as follows.

"The recent move by the Government to alter the definition of handlooms once again brought home the callous attitude of the state towards this sector. With support from important and influential individuals and organizations, like yours, we were able to put pressure on the Textile department to at least shelve the idea for the present. [...]There is no guarantee however that they will [not] come up with some other idea that will be directly against the interests of the sector. If we look at the previous record of the State and Department, we can find any number of instances where the policies did not help the handloom weaver and instead served other interests." 52

The responses of the civil society actors, activists, and scholars in this meeting were revealing

51 http://www.livemint.com/Industry/bAQbFuEgGCEFrrUGOm7zxJ/ The-power loom-lobby-is-out-to-destroy-Indias-handloom-advan.html

52 https://www.facebook.com/events/619297294790048/ permalink/620387774681000/ in their multiplicity. ${ }^{53}$ One activist actor pleaded for an understanding of the history of handloom weaving in order to contextualize the current decline. "We have to share with our weaver and activist friends how weaving has been deliberately decimated in colonial times by the East India Company, and continued by our own state, in order to advantage the mechanized textile lobby." Another actor rued the absence of policy makers in the meeting. "But policy makers and enumerators don't have time for us. We need to talk to them." Another empathetic social worker wondered why contemporary society and academics were unmoved by the crisis. "Why are these questions not of interest to people, when weavers are committing suicide, why do social science departments not conduct studies? Why have we come to a point where our weavers think there is no one for us, we have to commit suicide?"

A young NGO leader presented another perennial opposition between the weaver and the consumer, welfare, and market. "Are we working for the weaver, or for the consumer? Government policies will not serve: if handloom is not to be decimated, we need to work with Corporates." A more mainstream actor from the financial sector urged for a progressive look towards the issue. "There is a huge opportunity to reach global markets, we should not limit ourselves- we need to think not just nationally but globally." A handloom policy analyst suggested the problem was perspective regarding technology. "The way we all look at technology is problematic." An environmental activist suggested focusing on climate change. "Sustainability is a big value now, and we should focus on this, on environmental sustainability also as ethical business." A young handloom NGO leader suggested that consensus must be reached. "We have to first integrate all the people who matter to make our point, this is important. Somewhere we have to reach out to consumers, it is true, but we have to importantly reach policy makers." A provocative political activist played the devil's advocate and

53 All quotes are from the transcript of the meeting that I attended as observer on February 2014 
wondered aloud "If handloom is dying, we should let it die. Why should we save something that is dying? We who are in rural production, we have to change along with changing times, and promote it in the way that will work." A woman's rights activist was torn between the elitism of the product and its beauty. "It seems to be only for the elite, it is beautiful, but it is expensive, so I am a bit confused." A production worker from a handloom NGO warned that this move would affect weaver morale. "The weaver gets angry, and loses trust."

The argumentative even conflict ridden nature of the different perspectives seems to be in contrast to the stated purpose of the participants to reach consensus and speak with a unified voice against the government's move. However, common themes did emerge. The different actors could be seen to be responding to the exogenous factors that effected handloom weaver livelihoods. Nationalism in the 1940s, socialism in the 1950s and 1960s, liberalization, foreign funding, and NGO interventions in the 1990 s, and social media and e-marketing platforms today, affect handloom like many other livelihoods in rural India. Among the activists were technologists, marketing agents, political activists, social entrepreneurs, designers, and even academics, who leveraged and optimized resources for their constituency. This voluntary participation of different kinds of professional actors in the different capacities of field workers, consultants, policy workers, and so on softened the distinctions between theory and practice and generated further ethnographic knowledge and epistemological debate through variants of reflective “observant participation” (Mosse 2006, Gow 2008, Rottenburg 2009).

Parallels can be drawn between Amartya Sen's commentary on Indians' predilection for debate (Sen 2005), and the nature of the interaction (and many others in which I was a participant) that I present above. According to Sen, argumentation is not necessarily divisive; it is through resolving argumentative positions that possibilities for new solutions emerge as third alternatives to dialectic framings. This process can be generative, as evidenced by the multiplicity of engagements, as well as diversity of solutions that seek to resolve the problem of handloom livelihoods in contemporary India.

\subsection{INTERPRETATIVE FLEXIBILITY OF HANDLOOM'S UNSUSTAINABILITY}

The substance of this chapter is that whether or not handloom livelihoods are perceived as sustainable depends on how the existing sociotechnical ensemble they are embedded in interprets their problem, and acts to ameliorate the vulnerability that emerges from that interpretation. This is what the multiplicity of problem definitions and solutions is all about. In this context, the emergence of unsustainability as a dominant way of describing livelihood problems becomes an important topic for study for STS. What assumptions are embedded in its framing? Where does it reify existing conceptual categories? In what sense does it allow us to comprehend the problems of vulnerability in traditional technologies? If unsustainability of handloom is seen as the culminating effect of the inevitable modernization of technology, how will we ever dismiss technological determinism from the public agenda? To what extent then can we facilitate a "more reflexive form of modernization," (Hajer 1995, 4) one that is democratic in its framing of traditional livelihoods?

In order to assess the usefulness of conceptualizing "handloom unsustainability" for our purpose, we need to understand the acceptance of the notion of unsustainability in handloom livelihoods, and how it is taken up in actual practice. Social constructivists have shown us that different actors are likely to hold differing perceptions of what the problem "really" is, rather than the single problem-single answer model in politics. (Hajer 1995, 43, Bijker et al. 1987 (2012)) For this reason, this chapter contains a fairly detailed description of the discourses around the emergence of the notion of 
unsustainability of handlooms in different sections of Indian society. Discourse is defined as "a specific ensemble of ideas, concepts and categorizations that are produced, reproduced and transformed in a particular set of practices and through which meaning is given to physical and social realities" (Hajer 1995, 44). Here I use discourse as a signifier primarily to disentangle different social groups' representations of handloom livelihoods. Within each discourse is embedded the actors' understanding of unsustainability of handloom livelihoods, which make perfect sense when taken by themselves, but are only part of the debate that exists in the larger ensemble, in contexts of the other actors' actions and interventions that "do not function according to the discursive logic of that original discourse" (Hajer 1995, 46)

Discourse analysis has roots in analysis of ideology, rhetoric, the sociology of science, and language philosophy up to post-positivist interpretative traditions (Hajer 1995, 43). It shares much common ground with social constructivism, to which I add the argumentative tradition (Sen 2005, Hajer 1995, 58) to show how old arrangements have developed, and new arrangements may be developed in the handloom ensemble, that allow handloom to sustain itself. These arrangements between social groups in the ensemble are a result of coherence in discourses in parts of the ensemble, rather than consensus across all. In order to bring out the multiple discourses in handloom livelihoods as our actors may see them, I draw from the conceptual leitmotif of the sociotechnical ensemble. In doing so, I extend the unit of analysis from weaver to sociotechnical ensemble. As important contributors to the livelihood discourses, I include the following as relevant social groups and their institutions in the handloom ensemble - consumers, business, and textile industry actors who form the market; state supported primary weaver co-operatives, policy planners, state, and public sector institutions that support handloom; cultural conservation groups, activists, media groups, and civil society actors such as NGOs that wish to alleviate vulnerability for weavers; and most important, the weavers, allied workers and master weavers who are important to production. In the following sections, I am then able to show interpretative flexibility in the understanding of unsustainability of handloom livelihoods within each group's discourse.

While presenting the RSGs, I also give a historical account of their discourses. Some of these discourses have already been discussed in the literature review in Chapter 2, so readers will perceive an overlap with the arguments in the next four sections. I reintroduce them again since I will later in the chapter be discussing how discourse alliances form between the different RSGs.

\subsubsection{BUSINESS GROUPS: CONSUMERS, RETAILERS AND TEXTILE INDUSTRY ACTORS}

Handloom cloth is an economic commodity which Indian society has valued for different reasons through time. In pre-colonial times, cloth was important not "merely in fixing and symbolizing social and political statuses, but (also in) transmitting holiness, purity, and pollution" (Bayly 1986, loc5692). The spirit of the gift and the perception of "evil" continued to be association with cloth, even within a fully developed cash economy - in the early 20th century, during th e Indian struggle for independence, handloom cloth could "evoke powerful symbols of community and right conduct" (Bayly 1986, loc 7331). Later, in the post-liberalization period of the 1990s, handloom cloth acquired value in emerging markets with socially responsible customers. Currently, the ecological dimension of sustainable production for societies concerned about an energy-stressed future adds further value.

Among Indian women, the saree continues to reinvent itself across various market niches, from the coarse daily wear to the fine occasional wear: as a category, it clocked an impressive 8.8 percent annual growth in value terms between 
1998 and 2006 to become a 53,459-crore market, whereas all other textile categories reported a decline in growth rate in value terms. This was the prerecession growth period, when the economy was growing, with growth opportunities for women and disposable incomes. Growth rate in volume terms accelerated to 8.4 percent during the same time; the humble saree was reported to make up a \$12-billion plus market, which accounted for more than one third of total consumption of apparel and household textiles in India. ${ }^{54}$ Generally, one in five of the total cloth production is estimated to be handloom. ${ }^{55}$ There was a downturn during 2008-2009, but the textile ministry plots an upward trajectory in the following years leading to $2013-2014 .{ }^{56} \mathrm{~A}$ report from Reliance, one of the largest textile companies predicts that by 2026 one third of all fabric production across sectors will be sarees. ${ }^{57}$

Currently, India's textile industry contributes about 14 percent to industrial production, 2 percent to the GDP, and 11 percent to the country's export earnings. ${ }^{58}$ The textile industry, as a whole, employs around 35 million people; the unorganized sectors of knitting and hosiery, powerloom and handloom between them account for 90 percent of jobs. Two main weaknesses of the textile industry are stated as its technological backwardness; while power loom runs mostly on obsolete machinery, handlooms are not automated; and the fragmented nature of the decentralized weaving, processing, and garmenting segments. A core component of government strategy is the provision of technology upgradation schemes, both for powerloom and handloom. Power loom and handloom products compete for inputs as well as market share, whereas the ministry that serves both is the same, leading to allegations of

$54 \mathrm{http}: / /$ articles.economictimes.indiatimes.com/2008-07-08/ news/27726724_1_saree-growth-rate-textiles[ICRA report quoting statistics from the ministry of textiles] last retrieved 6 July 2015

55 http://texmin.nic.in/annualrep/ar_14_15_english.pdflast retrieved 6 July 2015

56 http://texmin.nic.in/annualrep/ar $14 \quad 15$ english.pdflast retrieved 6 July 2015

57 https://www.academia.edu/3362720/Apparel Demand Estimation in_India_by_End_Use_2011_to_2026last retrieved 6 July 2015

58 Strategic plan 12-16 http://texmin.nic.in/aboutus/rfd/strategic plan_2011_2016.pdflast retrieved 6 July 2015 conflicts between the interests of each, with regard to the other. Generally, they also share geographies, and historically have shared local labor and capital (Roy 1999). In fact, the fast pace of productivity advance in the handloom weaving sector in the late 19 th and early 20th century could be attributed to the adoption of techniques from the industrialized sector (Sivasubramonian 2000).

Cotton and textiles have been at the center of India's journey to industrialization and modernity. Accompanied as it was by the experience of colonization, and subsequent fight for freedom from colonial masters, the journey to modernity has not been a uniformly positive one. Particularly in textiles, rather than gain from the increase in productivity that industrialization brought, by the time India gained her freedom in 1947, she had lost a large part of her superiority and popularity in the cloth markets of the world. During the 17th and 18th centuries, the opening of the sea routes expanded the export trade. This had the effect on the kind of products being woven by handloom weavers, as they increasingly produced for distant markets, where previously they had produced for local consumption. An intermediary class of trader financiers emerged, who mediated between the producer and the distant market.

Seemanthini Niranjana, policy activist and scholar of Indian handlooms, presents a balanced perspective of the debate around the impact of British rule on the handloom industry (Niranjana and Vinayan 2001). The debate is centered on whether colonial contact destroyed traditional Indian industry or created conditions for creative reorganization of the institutional structures and adaptation of the handloom industry (Roy 1999). Marx (Marx 1853-54 (1979)) suggests the first: "It was the British intruder who broke up the Indian handloom and destroyed the spinning wheel. England began with driving the Indian cottons from the European market; it then introduced twist into Hindustan, and in the end inundated the very mother country of cotton with cottons. From 1818 to 1836 the export of twist from Great Britain to 
India rose in the proportion of 1 to 5200 . In1824, the export of British muslins to India hardly amounted to $1,000,000$ yards, whereas in 1837 it surpassed 64,000,000 yards" (Marx 1853-54 (1979), 128).

The survival of the indigenous artisanal economy to date needs explanation, historians, and scholars have documented this dynamism in response to changes in conditions under which cloth was produced and sold (Baker 1984, Harnetty 1991, Haynes 1996, Roy 1999, 1998a, Specker 1989). From exporting textiles to Britain, India became a systematic supplier of raw cotton to the British mills set up during the Industrial revolution, as early as from 1788 (Buchanan 1934, 195). The first assignment of British textiles reached India in 1821, and was the start of the decline of Indian handloom (Das 2001, 19). The different forms of industrialization-railway transport of cotton, mechanized spinning, and import of synthetic dyes served to sever the connection between agrarian and artisan communities-agrarian labor were eliminated from the textile industry (Wendt 2005b). The female workforce employed in spinning, for instance, were the worst affected by the import of cheap yarn from England (Parthasarathi 2009).

Therefore, some important changes were wrought; first, there was a disruption in the links between hitherto integrated processes such as spinning of yarn and weaving of cloth. Second, the independence of the individual weaver dwindled, as yarn dealers and financiers played increasingly powerful roles in production and marketing. Finally, indigenous knowledge was replaced in most parts by industrial technology, as capital was put to work to increase productivity. As a result, the handloom was increasingly marginalized, while mechanization was seen as a sign of progress.

The handloom sector had become dependent on yarn produced by mills, while facing competition from cloth produced by mills, around the First World War. This created a competitive relation between the sectors and problems for the handloom industry; around the time of the Second World War, the adverse effect of expansion of mills on the livelihoods of handloom weavers was realized (Niranjana and Vinayan 2001). Certain concessions came to be given to handloom, and growth of the mill sector was regulated. The power loom sector, a curious intermediary between pre-existing handloom and mill segments emerged from the 1920s onward. It consisted of hundreds of small units set up by enterprising individuals, of 5-10 power looms, usually discarded machinery of the composite mills. They functioned below the regulatory radar, and accrued benefits of being cottage industries, and a number of handloom weavers switched to work in power looms. The Ministry of Labor reports by 1983 say "The growth of power loom was so rapid that yesterday's traditional handloom weaving centres also grew to be centers of power loom industry. The traditional handloom centres like Malegaon, Ichalkaranji in Maharashtra, Burhanpur in M.P., Belgaum in Karnataka, Karimnagar in A.P., Erode and Salem in Tamilnadu...became power loom centres as well" (GOI 1988, 3).

Several scholars have traced technological trajectories of the textile industry in India over the last century, against the changing landscape of industrialization, colonization, and differing social and geographic circumstances. N. K. Meera (Meera 2011) concludes from the study of handloom weavers in Coastal Andhra during the late 19th and early 20th century that "the history of industrialization in the West is taken primarily to mean the evolution of the factory from craft industry, generally presupposing the prior developments of a market economy, the social differentiation of the peasantry and the changing legal and social structures.

In India all these forces were working together at the same time and if some showed signs of acceleration in the late nineteenth century (as seen in the case of Andhra), that development usually had long historical roots, predating the imposition of colonial rule" (Meera 2011, 41). Haynes points to the distinct pattern of industrialization that took place in the textile sector India during the early 20th century, as a result of "a convergence between patterns of change that had been taking place 
within artisan communities and the strategies of larger capitalists from outside those communities" (Haynes 2001, 197). Nineteenth century processes of industrialization led to the professionalization and masculinization ${ }^{59}$ in the handloom textile industry (Wendt). The Indian bourgeoisie began to expand into industrial activity, and large merchant capital or indigenous origin was transformed into large industrial capital around the late 19th century. Whether the colonial state aligned or not with indigenous industrialization is under debate, but it is clear that in the first half of the century, with the various economic and politicalinfluences coming into operation the Indian mills made progressrapidly whereas the handlooms were left neglected for sometime (Meera 2011, 154).

During the turn of the last century, the "swadesi" movement stirred entrepreneurs to act against foreign industrial interests. N. K. Meera (Meera 2011) explores the contradictory connections between the mills and handloom weavers, particularly in relation to the ambiguous role that the business class played in the Swadeshi movement. On the one hand, the business class expanded into industrial activity, on the other, they participated in the Khaddar (hand spinning) movement of Gandhi, supporting handloom weaving, and lobbying for protection for handloom against mill competition.

Similarly, colonial governments were ambiguous about how handlooms and mills would co-exist, in the Indian textile industry. Alfred Chatterton was appointed by the Government as the Director of Industrial and Technical Enquiries in 1906, where he supervised experiments in improved methods of weaving, leading to the introduction of the fly shuttle loom, displacing the country loom. The Department of Industries came into being in March 1914, in order to view all matters affecting industries or industrial education, and one of its core aims was to ascertain whether conditions of handloom weavers could be improved by introducing different machinery for weaving.

59 For detailed break ups of contribution of women to family earnings see in 17th-18th centuries (Wendt 2005b, 25)
P. T. Chettiar, leader of the Devanga community made similar experiments at great cost, in his factory. While some of the weaving centers of coastal Andhra took to these looms, some others attached fly shuttles to their old looms.

In areas where Gandhian influence and the 'Khaddar' movement prevailed, so did the old looms continue to ply. On the other hand, efforts were made to mechanize part of the preparation machinery such as winding, warping and sizing, dyeing, as well as for cotton spinning. Under the auspices of the Government of Madras, the All India Charkha Committee introduced power-driven charkas, to increase productivity in the Khadi and Handloom sector, to protect weaver livelihoods. Gandhi in attempting to reduce the antagonistic position of the mill owners who, thus, far had supported hand spinning, in fact urged mill owners "to make common cause with Khadi as there was enough room for both of them in the years to come," such interventions make it particularly difficult to disentangle the ideological from the "purely material" (Meera 2011, 36).

The emergence of the power loom demonstrates a critical break from the western trajectories of industrialization in the Indian textile industry. Roy (Roy 1998a) refers to the "dismantling" of mill weaving in the Indian cotton textile industry in the 20th century, as against their rise in the 19th century. The new system that emerged, referred to as "power loom sector" characterized by "(a) deintegration of processes, (b) an organization that utilizes inter-firm co-ordination more than intrafirm hierarchy, and (c) agrarian-artisanal origin of capital" (Roy 1998a). Power looms consist of small firms with 6-20 looms, and first appeared at the turn of the century, when communities with experience in handloom weaving invested in their growth.

Weaver capitalists of western India who hereditarily owned up to weaving as their profession expanded their operations and invested in technological innovation in the 1920s and 1930s. They began to buy discarded looms from the mills, place them in their homes and manufacture cloth 
using oil or electric power (Haynes 2001, 173). Eventually, mills and power looms ceased to have competitive relations, as mills were highly capital intensive and became less viable, and capital shifted out of the mill network to power looms by 1960 s. At this stage Roy suggests, the handloom root of power loom was diluted (Roy 1998a).

Haynes, focusing on the period between 1920 and 1950 directs attention to the importance of this kind of "informal" industry in the history of industrialization. Since power looms were largely organized as small firms, they operated under the regulatory radar, especially in the areas of taxation and labor law, wages could be kept low, and workers hired only on a casual basis, avoiding unionizing He draws parallels to the concept of "flexible specialization" formulated by Charles Sabel and Jonathan Zeitlin in depicting 19th century industrial change in Europe outside Britain (Piore and Charles 1984), but he adds that this flexibility gave rise to another one, the ability to add and drop workers without fear of strong resistance organized by trade unions. The development of this industry depended though on the prior existence of the large-scale mill for its technology; Haynes refers to this development as "secondary industrialization" (Haynes 2001, 185). An important scholarly denouncement of the consequences of such an informal industrialization is of Jan Breman (Breman 1996).

Policy makers in Delhi withdrew from their policy of protection for labor intensive handloom production, which had been in place from 1948, in 1985. This policy had frozen mill capacity in weaving, exempted handloom product from excise duty, charged lower price for hank yarn used by the handloom industry, checked growth of power looms by a scheme of licensing installation and reserved some products solely for handloom, mainly coarse and colored sarees. However, these conditions of economic control became unimplementable and difficult to monitor, particularly in the face of powerful power loom lobbies that controlled more than half of the entire textile production in India. The "contradiction between Delhi's theory and the regions' practice became stark" (Roy 1998a, 905). Furthermore, the policy legalized all power looms, and the aura of illegitimacy around power looms began to wane. After economic liberalization in the 1990 s, there was uncertainty in the cloth market, forcing out small players in the power loom sector, and consolidating the fortunes of the larger ones. Today, the official share of power loom production stands at almost 80 percent of textile production in India, with official policy reiterating the need for technological upgradation in order to become competitive in global markets.

Yet, the vibrancy of demand for handloom continues: making it attractive for power looms to imitate handloom products and compete for a share of their market. There are many instances of handloom product being successfully sold through innovating domestic retail models, including those that sell both handloom and power loom fabric interchangeably. Cottage Industries, Contemporary Arts \& Crafts, Sohan, Anokhi, Sasha, and Fabindia ${ }^{60}$ of John Bissell were among the marketing agencies that while supporting livelihoods created new market niches for handloom. Other examples of market niches include the older ritual product markets which tend to be regional, the cultural identity product market which tends to be global, the fashion market for luxury and customized product, the green and sustainable market, which is trendy and attracts socially responsible young customers and the ethnic boutiques with their followings. Since customers in these niches tend not to necessarily be bound by geographies, these products are increasingly entering online spaces, in order to reach a dispersed niche. In most mainstream retail, they compete with machine produced textiles, customers often cannot tell the difference; sometimes even when they do, they opt for the cheaper imitation. This has given rise to accusations of infringement of intellectual property rights by power loom on handloom,${ }^{61}$ and a

60 http://www.fashionunited.in/news/apparel/fabindia-gets-fipb-nodto-hike-fdi-to-495-220520123636last retrieved 6 July 2015

$61 \mathrm{http}: / /$ www.thehindu.com/todays-paper/tp-national/tp-newdelhi/ handloom-weavers-oppose-intrusion-of-power-looms/ article3925024.ecelast retrieved 6 July 2015 
plethora of state interventions to counter this effect: the handloom reservation act, ${ }^{62}$ and more recently the GI and Craftmark to certify authenticity in textiles.

At the same time, approaches to marketing that aimed at equity were being experimented with internationally in the neoliberal market place of the 1980s and 1990s. Conceived in the heart of the free market ideology, in the mid-1990s, the term "triple bottom line" referred to performance on three axes for sustainable practices for businesses in capitalist economies: financial profitability, social responsibility, and environmental impacts (Elkington 1998). For corporations that work within a market rationale, this was a possible transformative intervention in their goal of achieving public good. While the profit parameter continued to be advantaged over the social and environmental parameters as a condition for investment (O'Laughlin 2008), it laid the foundation for thinking of new ways to green capitalism and to hold corporates responsible toward society and the planet through sustainable development ideals.

Bringing society and market closer, new approaches such as social entrepreneurship, social marketing that have been taken up by NGOs in particular in order to make a place for agricultural and artisanal produce in the emerging organic and sustainable consumption market niches (Loconto 2014).These efforts are nascent, particularly as they tend to offer long term social gains to society and environmental gains to the planet, rather than short term returns on capital. In addition, critics of this approachwarn us that such all-encompassing discourses may "conceal more than they reveal about what is at stake" (Pestre 2008, 101), that is, end up serving interests of holders of capital, even as they attempt to serve producers and consumers.

\subsubsection{Public Sector Groups: Policy planners, state institutions and Weaver CO-OPERATIVES}

The Development Commissioner of Handlooms was set up in 1975 initially under the department of Commerce, and is headed by a civil servant who currently has the standing of Additional Secretary, with 30 years of experience in the Indian Administrative Services, second in charge only to the Secretary of Textiles, who reports to the minister of Textiles. The office is assisted by 25 Weavers Service Centers that have a function in "skill upgradation, capacity building, and dissemination technological intervention for reducing the drudgery to the handloom weavers and better productivity, thereby improving earnings for the weavers." ${ }^{3}$ They provide design input, technology training, and market linkages. In addition, the NHDC, located in Lucknow provides input support such as yarn, dye materials, mainly through the co-operatives.

At the state level, the Department of Handlooms and Textiles oversees Handlooms and

62 http://www.thehindu.com/opinion/op-ed/the-handloom-reservationact-more-power-to-skilled-hands/article7170956.ecelast retrieved 6 July 2015

63 http://handlooms.nic.in/User_Panel/UserView.aspx?TypeID=1191
Powerlooms in the co-operative and decentralized sector; thus, they are charged with supervising in the erstwhile state of Andhra Pradesh, (now Andhra Pradesh and Telangana) the working of Weavers Co-operative Societies; Apex Societies like APCO, the public sector marketing agency for handlooms; Power loom Societies and the implementation of schemes to support handloom and power loom sectors. Apart from the three regional offices, there are 18 offices of Assistant Directors in 18 districts, and two Weaver's Service Centers that impart training to members of the societies to work on "improved" looms and upgrade their skills. There is a provision in the 1985 textile policy of reserving 22 varieties of products from powerloom imitation through the Handlooms (Reservation of Articles for Production) Act of $1985 .{ }^{64}$ The DC Handlooms at the center level also oversees its implementation through its Enforcement Wing, with the regional offices at Chennai and Ahmedabad. The Department

64 http://handlooms.nic.in/writereaddata/UploadFile/Act\%201985.pdf 
has established an Indian Institute of Handloom technology in Venkatagiri, in 1992, offering a diploma course in Handloom, which has since proliferated.

Handloom policy before 1985 reflected the state's attempts to balance a socialist agenda protecting handloom livelihoods, and a neo-liberal agenda of growth through mechanization of the textile sector. The Industrial policy of 1948 had a stated goal of "supporting cottage and village and small scale industries by restricting the volume of production in the large scale sector" ${ }^{\prime \prime 5}$ as did the Cotton Textile Order passed in the same year to protect handlooms and power looms from the mill sector (Vinayan 2006).

Among the many expert committees, the government instituted to resolve its position, Kanungo Commission in 1954 first differentiated between handloom and power loom, recommending a progressive conversion of handlooms to power looms, over a period of 15 to 20 years (Correspondent 1954), the Karve Committee suggested the opposite, though making the same differentiation between handloom and power loom that handloom be protected through "freezing mill and power loom output at existing levels" (GOI 1955, 89). The textile policy of 1956 accepted the recommendations of the Karve Commission, supporting employment over productivity concerns. In 1964, the Ashok Mehta Committee reiterated the perspectives of the Kanungo Committee, and this time the government gave permission for the planned expansion of the power loom sector. In 1974, the Sivaraman Committee report which was pro-handloom, suggested that handloom might need protection from the power loom, pointing to loss of employment in handloom for every power loom set up (GOI 1974).

Later policy directives continued to reflect the competing ideological perspectives of employment versus growth through productivity, and even as the

65 Industrial Policy Highlights, Office of the Economic Advisor, Ministry of Commerce and Industry (MOCI), accessed on 20 October, 2013, http://eaindustry.nic.in/handbk/chap001.pdflast retrieved 6 July 2015 commissioner of handlooms was set up in 1976, schemes put in place to support weavers, and the NHDC set up to procure yarn, the New Textile Policy of 1985 was a decisive shift towards positioning powerloom and mill as the growth sectors, and handloom as a declining industry in need of welfare. In addition to the handloom reservation act, the government also now introduced the Workshed cum Housing scheme in 1985-1986, and introduced the Cotton Textile Order of 1986 which obliged cotton spinning mills to produce 50 percent of their yarn in the form of hank yarn.

Three more expert committee reports were commissioned by the government; the Abid Hussein report (1990), the Mira Seth Report (1996), and Satyam Committee Report (1999). ${ }^{66}$ As before, the first two that were pro-handloom was followed by one that was more reflective of the promechanization paradigm; in 2000 the government rewrote its socialist textile policy based on the recommendations of the Satyam Committee report, in tune with the neo-liberal thinking of the time. This was aggressively debated by Handloom activists and NGOs, and in 2001, for the first time, there was a report on the handloom industry submitted to the planning commission that was independently researched by these actors, titled "The growth and prospects of the handloom Industry" (Niranjana and Vinayan 2001). This loose confederation of handloom activist organizations and NGOs continued to speak up against discriminatory policies towards handloom of the government. ${ }^{67}$

An important village-based initiative to support handloom livelihoods was the cooperative effort in Andhra Pradesh and Telangana in the Deccan, which found inspiration in the socialistic ideology; visualizing co-operation as a significant tool of change as early as the 1900s. Co-operatives were resolutely utopian- "rejecting exploitative control by merchants and middlemen,

66 For a detailed discussion of the different expert committees and surveys from 1930 onward see (Niranjana and Vinayan 2001)

$67 \mathrm{http}: / /$ www.thehindu.com/todays-paper/tp-national/tp-newdelhi/ handloom-weavers-oppose-intrusion-of-power-looms/ article3925024.ecelast retrieved 6 July 2015 
artisans would band together to forge harmonious egalitarian relationships of mutual assistance, suppressing individualistic strivings for personal profit, craftsmen would pool resources to ensure an adequate livelihood for everyone" (McGowan 2009, 139). The objective was to ease poverty through economic collaboration and collective action. The central idea of co-operative organizing was to be the "emancipation of the workman from the blighting monotony of factory life" (Shah 1919, 141). The idea was to maintain and protect economic autonomy and also social autonomy, thereby keeping artisans in charge of production rather than combining them as wage labor into centralized factories (McGowan 2009, 140).

Urgency of the problems of indebtedness, oppression by master weavers and low wages among handloom weavers, identified by the early surveys of the handloom industry (Ranga 1930, Sahai 1933) urged the formation of co-operative bodies that could handle some of these problems. The report of the Fact-Finding Committee (GOI 1942)emphasized the strengthening of the weavers co-operatives as an important strategy in supporting the sector. Initially, providing yarn at subsidized rates was the main concern and later marketing emerged as a concern. Co-operatives were also seen as a vehicle that could help the weavers circumvent corrupt practices in yarn supply by the government during crises (Niranjana and Vinayan 2001, 42).

For producers to improve their negotiation with markets, collective action was seen as an important tool. Envisioned as a socialist democracy, a democratic nation whose economic development would be based on the ideal of shared wealth, the newly formed Indian government proclaimed that it would incorporate the principle of co-operatives into various segments of her development. In 1949, around hundred co-operative societies were formed in the Telangana region; in 1950, the Hyderabad Central Handloom co-operative society was formed to co-ordinate the working of these primary societies. This was merged along with apex body of the Rayalseema region, into APCO, a public sector institution in 1975. It was to a large extent instrumental in improving the lot of the weavers at that time. During this time co-operatives for example in Yemmiganur, Angara, and Mori thrived under good governance both at the co-operative level as well as at the state level. However, under active government sponsorship co-operatives proliferated to double their number, during the period between 1975 and 1985, without reference to their viability or sustainability (Mukund and Sundari 2001, 2).The initiative degenerated, "rendering futile any generalization on the effective functioning of weavers' co-operatives on the whole" (Niranjana and Vinayan 2001, 42). The co-operative sector became open to corruption as well as inefficiencies of public sector organizations: arbitrary merger of co-operatives, control exerted by master weavers and local power groups, the politicization of cooperatives, misappropriation of funds and overall mismanagement are some of the factors that contributed to this degeneration (Mukund and Sundari 2001, 115).

Even though handloom weavers were organized into weaver co-operatives, the notion of kinship and community ${ }^{68}$ continued to be important, implicit in the interrelated nature of personal, social, and economic relations in the handloom industry. Co-operatives are seen as less problematic by secular NGOs than caste organizations, which by definition exclude non-weaving caste members of the handloom ensemble. On the other hand, since co-operatives are organized only with weavers as members, rather than membership across the production ensemble of sizers, warpers, dyers, and reed makers to name a few, most co-operatives end up with members of particular weaver castes; for example either Padmasali or Devangula in the case of the two weaving societies in the village of Ponduru.

Another significant change in the 1985 textile policy was that the textile industry was segregated in terms of process — spinning, weaving,

68 For discussion see (Venkatesan 2009a, 167) 
and value addition — rather than compartmentalized as mill, power loom, and handloom in order to avoid "structural rigidities" (Srinivasulu 1996). Critics saw it as a political move, rather than a practical one, in order to withdraw the protection that handlooms had enjoyed so far, through state policy. In any case, it paved the way for conceptualizing policy interventions that could span both power loom and handloom, such as the cluster scheme.

Michael Porter first introduced the notion of the industry cluster in 1990, in "The Competitive Advantage of Nations" (Porter 2011). UNIDO (United Nations Industrial Development Organization), defines a cluster as a "sectoral and especially small and medium, which share a future, both in terms of opportunities and threats" (Ceglie and Dini 1999). The ability of particular clusters to survive and thrive against competition from mass production led Piore and Sabel to identify flexibility and specialization as alternatives to the Fordist model (Piore and Charles 1984). Fordism, exemplified by the mass-production systems used by car maker Henry Ford (1863-1947), gave workers high wages in return for intensive work.

In the Flexible Specialization model of Piore and Sabel, clusters are viewed as models of flexible specialization, where efficiency in production and organizational adaptability can be enhanced by economies of scale and scope in regional and sectoral settings. In this model, labor is considered as a flexible factor of production contributing to the overall performance of production; flexibility refers to the ability of multi-skilled workers to shift across jobs as and when production requires. Successful clusters were associated with trust relationships between employers and workers, the latter sorted new problems and issues, and constantly learnt new skills. In this framework, labor is a resource to be developed and invested in, not a cost to be minimized, thus giving craft traditions an advantage (Holmstrom 1993).

The introduction of the concept of "collective efficiency" by Schmitz in the year 1999 was a major shift in the theory of cluster. Schmitz's
(Schmitz 1995) definition of "collective efficiency" as "the competitive advantage derived from local external economies and joint action," acting as a catalyst for growth, became then popular. With the "collective efficiency" theory, the high road to growth was made accessible to small enterprises, focusing on the intracluster productive and cooperative networks. Early in the 2000s, UNIDO adopted the cluster-based approach as one of its strategies for contributing to the development of small and medium enterprises in developing countries and as a means of promoting sustainable and equitable growth, while achieving poverty reduction goals.

Cluster development formed the basis of the government scheme ${ }^{69}$ introduced in 2006, as the Integrated Handloom Cluster Development Programme (Thomas 2014).The Government of India (GOI) had constituted an Expert Committee on Small Enterprises in 1996 headed by Prof Abid Hussain (Report of the Expert Committee on Small Enterprises, chaired by Prof. Abid Hussein, Government of India, 1996) who observed that reservations had played only a limited role in promoting small scale industries and advocated cluster-support policies, and focused on technology interventions. In 2005-2006, the Development Commissioner, Ministry of Textiles, GoI, introduced clusters in Handloom industry. The Integrated Handloom Cluster Development Scheme (IHCDP) was an attempt to facilitate the sustainable development of handloom weavers located inside and outside identified handloom clusters into a cohesive self-managing and competitive socioeconomic unit. To avail the support this scheme offered, weaving areas and communities identified themselves as small and medium scale enterprises within a cluster, and accessed new marketing networks with the support of the Cluster development agency. As a result, the cluster intervention became a vehicle for weavers to form their own companies

69 http://handlooms.nic.in/writereaddata/1202.pdf, last retrieved 6 July 2015 
and access new market players; but in the absence of the mediating presence of democratic NGOs, there was no protection from market domination.

The cluster approach was much debated; with Civil Society Organizations who evaluated both the implementation as well as the concept of cluster development suggesting that the cluster approach might well help resourced master weavers to reach new markets, but did not translate well in practice to alleviate poverty of vulnerable producer groups. In addition, in post liberalization India, the government had chosen to take a back step, and was criticised for handing over the prime mover role in economic growth to the private sector. In an endeavor to retrieve its position, implementation and governance of the cluster program was kept within public sector institutions. As a result, the cluster program became another scheme in the long line of government led marketing efforts for handloom that had not delivered its promise.

In the continuing trend to conflate the categories of handloom and power loom came from the Ministry of Textiles, a proposed change in the definition of handloom in 2013. A new definition of handloom as "Any loom, other than power loom; and includes any hybrid loom on which, at least one process for weaving requires manual intervention or human energy for production." Loosely titled "a hybrid loom" the redefinition seemed to suggest that the answer to the problem lies in mechanizing the loom. In response, there was an outcry from civil society organizations over this redefinition, which resulted in the change being retracted by the government in early 2015.

\subsubsection{CIVIL SOCIETY GROUPS: CULTURAL CONSERVATION GROUPS, ACTIVISTS GROUPS, AND NGOS}

In order to explain the unique place that craft occupies in the Indian nation's imagination, I trace a genealogy from art historian Ananda Coomaraswamy (1877-1947), credited with introducing Indian art to the west, through Kamaladevi Chattopadhyay (1903-1988), social reformer and freedom fighter, who singlehandedly turned around the fortunes of craftspeople in independent India and her contemporary Pupul Jayakar (1915-1997) cultural czarina who took Indian craft to international audiences in the 1980s. The institutions that these women built shape what is known as the craft movement in post-independent India.

Ananda Coomaraswamy was a thinker, scholar and linguist with a profound knowledge of the scriptures, mythology, doctrines, and arts of many cultures and disciplines. After the early death of his Tamil father, he was brought up in England by his English mother, before returning to then Ceylon, the place of his birth for his doctoral studies in geology. Here, he became absorbed in the study of the traditional arts and crafts of Ceylon.
He was a leading figure along with scholars such as EB Havell and Sir George Birdwood who took an early interest in India's arts and crafts. In his social ideas, he found that he had been anticipated by the work of William Blake, John Ruskin and William Morris, who represented the foremost critics of industrialism. Morris who famously proclaimed in the 1880 s that "Art is man's expression of his joy in labour," in turn drew his knowledge of Indian craft and art from the work and writings of Sir George Birdwood who authored in 1880 "The industrial arts of India" which became a source of inspiration to the arts and crafts movement.

For many years, Coomaraswamy was preoccupied with the reciprocal relations between daily life and work, the art of a period and the social and spiritual values that governed the civilization in question. He did not subscribe to art noveau's slogan of "art for art's sake"; rather according to his biographer history of art was for him "a question of setting right what had gone amiss partly through ignorance of the past" (Lipsey 1977, 20); thus, he differentiated between the more or less precarious 
"recognition" of "originality" in modern art, and the intelligibility of traditional crafts that was based on "legibility" of a symbolic language (Oldmeadow 2004, 199). Tapati Guha Thakurta (Guha-Thakurta 1995 ) provides a cautionary note on this orientalist framing of Indian art and craft. The statement of Morrissian and Orientalist EB Havell, one of the early proponents of the revival of Indian art about the Indian weaver of the turn of the century India seems to prove right fears of an essentializing and paternalistic view of India.

"Heredity makes the Indian caste weaver a highly skilled artisan, and... his Swadeshi way of thinking does not give the laborer that passion for mere money-making which the West calls laudable ambition.... Every peasant believes that if he is faithful to his dharma (his duty to God and the State) in this life, his karma (place in the cosmos) may make him a king in the next re-birth. Why then should he struggle for mere wealth in this?" (Havell 1910, 163)cited in (Banerji 2002)

Yet, this perspective held the imagination of those who sought to stem the onslaught of industrialization. Summed up in Coomaraswamy's caustic statement "Real culture breeds a race of men able to ask what kind of work is worth doing" is his denouncement of modern education. He believed that it had led to an industrialized society that was inimical to true human development (Oldmeadow 2004, 197). This is echoed in MK Gandhi's summing up of Ruskin's anti-industrial utopianism in his autobiography, "that a life of labour, i.e., the life of the tiller of the soil and the handicraftsman, is the life worth living." (Brantlinger 1996, 467) During the freedom struggle, Coomarasawamy was also part of the swadeshi movement of MK Gandhi, due to his close involvement with the Tagore family, in terms of the need of sustaining traditional artisanship. These movements laid the foundation for the post-independent development of crafts, led by stalwarts such as Kamaladevi Chattopadhyay (Srinivasan 2012) and Pupul Jayakar.

Kamaladevi became involved in the freedom movement at a time when the women's movement and the freedom movement were reinforcing one another. The non-violent philosophy of the self-rule movement encouraged, women of all classes and positions to speak out and demanded a place for themselves in the freedom movement. Kamaladevi herself, born in a traditional Konkani family in 1903, was married at 14 and widowed shortly thereafter. She remarried of her own choice to a rank outsider to her caste, a Bengali poet when she was 20, separated from him ten years later in 1933 and was ostracized by society many times.

She broke almost every social rule an Indian woman could. Kamaladevi never yielded to its pressure, but followed her conscience in both her public and private life (Cobb 1975). Troubled by the "chequer board understanding of community life" of the male leaders of her time and their tendency to treat social evils as different malfunctioning constituents of society, she credited Gandhi with presenting a single canvas - that of Sarvodaya (enlightenment for all) (Chattopadhayay 1983, 2). Kamaladevi's early efforts at craft-basedlivelihoods were to help rehabilitate women who were floodinginto refugee camps from what was now Pakistan. It is probably not by chance that she decided that rehabilitating them through promoting their craftsmanship would provide solace in their dispossessed and uprooted situation. She went on to set up the Cottage Industries Board, the Indian Co-operative Union, the All India Handicrafts \& Handloom Board, the Cottage Industries Emporium, Regional Design Centres, new experiments through Marketing Clinics in different regions, the Crafts Council of India, the Crafts Museum, the national and state awards that have done so much to recognize excellence - milestones on Kamaladevi's journey toward a craft renaissance ${ }^{70}$ in Nehruvian India.

Still she rued the Indian scene of the 1970s when social work had become the "leisure hour pastime" of the affluent class, far from a time with no grants, awards, titles, or press publicity. In her introduction to her book "Indian women's battle

70 http://ccrtindia.gov.in/downloads/other/lecture_5_pro_ashoke_ chatterjee.pdflast retrieved 6 July 2015 
for freedom" (Chattopadhayay 1983) Kamaladevi Chattopadhyay is critical of the history of the social reform movement, which left out women's efforts of her time. Referring to it as a grievous injustice toward the heroic efforts of women toward their own betterment against unimaginable hostility and deterrents, she rues that it is "as though whatever changes were brought about, were men's endeavors alone for social changes and thereby for the amelioration of the women" (Chattopadhayay 1983, 1). Her biographer Sakuntala Narsimhan, suggests that Kamaladevi's swadeshi convictions were also largely fuelled by her feminist agenda: mass production had dealt a deathblow to women who formed the bulk of the work force in unorganized sectors such as traditional crafts (Narasimhan 1999). According to craft historian Jasleen Dhamija, Kamaladevi sensed the importance of combining self-sufficiency with aesthetic fulfillment as evidenced in her statement that everyone had the right to beautiful radiant things, she saw the revival of craft as "linked to our sense of self-worth."

Pupul Jayakar (1915-1997) another influential figure in the post-independence crafts movement, in contrast was a Nehruvian. She was appointed the chairperson of the All India Handloom Board in the 1950s by Nehru, and was a close friend and biographer to the Nehru family. Spiritual leader J. Krishnamurthi inspired her. With the tacit unstinting support of Nehru, who asked her to look at the handloom sector and build a viable industry, she was able to build weavers service centers, public sector marketing structures, and design institutions, the National Institute of Design amongst them. ${ }^{72}$ On the one hand, she recognized the need for repositioning Indian handmade products for the world, investing in design and design education, on the other hand, in her book "The Earth Mother" (Jayakar 1989), she warns that "the danger to rural India lies in its accepting the values and norms of

71 http://www.frontline.in/static/html/fl2101 stories/20040116001609300.htmlast retrieved 6 July 2015

72 http://www.craftrevival.org/voiceDetails.asp?Code $=311$ last retrieved 6 July 2015 technological culture and of a consumer-oriented society, and in doing so, losing communion with nature and its inexhaustible resources of energy. The danger is of losing the sense of mysterious sacredness of the earth that 'life-giving, tranquil, fragrant, auspicious Mother' invoked in the Atharva Veda" (Jayakar 1989, 26). On the other hand, as the head of the Handicrafts and Handlooms Export Corporation of the Government of India, she put Indian textiles on to the international map through the Festivals of India where she took craft and art of India to America, Paris, and London, in the 1980s. As a result, she established that arts and crafts were not just an invaluable cultural asset, but also equally an economic force.

Activists from within the weaver communities in the state of Andhra Pradesh who led "udyamalu" (revolutions) such as Pragada Kotaiah, had the ear of policy makers, in the 1960s and 1970s, this was not anymore true with union leaders such as Macherla Mohan Rao of the Rashtriya Chenetha Karmika Samakhya [RCKS], who find themselves targeted by administrators as anti-state. For weaver activists, the exploitation of weavers by master weavers is an important concern; they see the state as an important mediator. Toward that end, they pin their hopes onto the co-operative endeavor, which degeneration in the last decades has led to much heartburn and disappointment, with a renewed effort to come up with new cooperative structures which would succeed where the older efforts failed. ${ }^{73}$ Another major concern is the imitation of handloom products by automated power loom, again here a legislation set up the state, the handloom reservation act of 1985 is seen as an important intervention to protect handloom's interest in the market.

The new textile policy of 1985 , seen to be anti-handloom and pro mechanized textile production galvanized a new generation of Civil Society actors into action supporting craft livelihoods through promoting NGOs. The policy heralded the opening up of the markets, as part

73 Discussion with Weaver activist Mohan Rao January $8^{\text {th }} 2015$ 
of the state's economic liberalization policies. Liberalization measures were aimed at driving growth and productivity stressing on competition and free trade, with the state withdrawing from as many aspects of economic activity as possible. India under the regime of Rajiv Gandhi, favored a change in policy that shifted production toward cheaper and competitive products for the global market. In particular, this resulted in a vigorous espousal of the export of raw cotton and yarn which had a destabilizing effect on prices of cotton, the mainstay of handloom weaving.

By the mid-1990s, handloom weavers were in acute distress, with reports of suicides in what were previously successful weaving centers. ${ }^{74}$ The Indian government responded with schemes to "develop" handlooms, and sustain them in the market. Up until then NGOs were largely working on the ground, mobilizing weavers for collective action; now they took up marketing functions themselves. This was encouraged both by the state, as well as International Development agencies. However, handloom, with its peculiar combination of being traditional technology, cultural identity, rural livelihood, co-operative led, and market friendly, presented a particular challenge to standard views of development.

In the wake of the state's perceived apathy to craftspeople, a new generation of activists from elite and socially privileged backgrounds played a key role from the 1970s onward in bringing the "craft sector" into the emerging urban markets through NGO institutions. They envisioned support for the craft sector from enlightened customers, and led a whole generation of aspirational women who followed their example into a new marketplace of craft. Here, through exercising consumer choice, women would express their individuality and their newly emerging social consciousness. These were also early attempts to articulate new relationships between design, technology, and development in artisan production, through stepping "down" from

74 Discussion, Mohan Rao, Weaver activist January $8^{\text {th }}, 2015$ social ivory towers, into real worlds of artisans, ${ }^{75}$ very often at personal cost. These leaders wielded aesthetic sensibility that has had a lasting influence in defining craft products and continues to set standards in the market.

Pioneers among them were SEWA, in Ahmedabad led by Ela Bhatt, Social Work and Research Centre in Tilonia by Bunker Roy, Dastkar headed by Laila Tyabji, Dastkari Haat Samithi by Jaya Jaitly, Gita Ram of Industree and Uzramma of Dastkar Andhra in the south. ${ }^{76}$ NGOs were seen by the State as "good and viable" agencies, which could deliver managerial and market related services of design and technology to support handloom livelihoods. From an agenda of employment before 1985, the efforts to support handloom were now polarized between "welfare" which is charity based, and "market," which is revenue generating for the NGOs along with the weavers. In this, NGOs followed the model of sustainable business, differentiating themselves from purely financial enterprises, as social enterprises; espousing entrepreneurship that had financial as well as social returns. ${ }^{78}$

Echoing this sentiment, of a respectful acceptance of the market place as a space familiar to Indian artisans throughout history, Ashoke Chatterjee, past president of the Crafts Council of India, and ex-director of NID, on the occasion of the 5 th memorial lecture of Kamaladevi acknowledged that perhaps there is a need to accept the place of the market in achieving livelihood sustainability for craftspeople, and can deliver meaningful livelihoods. He suggests that "the challenge therefore is not one of market threat but rather fostering the capacity

75 [Laila Tyabji http://vimeo.com/21160780last retrieved 6 July 2015 UzraBilgramihttp://www.craftrevival.org/voiceDetails. asp?Code $=31$, last retrieved 6 July] Jaya Jaitley 2015http://www.niyogibooks.com/crafts-atlas-of-india. html, last retrieved 6 July

Rita Kapur Chisti, http://www.youtube.com/ watch? $\mathrm{v}=$ mbqqeNCfQIk.last retrieved 6 July 2015

76 For extended list see http://www.craftrevival.org/voiceDetails. asp?Code $=311$ last retrieved 6 July

77 Compendium of handloom schemes (Niranjana and Vinayan 2001)

78 This was the time when microfinance institutions were on a growth trajectory, but the link to sustaining handloom livelihoods had not materialized, this turned out to be a protection when the microfinance bubble burst after 2006 
of artisans to negotiate effectively with the market, and effectively protect their own interests within a situation of constant change and unrelenting competition." 79

Following in the tradition of intervening in design in order to market craft products, NGOs regularly employed designers with the ambitious directive of delivering income and sustainable livelihoods for craftspeople. At one level, Gandhian ideals of Swaraj, or self-determination for weavers and their livelihoods and the ideals of Swa-avalamban or self-sufficiency in production and consumption played an important role in framing development projects of craft NGOs. At another level, these development interventions had another effect of commodifying cultural products through "selected groups [being] identified as craft communities and the manipulation of the forms of artisanal products in order to make them more desirable to contemporary urban audiences" (Venkatesan 2009a, 37). The NGO as trader can be appropriately described, she suggests, as "the wanderer who comes today and stays tomorrow" (Simmel 1950, 402).

By 2010, foreign funding as well as state funding through NGOs dropped down to a trickle, as International Development agencies underwent painful budget cuts, and the state withdrew further.
The new socially responsible corporate became the new funder. The entrepreneurial social enterprise and the social and environmentally conscious corporate, both attempt to balance social, financial, and environmental outcomes, albeit for different ends. Impact is measured in terms of success and sustainability of livelihoods in the new markets. At the same time, activists under the banner of the "All India Federation of handloom weavers" continue to agitate for the enforcement of the Handloom Reservation Act of 1985 that prohibits the production and imitation of 22 items that handlooms produce, that still continues to be violated by power loom producers. In 2014, swaraj and swadesi, selfgovernance and self-sufficiency, make a comeback, albeit in a way that Gandhi would not recognize; after a decade of market failures has resulted in more than one third of weavers abandoning weaving as livelihood. The responsible customer is now not just socially and environmentally conscious, but also a patriotic citizen, in consuming local handmade; swadesi. The new market structures come into play, the Times of India reports in Sept 2014, that "India's largest e-tailer, Flipkart, has planned to set foot on the holy land of Banaras, now the constituency of Prime Minister Narendra Modi, and launch a pilot project to get the city weavers join the e-bandwagon," $" 80$ echoing the message of swaraj.

\subsubsection{ProducER GROUPS: WEAVERS, ALLIED WORKERS AND MASTER WEAVERS}

Weavers' terms for progress in livelihood (purogathi) associated with sustainability and migration (valasa vellipovadam) associated with unsustainability; both have a dimension of mobility that is historically characteristic to the weaving community. In his study of weavers in the 18th century, Parthasarathy contends that "weavers' reputation for easy mobility suggests that they led simple lives and had few possessions" (Parthasarathi 2001, loc 213). Mobility seems to have been key to the power of weavers; if due to circumstances in the market they accumulated debt, which proved burdensome, they packed up their looms and possessions and moved elsewhere, en-masse. Evidently, spatial mobility was the norm rather than the exception, according to scholar Christopher Bayly who has shown that the traditional and static village did not always characterize India, but was a product of the 19th century colonial transformation (Bayly 1983).

Migration was an integral part of "weaver subsistence and survival strategy," at the same time the threat of migration served as an "important

79 http://ccrtindia.gov.in/virasat.phplast retrieved 6 July

80 http://timesofindia.indiatimes.com/city/lucknow/Modis-Varanasiweavers-to-sell-online-courtesy-Flipkart/articleshow/41723292.cms 
weaver (and producer) tactic and bargaining chip during conflicts with merchants and states." (Parthasarathi 2001, loc 414). For example, Pasthasarathy refers to the desertion ritual, which accompanied the annual renewal of agricultural labor "adimai" who were bonded to their landlords. In this ritual, the adimai left the village in which they resided the previous year, and their agricultural superiors would beseech them to return (Parthasarathi 2001, loc 630). In contrast to local norms where mobility was an accepted response to oppression, he suggests that the limits on this mobility in colonial India imposed by the British East India company broke the back of weavers' negotiation power with colonial traders.

Most practicing weavers today have been born into weaving, it is still largely a hereditary occupation; castes such as padmasali, pattusali, and devangula castes continue to stand for specialist weaving communities in Andhra Pradesh. As such, weavers refer to their work as kula vritti, translatable at once as community occupation, and a caste vocation. Weavers take pride in their caste, in their origin myths. Their identity is strongly defined by the positive attributes of the caste; they identify themselves as a brahmanical caste that carries technical skill and creative ability. At the same time, they pride themselves on a patient and non-combative temperament ${ }^{81}$ : this allows weavers to sit for long periods of time focusing on skilled tasks. Their discourses are dominated by the livelihood anxiety that they constantly are prey to in the changing markets, and the lack of interest from the state to their circumstance. At a third level, the cultural pigeonholing of weaving as traditional becomes a constraint to progress for young weavers, who prefer to shift to other livelihoods that afford progress into a modern identity, preferably through education.

Caste is one of the most contentious issues in Indian society today, and academic literature regarding caste is mostly about the systematic

81 Focus Group Discussion, Mandapeta, January 23 ${ }^{\text {rd }}, 2012$ repression it engenders on groups of people who are seen as "impure." Caste becomes an institutional mechanism for transmitting prejudices that make it a system of oppression, at the same time it transmits skills, values, habits that define identity in society. Since the occupation of weaving is hereditary, caste is an important identifier of the weaver community, and by the state: from pre independence classified as "other Backward Class (BC-B-17)." hierarchy, where handloom weaver castes hover uneasily in the middle of the social order, continues to define social status for weaving communities.

The origin myth of one of the weaver castes, the Padmasaali is recited by the nomadic tribe of Kunapulivaru, the Bhavana Rishi Mahatyam. It explains the origin and evolution of the Padmasali community from an undated religious text referred to as the Markandeyapuranam ${ }^{83}$ (Pargiter 1904). Bhavana Rishi was the celestial weaver, who sprang from the sacrificial fire of Markandeya, the legendary devotee of Siva, who through his grace eluded death. This story was purported to have been written in the 16th century by Narasimha Kavi (Sadanandam 2008). Weavers had championed the radical Virasaiva movement that advocated caste negation and anti-casteism in the 12th century. Jedara Dasimayya, one of the key proponents of this movement was a weaver himself. This movement fell prey later to caste-exultation, and weavers tried to obtain higher caste credentials and privileges (Ramaswamy 2006). To this day, they wear the sacred thread, which accords them the same status as the highest of castes.

Bayly (Bayly 1986) points out to us the deep ambiguity that was attached to the status of the weaver in Indian society, suggesting that the low caste status seems best explained in terms of historical contingencies. On the one hand, manual work was regarded as degrading in the Hindu scheme of occupational precedence. On the other hand, the Manu shastra ordains that the

82 http://www.ncbc.nic.in/Writereaddata/note31635297173742607492.pdf

83 A digital copy of the English translation of the text by FE Pargiter is available at http://wisdomlib.org/hinduism/book/the-markandeyapurana/ 
"the hand of the artisan is always pure," weaving is an act of creation, almost worship, a notion central to the creation myths that is foundational to caste pride of weavers (Bühler 1886, 191) in (Bayly 1986, loc5866).

There is an increasing distance between caste-based production systems, where genealogy and family antecedents predetermine occupation, and merit-based open education systems, where occupation is perceived as an individual choice. Handloom weavers strategically straddle both worlds, educating their children in formal schools, and simultaneously educating them in weaving at home: where children succeeded in the competitive educational system, parents resourced them to achieve; otherwise the caste occupation (kula vritt) was always available as a livelihood backup. This was in line with the aspirations for social mobility of the community, while retaining their traditional social identity-education was a way for weaver communities to self-identify as technologists without the label of manual workers. In this way, weavers can improve their status and enhance their caste identity.

Like in the current climate as the census figures show, weavers also historically wove for subsistence, domestic consumption and as leisure activity. Generally, while it is understood that "professional" weavers come from specialist castes, scholars Swarnalatha, Washbrook, and Karuna Miryam trace the emergence of "Pariah" (untouchable) weavers. Swarnalatha Potukuchi traces the emergence of "Pariah" weavers to the bhakti and virasaiva movements of the 12th and 13th centuries, which preached egalitarianism (Potukuchi 2005, 39-44). Washbrook suggests that the political chaos of the 18th century loosened caste hierarches and again allowed the entry of untouchable castes into weaving (Washbrook 1993, 73,81).

Karuna Mariyam reports that in the 19th century as much as half of the weaving population in some districts was "Pariah," particularly in the drier parts where agriculture was less employment generating, where there was easy access to cotton and yarn. Pariahs ${ }^{84}$ wove cloth for local consumption, were specialist spinners and played a prominent role in weaving, though they gradually disappeared from weaving toward the end of the 19th century, even from memory. Karuna Miryam attributes this to different kinds of exclusions: from new technologies, from new ways of organizing production and from new and emerging production and marketing networks (Miryam 2014, 189). This adds to our understanding of how particular narratives become excluded, requiring a patient dissection of dominant discourses regarding the history of weaving to unearth lesser known realities of invisible populations.

Of the many categories of current day weavers, preloom workers and weaving labor continue to be the most impoverished. During acute crises in input supply or market demand, it is these groups as well as weavers who do not own their own looms, but work as weaving labor, "coolie" weavers that are worst affected. Preloom workers' work is less visible compared to that of weaving. However, their livelihoods are none-the-less integrally tied up with handloom. Scale wise; the ratio of these sizers, warpers, and dyers to weavers is small, according to the handloom census: in some cases, weavers themselves take on the activities of sizing and dyeing. This adds to the inconspicuousness of preloom workers. Sizers and warpers, and in many cases dyers who service handloom are solely dependent on the handloom industry for livelihoods. However, whether decentralized in weaving villages like Muramunda or centralized in weaving centers like Chirala, these activities also often require less permanent labor.

The weaving labor usually also belong to socially and culturally deprived classes. In the villages of East Godavari, ${ }^{85}$ Goudas, Settibalijas, Kapulu, Rajakulu, and Scheduled Castes (Pariahs, Dalits) constitute the labor class, they are mostly agricultural labor. In many cases, women labor

84 For a discussion on the role of caste and purity/"pollution" with reference to work see (Miryam 2014), (Mosse 1994)

85 Field notes M Soumithri for DA August 29th, 2012 
from the labor class take up ancillary work in handloom, usually on a part time basis, as in the case of sizing, where the physical demands would be too high on them for full time work, and winding bobbins for warping which can be simultaneously done by many people.

The location of handloom weaving in rural areas with few other opportunities for work becomes a spatial determinant of employment and the labor market (Spicker 2007, 40). Workers in this group cannot be said to have a relationship to formal economy, as they tend to be part time, and seasonal, finding and taking up work when it is available. When work is scarce, they experience unemployment, and their labor is not remunerated adequately. In such situations, only migration to the city can improve conditions of employment.

Master-weavers are an important subcategory of weavers, who provide capital as well as the marketing links. Generally, the face of the market for a majority of weavers is the master weaver-trader from their own village, who runs the traditional family business. The "master weaver" first emerged in the Vijayanagar period (1336-1646), due to increased urbanization and demand characterized by changes in styles of costume. Weavers were subordinated to the master weaver, some of who belonged to trading castes, but who "sometimes emerged from the ranks of the artisans" (Ramaswamy 1985a). From the 1930s on in the Deccan area, the "putting-out" system, where weavers wove at home on their own looms for a trader, or a master weaver, or his agent, became dominant (Roy 1993, 73). Usually, the master weaver is a person from the weaving caste, ${ }^{86}$ who does not engage in weaving, but controls the production of weavers under him, either directly or indirectly, through agents. A key component of the capital labor relationship between master weaver and weaver, in addition to the raw materials is the "advance." These were binding debts, and tied the weaver to the master weaver. Higher skilled weavers at good times could demand

86 For the different and changing relations in production between weavers and traders in the 19th-20th century see (Miryam 2014) large advances, and switch owners if dissatisfied, on the other hand during hard times, they would be forced to work for lower wages (De Neve 2005).

The master weaver supplies the yarn and specifies the design and markets the product when it is ready. The consumption loans and/or advances, provided by the master-weaver can over time render the weaver completely indebted to the master weaver. This unequal relation makes it possible for the master weaver to pass on losses to the indebted weaver when there is a market squeeze, either due to yarn price fluctuations in the global market, or market price fluctuation due to competition from power loom imitations. The master weaver and weaver relationship is, therefore, an uneasy one, dominated by the circumstances of market demand. Skilled weavers have more negotiation than less skilled ones; they may move on from their existing master weaver to another who might offer more remuneration for their skill. Therefore, the master weaver faces both fluctuating demand and fluctuation in work force that affect returns on his capital investment.

For the contemporary weaver, the moment of unsustainability is supposedly never so clear as when he stops weaving and migrates out of the village. Policy makers view the movement of large numbers of people out of the village as an indication of unsustainability of handloom livelihoods within the village. On the other hand, the policy view of weaver migration with its embedded assumption of unsustainability adds nothing to the understanding of why some weavers stay back and continue to weave and others leave. Mindful of the idea that migration from village to the city or from traditional to modern livelihoods does not itself offer a way out of poverty, I instead focus on the mobility itself, and the conditions that lead up to it. Mobility includes movements in and out of weaving as livelihood, rural-urban mobility, and it broadens into (possibly intergenerational) movements into new identities. I will argue that rather than a linear and continuous migration out of weaving, a more flexible mobility, a process of movements to and fro, inward and 
outward, is taking place. From the accounts of the weavers, I draw three general sites of mobility across internal lifecycle, external livelihood conditions, and identity. Change that came with natural transitions in weavers' lifecycle that could cause a weaver to move, changes in external livelihood conditions that could also cause temporary mobility within groups of weavers, in order to manage the instability in supply and demand and third, a quest for a different identity that could trigger mobility in younger weavers out of caste-based community identity (Mamidipudi, Syamasundari, and Bijker 2012).

Maanem Vishwanath was a weaver who had left weaving and his home village Ponduru, seeking work in the city (valasa vellipovadam). For weavers, this is a time-honored route out of distress in livelihood, caused either by oppressive masters or difficulties in making ends meet, valasa equally means to migrate, as well as to escape through fleeing. Vishwanath came back to Ponduru, when he accepted that the move to the city cost him his dignity alongside loss of livelihood. He spoke in resignation of the search for unskilled work in the city, washing bathrooms, cleaning chemical waste, and the decision to come back. "Look at my hands, they are smooth" he said, "they are ground to this smoothness by the threads of the yarn that we run them over, time and again, these hands are not made for manual labour, but I couldn't make both ends meet, I had to leave."

He could not afford marriages for his daughters on his weaver's income-he responds to the social censure of being unable to pay the necessary dowry by saying that a wife had now become someone who could bring you a gold chain that you could "hang" around your neck, rather than someone who lived with you and shared your life. "Did you ever think of your wife as a burden that you had to be paid to carry" he asks. He does not elaborate on time spent in the city looking for work, says that there is no self-respect in that kind of work; "when I could not bring myself to wash bathrooms anymore, I decided to move back to do the same work [manual labour] here [in the village]" ${ }^{87}$. Vishwanath did not make it big in the city, and what he regained in the move back to the village was a life with some dignity even in the face of failure, in the company of known people. The interview itself was an example; conducted in the open front courtyard of a small house, where he played host, while for the duration, the real owners of the house sat on the steps, so that both he and the outsiders interviewing him were not materially confronted with his homeless state.

Movement between agrarian socio-economic classes, educational classes, productivity of land, and access to transformative public policy has been used to define upward or downward trajectories of mobility in farming households (Athreya et al. 1986, Djurfeldt et al. 2008, Kumar, Heath, and Heath 2002). There is little data or analysis available on where weavers who migrate to cities end up; nor on classes and categories of weavers and artisan labor that are particularly vulnerable to downward mobility.

In their case, Jan Breman (2005) suggests that becoming loomless and moving to the bottom of the power loom labor hierarchy, or into the informal urban economy-could be the first step along the slippery slope to downward mobility for vulnerable weavers. Breman (1996) questions whether rural migrants are absorbed into the informal economy and move upward into the formal sector, as received wisdom would have us believe. He argues that large contingents of landless labor "are forced to remain on the march between town and countryside as well as between different economic sectors and various employment modalities" (Breman 1996, 2003:4156), thus exhibiting downward mobility.

Unsustainability in weaving is colloquially expressed in terms of inadequacy of income (gittubaatu ledu) to fulfill needs (avasaralu). By any account, handloom weaving had to be sustainable for the weaver to fulfill the needs that could be simply enumerated-apart from the basic food, shelter, and clothing, the list included the children's education, both boys and girls, some gold for the

87 Interview, Maanem Vishwanath, February $25^{\text {th }}, 2010$ 
women of the family, which amounted to capital or savings that could be converted to cash in times of need, reasonable circumstances to offer support, or some auxiliary work for older family members to live with self-respect. Social obligations had to be fulfilled and a little set aside for crisis, especially in health, there had to be some annual surplus for religious rituals, or the odd pilgrimage. Over time, there had to be enough saved to build a house and for their own old age.

This approach to sustainability in livelihood is embedded in the idea of leading a good life - in Soumhya Venkatesan's study of mat weavers in South India, "what it is to be a good Muslim, how to fulfill one's obligations to others, what are one's own ambitious, how do other people position one, and how can one resist, work with or opt out of such positions" (Venkatesan 2009a, 95). On another note, while "avasaralu" denoted basic needs, weavers' aspirations were not unimaginatively bound to the mundane. Gold, in the form of jewelry accrued from surplus in earnings was considered "avasaram" or a need, rather than luxury. The women there joked about their husbands' incapability to satisfy them with the gold they "deserved" and had been earned as partners on the loom; gold was not anymore a metaphor for desire and greed to own something of value but became key to the woman's financial role. It is at once her area of expertise, the household's capital, the hedge against bad times and the legitimate assertion of the woman's right to the family resource. Therefore, the wife of the master weaver in Mandapeta Pentarao, who never emerged from the kitchen ostensibly intent on preparing food for the visiting guests, was credited by the weavers in the group for having decided the time and place that the household would separate from the familyrun business and set up on their own, pawning her jewelry to offset the financial risk.

Therefore, unsustainability in livelihood was not measured in terms of wage at the present time, and most weavers spoke in terms of good times and bad times in weaving. Rather, it was when there were long periods when market was unable to provide them work to capacity, or if there were frequent fluctuations in wage causing instability, that their livelihoods became unsustainable. If these difficult circumstances overlapped with transition points in the lifecycle of the weaver, then the unsustainability would force a weaver into considering a change in livelihood-a pregnant wife, having small children, which meant that the weaver was alone at the loom, a health problem of an aging father that became chronic, sons of university-going age, and daughters of marriageable age. However, these were inherent to the lifecycle of the weaver, and had to be faced as being inevitable in lean times and would be faced depending on the resilience of the weaver household to stresses.

Boodida Appa Rao, at 45, is a weaver who was able to stay in weaving even as he responded to the stresses of lifecycle and livelihood and is considered successful by his peers. He says that the community is not anymore united in its goal of clothing the world around them as they once did, taking pride in the kula vritti or caste occupation. It is because "everyone has become selfish, they want to work on their own, and get their i ndividual returns." ${ }^{88}$

This is a community that knows what it means to work together and articulate clearly and constantly the constraints of doing that "Naluguri tho koodina pani" (work that takes four people to come together). Ponduru has its Muslim reed makers, its Reddy women customers, still. Both Devangulas and Padmasali are Hindu castes that still weave here. The whole family works with each other, both on loom and outside the loom to keep the household together. Boodidi Appa Rao's concern for his wife Rashmi and her willingness to keep the loom working and earn, while he explored other livelihood options made him more resilient to adversity. He too left weaving at a point of financial stress, but for a short while. He was able find work in the nearby stone quarry without leaving the village when he needed extra income, whereas his

88 Interview Boodida Apparao 25 $5^{\text {th }}$ Feb. 2010 
wife continued on the loom and complemented the income of his household. This gave his sons the opportunity to continue in school without disrupting their education. However, a life away from home was not easy, and once his financial need was past, he came back to the village. Today he continues to weave with his wife, refusing to become dependent on his now grown up children and move into the city with them. Yet, his educated children prefer to work in modern settings, in local textile mass production factories where they feel they are individuated and valued as skilled workers, rather than part of a community activity for which there is no individual progress (purogathi).

Weavers still migrate en-masse to escape adverse conditions and bad times. Even today, whole communities of weavers move in and out of weaving at times of distress in weaving. In Chirala, when the power loom started imitating the staple handloom jacquard saree for a lower price, the wage fell, causing almost thousand weavers to look for additional work in the nearby city as construction labor. The men would travel to and fro from the construction sites, but the wives continued to weave at home. These were desperate times, generally weavers did not do hard agricultural labor as they had to preserve the suppleness of their hands and fingers for work at the loom (Parthasarathi 2001, loc 221). Gopi, an innovative weaver in Chirala, says that this kind of migration has happened often enough in the past. It was reversed when one of the more skilled weavers innovated a new design, which would create demand, and provide work in weaving again. Senior weaver Gadde Veeraraghavulu elaborates on this to and from movement, he says there are two boys on his street who have come back to weaving, both have masters degrees, one even in pharmacology, but could not find jobs. They have families, who have to be supported, and while waiting for better jobs, they weave; "at least now, their families can eat," ${ }^{\circ 9}$ he says. In some cases, an out-of-work child will come back from the city and weave for a while, to add to the family's income, while waiting for a better opportunity. The acceptance of mobility as a response to vulnerability in livelihood was evidenced in the ease with which migrant weavers were accepted back into weaving by the community, there was no stigma attached to leaving weaving during difficult times or coming back to it when opportunity presented itself.

An important measure for external shock that impacted livelihood in bad times is "Karuvu," referring to conditions of drought when not just weaving but most occupations in the village did not meet basic needs. The middle class (madhya taragati) weaver experienced a push toward what previously was perceived as a life and livelihood of less social status, and income. This type of mobility was also more apt to be found in large weaving centers, where crises in yarn prices or demand hit weavers' wage uniformly, and they responded as a group. Parthasarathy suggests that weavers had always "possessed networks which kept them abreast of conditions in various locales" (Parthasarathi 2001, loc 429).

In the words of Satyanarayana, a weaver from Ampolu who had used this network to find his way to the city, "I think there were $50-60$ people from here, that's why that street used to be called Ampolu gully [street]. If we got onto an auto in the Hyderabad railway station [when we got off the train from Ampolu] and asked for Ampolu gully, they took us there. The Ampolu here was put there too, ${ }^{90}$ he says. When he heard through the same network that there was work in weaving again in Ampolu, he came back to the village to work and live (Mamidipudi, Syamasundari, and Bijker 2012). Weavers also moved to other thriving weaving areas and continued weaving, this was an entrepreneurial move toward better opportunities for their skill, or, as in villages like Mangalagiri, they reskilled themselves in other crafts. During the ten years from 2002 onward, when 10,000 looms in Mangalagiri dropped to five hundred, the neighbouring villages 
saw an increase in Devangulas (a weaving caste) taking up jewelry making, almost exactly to the tune of 10,000 .

Where more promising futures could only be assured by leaving behind weaving, a move to the city fulfills aspirations for a modern life and identity- to the identity of an upwardly mobilesecular-neoliberal subject (De Neve 2003). De Neve's work on the garment industry in Tiruppur focuses on mobility of workers from rural areas into urban industrial settings. Relating migrant workers' desire for social mobility and modernity, he argues that prospects of mobility and migration to the town and better opportunity can in themselves be experienced as what modernity stands for. Migrants in turn experience modernity as aspirations of social mobility and conflict of identity. Commitment to a livelihood or a physical location depends on the concrete returns from the livelihood they are engaged in, and such returns would decide whether workers feel empowered by modernity or return with feelings of loss and despair to the village (De Neve 2003). Such population movements are not simple economic reactions to push and pull, but embedded in local customs and ideologies (De Haan 1999, 2011).

Boodidi Appa Rao illustrates this clearly in his interview: while in an older time, weavers used mobility as a strategy to escape oppressive market conditions; in his time, weavers did not have to leave home and hearth, if he did it was "naamosikaram"- below the dignity of the weaver. Now again today, people go where their livelihoods take them, and it is acceptable to the community (Mamidipudi, Syamasundari, and Bijker 2012). These are seen as the imperative of a middle class household (Madhya taragati kutumbam) in a modern world. In this transition to the "modern" identity, caste and community operate as social and cultural markers, rather than as occupational ones. The move entails the abandoning of the caste occupation (kula vritti), a move that is better defended in the pursuit of social mobility, rather than financial mobility alone. Therefore,
Krishna Rao, a senior weaver and manager of cooperative, considers a city boy as unsuitable sonin-law material for his educated daughter even though he belongs to the Devangula caste, because he is engaged in construction (manual) work that is lower in the occupational hierarchy, rather than intellectual pursuits that would place him higher.

Mobility in identity is sought through selfidentification of the weaving caste with expertise and skilled practices whether in weaving or outside it. Gopi, a successful weaver in Chirala proudly identifies himself as belonging to a caste that "since time immemorial has clothed man who was before that a savage wearing leaves, and bark." ${ }^{\text {91 }}$ Adopting new technologies, for instance in dyeing or in designing, allows for a reinvention of the identity of the weaver as progressive: "don't try to teach me what my grandfather used to weave" ${ }^{\prime 92}$ scoffed one young jacquard weaver to a trainer in a government program for reviving traditional techniques.

History of cloth in India shows "how things could retain the quality of the people who fashioned and exchanged them, even in a fully monetized economy" (Bayly, loc 5704). As much as the quality of the people who fashioned and exchanged them affected the quality of the cloth, the changing meaning of cloth equally impinges on the identity of the producer of cloth himself or herself. For instance, weavers, both Hindu and Muslim could improve on their status by "creating finer and purer commodities" (Bayly 1986, loc 5882), as a tactic for raising status. Therefore, it could be conjectured that when the status of the cloth that weavers' produced fluctuates in a market that does not value hand-woven cloth, it can have a powerful lowering effect on the status of the weavers themselves.

To counter these effects, the narratives of weavers show practices of self-construction of identity (Hall 1996) that interpret skill and expertise within larger definitions than just that of handloom production, for example as designers and technologists in growth industries such as power loom or even computers. Therefore, they

91 Interview, Gopichand, February $28^{\text {th }}, 2010$

92 Interview, Balaji, January 27th, 2012 
carry the technical attributes of the weaving caste to other modern occupations like engineering and design, now liberated from the association that craft expertise carries of manual work.

This mobility from the identity of castebased laboring handloom weaver to educated secular contemporary technologist is usually intergenerational, and a general trend rather than individual choice. University educated children of weavers who are not engaged in weaving continue to recognize the technical expertise involved in weaving, ${ }^{93}$ and identify themselves as part of the weaving caste, even though they do not anymore practice their caste occupation (kula vritti). ${ }^{94}$ Weavers make this possible for themselves by identifying caste by its social and cultural dimensions: stressing on positive social attributes of the weaving caste-for example, of responsibly fulfilling obligations: personal financial obligations to elders, professional obligations to their new occupations, and social obligations to the less fortunate in the village they have left behind, to younger family members and so on. Mobility out of the narrow definitions of handloom that boxes members into the narratives of unproductivity, obsolescence and financial unsustainability is, thus, achieved.

As the stories in this section demonstrate, trajectories of weavers are not pre-determined. I use the notion of trajectories not to focus on movements from the position of unsustainability to the position of sustainability, but to explicate the multiplicity of trajectories possible, which make up a continuum of outcomes between sustainability and unsustainability. I make multiple shifts in the unit of analysis in this chapter: from weaver to ensemble, from actor to social groups, from a singular position of unsustainability to multiplicities of vulnerabilities, which lead to a multiplicity of possible outcomes for weavers. All these are meant to highlight the continuum of trajectories, none of which are predetermined.

\subsection{CONCEPTUALIZING VULNERABILITY IN HANDLOOM WEAVER LIVELIHOODS}

In the sections above, I attempted to undertake a study of discourses around handloom livelihoods: what they mean to the different people in the handloom ensemble, and where these discourses come from. We can now assess the usefulness of the notion of "unsustainability" in handloom livelihoods for our purpose of understanding the persistence of handloom weaving in India. We see that in actual practice, this notion is contested, even within each of the groups' discourses. In general, actors frame the notion of unsustainability in technological, economic, and financial terms, but draw on social and cultural discourses to frame the opposite, sustainability. In this struggle lies the politics of framing handloom livelihoods as unsustainable. If we are to analyze how handloom weavers survive and sustain themselves in what appear to be risky livelihoods, observing vulnerability in handloom livelihoods may be a better starting point. As a conceptual tool, vulnerability offers three things: first a legitimate place for lived experience of vulnerability as narrated by weavers themselves, and a way to understand different actors' responses to those vulnerabilities. Second, rather than a singular notion of unsustainability, vulnerabilities can be multiple, across technological, economic, as well as social and cultural axes. Different actors give different meanings to vulnerabilities (Hommels, Mesman, and Bijker 2014). This multiplicity makes for a particularly slippery notion of "the problem" of handloom livelihoods. As a result, the notion of a singular fix-all solution to the problem also disappears, as does the singular framing of "the vulnerability" of weaving livelihoods-whether economic unsustainability or poverty. It follows

93 Interviews, Tutika and Mangamma, February 27-28th, 2010

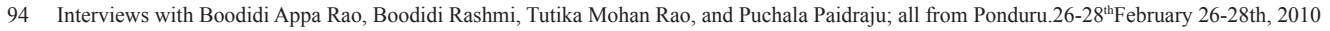


from the multiplicity of problems and solutions detailed by the social groups in the handloom STE that economic sustainability is displaced as the only vulnerability; in fact weavers face a multiplicity of vulnerabilities. Third, vulnerability is emergent under particular conditions (Bijker, Hommels, and Mesman 2014, 25), this takes cognizance of the dynamic nature of change in handloom livelihoods. As a result, it is a concept that allows us to perceive sustainability as well as unsustainability in weavers' livelihoods.

Talking of vulnerability as "goals, values, and worldviews" (Bijker, Hommels, and Mesman 2014 , 5) explicates the place of discourse in framing vulnerabilities. Concerned social groups in the handloom STE gain coherence in their response to vulnerabilities through discourse coalitions (Hajer 1995) - through aligning discourses through argumentation, so that they may form coalitions to jointly intervene towards what they consider desirable outcomes for weavers. In order to analyze how these coalitions form, I first disentangle the multiple emerging vulnerabilities and divergent actions and interventions in the handloom ensemble. This helps us see the generative possibilities of the argumentative approach.

Finally in this section, I will describe weaver actions and choices in livelihoodsas they navigate through the different outcomes generated by social groups' interventions in the STE. Weavers respond to vulnerabilities that they face, some with resilience and hope, some with despair; individually as well as collectively. What affords generative possibilities for weavers is how other social groups in the handloom STE such as NGOs, state, markets respond to these vulnerabilities. Telling a story of the choices that these afford to a weaver as he navigates through a livelihood in weaving, I present evidence of the importance of multiplicity in discourses for constructing positive outcomes, where vulnerability has led to sustainability.

\subsubsection{EMERGENT NATURE OF VULNERABILITY IN WEAVER LIVELIHOODS}

In order to explain the emergent nature of vulnerability in weavers' livelihood, I go back to the example of migration, where weaver livelihoods are at their most vulnerable. We come to the story of Maanem Vishwanath, the weaver from Ponduru, who did not weave anymore. The interview with him was in the front veranda of a reasonably sized village home. A group of women were gathered sitting down on the little raised cement step in front of the house. Vishwanath was curious about why we were there, and we explained that we had to come to study why weaving became unsustainable, for him, and for many weavers like him. ${ }^{95}$ This was not his home; we interviewed him in the cooperative manager's house. Vishwanath's wife was sitting with the group of women outside, but she never made herself known. The pain and wisdom that accompanied his story made it difficult to miss the acute vulnerability, of aging in a profession,

95 Refer List of Weaver Interviews, section 8.4 and moving to the city in search of unskilled work. Explaining how he could not keep up with the pressure of productivity, as he aged, he said "It got to a point that if I went to the bathroom, my wife would anxiously ask, how long will you take?" He is grateful for the one good meal provided for his wife in the hotel where she now works, a statement that reveals his sense of inadequacy for all the times his wife went hungry, in the city. Time and again, the weavers' stories of poverty are accompanied by clear experiences of acute vulnerability, even when successfully bypassed but more so in the face of failure (Shah 2014).

Such acute vulnerability emerges for the weaver at distinct moments of time. Individual weavers who experience loss of income together with a loss of face within the community lose social support. The only way then to seek refuge from social censure is the anonymity of the city. The weaver with his four daughters who needed to find the money to marry off his daughters, or the weaver 
indebted beyond the capacity to recoup — these lose hope and succumb first. We see that this vulnerability can be acute and experienced as isolation by the individual from the community - the response to this vulnerability is the urge to escape:mobility as a way to survival and overcoming of this acute vulnerability.

There can also be a chronic vulnerability, of being in a livelihood that has to respond continuously to sharp external shocks such as sudden increase in yarn prices. When there are no institutions that absorb these shocks, the weavers' community is without protection to these changes. This constant uncertainty causes a fatigue that the community experiences over long periods - chronic vulnerability. In some cases, supporting institutions are able to absorb some of these shocks and can act as buffers. For instance, a capable president who managed the external linkages that are needed to support the marketing work of his co-operative, thus, supported the Ampolu weavers' co-operative with its hundred members. Weavers here were treated with respect, and youngsters from other castes were invited into this co-operative, breaking caste barrier. Vulnerable weavers were given shelter, and light work, so that they could spend their old age with self-respect. Before the current president took over the running of the society, there was a huge exodus of weavers to the city of Hyderabad. However, with the support of the new president, weavers came back to work in Ampolu. The state of chronic vulnerability also produces a community that shows itself able to take the shocks and stresses of a livelihood eked out in an uncertain environment, who use mobility to move out as well as back into weaving.

There is a third more systemic vulnerability that emerges for weavers when they feel diminished by the discourse of productivity and progress that labels their technology as obsolete. Weavers feel socially vulnerable in a society that refuses to afford a more promising future to handloom. This becomes endemic and difficult to root out, regardless of occasional success in the market place. This mobility is one directional, as it always frames a weaver as being on the losing side of the livelihood battle. It is this systemic social vulnerability that needs to be overcome, through society's recognition of the resilience of weavers - and the trajectories of sustainability that they craft.

In the everyday meaning of vulnerability that I use, it refers to changes in livelihood conditions, particularly the extent to which changes could harm a community. Vulnerability cannot be understood by looking only at the inside of a system, it also relates to the external environment; it is as "an emergent property, a quality that gets built into systems over time, by actors in specific contexts" (Bijker, Hommels, and Mesman 2014, 25). What do we gain in understanding vulnerability as emergent? Let us take the example of poverty, by far the largest livelihood vulnerability of handloom communities; vulnerable weavers very quickly drop below the poverty line, as there is little buffer from the changes in the market. Poverty can also be understood as an outcome that is emergent in particular contexts: weavers who don't own looms are more vulnerable to becoming poverty stricken than better off weavers with land, those with the ability to move to another profession, or those better able to access state or civil society support. In this reading, vulnerability in livelihood for this group of weavers becomes constituted not just in economic, but also in material, social, and structural terms. Importantly, framed as an emergent condition, vulnerability affords possibilities that weavers can resist its detrimental outcomes.

Scholarship in livelihood studies too point to people's ability to resist, recover, and cope with detrimental impacts (Wisner et al. 1994). Chambers and Conway first moved away from a focus on economic resources, the "income and expenditure" model to argue for a holistic model of sustainable livelihoods (SL) which included people, their capabilities and their means of living (Chambers and Conway 1992). Later scholarship drew on invisible social and human dimensions of livelihood (Appendini 2001, Bebbington 1999) emphasizing 
on matters of ownership and circulation of information, management of skills and relationships, and affirmation of group identity and group identity. Meeting social obligations of security, identity, and status are equally seen as livelihood tasks (Wallman 1984). Social and cultural dimensions have been examined from the perspective of vulnerable populations, as a lack of entitlement to resource (Sen 1981). Therefore, the sustainable livelihood approach develops into a constructivist relational concept "where multiple dimensions of the natural and social kind are relevant to the question of how the vulnerable livelihood conditions of [marginal] communities are shaped" (Quartz 2014, 37).

The concept of vulnerability is useful in explicating the adversity that weavers face, as well as opportunities that weavers create for themselves in sustaining their livelihoods. It is important to be aware that the labeling of certain groups or regions as vulnerable can result in "potentially regressive policy decisions and justifications for intervention that undermine community autonomy or increase marginalization" (Miller et al. 2010). Instead, Garmezy defines resiliency, as "a process of, or a capacity for, or the outcome of successful adaptation despite challenging and threatening circumstances." (Garmezy 1991) In almost all definitions of resilience, characteristics of the individual, nature of the context, the presence of adversity and the counteracting, and protective factors are included (Smith and Schonert-Reichl 2013, 122); resilience like vulnerability is not absolute, but relative individuals who are resilient in one context may become vulnerable in another (Smith and Schonert-Reichl 2013, 123). Keeping in mind these caveats, I stay with the framing of vulnerability in handloom livelihoods, arguing that vulnerability is a "condition humane," necessary condition for openness to change. Taking the analyses of vulnerability not just as something negative but exploring its positive aspect makes possible a turn to a strength-based approach to the groups facing livelihood vulnerabilities.

96 Presentation Prajit Basu in Nano-Dev Conference Brussels 7/11/14
Now, it becomes possible to understand mobility as resilient practice in livelihoods. We can explain why all the weavers do not respond equally to the livelihood stress at this moment, this response is mediated by the stage in the lifecycle of the weaver and his or her resilience at that point. This resilience diffuses the effect of an external crisis on the handloom system. Weavers are not uniform units of production lined up in a factory; they are linked together in a heterogeneous production network that forms a sociotechnical ensemble. During times of external crisis, a small core of the system remains stable, as strongly embedded weavers continue to weave, whereas the peripheries expand and contract with the to-and-fro movement of individual entrepreneurial weavers who jump in and out when the carrying capacity of the system increases or depletes. What then emerges is an image of a system that grows or shrinks in response to opportunity or threat in the environment, constantly striving toward its own sustainability.

We then understand the importance of the practices of mobility that its more open members display, rather like jumping off a home ship that is carrying too much load in bad weather, and swimming alongside on their own steam, till fair weather allows them to hop back on. There are casualties, of course, but the ship continues its journey, ferrying people from vulnerability to sustainability. Mobility then is not a symptom of the unsustainability of handloom weavers, but is indeed a function that keeps the scale of livelihoods sustainable in the market. Explained in these terms, the expanding and contracting sociotechnical ensemble of handloom weaving behaves like any other resilient market network, rather than as an unsustainable production system.

Focusing on responses to emergent vulnerabilities in handloom livelihoods illustrates a new trajectory that of vulnerability to sustainability, not only to unsustainability. Financial unsustainability or poverty is the biggest vulner ability of weavers. This vulnerability can become exacerbated by lifecycle and livelihood crises, not 
all financial, and force some weavers to move out of weaving. Vulnerability becomes an important concept to locate how, when and for whom weaving becomes economically unsustainable. Some weavers find themselves more vulnerable and move out of weaving but spiral downward. Some weavers are more entrepreneurial and find other ways of making a livelihood to sustain them through bad times in weaving, and come back to it in better times. Others sustain themselves in new livelihoods, for example, construction work. Studying these movements as responses to vulnerability, we can conceptualize this mobility and movement out of weaving as strategic and informed responses to emergent vulnerability, rather than migration that is proof of livelihood unsustainability. Unsustainability is the narrative, when weavers become vulnerable to poverty, and migration is one response to this vulnerability: in our new understanding, unsustainability becomes explanation, rather than what needs to be explained.

\subsubsection{MUltiplicity OF VULNERABILITIES IN THE HANDLOOM SOCIOTECHNICAL ENSEMBLE}

Through extending the unit of analysis from the weaver to the sociotechnical ensemble earlier in section 3.2, I have already established that vulnerabilities in weaver livelihoods are multiple. Rather than recapitulate the discourses of the different actors and social groups laid out in and sections 3.2 and 3.3, I draw on these different framings of vulnerabilities from discourses already described in these sections. In addition to the study of official policy documents and historical reports, I go beyond to the study of literature and verbal texts generated by NGOs and social movements (Hajer 1995).

In analyzing such material, I take recourse to more interpretive means of identifying recurrent themes. I detail four sets of groups: producers, public sector groups, civil society groups, and market groups [Tables 3.1-3.4]. The first columns of the four tables further differentiate the social groups in the handloom STE. This is a first step to explicate differences in discourses along location and function in the handloom STE. The social groups of sizers, warpers, dyers, and unskilled labor; weavers, master-weavers constitute the producer population; it is their livelihoods that are primarily at stake in this discussion. The social group of policy makers in the state machinery (officials in the government textile departments public sector institutions and local state sponsored co-operatives form the public sector groups) form the public sector group and represent the State. The social group of researchers, media, and activists develop scholarly perspectives as well as present opinions to larger society. This section contains other civil society players like NGOs who cut across activist as well as interventionist roles and work toward better societal outcomes. The market social groups are the entrepreneurs, marketing agencies, retailers, and customers who buy the handloom product and the textile industry players. The category includes power loom operators, mill owners, and garment exporters who are at the market end are also represented in this table, as important groups in the livelihood discourse. There are overlaps between the groups, for example, activists who work in NGOs, or are from weaver backgrounds, or master weavers and co-operatives who both aggregate production, designers, and technologists who may work for the state, independently or in the NGOs; for them, I foreground physical location, rather than function. 


\begin{tabular}{|c|c|c|c|c|}
\hline $\begin{array}{c}\text { Relevant social } \\
\text { group }\end{array}$ & $\begin{array}{c}\text { Discourse regarding } \\
\text { handloom weaving }\end{array}$ & $\begin{array}{c}\text { E merging vulnerability } \\
\text { for handloom weaver }\end{array}$ & $\begin{array}{c}\text { Desirable outcome } \\
\text { framed by the } \\
\text { discourse }\end{array}$ & $\begin{array}{c}\text { What weaver } \\
\text { perceives as desirable } \\
\text { outcome }\end{array}$ \\
\hline Allied workers & Drudgery & No returns on labor & Employment & Employment \\
\hline Weavers & Mobility & $\begin{array}{c}\text { Dropping below } \\
\text { poverty line }\end{array}$ & $\begin{array}{c}\text { Sustainable livelihood } \\
\text { outcomes }\end{array}$ & $\begin{array}{c}\text { Sustainable livelihood } \\
\text { outcomes (Gittubaatu) }\end{array}$ \\
\hline Master weavers & $\begin{array}{c}\text { Fluctuant work force } \\
\text { and demand }\end{array}$ & $\begin{array}{c}\text { Fluctuating wage based on } \\
\text { demand }\end{array}$ & $\begin{array}{c}\text { Social and financial } \\
\text { gain for family firm }\end{array}$ & Value for skill \\
\hline
\end{tabular}

Table 3.1: Social groups of producers, their dominant discourses framing vulnerability of weaver, and related desirable outcomes in the sociotechnical ensemble

\begin{tabular}{|c|c|c|c|c|}
\hline $\begin{array}{c}\text { Relevant social } \\
\text { group }\end{array}$ & $\begin{array}{c}\text { Discourse regarding } \\
\text { handloom weaving }\end{array}$ & $\begin{array}{c}\text { E merging vulnerability for } \\
\text { handloom weaver }\end{array}$ & $\begin{array}{c}\text { Desirable outcome } \\
\text { framed by the } \\
\text { discourse }\end{array}$ & $\begin{array}{c}\text { What weaver perceives } \\
\text { as desirable outcome }\end{array}$ \\
\hline $\begin{array}{c}\text { Planners and } \\
\text { policy makers }\end{array}$ & $\begin{array}{c}\text { Progress through } \\
\text { modernization }\end{array}$ & Sunset industry & $\begin{array}{c}\text { Contribution to GDP } \\
\text { and national export }\end{array}$ & Promising futures \\
\hline $\begin{array}{c}\text { Public sector } \\
\text { support } \\
\text { organizations }\end{array}$ & $\begin{array}{c}\text { Developmental and } \\
\text { welfare schemes }\end{array}$ & $\begin{array}{c}\text { Decentralized and dispersed } \\
\text { sector }\end{array}$ & $\begin{array}{c}\text { Effective delivery of } \\
\text { policy }\end{array}$ & $\begin{array}{c}\text { Equitable access to } \\
\text { support }\end{array}$ \\
\hline $\begin{array}{c}\text { State sponsored } \\
\text { co-operatives }\end{array}$ & Collective action & Static or slow growth & Service to members & Livelihood stability \\
\hline
\end{tabular}

Table 3.2: Social groups of public sector, their dominant discourses framing vulnerability of weaver, and related desirable outcomes in the sociotechnical ensemble

\begin{tabular}{|c|c|c|c|c|}
\hline $\begin{array}{c}\text { Relevant social } \\
\text { group }\end{array}$ & $\begin{array}{c}\text { Discourse regarding } \\
\text { handloom weaving }\end{array}$ & $\begin{array}{c}\text { E merging vulnerability for } \\
\text { handloom weaver }\end{array}$ & $\begin{array}{c}\text { Desirable outcome } \\
\text { framed by the } \\
\text { discourse }\end{array}$ & $\begin{array}{c}\text { What weaver } \\
\text { perceives as desirable } \\
\text { outcome }\end{array}$ \\
\hline $\begin{array}{c}\text { Academics, Media, } \\
\text { Activists }\end{array}$ & $\begin{array}{c}\text { Independent voices } \\
\text { and empowerment }\end{array}$ & Paternalism & Autonomy for weaver & $\begin{array}{c}\text { Social, political } \\
\text { representation }\end{array}$ \\
\hline NGOs & $\begin{array}{c}\text { Self-sufficiency } \\
\text { in production and } \\
\text { market }\end{array}$ & Competing market forces & $\begin{array}{c}\text { Identity and Self- } \\
\text { sufficiency of weavers }\end{array}$ & Market recognition \\
\hline $\begin{array}{c}\text { Craft conservation } \\
\text { groups/ lead users }\end{array}$ & Heritage & $\begin{array}{c}\text { Loss of cultural and aesthetic } \\
\text { heritage }\end{array}$ & $\begin{array}{c}\text { Self-worth for } \\
\text { craftsperson in } \\
\text { changing markets }\end{array}$ & Cultural capital \\
\hline
\end{tabular}

Table 3.3: Social groups of Civil Society, their dominant discourses framing vulnerability of weaver, and related desirable outcomes in the sociotechnical ensemble

\begin{tabular}{|c|c|c|c|c|}
\hline $\begin{array}{c}\text { Relevant social } \\
\text { group }\end{array}$ & $\begin{array}{c}\text { Dominant discourse } \\
\text { regarding handloom } \\
\text { weaving }\end{array}$ & $\begin{array}{c}\text { E merging vulnerability for } \\
\text { handloom weaver }\end{array}$ & $\begin{array}{c}\text { Desirable outcome } \\
\text { framed by the } \\
\text { discourse }\end{array}$ & $\begin{array}{c}\text { What weaver } \\
\text { perceives as desirable } \\
\text { outcome }\end{array}$ \\
\hline Entrepreneurs & Enterprise & Dispersed markets & Firm growth & Market Niche growth \\
\hline $\begin{array}{c}\text { Retailers, online } \\
\text { platforms }\end{array}$ & $\begin{array}{c}\text { Competition from } \\
\text { lower cost (power } \\
\text { loom) imitations }\end{array}$ & Reduction in value & $\begin{array}{c}\text { Increase in market } \\
\text { share }\end{array}$ & $\begin{array}{c}\text { Access to emerging } \\
\text { market niches }\end{array}$ \\
\hline $\begin{array}{c}\text { Textile and clothing } \\
\text { industry }\end{array}$ & $\begin{array}{c}\text { Technological } \\
\text { upgradation for } \\
\text { productivity }\end{array}$ & Mechanization of handloom & Innovation & $\begin{array}{c}\text { Recognition as } \\
\text { innovator }\end{array}$ \\
\hline
\end{tabular}

Table 3.4: Social groups of market, their dominant discourses framing vulnerability of weaver, and related desirable outcomes in the sociotechnical ensemble 
I propose the tables as a step to disentangle the multiple discourses, rather than to define clearly bounded domains. In addition to being informed by my earlier description of the discourses, the analysis has been extracted from public and private meetings between spokespeople for each of those groups, which I have been part of in my work with them. I detail in the table above indicative rather than exclusive examples of each group's discourses; the intent is to explicate through broad strokes the multiplicity of discourses, vulnerabilities, and desirable outcomes, rather than diagnose and prescribe solutions. I use the table to illustrate how different outcomes obtain as specific vulnerabilities emerge from actors ${ }^{97}$ discourses.

\subsubsection{THE ARGUMENTATIVE APPROACH AS GENERATIVE}

How can we relate the multiplicity of vulnerabilities in handloom livelihoods to coherent interventions by the actors in the STE that can sustain weavers? Multiplicity is the opposite of convergence; it evidences the lack of consensus in the sociotechnical ensemble of handloom. How then do actors intervene? When do such interventions lead to unified outcomes that are generative for weaver livelihoods? In order to explain coherence as a unifying force in the STE, I use the work of Hajer (Hajer 1995), who proposes the argumentative approach to explain how dominant policy discourses emerge out of diverse claims. The argumentative approach builds on social constructivist as well as discourse analysis, and overlaps with Sen's cultural explanation of the argumentative tradition in India (Sen 2005).

In relating actors and social groups in my analysis, I suggest that an actor's membership in the group comes from understanding the internal rules that make those discourses function as a structure to behavior (Foucault 1991). Rather than considering discourse as a medium through which individuals manipulate the world, discourse represents a set of ideologies, histories, and social practices. This facilitates the embedding of discourses in social groups: it becomes possible to think of discourse as a set of rules that may bind a group of people who understand its web of practices together, who may then collectively position the problem in a particular way. Then each member of the group can ostensibly represent it, say for instance as an actor in a meeting, or field worker in intervention.

In order to further understand the effect of discourse on the workings of various interventions in a given domain, and to understand how different discourses which are distinct come to influence each other, Haier refers to argumentative interaction (Hajer 1995, 54). He focuses on the constitutive role of discourse in political processes and allocates a central role to the discoursing subjects. This he suggests complements the use of discourse theories of Foucault, which are ambivalent about the role of the discoursing subject. The argumentative approach conceives of politics as a struggle for discursive hegemony, whose dynamics are determined by three factors "credibility, acceptability, and trust."

Credibility leads actors to believe in the subject-position that their discourse implies for them, and to live by the structure-position; acceptability results in that position appearing attractive or necessary; trust refers to suppressing doubt and managing inherent uncertainties that might otherwise cause the discourse to be rejected by its detractors (Hajer 1995, 59). Hajer puts forward the concept of story line and discourse coalition as "mid-level" concepts that can show how discursive orders are maintained, as well as transformed. Hajer defines story lines as "narratives of social reality through which elements from many different domains are combined and that provide actors with a set of symbolic references that suggest a common understanding" (Hajer 1995, 62), which essentially work like metaphors. Therefore, they become the basis for creations of coalitions amongst the actors. He further defines discourse coalitions as the ensemble of a set of story lines.

97 Drawn from interviews across the social groups, as well as focus group discussions, public meetings and policy documents detailed at the end of the thesis. 
In the case of the handloom ensemble, the unsustainability of handloom can be used as an example for a discourse coalition. ${ }^{98}$ It is based on credible, necessary, and trustworthy story lines for the actors in that coalition: financial unsustainability of handloom product in the mass market for mechanized textiles as a story line for Industry groups; the drudgery of manual weaving, weavers migration as a story line for weaver groups, the regressive caste-based nature of handloom as story line for civil society activists and modernization of unproductive technology as story line for the state groups. Each story line replaces complex debates. Certain sections though, find it has strong explanatory power, with reference to handloom. It does not require a complex rethinking of ideals of technological determinism and social realities. Therefore, it becomes a powerful discourse.

Such notions are constructed interdiscursively, that is "an understanding of the phenomena necessarily requires the combination of knowledge claims that are the product of distinct discourses"(Hajer 1995, 61). This analysis produces another insight, that when groups understand each other's positions, if there is argumentation to generate new alternatives, then there can be change. That is, the same process that inter-discursively produces notions of unsustainability can be used to generate the opposite, the persistence of handloom, and its sustainability. One can now see how argumentation can indeed become generative. Therefore, while Hajer uses the understanding of discourse theory to study how discourses become hegemonic, in this chapter, I use it to study the other situation: how there come to be a multiplicity of discourses of handloom.

While doing so, I do not offer an analysis of the processes of negotiation, discursive practices, and modes of interpersonal communication that Hajer's argumentative approach builds on. For now, I put these aside, instead substituting it with an all-encompassing term, the "argumentative tradition" that Indians are known for. Put a bunch

98 For a description of Hajer's example of ecological modernization, using the argumentative approach, see (Hajer 1995, 65) of Indians together and they will argue: it is socially accepted that there is great value in standing up for one's position, at all and any cost; in drawing rooms, over coffee and dining tables, on the street, in a car ride; the location is immaterial to both the discourse, and the discoursing subject. So how does inter-discursivity work when there is such societal value for being true to one's discourse and one's credibility in society is predicated on being seen as coming from such an unflinching position?

Hajer's "story line" and "discourse coalition" work very well here too to explain how discourses influence each other even in such a bounded situation. We see that in situations where there is varying mistrust of each other's discourses, actors judiciously align based on the credibility of the other actors, and only partially accept the other's story line: for example in the case of activist's distrust of state, or market, aligning on state poverty alleviation programs or social enterprise partnerships. Deficits in trust lead to uncertain and temporary coalitions; where trust is strong, the coalitions tend to last longer. This becomes important, since I use discourse-coalitions not just to explain political policy making processes but also interventions with proposed outcomes which require mobilization of scarce resources, and need long term commitments to be fulfilled by many parties.

In a next step, in the figure below, I juxtapose evidence of outcomes to weavers from such coalitions of discourses and their story lines. Some outcomes are more visible than others, alerting us to their dominance, but at the same time, we see that there is a plethora of outcomes. For example, we have already seen how the discourse of unsustainability emerges from the story line of migration, between market, industry, and weaver groups [Fig. 3.2]. On the other hand, the presence of well-functioning co-operatives with their commitment to the livelihoods of its members, and the NGO's solution of gaining self-sufficiency for weavers could combine to produce another image, of weaving as sustainable for weavers and equitable for society. In this case, the weavers' mobility takes a more sustainable direction toward new markets and new products [Fig. 3.6]. 


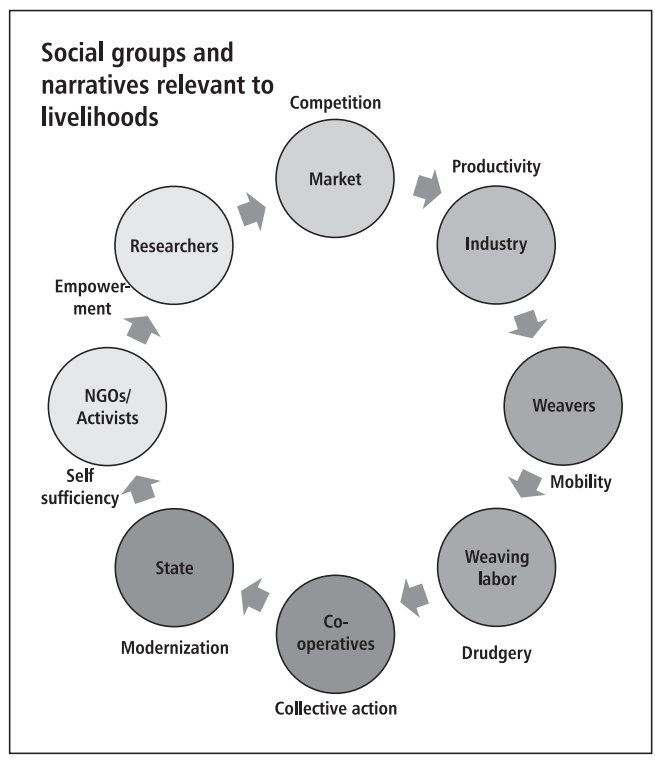

[Fig. 3.1 Social groups]

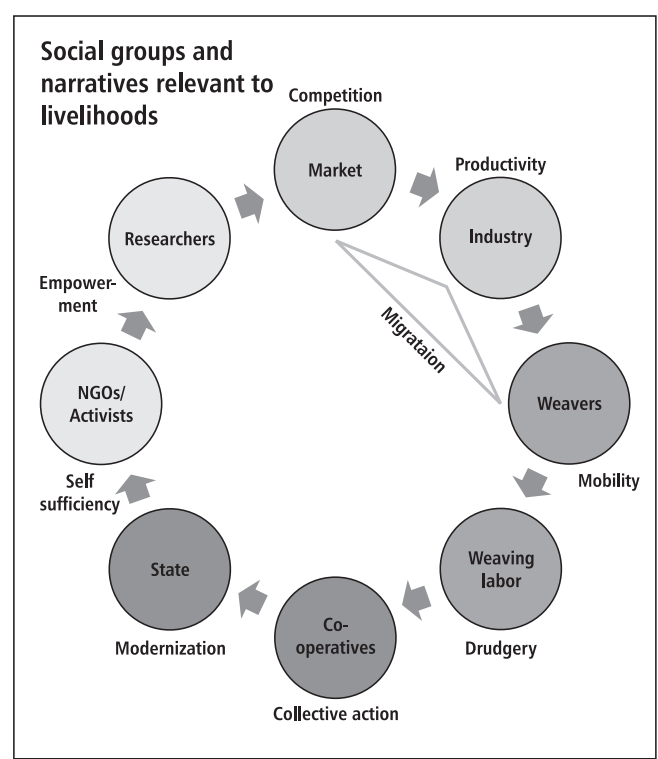

[Fig. 3.2 Migration]

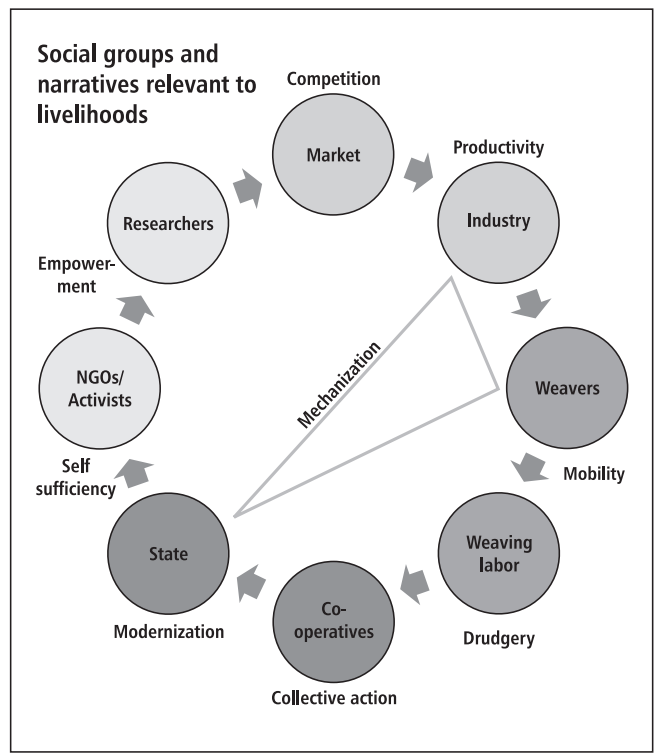

[Fig. 3.3 Mechanisation]

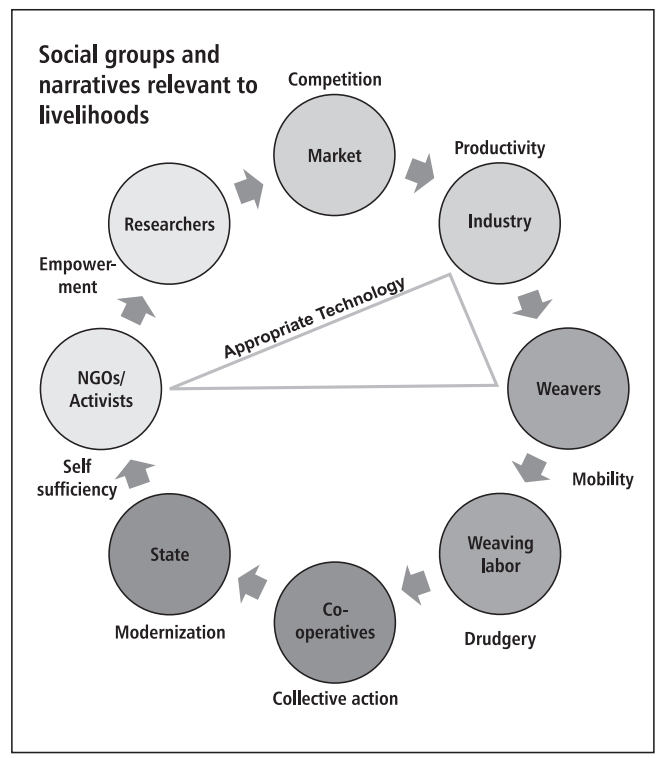

[Fig. 3.4: Appropriate technology] 


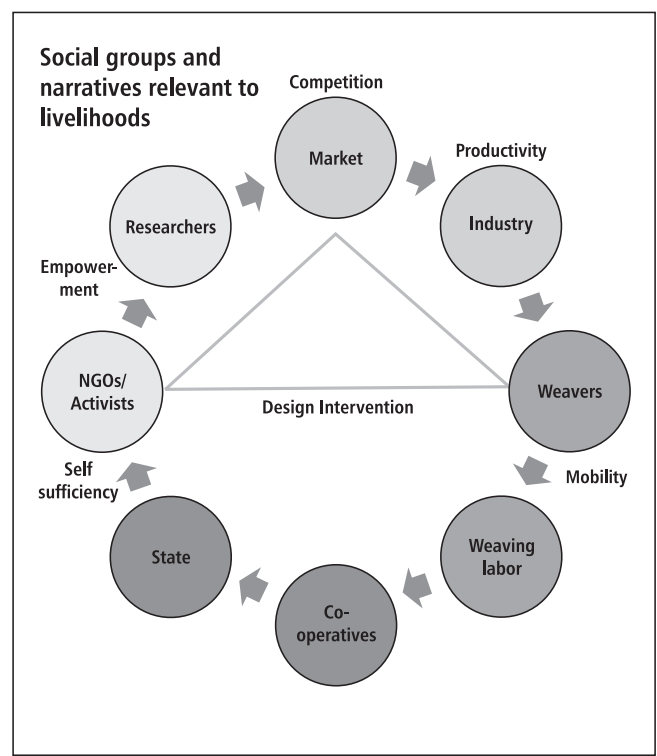

[Fig. 3.5: Design Intervention]

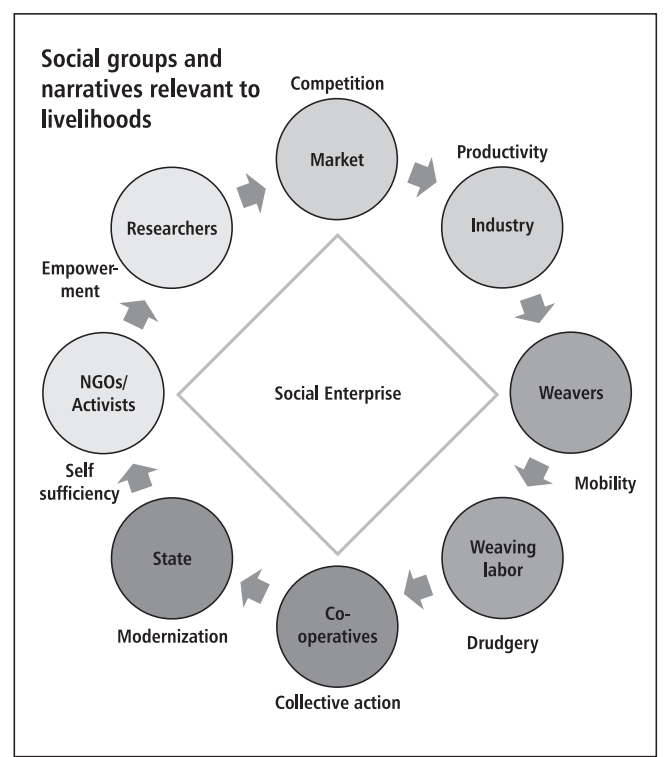

[Fig 3.6: Social enterprise]

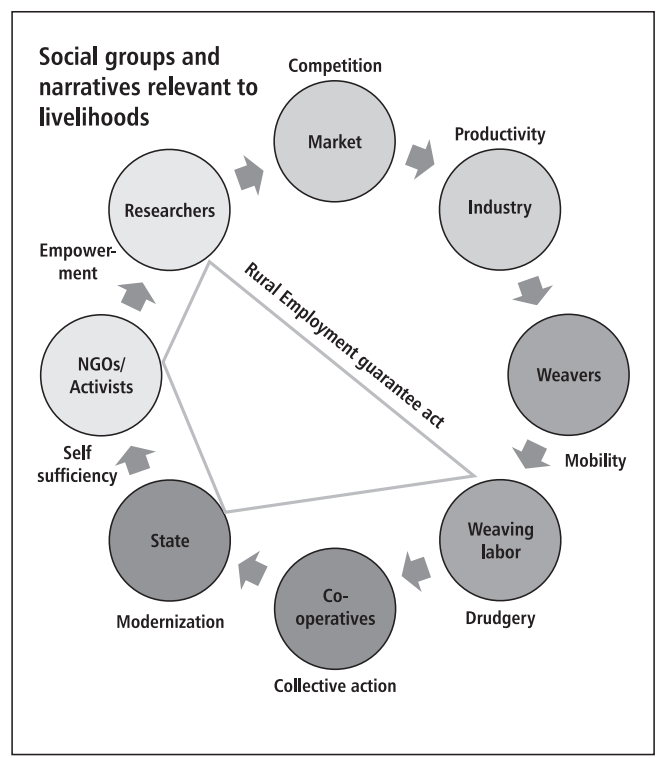

[Fig 3.7: NREGA]

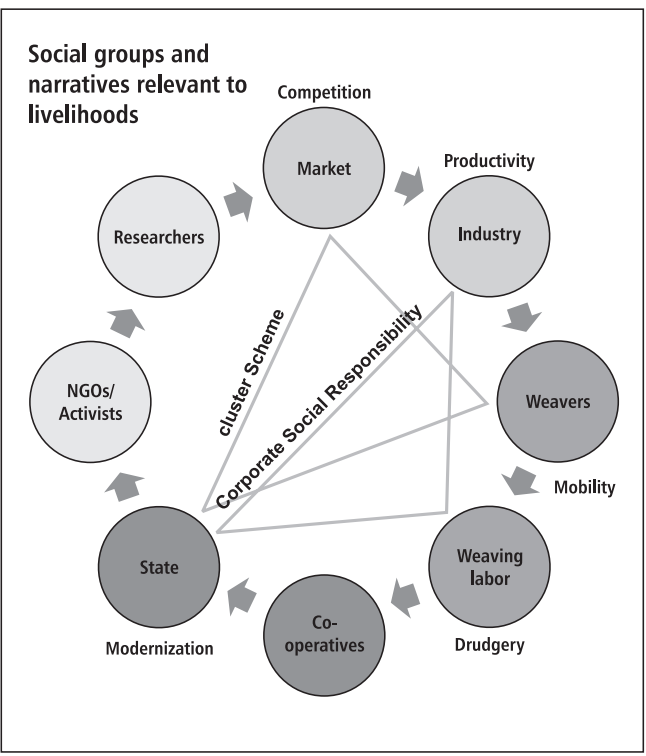

[F ig 3.8: CSR, Cluster scheme] 


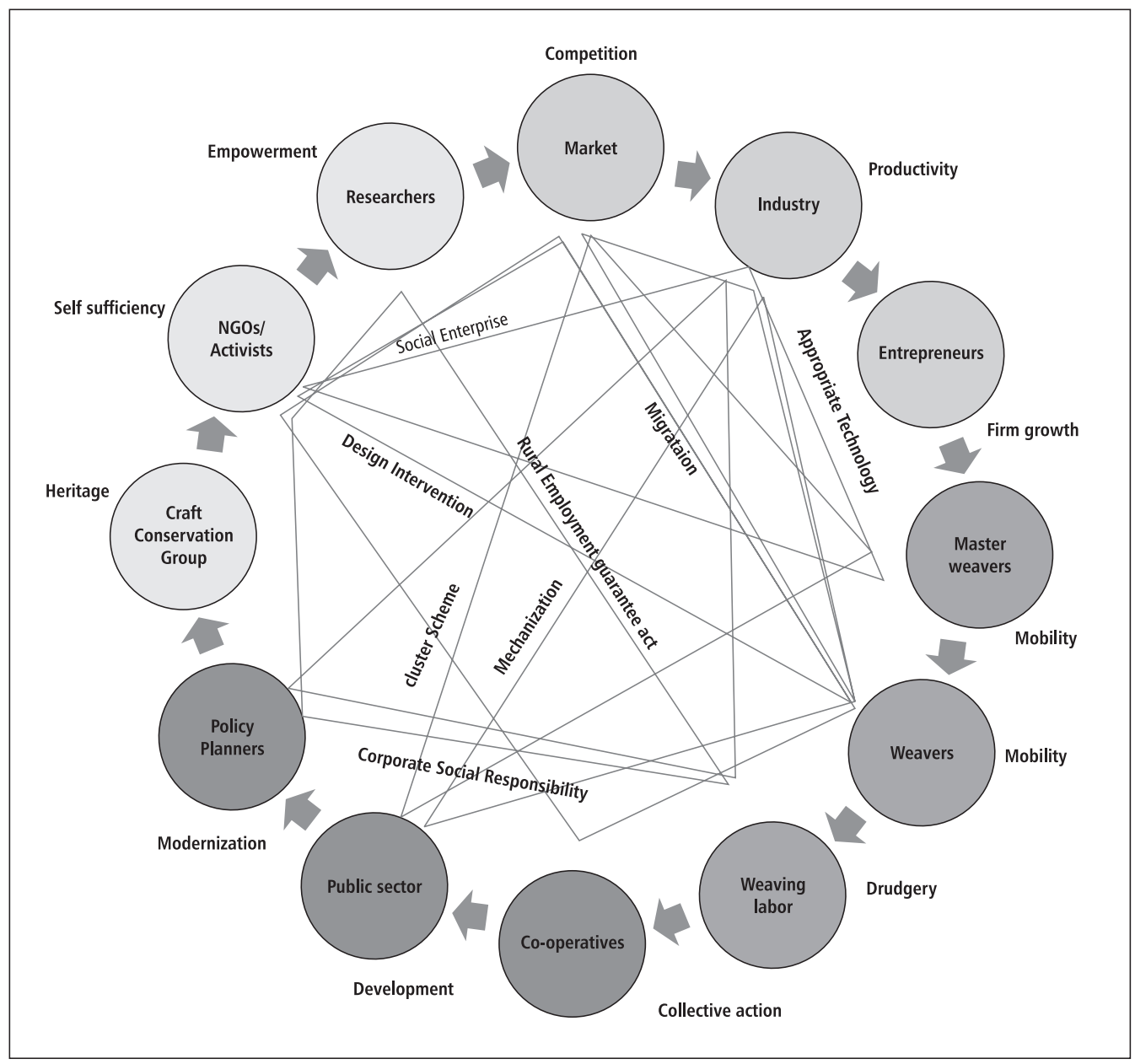

[Fig 3.9: Demonstrating how the entangled discourses emerge between the social groups]

Another familiar outcome of technological intervention between industry and state is that of mechanization. Industry groups define vulnerability in handloom as that of unproductive technology. When aligned with the progress and modernization agendas of the state toward its traditional craftsperson citizens, technological upgradation through mechanization seems the logical outcome [Fig. 3.3]. At the same time, this technologically deterministic solution of mechanization is resisted by alignments between other groups. Interventionist
NGOs align with Industry goals of finding technical solutions, actors are able to work toward appropriate technology that builds on the strength of customizable and decentralized nature of handloom technology, rather than toward productivity [Fig. 3.4]. Such agendas are possible only if the NGO is able to bring in sufficient investments out of philanthropy, or pay them out of subsequent market profits.

Engaging with enterprise, through marketing is another axis of alignment for social groups in the STE. NGOs can intervene through design, when 
aligned with enterprising craftspeople, and engaged lead users from the market [Fig. 3.5]. In another context, the marketing approaches of enterprising NGOs may align with the service agenda of cooperatives and through collective action negotiate with powerful market players and gain equity for weavers in the transaction. While marketing only to public sector agencies is inadequate to meet supply, in conjunction with marketing through NGOs, co-operatives can become more robust in matching demand and supply. This support makes marketing of products of vulnerable groups, such as aging weavers possible or medium-skilled weavers possible, through loom support programs run as social enterprises [Fig. 3.6].

The state organized weavers into modern co-operative institutions along the lines of western socialism. Contemporarian Indian intellectuals found the caste bound identity of weavers regressive within their discourses of social justice. When discourses of progress of activists and the state aligned, weavers were reinvented as secular citizens of the state, through membership in the state co-operatives. Now they and their incomes are enumerated, and their rights can then be invoked, for example through the NREGA act providing employment guarantee to those below the poverty line [Fig. 3.7]. However, the conflict of a caste occupation in a modern world is not so easily resolved, and throws the identity of the practicing weaver into flux. Practicing weavers see NREGA as a program for the lowest castes; not by design, but by default, since very often social and financial deprivations go together for the poorest of the poor. The weaver who is higher in the caste hierarchy is now in a bind, as the daily wage of the lower caste manual worker is higher than his own. Participating in the NREGA program means an association that would lower his social status and identity. Still, the conflict itself draws attention and succeeds very often in giving voice to weavers as an outcome, and making possible the weaver's participation in public debates regarding handloom.
This analysis has explanatory power regarding the seemingly divergent policies of the state with respect to handloom, the different departments that deal with handloom and craft "30 ministries, departments and authorities who impinge on artisans, ... and do not consult," 99 and their changing political agendas. The basis for major policies such as the cluster scheme, Public Private Partnerships, designer support schemes, NREGA, National rural livelihood development program, CSR to name a few can be explained in terms of alignments of discourses. The socialist state has a moderating effect on the industry led marketing interventions, leading to ethical business outcomes, and philanthropic investments, for example with the CSR programs [Fig. 3.8].

As a result of the state aligning with industry and market, schemes can be taken up such as the Cluster development scheme, which have elements of state-sponsored infrastructure support, promotion, capacity building for market activities, can be taken up. In order to aggregate production, such interventions might choose to partner with master weavers and, where possible, co-operatives, rather than individual weavers [Fig. 3.8]. Seen with this lens, we gain some perspective on the contradictory impulses of the state: on the one hand to mechanize as technological upgradation, and on the other to museumize heritage; on the one hand supporting co-operative enterprise that builds on handloom strengths and on the other setting up welfare programs that subsidize weaknesses, and so on.

To summarize, the presence of the multiple discourses around vulnerability in the sociotechnical ensemble seems counterproductive [Fig. 3.9], till we see how discourse coalitions tend to develop between certain groups in the ensemble, shaping interventions, and outcomes for weavers. These coalitions create some coherence around which the handloom STE can organize its actions. Key players' presence in the STE tends to predict what kind of coalitions would form, and what kind of

99 Ashoke Chatterjee, http://ccrtindia.gov.in/downloads/other/ lecture_5_pro_ashoke_chatterjee.pdf 
solutions would emerge as a result. Therefore, the multiplicity of discourses and social groups in the handloom STE can be seen as a precondition for generating a multiplicity of opportunities for weavers. From this understanding, we can see that just as negative outcomes such as the standard image of handloom as unsustainable are generated through such discourse coalitions, positive outcomes too could be generated. These changing coalitions can also explain seemingly contradictory solutions and policies being framed, sometimes by the same actors when part of different coalitions.

Activists who work with weavers caution us not to fall into the policy trap of referring to "The weaver," as if he or she were a universal entity; there are weavers and weavers, as we shall see. In the following section, I narrate the multiple facets of a handloom weaver's livelihood, as he or she interacts with the multiple environments, which afford multiple livelihood possibilities. In order to capture snapshots of what is essentially an evolving journey, I present it to use a cubist metaphor as a work in motion.

I use a literary style from traditional Indian theatre - the voice of the master narrator, the "suthradaara"- to reconstruct the following livelihood narrative on the basis of interviews with different informants. The word suthradaara, which is the same in most Indian languages, has a root in Sanskrit and literally means "donning the part." The suthradhara is the teller of the story, but he himself plays different characters during the course of the play too. In this way, the storyteller becomes the voice of many people, and his story becomes about more individuals than one. This, for those who are not familiar with this style of narrative, is the singular voice of the 'I' in the following section. I use this as an aid for the reader to walk in the shoes of the weaver as he negotiates the different conditions that affect different aspects of his livelihood.

\subsubsection{ANAGANAGAA OKA NETHAGADU: ONCE UPON A TIME, A WEAVER...}

I am a weaver by birth, as indeed most weavers today are: I am born to parents who are weavers whose parents were weavers, for as long as they can remember. Growing up, in the interior villages of Andhra Pradesh and Telangana, I will go to school unless my parents migrate to the city, and growing up years at school are disrupted. If my parents have found a stable market for their skills, they would be able to afford a good education for me. They will encourage me to study, as all weavers do their children, rather than stay back in weaving, but weaving is the hereditary vocation (kula vritti) that I can always fall back on.

"My father tried to make me go back to the school, but after the seventh standard, I came into the vocation (vritti)." 100 If I chose to stay in weaving, at home first I will learn simple tasks by observing my parents weave. If I do well in school, then I will go on to higher education outside the village; otherwise once I am "tenth pass" his father may decide to keep me home and working on the loom, to keep me out of mischief. Doing well at school will not be enough to guarantee me a university education, my parents may not be able to financially afford it. I may have to settle for a non-professional degree, where I aspired to be an engineer, or a teacher like other weaver children with better off parents. In that case, my father will be philosophical, especially when he thinks of the money he will need to get my sisters married. "He was upset, had a tantrum, didn't talk to anyone for a week, we left him alone, he didn't eat for a week, but what could be done, it was just not possible." 101

As a beginner weaver I will only be allowed to perform the basics of weaving at the loom, with time I will master the ancillary activities of warping, setting up the loom for new designs, choosing color, and product. I will be made known to my father's 
professional community: the dyer, the warper, the master weaver, and the co-operative manager; so that I can slowly take up my own place in it. If I am the eldest son, the right to my father's loom is first mine, even if my younger brother chooses to weave we may not be able to raise the capital needed for acquiring a second loom for the house.

Marriage is usually to a girl from my own caste. If I marry out of the community, there is a danger that I will be socially ostracized. Even if she is accepted by my family, she will not know how to weave, and I might well have to move out to another profession: "I had a love marriage, without my parent's permission, so I left the $100 \mathrm{~m}^{\prime 102}$. M y sisters are not taught the fine points of weaving; knowing that the girl will possibly marry into a competitor's home deters this. Women weavers who weave by themselves are an exception; weaving at home requires two pairs of hands; in particular a man to take care of the "outside" work of sizing, trading, and so on which a lone woman may find difficult, even if she is proficient in the actual weaving work. However, it is possible, if the community of weavers around her or the co-operative is supportive.

Taking care of older parents, whether as the son or daughter-in-law, or the daughter who lives nearby and comes home to cook for a widower father is the norm for girls and boys. E ven when we young men leave the house, it is a matter of pride when we are able to take care of our parents in their old age in whichever cities we are now making a livelihood. My father may prefer to stay independent of me, in his own house even as he ages, instead welcoming the extended family for festivals and holiday in his own home, "because those city houses are not big enough for us." 103 Or he may put away the loom in the attic and move to the city, even if he has many working years left. Knowing he can leave gives him better bargaining power with the master weaver. "The master weaver said to my father, 'I won't

102 Interview, Allada Asiri Naidu, February 26th, 2010

103 Interview, Boodida Appa Rao, February 25th, 2010 give you a warp this time,' so he came to me for the festival, threatening the master weaver that he may never come back." 104

If there is a factory or industry in the vicinity of my village, I might decide to find work there. If I am still living at home, I will continue weaving in my spare time for the family business. The kind of work I find outside may not be satisfying, but the wage would make up for that. "They pay a good wage, and extra for housing, and for children's education, and then even if the work is not so good [working in a jute factory] it still is a better choice than weaving." 1050 therwise, I have friends in the cities, from the village, who are not weavers. They may help me find a job in the city. It's a matter of luck, if they are in a good position themselves, then I will get a good job, like a sales person or accountant in a shop. If I end up in a menial job or having to sell liquor, I can only afford to live on the premises, and may well get into bad habits myself.

If I am a capable weaver, I will shift from one kind of technique to another, taking pride in my talent and skill. "I can learn anything, if there is somebody who is weaving something really nice, then I will use another warp length and conquer it somehow or other...I have a curiosity and interest in it...how can it be that I can't do something that someone el se can do? I have been born in this, I have worked in this, somehow or other, I feel that I can learn the new work... I do have the determination.... if one has the education/skill [vidya] then one can achieve anything, without it we are of no use to anyone." 106

My household is my work force, my wife is also a partner at the loom: "if we quarrel too much then the work stops and we don't eat ${ }^{107 " \text {; she }}$ is the person who takes care of the children and older in-laws early on, who keeps the loom running when the family needs me to work in greener pastures in middle age, the mature woman who

104 Interview, Venkat Rao, February 25th, 2010

105 Interview, Venkat Rao, February 25th,, 2010

106 Interview, Appa Rao, February 25th, 2010

107 Interview, Ramalakshmi, January 28th, 2012 
weaves alongside me again in the autumn years, she forms the foundation on which I churn out my daily livelihood. It is an open secret that "weaver marriages are made of gold," 108 since we work together and live together in fair harmony.

F eeding an extra mouth can tip the balance between making ends meet, and having to migrate out in search of work. In a group of six who work together, one person with the vice of alcoholism is enough to tip us downward. "Where there is no bad habit, then it is just enough, imagine if there was what would happen." 109 III health and disability can also tip the balance toward penury for the entire family.

$0 r$, I may be more enterprising than others around me, add a couple of looms to my production, so that over timel become a master-weaver by dint of taking market risks, and turning around my meagre capital. Handloom weaving is a family business: as one learns to weave, innovate, and create for the market, one learns the lessons of personal and social interaction. Both family and business are at stake if relationships sour, the stakes double in such a venture. Since breaking out of the family business means risking family ties with my brothers and uncles, my wife may be the one who tells me when it is time to break out of the family business and start our own, pawning her gold for working capital. My daughter who refuses to marry a weaver if he will not work in an office, for whom she can "send lunch in a box," 110 stands for the aspiration of the community which fears it is being left behind by the modern world. If I move out successfully into another profession, my only contact with weaving will be during occasional visits. M y son will become unfamiliar with the vocabulary of the loom and will not know even to say "pogu" (hank yarn) not "thaadu" (thread), when referring to the warp on the loom. "Even though he carries my own blood, he is ignorant of weaving." 111

108 Weaver in Daram, Public meeting, October 2011

109 Interview, Rashmi Rao February 25th, 2010

110 Interview, Rashmi February 25th,, 2010

111 Interview, Krishna Rao February 25th, 2010
Where we weavers do well, farmers are envious "they live like kings, in this village". When farming does badly, "karuvu" drought is pervasive in the village, signaling to us a time when we may need to shore up against a season of hardship. Although I recognize the technical knowledge I possess, I am aware that it is not recognized as such outside of weaving. I may then end up as unskilled labor in the city, if I migrate there looking for work: "we don't have any education or jobs, who will give us proper work?" 112

If I am good at marketing, I would instead set out of the village, with a bundle of sarees on my back to find new patrons, and in time it is possible that traders would come to the village, in search of the wares that I showed them a taste of. If I innovate successfully using my skills, the entire village comes to be known for the type of saree I am weaving, and more weavers will travel to our village in search of work, and surrounding villages too will find livelihood out of my innovation. There is a downside, if the market for what I weave reaches a scale that catches the eye of the power loom competition. The power loom operators will find a way to make a cheaper imitation, which will cut into my market, and the wage for my product will spiral down, leaving all of us vulnerable.

Cotton prices as well as market demand fluctuate and are out of our control; if the master weaver is able to contain them, then I will fare well. If not, my membership in the village co-operative can become a support in hard times. While the management is political and can play favorites, in general, if I have elected a good board and have a strong president of the society, they will try and find work for me. "We all, when the president behaved badly got together against him and made him behave himself, even the government stood by us, when we did that."

A good president or manager would negotiate well with the government officials and use the resources that the government allocates for

112 Interview, Maanem Vishwanath February 25th, 2010 
us. "The intention of the government is good, they want to uplift the weavers." ${ }^{113}$ At the same time, the president needs to know how to leverage the resources; an increase in training, an increase in remuneration during the training, all are needed to enjoy the fruits of the training. Since the government offers schemes that will support infrastructure with the help of the local state District Rural Development Agency (DRDA), weavers may move their looms into a kind of shed, where other men and women can go to weave. This will help women to weave as well as non-weaving communities to get into weaving, since there are people who will train them, rather than expect that they will al ready know how to weave. "We took a building, and made a unit and built looms under the shed, and then women who previously only did preparatory work have now successfully come into weaving." 114 Working with the government can mean that workers have to be organized to fight back against corruption. The co-operative is an important institution for me, particularly when members, board and management work well together, to access all kinds of government support and schemes.

"From the beginning, we are saying that our co-operatives need to enlighten themselves, the staff, the management, and the members; we should be able to make the government work for us. That is the important thing, we are so scared that if we ask them loudly they may not even give us what we get now, they feel insecure, then the weaver bows his head to that. Why does he do that, because he has no knowledge. First he has to be educated, then they will fight for themselves, and we don't have to do it for them. That is the important reason why even in places like Chirala which are successful handloom centers, co-operatives have failed." 115

If the co-operative is able to link with a good market partner or an intermediary voluntary organization, then there is stability in livelihood for all of us members. "All the weavers who worked with Dastkar Andhra [NGO] have been able to educate their children up to a [university] degree." 116 Then I can learn new technologies, explore my creativity in weaving for new markets, and get support during lean times. "If there is income, it doesn't matter, even if it old fashioned. Look at Dharmawaram [a successful silk weaving center], not just weaving castes, but all-Brahmin, Reddy, they are all in weaving, they run the jacquards, they make the designs and they even weave and they market. And it glorious to see." 117 In the end, I will evaluate myself on how successfully I have fulfilled my obligations to my family and community, and this will add to my identity and self-esteem and become a mark of my success as a weaver.

\subsection{SUSTAINABILITY: SOMEWHERE BETWEEN SUICIDE AND SUCCESS}

The analysis linking vulnerability and sustainability in livelihoods rests on four important steps. First, on recognizing the emergent nature of vulnerability in weaving livelihoods, vulnerability emerges in weavers' livelihoods as their working lifecycle changes in response to internal changes as well as external ones. Second, I extend the unit of analysis from weavers to the sociotechnical ensemble (STE) of handloom: weavers are part of sociotechnical ensembles in which different social groups are present. Each social group associates a different vulnerability with handloom livelihoods based on its own discourse, thus vulnerabilities present as being multiple in weaver livelihoods. As a result of the multiplicity in discourses of vulnerability, the singular fix-all solution too disappears, as does the singular framing of "the vulnerability" of weaving livelihoods-whether
113 Interview, Kasina Prasada Rao, February 27th, 2010

114 Interview, Kasina Prasada Rao, February 27th, 2010

115 Interview, Kasina Prasad Rao, February 27th, 2010
116 Interview, Puchala Paidraju, February 26th, 2010

117 Interview, Kasina Prasada Rao, February 27th, 2010 
economic unsustainability or poverty. This allows us to focus on handloom livelihoods as a sociocultural idea, rather than just an economic one.

Third, based on potential overlaps in these discourses, social groups ally themselves into different coalitions across the STE. These different coalitions respond to exogenous changes based on their different internal capacities. Experience shows that some coalitions have the effect of alleviating and others exacerbating livelihood vulnerabilities. This explains the plurality of outcomes in the livelihood environment. Fourth, weavers' capabilities and responses to emerging vulnerability are not homogenous. If handloom livelihoods are to be sustained, "people may be vulnerable, and their situation may seem inescapable but applying a constructivist perspective may offer new perspectives and coping strategies" (Bijker, Hommels, and Mesman 2014, 21), a statement that augurs well for a culture where prophecies tend to carry certain weight. Such an analysis could possibly allow for more promising possibilities for livelihoods in handloom; offering the weaver hope, while facing the reality of adversity. Depending on their environment, the STE that they are embedded in, weavers make choices that navigate to different outcomes. These trajectories trace a continuum from unsustainability to sustainability in livelihood. From a research perspective, tracing these varying weaving trajectories helps us understand the opposite ends of suicide and success in weaving livelihoods, as well as the middle routes of resilience which can lead to sustainable outcomes in the face of vulnerability. An understanding of how vulnerability and sustainability are linked evidences the emergent nature of not just vulnerability but also sustainability, in weaver livelihoods.

This understanding challenges the idea that vulnerability is a deficit that is inherent to particular social groups, ensembles, or situations, which when filled leads to sustainability. Emergent vulnerability asks for a response, not just of someone powerful to fix it but also of the ones vulnerable to cope with the change caused by its emergence. A change in the market place when a saree loses its market value because of power loom imitations can cause vulnerability to the weaver, an innovative NGO may intercede in response with a new design through interacting with another segment of the market. The innovative weaver in turn will interact with such an NGO to produce a range of products targeting the emerging market. Others will wait to see if the product innovation is scalable in the market. In the absence of narratives of success, or of hope, some weavers will become despondent and migrate out of weaving. Where there is hope, innovation will sustain a core group of resilient weavers, affording the possibility of sustainability for more with time and renewed effort.

From this analysis, we see that presence of more social groups in the ensemble in interaction with each other, with larger heterogeneity of functions brings an increased awareness of imminent changes and a sense of coherence to the response associated with the change. Absence of particular groups diminishes possibilities, for example if the state is not present in the ensemble and the business groups are dominant, vulnerability will lead to mobility out of weaving and financial unsustainability for large number of weavers. Similarly, if civil society organizations are not present in the ensemble, the terms of negotiation for weavers may be less conducive to equity and social sustainability. If the market is not present in the ensemble, there may not be trajectories to fulfill weaver's aspiration of growth, leading weavers to abandon weaving for other professions, resulting in the loss of their knowledge of a sustainable technology that offers hope for the future. Therefore, heterogeneity of social groups in the ensemble does not only result in divergence and conflict that cause break down, on the contrary, they also become promotive and protective factors that facilitate multiplicity of solutions. This understanding locates coherence rather than consensus as the basis for action in the STE.

In conclusion, I lay out three important criteria for appraising sustainable outcomes in sociotechnical ensembles. The first is on the 
aspect of being open, so that change is not shaped in entirety by either external contingencies or internally predetermined. In a robust ensemble, success is not so different from the daily grind of sustainability with routine tinkering in the margins and the clanging and shushing sounds of maintenance. Even as different social groups in the handloom STE interact to generate interventions, the weaver is not himself a constant, nor does he or she have a standard trajectory in response to these interventions. Depending on his or her openness to change, they can choose to make themselves vulnerable to new outcomes. Choosing such vulnerability can have a positive effect: as "openness to change and willingness to engage with the uncertainties that are associated with learning and innovating" (Bijker, Hommels, and Mesman 2014, 7). As a result, new trajectories can emerge, affording possibilities for sustainability, which may not have previously existed.

The second condition is relational, where change is constrained to be reciprocal and symmetric to the different social groups in the ensemble. In an equal society, with good governance practices in place, business and government may not need civil society organizations to ensure equitable economic outcomes for vulnerable producers. Then, democratizing ownership may be a good way of ensuring reciprocity between producer and market. In unequal societies, the assumption that inclusion in a business relationship or participation in the value chain is equal to access has to be put aside. Being present in the same sociotechnical ensemble alongside dominant market players will not lead automatically to better access to market for weavers. In these highly unequal ensembles, argumentation is the interactionist dynamic that generates alternative discourses, for which strong civil society players are needed, to offset power differentials and to give equity a better chance. Civil society interventions, while they may not make huge strides in systemic changes toward equality, can help democratize interactions and mediate existing power differentials. A strong public that can accommodate argumentation and social conflict over emerging inequalities; as well as civil society that intervenes to effectively offset the inequalities become a necessary condition for sustainability.

It is plausible that heterogeneity in the groups leads to heterogeneity in relationships between the groups. Some of the relationships in the ensemble are formalized and legally binding, for example between the co-operative and the bank, and some are not, for example between the masterweaver trader and weavers. Some relationships are based on personal trust relations, and some others on contractual obligations. Financial liability stands on shaky ground when these relations operate unevenly across the different players. For example, since ownership of designs by handloom weavers is not legally recognized, when power loom weavers imitate the designs and market them at a lower cost, they are not held liable. Liability of the state public sector organizations for dues owed to the co-operatives is often not enforced, since co-operatives, which are partially public sector organizations, are lower down in the hierarchical pecking order of public institutions and cannot hold organizations that are higher up accountable. The handloom sector is dependent on the integrated mills for stable and affordable yarn supply; the state enjoins mills to produce hank yarn for handloom weaving compulsorily to protect input supply to the handloom industry. Mills also produce cloth that competes in the same market as handloom product. If mills were to increase prices of yarn supplied to weavers, handloom fabric would become more expensive; by keeping their own prices low, they would gain a price edge in the market. There is no legal mechanism to control this credibly. The state textile department is equally responsible for handlooms, power looms, as well as mills, and this compromises any steps that may take to protect handloom against power looms or mills.

NGOs and CSOs are not-for-profit voluntary agencies that are not legally allowed to trade or 
take up business functions; when they operate in marketing in order to mediate the relationship between weavers and market corporates, it is below the regulatory radar. Investments as well as loses borne by them are invisible; by the same coin, if they fail, there is no legal framework that holds them accountable to either weavers or the public, making them susceptible to allegations of fraud. However, weavers are not passive participants; they are active agents who modify their trajectories and expectations according to changing conditions. When an equitable oasis is generated through the aegis of NGOs and CSOs, markets, or state institutions, the weaver, who may otherwise feel that suicide is the only dissent he can place in public view when unsupported, finds a place to speak. In this oasis, however small it may be, resilience is built, as the livelihood of the weaver flourishes, giving hope to others.

It can be conjectured that knowledge of the interactive dynamic between groups in the STE warns weavers about the potential lock-ins of trajectories and livelihood outcomes. For example, techno-managerial fixes of state, market, and industry that plan for financial and environmentally sustainable outcomes will tend to leave issues of equity and social sustainability behind. This knowledge can help weavers plan for sustainable social outcomes, through actively seeking the participation of groups with more democratic ideals, whether from academics, media, or civil society activists.

The third condition of sustainability is directional: not linear, nor yet cyclical, sustainable trajectories have to be charted in uncertain and unpredictable waters that bring with them both hope and despair. The particular problem of being labeled a "backward" society is that the future can play out only along two possible trajectoriesone is of a steep ascent forward to catch up with a distant utopia of success, and the second is of a slippery descent backward to suicidal dystopia. The trajectories of resilient weavers who break out of this bind afford new possibilities and pathways to others in the same bind. I translate "sustainable" as "susthiramaina" in Telugu to describe handloom socio-technology: which also means "that which has stability over time." This is a reminder that vulnerability and stability are not opposites, but they construct each other. Livelihood trajectories in weaving that tend toward sustainability, rather than the extremes of suicide or success, always also tend toward stability over time. Such understandings generate opportunities for researchers to examine how different cultures craft sustainable futures, countering dominant imaginations of development, and success that are proving unsustainable for peopleas well as the planet. 


\section{4| FROM INTERVENTION TO MEDIATION: DESIGNING FOR SOCIAL CHANGE}

In this chapter, I study the practices of designers who intervene to bring about social change in vulnerable craft communities. Approximately, six million craftspeople and an additional three million handloom artisans in India make their livelihoods from craft according to the All India Censustaking only the craft census, actually up from 4.76 million in 1995-1996. ${ }^{118}$ While there is insufficient data regarding what their incomes might be, we know that craft activists report large-scale distress in craftspeople's livelihoods, particularly during the economic downturn in the last decade.

Design is claimed to be a key intervention in national policy for promoting craftpeople's livelihoods, but the challenge of designing successfully for craft production can weigh heavily on designers who do attempt it. Designer goods are products of creative expression and valued as such: they dazzle the catwalks of high fashion and the launches of hi-tech gizmos. However, working for vulnerable craftspeople calls for designers to step voluntarily out of that world into risky endeavors, to "combine hand, heart, and head" 119 in chronically under-resourced conditions. They have to succeed in markets that have no space for error; the consequences of failure could irreparably damage craft producers' already vulnerable livelihoods.

118 Reported in the Economic Times [The Times of India], http://articles. economictimes.indiatimes.com/2013-04-29/news/38904849_1_ artisans-handicrafts-census, last retrieved on 22 June 2015 also refer to the contested nature of definitions of craftspeople that impacts census data in (Viswanathan 2013)

119 Designer L, interview (see later in the chapter).
Design is a much-contested term; relatively new to the Indian craft vocabulary. Commenting that the Indian languages do not have an equivalent term for "design," Ashoke Chatterjee, craft activist and former director of the National Institute of Design [NID], suggests that we should "go back to the embracing understanding of (design as) "kala": as the integrated understanding of art and craft that is our [Indian] heritage." ${ }^{120}$ In this chapter, I use the term "design" to refer to the design of material objects or "things" 121; as well as "strategic design to create value through innovative products and services... as service through rigorous creativity... for positive social and economic outcomes." (Telier et al. 2011). Design, thus defined, becomes a way to improve social as well as economic outcomes for vulnerable craftspeople.

In this chapter, I propose that extending the unit of analysis from craftsperson to the ensemble can be useful for actors who try to work toward better outcomes for craftspeople. In this case, the actors I refer to are the particular social group of designers, as they intervene in livelihoods of craftspeople toward social change. The question that I asked designers was "how can understanding outcomes for craftspeople help in building a common understanding of the role of design in

120 Ashoke Chatterjee, in email to the author, commenting on a previous draft of this paper, $29^{\text {th }}$ April 2013.

121 For a discussion on the designing of 'things', see (Bjögvinsson, Ehn, and Hillgren 2012) 
intervening in craft livelihoods for social change?" From their narratives I was able to further answer the question "how do designers and craftspeople work together to bring about social change in the lives of craftspeople?" This chapter introduces aesthetic expertise as an important aspect of craft

\subsection{CURTAIN RAISER}

Designer and key founder member of the crafts movement in India, Laila Tyabji questions the perception of design as "ornamental irrelevance" and argues to conceive it as "a paradigm for development."122 Speaking both as designer and development worker, she illustrates the problem of design in craft using the now well-known "tea cosy" example. The tea cosy is probably as old as the afternoon tea drinking habit of the British. Introduced into English society in the Victorian era, the function of the tea cosy was to extend social activities in aristocratic tea parties by preventing tea from cooling down. Almost the second object that an Indian craftswoman makes on her journey to economic freedom is the tea cosy. The shape is always wrong, Tyabji says: "is it a bolster cover, or a dunce cap?" because the craftswomen do not understand how it is used, have never been shown a teapot. However, how does one mediate between the centuries old repertoire of the Indian craft producer and the ritualized tea-drinking habit of the Anglophile consumer? Starting from this puzzle, I arrive at the main issue that this chapter seeks to address: understanding how designers mediate between deepening economic, social, and cultural divides in order to make design truly a paradigm for development of craftspeople.

In retrospect, we can see three phases of design intervention in craft in independent India. Committed individuals from the nationalistic movement onward successfully supported craft ways of life, integrating them into the emerging nation state in the 1950s and 1960s(McGowan

$122 \mathrm{http}$ //www.craftrevival.org/voiceDetails.asp?Code=178, last retrieved on $5^{\text {th }}$ April 2013. practice. In addition it draws attention to the distributed nature of aesthetic expertise across the craft ensemble, not limited to the designer. This lays the foundation for the comparison of craft practices across science and art, which I will elaborate in my conclusions.

2009). Subsequently, in the 1970 s focus shifted to social movements, which put craft producers at the forefront through income generation projects and saw craft products as cultural legacy. In the liberalized markets of the 1980s and 1990s, craftspeople were mobilized to produce for the emerging urban markets and sustain themselves (Venkatesan 2009a).

Donors and policy makers may have idealtypical models of intervention, but NGOs have to mediate between theories, field realities, and their own resources and capabilities, and thus create selfreflexive conceptual frames to act effectively in their particular contexts (Long and Van der Ploeg 2008). This chapter is based on research commissioned by Dastkar Andhra to reflect on Dastkar Andhra's practices of technology and design intervention, and reported in a seminar organized by them in 2012. In addition, it is informed by discussions on design interventions within Dastkar Andhra, while I was part of the organization over the 15 years between 1995 and 2010. ${ }^{123}$

As part of the research on methodology for design interventions, discussions were held with design practitioners inside and outside Dastkar Andhra-across crafts, across India. Some of the designers who participated in the study were professionally trained, others in the focus groups also included technologists, design educators, merchandisers for retail chains, one weaverdyer, and even an animal geneticist. Although not necessarily known to the mainstream design world,

123 Key participants in these discussions, in past and present, were Uzramma, Seemanthini Niranjana, Latha Tummuru, Syamasundari. B., and Durgalaxmi Venkataswamy, and weaver Tonny à Campo. 
each is well recognized within the craft world and associated with products that are considered excellently designed-whether evaluated on parameters of production, consumption, aesthetics, or income generation for craftspeople. ${ }^{124}$ Multiple designer narratives emerged and could be explored as a result of the various focus groups, interviews, and participant observations. The narratives that contour the journey of these designers from the 1990s to the present form the empirical base of this chapter. I analyze these to form a meta-narrative that explores how design can be understood and further shaped as an intervention to improve the livelihoods of craftspeople.

The goal of this chapter is to study how design could support vulnerable livelihoods in craft, rather than evaluate what was designed- " "designer goods." Studying the practices of reflexive designers (Schön 1983, 76) who mediate social, technical, and cultural worlds will offer a new way of understanding heterogeneous sociotechnical craft ensembles also as design cultures.

\subsection{DESIGN INTERVENTION IN CRAFT LIVELIHOODS}

Baudrillard (1975) confers the status of artisan on someone who has ownership of his labor power as well as ownership of his means of production. Therefore, in the case of the artisan class "the process of production [is] controlled by the producer, but $(\ldots)$ the collective process remains internal to the group, and (...) producer and consumers are the same people, above all defined through the reciprocity of the group" (Baudrillard 1975, 96-97). The pan-Indian census of 2010 counts 6.8 million people as engaged in craft livelihoods in India. According to a recent study of the Crafts Council of India, crafts are defined as "products or services provided by artisans, working primarily with their hands. The artisan very often uses traditional knowledge and her/his direct manual contribution forms a substantial or distinctive part of the end product or service. Usually there are minimal or limited inputs from machines. (...) An artisan is a person with special hand skills, often handed down traditionally across generations, and often linked to a complex traditional knowledge system encompassing the material, technology and / or design aspects" (India 2011, 33) Craft textile

124 The designers in the focus groups included: Sangeeta Sen, Tarun Deep Giridher, Jinnan K B, Gopi Krishna, Aditi Shah Aman, Saktivel Vilvapathy, Kamal Kishore, and Latha Tummuru. My foray into corporate design through consulting with the jewellery atelier Rasvihar, and its creative director Ahalya S. and her marketing assistant Madhumati Thomas also contributed to this chapter. producers - or handloom weavers - too form a substantial part this category.

State policy-makers position design as key to innovation and growth for craft in the market [See section 3.3.1]. They see designers as powerful change agents in the fortunes of craftspeople. ${ }^{125}$ Individuals, more visibly women, from elite and socially privileged backgrounds played key roles in design from the 1970s onward to bring the "craft sector" into the public domain (see Section 3.3.2). These women were designers by virtue of their enculturation in upper class aesthetics as much as, or more than by training. Driven by personal ideals, they stepped down from social ivory towers into the worlds of artisans. ${ }^{126}$ They envisioned support for the craft sector from enlightened customers, and led a whole generation of aspirational craftspeople

125 A large number of "schemes" from the State and Central governments have "design" as a large component in order to support diminishing market performance of the handloom craft. For the handloom sector alone, in the 11th Five Year Plan, 60 per cent of budget allocation is for design interventions. In the subsequent five-year plan, recommendations were made for giving design executives in the cluster programs more responsibility in marketing, for setting up design studios, and for linking design institutes to NGOs to improve development impacts. From http://planningcommission.nic.in/ aboutus/committee/strgrp12/str_handloom0305.pdf. Last retrieved April 5th 2013

126 Examples are Laila Tyabji (http://vimeo.com/21160780), Uzra Bilgrami (http://www.craftrevival.org/voiceDetails.asp?Code=31), Jaya Jaitley (http://www.niyogibooks.com/crafts-atlas-ofindia.html), and Rita Kapur Chisti, (http://www.youtube.com/ watch? $\mathrm{v}=$ mbqqeNCfQIk). All last accessed on 5th April 2013. 
into a new marketplace for craft. Gifted leaders whose aesthetic standards have had a lasting influence in defining craft products, theirs were the initial attempts to articulate a new relationship between design, technology, and development for artisan production in a nation hurtling toward modernization, as it raced to "catch up' with the rest of the developed world.

Non-governmental organizations that intervene in livelihoods through marketing craft on the other hand rely on multiple interventions (see Section 3.3.2), one of which is to maximize designer input. Another approach is to extend the design function to craftspeople themselves in order to help them realize better incomes, and validate cultural repertoires they carry from generations of practice. Some intervening agencies working in craft livelihoods have taken up design education for craftspeople as a way to cultivate designers who are closer to the lived reality of craftspeople. Though the experiments have been small, these have yielded promising results. ${ }^{127}$ In craft retail organizations, which need to be more responsive to market forces, the design function itself may be overtaken by market functions, and driven by information regarding trends and customer preferences. In village networks, the master-weaver or co-operative traditionally played this role (see Section 3.2.4).

Even when professional designers are hired, the multiple agendas that proliferate in intervening in craft frequently create confusion (Phillips 2004, 1). What is being designed: process or product, or both? Whose preferences should come first: craftsperson, designer, or consumer? For whose benefit does the designer work: for livelihood, craft preservation, cultural identity, market, or innovation? How can these innovative experiments be scaled up to reach more craftspeople? These questions are framed in a way that it often generates conflict in the relationships between designers and craftspeople in defining goals, in planning, in building capacities, and finally in evaluating the outcomes of design interventions. These conflicts often leave designers with a sense of disappointment with what is achieved. ${ }^{128}$

In examining how design and craft production can be combined, we have to start with an analytical distinction between craftspeople (as designers), and designers (servicing craftspeople). Ashoke Chatterjee argues: "Artisans are designers. They also have the advantage of being artists, which few designers can claim because of the important professional distinction between 'art' and 'design'." ${ }^{29}$ For designers on the other hand, design "is always about service to others, to a client. It is always about problem-solving, and about solving problems through teamwork." 130

Designers have demonstrated the potential of design as a proven strategy for poverty alleviation of craftspeople in India (Chatterjee 2005, India 2011). Indeed, policy makers, design intellectuals and craftspeople themselves are in rare agreement that design is a necessary intervention for alleviating poverty in craft livelihoods. They are also agreed that more needs to be done in the way of fleshing out how this is to be achieved for the benefit of millions of craftspeople.
127 For example, the design school for artisans Kalaraksha, http://www. kala-raksha.org/vidhyalaya.htm (last accessed on 5th April 2013).
128 Interviews with designers; see section below.

129 Ashoke Chatterjee, former director of NID, in email to the author. Emphasis in the original.

130 idem. 


\section{3}

\section{NARRATIVES OF DESIGNERS}

The designer interviews revealed a wide difference in design practices, even as designers shared a common passion for craft. In each designer it was possible to identify an underlying ideal and an approach to design, which together formed the essence of his or her style of design practice. These combinations of ideal and approach, I discovered, individualize them as creative people. Sometimes one approach was oppositional to another designer's approach: one designer's ideal of "institutionalizing design," for instance, contrasted to another's call for identity and differentiation through "co-creation" between designer and craftsperson. A third ideal of design as "reciprocity" was seemingly at odds with a fourth designer's ideal of a "do nothing" approach. These contradictions between the ideals became clear to all designers during the focus group discussions. Nevertheless, they did not find it necessary to resolve these contradictions, ${ }^{131}$ or create a common approach or forum for promoting livelihoods of craftspeople. Yet, they all agreed that design was a collaborative process.

This multiplicity of ideal practices that emerged among the designers posed an interesting dilemma for the researcher [Fig 4.1], in consolidating design practice and distilling from it a methodology for design and intervention. In fact, the different ideals of the designers suggested that attempting a unified framework for design might even be counterproductive as we will see from the cases below. In this chapter, though my research builds on an analysis of all designers in the various focus groups and practices, for the argument in this chapter a presentation of three designer cases suffices.

\section{Case 1: Intervening in livelihoods of handloom weavers: $L$. \\ Design I deal: Institution building; \\ Design approach Problem solving}

L.'s trajectory into craft design is unusual. She first trained in a polytechnic as a seamstress before joining the National Institute of Design in Ahmedabad [NID] to study Apparel Design. Talking of her first encounter with abject poverty, her face crumples. "There is no food to eat. You go to their village, the houses, they eat only roti [dry bread] and onion or they give you goat's milk tea." It translated into worry about the marketability of her designs. "I used to have nightmares: now that we've introduced this range, will it sell or not, will the weavers die or will the NGO sink?"

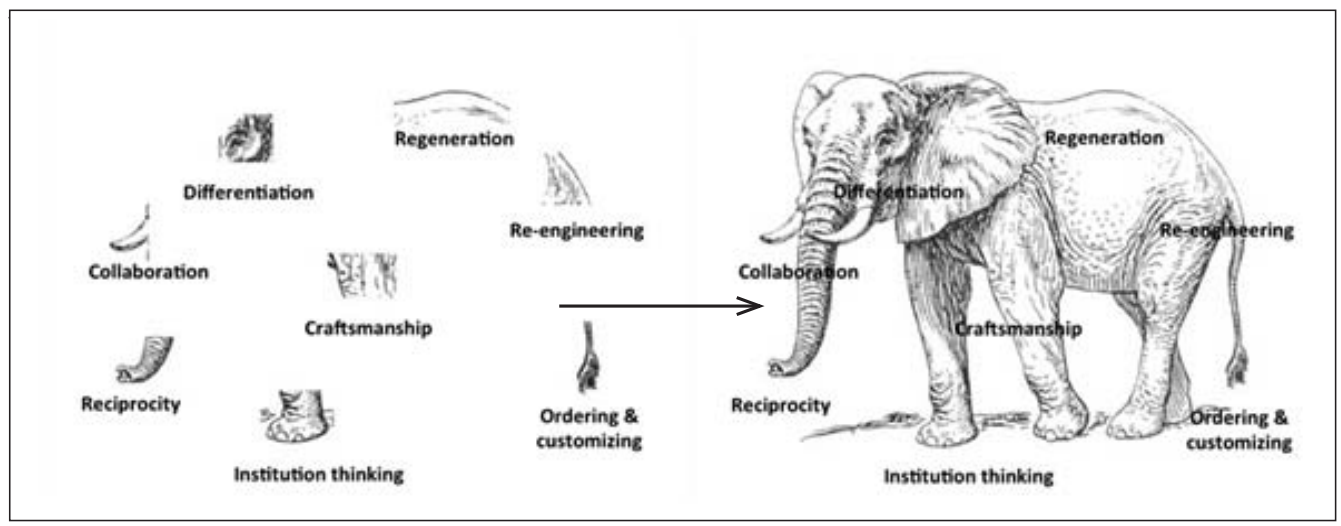

[Fig. 4.1 The dilemma of the task of consolidating design practice into an integrated method]

131 There are a remarkable number of amateur designers, who intervene between crafts people and markets, these actors are well tolerated and even respected by professional designers. The proof of design skills of these amateurs is not in the professional degree, but in the ability to successfully mobilise the market for the products they design. 
She relates how her anxiety made her travel from the design institute in Ahmedabad to field sites in Rajasthan and Gujarat, and to marketing spaces in Delhi-a triangular engagement between Design, Production, and Marketing that she carried into all her design work. Talking of her career in more than eight NGOs, she says, "I always had work, because along with designing, I was willing to train craftspeople in skills that helped them produce for the market." She stresses on the financial vulnerability of the craftspeople for whom she designed. "I was first intuitively aware, and then very, very clear that you have to create livelihoods and you should not create competition between artisans, because the same customers buy the products of all the artisans."

On her role as designer, she says "I realized that in the market, in domestic markets, they do not have design studios; they do not invest in designers for their retail. This makes them dependent on suppliers to show them how the product would look once it was made. I would help them with this visualization for the products that our weavers could make. I was engaged in a market-led design process. It was production-friendly: you are not traumatizing the weaver, you are not asking for production which he can't do, but you are definitely making something which the market wants, so that risks to the producer due to trend fluctuations are reduced." On what her approach to design was, she is clear: "maybe because I worked on very basic weaving with village cooperatives, which in itself did not carry an identity for the market, I worked on quality standards rather than specific identities that are market recognisable." For her, market delivery is an important part of the design process. "If your design fails, you know immediately, because the turnover or the stock levels will tell you that it is not doing well (...) It is a continuous evaluation and quite an exciting one, because you want at the end of the day the design to also sell, that's how livelihoods can carry on." L. has a clear commitment to an institutional intervention that has to constantly generate livelihoods for vulnerable craftspeople, through sale of their products, month after month.

\section{Case 2: Integrating new networks of producers and consumers: $G$.}

Design ideal: Craft I dentity; Design approach Collaboration

G.'s placid demeanor hides the soul of a firebreathing revolutionary, a fire that 25 years of living with the poorest and most deprived of craftspeople has not quenched. He dismisses his early social work experience in a few words: "One has great ideas of health and water sanitation programs, but in the village life is not divided up like that." The community he lived with was a "denotified" tribe. These were nomadic tribes that had been notified as criminals by the British administration and "denotified" by the Indian government after Independence. The name change did not affect their status, however: the communities G. worked with survive on petty robbery and on brewing illicit alcohol.

G. and his weaver colleague decided to teach the women weaving, on their request. They bought cheap wood, made simple looms, and he taught the women to weave simple "pattis" —straps of thre to four inches wide, which were still being made by weavers in that area. Out of these straps, he decided to fashion bags, again from seeing local shepherds carrying such bags. "The identity was in the local village. We did not get any outside designer, and we couldn't afford them in any case. Different kinds of local artisans got together and we discovered local technologies: the leather strap makers, the brass buckle metal workers, the rope twisters, and so on." Some of his products had as many as eight different communities working on them. "Then it has identity: that story is what sells even to far-away European buyers; it is the regional identity that sells it." He rues the development paradigm that is incapable of "listening for the craft solution." This lack of respect or understanding of the differences between local craft production and mechanized mass production leads in his view to the (design) interventionist's failure. 
He does not see any one clear point for design intervention, or a clear single agent of design. "Our crafts people had a good sense of color distribution, and invariably the product that one of them had made for their own use with things that were left over, the market would want that. What we did was default, not design." He acknowledges the interactive nature of designing. "With time, our product excited designers and merchandisers; lots of actors contributed: retailers, customers. You need feedback and iterative production with a critical mass of merchandising information; only then a design becomes robust. You cannot make a hero or a heroine out of a designer: once you do that, you make them fail your expectations." G.'s notion of design is rooted in an earthly confidence in "our craftspeople" that does not ask for guarantees from the market or any sponsor. Instead, it draws strongly on the instinct of craftiness: an agility of the mind as much as dexterity of the hand.

\section{Case 3: Reskilling potters through} shaping design culture: J.

\section{Design Ideal: Regeneration;}

Design approach: Bottom up

J. has the reputation of being an ideologue, and an iconoclast among his peers; and he owns up to that reputation. "I went to the artisan community to learn a holistic way of being for myself. Designing was tricky, because I didn't want to impose anything on them." He says he went as a "bankrupt person in a modern world who was searching for his own identity and culture." "But the pottery group I went to had stopped being potters almost thirty years ago, they survived by prostituting their women." When he first started working with them, in order to not impose his own ideas on this fledgling exploration he forced himself to just sit still and "do nothing." Since the technology of making pots or pottery tiles by hand required the potter to remake the object each time, it could not be mindlessly replicated. There could be no automation, no "dehumanizing" mold to press into. As producers were persuaded to take up simple tasks of production, craft skills were regenerated. Slowly, the artisans used everyday "kitchen" skills to come up with new ideas for pottery. In due time, the potters made beautiful products that niche markets began to value.

Any process where a task was delegated to a machine, such as the kiln, or where J. took up ownership, the craftspeople stopped learning: it stopped being "their job." However, by stepping back and giving them space and time, J. participated in regenerating their craft while they developed a unique aesthetic that they could call their own. Rather than treating craftspeople as production partners for his designed objects, over the years, he shaped choices of technologies of production so that they could express themselves. His intention was served: the potters he worked with are now recognized as artists in their own right, and are commissioned to build on-site murals. However, he himself became redundant and returned to being an outsider. "I don't belong there anymore." J.'s ideal of regenerative design includes a rational acceptance of the two sides of any intention, doing and not doing.

\section{The cases reviewed}

The cases form a colorful set of very different design ideals and approaches. Looking back, what unified them was the way in which the stories were told; the designers had very similar ways of narrating their journey into craft. Binder and his colleagues report "a similarity among the designers in how they created their narrative. The designers produced coherent stories that joined any piece of work in a consistent self portrayal, but what was recounted was much less a tale of accomplished projects than a narrative of production." (Nickelsen and Binder 2008, 164) I found similarly individualized accounts of designers narrating their practice: self-reflexive, yet narrated as a personal tale of accomplishments and failures.

Still, some generalizations can be made regarding the multifarious practices of designers. First, all the designers carry ideals that are particular 
to themselves, rather than following general principles or methodologies, and they perceive the puzzles they engaged with too as being specific. Second, they link this ideal to their particularized practice, as an approach to design action, such as "regenerative," or "problem solving." This leads to an important and now self-evident third observation: as much as ideals and approaches of designers are not uniform, the craftspeople that designers work with are heterogeneous too. From our cases, we see that crafts groups carry very different vulnerabilities and capabilities: low or high skilled, low or high wage earning, and at low or high risks from market fluctuations. Designers align their ideals and approaches to the particular capabilities and vulnerabilities of the craftspeople they work with. In this way, they maintain a multiplicity of practices as a group.

For example, J. describes the potter community he works with as a group with hardly any skills, no buffering income, and at risk of falling out of markets into subsistence economies, and social exclusion. For such a group his approach of regeneration from the bottom up to build identity and self-esteem seems best. The groups L. works with are moderately skilled craftspeople who cannot produce finely differentiated products. L. carries her idealism rationally and assumes a design approach of problem solving to create standardized products of robust and recognizable quality. She builds institutional linkages with the market, which generate stable incomes and reduce livelihood risks substantially.

On the other hand, designer S. works with skilled craftspeople who produce by responding to market information that she provides; she sees her role as a facilitator who links them to connoisseurs of craft. Keeping the identity of each craft product differentiated is important in her design ideal of cocreation. By drawing on observations like these, I shall now explore ways to converge the multiplicities of design practices and their outcomes, by relating design ideals, design approaches, and design actions to each other and to a development agenda of intervention.

\subsection{From Design Methodology to Cultures of Design}

Development theories initially advocated "intervention," and later vilified it as a tool that would keep the underdeveloped section of the population excluded from the benefits that the developed enjoyed (Hettne 2008). Interventionist approaches were seen as furthering flawed development agendas that were decontextualizing, depoliticizing, and deterministic (Ferguson 1990). In national policy discourse, design continued to be framed as a desirable intervention in craft livelihoods; in line with development programs that are deployed as "a toolkit" (Nair 2001, 403) to alleviate poverty. From this emerged the need for policy implementing agencies to come up with a design methodology, which could scale successful interventional experiments in supporting craft livelihoods.

STS scholars relate to intervention more positively. The notion of "intervention" can be "unpacked" (Zuiderent-Jerak and Jensen 2007, 230). This then allows for "taking the multiplicity of the setting into account when identifying acting space and working on solutions for perceived problems" which will "result is an interventionist research strategy that abandons 'control' as a useful concept for structuring interventions" (Zuiderent 2003, 74). This insight about researcher interventions is what I base this study of designer interventions in craft as well.

As the case-stories in the previous section have demonstrated, understanding designers as sole agents of design with predetermined methods to intervene does not adequately describe design in craft. I now introduce the intermediate notion of "interaction" to understand design as a collaborative and combinatory activity. Interaction brings back the concept of the sociotechnical ensemble in order to describe the craft network, like we have earlier 
described the handloom ensemble (Mamidipudi, Syamasundari, and Bijker 2012). Interaction focuses on the presence of the designer, the craftsperson, and the customer, in the sociotechnical ensemble; this presence is not passive and pre-given; on the contrary, it is an active recognition of the different social groups and their expertise in the network engaged in reciprocal relationships. These actors belong to different social groups, who by interacting with other social groups in the craft ensemble, participate in the social construction of the designed product (Pinch and Bijker 1984).

In this understanding of craft networks, the designer is not external and producing "design from nowhere" (Suchman 2002, 95), but socially present (Markus 1978) inside the ensemble. Form and content of products are negotiated through interaction; not just discursively between social groups, but through reconstructing social practices as technologies of production (Suchman et al. 1999). Consumers too now become social, relational, and active participants (Appadurai 1988) in the ensemble, and not just individualized economic actors. For understanding the relatively new role of designers and design in Indian craft contexts, the conceptual move to "interaction" from "intervention" mirrors in an interesting way "the difference that exists between a process by which an old culture assimilates a modern, creative discipline and the one which is rather superficially grafted on as an act of technology transfer" (Vyas 1991, 187).

Therefore, designers and consumers become part of the ensembles that craftspeople are embedded in; ideals, approaches, and capabilities are aligned within such sociotechnical ensembles, as a result of which value is created for the product. From this understanding of the ensemble, it is a small step to recognize that craft ensembles that have different social groups, that is, different designers, different kinds of craftspeople with different technologies, and institutions and different customers, would very well have different social realities and design cultures. Now it becomes important to identify effects of design work in the social and cultural realms of craft livelihoods, as well as in the economic realm. In support for extending the contribution of design beyond the economic to social change for the craftsperson, Kasturi quotes Sen: "In looking for a fuller understanding of the role of design, we have to take note of its direct relevance to the well-being and freedom of the craftsperson, its indirect role through influencing social change, and its indirect role through influencing economic production." (Sen 1999, Kasturi 2005, 77). The objective of this chapter is not a narrow evaluation of design outcomes toward a predetermined set of desirable economic outcomes. In extending outcomes to the social and cultural realms, we come to see that the designer narratives give a clear directive of where positive contributions may be harvested, and the opportunities for social change that abound in design practice.

There is an additional advantage to making this shift: as referred to in the earlier chapter on livelihoods [Chapter 3]. Bringing coherence to competing discourses and ideals in craft and handloom ensembles can be generative for vulnerable livelihoods. Rather than debate between what are considered competing ideals: top down approaches of designers vs. bottom up progress of craftspeople, progress that the development worker is striving toward vs. conservation agendas of cultural connoisseurs, institutionalization of livelihood support vs. identity and self esteem of craftsperson, art or functionality, caste or social class; we can describe them as all part of a complex sociotechnical ensemble, and playing their part in building positive outcomes for craftspeople.

Finally, extending the notion of "cultures of technology" - as a way of thinking about technology_to "cultures of design," I shall argue for a new way to understand the work of the designer: as cultural mediation. ${ }^{132}$ I will draw

132 The concept of mediation with reference to technology design is used by philosophers of technology such as Peter-Paul Verbeek (Verbeek 2006) to explain how designers help to shape the mediating roles of technologies and artefacts or 'things'. I use the term with reference to how designers perform the work of cultural intermediaries between aesthetic values of different producer and user groups. 
on studies of design as design culture (Highmore 2009 , 2) and mirror the methodological shifts in STS of seeing societies as technological cultures (Bijker 2012). I propose that studying design as design culture predicates the everyday presence of design in our designed worlds (Highmore 2009, 4). Designers are cultural intermediaries; workers engaged in "occupations involving presentation and representation (...) providing symbolic goods and services" (Bourdieu 2008, 359). They mediate between creative artists and consumers (Negus 2002), in this case between the production by craftspeople and the consumption by middle and upper classes, through mediating aesthetics. Cultures of design in craft can then be seen to have distinct attributes that enable designers to bring about outcomes that lead to social change for craftspeople.

\subsection{CONCEPTUALIZING INTERVENTION, INTERACTION, AND MEDIATION}

The three conceptual frames of "intervention," "interaction," and "mediation" describe the same design worlds, but characterize them in three different ways. In the first, the world of craftspeople is studied using the unit of analysis of the producer group, in the second, the unit is the sociotechnical ensemble, and in the third, it is design culture. In each case, specific aspects of design work are accentuated, which results in foregrounding particular outcomes to craftspeople. "Intervention" as design activity stresses the economic outcome, "interaction" the social effect, and "mediation" the cultural results of the design work [See Table 4.1 for summary]. The shift from economic to social and from social to cultural also follows Bourdieu's notion of forms of capital. Economic capital is directly convertible to money, social capital is made up of social connections, which are convertible under certain conditions to economic capital, and cultural capital is accumulated stock of knowledge acquired over time, which too is convertible to economic capital under certain conditions (Bourdieu 2008).

\begin{tabular}{|c|c|c|c|}
\hline Conceptual frame & Intervention & Interaction & Mediation \\
\hline Emphasis is on: & Economic & Social & Cultural \\
\hline $\begin{array}{l}\text { A nalysis of craft } \\
\text { domain as: }\end{array}$ & Producer group & Sociotechnical ensemble & Design culture \\
\hline Identifies designer as: & Idealistic, individualistic & Interactional expert & Cultural mediator \\
\hline $\begin{array}{l}\text { Highlights aspect of } \\
\text { design which is: }\end{array}$ & $\begin{array}{l}\text { Technical [for e.g., drawing, } \\
\text { modeling] }\end{array}$ & + Combinatory & + Cultural identity \\
\hline $\begin{array}{l}\text { Ensures mobility of } \\
\text { design through: }\end{array}$ & Artefacts, drawings & $\begin{array}{l}+ \text { Discursive and social } \\
\text { practices to integrate social } \\
\text { groups in the network }\end{array}$ & $\begin{array}{l}+ \text { Cultural mediation that brokers } \\
\text { aesthetic between cultural } \\
\text { preferences }\end{array}$ \\
\hline $\begin{array}{l}\text { Designer mobility is } \\
\text { characterized as: }\end{array}$ & $\begin{array}{l}\text { To and fro between physical } \\
\text { worlds of producers and } \\
\text { consumers }\end{array}$ & $\begin{array}{l}+ \text { Collaborative between the } \\
\text { social worlds in the network }\end{array}$ & $\begin{array}{l}\text { +Iterative in between design } \\
\text { cultures }\end{array}$ \\
\hline $\begin{array}{l}\text { Design activity } \\
\text { innovates: }\end{array}$ & Production & +Sociotechnical ensemble & +Aesthetic \\
\hline $\begin{array}{l}\text { Positive outcome on } \\
\text { craftspeople is: }\end{array}$ & Income and economic value & $\begin{array}{l}\text { + Market recognition and } \\
\text { identity for product }\end{array}$ & $\begin{array}{l}\text { +Cultural and social capital for } \\
\text { craftsperson }\end{array}$ \\
\hline
\end{tabular}

Table 4.1 Three complementary conceptual frames for interpreting design work in crafts; the + highlights an accumulative aspect 


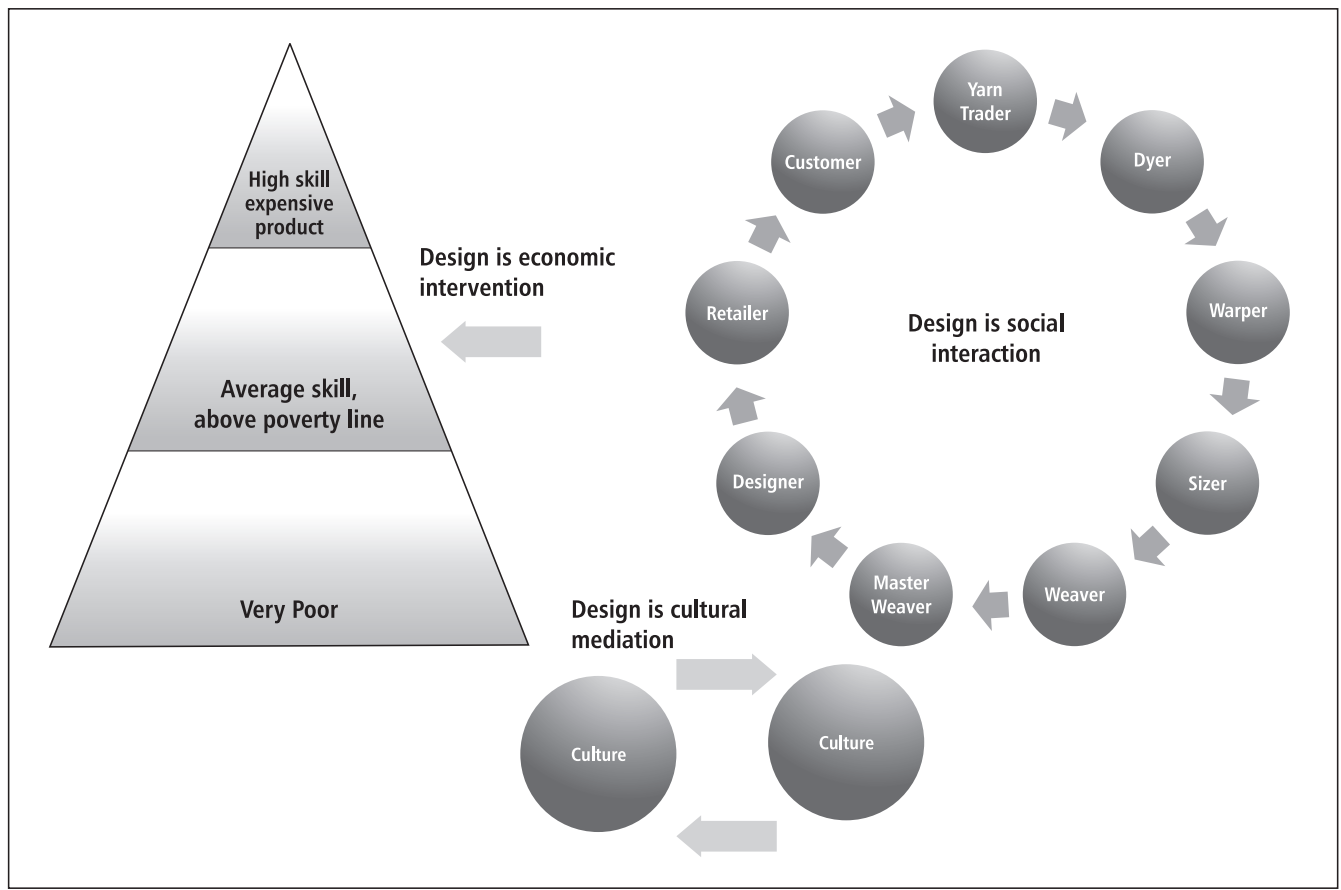

[Fig. 4.2 Three conceptual frames]

However, the three conceptual frames are not merely alternatives; they can also be seen as complementary and consecutively adding a new dimension to the previous framework, rather than simply replacing it. This then will have consequences on the conceptualization of designer interventions and interpretation of outcomes.

\subsubsection{DESIGN AS INTERVENTION}

From the cases, we see that designers choose interventions based on their own ideals and approaches and match them to the craft groups' capabilities and vulnerabilities, resulting in a multiplicity of design intervention methods. When they use the interventionist frame, designers (and policy makers) generally treat craftspeople as producers categorized by income, in a way that homogenizes technical expertise and skill of the craftspeople. This income is usually computed as an indicator of existing market value for that craftsperson's labor. From the design narratives, we find that craftspeople who are sufficiently embedded in socio-economic relations, such as

weavers organized in a co-operative, but whose livelihoods are acutely vulnerable to market fluctuations benefit most from such interventions. Such artisans benefit from design intervention during lean periods in market demand, preferably channeled through institutional support to buffer them from acute income fluctuations. For these craftspeople a designer like L. [Case 1], who intervenes to provide regular work for the craftsperson in a fluctuant market through her design, serves best. The weavers that designer L. works with act as a producer group that leaves design innovation largely to the designer who directs them. The approach of the designer by 
default becomes individualistic. This ties in with the limited policy understanding of designer as sole agent of design, who expresses his or her individual creativity for craftspeople and constrains them to passively produce. Instead, we see that while the creativity of the design rests on L., so does the responsibility of institutionalizing it. In the interventionist frame, the designer usually has to continuously match the market to existing production capabilities, in order to provide sustained work, alongside providing design inputs.

Design inputs have to travel between designers, craftspeople, and marketing agencies. Since the designer and consumers are urban based, and usually not in the same location; and the craftspeople are rural based, design has to be mobilized through physical representations that can travel. Key design aspects in the interventionist frame are techniques such as drawing, modeling, and more recently digital technologies. Therefore, drawings, prototypes, samples, artefacts, travel between the physical locations of the designer, urban consumers, and rural producers, and constitute design inputs.

These approaches have proven to generate incomes fulfilling an important economic outcome (Thomas 2006, 59). However, upward mobility and social status that craftspeople aspire to are not accounted for, since social class boundaries act as insulating ceilings that constrain mobility. In the market place, the craft product from the interventionist frame is generally not perceived or

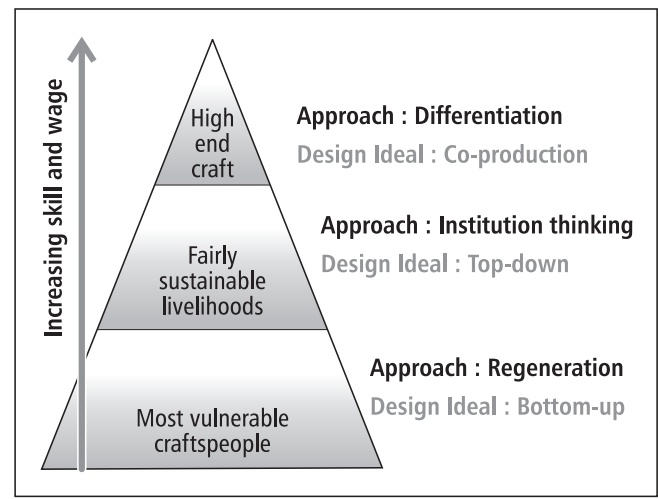

[Fig. 4.3 Matching Approach, Design ideal and Craft group]

marketed as a uniquely designed product: it tends to be ubiquitous, as it has to cater to existing trends in the market alongside other products. Furthermore, the location of designer as the "solution" outside the "problem" of the craftsperson's poverty reinforces the discursive distance between designer and the beneficiary of design-also possibly creating dependencies.

It is at this stage that we take the next step, loosening up the construct with regard to the social dimension, by describing craft groups as embedded in complex production and consumption ensembles, rather than as individual production units ordered by income and skill. Designers [and consumers] now too can be seen to have a social presence inside the net worked ensembles, rather than being external to them, and value and design are constructed through interaction between the different actors present in the ensemble.

\subsubsection{DESIGN AS INTERACTION: COMBINING TECHNICAL, MATERIAL AND AESTHETIC EXPERTISE IN THE CRAFT ENSEMBLE}

Describing craftspeople and designers as embedded in reciprocal relationships in the sociotechnical ensembles suggests that designers act from inside the producer and consumer networks, rather than outside. Furthermore, I will demonstrate that "design as interaction" highlights the aesthetic expertise dimension in the ensemble of craftspeople's art, consumer's preferences, and the designer's creativity-it is this distributed aesthetic expertise that is pressed into service of design through designers' interaction with craftspeople. By framing design activity as interaction, I want to explore the relational aspect of design. 

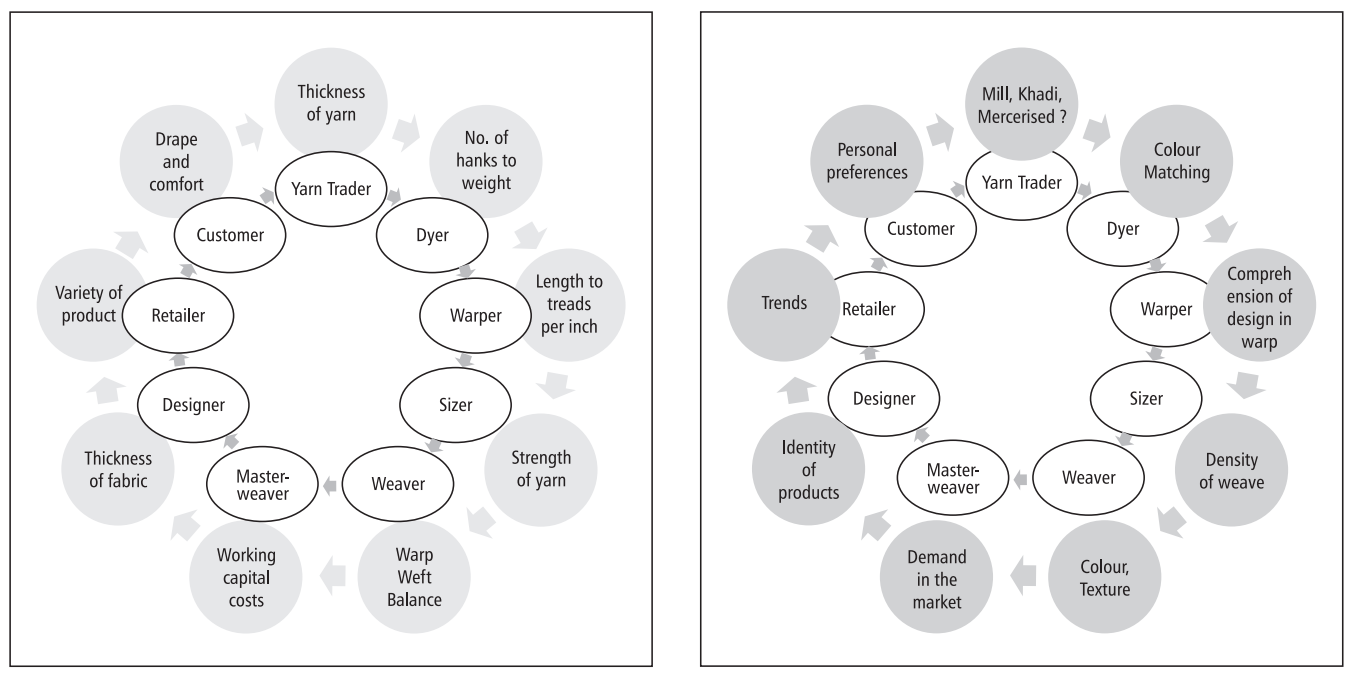

[F ig. 4.4 Distributed technical and aesthetic expertise in the handloom sociotechnical ensemble]

Designers stress that design expertise is always and without exception linked to the visual aesthetic: "something that catches the eyeball," "elicits response through sensory/ visual stimulation." However, it is not only visual expertise that designers call upon when designing in craft ensembles. Designers define their trade also as including expertise on technology and materials: "layers of technical skills" and "mastery over a particular set of materials, for which the designer is known." That partly relativizes the importance of visual aesthetics in design solutions: "Issues of visual aesthetics so often dominate, but (...) they are not the purpose of design. [That is, rather, problem solving. And those] solutions could be of technology, of manufacturing process, of materials, of cost and economy, of documentation and research, of packaging, etc." 133

Paying attention to the organization of technology in the ensemble makes visible the different kinds of technical expertise that exists across the ensemble: amongst farmers, spinners, warpers, sizers, dyers, weavers, and traders; and even amongst customers who use technologies of consumption. Acknowledging the material nature of design localizes and embeds it in the physical worlds across which the ensemble stretches: the verandah of the weaver's house, the sizing street, the warping drum, the presence of water vapor in the atmosphere measured as humidity ${ }^{134}$ in the village, the display mannequin of the retail store, the lighting in the trial room, to the clothes line in the customer's home. When such an ensemble performs design, it draws on aesthetic capability in each of the different participants in the craft network to a lesser or greater extent; and not only in the designer. At the same time, it points to the importance of the combinatory activity of the designer who works to bring this aesthetic expertise together, in order to create value for the designed product. 


\subsubsection{Methodological INTERMEZZO: THE WORK OF THE DESIGNER FROM A CONSTRUCTIVIST VIEWPOINT}

The technical, material as well as visual aesthetic capabilities that craftspeople have, must be taken into account and mobilized by designers in the service of design. G. (Case 2) leverages this distributed capability in the system, spending long periods of time in the village he works in, far beyond initial "summer holiday type of visits." Each participant in G.'s production network brings aesthetic capability that he is able to integrate into the making of the product: weaver, leather-worker, metal smith, dyer, even market representatives such as merchandiser.

If the designer is not the sole agent of aesthetic design, what does he or she do in the craft ensemble? I employ a constructivist perspective in this analysis. Rather than assuming that intrinsic properties of actors and objects explain how they relate to each other, I trace the work that is performed to make things happen, to create connections, and to shape identities. This perspective helps to understand the role of the designer. We can imagine that the designer's task lies in stimulating interactions between actors to construct a designed product with market value. Weavers come with large repertoires of motifs and material knowledge accumulated from generations of practice; the consumer comes with her repertoire of sarees already owned or newly desired; the technologist comes with registers of color standardization and quality norms. Conversion of these capabilities distributed across the ensemble into value is design made durable. The integration of this distributed and diverse capability is operationalized by the designer through interacting in the social world of the ensemble in the service of design.

The production part of the network and the consumption part of the ensemble may occupy different social worlds, as in the case of rural craftspeople and urban middle class consumers. Social and financial hierarchies exist between the different groups, which have to be negotiated in order that the groups can transact productively. In the real world of designing with craftspeople, alongside designing products, social worlds have to be negotiated, for which designers may not be prepared in their training (Cuff 1992, 251). Urban designers may perceive the move needed to become part of the production world as being "downward." Similarly, integrating new groups of elite customers into the network may require designers to move "upward" to those social worlds. Designers experience these travels as intense learning experiences. Describing this encounter with the social world of craftspeople, one designer said: "I go to the weavers' houses to design, because otherwise I don't understand its social relevance." Another uses the journey as a way to understand "a different reality where craft is a way of life, not just a product to be consumed." Faced with the daunting prospect of moving up into consumer social worlds in order to market craft, a third designer says it can raise existential issues; "the designer's social background has a key role (...), which cultural background we come from, that can limit the aesthetic group we can cater to."

Successful design practices include social competencies of dealing with professional as well as personal relations, with protocols of formal retail spaces as well as of being personal guests in weaver homes, with negotiating social hierarchies. Designer tasks include "the invisible connection between the persons who do the technology, the marketing, the management, the production, and the buyer, that the designer has to make."135 We could conceptualize this task as the work of innovating a new sociotechnical ensemble within which value for the product is realized. For instance, by including trend-setting merchandisers that he interacts with when marketing in exhibitions to his craft ensemble, designer G. [Case2] ensures that the products gain visibility and identity in elite markets that contribute to their financial and social value. In doing so, he succeeds in innovating a sociotechnical ensemble within which craft product

135 Designer Interview Tarun in Senior Designer's group meeting, January 10th, 2012 
of the community he works with can be reciprocally designed, produced, and valued.

Social practices of interaction between the different actors in the ensemble, thus, become important as technologies of production (Suchman et al. 1999). This implies participation of the designer in social practices of the various groups: "utna baitna," getting up and sitting down together-a metaphor of not just being acquainted, but engaging in common social practices. This is not interaction for its own sake, or sociability; it is social interaction in order to make and maintain economic value. Since producers and consumers are part of social groups who share aesthetic taste, stimulating their interaction results in the collaborative design of a product for which there is an economic value in the innovated ensemble. From this understanding, design may be framed as interaction.

\subsubsection{DESIGN AS MEDIATION}

Characterizing craft as design culture allows us to pay attention to the cultural meanings of the objects of production, as in the example of the tea cosy. Social groups in the ensemble socially construct the value of designed objects. This value is associated with cultural meanings that those groups carry. Skills, tools, available technologies, markets, materials, users, geographical locations, aesthetics, identities, ideals, and cultural memory, they all play a role in craft design culture.

Craftspeople occupy a curious position by virtue of their co-existence with industrial cultures. Within art and craft design cultures, they carry cultural capital and are, thus, highly valued. In an

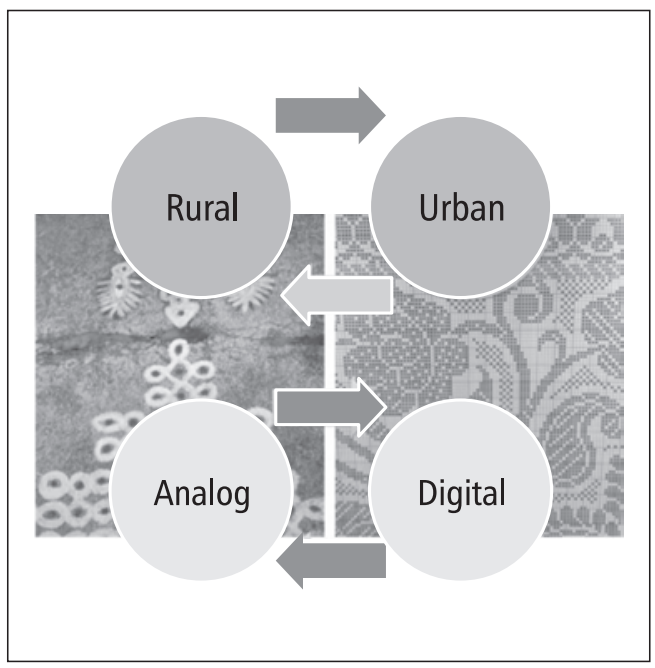

[Fig. 4.5 Mediating cultures]

industrial design culture that values productivity and efficiency of time, their standing is inferior: craft is seen as an outdated and obsolete technology. Regardless of this perception difference, contemporary sociotechnical ensembles of craft seem to be able to transcend this divide to produce a culture of design that is distinctive. Craft design culture perceives itself and can be perceived by others as being different from other design cultures in terms of the nature of its production technology, its social organization, the localized materiality, its product repertoire, and the aesthetic. Especially, the latter is an important tool of differentiation.

By characterizing craft as design culture, I want to argue that designers are creative cultural mediators between producers and consumers who are not just different social groups, but may represent different aesthetic cultures. Bringing new groups into the network is not only anymore a function of social competencebut also of cultural adequacy. Designers have to engage iteratively in production-consumption cycles (Telier et al. 2011) with new customer groups in order to mutually construct value.

Mediating requires designers to recognize and take into account multiple aesthetic sensibilities, and balance them so that the one does not overpower the other. If market trends to take over, then craftspeople could become passive producers; if craft heritage is put first, stagnation in demand could be the effect. Each iteration of design shapes an emerging cultural product that has 
to bridge the aesthetic of both the producer and the consumer. J. exemplifies (Case 3) the designer who mediates between design cultures: of the traditional rural potters and of the rising urban middle class. J.'s approach of first regenerating a unique craft sensibility in the potters before reaching out to discerning customers who would recognize and cultivate a sensibility toward this craft, means that he actively rejects short-term market demands that would disrupt the careful mediation between the aesthetics of producers and consumers.

How do designers mediate aesthetics between different cultural groups? When encountering the aesthetic values of a cultural group or its cultural objects, designers generally do not evaluate it as "good" or "bad" design. They strive to comprehend the value that a particular design culture promotes. They "read" taste. This implies reading particular registries of aesthetic value among producers, users, and consumers through sensitivity to cultural memory. ${ }^{136}$ Yet, this is not an individual evaluation. Woodward (Woodward and Emmison 2001, 298) discusses the personal/collective tension in taste, aesthetics and fashion, and the universal characteristic of judgment of taste. Value is constructed for a particular craft product when people belonging to one design culture collectively

\subsubsection{KALA [ARTISTRY] AND DESIGN}

Ashok Chatterjee refers to the notion of "kala" or artistry, which integrates art and craft, as an important attribute of the Indian craftsperson. In the context of design, I will translate it as aesthetic expertise that master craftspeople acquire over time, which is inextricably intertwined with their technical expertise, visualized in the rich repertoire from the past that constitutes their heritage. In addition, this artistry springs from collectively held community knowledge of local material, and the skill to manipulate it in order to produce things

136 For discussion on cultural traditions in design in India, see (Das 2005), and for discussion on Indian equivalence to the concept of design, see (Vyas 2006). agree on its aesthetic quality. It is possible to differentiate between tastes of different groups, since visual and cognitive judgments are inherent to making this judgment (Leder et al. 2004, 502). Rather than being arbiters of high-brow culture, designers' role now becomes the evaluation and translation of cultures (Skeggs 2004, 148). The capability to recognize and translate across different cultures is a meta expertise in differentiating aesthetics. This expertise is not just the refinement of one's own aesthetic or "taste," but the ability to differentiate and understand different "tastes." Designers who mediate between design cultures demonstrate this expertise.

Craftspeople too seem to be able to cultivate this expertise, through association with designers. Traditional craft education is based on social learning processes of apprenticeships and learning by doing. This predisposes craftspeople to acquiring expertise through social learning processes that are reflexive, that is, characterized by a permanent process of evaluation, monitoring, and giving feedback, consciously and unconsciously (Van Lieshout, Egyedi, and Bijker 2001, 49). Conversely, this explains how cultural mediators who may not be trained designers, such as master weavers who travel between city and village, acquire this expertise and effectively play the role of the designer in their networks.

of beauty. The concept of "kala" that combines technical, material, and aesthetic expertise in a craftsperson brings together the understanding of craft as means of production, and craft as art.

We can imagine that this expertise then exists as an attribute that all the different craftspeople in the ensemble carry; thus, aesthetic expertise is distributed, in the ensemble, rather than concentrated only in the "designer." In order to illustrate the distributed nature of aesthetic expertise, I use the example of the demand for organic handloom product created by innovative users, which requires introduction of organic cotton grown by small farmers into the handloom 
ensemble. As a first step, I will elucidate the process of sociotechnical change that this entails.

Generally, cotton handloom weavers use mill-spun cotton yarn, which is categorized in terms of "counts."137 The count of the yarn is a number; this same number communicates staple length to the farmer, weight to the trader of cotton, and thickness to the spinner. It is used to calculate weight in units of lengths (called hanks) across the network. Further in the network, the "count" converts to "pick" (i.e., yarn density per inch) as an indication for the time needed and therefore for the required labor in weaving. It translates into color absorption for the dyer, resolution of the motif for the designer, and weight and drape for the consumer.

Local production of fabric through the introduction of organic cotton varieties is first and foremost a change in count, as local cottons tend to be short staple and thicker. Initially, this seems a mere numerical change-from 60 to 20 . However, in order that this change is effected, it has to be negotiated back and forth at every stage; between cotton trader and dyer, dyer and warper, warper and sizer, sizer and weaver, and so on. As the new number travels across each stage of the work and part of the network, the object it describes takes form and shape, until finally the consumer identifies and chooses it as a textured, local, organic fabric, setting off the next cycle of production and consumption. When this point is reached there is an agreement on the number of the count that will circulate in the ensemble, and technology is stabilized. Here ends the process of sociotechnical change.

However, this is not the complete story of the change involved. At each stage, as the count is being negotiated, another judgment is being called for that each actor has to make in parallel. The yarn trader has to judge the quality of the yarn in terms of its luster [what dyers refer to in English as shining]; the warper has to judge on what kind

137 For an analysis of textile production in early modern India, using counts "Cotton was sold in candies; thread was sold in bundles; cloth pieces had diverse thread counts and dimensions; bales or packs of cloth contain different numbers, sizes and weights of cloths", see (Wendt 2005b, 4). of differentiation in warp texture it can take; the sizer has to judge in terms of what the smoothness of yarn would do for texture of the final fabric; the dyer has to judge whether color matching could be achieved and to what extent; the weaver has to judge for the closeness of weaving and the resultant visual and tactile quality of the fabric; the designer has to judge for suitability for surface ornamentation - what kind of motif, or print, for example, and so on. These judgments clearly are aesthetic judgments. It is these capabilities that will come into play across the ensemble to construct the design of a new product. These judgments are made from experience, from aesthetic capability, as well as drawing on the historical repertoire that each group carries; color palettes, motifs, design and product samples, and so on. When craftspeople make this evaluation, it also evidences their deep engagement with the material that they work in, and their innate capability of manipulating it. This capability of creating products that consistently meet new quality parameters using their old skills and familiar inputs is seen by skilled craftspeople as part of their expertise. ${ }^{138}$

The attribute of "kala" [artistry] is, thus, a combination of material, technical, and aesthetic capability; but it is also mastery and expression of these capabilities in the crafted object. It is an approach that integrates rather than divides the shared cultural values of beauty and function in the object of production (Botnick and Raja 2011, 47). When the craftsperson carries a high quality of kala [artistry], then his craft is that much more sophisticated. The presence of such a craftsperson in an ensemble predicates the presence and active interaction of customers who value such sophistication, in the same ensemble (Appadurai 1988). In turn, the aesthetic quality of the entire ensemble becomes very high. This demonstrates

138 This brings to focus another important difference between craft and mechanized production. The window of variation in inputs is much less for machines that cannot handle such variation, compared to craftspeople who are inured to it. But, again, if the productivity value overtakes the ensemble, then craftspeople with the capability to deal with non-standard material will demand standardized material in order to meet the productivity demands. 
that not just different kinds of technical expertise exist, there are also different kinds of aesthetic expertise: in dyeing, in weaving, in apparel making, in use, and so on.

To this understanding of "kala" [artistry] in craft, I map the scholarly understanding of craft in design and the role of intention in design. In "The Craftsman" (Sennett 2008), Architect and designer Renzo Piano explains his working procedure in design as starting by sketching [an intention], followed by drawing, then making a model, and finally to realityand back to drawing creating a circularity between thinking, drawing and making and back. Therefore, Piano says, sketches are pictures of possibility. This practice is analogous to the craftsman's approach to making - in Piano's words, "you think and you do at the same time, you draw and you make, you do it, you redo it and you redo it again" (Sennett 2008, 40). If we think as Tim Ingold does, of simulation as a synonym for design, we begin to understand that each iteration of "doing" is a simulation, which strengthens the design. Thus, design is not just intention; it is circular - thinking and doing, drawing and making. Design as skilled practice is "immanent in the activity itself" (Ingold 2001, 27).

The Russian neuroscientist Nicolai Bernstein (Bernshteĭn 1996) suggests that the essence of skilled practice lies not just in dexterity of bodily movement, but in the responsiveness of these movements to the environment that is never the same from one moment to the next. It is as much the activity itself that generates the form, as the design that precedes it. In addition, making arises within the process of use; use is the outcome as much as the intent (Ingold 2001, 21). If one thinks that use is realized as pre-intended purpose, then we refer the action of making back to the prior intention that motivates it - as if the activity of making the manufactured object [whether fabric or drawing] issued directly from the design and only needed to be transcribed onto the material. This stress on prior intention of the designer denies the creativity of the environmentally situated and perceptually engaged activity that is of use. Based on this understanding,
Ingold (Ingold, 2001, 1020) suggests that design as intention underdetermines the form of the thing that is made: design does not contain all that one can know to account for the final form. Design instead should be read "forward" toward improvisation and opening up, rather than "backward" to intention (Ingold 2009). Therefore, design, when crafted through improvisation, can aspire to being art.

For both designer and craftsperson, creative intuition is an important goal. Sennett suggests that the first step to be learnt is to learn to let go. The student must learn to be so absorbed in the task that she becomes the thing on which she is working. She is no more counting the repetitions; she can stay alert for long periods, and improve (Sennett 2008, 176). She lets go of her rational mind and lets bodily memory take over. It is at this point that we see the relevance of repetitive action described as rhythmic skill (Sennett 2008, 177). Intuition for a craftsperson begins with the sense of what is not, yet what could be-driven by feeling frustrated by a tool's limits, or provoked by its untested possibilities (Sennett 2008, 209), embedded in the everyday opportunity for change that the iterative making of designed objects brings; whatever the tool of making may be.

What does this add to our understanding of the expertise that weavers carry, of artistry, ["kala"] and what designers carry, of design intent? In examining how design and craft production can be related, ${ }^{139}$ we started with an analytical distinction between craftspeople (as designers), and designers (servicing craftspeople). As Ashoke Chatterjee has eloquently argued, artisans are designers, but without the professional distinction between art and design; indeed their definition of design is closer to artistry [kala], which does not seek a distinction between art and craft. ${ }^{140}$ For designers too, design when crafted through improvisation can aspire to being art [istry]. Yet design has intent, "it

139 For a discussion on craftsman vs. designer in mass production technologies, see (Risatti 2009).

140 Ashoke Chatterjee, former director of NID, in email to the author. Emphasis in the original. 
is problem solving, and about solving problems [of craftspeople] through teamwork." ${ }^{141}$ We can see that craft artistry "kala" assumes the creative pinnacle of art, yet it may not presume to the designer intent of bringing value to those products through combining financial, social and cultural functions. In order to achieve those goals, designers have to engage in combinatory activity, not just engage their own artistry. They have to combine social groups, as well as combine the distributed expertise and artistry in the ensemble toward new products for new markets. Once we understand this, we also understand how weavers, users, sizers, and warpers who carry artistry in their own right, yet who also engage in combinatory activities in the service of creating value in the sociotechnical ensemble are all potential design agents, if they so chose.

In summary, I show that in the constructivist analysis of design the craft object is a combination

\subsection{DESIGNING FOR SOCIAL CHANGE}

Bourdieu, in his essay "Distinction: A Social Critique of the Judgment of Taste," links cultural practices of production and consumption of art and aesthetic to education and social origin. He defines culture as an internalized code that is historical and self-referential; "Aesthetic perception is necessarily historical, in as much as it is differential, relational, attentive to the deviations (écarts) which make styles" (Bourdieu 1984, 4). He then suggests that "art and cultural consumption are predisposed, consciously and deliberately or not, to fulfill a social function of legitimating social differences" (Bourdieu 1984, 7). Trigg (Trigg 2001, 113) develops Veblen's idea of culture as a barrier to social mobility, and Bourdieu's idea of a trickle-around model of acquiring cultural capital: feedback of taste can be bottom up: from the lower rungs of the social ladder to the top, bypassing the middle. I have been using this notion of cultural practice, functioning as cultural

141 idem. of the different actors' -designers, craftspeople, users'- intent, artistry and innovation, and has financial, social and cultural functions. This leads to the final attribute of the design culture in craft that I will describe in this chapter. The craft ensemble has many groups, each crafting for and using the other's product, at the same time transforming the product as it passes through their hands. Each group is, thus, a potential site of innovating the product. In turn, the activity of combining the outputs of this simultaneously innovating ensemble, whether performed by designers or craftspeople, can never be driven solely by managerial intention, it can also be labeled in Schumpeterian terms as the entrepreneurial function. Further, this entrepreneurial function that is particular to craft design culture has to be collaborative and open to multiple possibilities of innovation -in other words, innovative.

identifier, and social differentiator to understand how acquiring cultural capital effects social change for craftspeople. I will show how craftspeople who are on the lower rungs of the social ladder, through their association with customers who are at the top, are able to bypass the middle.

Design in this case is not about craftspeople imitating the aesthetic of higher classes to market their production. The crafts person cannot be an imitator of fashion, a lenient individual who believes in social similarity and adapts himself to surrounding elements. In fact, that would be a route to disaster. The fashions of the upper stratum of society are never identical with those of the immediately lower or the middle classes. Indeed, the former abandon them as soon as the latter prepares to appropriate them (Simmel 1957). We see that craftspeople initially do produce by following trends of cultural groups higher on the social ladder. Through reflexive social learning processes of feedback and evaluation from designers, and often customers, they learn the designer expertise of reading taste. 
Over time they acquire the capability to experiment and design cultural objects that influence taste rather than imitate fashion. When craftspeople exercise this aesthetic expertise, they become trendsetters, rather than market followers. They affect the tastes of groups higher in the social hierarchy, generating cultural capital for themselves (Bourdieu 2008). At this point the fortunes of craftspeople are reversed. Rather than having a deficit of financial capital that acts as a barrier to social mobility, they acquire enough cultural capital to then pave the way to the social change they aspire for. This leads to an upward social mobility that craftspeople experience as empowering. This understanding is counterintuitive; since it signifies a gradual reversal of roles that is almost imperceptible.

Generally, at this point, the craftsperson does not anymore need the designer to mediate cultures of production and consumption. Not only has he or she acquired design skills; the goal of social change too has been achieved. It is possible that designers, who tend to value intuition over rational thinking in their practice of design ${ }^{142}$ do not recognize this positive change of fortune for the craftsperson, and focus on their own redundancy, and perceive it as failure. However, I propose that in order to design for social change, designers have to become cognitive of the democratizing of the social hierarchy that has been achieved through mediating cultures. They have to recognize the reversal that occurs when production of culture, rather than its consumption, creates possibilities of social mobility for the craftsperson. Rather than acquiring cultural capital through expending economic capital as the middle classes do, (Trigg 2001) craftspeople can acquire and expend cultural capital to achieve their social aspirations. The "financial" is not anymore the only instrument of social mobility for craftspeople who have aesthetic capability; the "cultural" is a powerful tool that designers can leverage. When designers facilitate this, they propel social change. Yet, this is not to be confused with the socialism of upper class aesthetes, social reformers, educators, and clergy of turn of the century England, who aimed to bring beauty and light to the laboring poor through "institutionalized aestheticism as a species of philanthropy" (Maltz 2006, 2). It is not the consumption of beauty through creating access to cultural spaces, but the production of aesthetic beauty to accrue cultural and social capital that is the goal of this endeavor.

If this conclusion is correct, there are two lessons to be learnt for designing and for social change. First, craftspeople by virtue of their collective and embodied learning practices are predisposed to acquiring aesthetic expertise involved in designing, through associating with designers. This expertise can be leveraged by craftspeople as cultural capital that provides them upward social mobility as well as financial rewards. At this point, even though designers' efforts have contributed to equity of craftspeople, it is not attributed to the success of the designer, but to the craftsperson, resulting in the designer's efforts becoming invisible. Second, it is only in recognizing the expert knowledge and aesthetic capability of craft production that designers can participate in ensembles with crafts groups and design for social change. In turn society has to recognize that if craftspeople's livelihoods need to be served by designers, then these designers' professional advancement will have to be resourced so that they can continue to do so, even in the face of their own sense of failure.

142 Aditi Shah Aman, Designer interviews 
4.7

\section{CONCLUSION}

In conclusion, I summarize the different framings of design as Intervention, Interaction, and Mediation. We see that designers have different, sometimes conflicting ideals and approaches when intervening in craftspeople's livelihoods. This brings about a multiplicity in design interventions, where rather than building common methodology between each other, they align their ideals and approaches with craftspeople's vulnerabilities and capabilities. This reminds us that craftspeople too are differentiated in skill, social class, and income, in contrast to the homogeneous craftsperson who is the object of policy. Design as Intervention is structured for impacting economic outcomes; design interventions have been shown to be positive in supporting craft livelihoods.

Design as Interaction recognizes the technical and material expertise as well as aesthetic capabilities of craftspeople, rather than considering the designer as the sole agent of design. Every social group in the craft ensemble is required to make aesthetic judgments based on their capability, when they participate in the design process, and execute it using their technical and material expertise. Designers in this understanding are not external but embedded in the social worlds of the ensembles they act in and upon. They engage in social practices of interaction that drive sociotechnical change and design work. Design as Interaction recognizes the relational and reciprocal aspect of design workthat combines distributed aesthetic capability of all the different experts in the ensemble. In order to link craft producers to new consumer groups that will widen markets for their products, it requires designers to innovate new sociotechnical ensembles of production and consumption. This increases social visibility and market recognition for the designed product, thus improving product value.

Understanding different cultures of design helps transcending polarities such as progress versus conservation; standardization versus unique identification, and so on; false polarities which may otherwise dominate the discourse of craft production with detrimental effects. Instead, we can see that designers creatively mediate iteratively between aesthetic preferences of diverse social and cultural groups to order to build new products and new markets. Craftspeople can acquire this design expertise through social learning processes when working with designers who act as cultural mediators. Such craftspeople are potential design agents. Craftspeople, thus, accumulate cultural capital and opportunities for financial as well as social mobility. Recognizing that developing aesthetic and design expertise in craftspeople disrupts social hierarchies, which gives designers new tools to design for social change-design then becomes a democratizing paradigm for development that is the indivisible quest for that which truly is equitable and beautiful.

I add a final note on artistry [kala] within the culture of design in traditional craft. Traditional repertoires, technical, aesthetic, and material expertise are inextricably tied together in craft practice, mastery over these combined capabilities in craft parlance can be understood as artistry [kala]. This attribute of craftspeople does not differentiate between art and craft; it is artistry that is expressed in the crafting of the object. Such artistry can exist as a beautiful craft object, yet be unfulfilled in use, waiting to reach its market. "Design" as we have seen in this analysis can be understood as the combinatory activity across economic, social, and cultural functions that are in the service of increasing value of the product. Design can exist as intention, yet unfulfilled in the making, waiting to be crafted. It is when designers engage in artistic expression to make craft objects and when craftspeople engage in combinatory activities of building value for craft objects that these categories can be conflated. 


\section{5 | HANDLOOM AS ADAPTIVE SOCIO-TECHNOLOGY: ROUTINE, RECIPE, AND RITUAL IN COLOR}

In this chapter, I study handloom as adaptive socio-technology. The key question is "how does handloom weaving succeed in adapting to the changing world, while the hand-operated loom itself looks unchanging?" I develop the idea that I have introduced in the previous chapter of handloom as an ensemble of technologies, with different kinds of expertise and a system of knowledge based on craftsmanship. I examine adaptive change in the sociotechnical ensemble of handloom in terms of change in technology, change in expert practices, and change in knowledge practices. Through narrating three different stories, I introduce different concepts in order to explain how the handloom ensemble acquires new technologies, renews existing expertise, and remembers old knowledge. The three concepts I will use are technological frame (Bijker 1995), interactional expertise (Collins and Evans 2007), and memory practices (Bowker 2005).

The three stories are not about the loom, but on dyeing, a key technology in the sociotechnical ensemble of handloom. In the first story, I trace a routine transfer of reactive dye technology from the mechanized group of textile technologies into handloom weaving by handloom weaver cooperatives in rural Andhra Pradesh during the period of 2008 to 2012. Obduracy or difficulty in change arises not so much from the reactive dye technology, as from the conflicting technological frames of the actors in the relevant social groups regarding that technology. These have to be adapted in order that the new technology of reactive dyes is stabilized into the handloom ensemble.

Bijker's (Bijker 1995, 191) concept of technological frame relates technologies to the ideas that they encapsulate for social groups. It refers to the shared meanings of a technology held by a social group, which structure the interactions of relevant social groups around it. Technological frames are both constraining and enabling, they provide specific contexts within which actors interact with technologies. I show that the technological frame of handloom has to be adapted by actors from different social groups in order to catalyze sociotechnical change in the handloom ensemble. In order to deal with difficulties in dealing with conflicts of different groups who frame the problem at hand differently, I follow the line of thinking of "frame reconstruction," a strategy of constructing a new problem setting story, in which "we attempt to integrate conflicting frames by including features and relations drawn from earlier stories" (Schön 1979, 270).

Actors who catalyze change in the handloom ensemble demonstrate interactional expertise. Interactional expertise is a form of expertise where actors do not possess specialist knowledge, the kind of knowledge that we generally refer to as expertise, but acquire the language to interact with experts with that specialist knowledge (Collins and Evans 2007, 35). Collins treats expertise as something real and substantive to be acquired through socialization 
into the practices of an expert group: this he does through analyzing the meaning of expertise as the foundation of the practice of science and technology. High on his categories of expertises is interactional expertise which is the ability to master the language of a specialist domain in the "absence of practical competence" (Collins 2010, 303), where "contributory expertise" enables one to contribute to a domain of practice. Actors with interactional expertise who are included in both the technological frames of handloom as well as mechanized production are necessary to introduce new technologies from one to the other. This allows us to understand how expertise in reactive dyeing can be transferred from the antagonistic social groups of the mechanized power loom ensemble to those of the handloom ensemble.

The second story is the reinvention of natural dyes in contemporary handloom weaving practice, by Dastkar Andhra field workers in Hyderabad along with weavers in the village of Chinnuru, some 400 kilometers apart. In the timeline of Dastkar Andhra's work in dyeing, it is a precursor to the reactive dye story, and spans a period of 10 years, starting from the early 90s. It is narrated as a set of recipes for the dyeing of cotton yarn using dyes of vegetable and mineral origin, through the autobiographical lens of my notes as a field worker. Field experiments and training workshops become sites of socialization where actors from diverse fields of expertise symmetrically interact in order to understand, translate, and produce new insights that reinvent natural dyeing as contemporary technology.

Interactional expertise (Collins 2004) here mediates between propositional knowledge and embodied skill. Engineers and craftspeople with interactional expertise create new vocabularies that they use to build recipes for a new technology, reinventing natural dyeing. In this case, we take the knowledge of dyeing to be contributory expertise, with craftspeople more engaged with the embodied skill, and engineers at the propositional knowledge end of dyeing. Neither can innovate a new technology without the others' participation, which is made possible only through each acquiring interactional expertise in the other's specialty through enculturation.

Indigo dyeing is the subject of the final story, set in the late 90s; a community remembers, regains, and re-establishes a technology that had been practiced for centuries and is on the verge of being lost. Yellappa, an 80-year-old dyer, is the protagonist of the story, and the technology redeemed is of the Indigo fermentation vat.

I contrast Indigo science and Indigo craft, while demonstrating that both exist in the handloom knowledge system. Indigo as craft knowledge does not conform to a classificatory rite of passage into science, to be counted as knowledge, and avoid being rendered as invisible (Star 1991). The attempt to classify Indigo uncovers instead Indigo craft's singularity, making it "difficult to classify" (Bowker 2005, loc 2211).

I propose that a more productive way to study such a knowledge system is to understand knowledge in terms of tacit knowledge (Polanyi 1966), where explicit knowledge is always an explication of tacit knowledge built around a specialist domain of expertise. Polanyi (Polanyi 1966) first stated that we can know more than we can tell, referring to knowledge that human beings develop through experience and cannot be known through books and manuals. Collins (Collins 2010) further distinguishes three kinds of tacit knowledge: relational tacit knowledge or tacit knowledge that with some effort can be made explicit, somatic tacit knowledge, tacit knowledge that is tied to the human body, and collective tacit knowledge, or knowledge that is social and collective, and embodied in society.

Somatic tacit knowledge is tacit because it is linked to the human body. Polanyi uses the famous example of bicycle riding in his introduction to tacit knowledge. Bicycle riding does not require knowledge of the physics to calculate balance, since that is not the way a person learns to ride a bicycle; it requires practice and training to establish this capacity in a way that we cannot make explicit. 
Since this knowledge is embodied in our human body, we think of it as tacit, but Collins suggests that in principal it is not inexplicable. Strong or collective tacit knowledge is all about knowledge being collective and acquired through social interaction. The example of bicycle riding should not be about balancing on an empty field but about riding in traffic. This, for example, involves knowing how to make eye contact with car drivers on a busy junction, knowing which traffic signs to obey and which to ignore, predicting the behavior of cars, pedestrians, and other cyclists; and knowing how these rules would be different in other cities. Only from participating in a social world and interacting with other people can we learn this kind of knowledge. Where somatic tacit knowledge is embodied in the human body, collective tacit knowledge is embodied in society. Craft knowledge, as I shall demonstrate, can be seen as tacit in both ways, and thus, learning it requires interaction and immersion in an expert group.

In the Indigo story, the Indigo community engages in collective remembrance, so that the forgotten Indigo dyeing traverses the distance from the past to present, as a combination of tacit knowledge [that includes somatic and collective tacit knowledge] and explicit knowledge [that includes science] (Collins 2010). In order to capture the effects of such temporality on sociotechnical change, I refer to the work of Geoffrey Bowker, titled "Memory Practices in Science" (Bowker 2005). Different knowledge systems have different ways of recalling some and "forgetting" other knowledge from the past. This memory, Bowker suggests, is held in classificatory systems of the past and present. Writing of knowledge held in classificatory systems Bowker suggests that the job of the archive is to consolidate a classification system that makes it possible to "forget the particular" (Bowker 2005, loc 3731). Since now the archive is the repository of all past knowledge, or at least of "useful" past knowledge, it leaves one with a fear of what would happen if one day, we woke up to a world with no archives. Yet, there would still be memory - "all life does is to transform its environment by leaving memory traces in it, thereby increasing its chances for success" (Bowker 2005, loc 339). In the case of Indigo dyeing, traces of over 2000 years exist; in rituals, in museums, in stories, in colors, fragments of fabrics in old cupboards, in manuals, in archival texts, and in associations and social relations. As in the case of 14th century artisans in Europe who expressed an identifiable epistemology through their works of art (Smith 2004, 25), it is through such traces that Indigo knowledge is remembered and redeemed.

I will discuss not just how change takes place in the handloom ensemble but also how change is stabilized. In the first story, change in technology is initially stabilized in the handloom STE around market standards; later, compatibility standards stabilize the newly made ensembles. In the second story, written recipes are used to stabilize exchange in expertise across the technological cultures of urban technologists and rural craft practitioners. In the third story, old vocabularies have to be relearned to stabilize change in knowledge practices. Once stabilized, standards, recipes, and vocabularies can travel and thus mobilize handloom knowledge across the STE, across sociotechnical cultures and through time.

The three stories are literally of different colors; one is of a vibrant-almost folk palettelime yellow, parrot green, aaku pacha [leaf green], and pasupu [turmeric yellow]; another is of an earthy range of vegetable colors that are difficult to pinpoint on the Newtonian color spectrum; al, katha, chevalikudi, danima, and kasimi; the final one is just of Indigo [N eeli], or deep blue black. Any initiative to study the history of the craft of dyeing in India would chronologically start with Indigo, the known practice of which is at least 2000 years old, and go on to natural dyes, which are documented in the colonial British archives. Reactive dyes would make an entry only much later, as part of the technology of chemical dyes, which were a product of industrialization in the 19th century. 
Yet in this chapter, I introduce them first to the reader, as the most recent adaptation of the handloom ensemble to new technologies, followed by the reinvention of natural dyes, and end with remembering the craft of Indigo. The three stories on dyeing have been chosen based on two criteria; first, dyeing technology is sufficiently an exemplar of the technologies in the sociotechnical ensemble of handloom that characteristics of sociotechnical change in dyeing can be generalized across the handloom ensemble; second, dyeing has sufficiently discernable variants, which explicate the aspects of specialization and standardization on which I base my theoretical understanding of sociotechnical change in handloom.

The economist Schumpeter refers to adaptive response as a way by which an industry develops in reaction to a change in condition by expansion within existing practice, rather than do something that is outside of the range of existing practice (Schumpeter 1947, 150). At the same time, the "change in condition" may be external to the existing practices; to which the industry responds with adaptations that result in sociotechnical change. I use the term adaptive in the sense of being responsive to external change, rather than in its evolutionary sense. In order to explain change in the handloom STE, that still maintains the unchanging nature of the loom I propose that diverse kinds of experts from inside as well as outside the ensemble interact with each other to catalyze change that maintains value for existing skills, displaying an adaptive style of change that is "shaped by regional and national experiences" (Hughes 1987 (2012), 70). Over time, this adaptive style results in the acquisition and accumulation of technologies, expertise, and knowledge in the handloom STE.

\subsection{A ROUTINE CASE OF TECHNOLOGY TRANSFER: REACTIVE DYES}

India has been known historically for color and coloring of textiles, particularly using dyes of natural and vegetable origin. Color is one of the defining attributes of Indian textiles, the muted vegetable and natural shades coexisting with the vibrant saffrons, magentas, and ochres of chemically synthesized dyes. Indian dyers have in the past famously been called master dyers to the world (Gittinger 1982), exporting textiles as far back as 7 th century. Fragments of Indian hand woven and block printed trade cloth have been found in excavations in Fustat [Old Cairo] that date to before 2000 BC (Balfour-Paul 1998).

At the end of the 19th century, Indigo was synthesized in Europe, by the middle of the 20th century globally the textile industry shifted to chemical dyestuffs and to mechanized dyeing. The new color technology had to be managed. The American efforts focused on the commercializing of color inventions into the market as innovations. In 1898, Albert Munsell, an American professor of drawing dedicated himself to creating "a practical color system for art and commerce" in order to "improve taste." Another example of earlier efforts to systematize color was by Milton Bradley, a prominent American chromolithographer and color educationist of the $1880 \mathrm{~s}$. He was involved in a fiery art-versus-science debate that raged between color systems based on the theory of light and color systems rooted in printing conventions, which "bridged the chasm between the science of color and practice of color in the use of pigments" (Blaszczyk 2012, 49). Sophisticated spectrophotometers that give numerical values to the colors we see were introduced to measure colors; though samples continue to play an important role in communicating and matching color, particularly for textiles. Color trends become an important site for communication across globalizing contexts: Blaszczyk opens her book on color with "Lime green is a fabulous color for blondes.” (Blaszczyk 2012, xiii)

Color is an outcome of technological processes, dyeing is the practice of color making on a medium. Standardizing synthetic color production 
and grading colorfastness, with a view to creating international standards that could stand up to "a court of law" has a long history (Krais 1927, 148). Color standards were transformed by the discovery of synthetic dye; "Azo dyes offered the textile industry additional color-fast alternatives to natural dyes;" as a result the American Carpet Trade Review reports in 1878 that "customers had begun to expect more from their dyes" (Blaszczyk 2012, 27). Fastness of color was measured as resistance to change in color when the dyed product was exposed to various elements of daily use; for example, sunlight, soap, and pollution (Blaszczyk 2012, 24). Early attempts to standardize fastness decreed that the measure was relative, rather than absolute; as illustrated by one account of standardizing tests for light fastness by Dr. Paul Krais, Chemist and Chairman of the German Colour Fastness Commission, "Victoria Blue B precipitated on china had been used for the purpose of forming a scale of exposure" (Krais 1927, 148). In 1927, the Journal of Textile Institute Proceedings reports four perspectives on colorfastness: color-fastness from the "Point of View of the Maker", followed by the User, the Launderer and the Research worker. ${ }^{143}$ Since 1947, tests for light fastness, washing fastness, rubbing fastness, and stain fastness are standardized internationally by ISO into quantifiable measures, and dyed textiles are expected to meet these standards: the scale is 1:8 to light fastness and 1:5 for other fastness. ${ }^{144}$

Dyeing is a major service demanded by the textile industry, with the dyestuff sector becoming in recent years one of the core chemical industries in India. These include basic dyes; azo acid and direct dyes; disperse dyes; fast color bases; reactive dyes; sulfur dyes; vat dyes; organic pigments, napthols; and optical brighteners. ${ }^{145}$ In 1994, Europe, particularly Germany, the second largest importer of Indian textiles, banned the import of

143 "Institute meetings on colour fastness." J ournal of the Textile Institute Proceedings1 8, no. 10, 1927: 209

144 For detailed list of tests see http://www.scribd.com/doc/80781938/ Colour-Fastness, http://www.scribd.com/doc/60704995/BS-enISO-105-A01-1996-Textiles-Tests-for-Colour-Fastness for ISO stantards:http://www.iso.org/iso/iso_catalogue/catalogue_ics/ catalogue_ics_browse.htm?ICS1 $=59 \&$ ICS2 $=080 \&$ ICS3 $=01$

145 http://www.dmai.org/profile.htm textiles that used di-Azo dyes for coloring, through an ordinance known as "German Consumer Goods Ordinance." Azo dyes are a class of synthetic organic dyes that contain nitrogen and belong to the Azo group. In a study undertaken by the Ecological and Toxicological Association of the Dyestuff Manufacturing Industry [ETAD] in Germany, 4000 dyestuffs were assessed as health risks; basic dyes and diazo dyes were found most toxic (Nadigera 2001). These dyes were found to be potentially carcinogenic to the user (Anliker 1979). Shortly after, the Government of India banned the use of hazardous dyes validating the initiative of the German government supporting its consumers. "The very fact that the government of India has banned the use of hazardous dyes is enough to prove that initiative taken by Germany was fully tenable and based on firm consideration of a long-term concern for the consumer the world over," responded Dietrich Kebschull, then director of Indo-German Export Promotion (IGEP). ${ }^{146}$

However, the ban had fairly disastrous effects on small producers of textiles engaged in export, particularly those who could not shift quickly enough to the newer dyeing technologies. Export rejections became the norm, breaking the back of many small producers, particularly in handloom. Master weavers who supplied to such markets acknowledged the importance of meeting market standards; Subbarao, ${ }^{147}$ a dyer in the weaving village of Mangalagiri known for its fastness of colors, says it is so important that the recipes are proprietorial information of the master-weavers. "If the masterweaver trusts you, then he will tell you the recipe and leave it to you, otherwise, he will stand there and supervise the dyeing himself."

With the regulation of the use of dye stuffs that were deemed hazardous to the consumer and environment (Nadigera 2001, Hessel et al. 2007), a new market standard of environmental friendliness arrived on the dyeing horizon. This would entail change in dyeing practices in the handloom ensemble in order to meet the new market standard.

\footnotetext{
$146 \mathrm{http} / /$ www.indiaenvironmentportal.org.in/content/13428/goodbyeazo-dyes/

147 Interview Subbarao November 17th, 2011
} 


\subsubsection{TECHNOLOGICAL FRAME AND SOCIOTECHNICAL CHANGE IN HANDLOOM}

The case of the handloom ensemble acquiring reactive dye technology can be read as a routine technology transfer from the power loom sector to craft livelihoods, in order to contemporize craft production. This requires transfer of technology between social groups acting from within differing technological frames that of handloom and mechanized production. I now explicitly stress the temporal dimension of the technological frame in ordering sociotechnical change in handloom; as maintaining continuity [of past practices] as well as promising change [in future practices]. When used in this way, the technological frame is the boundary that constitutes a particular technological culture, in this case "handloom" technological culture; where the boundary mediates technological changes over time so that the STE of handloom of the past can still continue to be framed as "handloom", even as it changes. In order to do so, the technological frame that attributes meaning to the artefact is subject to adaptation.

Thus, my analysis progresses in three steps:

1. Actors are not part of only one technological frame; they may be included in multiple frames. As a first step in this analysis, I will first describe actors from relevant social groups with respect to their technological frame, which binds them as a group

2. Second, I will describe the construction and stabilization of the artefact reactive dye in the respective technological frames of the different social groups. This will illustrate how the different social groups construct the reactive dye artefact in order to stabilize it in their technological frame

3. Third, I will explain how this constructed reactive dye technology is stabilized in the handloom technological frame and the resultant adaptation of the handloom technological frame.

The relevant social groups that I chose as a first step are those that play important roles in this process. They are the development workers in the CSO Dastkar Andhra, the handloom weaver co-operatives to whom they also provided marketing support, the professional dye-houses in the areas where the co-operatives operate, and the dyers, some entrepreneurial, some hired by the co-operatives themselves. Geographically, the locations of the co-operatives, dye-house owners and dyers, are contiguous in the east Godavari district of Andhra Pradesh. The co-operatives and dyers belong to the handloom technological frame while the entrepreneurial dye-house owners are the only social group who belong to the power loom technological frame, rather than handloom, though they service handloom producers. The actor from the CSO, I will show, is included in both frames, and facilitates the introduction of the reactive dye technology from the power loom technological frame to the handloom one. 

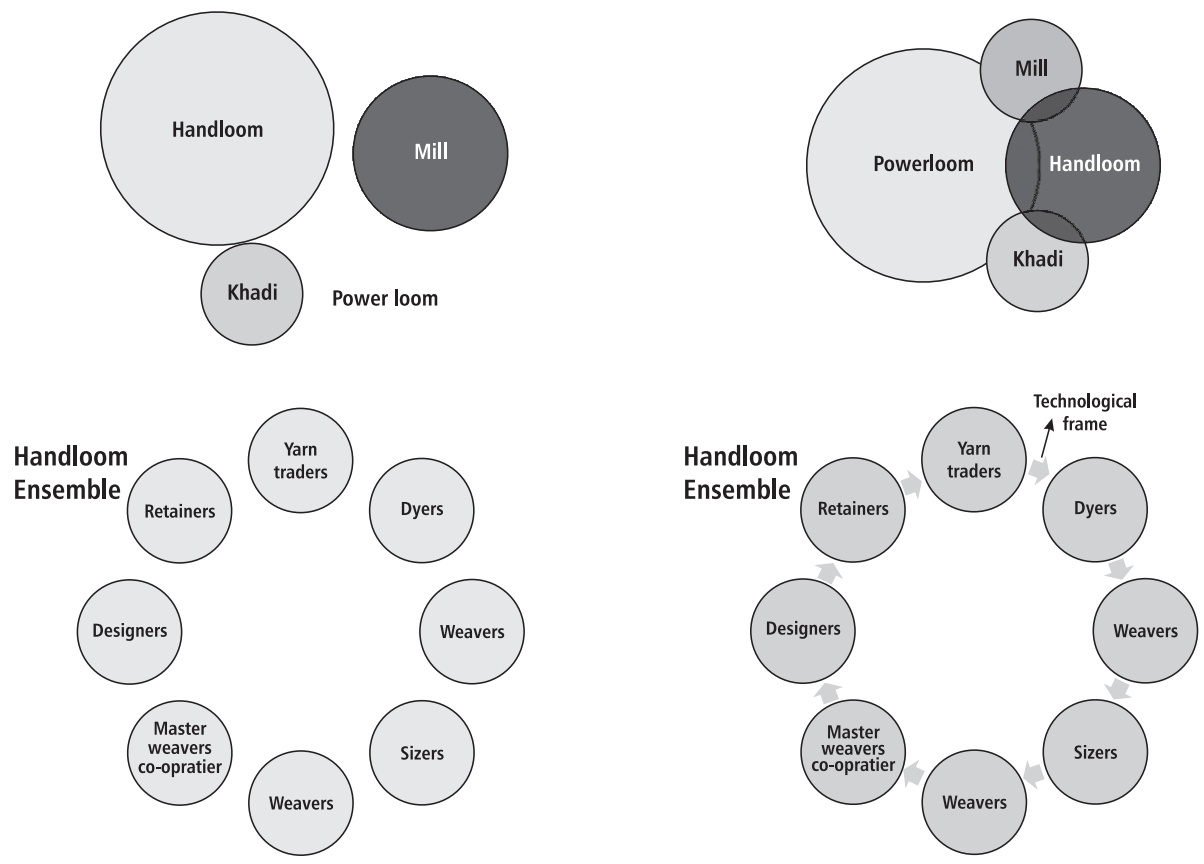

Fig. 5.1 An impressionist sketch of the Indian textile Industry, with the size of the circles broadly indicating number of people involved:

5.1a. The four main textile production systems

$5.1 \mathrm{~b}$. The enmeshed production systems

5.1c. The social groups that are relevant for understanding the sociotechnical ensemble

$5.1 \mathrm{~d}$. The relevant social groups are joined by sharing the same technological of handloom frame

Initially, reactive dye technology is a mechanized technology that is not part of the handloom social groups' technological frame. I first describe how each relevant social group interacts with the new artefact and stabilizes it in their individual technological frames. The technological frames of each of these social groups characteristically display a key thrust. As I will explain in the next sections, in the case of the CSO the technological frame can broadly be understood as "sustainable production," for the co-operatives as "service" [seva]; for the dyers as "skill" [kala, panitanam], for the dyer entrepreneurs as "firm growth."

\subsubsection{SOCIAL GROUPS AND THEIR TECHNOLOGICAL FRAMES}

Historical discourses influence the key characteristics of each of the technological frames. I have detailed these in Chapter 3, with regard to livelihoods. In this chapter, I define them with respect to how they inform choices in technology.
For the CSO actors, the import of British-made cloth and the ensuing destruction of the Indian handicraft industry became a dominant theme in the nationalist movement of the early to mid-20th century (Bayly 1986). Therefore, allegiances to 
important social movements during the formation of independent India in the early 20th century inform the social groups' engaged positions in the technological frame of handloom. Indian society took seriously the symbolism of Gandhian spinning as right technology, the support of Khadi [handspun] as village self-sufficiency, cloth as swadeshi [home country product] evoking right conduct (Bayly 1986). Gandhi's ideal of India's spiritual civilization where "people lived in small scale self-sustaining communities, where co-operation replaced competition, and community prevailed against domination and exploitation" (Brown and Parel 2011, 57) became a call to Civil Society Organizations who took to practical reconstruction work at the village level. This vision of sustainable production as promoting social cohesion, livelihood sustainability and autonomy of the rural producer ran strongly through the CSO technological frame.

The institution of the village Co-operative on the other hand found support as a modern institution for vulnerable producers providing marketing services from the 1940s on, both among weavers as well as the state (Mukund and Syamasundari 1998). "Service" 148 [seva bhavana] to vulnerable weaver members became an important goal of the technological frame of weaver co-operatives.

I use the writings of the Dalit leader, Ambedkar, to approximate a standpoint for the angered handloom weaver whose skill is disappeared as labor in mainstream discourse. Ambedkar, the author of the Indian constitution, born into that social class that was subject to degradation gave voice to the historical experience of caste oppression within Indian social and cultural hierarchies, of certain groups of people. While holding to the view that the experience of oppression was underdetermined in its explication and only partially understood by those not oppressed, he advocated reason as a way to human dignity (Rodrigues 2011). Ambedkar saw knowledge as eminently practical and as

148 Translated from the Telugu "sevaa bhaavana" where the service imperative is not a market function alone, but brings with it the connotation "to serve" someone. active engagement with practice (Rodrigues 2011, 57). Echoing this position, a recurring theme of differentiating between labor and skill, where skill is recognized and valued as expert knowledge of "doing" [kala, panitanam] as against labor [shrama] is an important aspect of the technological frame of weavers.

Since culture is less of a sacred cow for Ambedkar, he is able to see its susceptibility to change. He understood that cultural communities could alter seemingly permanent cultures "by reviewing and reformulating used ways of life without necessarily abdicating their cultures" (Rodrigues 2011, 58). In opposition to the admiration Gandhi receives for wearing a Khadi loin cloth, Ambedkar receives adulation from a Dalit woman for wearing a blue suit. The blue suit symbolizes Ambedkar's escape from the fate that society has in store for him, of wearing a loincloth (Guha 1989a, 8), or in the case of the weaver, escaping from the "pit" of the handloom, which was his lot by birth. This framing finds an echo in dyers' technological frames; they are less self-conscious about adapting their technologies of production to the market, or learning new skills of dyeing if there are sufficient reasons to do so, or threaten to abandon it altogether if the experience of vulnerability was too traumatic.

Together, these form the basis for different interests, which have to be constantly balanced in the handloom technological frame, during the process of sociotechnical change. Each of the social groups' individual technological frame offers a solution to a problem not taken too seriously by another frame, it is only through "amortizing the vested interests" (Aibar and Bijker 1997, 17) of the different groups that the reactive dyes are stabilized in the technological frame of handloom. There are deep inequalities that already exist between the social groups, for example between the CSO marketing agency, Dastkar Andhra Marketing Agency [DAMA], and the dyers. Some groups are more vulnerable to negative outcomes of change 
than others, and those groups are not necessarily the ones whose technological frames are dominant in the field. Equally there are also norms that inform these interactions and endeavor to mitigate differences in dominant and vulnerable positions, historically. As we will see, no one group wins a total victory, but each gains sufficiently from the solution of reactive dyes to allow for the adoption of reactive dyes first within its technological frame, and later for stabilization in the handloom technological frame. Where there is no interest or no such a gain that social group opts out of the handloom technological frame. The elements of the new technological frame of handloom that includes reactive dye technology are made up through the interactions between the realities of the CSO technologist, the cooperative manager, the dyer entrepreneur, and the dyer himself, including the regulatory authorities, marketing agencies and customers whose standards completed the frame. This list of positions is not exhaustive but the ones I chose to focus on in the following story.

\subsubsection{STABILIZATION OF THE ARTEFACT REACTIVE DYE IN THE RESPECTIVE TECHNOLOGICAL FRAMES}

\section{The relevant social group of civil society} organizations and the technological frame of sustainable production

CSO organizations such as Dastkar Andhra form a relevant social group that predominantly sees their role as supporting the livelihoods of vulnerable handloom weavers, through policy interventions as well as market interventions. They work exclusively for the handloom ensemble, like the handloom weaver co-operatives who they partner with. Dastkar Andhra treaded carefully on the technological domain of weaving, which it framed largely as the purview of the weavers, as compared to the marketing domain, which it saw as its own. The technology program of Dastkar Andhra therefore focused on weavers' control over their technology at the production end in partnership with local co-operatives, while building value for craft skill in urban markets. Their technological frame was influenced by Gandhian writings during the nationalistic movement, which critiqued the imposition of western technologies on India by her colonial masters (Appadorai 1976, 5) quoted in (Rodrigues 2011, 60). Gandhi tempered his criticism with an appreciation of the spirit of enquiry of western science; relating it to his quest for truth "in place of being satisfied with tradition without question, and implied intellectual curiosity, rigorous pursuit of truth and critical examination of established beliefs" (Parekh 1989, 31). His concept of swadeshi [home economy] provided a balance; it was at once a "kin concept alongside culture, community, and tradition" that denoted a way of life to which one belonged, as well as protection of "home" industries such as Khadi and Handloom (Rodrigues 2011). This endorsed both the spiritual duty of common Indians to support something good and the moral duty of secular citizens to sustain communities, toward the eventual end of economic self-sufficiency for India's villages. Handloom cloth continued to evoke community and right conduct, post-independence, this perspective of supporting "sustainable production" strongly influenced the technological frame of civil society organizations such as Dastkar Andhra.

The goal of the textile technologist in charge of the reactive dyes technology program, Durgalakshmi Venkataswamy was "to build a sustainable program to augment resources in the decentralized handloom sector." 149 She hoped to create "new energies for and around weaving, by engaging differently," while taking into cognizance Dastkar Andhra's stated intentions to draw its boundaries clearly,

“..of what it considers 'its' space for innovation; and in articulating the technical innovation

149 Presentation at Cultures of Design and Technology Seminar, DA 
as the domain of the weaver, would seem to be resisting the possibility of innovating on weaving technology. However, this is a shifting point, where collaborations on technology are continuously undertaken, in order to create conditions where weavers can innovate." 150

In her opinion, the reactive dye technology was a "new technology that fit into the ethos of handloom." 151 Her claim was that environment friendly reactive dyes were in fact more in line with the nonpolluting nature of existing handloom technologies than the widely practiced azo-dyes. At the time, Dastkar Andhra was already seeing dyeing as a technology that needed streamlining, in order to meet market standards. In general, dyeing standards in handloom products were not meeting customer expectations; weavers had had to shift to buying pre-dyed yarn in order to meet market standards of colorfastness, rather than take up dyeing locally. However, here the color palette was limited. Dastkar Andhra defined the problem in existing dyeing technology as the weavers' lack of autonomy over color; resulting eventually in a loss of market value for their fabric, which would affect livelihood. Once this problem was defined, they offered the solution of reactive dyes, rendering it as a technology to produce "smaller dye lots and more colors per order"152 flexible to market demand. ${ }^{153}$ This intervention was aligned with the stated goals of Dastkar Andhra that focused on weaver and dyer autonomy over technology and would bring increased return to artisans through improving craft skills in dyeing.

Reactive dyeing was being used in mechanized cabinet dyeing cabinets, in the power loom textile sector, particularly for hosiery and knit wear. It was converted back into handloom

150 Blue note DA

151 Interview Durgalakshmi $24^{\text {th }}$ November 2011

152 Interview Srirangam November 23rd, 2011

153 Vat dyes and Napthols, particularly napthols were more suitable initially for smaller dye lots than reactive dyes; Dastkar Andhra with the help of the Weavers Service Centre in Hyderabad adapted reactive dye practices to suit smaller dye lots required for handloom weaving. What reactive dyes provided was a wider color palette, ecofriendly standards, and fastness standards of the market. practice as manual dyeing skill, using technical expertise from the Weavers' Service Centre, a technical institute that was set up by the state to support handloom weavers, and the technical team of Dastkar Andhra, who were able to identify and convince key dyers and co-operatives to take up the training. At the same time, labor saving devices such as hank washing machines and mechanized hydro extractors for wringing out water evenly were introduced to the co-operatives and dyehouses by Durga, as tools to "reduce the burden of manual labor" 154 on the dyer, without taking away dyers' autonomy or skills. Protocols for checking output of the co-operatives through fastness testing in reputed laboratories were set up by production field workers in Dastkar Andhra and communicated to the dye-house managers, so that progress could be monitored.

The weaver co-operatives were the obvious partners to work with on introducing reactive dyes to the handloom ensemble, since they were already providing yarn and marketing support to their weaver members. Training was taken up in weaver co-operatives in four districts. Dyers were trained in reactive dyes and new dyers were hired wherever necessary. The co-operatives' resources for working capital were limited: co-operatives were notoriously cash starved, in some units infrastructure had to be invested in. Effluent plants were set up by Dastkar Andhra at the co-operative level to meet environmental safety standards; financial sustainability would have to be achieved by the costs of setting it up being borne by returns to the co-operatives on dyeing services. Dastkar Andhra through its marketing agency DAMA assured marketing support to the co-operatives during and after the transition to environment friendly dyes.

Over three years, Durga and her team worked to set up and "modernize" four dye-houses, seven more were refurbished with new equipment and training, and all production to the marketing agency DAMA from the co-operatives was successfully

154 Interview Durgalakshmi Venkataswamy November 24th, 2011 
converted to reactive dyes that met customer standards of fastness and color matching. ${ }^{155}$ Reactive dyes entered the technological frame of the CSO as a technology of sustainable production; in turn their technological frame had to adapt too. In constraining weavers and dyers to accept a new market standard, they were compromising the condition of autonomy of weavers, in order to be consistent with the key characteristic of sustainable production.

Therelevant social group of weaver co-operatives and their technological frame of "service" [seva] to weaver members.

The manager of the prosperous handloom weaver's co-operative of Pulugurtha village D.V.V. Satyanarayana is well-satisfied with the reactive dyes program. He asserts that it has solved the problem of dyeing often encountered when customers complain about colorfastness and the problem of not getting the right shade of color that causes dissatisfaction among retail buyers. Because of this, "the weaver's burden is eased a little bit and his livelihood is a bit better, the dyehouse has solved the yarn dyeing problem." The problem he outlines is of standardization: though they have been dyeing since 1991, their dyer is a master of technique [vidhanam] but does not know "book learning" [chaduvukovadam]. The lack of "book learning" is why they could not solve problems that they encountered in dyeing. Along with advice on techniques that the Dastkar Andhra team taught them, the dyeing equipment too had made a large difference to the quality of dyeing and reduced labor for the dyer. The mechanized hydroextractor that is used to wring water out is mentioned with appreciation. In addition to adding

155 The two co-operatives of Pasalapudi and Pulagurtha had existing dye units which were refurbished; including the dye-house building, and in one case including a water softening plant, hank washing machine and hydro extractor as "modernizing" inputs. Only Rajavolu built a new dye-house from scratch, and seven other dye-houses were upgraded with equipment and training: Nidubrolu, Pasalapudi, Pulagurtha, Siddipet, Kothapalli, Veeravaram, Katheru; natural dye units upgraded - NIRD, Ponduru and Singapuram). quality, Dastkar Andhra's concern for reducing the burden of the labor of the dyer is evidenced to him in this program.

After the training in reactive dyes, he understands quality in terms of meeting color matching and fastness standards, as articulated by the paying customer. For example, APCO, the apex marketing organization of the handloom cooperatives is less critical of quality parameters of color matching and evenness, but more particular about the price. The customer who insists on quality is also the customer who is willing to pay for it, like in the case of Dastkar Andhra. If the quality is right, he says, the price is less important - "then customers do not mind if we charge one or two rupees or even ten rupees more." It is for those customers he provides reactive dyed product. For the co-operative manager, the shift in dyeing practices is less about the specific change in dyeing technology to environment friendly dyeing, ${ }^{156}$ but more a general solution to meet the standards that new markets demanded.

Handloom weaver co-operatives are membership based organizations for rural producers; and usually named after the village where they and their members are located. To be successful, it had long been felt that [handloom] co-operatives have to perform functions of production, finance as well as marketing for their producer members (Kurien 1978). In the case of handloom, co-operatives were also seen as a plank for development support, so that the state could channel welfare and livelihood support to weaver members (Madan 2007). One of the reasons for the steady decline in number of handlooms during the $90 \mathrm{~s}$ was seen as the failure of co-operative functioning (Mukund and Syamasundari 1998). Since the co-operative was conceived by the state as a vehicle to support handloom weavers, the management of the cooperatives felt themselves accountable for the wellbeing or lack of it, of the weavers, in successive

156 Vat dyes are environment friendly safe dyes, but vat dyes are more expensive than napthol and reactive dyes, and so used only where napthols do not provide the required shade. Reactive dyes on the other hand have both the price and variety advantage over vat dyes. 
phases of decline (Abdul 1996). As the state further withdrew from direct marketing activities and provision of credit in Andhra Pradesh, the cooperatives working with DAMA took to a model of disaggregating market risk, through servicing the state marketing body APCO, local markets, as well as DAMA. It was this mix of enterprise and service to the weaver members that co-operatives displayed in their interactions around reactive dye technologies. From this position, they found it important to institutionalize technology services; both in quality and quantity, "We have everything that a weaver needs, by ourselves, everything. He [the weaver] doesn't have to go anywhere else, dyeing, yarn depot, everything is here!"157 The tangible infrastructure of the dye-house and the equipment became credible signs of service to the weaver in the institution, further easing reactive dyeing into their technological frame.

An additional point of pride is the guarantee that the co-operatives are able to assure the weaver on color quality. Right now, the reactive dye technology is used mainly for orders that are received from Dastkar Andhra. However, this might change. Learning the new technology was relatively easy "we have many skilled dyers here, and we are always training new people; in fact we 'prepare' the dyeing work force for the whole district." 158 The training in standardization of color matching and fastness has been the biggest value addition of the reactive dyes program. Satyanarayana adds another aspect to the learning, "we learned shades, colour combinations, [while learning reactive dyes] before that, we would do something, but not think so much, but this new way of combining colours we learned." The reactive dye technology re-enforced co-operative managements' self-perception as quality service providers who provided end-to-end solutions to weaver members. ${ }^{159}$

157 Interviews DVV Satyanarayana, Virupaksham November 17th, 2011

158 Interview DVV Satyanarayana, November 17th, 2011

159 Interview DVV Satyanarayana November 17th, 2011
However, the reactive dye technology, the most important breakthrough for the cooperative, resulted in "freedom in color" for its weaver members; as palette, as technology, and as service that they could credibly provide to weaver members. It was in this form that reactive dyes were stabilized in their technological frame of "service." In addition, in being trained to achieve market standards of fastness in reactive dyes, they adapted their technological frame of service to weavers, to include servicing the market.

\section{The relevant social group of dye-house entrepreneurs and their technological frame of firm growth}

The dye-house entrepreneurs who provide dyeing services to the co-operatives and weavers do not carry a value preference for either handloom or power loom in their technological frame of firm growth; as long as they provide a market. Ergo, the dye-house provides both manual and mechanized dyeing; it practices napthol, azo free, and reactive dyes across handloom, power loom production, servicing local and export markets. Their technological frame is stabilized around scaling up, rather than an attachment to any particular technology per se. As a result, in their technological frame reactive dyes and handlooms do not necessarily always go together. More important, their technological frame is neutral to hand weaving and mechanized weaving, manual and mechanized dyeing. This is in direct contrast to the technological frames of the CSO and the weaver co-operatives, where growth is always and irretrievably in relation to that of handloom weavers.

Dye-houses in Andhra Pradesh proliferated after the regulatory clamp down on dye-houses in Tiruppur, in Tamil Nadu, one of the largest centers of garment export in India. Tiruppur produces around 15,000 crore rupees worth of goods, employing $5,00,000$ workers. In 2011, the closure of the dyeing units due to pollution control issues made 
"life miserable" for the exporters in the area. ${ }^{160}$ As a result, exporters explored actively other places where dyeing could be taken up at competitive prices. A lot of dyeing moved to Andhra Pradesh, as pollution control was not so active here, but eventually here too, it became a concern. ${ }^{161}$ Most of these manufacturers belonged to the power loom sector. Power looms have the largest share of the market, competing successfully with mills, leveraging the regulatory cracks that pertain to large factories. Workshop owners particularly evade taxation and labor law (Haynes 2001, 171). This gives them an unfair advantage over handloom products in the markets. Mass produced power loom products are very often passed off in the markets as handloom, deflating prices for handloom products. In general, though there are regulations like the handloom reservation act, the attempt to protect handloom from power loom imitations through reserving particular products for sole production by handloom is almost impossible to enforce (Srinivasulu 1996).

Against the backdrop of this rather weak regulatory environment, dye-houses in Chirala found the strong pollution control board a surprising exception; willing and able to enforce its mandate on defaulters. One such dye-house owner Balaji, of the Balaji dye-house in Chirala had previously gotten into regulatory trouble over the azo ban; and had to close the dyeing unit down. Following that regulatory episode, he shifted to reactive dyes, now he claims that his unit is totally azo-free, geared for export. The dyeing process is not manual, but uses machines like the cabinet dyeing machine. This did not automatically mean that they dyed solely for power looms; in fact it was to meet export quantities in handloom that they shifted to cabinet dyeing. "We used to do 200 bales of cotton manually, so we started with two machines, then we started dyeing

$160 \mathrm{http} / /$ www.thehindubusinessline.com/economy/tirupur-exportersscurrying-for-dyeing-facilities/article1517559.ecelast retrieved 6 July 2015

161 http://www.thehindu.com/news/cities/Vijayawada/pcb-closureorders/article2973280. ecelast retrieved 6 July 2015 for Chirala Handlooms, to keep the machines busy." In fact, for Balaji, the correlation is not between manual dyeing and handloom, mechanized dyeing technology and power loom; the task is to match quality and quantity of the demand to the right dyeing technology. The choice is determined by the price points and the color palette, and always dictated by the customer.

Balaji has concerns about handloom; growth is in the mechanized power loom sector, rather than handloom just now. He proposes to shift to cone and cheese dyeing technologies, the coming year in order to better service the power loom sector. As his family grows, [six brothers now in the business] it becomes "important to develop," and follow demand. As growth in dyeing quantities will automatically increase effluents, reactive dyeing becomes a mandatory technology in his technological frame of firm growth.

His differentiation of regulatory cutoffs is fine; as of now the unit does not have "enough" effluent to warrant effluent treatment, they are able to get by with chlorination, since reactive dyes do not contain heavy metals. "Only one lakh litres of dyebath" he insists, "rest is washing," and quotes the ration that is acceptable to the local pollution board "12 washes, which dilutes and reduces the ratio of color to $1: 17$ ". Since the dyeing is mechanized, this unit is less dependent on labor, but he is careful that they have back up power generators for their machines, since power supply is erratic. He finds it important to make a distinction between dyers as "labor" and as "skilled" technicians who can run the machines, though both need to be experienced; "all eyes are not the same, color is subjective." This is in direct contrast to the small dyer-entrepreneurs and co-operative dye-houses which continue to depend on manual dyeing and for whom the dyer provides expertise of dyeing as well as labor.

Since the dye-house owner social group already belonged to the technological frame of mechanized production, which is native to reactive dyeing, we see that taking up reactive dyes did not necessitate any adaptation of their technological frame. 
The relevant social group of dyers and their technological frame of Skill [kala, panitanam]

The dye group of Napthols are known to be the most complex dye application process, when used in the mechanized dyeing industry, requiring skilled technicians and precise chemistry. However, across manual dye-houses in Andhra Pradesh, napthols are widely used, with a sense of ease by both the dyer and dye worker. This is because they lend themselves to manual dyeing- "domestic utensils can be used, in the absence of machines and process time is minimal, reducing costs."162 Similarly, dyers in the handloom ensemble took to reactive dye processes easily, in all the places where Dastkar Andhra introduced them. They were seen to be more labor intensive than azo or napthol; but since the dyestuff cost was cheaper than vat dyes, the difference would go as wage to the dyers. ${ }^{163}$

Dyeing skill of the master craftsman in dyeing reactive dyes is made up of different elements as described by dyers. Mangalagiri is known for its fastness of dyeing, here Narasimha Rao, the master dyer hired by Dastkar Andhra points out, ability to solve problems encountered in dyeing differentiates between skill and labor. Skill is also necessary to deconstruct what went into a particular color, in percentages, as recipe. Thinking up a new color required technical craftsmanship; a color had to be thought of, and then tried out, to see if it would work. Pointing to the detailed documentation maintained by a senior dyer in his sixties, who stripped down to the waist was working in the yarn tirelessly, Narsimha Rao insists "this is technical," 164 lest one missed the technical skill belied by the laboring

162 Interview, Durgalakshmi, November 24th, 2011

163 Co-ops charge a fixed rate for dyeing especially when dyeing for the marketing agencies of DAMA and APCO, the government apex marketing body. This rate is an average approximation of both napthols and vat dyes. When reactives were by DA introduced, it fit well within this price range as per DAMA rates. One of the reasons that the co-operatives didnot use it for APCO or their own production was because dyeing rates were much lower in those cases; For DAMA, dyeing rate was Rs 280-320/ $4.54 \mathrm{~kg}$ (bundle), APCO only paid Rs 180/bundle: napthols were preferred because of the low dye cost).

164 Interview, Narsimha Rao, November 17th, 2011 body.

For Sreenivasa Rao, the dyer-entreprenuer of a dye-house in the village of Mangalagiri, the shift to reactive dyes was to meet the standards of the export market, but he also understands its production value. He refers to his dyer Kotiah whose "body could not take [the azo based] vat and napthol dyes" because "it eats up your skin." 165 Sreenivasa Rao uses recipes to figure out color matching, through a two-stage process: he makes the recipe for a sample first before scaling it up. Recipes vary with the choice of dyeing process; the cabinet dyeing recipe would not work for the manual dyeing; as even the quality of the water and the "density" of the caustic soda could affect color. Srirangam, ${ }^{166}$ dyer entrepreneur in the Rajavolu co-operative dye-house explains it as a process of "thinking together with the dyer". He works out the recipes along with the dyer in his unit; "he almost reads my mind." Both experience and "alochana" [figuring out through thinking] are necessary for producing new colors, even if cloth samples are given. The participation of the experienced dyer is critical in coming up with the recipe, and therefore, he is able to appreciate the engagement of his dyer who is "constantly improving." The result, he says, is a color palette that has almost 300 colors.

The palette was an important criterion for displaying his skill; sometimes he would "top up" a reactive dye color with azo-based dyes, to get the right shade. Dyeing is "creation" to his mind and has to be taken up with "chittashuddhi," a combination of focus and a sense of responsibility that was almost sacred. Rather than regarded as technology, reactive dyeing was artistry [kala] as well as problem solving expertise, and the ability to think up new and attractive color palettes. These loomed larger than the chemistry or environment friendly attributes of reactive dyes. His training in the technology of reactive dyes was only the entry; he intended to practice and internalize the learning till it became art.

In the technological frame of the dyers, value

165 Interview, Srinivasa Rao, November22nd, 2011

166 Interview, Srirangam, November23rd, 2011 
for skill, and the reduction of drudgery inducing labor is an overarching theme. Introduction of mechanized labor saving devices by Dastkar Andhra reinforced this same theme; coupled as they were with training in new dyeing techniques, as well as increased value for dyeing skill in meeting market standards. It is this framing of reactive dyes, as dyeing skill that is differentiated from labor that allowed the stabilization of reactive dyes in the dyers' technological frame. Here too, the technological frame of skill of the dyers had to be adapted to include the skill of dyeing to market standards: in terms of fastness, in diversity of palette, as well as in matching and customizing.

\subsubsection{THE STABILIZATION OF REACTIVE DYE TECHNOLOGY IN THE HANDLOOM TECHNOLOGICAL FRAME}

In this third step, I describe the interactions of the social groups in stabilizing reactive dye technology in the technological frame of handloom. Each of the social groups discussed above had defined a problem for which reactive dyes provided a solution, within their technological frame. For the urban technologist Durga and the CSO Dastkar Andhra, reactive dyes were framed as environment friendly technologies of sustainable production, in line with the other technologies of sustainable production in handloom. Particularly, effluent treatment that would make the water 100 percent safe made up a critical component of their technological frame. Reducing drudgery for dyeing labor through labor-saving tools, without deskilling the dyer was a critical component, to be actualized by value for dyeing expertise in the cloth market. Most important reactive dyes met market standards and made for autonomy in color for weavers, this created an overlap with co-operative and dyer technological frames.

In the technological frame of the Cooperative, reactive dye technology became a means to service weaver requirements as well as meet market standards in fastness and matching. Cooperative managements did not perceive the value of reactive dyes so much in keeping their environment safe, as much as a market standard that they met on demand, alongside fastness and matching. Contrary to Dastkar Andhra's expectation, they did not take up effluent treatment, nor did they use reactive dyes as standardized dyeing practice, instead selectively using it in the case of markets that demanded environment friendly values in technology. They took it on themselves to reduce market pressure on the weaver members by turning it into a pre-loom technical service that they could offer to the weaver. As a result they achieved what they referred to as "freedom in color" through institutionalizing standardized dyeing services to the weaver members. Their technological frame overlapped with Dastkar Andhra on the elements of autonomy over color for weavers, as well as in reducing labor for dyeing labor. Co-operatives took up market standards as part of their quality service provision in dyeing to weavers.

The dye-house owners in Chirala and Mangalagiri who engaged in large scale dyeing framed reactive dyes as a solution to a regulatory issue. They also, like the co-operatives, did not hold with the idea that environment friendly values went hand in hand with decentralization and manual production. They saw no contradiction in providing reactive dye services to both handloom and power loom weavers. Their dyeing processes were mechanized, as well as manual, depending on the price point, and scale, the skill of their technicians lay in being versatile and flexible to new technologies, rather than expertise in one kind of dyeing. There were no inherent standards in their practices, instead they listened well to the customers standards and provided for them. On the one hand, this framing of reactive dyes evidenced that in practice, power loom and handloom actors were not disengaged from each other; production functions, services, and values could often overlap across both sectors. On the other, this framing did not hold water in the handloom actors' technological frame, where 
the mechanized power loom was a direct antithesis to their sustainable production frame.

Reactive dyes evidenced that regulation could work, under the aegis of a strong governance structure, even if it worked against power loom interests. In an environment where dye-houses that did not comply with regulatory stipulations were shut down, the shift to reactive dyes was framed firmly as a regulatory issue, which could come in the way of firm scaling and growth if it was not carefully managed. In contrast, it was the handloom co-operatives that refused to take the issue of regulation in the practice of reactive dyeing on board and treated effluent plants as superfluous at their scale of production. This reduced costs and gained them some competitive advantage over the power loom product that in this case fell under the regulatory eye, using a trick that power looms themselves commonly used against the mill sector.

In the technological frame of the dyer, where skill is the overarching value, the solution that reactive dyes offers is of a color palette. Skill is needed to decipher color already dyed into a sample, skill is needed to think of a new color, skill is needed to tinker with an existing color to scale up dyeing, or down; to vary the color or standardize it; or to set right a "failed" color. In all this, the recipe is constructed as a fixed point of reference. Tinkering with process is the norm, dyers "top up" the color using azo dye processes, this too requires skill of a particular kind, and it is sanctioned if in the service of achieving the right shade in the color palette. The dyer turns "creator," his journey in building skills is an eternal quest. In the dyers' technological frame where skill plays such an important part, the external training and resource provided, once converted into skill, eventually becomes invisible in the narrative. The dyer becomes one with his technology and is focused only on meeting the next challenge to his skill, and of meeting market standards, and gaining value from the market for it.

One important event marked the closure in the process of sociotechnical change and the successful addition of the new reactive dye technology to the handloom ensemble. The women of the weaver households that wove for Dastkar Andhra were asked to participate in telling their stories on camera, wearing reactive dyed sarees, for marketing Dastkar Andhra's reactive dye products. This was the first time that these women chose to wear sarees that had been woven in their village, in their own households. Even in the old days when cotton was the fabric of the poor and silk of the well-off; colored cotton sarees, particularly with fast color were not within the financial reach of most. On request, color could be obtained albeit for a short while; the rangaari, a dyer by caste (Siraj-ulHassan 1920, 65), could make an old saree new by redyeing it using local fugitive colors like turmeric Curcuma longa and annatto, Bixa orellana. When weaver women in the village co-operative agreed to become users of Dastkar Andhra's reactive dye sarees, it bridged the positions of the CSO and the standpoint of the weaver collaborators.

Interests were amortized, of each of the social groups, in order to stabilize reactive dyes. Co-operatives retained older practices of napthols from the older di-azo-family of dyes, even in reactive dye-houses that had been set up newly, particularly when servicing local markets. Second, the effluent treatment plants though set up at considerable cost to treat waste water from reactive dyeing, were not found as being useful by the co-operatives who chose to leave out this final step in the reactive dye technology. These were in contradiction to the Dastkar Andhra's goal of stabilizing reactive dyes as the dyeing technology of choice in the technological frame of handloom. ${ }^{167}$ However, in choosing to change their sociotechnical practices selectively, co-operatives and dyers chose reason without abdicating their culture and achieved autonomy.

The environment friendly aspect is the standard associated with particular markets, rather

167 In fact, Durga's goal was to introduce responsible practices of cleaning effluents from all three kinds of dyes -vats, napthols as well as reactive before discharge, but since co-operatives associated it only with reactive dyes, they did not take up the practice for any of their dyeing effluents. 
than an inherent attribute of handloom production. Co-operatives saw the utility of reactive dyes technology in terms of market objectives of color fastness and matching, which they achieved using the new tools and infrastructure. Environmental friendliness was framed by them as a particular market standard; such as when producing for Dastkar Andhra, rather than a universal value in all their dyeing. Co-operatives exercised a clear choice to match dyeing practices to market demand and returns; this made for different dyeing objectives for different markets.

Eventually, reactive dyeing stabilized as one of the dyeing technologies in the handloom ensemble rather than totally replacing direct and azo dyes. Dastkar Andhra accepted that the technological frame of reactive dyes in handloom would not include effluent treatment, since the cooperatives and dyers did not take up environmental toxicity as a problem to be solved. In accepting and understanding this choice of the co-operative, Dastkar Andhra upheld its stated goal; to not impose but to facilitate sociotechnical change in the handloom ensemble.

Mechanization was strictly not included in the final frame, which featured in the technological frame of the large scale dye-house owners who were equally in the service of power looms. Reactive dyes enter the technological frame of handloom as skill, through framing standardization as a positive outcome of dyers' skill, rather than negative attribute of the market. The reactive dye color palette was deemed successful in the urban markets of the Dastkar Andhra Marketing Agency, giving returns to the dyers, while reducing drudgery. Value for dyer skill, reducing drudgery through labor-saving devices, and institutionalizing dyeing services to meet market standards achieves "freedom in color," it brought the technological frames of the social groups of the CSO, the co-operatives and the dyers together.

In order to understand obduracy in the technological frame of handloom, I refer to the social group of the dye-house owners. While all the other social groups adapt their technological frame and take up elements from each other, the entrepreneurial dye-house owner does not. Neither does the technological frame of handloom take up mechanization, though it values labor-saving devices that reduce drudgery. A fine distinction is made between mechanization to reduce "shrama" or labor, and mechanization that replaces "panitanam" or skill. Where it is understood by the actors that the repetitive nature of the manual work does not bring about skill, the actors embrace drudgery reducing mechanized tools. Where repetitive activity is needed to build skill and includes abstract thinking [alochana], they resist mechanization. The "unchanging" loom is the evidence of how this distinction operates. The obduracy of the handloom technological frame with regard to this distinction is the unchanging feature that allows for the adapted technological frame to continue being credible as the handloom technological frame, even as new technologies are added. Therefore, the social group of entrepreneurial dye-house owners summarily exited the handloom ensemble, even though their technology - that of reactive dyes - stabilized in it. This illustrates the unique dynamics of change in the sociotechnical ensemble of handloom; adaptation in the technological frame, that is, to include market standards, while maintaining continuity in the general frame regarding autonomy, value of skill, and reducing of drudgery. 


\subsection{CATAlyzing SOCIOTECHnical Change: Role of InTERACTIOnAl Experts}

In this story, the primary unit of analysis is the handloom ensemble whose social groups are bound by a technological frame. In order to look at sociotechnical change in such an ensemble, we need to pay attention to interactional experts; actors who do not themselves possess specialist knowledge in a particular domain, but acquire the language to interact with experts with specialist knowledge (Collins and Evans 2007, 35). Actors who catalyze sociotechnical changes in the handloom ensemble necessarily possess interactional expertise in both the handloom and the mechanized textile sector.

I use the concept of "inclusion" in technological frames to understand how actors with interactional expertise are able to catalyze sociotechnical change. Technological frames are not rigid structures that hold actors uniformly in place; actors can have different levels of inclusion in a frame. Inclusion describes actors' level of involvement with a frame and also explains actors' involvement in multiple frames. If an actor has high inclusion, it means that "she thinks, acts and interacts to a large extent in terms of that technological frame" (Bijker 1995, 143). Actors who are included in multiple technological frames will have "different degrees of inclusion in the associated technological frames" (Bijker 1995, 143).

Actors catalyze socio technical adaptation through introducing technology from one technological frame to the other, this requires that they have inclusion in both frames. Inclusion is not a function of location; I suggest that it has to do with having interactional expertise (Collins and Evans 2007) that allows them to interact with experts in both handloom as well as power loom and mechanized textile systems [see Fig.5.2].

In the case of reactive dyeing, the CSO actor from the technological frame of sustainable production had interactional expertise and

Reactive dye technology from powerloom to handloom

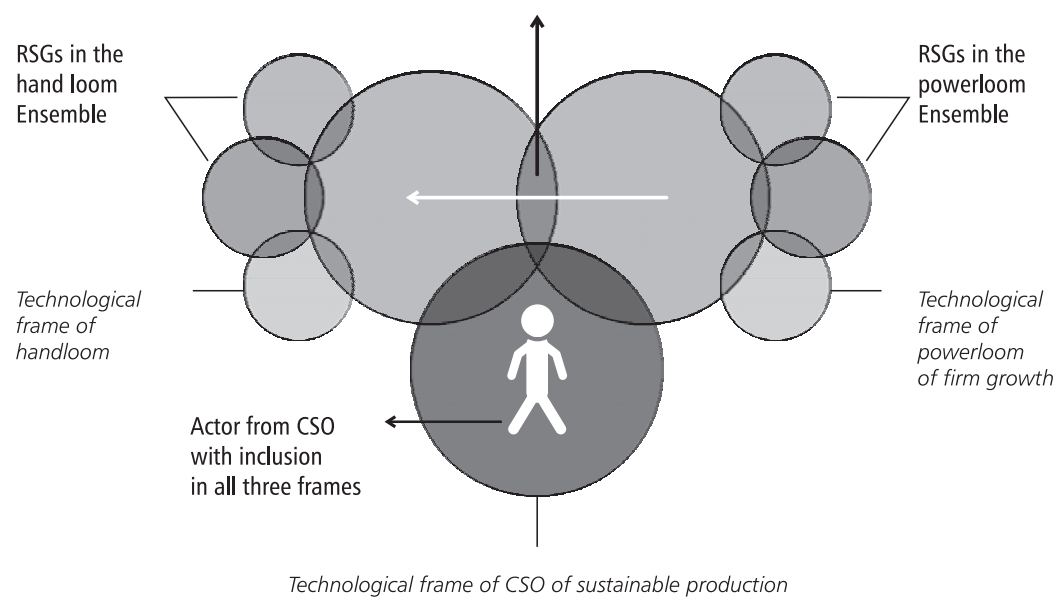

[Fig. 5.2 Inclusion of actor in the three frames of handloom, power loom and the CSO] 
inclusion in both the industrial as well as the handloom technological frames. As a result, she is able to stimulate interaction between experts in reactive dyes in the industrial frame and dyeing experts in the handloom frame, and succeeds in introducing reactive dyes to the handloom frame. If we understand inclusion in different technological frames as being gained through the acquisition of interactional expertise from socialization, it explains how an actor from a social group in one technological frame is simultaneously able to be included in multiple technological frames, regardless of the oppositional nature of those frames to each other, as in mechanized and manually operated technologies.

Interactional experts can stimulate interaction between contributory experts within the different technological frames. For example, interactional experts such as the co-operative manager D.V.V. Satyanarayana who speak both the language of market as well as dyeing technology translate standards of customer expectations to reactive dyers. Where interactional experts do not act, for example between sizers and customers, ${ }^{168}$ the translation between needs of customers who shifted from draping sarees to wearing apparel, and sizers who have to now produce fabric that cuts well, rather than drapes, [through sizing that allows for closer weave] does not happen. As a result, not only do the sizers not change their sizing practices, but the un-translated need of the consumer to the producer means that cutting and tailoring technologies are not adapted into the handloom ensemble. Interactional experts are needed to reflect on the articulated and unarticulated problems of the handloom ensemble, and translate between contributory experts and catalyze changes in sociotechnical practices in the handloom ensemble.
Inclusion of actors in multiple technological frames can be seen as an interactionist dynamic between different technological frames. Actions of individuals with inclusion in multiple technological frames shape trajectories of sociotechnical change in ensembles. Equally, actors who are included in multiple technological frames can find themselves "between two worlds" belonging fully to neither, and risking losing inclusion in both. This is relevant, since it is important to note that the boundaries between the two technological frames of mechanized production and handloom did not blur or soften. The calibration between actors in the two frames was purely "processual," collaboration without consensus. (Centellas, Smardon, and Fifield 2013, 329)

To summarize, using the concept of technological frame helps explicate the nature of sociotechnical change in the handloom ensemble. Reactive dye technology is adopted, not just as practice but also as theory, goal, and problem solving strategy. In the process, the technological frame of handloom undergoes some change. In the changed technological frame of handloom, the imperative of meeting market standards of color matching and colorfastness becomes an important point of closure, where before it had been contested. The original technological frame of handloom had the elements of autonomy in color, reduction in dyeing labor, and value for dyeing skill; the adapted frame combines them with market standardization. The technological frame has changed, but continues to be the technological frame of handloom. In this understanding, the cyclical movement becomes actor-artefactensemble-technological frame-relevant social groups - new social groups - new artefactextended ensemble - adapted technological frame.

168 Meeting, sizing November 26th, 2011 


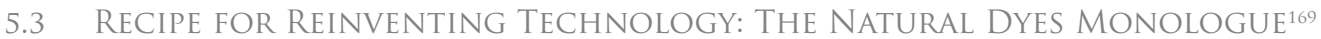

The second story in this chapter is of the reinvention of forgotten natural dyeing practices as a contemporary technology in the handloom ensemble. Unlike the adoption of reactive dyes, which is a modern technology, this effort could be read as an effort to conserve a traditional craft that is many centuries old. However, natural dyes are reinvented as a contemporary technology, through renewing the craft expertise of dyeing with natural materials using knowledge from archival records. The transfer of knowledge from archival records and texts of colonial times to contemporary handloom weaving practice requires the engagement of both modern and traditional technologists. The formal domains of reading, writing, and training are the expertise of some social groups; skilled and material practices of dyeing are the expertise of others. If in the past, the interaction between the colonial scholar and native dyer resulted in recording natural dyeing practices for the archive, the contemporary interaction is an effort in the opposite direction; in writing recipes that renew craftspeople's natural dyeing expertise.

I focus on sites of interaction where the various experts dialogue in order to produce the new technology. Engineers and weaver-dyers interact symmetrically, even democratically; deliberately laying aside the older hierarchies of technological practices; for example engineers hold back from automatically privileging global "universal" laws over "local" norms, weavers learn to verbalize and explicate their expertise. Color by color, natural dyeing is reinvented as a technology in the handloom ensemble. This renewed expertise is evidenced in a set of reconstructed natural dye recipes.

In the previous section, I described the adaptation of the technological frame of handloom in order to adopt new technology [reactive dyes] into the handloom ensemble. What is on the agenda here is developing a new technology through reinventing the old: while the natural dyed product is old, the technology of producing it is contemporary. Most narratives of encounters between traditional and modern knowledge result almost inevitably in the modern knowledge gaining the upper hand. This is not the case in the natural dye trajectory that I will describe in the following section. A clear understanding of how this alternative trajectory was shaped is a preliminary necessity to understanding the successful reinvention. Some of the key characteristics of this interaction are best identified in the progression of the natural dye color palette, formulated over a period of almost a decade, one recipe to the next, which I relate in the following sections. These recipes are ordered, as they would be in a training workshop for artisans. In the workshop, each following color is also an introduction to the next technique; the first recipe is the simplest and the last the most complex. Here, I use them as stages in story telling of reinvention of the technology, each stage building on the previous.

The first recipe of Naga red is an example of the kind of propositional knowledge available in archives about past natural dyeing practices. It is a recipe drawn from observing "native" practice of dyeing by colonial observers around the 1880s. This text forms almost 100 years later, the basis of efforts to reconstruct the recipes for contemporary craft practice by natural dyeing experts. One of these experts is KV Chandramouli, a chemist and the grand old man of natural dyes in India. What follows is the beginning of the story of the effort to revive natural dyes by the CSO Dastkar Andhra under his tutelage.

The second recipe is of the color brown, referred to as Katha. This is an early example of a recipe that is reconstructed by the Dastkar Andhra field workers who have expertise in the

169 As part of the team in Dastkar Andhra, a CSO working to revive the use of natural dyes in handloom, field workers were required to maintain regular field notes. These particular field notes were written by me from 1991 to 2000, and had formed the basis for annual reports for the organization. They are not scholarly, but useful to show how the field workers thought through the process of sociotechnical change. Chronologically in time, the work on natural dyes in Dastkar Andhra comes before the Indigo effort. 
use of propositional knowledge; they are literate. In the section that follows, this algorithmic style of standardization of a dyeing process is compared to an artisanal process. The engineer seeks to standardize recipes to standardize color, the craftsperson seeks to explain processes and their effect on color outcomes. Generally, since the first is considered more scientific, the craftsperson's knowledge of color is vulnerable and continues to be tacit.

From this recognition, we move to the third recipe "Danima" or Pomegranate. Clearly, this recipe now tries to combine both: the algorithmic standardized form of recipe as well as capturing the processes involved in dyeing. In the section that follows, I narrate the next stage in reviving natural dyes, which is its mobilization into new locations of practice. The recipe is in the form of propositional knowledge, text, and thus is mobile. Since it also incorporates the vocabulary of the dyers, it can be decoded in each new practice location. Therefore, it is possible to train new groups of dyers in the use of these recipes, resulting in the new technology of natural dyeing being mobilized.

The fourth recipe is that of Chevalikudi, red. By now the Dastkar Andhra workers as well as the craftspeople have acquired interactional expertise with regard to each other's practice. Color fastness is the challenge now. This requires tacit knowledge that is not available to the expert in propositional knowledge. It requires the craftsperson who understands underlying principles of dyeing to make an intuitive leap and decipher his own practices from the past, and reconstruct traditional color fastness practices.

The last recipe is the one for black, Kasimi. By now dyers could learn from each other, without mediation by the Dastkar Andhra workers or their propositional knowledge base. The traditional recipe of making black out of rusted iron filings spreads fairly quickly through the natural dyeing community. At the same time, a small book on natural dyeing is brought out by Dastkar Andhra, in collaboration with partners, in four vernacular languages. In a sense, this marks the end of the explorative phase of rediscovery of natural dyes, and natural dyeing becomes a viable technology in the handloom ensemble. All together, these form the "recipe" for reinventing a new technology in the handloom ensemble.

\subsubsection{Recipe 1: Naga Red Rubia Sikkimensis}

\section{Color: deep brownish red}

Process-(According to Dr. Watt) "The process of extracting the dye is curious. A woman came one morning to the Residency, Manipur, bringing with her $1^{\text {st }}$ two or three bundles of the root and stem of Rubia Sikkimensis, $2^{\text {nd }}$, a slab of bark of Q uercus fenestrate, Roxb; $3^{\text {rd }}$ a bundle of twigs and leaves of Symplocos racemosa, Roxb; $4^{\text {th }}$ a packet of seed and specimen of the plant yielding these seeds, which I identified as Leucos cephalotes, Sprend, a Labiate plant common in fields throughout India. [...] but I can find no mention of this fact in works on Indian Economic Borany; $5^{\text {th }}$, two skeins of cotton thread, one of which was of yellow colour and had been prepared before-hand by a process which I was to see applied to the second one-it had been steeped in some mordant or metallic salt; $6^{\text {th }}$ to earthen vessals and $7^{\text {th }}$, a small basket" $[\ldots]$ "I am told that it was necessary first to prepare the second cotton skein [which was yellow], in order to give it time to dry. [...] The liquid [to be used for mordanting] tasted bitter and no doubt contained some alkali salt which I have not as yet had time to identify chemically".

[Vol. VI, Part-1,1892] p.577, reproduced from "The Natural Dyes of India" by KV Chandramouli; from Note on varieties of Rubia: Dr. George Watt "Dictionary of Indian Economic Products," Six volumes, Calcutta, 1889-93 (Watt $1889,577)$ cited in (Mohanty, Chandramouli, and Naik 1987, 188) 
This is a documented discussion between the colonial scholars George Watt and Major Trotter on whether the Naga red, a deep reddish brown is produced using the proliferous dye bearing plant Rubia Cordifolia, or another more native herb Rubia Sikkimensis. Watt goes on to compare his own account with that of his friend Major Trotter, to confirm that indeed the source for the Naga red used by the hill tribes of Manipur to color their clothes, hair, decorations for spears, shields and bamboo, and cane work was Rubia Sikkimensis, rather than the Rubia Cordifolia. Clearly, the intention of Dr. Watt is the classification of dye materials as economic products, rather than the dye recipe itself.

It is such documentation that formed the basis of the reconstruction by the Dastkar Andhra team, of natural dye expertise that was no more in practice, with the help of KV Chandramouli, the author of the book this recipe is quoted in.

"The first experience we had of "Sir" K.V. Chandramouli was when we took him to Eluru in West Godavari district to teach natural dyeing to the woolen pile carpet weavers. We had heard his name, as the authority or natural dyeing, and I had recommended to the state's Handicrafts Corporation that it should retain him as a consultant. It was 1991, Chandramouli had just retired from government service, and we were a fledging group, an offshoot of the bigger Delhi based Dastkar, working with artisans in Andhra Pradesh. I was in my late forties, a retired housewife with a dream of peace and harmony in industry, and Annapurna was 22, an electronics engineer in revolt, a trained classical musician. Salim was a driver. I had done some reading on natural dyeing in the old British gazetteers, but the other two were completely new to it, to carpet weaving, and in fact to craft production."

So begins Uzramma's "Requiem for a master" 170 written immediately after KV

170 http://malkhaindia.blogspot.nl/2011/07/here-is-uzrammas-accountof-dastkar.html, Deccan Herald, May 51998
Chandramouli's death in 1998. Looking back, the time Sri KV Chandramouli spent with Dastkar Andhra was very small, but in the history of natural dyeing, it was a very important part. Natural dyeing was a traditional artisan practice that had almost disappeared due to a steady shift to chemical dyeing over the last 100 years. As a young chemist in the 50 s, Chandramouli had traveled with Kamaladevi, the renowned patron of crafts from before India's Independence and been encouraged by her to learn from artisans and translate their work into scientific documents. By the time we knew him in early 1990 , he was extensively traveled, drawn to the most obscure village by the scent of the natural dyes that he was fascinated by. This knowledge he hoarded in little notebooks filled with spidery writing, along with the old samples that he obsessively collected. Chandramouli was already in his sixties when he started work with Uzramma, the founder of the CSO Dastkar Andhra, and had spent a large part of his life discovering obscure pockets and practices of natural dyes.

The early part of his career had been spent in collecting information on dyeing practices, now that the artisans themselves had forgotten it. The later part was about disseminating it back into craft practice. When he drew pictures of living practices he had seen, and which no longer existed, there was nostalgia but strangely no mourning, he was too optimistic a personality to indulge in melancholy. One thing he had been infected by from the practices of artisans: he was extremely secretive with his knowledge. Nothing was won easily from him. He inspired love from the artisans and frustration in equal parts during his training. He was always leaving a critical ingredient out and constantly gauging how much he would share with a new group. Whether it was intentional or a natural tendency to tinker with the recipe was not clear. He suffered from a heart condition and Uzramma faced a certain amount of censure from his family, who felt that he should be straining himself less. At the end, six years later, his death still came as a shock to his little band of followers, and was a great loss 
to all who had grown to love him and expected him to outlive his condition, in the contrary and strong willed way that he had.

Up until the late 80 s and 90 s, Chandramouli was typical of the prominent personalities in cultural fields, crafts, and textiles. The post 90 s was a period of hectic change, the landscape dotted with men and women of enormous talent and capabilities who institutionalised efforts that later came to define the craft sector. They created opportunities for young designers and managers with skills of marketing, communication, and organization, to join the effort to support craft livelihoods. In Dastkar Andhra alone, through the 90s, there were a network of half a dozen young field workers at any point of time, working on issues as diverse as tribal art, cotton spinning, dyeing, pottery, bamboo work, music, reforestation, to name some. The following account is one example out of the many efforts of the loose network of urban educated young engineers, designers, and social workers, including myself who became associated with the organization from 1990 to 2000 .

The opening up of the market in the late eighties played a definitive role in changing the nature of engagement of craftspeople with the market. There was again a place in the market for handloom weavers' products that was out of the ordinary and a small but influential niche of discerning consumers who would pay the price for it. So it was that in the 1990s, Uzramma used this opportunity to start a program of bringing back natural dyeing expertise to the field, under the aegis of the CSO Dastkar Andhra. The program did not start as a marketing effort: the stated intent of the program was to reintroduce natural dyeing into the practice of handloom weavers, for local sale, and revive products that had died as far back as a 100 years ago. ${ }^{171}$ The normative underpinning of the natural dyes program was to increase the control of the weaver over the production process and make the village economy more sustainable. With dyeing in his control, the weaver could exercise choice over colors, and introducing natural dyes would increase not just the repertoire but also allow him decision making about design. It was only later, when the effort to market locally failed that natural dyeing became a way to differentiate the product from its competition in the market. The consequent increase in price would directly be given to the weaver, as wage, and sustain his livelihood in a fickle market. The CSO agenda grew to include formal engagement with the market, and came to be known as a livelihood support organization for craftspeople.

Since the weavers did not practice natural dyeing anymore, they would need to relearn it. Odellu, the weaver-dyer in Chinnur remembers how weaving and dyeing were organized in his childhood, in the district of Adilabad. The women in the village, who belonged to non weaving farming communities would spin, and the weavers would give them sarees in return. During such a transaction, the woman would tell the weaver what kind of saree she would like to have and in what colors. ${ }^{172}$ The conversation took place against the backdrop of a common vocabulary on textiles. It consisted both of the tangible elements such as texture, quality and color, as well as the intangible elements such as motifs and colors of particular ritual and aesthetic relevance. However, this relation did not anymore exist in the village in 1990. The weaver now only wove the saree that the master-weaver or co-operative ordered. His sphere of decision making and eventually his capability in color did not anymore extend beyond the basic color palette that was available in the colored yarn market.

Uzramma's recall and personal sense of loss of the craft of dyeing made the quest real for others who she inspired to take up the task. She insisted on tracing the nomenclature of the dye material across archival texts and geographies; for example, the dye al was al morinda, Chevalikudi in the Deccan, 
chaya veru in the South, and Alizarine in common usage. These materials were not the same; but they all were used in dyeing cotton deep red. Alizarine was a coal tar extract, one of the first versions of synthetic color that was taken up by some, notably the artisans in block printing, who then refused to move on to more contemporary chemical dyes. As a result, the practice of using Alizarine in those places is so old that Alizarine is referred to as a natural dye. The recipe above is one that attempts to clear just one such confusion in 1892 .

The quest for living practices of traditional technologies in color led the merry band of Uzramma's color field workers not just to the block printers and yarn dyers but also to the metal workers, bamboo artisans, carpet makers, temple cloth painters, lathe turned toy makers, and their dyeing technologies. The weavers themselves could only recall very faintly a time when dyeing practices and materials were "natural." In each case, the story was similar, most of the knowledge of the technology was lost, some of the practices existed, but there was sometimes not enough understanding of underlying principles of why certain practices, rather than others were followed. When old practices were abandoned, for instance in the case of the brass workers and their traditional furnaces, there was no clear understanding of why they did so, what remained was mostly in the practices of handling material.

A mediating step between the measures and description of archival material and on the ground practices of traditional dyers was the dyeing recipe. The measures were old standards in complex multiples of units that were not in common usage anymore. The initial approach of the urban educated team was to create a controlled space and control as many variables, and approximate the process as closely as possible from the text, in order to generate a standardized recipe. Their challenge was not just the conversion of quantities, or locating the dye material but also the material practices, for example, lighting a wood stove, keeping it working for long periods of time at an even temperature and washing the yarn in flowing river water. The older recipes had to be reworked using chemical substitutes for naturally occurring minerals used in dyeing in order to control quality, in the absence of the skill to deal with uncertain purities in naturally occurring materials. Quantities of chemical substitutes used needed careful titration so that the claim to be "natural" could still be made. The recipe for Katha that the group finally decided upon as being standard and could be carried to the weavers is given below.

\subsubsection{Recipe 2: Katha; Acasia Catechu}

\section{Color: Brown}

For one kg of yarn

$15 \%$ Katha by weight of yarn: 150 gm Katha

$1 \%$ coppersulphate or neeli thutham by weight of Katha: 1.5 gm cuso 4

Boil 20 litres of water, and add powdered Katha. Stir for 20 minutes, add copper sulphate and dissolve well. Once the color is boiled well for 20 minutes, immerse one kilo of pre-washed, moistened cotton yarn into the dyebath. Turn regularly, for 45 minutes for even dyeing. Squeeze excess water out.
Wash in cold water till all excess color runs out. Dry in shade.

While the literate group used this standardized recipe, the carpet weaver Mastan in Eluru, recorded the following recipe for training new dyers. The difference between the algorithmic language adopted by the engineer and heuristics of the craftsperson is demonstrated clearly.

"first, make sure you have enough washed yarn for a full day's dyeing. P owder the dye material, so that there are no lumps, because these will stick to the yarn, and cause spots that will show up only when the yarn is dry. The quality of the Katha tends 
to be inconsistent, so don't worry if you end up using too much, it is the colour that matters, not the recipe. of course, you can only match the colour to a sample if you are experienced enough to know how the colour you see on wet yarn will look, when dry, so keep your eyes peeled, and always look at the colour when wet and then again when dry. Once the colour is cooked, dip your yarn into the dyebath immediately; overcooking the colour makes it dull. $M$ easurements by volume are easier than by weight, so make a mental reminder to yourself on the sizes of the containers you use." 173

This description of the process reads as a string of solutions crafted together for problems encountered in practice, rather than a linear process in time. There is no separation of material and process. Unlike the first recipe, there is no linearity in the narrative, dyeing is repeated time and again till the color is right. This becomes clear when the weaver says "always look at the color when wet and then again when dry"; an implicit pointer to the problem solving nature of learning while doing. The dyer instead points to time cyclesfor example, one has to wait for wet yarn to dry to gauge evenness, on the other hand, once dry, it is too late to rectify the color, if you had not paid attention when wet. The structure that this kind of time imposes on the weaver's narrative is quite different from the structure of the recipe in the text.

Both recipes standardize the color for replication. The first uses language of percentages and unit weights and seemingly universal measures that communicate easily to other engineers. The weaver, on the other hand, seems not to deal with "facts" but reports on the process in a "natural" manner. However, on closer observation, he too records information that standardizes color. The difference in the two recipes is obtained from the nature of differences between the engineer and the craftsperson's knowledge, and the difference in the value that is being standardized.
Another underlying assumption that obfuscates this simple difference is the bias against embodied knowledge as being unscientific. Colonial authors wrote monographs that combined descriptions of industrial organization with those of caste characteristics, religious practices, and kinship relations - by emphasizing the way artisans used touch, taste, smell, and intuition to guide their practices (McGowan 2009, 52). Talking of the Bhavsars, Chippas, Rangaris, and Khatris, the groups responsible for cotton dyeing, C.G.H. Fawcett in his "Monograph on Dyes and Dyeing in the Bombay Presidency" (Fawcett 1908) returns to two themes - the primitiveness of the tools and the embodied nature of the work. He refers to the inexact methods, the varying purity and strength of material from natural sources, variable weather conditions, combining quantities by eye rather than exact measurement. Therefore, according to him, dyeing was always uncertain and did not rely on scientific principles but was archaic and primitive in technologies (McGowan 2009, 53). If we ignore the negative value for uncertainty in dyeing process that Fawcett reads as unscientific, which yet results in certain and fast colors that masterdyers of India were known for, we see that in the hands of the craft dyer, dyeing becomes a transformative process, rather than a standardizing one. When we take the recipe to be a standardizing process, we could imagine that the recipe in principle constrained not just outputs, but inputs and processes to be standard, measuring as it does the inputs in percentages and purity values. Therefore, standardizing technology implied an assumption that inputs could not vary with natural causes, since a standard recipe would not be able to deal with such a variance. However in the craftsperson's hands, standardization is not a pre-requisite but on outcome ${ }^{174}$ of exerting knowledge of material and embodied skill to convert nonstandard inputs into standard outputs depending on the standard that is being sought.

174 Paraphrasing Soumhya Venkatesan who suggests that "skill is outcome, not pre-requisite" in (Venkatesan 2009a)

173 Personal notes from natural dyes workshop 92, annapurna 
Consider the urban engineer and her weaver colleague, working on standardizing weights and measures in the field. The weaver refers to a measure that he calls the "veesa," or "Vis," a measure of weight [1400 grams]. However, there is not one standard weighing stone that is produced, instead the veesa turns out to be many veesas, little metal pots of varying sizes that sit in line on a shelf; neyyi veesa [the veesa to measure clarified butter], the biyyam veesa [the veesa to measure rice], and so on. Each little pot when full would have measured by volume exactly one veesa by weight of the thing it is supposed to measure the clarified butter or rice. To the engineer, in comparison, the metric weights and measure system appear simpler and standardized; indeed in most cases outside of handloom, these have replaced the older system. Attempts made to conserve the older system are apt to be seen by the engineer as measures to preserve the pluralistic values embedded in the many little nonstandard pots, seen as a celebration of diversity. Any pushing back of the replacement of this system by weavers or any other social group is seen predominantly as a plea for conservation of culture, and way of life; thus, these groups are perceived as regressive in their attitude to technology.

However, stepping back from the visual of the quaint little pots with their association with culture, and examining their use, the weaver explains that the veesa chambu is always also accompanied by a weighing scale, with a veesa billa [iron weighing measure of one veesa]. This is typically how the weighing measure was used; usually the "ghee" clarified butter was measured out first in the little pot to the mutual satisfaction of the trader and the customer. If at any point, the customer suspected that it had been adulterated, he could challenge the trader to weigh it. When weighed using the weighing measure, if it was pure, the weight would equal one veesa, if not, depending on the specific density of whatever material had been used to dilute it, the weight would be a little more or less than veesa, indicating it had been adulterated. What was being measured using the veesa chambu was weight and volume, it is true, but the standardization function it performed was neither of weight nor volume. The veesa chambu standardized purity, since purity was the quality that the customer valued in the transaction. Following Bourdieu, Wilk suggests that when standards are taken for granted, people are operating on unspoken shared understanding and physical perception or habitus (Wilk 1999) or in this case, the concept of purity. Since the standard was ubiquitous, the user was unable to explain the breach caused by the change in standard, even while perceiving the breach of the value as a transgression. It was only in the interaction between the engineer and weaver in a new context of use that the value, and thus, the relevance of the standard is explicated.

\subsubsection{Recipe 3: Danima, Punica Granatum}

\section{Color: Yellow}

\section{For onekg of yarn}

$50 \%$ Danima weight of yarn: 500 gm Danima

$10 \%$ myrobalam solution or karakkai by weight of Yarn: $100 \mathrm{gm}$

$20 \%$ Alum by weight of Danima by weight of Yarn: $200 \mathrm{gm}$

Stage 1: Wash the yarn well

Stage 2: Pre-treat with

M yrobabalam for fastness

Stage 3: Mordant with Alum for color fixing

Stage 4: Dye in Danima dye solution

Stage 5: Wash and rinse well and dry in shade

The next step in reinventing natural dyeing as new technology was to mobilize the recipes to other locations and dyeing groups. Training was an ongoing task; the dyeing workshops conducted by Dastkar Andhra became the site for collective problem solving between the different people engaged in natural dyeing.

A workshop in natural dyes, if it was for beginners, as this one was, was a bit like a cooking show on TV. Most of the preparation had to be done prior to the workshop itself, and the process had to be broken up into bite sized stages for presentation, 
rather than entire colors. To elaborate, the color Danima needed pretreatment for fastness. Cotton, unlike animal fibers like silk and wool, needed to be washed well, and predipped in a mordant before dyeing. Otherwise, the color would not "fix" on the yarn. Katha alone already contained the mordant tannin, which fixed the color. Even so, if the color had to be deepened, it helped to dip dyed Katha yarn in other mordants. This meant that previously dyed dry Katha yarn had to be available to demonstrate this process, since the freshly dyed Katha yarn could not be immersed into another hot dyebath before it had been washed thoroughly. The above description is how the recipe for Danima looked, when taken up by itself. As we can see, the important change in this recipe, in comparison to earlier Katha recipe is that this recipe communicates the importance of the different stages of dyeing and their relation to fastness and brightness. Dyers needed to learn underlying principles of each process so that they could combine different materials in order to increase the palette.

There were at least five important stages in dyeing in general [Table 5.1], and sessions were divided according to the stages. The stages were washing the yarn, pretreatment, mordanting, dyeing, post mordanting, and finally washing and drying. These stages were reiterated during the workshop, so that dyers understood underlying principles, as well as learnt the recipes for particular color outcomes.

\begin{tabular}{|c|c|c|c|c|}
\hline & Morning & & Afternoon & \\
\hline Day & Stressing importance of Pre-treatment & Mordanting & Coloring & Post-mordanting \\
\hline 1 & Scouring/washing & & Katha & $\begin{array}{c}\text { Coppersulphate,Potassium } \\
\text { dichromate ferrous sulphate }\end{array}$ \\
\hline 2 & Myrobalam & $\begin{array}{c}\text { Alum } \\
\text { mordanting }\end{array}$ & Ratanjot & Ferrous sulphate \\
\hline 3 & & $\begin{array}{c}\text { Alum } \\
\text { mordanting }\end{array}$ & Chevalikudi & \\
\hline 4 & & Black vat & Indigo vat & \\
\hline 5 & & Test dyeing & & \\
\hline 6 & & &
\end{tabular}

Table5.1 Schedule of natural dyeing workshop ${ }^{175}$

The other reason that I compare this process to a TV show is that it had to cater to a diverse audience of dyers. Some had never seen vegetable dyeing before, but were curious; some were skeptical, so a running commentary to keep them engaged was important. Jagada Rajappa, the natural dyes resource person [who we will meet later in the next story] and Uzramma were "eminent personalities" who stimulated engagement. Having a sufficient number of young

175 Natural Dyes notes 92, Annapurna Mamidipudi [personal] dyers increased credibility of the technology. There were experienced dyer entrepreneurs, who would tend to wander off if the training was too basic, or look impatient, and for those we needed the grand old man of dyeing, Chandramouli, who could in a man-to-man manner add a remark or two as things progressed. In addition, these beginner workshops played a strong role of promotion for natural dyeing itself; to people from government offices, young designers who were looking for new technologies to differentiate their product, or even passersby who came out of curiosity into the dyeing workshop. The 
learning atmosphere was spiced with the familiar strangeness provided by the earthy smells and colors of rural craft in an unexpected urban setting.

The physical infrastructure of these makeshift dye-houses was variable based on what was available. The dirt floor had to be plastered with mud, the stoves were made on-site by women, migrant labor who were from rural areas hired by a local contractor to set up the dyeing site. The confidence with which they stacked the bricks to a precise height that would make the heat most effective, based on the size of the large vessel that would be placed on it, the plastering with cowdung and mud till a reasonable crust had formed, these could only come from the experience of daily practice.

The preparatory work included the laying out of mud stoves in a particular order. At the far end would be a line of four for hot water, and two down each side, with enough space around each to allow for the group to watch. The stoves were decorated with traditional patterns in chalk, drawn painstakingly the previous day, as part of the ritual making of a place of work. There was colored yarn hung everywhere, inviting touch and feel, a sensory riot that could not but appeal to the jaded urban soul.

Chandramouli had a heart condition, he was advised not to lift heavy things or strain himself; but like a little boy having fun, he would dart around, checking this dye-bath here, dipping his fingers into another there. Since the floor of the workspace was basically mud, it had to be prepared by picking out the larger stones beforehand. Typically, a thick red cotton dhurrie rug would be placed over it, covering a multitude of uneven surfaces. The tassles on the rug ends added further danger, and Salim, Uzramma's driver, who would go on to become a master Indigo dyer would chase after the old man, to prevent him from falling. "I'm ok, I'm ok, don't worry' he would say, after tripping over the same spot for the fourth time. On one such trip, Salim noticed him adding something to the dyebath rather furtively, and came back anxiously to report to Uzramma. "The artisans think the old man is not revealing his secrets, and I now begin to think so too...he is adding things without telling us". When quizzed about it, he chuckled merrily and said "I should have guessed Salim would see, I'm not adding anything new, just adjusting some quantities, because though I give you a standard recipe, sometimes the dyebath needs more than I initially thought." It became apparent to the artisans and to Salim, there was no perfect recipe; so there could be no perfect translation; the recipes would form "broad supervisory guidelines."

Uzramma's practices of reading archives and writing made text important both as the source of the recipe as well as the mode of documentation for the trial recipes that was being worked out. Salim, driver by profession who was illiterate, but with enough letters to use them as aide to memory, provided an important link in shaping the structure of the text. In his practice, the recipe became a sequence of actions; it was not limited to percentages, and weights, but focused on stages of dyeing, which would make for fast and deep colors.

Finally, the quantities dyed in these workshops were small, in order to demonstrate the process quickly; so issues in production quantities were not necessarily engaged in this demonstration. The next challenge to the natural dye agenda was colorfastness in production. As mentioned earlier, Indian dyes had been known for their fastness, particularly the Indigo blue and the madder red. Unlike in the case of reactive dyes, fastness was not perceived so much as a market standard by the actors, but as an important production attribute. As such, as we will see below, the natural dyeing group persisted in their attempts to achieve color fastness; though it was only after much trial and error that a recipe was approximated that yielded a deep red on dyeing, which was also color fast. 


\subsubsection{Recipe 4: CheVAlikudi, Rubia tinctoria}

\section{Color: Red}

\section{For onekg of yarn}

$50 \%$ Chevalikudi weight of yarn: $500 \mathrm{gm}$ Chevalikudi

$10 \%$ myrobalam solution or karakkai by weight of Yarn: $100 \mathrm{gm}$

$20 \%$ Alum by weight of Chevalikudi by weight of Yarn: $200 \mathrm{gm}$

For a warp length of ....meters, the yarn required for warp would be ... kg, and weft would be ... kg. F ifteen days before the current warp being woven is due to finish, yarn has to be washed, and mordanted in myrobalam solution. The yarn has to rest for at least ten days, in a dark cool place, before being dyed in Chavalikudi, on yarn pretreated with alum mordant, for good color.

In teaching natural dyes to beginners, Chandramouli had simplified the original recipes, extracted from routines of weavers many decades back. For instance, there was not anymore a daily visit to the river to wash clothes and yarn; the recipes had to be modified to work without flowing water. Similarly, to fix the color the pretreatment of yarn with myrobalam was substituted by the addition of cream of tartar into the dyebath. Weavers did not dye the yarn themselves. The actual dyeing was usually the domain of a small community of dyers, who performed that service for the entire village and were very much in demand. These dyers had become habituated to dyeing that did not require multiple stages; the mordanting was particularly labor intensive, it doubled the labor without giving credible results in terms of wage. So, it meant that skilled dyers who could handle and dye production quantities of yarn to the standard of the market had to be trained.

When weavers and dyers took back the newly learned processes to their place of practice, it became important to have consistent production values if they had to meet market standards. So began the quest for color fastness. Of course the test of the fastness of color is not at the time of dyeing but at the time of use. Information on color "bleeding" came back in the form of complaints from disgruntled customers, who insisted on having their money back, costing the organization money it could ill afford. Colorfastness was something that had been much touted, especially for the natural vat dyes of Indigo and for the red dyes of the Deccan. Finding out how craftspeople of the past had attained those standards became important, so that natural dyes could hold their own under the onslaught of machine washing and harsher detergents. However, at the same time, an over emphasis on "authentic" practices attributed to the weaver of the past -who had lived in perceptibly different conditions from the weaver of the present- would quickly become oppressive in current practice.

Indeed, since the weavers of Chinnur had started with the easy methods of dyeing, it became very difficult to convince them of the need to pretreat the yarn before dyeing. The weavers insisted that since yarn was being bought in Hyderabad and sent to Chinnur, an overnight away by bus; Salim should wash and pretreat the yarn in the Hyderabad dye-house, before sending it to Chinnur. The weavers would do the color dyeing as they were accustomed to, but not more.

As a result of Salim's treatment of the yarn in myrobalam before the dyeing, the colors were immediately more fast, and quite unexpectedly, much brighter. Odellu, the weaver in Chinnur who lead the group, conceded that it was important to pre-treat the yarn in Myrobalam and they started the process themselves. However, very soon there were complaints from the customers, the colors were much less bright and were not fast. Salim could not explain it; the process was the same, the dyematerials was the same; meanwhile accusations were thrown at Salim by the Chinnur weavers that he was refusing to share a secret ingredient, while he was at his wits end trying to explain what was wrong.

He wondered if the water was different and affected the color which was potentially a disaster, 
because it could not be sorted out easily. A new well was dug near the weavers' colony and the water tested; without improving matters. Till one day suddenly not just the Chevalikudi red, but also the Katha, which did not need mordanting suddenly turned deep and fast. Amid much excitement, Odellu explained how this had happened: "I wondered what it was that a bus ride from Hyderabad to Chinnur could do for the yarn, which I could not! And I realized that the yarn needed to rest, to let the Myrobalam do its work on it. And when I realized that I let it sit for fifteen days, and look what happened." He continued "Katha doesn't need the pre-treatment with Myrobalam, so we decided to let it rest after dyeing. If we left it just like that to dry, then it became patchy, due to uneven drying. So, in order that it dried evenly, we moistened it, wrapped it in a sack cloth, and left it in the dark overnight, and this is what we got the next morning!' Since Katha had tannin, the material in Myrobalam that fixed color on cotton yarn, it benefitted from curing post dyeing; unlike Chevalikudi which needed to be mordant with tannin from Myrobalam prior to the dyeing.

Like Salim, Odellu understood dyeing in practical terms, of active physical engagement, but in addition, he also understood periods of rest; what the archival records called "curing." Interestingly, the processes of waiting and curing, strikingly new in the beginning to the recipe writers, quickly entered the practice of all of the dyers and weavers in the network. Conversely, it disappeared again from the explicit recipe of the dyeing. Since perforce all mordanted yarn was cured for 15 days before dyeing, it was not anymore considered necessary to mention curing times, in the documentation, and became part of the "natural" cycle of dyeing practice.

By this time, Dastkar Andhra had trained more than a hundred groups in the use of the recipes. Enough had been learnt about the processes of natural dyeing and their functions to extend it to other locally available materials; Ratanjot for grey, onion peel for pink, marigold flowers for yellow, and so on, though these were used only in small quantities, since the color fluctuated with the quality of dye material. Production of natural dye product was not anymore limited to the workshops, but was carried out by groups as part of their routine dyeing. This meant that dyeing was continuous with weaving rather than an interruption.

It now became feasible to introduce the black vat, a continuous fermentation vat, directly to palette of natural dyes. Unlike the other color, black which is the subject of the next recipe in this list was obtained from reducing scrap iron to iron acetate. This process that had to be watched over, and took 10 to 15 days, and could only be taken up by mature dyers in their establishments. Once the recipe was perfected, it traveled easily, because of the availability of ingredients, scrap iron and jaggery [unrefined brown sugar]. In addition to fastness, the cheapness of ingredients in comparison to chemical dyes made it a desirable addition to the color palette of even mainstream dyers who did not use other natural colors.

\subsubsection{ReCipe 5: Kasimi, Continuous Fermentation Vat}

\section{Color: Black}

Recipe for color concentrate solution, to be diluted with water for use with yarn as required.

$3 \mathrm{~kg}$ of sugarcane, $1.1 / 2 \mathrm{~kg}$ of palm jiggery and $3 \mathrm{~kg}$ of rusted iron scrap bits are taken in an earthen pot. About 90 litres of water is added, pot is covered and left for one week. The resulting black solution is used for dyeing yarn that has been pretreated in myrobalam.
In 1997 Dastkar Andhra additionally invested in a strong livelihood support program with four new handloom co-operatives, in diverse locations in Andhra: Nalgonda, Chirala, Guntur, and East Godavari. In these new places, the variables that could not be controlled as in a laboratory setting affected natural dyes. The quality of the water and the dye material could vary tremendously, creating 
an uncertain atmosphere to the on-site training workshops. Specifically, if there were new skeptical weavers, controlling the process to produce color to their satisfaction took all of Jagada and Salim's ingenuity and talent. In effect every new location was an experiment in color palette and had to be standardized before entering production and market. Only the black dye vat seemed to stand the test of time and place. The recipe that we used was an old one from the practice of Guruppa Chetty, the seniormost practitioner of kalamkari, the art of natural dye temple cloth painting in Kalahasti. "One must have the experience to judge when the mixture is ready, as keeping the mixture in the pot for a longer time tends to reduce the intensity of the black colour and the tone becomes reddish" writes Chandramouli, in describing the black process of the Kalamkari printers (Mohanty, Chandramouli, and Naik 1987, 102). Experience was indeed available with the recent proliferation of natural dyers, who quickly tinkered with and assimilated the recipe into their palettes. The final recipe was integrated into many dye-houses effortlessly, it was cheap and effective.
The success of the black vat reduced worry about fastness of color, consistency and replicability of color, as well as cost compared to the existing chemical black. The black vat process was sufficiently familiar to weavers, because the materials usedrusted iron, brown sugar [jaggery] —were locally accessible to the weavers. This final recipe brought natural dyeing practices back into the home of the weaver, and thus closer to the loom. A smallish clay pot, from which the smell of the wood apple [velagapandu] emanated, became a fixture in natural dyeing establishments, be they households or cooperatives. Most important, it evidenced that natural dyeing was not anymore limited to the intermittent workshops conducted by outsiders, but had taken root in the daily practices of a mature dyeing community. The same year, for the first time, a small booklet in four South Indian languages was published, with the standardized recipes written in a format that we along with the artisans had developed, rather than in conventional documentation formats till then used for text. Keeping in mind that the manual of recipes was for artisans, the production values were kept low and affordable to artisans.

\subsection{STABILIZING SOCIOTECHNICAL CHANGE: VOCABULARIES, RECIPES, AND STANDARDS}

The starting point of this story is the recipe of Sir George Watt, a botanist and administrator in British India, in the 1880. The economic dictionaries within which this recipe along with many others was recorded were shaped by medical and biological taxonomies (Hoffenberg 2001) and intended to systematize native knowledge. Paradoxically, they became the only source of information regarding practices that had been lost in the interim century, for recovering natural dye knowledge. The use of these texts, as propositional knowledge - a set of formal rules and facts gained through reading and instruction-formed only part of the expertise of natural dyes. In order that this expertise was completely retrieved, these needed to be accompanied by a full immersion in the entire form of life, in the traditional dyeing practices of weavers and dyers. Experts with propositional knowledge and those with embodied skills worked together to jointly reinvent practice from archival texts. This resulted in the invention of a new vocabulary that could communicate across both kinds of expertise. This vocabulary was formalized through a set of recipes that could be written down, yet would communicate to rural practitioners. These recipes standardized production and mobilized it, so that it could travel to new locations. This resulted in the reinvention of traditional natural dye practices as new variant of dyeing technology; with its own protocols, knowledge and, eventually, market standards. 
Natural dye technology could not be completely stabilized in the handloom STE as a new variant of dyeing technology, until it successfully met the challenge of modern market standards of fastness. Particularly in the early stages, natural dye technology could not stand up to mechanized washing, and fastness standards. The natural dyeing groups found themselves having to address these questions internally, in order to provide a collective solution. Is there only one form of standardization possible? Is adhering to market standardization unequivocally good, or even inevitable? What costs does it come with for traditional technologies? One experience of standardization in traditional knowledge that bears comparison in answering these questions is the case of Ayurveda or traditional Indian herbal medicine. Political Scientist Madhulika Bannerjee points to the state's efforts to standardize and modernize processes and products in Ayurveda, which reduced its usefulness to a "mere supplier of new medicines, while dismissing its world view on the body, health and disease" (Banerjee 2002, 1136). Standardization was seen as a rational instrument of progress; progress that would provide industrial growth (Egyedi 1996). Referring to this process in Ayurveda as the "modernizing of a great tradition," Banerjee (Banerjee 2002, 1136) argues that this is the result of the overwhelming hegemonic forces of the dominant science technology and trade on the Ayurvedic medicine industry. These standards were experienced by the community of Ayurvedic practitioners as being oppressive, without taking into consideration the inherent quality of traditional medicines.

The natural dye groups did not take this route; here the actors exhibited a more symmetric interaction in negotiating between markets and practitioners, science and tradition. Unlike in the case of Ayurveda, the stated intention of all the actors was to establish natural dye technology in handloom practice, rather than universalize it as rational science, or standardize it for mass production. Before negotiating standards of color, engineer and artisan had combined two different vocabularies of knowledge; one that built algorithms based on facts and propositional knowledge and the other that built skill through enculturation (Collins 1987 (2012), 322). Interactional experts from artisan and engineering practice met to solve problems in order to standardize production. The actors made no knowledge claims; rather than as chemical equations that codified practice into science, the "formula" they produced was a little manual inscribed with recipes written in the vernacular languages using vocabulary that had been developed newly. At the same time, they resisted the temptation to cater to notions of the "authentic" and "natural way of life," which could have resulted in fossilizing the technology through romanticizing its past glory.

Uzramma had an amusing story that made the point in a chilling fashion; she said tribal people from her part of the country admired and loved the peer, the nomadic spiritual teachers so much that they would kill them and bury them in their land so that they could not leave. The story loses much in translation from the original language of the Deccan, Dakhni, but the message is clear. Museumizing natural dyes in order to preserve them would follow a similar logic. Instead, the reciprocal dialogues between the different experts give rise to stabilized recipes that natural dyers could use. The dialogue between artisan expertise and engineering expertise in problem solving paved the way to making a vocabulary for developing new knowledge, and natural dye practices were reinvented as sustainable technology for emerging markets.

The community of dyers encountered the market imperative to standardize color early in their efforts, and collectively reflected on the need for an internal consensus on production standards. Rather than proposing to meet "objective" market standards of color fastness, they offered customers specialized washing instructions, using nondetergent "natural" soaps that were less harsh on natural dyed fabric and demanded less stringent fastness parameters. With respect to standardization in color matching, on the other hand, they redefined the problem (Egyedi 2003): from consistency in color replication to consistency in color palette. In doing so, they focused on another attribute of color: harmony of palette. 
In order for natural dyes to then avoid being bracketed as being local knowledge (Porter 1995, 93), the network needed an agreed-upon common standard to produce comparability of activities over time and place (Timmermans and Berg 1997, 296). They achieved this by leveraging the use of a "standard" group of dye materials of natural origin. These dye materials yielded specialized colors; al red, danima yellow, karakai green, chevalikudi pink, and kasimi black; which came to be known as the standard natural dye palette. Internal consistency, as Uzramma explained in her 2002 paper titled "A future vision for natural dyes" 176 rather than color matching became the standard that the community of dyers and users reached consensus on. The practice of turning production constraints into market assets by negotiating with the customers became an extension of the symmetric negotiation practices between the different experts who reinvented the production technology. The consumers of natural dye products became part of the loosely connected community of natural dye producers, with overlapping values in production standards, rather than faceless customers demanding market standards of color fastness. Therefore, by getting user acceptance for new standards of evaluating quality in natural dyeing, actors stabilized natural dye technology in the handloom ensemble. The expertise of standardization turned natural dyeing into a new variant of dyeing technology in the handloom ensemble. Therefore, vocabularies, recipes, and standards become mechanisms for stabilization of sociotechnical change.

\subsection{A RITUAL IN COLOR: REDEEMING INDIGO}

Our final story, which is of Indigo, brings to focus an important aspect of handloom technology; the mobilization of knowledge in an ensemble that has diverse expertise and technologies acquired over time. In order that the lost art of Indigo dyeing be redeemed, the existence of all these different practices of mobilizing knowledge-face-to-face transmission of embodied skills, oral transmission, written transmission, as well as electronic transmissions of knowledge-is predicated, in a contemporaneous present. The destruction of an older system of transmission of knowledge is never completed, when a new one is adopted; knowledge lies distributed in different regimes of "memory practices"; or technologies of information transmission: from the past to the present (Bowker 2005, loc 60). Each regime produces knowledge about Indigo: the science of Indigo, the recipe of Indigo, and the tales of Indigo. At the same time, knowledge is embedded as bodily skill, as the dyer's expertise and in the materiality of his technological artefacts; the earthen pot, the insulating goat dung, and the saline earth.

176 A future vision for natural dyeing in India - ced.org.in last retrieved 6 July
What follows is the story of Indigo narrated through the cast of characters who between them can claim to know Indigo today. Each is a master of one aspect of Indigo that is vital to its existence. Between them, they securely hold the recipe, the science, and the craft of Indigo.

\section{In order of appeerance}

Yellappa

Vannappa

Padmini Balram

Guruppa Chetty

Uzramma

Salim
82 year old traditional Indigo dyer from Uruvakonda village

Yellappa's 30 year old son, training in Indigo dyeing

Designer from NID in Ahmedabad, who documented Yellappa's Indigo dyeing practices in the mid 90s

Kalamkari artist from Kalahasti

Founder of Dastkar Andhra, Dastkar Andhra Marketing Agency, Person behind natural dyes revival in South India

Car driver, Natural dyes trainer, Indigo dyer 
Jagada Rajappa

Odellu

Tadipatri Ramamurthy

Latha tummuru

Durgalaxmi Venkataswamy Textile technologist

Shaktivel Vilvapathy

\section{Glossary}

Caustic soda

Hydrose/Hydrosulphite

Chandrakali

Gorre Penda

German Indigo

Indigo (organic/natural)

Indoxyl

Kundalu

Lungi

Leucoindigo

M enthi

Saudu matti

Sunnam
Designer, Dyer, Faculty at NID

Designer, Owner of label

Ashwini, Pupil of KV

Chandramouli, Natural dyes

resource person, Dastkar

Andhra Natural dyes

training program

Chemist, Natural dyes expert, Author of "Natural dyeing Processes of India"

Cotton handloom weaver, natural dyer, Indigo dyer

Activist

Designer, Marketing

Sodium hydroxide, also known as Lye

Sodium Hydrosulphite

Literally flower of the moon, a type of saree

Sheep dung

Industrial Indigo Dye synthesized first in Germany

Dye extract of Plant Indigofera Tinctoria

Indoxyl radical is precursor to Leucoindigo in the fermentation vat

Clay pots

Men's wear

Reduced Indigo soluble in water

Fenugreek seeds

Alkaline River mud

Lime
Tagirasa

Vat

Yarn

Cassia Tora seeds

Three feet tall, clay pottery pot with eight-inch mouth

Cotton thread hanks

"Colour walks. And as itwalks, so itchanges. It is not something daubed onto a preexisting shape, filling a form, because colours have their own form, giving life and light to the world. Is colour an animal?"

'The Colour of the Sacred' (Taussig 2006)

Never does the question about the nature of color come so alive, as when asked of Indigo. Kattubadi Yellappa, a natural Indigo dyer for most of his working life describes the Indigo color as "a delicate girl child: treat her harshly, and she withdraws and swoons." ${ }^{177}$ Yellappa is an 82-year-old dyer who lives and practices his craft in a village deep in the interior of the erstwhile Andhra Pradesh state. He is the last one left in South India from the times when Indigo thrived, and is acknowledged to be the sole surviving keeper of the knowledge of traditional Indigo vat dyeing. His morning begins with the care of the Indigo dyeing pots buried in the mud three feet deep, up to their eight inch wide circular mouths. He sweeps the floor, cleans the rim of the pots thoroughly with an old rag, lifts down two small clay bowls filled with turmeric and vermilion, which he applies on the rim with a pinched thumb. If there are flowers in the garden, he will place them in front of each pot. Ritual offering? Or beautifying? It is difficult to tell. Belying his eight decades, he will work a long day, going through the many stages of dyeing cotton yarn Indigo blue. Indigo is indeed not something to be "daubed onto an existing shape" but a living breathing child whose every need and demand he is attuned to, through the days of his life.

177 Interview, Yellappa, 9th August 2013 


\subsubsection{INDIGO PAST}

Vannappa, Yellappa's son recalls from his childhood that his father tended 200 "kundalu" [earthen pots] in the village of Uruvakonda, walking from the home of one weaver to the next; checking the surface bloom by sight, adding lime-water where necessary by smell, diagnosing its "health" or "fatigue" through feeling its warmth with his hand, before moving on to the next. Just tempering the vats would take all afternoon. Color was not measured in time or in labor. "One bundle of yarn could take eight days to dye, dipping again and again, everyday, in a different pot each day." 178 Once the pot was in "flower," which took 15 days from first starting it and gave up its color, there was no need to skimp. "You could make it as dark as you wanted, "full dark," Vannappa says of those times of abundance. Equally vivid is the less palatable memory of the time in the 70s, when sealing up his Indigo vats, Yellappa worked as paid labor in the very same chemical dye units that had stolen his livelihood. As the weavers of Ananthapur shifted to chemical dyeing and silk saree markets, and the last of his clients took up "resham rangulu" [silk colors] there seemed then little reason to think Indigo would be redeemed. "First Ahmedabad, then Bombay, then Kalahasti and then Hyderabad ${ }^{179}$ " he tracks the journey that brought Indigo back to life; peoples the events with names, Padmini Balram, the designer from Ahmedabad who took him to NID, Guruppa Chetty, the Kalamkari artisan from Kalahasti, whom he met in Bombay; Uzramma, instrumental in bringing the vats in his house back to life.

Salim, his rough and tumble car driver apprentice, willy-nilly took up Indigo dyeing in the later nineties as part of his duties of driving Uzramma. He learnt natural dyeing from the masters: KV Chandramouli, the grand old man of natural dyes and Jagada Rajappa, his ardent pupil, herself a dyer and designer. Indigo was a lesson that took Salim 10 years to learn, even with regular support and trouble shooting from Yellappa. Salim was a small town boy from Warangal, transplanted

178 Interview Vannappa August 9th, 2013

179 Interview Yellappa August 9th, 2013 to the bustling metropolis of Hyderabad in search of a living; rather like the Indigo pots themselves from the far off village of Uruvakonda to the dye-house in the "Rural Technology Park" in the outskirts of Hyderabad. Indigo did not come easy to the city. "Can't ever tell, how it will behave, will the colour come, will it dye the yarn, will it stay on, will it fade, nothing is certain... ${ }^{180 "}$ ' However, 10 years of living with Indigo have left their mark, not least on his hands, blue to the elbow. Now a master dyer himself of Indigo, he admits, "You can't force the vat to give up its colour, it has to be coaxed." He buries his nose deep in the Indigo yarn and draws the color deep to fill his smoker's lungs to estimate how intense and fast the color will be on drying. "It has to smell like a fresh flower, not sharp, and not putrid,"

How to perceive the unperceivable? How to grasp color, which "working through layers of color and light, achieves its revelatory power through indirection and never by means of conscious confrontation because the real treasure is inaccessible to the intellect"? So anthropologist Taussig (Taussig 2006, 51) quotes Proust's narrator in "Time regained" (Proust 2000, 299) in his provocative essay titled "What colour is the sacred?" For Yellappa and Salim and many others of their ilk who continue to work in Indigo, the route to perceive and grasp Indigo is through their everyday practices. Yellappa carries an orange in his cloth bag, which he offers with affection to visitors to the Indigo vat: "Sit down for a minute, ammaayi" [daughter]. ${ }^{182}$ Salim cajoles his 20 -yearold scooter to drive the extra mile to drop guests of the dye-house to the bus stop. "Time for a change," he says, because "the vehicle regulation authorities can't, anymore, allow such an old machine on the roads." 183 Yellappa equally nurtures daughter and Indigo vat; old scooter and vat get the same handson maintenance from Salim.

\footnotetext{
180 Interview Salim September 11th, 2013

181 Interview Salim September 11th, 2013

182 Personal conversation, Yellappa November 28th, during the UNESCO International Natural dyes symposium 2007

183 Interview Salim September 11th
} 


\subsubsection{INDIGO PRESENT}

An initial apprentice of Yellappa, even before Salim, was Odellu, a cotton weaver from Chinnur, in Adilabad. He had worked actively to learn natural dyes; all except the elusive Indigo and used them in his handloom weaving practice. A weaver already for more than 10 years when he first learnt natural dyes along with Salim, Odellu best anticipated the combination of experiment and penance that learning Indigo dyeing would become for him. First, the teacher would have to bestow his blessing, months of hard practice would be mandatory, only then Indigo could be won. After Uzramma had inveigled a skeptical yet not unwilling Yellappa into teaching the secrets of Indigo dyeing to the weavers of Chinnur, Odellu and the other members of the Chinnur weaver sangam [Society] hosted Yellappa in Chinnur for over three months. It was the summer of 1997. His every whim was satisfied and every complaint "the food is not good, the bed is not soft"184 was borne. A home was built for the Indigo vats, to satisfy Yellappa that Odellu was a worthy student. Odellu's wife took up the assistant's role, grinding Indigo paste, carrying water, checking on the vats every morning, along with her husband. Better than Salim, Odellu understood that Indigo was a privilege that would come with lifelong responsibility. It was a chance he grasped with both hands. Odellu had seen the withering away of a life-world where weavers had been self-sufficient and respected members of society. There is a moment etched in memory that he recounts, talking about 30 years ago, "I gave in to curiosity, and bought a [draped lower garment for men] lungi from the city market when the mill fabric first came out; next thing I knew, a customer visiting my house, pointed to it and asked where can I buy that? We weavers axed the limb of the tree that we were sitting on with our own hands." 185

184 Interview Odellu October 12th

185 Odellu in Natural dyes workshop DA ' 99 where the author was present
It was the chimera of the city textiles and new and shiny trinkets from the market that had seduced him and his customers away from what had seemed familiar and boring, the handloom cloth he wove. With Indigo, he was being offered a second chance; a chance to relive the choice he regretted bitterly, a chance to anchor a lifestyle that was quickly becoming meaningless through the adoption of city ways. "Weavers in villages were kings those days, we wove in conditions of physical and mental felicity, always stopping before we could feel fatigue." "186 The Indigo vats brought the old routines back into Odellu's life, discarded practices half remembered, now comfortably embraced, as he wrestled with the seeding and rooting of Indigo dyeing practices into his working and living world. He describes his routine for normal days; balance the new vats with limewater, dye the yarn in the ripe "flowering" vats, clean out the depleted vats. Six of the twelve vats would be in flower, three more would still be early in the cycle of fermentation, while three others would be waning, ready for cleaning out and restarting. The three vats to be restarted would be cleaned out thoroughly, the residue of the Cassia Tora seeds and Indigo slime from the bottom of the pot scraped out carefully without hurting the mud pot. Odellu would then prepare the Indigo paste, boil new Cassia Tora seeds, soak the lime water from natural lime [sunnam], filter the water from the alkaline river mud; for replenishing the vats. This would begin the new vats' 15 -day cycle of fermentation, flowering, dyeing, and dying. The 12 vats were a universe in themselves, each vat a moon on a waxing and waning journey. However, like the moon, they could not be hurried or slowed down. They chimed at their individual pace, ruthlessly held to an internal clock that could only be controlled by setting 11 other clocks next to it, thus ensuring that there would always be six that were at the right stage for dyeing.

186 Odellu in Natural dyes workshop DA'99 where the author was present 


\subsubsection{INDIGO LOST}

If Yellappa is the master of Indigo, the grand magician of natural dyes was Chandramouli "Sir." Kamaladevi Chattopadhyay, the doyenne and patron saint of crafts and craftspeople during the freedom movement had bidden the young Chandramouli to travel to the ends of the earth, if necessary, and collect the knowledge of natural dyes, so that they may not be lost. He spent the better part of his life upholding this precept. His knowledge of the practice and theory of natural dyes was "encyclopedic." A chemist by training, a lifetime spent among craftspeople whose knowledge was under threat meant that he extensively documented natural dye practices as a way of fighting skewed Intellectual Property Right laws and practices of developed country market players. After his retirement from government service, in the late $80 \mathrm{~s}$, he found himself able to give back to the artisans what he had learned from them in the first place, conducting training workshops for craftspeople, and organizations who worked for craftspeople. It was at one such workshop that he met Uzramma. He delighted in following where she led, teaching traditional temple painter kalamkari artists, social workers, car drivers, and carpet weavers with equal enthusiasm and verve. He imbued the craft of natural dyes with drama; with flourishes of avante garde performance, and crafty sleight of hands, with "voila" movements that demanded applause from the audience. Color, in "Sir's" hands was a command performance.

However, Chandramouli "Sir" recognized that if natural dyeing was to survive, dyeing knowledge needed to be accessible both to the

\subsubsection{INDIGO RELEARNED}

The lost Indigo had to be relearned before it could become part of Salim or Odellu's present. Chandramouli "Sir" was no more but his apprentice and follower, Jagada Rajappa, whom we met earlier in the natural dyes monologue, became an important conduit to Odellu and Salim learning Indigo from Yellappa. traditional practitioners, as well as to newcomers. With craftspeople, he was unendingly patient, travelling to their homes and painfully working out solutions to particular problems in dyeing from his general principles. With newcomers, he introduced natural dyeing gently, using simplified methods, simple calculations that combined natural material and chemical mordants, home grown measures, and percentage calculations, without creating conflict or confusion. He taught Salim and Jagada Indigo dyeing using hydro-sulphite to reduce the insoluble Indigo dye into water. The hydro-sulphite and Caustic acted on Indigo replicating the action of the fermentation vat. However, this reaction was much faster than in the fermentation vat because of the potency of the chemicals. In the natural fermentation vat, this reaction is slower. When yarn is dyed in the Indigo vat, it picks up the greenish yellow liquid, which contains dissolved Leucoindigo in it. Exposed to air, the yarn turns blue; not because it absorbs the color, but because once oxidized the soluble Indigo in the Indigo dyebath turns back to Indigo, coating the surface of the yarn with blue. As the water is squeezed out, the oxidized and now insoluble Indigo is fast locked onto the yarn. The slower this process of coating, the more layers are added, till the deep intense blue of Indigo is achieved on the yarn. That is why, he would caution the instant process is not to be mistaken for true Indigo, not to be compared to the true continuous fermentation vat. And though the process seemed lost to mankind, the quest must forever be to find that holy grail. Chandramouli Sir died in 1997, just as Uzramma's efforts at locating Yellappa were coming to fruit and she was able to persuade him to help set up new Indigo vats in Chinnur.

Jagada's house in the suburbs of Hyderabad is filled with examples of natural dyes on paper, canvas, fabric, and even wood. Sarees, paintings, baskets, and toys - these are the works of master craftsmen encountered in her journey to master the art of dyeing. Jagada experimented with natural 
dyes before they became fashionable, starting from the early $80 \mathrm{~s}$, fascinated by the sophisticated colors that came from nature. When Jagada dips her hand into the Indigo color, it is not a fastidious dipping of fingers but a whole hearted immersion in the perfect warmth of the vat, which is exactly the temperature of the human body, not colder to touch nor warmer; in perfect balance of fermentation. However, when she draws her hand out of the vat, she has had its measure. What is in the vat, what went into the vat, what did not, she engages herself with it all. She even pokes about in the pile of "gorre penda" with curiosity, to see why goat dung is a better insulator of the vats than cow dung. When she grinds Indigo, the paste is smoother; when she washes the yarn, it is whiter. When she says the color is fast, it always is, and if the color is deep enough, she has already said it was. If it is not, then she will persevere till she knows why, preceded by a judicious "kaise karthe hain dekthe hain" 187 [How to do, we'll figure out] Jagada had worked with Salim and Odellu in earlier efforts of systematizing practices of natural dyeing, in Chinnur, and in setting up a dye-house in Hyderabad. She was the key resource for any training program in natural dyes, her willingness to share her knowledge, and fearless experimentation using local dye material was well known.

When Yellappa's existence was discovered, the traditional dyeing process that had been thought lost for all time was suddenly within Jagada's reach to be learnt. The dissatisfactory instant vatting recipe using chemicals like Hydro sulphite and Caustic Soda could now be dropped without ceremony; Indigo could be fermented using the Tagirasa seeds. Jagada's interest in the vat was unrelenting. Could the process be better controlled using methi [fenugreek] seeds? Or would the Indigo break down too quickly to Indigo dye, without allowing absorption by the yarn? What would happen in summer? In the winter? Overdyed with red? Or first dipped in yellow? There were not just a hundred and one shades of Indigo, from light to dark, but also Indigo purple, Indigo green, Indigo black, even Indigo lavender. There were always new shades of Indigo to be tried and perfected. Jagada was a self-taught dyer, her skills honed by assisting KV Chandramouli in his training workshops for artisans across India in the 1980s and 1990s. Jagada was the ideal sorcerer's apprentice, deciphering the magic spells of Indigo.

Jagada continues to be an inveterate traveler, following in the footsteps of KV Chandramouli, actively participating in the subterranean network of Indigo dyers, specialty craftspeople, treasures whose existence is carefully guarded and shared by connoisseurs only with other true lovers of Indigo. As a result, the sarees she designs and sells are rare masterpieces and experimental art at the same time. In the end, even the experiments that go awry end up in someone's wardrobe: to be worn and shown off with pride.

\subsubsection{INDIGO VISIONED}

Uzramma is the driving force behind the institutional revival of natural dyeing practices, particularly among handloom weavers in South India. When she first started working with artisans in the late $80 \mathrm{~s}$, she spent long hours in colonial archives, researching among other natural dyes. Her collection of books reflects the voracious range of her reading in literature, science, philosophy, biography, and arts. For Uzramma, history is not something that she reads about, but accounts of

real actions that have had real consequences for the present. This combination of fieldwork and archival research gives Uzramma authority as well as authenticity as a leader. Her vision for the future offers possibilities for directions not taken in the past. A question that she engages with is how intangible qualities that are to be sensed, and their perceivable realities that can be described objectively, come to be disconnected from each other in contemporary Indian society. The Indigo effort became a site for 
bringing together different ideas of color with its traditions and technologies of color making. In her vision for the future of natural dyeing in India, she makes a biting rejoinder about the neglect that artisan industries faced from contemporary society and the state: she writes,

"The blurring of economic engagement into its social context is a characteristic of human economic activity that is harmonious with nature,

\subsubsection{INDIGO TALES}

Till the chemical synthesis of Indigo, natural Indigo dyed products had been an important part of the export trade of India. "I t ought to be remembered that the whole of the merchandise which is exported from the Moghul kingdom, comes from four kinds of plants - that is to say, the shrub that produces the cotton from which a large quantity of cloth, coarse and fine, is made, the second is the plant which produces Indigo [....]" says Nicolas Manucci in the 17 th century. ${ }^{189}$ During colonial times, European planters exploited large tracts of leased farming land and poor farmers in Bengal and Bihar from the 1860 s on even as late as the First World War, to meet the demands of the textile markets in Europe. Indigo had been synthesized in Germany in 1880 , soon after the synthesis of Alizarin in 1869 , the red dye from coal tar, but the war kept British demand for natural Indigo up, till the British synthesized their own Indigo after the first world war (Travis et al. 1992). For Indian Indigo tenant farmers, the first blow fell when forced to produce Indigo for the British planters, on the tinkathia law. Tenant farmers were obliged to set aside 3 out of 20 katha of fertile land for growing Indigo for the British trade at a nominal rate (Mishra 1968).

Initially, British Planters did invest in scientific innovations in the cultivation and manufacture of Indigo. Indigo research Chemist

$188 \mathrm{http}: / /$ www.doccentre.net/index.php/role-of-universities/663-afuture-vision-for-natural-dyeing-in-india last retrieved July 62015

189 http://www.doccentre.net/index.php/role-of-universities/663-afuture-vision-for-natural-dyeing-in-indiaJuly 62015 [which fosters] a unique combination of intense specialization with large scale. This seamless melt of industry with daily life, this protective camouflage, while ensuring the sustainability of the activity, makes that activity as a whole invisible to the gaze of the colonial administrator, or the scientific observer, so that elements of the process can be isolated, atomized, studied and appropriated, while the activity itself is denied recognition or support"188

CA Davis argued forcefully that natural Indigo could compete with German synthetic Indigo. However, the planters had found a better substitute for Indigo in sugar and shifted to cultivating sugar as international prices of Indigo dropped. Britain synthesized her own Indigo and the tenant farmers were again forced to absorb the losses from the trade, when demand for natural Indigo fell (Kumar 2001). The peasants revolted against the planters' atrocities in 1860 (Bhattacharya 1977) and the dispute between Bengali peasants who produced and sold Indigo leaves and the European capitalists who manufactured Indigo dye from these leaves, came to be called the Indigo mutiny, demonstrating the friction between westernization, indigenous tradition, and commercialization (Roy 2011). In 1917, Champaran in Bihar became one of the earliest instances of civil disobedience by Gandhi (Gandhi 1948, 22) against the British, as thousands of Indigo farmers revolted against the double burden they had borne. Indigo became a symbol for the resistance against colonial hegemony.

Uzramma was a very young child when India gained her independence from British rule in 1947, but like many of her generation, she said that it was an "event that towered over my childhood and shaped my consciousness." Support for craft traditions was part of the Indian freedom movement, and women from three generations of the middle class have followed Kamaladevi Chattopadhyay's lead in working with Indian crafts. ${ }^{190}$ Uzramma's house is

190 Legacy of KV Chandramouli, Textile Newsletter PPST 
a shelter for travelers on all kinds of journeys. One can meet practically anyone there and one often did. One such guest was Tadipatri Ramamurthy. She took particular delight in watching him introduce himself to unsuspecting newcomers, "I'm an exconvict," his soft beaming face belying the truth of his words. Tadipatri Ramamurthy was an activist and social worker who had gotten on the wrong side of the local politicians and had been sent to jail on falsified evidence. Deeply grateful for friends like Uzramma, who supported the petitions that finally got him out on bail, he willingly went on a wild goose chase looking for the elusive "Indigo man."

Uzramma had heard of this Indigo dyer from Uruvakonda whose knowledge of Indigo dyeing had contributed to designer Padmini Balram's 1979 diploma thesis on Indigo in the National Institute of Design. She also knew of the famous Indigo

\subsubsection{STANDARDIZING INDIGO}

Durga is the most recent entrant to this cast, though not to our chapter, she is the protagonist from Dastkar Andhra in the reactive dye story. She is a textile technologist working on integrating robust dyeing practices into the indigenous textile producing areas of Andhra Pradesh. She saw explicit value in the color fastness of Indigo dyes, a sure win in the contemporary market place. Though generally natural dyes did not meet export standards; merchandisers would "regretfully turn down natural dye palettes, quoting color fastness issues," Indigo had the potential to bridge the gap. Fresh from successfully adapting reactive dyes to handloom production, a program that she worked on from 2006 to 2012, Durga found that Indigo presented a different challenge. How did one standardize a recipe that would make Indigo accessible to dyers in other weaving villages? The approaches of Salim, Odellu, and Yellappa seemed quite disparate, though they all used the same organic material. One scooped out the tagirasa mixture in the vat once the fermentation was complete; another swore that it had to be left
Chandrakali saree proverbially woven in that area, confirming the presence of Indigo dyers in the past. Yellappa's toothless chuckle is gleeful, when he describes how Ramamurthy went from house to house, finally finding him at work after two days of searching, to carry him off without any ceremony to Hyderabad to meet Uzramma. By the end of the trip, Yellappa found himself agreeing to travel to Chinnur and teach Odellu and the other Chinnur weavers Indigo dyeing. Soon after, Yellappa himself set up Indigo vats in his home, and took up dyeing for weavers across the weaver co-operatives of Andhra. Latha, a young designer working in Dastkar Andhra, the CSO founded by Uzramma, had first carried news of him to Uzramma from NID. Now she oversaw the marketing of these fabrics, and by 2003 the production-marketing loop for Indigo fabric was made robust.

in. One dipped the yarn in different vats; another dipped it in the same one over time. And indeed, how did one write up a formula for telling smell? Durga knew that this was not a new puzzle; looking for existing material on Indigo dyeing which could make her task simpler; she found in particular the work of Indigo scholar Jennifer Balfour-Paul useful. Balfour-Paul (Balfour-Paul 1998) describes fermentation vats in general. Fermentation vats are so called because they are based on bacterial fermentation. It is a live process, and cannot be hurried; microbes need time to do their work. The process involves converting the dye into a soluble reduced state; so there is a need for both fermenting and reducing agents, Cassio Tora [tagirasa] is one such. Alkalinity has to be provided, mainly in this case through alkaline river mud [soudu matti], this is essential to neutralize excess of lactic acid caused by fermentation.

The Indigo vat is a fermentation vat, Indigo dye needs to be fermented and reduced, as it is insoluble in water in its stable state. In the presence of Cassia Tora, Indigo undergoes fermentation. 
This solution is yellowish green in color. When cotton yarn is dipped into this yellowish green solution, it absorbs the reduced Indigo solution without needing to form a thorough chemical bond. The subtlest and deepest shades are built up as layers of color through repeated dips, which leave the core of the fiber undyed. Chemically speaking, the sheets of flat hydrogen bonded molecules are layered. The bonds are strong, hence Indigo is light fast, but the layers slide apart relatively easily hence the susceptibility to rubbing. Once dyed deep blue, Indigo is a color that lasts centuries; even when Indigo fabric gradually fades, with extensive washing, it retains a special quality, as a result of the layering of the dye. The vat itself is a pot made of clay pottery, since there was no source of direct heating; they needed to be deep enough and good insulators if dyeing was to be even.

Balfour Paul cautions that nourishing the dye vats with organic substances could be quite a challenge, as innumerable variables affect the process, not least the climate. The list is quite exhaustive, variability in color could be a result of "pretreatment of the yarn, concentration of the dye, temperature and $\mathrm{PH}$ value of the water in the vat, the speed of reduction and oxidation in the vat, length of immersion time, the number of times the yarn was immersed, efficacy of the replenishment of the chemicals in the vat, and the method by which yarn was circulated in the dyebath." BalfourPaul concludes "this underlying chemical principle never changes despite the wide variations in making of Indigo vats." 191 This underlying principle was the basis of the uniformity of color and fastness of Indigo, regardless of whether it came from Yellappa, Salim, or Odellu's vat, and inspite of the differences in processes between them. In learning to dye Indigo, each dyer had to know his vat well enough to stimulate the chemical process, rather than approximate or replicate the others' vat.

This indeed explained to Durga both the similarities and the differences in dyeing by Salim, Odellu, and Yellappa practicing Indigo dyeing

191 Field notes, Durgalakshmi Indigo project, November 24th, 2011 in Chinnur, Hyderabad, and Uruvakonda. There were echoes of these general principles in their individual practices. She pondered over what could make it easier for new dyers to learn Indigo dyeing, and incorporate it into their repertoire of colors. Dyers in many of the weaver co-operative dye-houses as well as privately run dye-houses were educated, and could follow recipes. However, the tacit knowledge around Indigo would be more of a challenge, particularly where life and work were woven together. "What is larger than life in that [Yellappa's] house is the vat, not personal living spaces. Living happens around the vat, and outside, under the tree and the lean-to...Indigo is the occupant."

When Durga asked them to increase production, almost 10 years after they first started dyeing Indigo, in 2012, both Odellu and Salim admitted that it was a step that Yellappa held back information on. What was it that was so elusivein the practice of Indigo dyeing that made key knowledge tacit? Durga's curiosity was aroused. Together the three of them visited Uravakonda. Salim and Odellu decided to sleep near the vats, in Yellappa's house, so as to not miss anything. Durga says, "I, at that point, didn't even dare to try to understand how it works." However, there was work to be done, to transcribe the dyeing practices of Yellappa, Salim, and Odellu into a method that could travel. She requested Pratibha Jain, an awarded Cookbook writer to take up the work of the recipe writing, along with Shaktivel Vilvapathy, a dyer and amateur chemist. The recipe would use Yellappa's vat as the source code. However, practices of Salim and Odellu would be documented too, in order to validate the logic of the recipe and its standardization.

"The sea is change, and the change is colour" continues Taussig (Taussig 2008, 1). He echoes this description from 1850 by a British eyewitness Grant about the extraction of Indigo dyes from the Indigo plant in colonial India- "When the beating commences, however, it generally presents a light green complexion. This through a variety of 
beautiful changes gradually darkens into a Prussian green, and from that, as the beating continues, and the colouring matter more perfectly develops itself (the froth having almost entirely subsided), into the intense deep blue of the ocean in stormy weather". ((Grant 1984, 128) cited in (Taussig 2006)) Thinking about Indigo in terms of chemical reactions and their properties, or in the way described above as by an "Englishman looking down at Bengali tribesmen" or as Yellappa who will not "start an Indigo vat if he has to watch it die" demands a familiarity with particular life worlds. Picture for instance Durga's

\subsubsection{THE CHEMISTRY OF INDIGO}

In contrast, one can also know that Indigo can be produced using 2-nitrobenzaldehyde with acetone in basic conditions, the reaction is known as the Baeyer-Drewson reaction. (For details of the chemical formulae, read (Travasso et al. 2003)) The industrial production of Indigo in Germany followed the synthesis of Indigo by Adolph von Baeyer (Meyer-Thurow 1982), in 1880, followed by the announcement of its chemical structure 3 years later. Britain synthesized and produced Indigo during the war years in order to meet the gap in supply from Germany; this profoundly affected British trade of Indian Indigo. By the end of the First World War, there was almost no natural Indigo being produced for export from India (Travis et al. 1992). Indigo production and dyeing survived in small islands of domestic use, where change had been gentler in coming, and allowed dyers like Yellappa to continue their profession till the mid-70s.

The chemistry of Indigo extends from the extraction of the color from the leaves into small cakes, the breaking down of Indigo in the Indigo vat

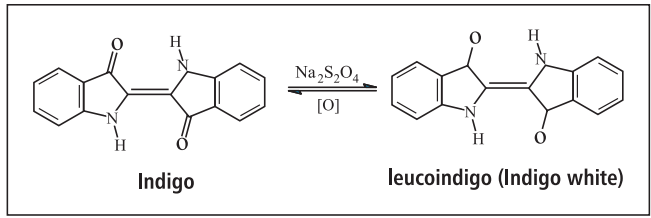

[Fig. 5.6 Chemical formula for the dyeing of Indigo] consternation on hearing that the delay in setting up new vats for recording the Indigo recipe in Uruvakonda was because "the weather was not suitable." Not suitable for collecting the sheep dung that would be packed as insulation around the three feet tall pots as they are installed into the ground. The right insulating warmth that facilitated fermentation was generated only from the dung of the sheep that had grazed on moist fresh grass from the first monsoon. "pachchi gaddi thinna gorre penda."192 The potency of that dung was such that they could perform their insulating function for up to 5 years.

into soluble leucoindigo (Travasso et al. 2003, 1) which is soluble in water, back to Indigo dye that is absorbed on to yarn through oxidation. Therefore, the chemical formula for the final dyeing process is described.

And yet Indigo dyeing is labor, to go back to Taussig; "Perhaps all labor has something of this quality, this eerie intimacy with things and with motions inseparable from the thing we call mind, only we take it for granted and don't notice it until we are hit with a broadside from the colonies. However, here it is work, hideous and extreme, yet something beautiful and worth writing home about, no doubt. It is the density and intimacy of the interaction with the inner life of the object world that astounds me, the harmonies and selftransforming movements of animating materials confined by the vat, exploding into obscene song and colour." (Taussig 2008, 8) Yellappa's labor seems ageless; he carries the knowledge of Indigo deep in it, and its burden. What would it mean, to retire such knowledge? What would it mean to carry it forward? For now, Yellappa announces his son Vannappa's education almost complete. "Nalugo taram" fourth generation Indigo dyer, he says, with some pride. Learning to tell color by smell takes time and experience. "not too much, not too little,

192 Interview Durga, citing Latha Tummuru on the phone with Yellappa 
the smell has to be "normal." 193 Of course, this calibration of the "normal" cannot be measured, it has to be cultivated through practice, of "at least two years." Smell is an exercise of bodily function, does it make Indigo labor? Writing a chemical formula for Indigo is an exercise in encoding it as science, does it make Indigo knowledge?

For Shakti, the Indigo vat is a labor of love. A weaver by birth, technical dyer by choice and designer by training, Shakti traverses the worlds of all three in the way he uses words. Objects selectively absorb and reflect light; the frequency of the light they reflect determines what color they are perceived to be. Indigo absorbs all visible light except the Indigo-blue shade, which it reflects; so is perceived to be Indigo-blue in color. He explains, “... the colour you see is what Indigo yarn cannot absorb, and reflects back at you; in fact Indigo is everything except that color that you see." As subsequent layers of Indigo are dyed in turn onto the yarn, this creates a complex pattern of reflection of Indigo-blues that makes Indigo dyed yarn special. According to him, the way to understand Indigo is to understand balance. Hydrogen and Oxygen are elements in air that are always in balance in 'normal' air. Balance is key, he asserts - "If the balance is off, then it effects change, for instance if Oxygen in air goes down then the human body will react by yawning, to expel hydrogen". When Indigo undergoes fermentation in the vat, hydrolysis occurs, water breaks up to Hydrogen and the hydroxyl ion. The free hydrogen is added to Indigo in the presence of the alkaline soudu matti, generating the Indoxyl Ion, which later becomes Indigo on oxidation in basic solution. (Russell and Kaupp 1969) “That's when the bubbles

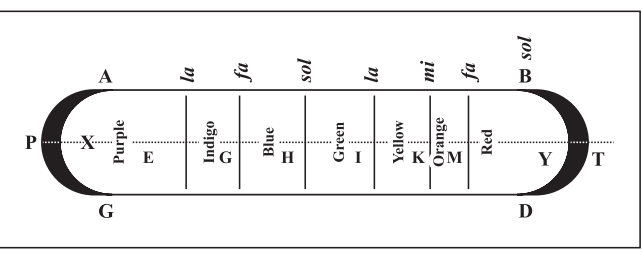

[Fig. 5.7 Newton's prismatic light] ${ }^{194}$

in the vat start popping out, the flowering...we know that Indigo is reduced Indoxyl. When we dip the yarn into the vat, the yarn picks it up, as it soaks in the solution." ${ }^{195}$ Once out of the pot, in the air, the reduced Indigo oxidizes back into insoluble Indigo, the water is squeezed out, but the Indigo is now locked into the yarn structure. "It doesn't react, only comes back to its natural balance."

In the mid-1660s, the young Isaac Newton shone a narrow beam of sunlight through a prism to produce a spectrum of colors (Westfall 1962). Around the same time the British East India Company started importing Indigo into Britain. Indigo was then ironically the latest contrivance from the east; it would go on to replace the native Woad as the dye material of choice (Clark et al. 1993). Newton acknowledged that the spectrum he produced using the prism had a continuum of colors. However, he placed seven prismatic colors on the color wheel of which Indigo was named as the color between purple and blue. It was 200 years later in 1880 that synthetic Indigo was discovered in Europe, and in another 100 years by the 1970s the use of natural Indigo had waned to its last few surviving practitioners. In 1998, Yellappa restarted his Indigo Vat. In 2014, I write this account of Indigo, as it is practiced today.
193 "Ekkuva vundaddu, thakkuva vundoddu, 'Normal' undaali." Vannappa Interview August 9th, 2013, he uses the English "normal"
194 Memoirs of the life, writings and discoveries of Sir Isaac Newton, Volume 1, (David 1855, 409)

195 Field notes Chinnur field trip October 12th, 2013 


\subsubsection{INDIGO REDEEMED}

As the early morning sun rises over the dry Ananthapur landscape, Yellappa walks to the back of his house to the vats. He carefully pulls down the yarn that Vannappa has hung out to dry in the shade of the roof the previous day. He looks at the color, before moistening it in readiness for the next dip. Inside the hut, it is cool, and riot with the smell of fermenting Indigo. Time seems to stand still, as he starts dipping and dyeing. In a little while, after its ninth immersion in Yellappa's Indigo dyebath, the cotton yarn will turn a particularly dense blue black, the color of the Chandrakali saree of yore. And in Taussig's (Taussig 2008) words, Indigo is redeemed.

\subsection{Mobilizing KNOWledge Through Time: Memory Practices in the HANDLOOM STE}

Two vocabularies are interwoven in the story of Indigo: the first is the Western one with its insistence on the standard chemical approach to creating an industrial dye, the other the Indian one with its persistence in linking with local plants, cultural repertoire, and vocabulary of smell, color, moon, and girl. Indigo when studied in the handloom ensemble does not lay claim to being universal science, so risks being classified as local and indigenous knowledge. Three decades of Science Technology Studies, and works such as the School Bus book (Bijker et al. 1987 (2012)), work of scholars such as Bruno Latour (Latour and Woolgar 1987) and Harry Collins (Collins 1974) have shown us that Science too is local; knowledge is always firmly tied to a locality. However, the two locals have a different quality; one of them can be recognized as socially performed and historically constructed and still be counted as universal knowledge; while the other cannot, without denying its very particular nature (Bowker 2005, loc 3209).

Titrating the amount of Cassiatora seeds and limewater required to ferment Indigo is expertise in material, measures, and chemical behavior that all Indigo dyers carry in their practice. Women customers, for example, use a vocabulary in color that they share with dyers, based on association, "blue for mourning" or as "chandrakali." In this case, it does not necessarily require knowledge of organic chemistry, since that is not the expertise that Indigo dyers or users employ to understand Indigo dyeing. Numbers and counting, as embedded in measures such as length, temperature, weight; standards such as recipes, fastness of color, reed pick; and materiality such as salinity, count of yarn, density of color abound in the sociotechnical ensemble of handloom. Weavers and dyers can tell numbers through touch and feel and smell; it is still in numbers that they count. Weavers refer to this as understanding of underlying principles [Parignaanam]. ${ }^{196}$

Indeed, as Pfaffenberger $(1992,512)$ points out, such communities have time-and-again built highly sophisticated sociotechnical systems which have been all but invisible through the eyes of western theory. Formal expertise in the use of these knowledge products is available with particular social groups in the ensemble; other social groups' expertise may be in the use of local material. Transfer of technology between forms of life that may seem to be incommensurable; for example, across knowing through chemistry and smell, can then be analyzed as a result of the relationship between the two distinct cultures or forms of life within which the knowledge is constituted (Ribeiro 2007, 15). This relationship manifests in the Indigo ensemble in the form of a remembered and shared vocabulary of color.

Yellappa can speak of the insulating qualities of the dung from the goat that has fed on fresh grass

196 Dyers meet, 26th November 2011, Hyderabad 
after the monsoon; yet his knowledge of Indigo is tacit; there are components that are yet to be made explicit, components that are embodied in his bodily skill, and components that are tacit because they are internal to the culture of knowledge that he is embedded in, such as using smell to tell color. Somatic or bodily skill is the basis of a significant part of knowledge in the handloom ensemble; tacit knowledge embedded in collective practices, many of which have travelled through generations of artisanal practice, continuously changing in response to changes in the environment. Transfer of tacit knowledge of Indigo requires transfer between contemporaneous artisans, as from Yellappa to Salim; from one generation to the next, from Yellappa to his son Vannappa, as well as transfer between dyers who understand dyeing through different ways of knowing it-Yellappa who is primarily a dyer with the craft of dyeing, and Shaktivel, a dyer trained in the science and chemistry of dyeing. Transfer of tacit knowledge across such a heterogeneous system predicates face-to-face interaction and enculturation.

In this heterogeneous knowledge system, which is full of tacit knowledge, when actual practice disappears, as in the case of Indigo dyeing, knowledge is mobilized across time as memoryembedded in this case in a shared vocabulary of color. Memory practices are usually specific to the different epochs of record keeping: "oral transmission, written transmission with tables or indices, simple file cards, mechanical writing and electronic sequencing" ((Le Goff 1992, 54) in (Bowker 2005, loc 443)). Generally, every act of migration across media and through time needs a contemporary constituency (Bowker 2005, loc 443). In the Indigo community, Indigo is not of a past epoch; it is present as memory, mobilized through time by the vocabulary of color of the social groups that form a close-knit constituency. Their vocabulary connects ideas of color and memories of associations with actual color samples, so that the forgotten bits can be reconstructed between the different actors.

Since Indigo dyeing is not yet in the present, it has to be redeemed from the past. Between them, the cast of characters who redeem Indigo hold multiple pasts: the past of mythology, the past of spirituality, the past of colonization and modernity, more recently the past of the museum, and the anthropological unchanging past of traditional cultures, all leading to the present moment. Indigo was temporarily lost in one epoch, because it was not classifiable as useful knowledge, and did not have scientific antecedents. It was redeemed when actors from the present, who formed a large enough constituency to engage in this particular act of migration, interrogated the dusty archives of an older but more memorable epoch.

As a result, the handloom ensemble can be seen to be unchanging even as it changes, through retaining its multiple memory practices: embodied craft, oral transmission using shared vocabularies, written archive to electronic database, to which I add collective memory. Not all experiences of sociotechnical change through time have been so salubrious, though. Often times, technologies from "traditional" systems are labeled as non-standard craft skills and best left in the past. At best, their existence is lauded as an example of the plurality of culture that traditional societies can put in museums, and are tolerated as vestigial symbols of a golden past when Indian knowledge reigned supreme. In such cases, there is a disruption in transmission, until, like Indigo, it is remembered and redeemed. 


\subsection{INTERMEZZO IN SCALE: COMPATIBILITY STANDARDS IN THE HETEROGENEOUS ENSEMBLE}

It follows from the above stories, then, that ostensibly traditional communities - such as those engaged in Indigo dyeing - exhibit a very sophisticated understanding of how their entire sociotechnical ensemble - and not just the weaving loom - works, and how it can be adapted to changing needs and times. This system building work focuses attention on sociotechnical wholes as the units of analysis, ${ }^{197}$ in which the individual entities such as dyeing technology and weaving technology are a part. In order to both build such wholes and achieve effective co-ordination between the heterogeneous knowledge, expertise and technologies that such wholes carry, standards become important. In the handloom ensemble, standards are at the same time required to patch together specialized technologies that work at different aggregation levels, acting as mechanisms that generate a continuum in scale.

In order to offer newcomers a glimpse into the nature of specialization that characterizes the handloom world, Uzramma would tell the story of the Kunche Erukula community in the Adilabad district. "The Kunche Erukula were a nomadic community, and the designated makers of the brush that weavers used to apply starch [sizing] on the warp to make it ready for weaving. The story goes that as the Kunche Erukula traveled from weaving village to weaving village, they would save their wage in the form of gold that they would bind into the brushes while repairing them, for safe keeping till they came back next to repair the brush. The art of making the brush was known to be so specialized, no weaver would dare take apart the binding of the brush and steal the gold, for fear of being unable to put it back, and ending up with no brush for starching their yarn."

The story transported the listener to a time when a sizing brush made of local fiber and twigs was worth more to the weaver than the gold that was hidden inside it, making a telling point about the value of the knowledge and technique of a

197 STS for Development, Chapter in the forthcoming Handbook for Science and Technology Studies, $4^{\text {th }}$ Edition brush maker. She also spoke of the respect that these different communities afforded to each other, and the importance of the taken-for-granted social interactions and relationships that kept the transactions robust. The story very effectively made the point of how finely specialized and varied the different technologies and social groups of handloom were, and of what scale: a whole community would make a livelihood out of specializing in making the brushes for the sizing.

Along with this great differentiation in specialization, as spinning, warping, sizing, weaving, reed making, brush making, and so on, handloom is also characterized by a wide variety of technologies within each specialist process. In the contemporary textile industry, the existence of these multiple textile genealogies-handloom, khadi, integrated mills, and power looms; and the porosity of their borders to each other add to cross-pollination in textile technologies. Newer technologies are continuously being added in parallel to the existing handloom ensemble. Over time, artefacts and functional variants of the different specialized technologies are acquired in parallel by the sociotechnical ensemble. In our dyeing example, these are natural dyeing technology, azo-based dyeing technology, and reactive dyeing technology.

Geography further adds to differentiation in material and techniques in dyeing; for example with the difference in water, certain villages come to be characterized by certain color palettes, which evolve into a distinct style of combining color. Handloom is characterized by its great differentiation, but implicit in that character is also one of particular and peculiar standards, whose chief function is to co-ordinate across the different technologies in each ensemble. Indeed, weavers and dyers meet standards in color in each of our three stories.

In Indigo the actors are individual and form a community; in natural dyes, actors are organized as a loose network of artisan groups and informal field workers and niche markets; in reactive dyes, the actors form social groups and institutions: the 
$\mathrm{CSO}$, the marketing agency, the dye-houses, the dyers, and the co-operatives. The Indigo community is an example of a close-knit group of dyers and users, where market standards can be negotiated based on personal trust in face-to-face interactions (Porter 1995). All of them share the same values and epistemological assumptions (Traweek 1988). Color is added on dip-by-dip over many days of dyeing, each successive dip a further immersion into the luxurious "deep blue" Indigo of the flower of the moon, Chandrakali saree. Traditionally, Indigo dye was seen as indelible; "the cloth would wear out before the color would fade" 198 ; thus, there was almost complete overlap between the past and present user expectations of fastness standards of Indigo. However, more importantly, it is the intimate nature of the sub-community of Indigo dyers and users that determines this time-tested standard as informal yet sacred.

At the other end of the scale spectrum, in the case of reactive dyes, measurable market standards as set by the industry operate strongly. Reactive dyes are of industrial origin and were designed to meet standards of uniformity in mass production. Unlike in Indigo, where standards remained relatively informal and uncodified; or natural dyes, which maintained internal standards in production and consumption, the pursuit of objective external standards was adopted in the reactive dye frame to protect those within "against outside pressures" (Feng 2003, 102). Standards could no more be negotiated at an individual level, but between obduracy and overlaps in technological frames of social groups that were dealt with at organizational levels. While meeting market standards, in keeping with the handloom "ethos," standards of fastness and matching as well as variety in palette were framed as functions of craftsmanship. Standardizing quality became the domain of the reactive dyer; market standards would be met through quality of skill, rather than an inherent attribute of reactive dye technology.

Though the reactive dyeing technology is environment friendly, it was not required to

198 Interview Yellappa August $9^{\text {th }} 2013$ meet external regulatory standards within the technological frame of handloom. Instead, this production standard was a semi voluntary norm within the handloom ensemble where anyway technologies tended to be of a scale that was local and environmentally sustainable: hand weaving, street sizing, household based, and so on. Therefore, we see that as the nature of the ensemble and social groups who negotiate the standards within it in each story vary, so do the standards, the standards process and the role that the standards play vary (Egyedi 1996).

In the heterogeneous ensemble of handloom no single social group "creates" the whole product. It is not market standards or production standards that unify such an ensemble and make the different elements interoperable, but compatibility standards that ensure co-ordination between different technologies (Windrum 2000). Industrial mills must provide yarn in hanks for the dyers, warpers, sizers, weavers in the handloom industry, [as against cones or cheese for industrial weaving]. Compatibility standards not only link different technologies of spinning, dyeing, weaving, sizing, they play an important role in linking one to many technologies where there are many functional variants within each technology. For example, yarn requirement in dyeing can vary based on the variant of dyeing technology-Indigo dyeing, natural dyeing, and reactive dyeing; further differentiated based on the various scales of the dyeing enterprise - individual dyer, co-operative, and large-scale dye-house; and even further by the eventual types of products weavers might chose to make - plain, bordered, extra weft weaving, to name a few. This kind of differentiation demands a particular kind of standardization that takes into account aggregation level [individual, household, small and large enterprises, mode [mechanized, tool, human], as well as technological variants to allow for interoperability.] Depending on what set of elements can be made interoperable by the compatibility standards, based on scale of the demand, the scale of the sociotechnical whole that is constructed varies. 


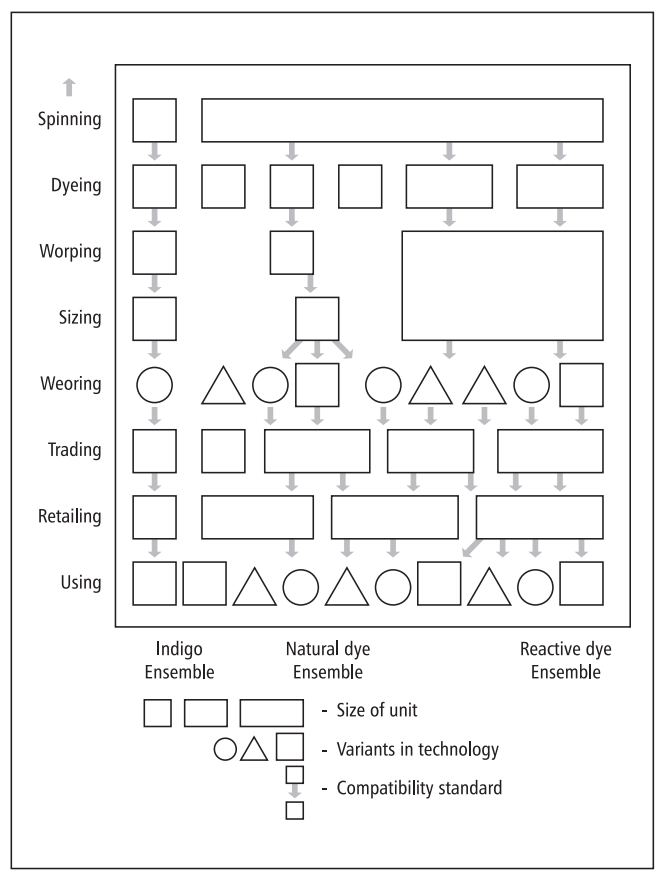

[Fig. 5.8 The multiple handloom ensembles, with the diverse modes, unit sizes of production and standardization points between multiple technological variants].

One comparison that we can make here is to the way Apps are innovated on a smartphone platform. Individual programmers create new innovations, across geographies, organizations, and operating systems, which can be incorporated

\subsection{CONCLUSION}

Sociotechnical change in the handloom ensemble is the focus of this chapter. The first story explained how actors in the handloom ensemble routinely acquire new technologies from the environment by adapting their technological frame, while maintaining the existing practice of the hand-operated loom. In the second story, I elaborated on the conditions under which actors with interactional expertise catalyze change in the handloom ensemble, using old recipes to formalize new knowledge in the present. In the third, I focused on the resultant back into the platform. ICT standards aim to ensure interoperability between IT systems, and within and between organizations and innovators. These standards can be seen to be as negotiations that allow coupling between market and production, open and proprietary software development systems, between individuals and large corporates and so on. These are compatibility standards; they make for interoperability, not just between like entities but also very heterogeneous entities.

Ensembles can be made up of very small as well as very large entities, depending on adequate interoperability between the two unlike entities. Therefore, scale emerges as a continuum across the different kinds of ensembles. This explains how the individual handloom weaver can equally function in the community-based Indigo ensemble, and in the larger reactive dye ensemble. It equally explains how the handloom ensemble operates in order to include the individual Indigo dyer, as well as the large marketing corporate. This counters the idea that the Indigo ensemble is inherently a small scale one that cannot scale up, while the corporate ensemble is inherently a large scale one that cannot include the Indigo dyer. Rather it is the innovation in compatibility standards that matches technologies of different levels of aggregation and makes them interoperable, which then becomes the point of study to understand scaling of sociotechnical wholes.

heterogeneity of rituals and knowledge practices that the handloom ensemble has accumulated over time, through a study of memory practices in Indigo.

Sociotechnical change in the handloom STE results in novel variants of technologies that operate in parallel in the ensemble. Change in individual technologies as well as their integration into ensembles requires stabilization. This is achieved through building vocabulary, textual recipes, and standards. However, once stabilization is achieved, these very same 
mechanisms are used-in the absence of formalized propositional texts-to mobilize embodied skills as knowledge: across the handloom STE, across technological cultures, and across time.

How do these mechanisms work to mobilize embodied skills as knowledge? Vocabularies become the carriers of knowledge of the past, turning them into technologies for the future. For example, Damayanti is a color named after a beautiful queen. Damayanti was the wife of the Nala, king of Nishada, and legend says that she was so sought after that he had to fight the gods to win her hand. When weaverartisans in East Godavari in Andhra Pradesh refer to a color as Damayanti, ${ }^{199}$ they do not refer to a particular color; rather Damayanti calls to their mind a certain depth and intensity in color that local dyers identify on sight and can replicate. What puzzled outsiders was how the different colors of green, brown, blue could all be referred to as Damayanti, but for dyers who were engaged with standardizing intensity of color, Damayanti offered no confusion.

Like other knowledge networks, handloom artisans have a common vocabulary and rules of communication through which handloom knowledge is articulated, which can only be learned through enculturation. When dyers have to learn technologies from outside their practice, they have to be acculturated into those rules. In the case of reinventing natural dyes, for example, the engineer had to learn the practice of dyeing, and the craftsperson was required to engage with documentation, reports, and text-together that resulted in an explication of recipe knowledge, as part of "learning how and why things are done in certain ways in particular sociotechnical locations" (Ribeiro 2007, 15). Then, they could build a new vocabulary that could be translated into practice by other dyers and engineers. In the absence of formal propositional texts, this vocabulary could be used to formalize the new dyeing technology through recipes that could travel. In effect, the recipe functions as propositional knowledge, now written down not in chemical equations, but in an emergent vocabulary of technological practice that communicates between practitioners, who have what can be described as technological literacy (Smith 2004). These written texts in the form of recipes stabilize change in expertise as well as mobilize expertise between physical locations and technological cultures.

In another example, standards offer the same rule-boundedness of propositional knowledge that facilitates stabilization or closure during the process of change. When social groups with different technological frames are constrained to adapt their frames in the process of knowledge exchange, standards emerge as sites of stabilization. The key question becomes what standard the group upholds itself tofastness in color, purity in butter [ghee] [Section 5.4.2], environmental sustainability for the planet [reactive dyes], and so on. Standards that stabilize as rules in turn can be mobilized and when others in the ensemble emulate them, they accrue value and travel just like propositional knowledge in the ensemble. Like formal texts, they function as "immutable mobiles," mechanisms by which knowledge can be stabilized into products that can be physically moved around (Latour 1986). 


\begin{tabular}{|c|c|c|c|}
\hline Technology & Reactivedyes & Natural dyes & Indigo \\
\hline $\begin{array}{c}\text { Example of sociotechnical } \\
\text { change }\end{array}$ & Acquiring new technology & $\begin{array}{c}\text { Generating new variant of } \\
\text { technology }\end{array}$ & Rembering a lost \\
technology
\end{tabular}

Table 5.2 Detailing sociotechnical change in the handloom ensemble, at the level of the technological system, expert system, and system of knowledge using three different instances in the technology of dyeing.

The question I started with in the beginning of this chapter was "how does handloom weaving succeed in adapting to the changing world, while the hand-operated loom itself looks unchanging?" To answer this, I have analyzed three cases of sociotechnical change in the handloom ensemble that evidence this style of adaptive change [Table 5.2]. Referring to the evolution of large technological systems, scholar Hughes suggests that as technology is made for one time and place, manifold difficulties arise in transfer to another time and place, leading to adaptation (Hughes 1987 (2012), 60). One could express handloom's transfer through time and place in similar terms. In response to changes in demand in the environment, individual actors, specific social groups, and entire handloom communities have drawn equally on internal resources, for example cultural memory and their conserved repertoire, as well as resources from industrial textile production systems and adapted. It is this adaptive response to the environment that allows handloom weaving to "persist right into the present" (Niranjana 2004), and upturns the received image of handloom as a pre-modern and traditional craft that is unchanging and an anachronism in a constantly changing world.

The technological frame of handloom is inflexibly attached to the manually operated loom and values skill-based knowledge. This predisposes technological change in the handloom ensemble to conserve the primacy of the hand-operated loom, and of skill-based knowledge, resulting in an accumulation of such technologies in the ensemble. Social groups in the handloom ensemble have to negotiate a balance between not scaling too much -acquiring mechanized technologies which scale to the optimal point where compatibility with the manually operated loom would still be possible-, and staying too small -being unable to leverage economies of scale of markets. In other words, the system strives to avoid lock-in to undesirable paths (Soete and Arundel 1993, 300). This reflexivity defines the core criterion for the careful acquisition of new technologies into the sociotechnical ensemble of handloom. 
This conservative style of change can be expressed using the concept of technological style, which stresses that system builders have creative latitude (Hughes 1987 (2012), 61). What defines technological style in the case of handloom is the choice that actors consistently make, to conserve deep craft and skill, whether on the loom or in any other technology in the ensemble; while the ensemble itself is open to adaptation in response to the changing environment. This technological style is seen to be characteristic of a "traditional" technology that evolves in close geographic proximity with industrial production. Maintaining the unchanging nature of the loom, while managing change in the ensemble, means that actors with interactional expertise across technological cultures constantly have to work on interoperability of technologies, expertise, and knowledge. I can now characterize this adaptive style of change as acquisitive of the new-technologies, expertise, and skills-and accumulative of the old.

This technological style resonates with the Gandhian idea of flexibility of tradition to adapt parts of the idea without losing sight of the whole, as well as Ambedkar's call for cultures that are stagnant to be open to new knowledge and change. It affords possibilities for actors to be able to choose to change or not to change existing practice, rather than follow a deterministic ideal of technology upgradation. It is from this freedom that the handloom ensemble acquires reactive dye technology, reinvents natural dyeing as new technology and redeems Indigo dyeing from its collective memory and transmits it to a new generation of producers and users-always keeping sight of the loom. 


\section{CULTURES OF INNOVATION IN HANDLOOM: THE CASE OF JAMDANI}

Does the argument of adaptive change of the previous chapter tell the whole story of sociotechnical change in handloom weaving? Does it fully explain the paradox that a labor-intensive craft has survived two centuries of mechanization and state supported industrialization in a market economy? Not quite: how can we understand the innovation that is happening? The purpose of this chapter is to answer this question. In this chapter, I describe a specific innovation in weaving [Jamdani], analyzing a specific aspect of innovation expertise of weavers - its tacit nature-within a technological culture that continuously effaces its innovations, and therefore, becomes vulnerable to the disqualification of being regressive. Since effacing itself is, I shall argue, an important aspect of the nature of innovation in handloom-being tacit by design, as it were-I introduce the case of Indian classical music, Karnatik music, to explore this aspect.

Although all the sociotechnical change that I have described so far could be read as a form of innovation, within policy and some social science discussions the term innovation is reserved for a quite specific use and imbued with positive connotations of being progressive. The specific characteristic of sociotechnical change that is labeled innovation is that it is explicitly planned. There has to be strategic intent to innovation, in the sense of having a problem-solving role. At the very least, it is intended to succeed in the market place and produce economic value. Yet, it is recognized that in practice innovation has an uncertain nature. Innovation is a creative endeavor and is dependent on social processes to negotiate its success in the market; these cannot be predetermined. It is these aspects, of problem solving, of referencing the social, of success in the market, and of creativity that I will foreground in this chapter: studying innovation in the sociotechnical ensemble of handloom.

In this final empirical chapter, I trace the revival of the almost extinct weaving technique of "Jamdani," into contemporary hand weaving practice in villages in and around the village of Uppada of Andhra Pradesh. In doing so, I find myself at sites of innovation, though they are not necessarily explicated as such by the actors. Today, increasingly, the lack of innovation by the craft producer is cited as a weakness that results in poor market prospects for craft (Liebl and Roy 2004). However, in this chapter I ask, when craft has in fact thrived in the market, as it has in Uppada, how does craft - in this case, handloom weavers - innovate?

The chapter starts with a short autobiographical trip, to September 1995. I was a field worker in an NGO, Dastkar Andhra when I first encountered the understated innovation culture of handloom in the Gadwal Saree weavers of Yemmiganur. I contrast this with the move by national policy makers to mechanize the "hand" loom; a response to the acute crisis of handloom 
weavers at the time of writing this chapter, from October of 2013 on. Moving out of the NGO intervention logic of providing the right solution, to the academic work of asking the right question, I attempt to tease out how weavers innovate in response to crises; I follow the response of skilled and entrepreneurial weavers to the cotton yarn price-rise crisis. Their solution to the yarn crisis is the creative shift "backward" to revive J amdani, a slow and laborious technique of weaving. This is in fair contradiction to the move to productivity through mechanization that policy-makers advice.

The following sections narrate stories of entrepreneurial actors who innovate on Jamdani as product; who are part of contemporary and innovative production and market ensembles. Every innovation story is followed with a discussion of it within contemporary innovation literature. The case of J amdani explicates the tacit nature of innovation in handloom; the skillful and delicate interweaving of endurance and hope that is continuously at work in creating new prospects for a tradition-bound technology under threat. In the penultimate section, using the example of traditional Indian art, classical Karnatik music, I explore the nature of innovation in traditional craft that constantly effaces its innovations, in service of maintaining continuity of its traditional identity. Over time, this erasure of innovation labels handloom culture as being regressive, rather than progressive. The concluding section summarizes the discussion on culture of innovation in handloom. In this chapter, through telling stories of the innovative weaver, I hope to take the reader on an open-ended exploration of innovation cultures in handloom.

\subsection{INTERLUDE: FLASHBACK TO 1995}

Indian mythology renders creation as the realm of a ubiquitous God Brahma - cursed to remain in unworshipped obscurity even as his consort Saraswati [6.1] reigns as the Goddess of speech and knowledge. Goddess or not, Saraswati is woman enough to allow herself sartorial preferences. She is generally depicted in a white and gold saree, woven using the Jamdani technique [6.2]. And hanging on to this metaphorical coat tail-in this case, her delicate saree end, I travel back in time to the weaving town of Yemmiganur: where I first came across the phenomenon of innovation that strives to recreate the "old" in the "new."

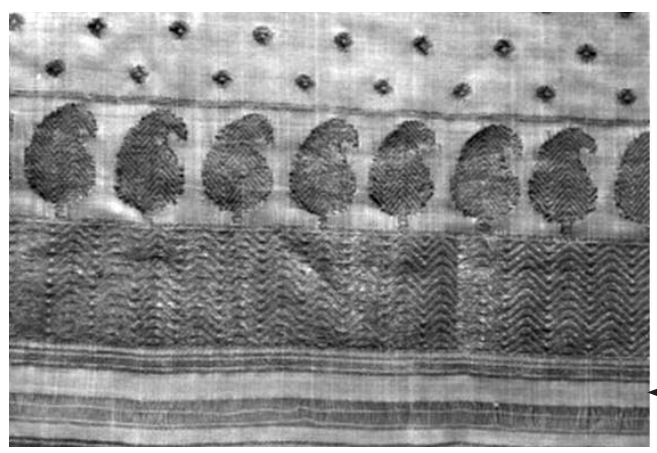

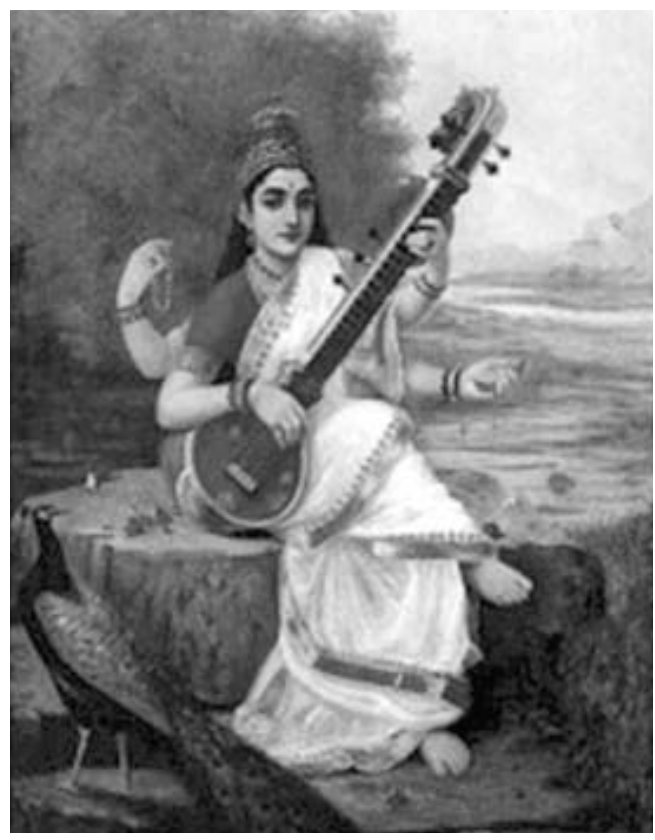

[Fig. 6.1 Painting of Goddess Saraswati by Raja Ravi Varma (1848-1906)]

[Fig. 6.2 Jamdani on silk from Banaras c. 1880 ([V\&A Museum)] 
Picture the little weaving village of Yemmiganur, if you will, in the heart of the scorching Deccan plateau. It is the home of more than 5000 weavers. Enter young researcher Mohammad, who is engaged in fieldwork for his doctoral thesis on handloom. He writes to Uzramma, the head of Dastkar Andhra, an NGO working with handloom weavers, an impassioned plea; the weavers of Yemmiganur are poor and starving, something must be done! Could Dastkar Andhra help? Yes, Uzramma replies, she would send a field worker to assess what help Dastkar Andhra could offer. Till that point, as a field worker, I had been working on establishing the practice of natural dyes, back into the "field" of handloom weavers in response to the recent ban of chemical dyed fabric export into Germany. An important question I was engaged with was "how should a traditional technology that has been forgotten by the community of practitioners be rooted back into living practice?" Obviously, this located the NGO field workers as problem solver interventionists; in effect asking "what should we do to make this happen?" In the style of young people who have charged themselves with changing the world, and who have not yet the life experience to understand change itself, there was no self-doubt. That comes inevitably as field workers become more experienced, most often in the form of the existential question, "how are we to decide what is 'good' for weavers to do or not do with their livelihoods?"

Dastkar Andhra those days was a peripatetic one-horse organization with no intention of getting anywhere in a rush. Uzramma spent long months in the villages, infrequently turning up at the Hyderabad office to attend to administrative formalities like paying the electricity bills. Those were not yet the days of email and cell phones. By the time Uzramma and Mohammad met to discuss my visit to Yemigannur, six months had passed since the writing of his letter. In my notes of that meeting, I point to an enduring confusion that stayed unresolved in my practice, till I set upon the journey of the $\mathrm{PhD}$ - when to act in the world and when to understand it. "It was not clear [ whether] I was going to assess possibilities of DA intervening there, or to understand the general situation as research [for the upcoming] PPST [Patriotic and People oriented Science and Technology] conference on traditional knowledge." 200

I travelled in the month of September 1995 to Yemiganur with Mohammad. Here, for the first time, I saw a functioning Handloom Weaver Cooperative Society. The vision of its founder, the late Machani Somappa was legendary. Not satisfied with providing production-marketing linkages to support weaver livelihoods through the co-operative, he had accessed bank loans for all the members to build houses in an adjacent colony, now called the Weavers Colony. These loans were to be paid back over 20 years through weaving for the society. The society had grown so prosperous in his time that they were able to afford their own retail outlets. The co-operative officials in the now dusty and derelict office spoke of him with eyes shining with pride, of the time in the past that he had faced up to the bullying state marketing agency APCO [Andhra Pradesh State Handloom Weavers Co-operative]. When the agency had refused to raise wages for the weaver, he stopped supplying them and instead sold all production through the co-operative's own shops, till finally the agency gave in, and raised the wage by 25 paise. After the visionary leader died in the mid-1980s his heirs moved on to other businesses, and lost interest in the co-operative, and it had fallen into decline.

Visiting houses of weavers now and talking to them, we found, to Mohammad's surprise, a thriving community, very different from the declining one he had seen six months back. The weavers previously were known to weave coarse cotton sarees, with simple borders using an attachment on the loom called the dobby. These products did not have a reach beyond the local market. But now, they were suddenly weaving a very special kind of fine saree using cotton, silk, and gold that had

200 Field notes Annapurna 95 
a strong identity in local and distant markets, the Gadwal saree. Gadwal was a weaving center almost 80 kilometers away. The Gadwal sare had a cotton body with silk borders and endpiece; this entailed weaving with three shuttles rather than one, and a meticulous attaching of silk yarn to the cotton warp on the loom. Weaving this specialized saree had led to success in the market for the Yemigannur weavers, so there was no more a need for support from an NGO, or scarcity in demand for work of the weavers. The shift to Gadwal though, required more labor-intensive skills, compared to what had been woven earlier. All received wisdom that up scaling would necessarily mean increase in productivity was countered; weavers had chosen a more traditional technology in the face of low wage from the market to their current products. Not just skilled weavers but also weavers down the skill pyramid had successfully changed to Gadwal weaving, in a very short span.

In the natural dyes program that Dastkar Andhra had initiated, we were trying very hard to get communities to take up valuable but older and more labor intensive technologies into practice [see section 5.4]. Here in Yemigannur, it seemed to have happened organically and effortlessly; without an interventionist problem solver's help. What could be learned from this? Not surprisingly, this naive framing of the question with the weaver as the "other" whose problem I had to solve was

\subsection{FLASH FORWARD: THE 2013 CRISIS}

In a news flash from The Indian Express that churned up handloom activists, columnist Anil Sasi reports on the government perspective on mechanization and handloom on May 27, 2013. He refers to the existential crisis in handloom, and the response of the Centre's course correction away from the small is beautiful philosophy. The shift to include mechanized operations in the manufacture of handloom he contends is "a virtual admission of the futility of funds thrown in year after year for the handloom sector." Furthermore, he points to not adequate to understanding weavers' reality. Predictably, the answer in the Gadwal case was not something I immediately understood then. I quote from my field notes of ' 95 — " Gadwal weaving in Yemigannur village was first started by a man whose wife was from the $\mathrm{G}$ adwal village. Though he himself did not make much of a success out of it, this brought the Gadwal master-weavers and traders to the village, with sized ${ }^{201}$, warped ready to weave yarn, and offered high coolie wage [daily wage] and the technique quickly spread amongst the weavers." 202

What I left out of my field notes is a conversation that is still fresh in memory. An old weaver, speaking of the weaver who set up the first Gadwal loom in the village had said with wry fellow feeling, "None of us here would give him our daughter to marry. Drank too much, he did, that fellow. So he went to Gadwal where they did not know him, and found a girl. When the father of that girl realized he was no-good, he tried to help his daughter by setting up Gadwal looms here and encouraged her to teach her husband the technique. Otherwise the secret of their technique would never have been given out here!" In the end, Dastkar Andhra did not intervene in Yemigannur, the cooperative too was to soon shift to Gadwal weaving, and Mohammad himself agreed that circumstances had changed. Through technological change wrought within their social networks, weavers had themselves brought about a change in their fortune.

the backward nature of handloom in comparison to the rest of the world; "while the textile industry is changing the world over, including India, handloom weavers are still tediously working hand-operated [looms]." ${ }^{203} \mathrm{He}$ reports that officials at the center

201 Typically, weavers would have to hire sizers and warpers to do this job, or do it themselves, increasing labor time spent on each warp

202 Field notes, Annapurna Dastkar Andhra, 95

$203 \mathrm{http} / /$ www.indianexpress.com/news/govt-may-include-mechanisedprocesses-under-handlooms/1121115/Anil Sasi : New Delhi, Mon May 272013 
justify this shift with words that indict handloom as livelihood - "a substantial population of weavers are still living in poor conditions."

Rebutting this perspective, activists Ritu Sethi and Devaki Jain write for the same paper on June 6, 2013. ${ }^{2046}$ No hands for the loom" they lament, calling this a "backdoor policy change" that bodes ill for the industry, they point to the competitive advantage of uniquely handmade, when supported by product differentiation and patenting that are shaped to the advantage of the seller. They recall the deliberations of the steering committee advising the 12th Five-Year Plan the past year, which offered prescriptions for renewal and growth. They point to "a significant aspect of handloom" that "cannot be quantified in monetary terms: the social and cultural significance of handlooms, the traditional knowledge associated with its production, and the entire handloom value chain that it sustains, including those who wear and value handloom."

While both perspectives are credible in themselves, they produce an opposition that is not. The positions of economic versus social and cultural, the policy overview versus the empirical particular, ask from us a middle view that is symmetric both to the dominant and the marginalized perspectives that prevail. And it is this symmetry that allows us a solution that is fair in aspect, that is, beautiful: like the Jamdani saree that is first and foremost created as, aspired to and bought for its beauty. In foregrounding beauty, a perspective that puts economic gain at the core of its argument is boorish, as much as a perspective that overly emphasizes the pain and deprivation of the marginalized as an argument is voyeuristic. Instead, the solution that must also be beautiful is a perspective that is lived, experienced, and constructed as being so.

However, before that, there was another old habit that I was cautioned away from: analysis that was limited by the constraint and capability to intervene. In mid-2011, I was meeting my supervisor Louk Box for only the third time, to discuss the understanding versus intervention dialectic that I was struggling with. In his email to me after that meeting, Louk cautioned me in his pithy style "I would like to see your study move out of the 'NGO intervention logic' that I caricature as 'Tell me what your problems are, for I have the solution.' The reverse is: 'Tell me what your solutions are, for I have a question.' Essentially, academic work is asking the right question; NG 0 work is providing the right solution. These are worlds apart." 205

Referring to my claim that the survival of handloom was proof of the adaptive capabilities of handloom weavers in the past, he wrote, "This would mean that in the coming months, you may wish to see what happens in the [weaving] communities when the cotton prices double, which may have disastrous consequences for the weavers, as you pointed out. If my reasoning is correct, this will be the proof of the pudding: will you be able to see in contemporary social relations rapid adaptations that allow certain weavers to reduce their vulnerability? If so, what social (labour relations and division of labour), economic (market access, pricing, credit) and technological (adoption of new work processes, new technologies) adaptations do you see and what are their implications for the respective communities (and possibly the relevant intervention agencies, like NGOS). Encouraged by this perspective, I looked for solutions that weavers were proposing in response to the current crisis - that of increasing cotton yarn prices. A poster made by Dastkar Andhra, as part of its advocacy for yarn price support for handloom weavers from the government, elucidates the background to the crisis. In the preceding years of 2009-2010, there had been an unprecedented increase in the price of cotton yarn used in handloom weaving in Andhra Pradesh. Between April 2009 and October 2010, an average increase in the hank yarn prices for the $40 \mathrm{~s}$ count was 55 percent; for $60 \mathrm{~s} 50$ percent, and for $80 \mathrm{~s}$ count 43 percent [Fig 6.3]. The burden in increase of the yarn price, according to Dastkar Andhra was forcing weavers into migration, and out of villages. 


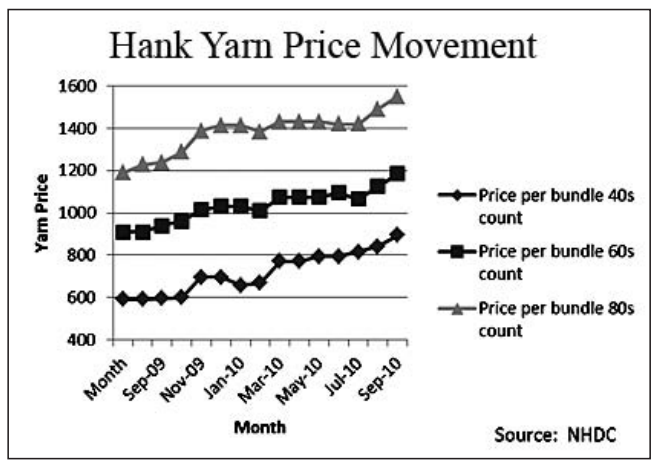

[Fig. 6.3 From the DA advocacy poster for government support for yarn prices]

Over the next six months, from September 2011 to March of 2012, working as participant observer, I traveled with members of Dastkar Andhra to the busy handloom centers of Chirala, Dwarapudi, and smaller weaving villages in the districts of East Godavari. Side by side with the technology and design research [of previous chapters], I asked weavers how they were coping with the increase in yarn price. The situation was bad, they said. No support from the government and no negotiation with the market. They bemoaned the deathblow to an already crippled industry. And indeed that is what it looked like. However, every now and then, in every one of the villages, there were a few who had done well for themselves in the time of the crisis, by trying something new; and it was these weavers that I followed.

Simultaneously, I was privy to the discussions in Dastkar Andhra on the vulnerability that this crisis engendered, for weavers. In order to garner support for the weavers in their crisis, both vulnerability and value ${ }^{206}$ had to be explicated in the handloom industry. Alleviating vulnerability meant that the state, civil society, and media needed to be mobilized, while value construction was generally seen as a market issue. In order to understand weaver response to the crisis, it was important to frame both in terms of weaver perception. I quote from an internal note of the core team of Dastkar Andhra on the project." Which weavers become vulnerable and move to the cities? Who moves to other livelihoods in the village? Which people in the weaving network take up work guarantee programs of the state such as the NREGA and how does that help in reducing vulnerabilities in livelihood? What makes laborious and relatively 'unproductive' work such as J amdani weaving desirable for weavers? What are the conditions and constraints for innovation in handloom?"

It was decided that the analysis would be split two ways; the intention of Dastkar Andhra was to alleviate vulnerability through intervention; thus, the first project was to develop a framework of what could be an ideal state-supported employment guarantee program for a rural household-based activity such as handloom. This would look at high-risk livelihoods, at the bottom end of income and skill, and seek to alleviate their vulnerability, through advocating to the government. The second project was to understand innovation in traditional knowledge systems - to follow the weaver innovators at the top of their game, those with the capability to find opportunity at the time of crisis and innovate their way out of it; creating a pathway for others to follow into stability. It would involve the study of risk-taking households that learned new skills, who acquired new technologies and sought to reach new markets and growth opportunities in response to the crisis. And this second project was the core of my fieldwork for the next year. 


\subsection{Framing Jamdani AS SOLUTION TO YARN PRICE Rise: INNOVATION, NOT REVIVAL}

My encounter with an unexpected response to the crisis in cotton yarn prices came in the house of the master weaver trader in Chendurthi in the Gollaprolu Mandalam of East Godavari district. Sitting outside the main house, in a little shed, a young man was poring over a large graph paper pattern. On being questioned, the young masterweaver Mandapati Papa $\mathrm{RaO}^{207}$ dismissed the youth as "my brother-in-law." This term, when used by an Andhra household, could imply a vast range of relationships; but in real terms, it communicates succinctly the half wary, half resigned acceptance that Andhra men tend to have of younger brothers of their wives. "A cocky young fellow, so I've put him onto learning the Jamdani loom as an experiment" he said. "He is clever, I must admit, at the rate he is going, he'll master it in a couple of weeks." Isn't that a difficult technique to learn in a couple of weeks? I wonder aloud. The master weaver looks a bit embarrassed, and answers with an airy "It's the easy method, he's using a [graph] paper." I was unfamiliar with that term, but intrigued: how could the complex J amdani technique be made "easy"?

Said to be of East Indian origin, where temperatures are high and the climate humid for the better part of the year, the Jamdani saree is a fine and delicate length of hand woven cotton fabric, embellished with beautiful flowered motifs in gold, silver, or silk yarn. Megasthenes, Greek ambassador to the Mauryan court (c.321-185 BCE) speaks of costumes of the people of India as "robes worked in gold, and flowered garments of the finest muslin" [a plain high-count cotton fabric] (Birdwood 1880, 235). It is during the Mughal period, [1556-1627] that these flowered or figured muslins came to be known as J amdani, and the patterns of the J amdanis of that period were clearly of Persian origin. Forbes Watson [18271892], who started his career as a physician in the Bombay medical service and became reporter

207 Interview master-weaver Papa Rao of Chendurthi for the Products of India at the India Office, London published "The Collections of the Textile Manufactures of India" in 1866, 18 volumes of mounted and classified samples of Indian textiles containing 700 examples in all. In the companion volume titled "Textile Manufacturers and costumes of the People of India," 1866, he refers to the figured muslins as being the monopoly of the government because of their complex design and expensive production (Watt 1904, 283). In the early 19th century, James Taylor, British surgeon, a former resident of Dacca gives a detailed account of Jamdani in the "Descriptive and Historical Account of the Cotton Manufactures of Dacca" (Taylor 1851) 208

"In manufacturing figured (Jamdani) fabrics, two weavers sit at the loom. They place the pattern, drawn upon paper, below the warp, and range along the track of the woof a number of cut threads equal to the flowers or parts of the design intended to be made; and then, with two small finepointed bamboo sticks, they draw each of these threads between as many threads of the warp as may be equal to the width of the figure which is to be formed. When all the threads have been brought between the warp they are drawn close by a stroke of the lay. The shuttle is then passed by one of the weavers through the shed, and the weft having been driven home, it is returned by the other weaver. The weavers resume their work with their pointed bamboo sticks, and repeat the operations with the lay and shuttle in the manner above described, observing each time to pass the flower threads between a greater or less number of the threads of the warp, in proportion to the size of the design to be formed."

Jamdanis were on view at the Delhi Arts Exhibition of 1902-1903, part of the Delhi Durbar, a massive demonstration of Britain's global military power organized by Lord Curzon. A catalogue

208 Quoted from Living Traditions, in The Cultural Survey of Bangladesh Glassie, Mahmud Dhaka 2007 
published for this exhibition describes in detail the Jamdanis in the early 20th century. Almost a 100 years later, in his book on the "Art and life in Bangladesh,"1997, Henry Glassie refers to the Jamdani motifs woven in Dhaka.

"Light or heavy, sprinkled or continuous, simple or complex, the designs are angular, repetitive, and geometric. They are named for things out of the world to which the geometric forms bear often fanciful resemblance. The usual objects of reference are alive with brightness, rich with color, and graceful in shape: jewels and stars or birds and flowers, the peacock and swan, the lotus or lily. Names are chosen to evoke natural beauty, which is identified with brilliance, color, and grace, and these qualities intensify in motifs titled in combination, such as the star-flower or the swan-flower."

Jamdani weavers were counted within handloom weaving as "masters" or skill-leaders in all the different] amdani weaving centers. The technique existed in pockets all across the Indian subcontinent, in Bengal, in Uttar Pradesh, in the Deccan and even further down south in the erstwhile Madras Presidency - here described as extra weft weaving. Jamdani weavers continue to be deemed the finest weavers of South Asia: J amdani weaving is "the yield of concentration, the moment in which planning melts into performance, and attention focuses precisely upon the little act in which the past and future merge." (Glassie and Mahmud 2007, 360)

The amdani technique then seems the ideal site to study innovation by weavers in handloom. In order to survive, Jamdani weavers must have innovated on their products for more than 2000 years through industrious application of their knowledge and creativity. However, it is neither the meticulous industry of the Jamdani weaverrather simplistically viewed as drudgery-nor the creativity of the Jamdani aesthetic (with its collaborative Hindu, Islamic, and Christian elements, but that is another story) rather romantically viewed as a symbol of India's glorious past that I foreground. Instead, it is the most recent innovation in the 2000 year new success of the Jamdani in the market that I would like to place before the reader. Clearly, if there were a place where weavers innovated, it would be here. If we are to find an ethos, a culture of innovation for handloom, it should be here.

I would like to differentiate here between Culture with a capital $\mathrm{C}$, and culture with a small c. Handloom is immediately and importantly identified by its cultural origins, as Culture with a capital "C": in its refined craft, its exotic strangeness and its symbolic meaning to Indian society. On the other hand, handloom culture with a small "c" is the system of shared knowledge and the processes that constitute this system. In describing innovation culture in handloom I describe handloom culture with a small c; not to be confused with its stately cousin, Culture with a big C.

Innovation by definition involves the creating and marketing of the new, perforce replacing the old. Schumpeter in his treatise on capitalism puts forward the concept of creative destruction as an enduring precursor to growth (Schumpeter 1942). It becomes a conundrum though, when addressed to innovation in craft. On one hand, innovation seems to predicate the destruction of the old in order to create the new. On the other hand, Craft is traditional technology with a long continuity of practice, where being old is exactly part of the positive identity. Rather than as new scientific invention that travels into the market, the framing of innovation as new combinations of existing resources (Schumpeter 1961) better explains innovation in handloom. The sociotechnical ensemble of handloom constantly recombines old resources with new to contemporize handloom technology. Here, the function of innovation is to introduce novelty into the economic sphere, which fuels continuity for the loom.

To extend the idea of innovation to traditional technologies seems not just unrealistic, but irrelevant. As a women's rights activist put it, "in this day and age, is it necessary for a woman to slave over the spinning wheel to make a living? ${ }^{209 "}$

209 Gita Ramaswamy, DA advisory board 1998 
Of course, being engaged in "modern" livelihoods, by definition is new and progressive, ${ }^{210}$ particularly in comparison with traditional industries such as textiles that are deemed "low-tech." However, handloom networks are made up of both "lowtech" and "high-tech" technologies equally; the mobile phone and computer exist alongside the warping drum and the loom. Understood in material terms, sociologists of technology tell us that every functioning technology is embedded within a complexsocio-legal-technical network-a sociotechnical ensemble. (Bijker 2001) In today's world there are no true "low tech sectors," (Von Tunzelmann and Acha 2005) not even in craft production.

When an economy develops in reaction to changes in condition by adding brains and hands to existing employments or expands within its existing practice it is "adaptive response." (Schumpeter 1947) [See Chapters3 and 5] In surviving in the face of competition from mechanized textile industry, handloom proves itself to be at least that. On the other hand, an economy or an innovating firm doing something outside of the range of existing practice may be termed as engaged in "creative response." (Schumpeter 1947, 150) [Chapter 4] However, this creative response can be identified as such only after the event: "Creative response, [..] from the standpoint of the observer who is in full possession of all the relevant facts can always be understood ex post, but it can practically never be understood ex ante". So, while adaptive responses dominate what economists refer to as "transitions," creative responses require a leap between situations between which there was no bridge; thus, "no deterministic credo can avail against this" (Schumpeter 1947, 150).

However, we are cautioned in innovation literature, not all creative responses that result in change can be considered to be innovations. Only those creative responses that are commercialized

210 " The motor field is modern" -Interview of Allada Asiri Naidu, 35 -year-old migrant ex-weaver now driving a hired auto rickshaw in the city. and linked to growth in the market place may be so categorized. It is this qualified understanding of innovation that links it to economic development. Then, as innovation scholar Fagerberg citing Schumpeter stresses, economic development can "be seen as a process of qualitative change, driven by innovation, taking place in historical time." (Fagerberg 2004, 18) In sustaining itself through creative responses to changes in condition, and adopting new combinations of resources, handloom is a site for innovation. Furthermore, contrary to most policy readings of handloom, I argue, the survival of the handloom industry is evidence of economic development in handloom, driven by an innovation culture that continues to respond creatively to the enormous changes in the world around it.

Reading Schumpeter on innovation from a constructivist perspective is like discovering a friend in a much revered but distant uncle; he repeatedly references the social, in what were previously seen as rational economic or linear knowledge functions. (Fagerberg 2004, 6) The linear model was based on the assumption that innovation is applied science, making scientific research a critical element. The linearity assumed in this perspective was that there were well-defined stages, of research in science, then development followed by production and finally marketing. Rosenberg and Kline in an influential paper (Kline and Rosenberg 1986) debunk this model of innovation as erroneous. While they agree that there is a relation between scientific research and innovation, it is not always a smooth oneway relationship. It is equally an uncertain social process.

This is in line with thinkers in the tradition of STS: technological inventions in the making are constructed by social groups (Pinch and Bijker 1984). Innovations are never only technical, but always sociotechnical (Rip, Joly, and Callon 2010) because organization competences, business linkages, and institutional structures drive technological innovations-for example, users of the different technologies have a role in innovating technology (Oudshoorn and Pinch 2003, Von 
Hippel 1998). Over time, the social construction of technological knowledge means that technical innovations shape market realities as much as they respond to them (Garud and Rappa 1994).

STS scholars (MacKenzie 1998) have challenged deterministic accounts of technology that characterized earlier sociological and economic accounts of technology. Pinch and Svedburg (Pinch and Swedberg 2008) in their important book "Living in a material world," tie economic and technological analysis together using STS concepts. Their rich notion of materiality encompasses the workings of technologies, social practices, and economies as material culture. They differentiate between economies with different material cultures, where distribution of profit takes place via market [exchange], state [redistribution], or the household [reciprocity]. Innovation embedded in each of these cultures would be servicing these different goals and would function differently. Economies dominated by exchange would tend to be more dynamic, driven by the desire to make profit. Economies based on redistribution and reciprocity are modeled on the idea of the household and the desirability of being able to satisfy the needs of the members. In such economies, while there is a necessity for reproduction they are not constantly driven to expand. (Pinch and Swedberg 2008, 9) Referring to particular commodities within economies, and how these are connected to concerns of culture Appadurai argues in "The social life of things" that cultures carry their regimes of value in space and time (Appadurai 1988). From this understanding, it is a small step to analyze innovation as embedded in cultures [some democratic, some less so; some formally regulated, some less so]. Different cultures would by definition have different cultures of innovation, making a case for multiplicity and diversity in innovation cultures. Innovation in handloom can now be understood from an innovation culture perspective (Bijker 2012).

It is important at this point to note that most innovation literature refers to innovation in what are perceived as growth industries. However, in these technologies too, there is a persistence of the vocabulary of craft and culture while describing innovation. Referring to innovation in Information Technology, Arthur concludes that it is a form of craft that needs to be built up slowly in a tradition; "not just in knowing what, but knowing how" within "a shared culture of beliefs, culture of practices and unspoken culture of common experiences" (Arthur 2002, 7). Innovation acts in contexts neither entirely economic nor technological, but in social and cultural (Tzeng 2009). There is a need to understand innovation temporally, to put it simply, history matters (Dobusch 2007). Calling innovation craft, Mintzberg (Mintzberg 1987, 83) says that in the craftsmen's mind, there is "a natural synthesis of the future, present and the past." The "old" then, is neither technology newly destroyed nor sterilely born; it exists as sociotechnical practice in a particular space and in cultural memory in a particular time. Innovation defined in these terms involves not just technological change, but social learning and cultural reinventions. Particularly, the usage of words such as craft, tradition, culture in describing technological innovation promises new possibilities of examining innovation in craft: to understand innovation as a new combination of what was in the past with what is now, to become what will be the future.

TheJ amdani story is not one of uninterrupted innovative practice. It is equally important to trace the journey of where Jamdani did not survive, as it is to understand how it did. The weaving center of Srikakulam is one of the centers of past glory of J amdani, a place where J amdani was practiced by relatively larger number of weavers, rather than the most talented and skilled master craftsmen. Another well-known region for J amdani in Andhra Pradesh in contemporary weaving practice was the weaving area around Venkatagiri. The new sites where Jamdani was reappearing were as far as 500 kilometers distant from the older places. In the traditional centers, in the last 20 years, the number of specialized weavers of Jamdani had slowly dwindled to the last couple. In Srikakulam, 
the technique was applied on Khadi, or handspun yarn. However, in the villages in and around the village of Uppada, almost 500 kilometers away from Venkatagiri in East Godavari district, the Jamdani technique had resurfaced on silk as well as cotton, in what was coming to be known as the "Uppada" Jamdani saree. It was this phenomenon that I was encountering as a response and solution to the cotton yarn price hike.

The traditional technique of Jamdani is similar to that of tapestry, where small shuttles of colored or metallic thread produce tiny motifs in the field of the saree fabric. In plain weaving, two sets of yarn cross perpendicularly to each other, to make up the cloth. The loom (a frame structure of wooden beams) is used for weaving these two sets of yarn together, and is usually constructed over the pit, to allow weavers to sit behind it. The set of yarn attached to the loom is called the warp, and the other set is the cross threads called the weft, that are woven under and over the warp threads to make up the cloth. The loom has a mechanism, called "shaft," by which some threads are lifted up, and others pressed down alternately, so that the weft thread can be woven through them. In the basic weave, the weaver presses alternate threads up and down, creating a space through which the weft shuttle can be inserted. This space is called the shed. The weaver uses feet pedals to move the shafts up and down and thus create the shed in the warp, while throwing the shuttle through the shed to carry the weft thread wound on it from one side

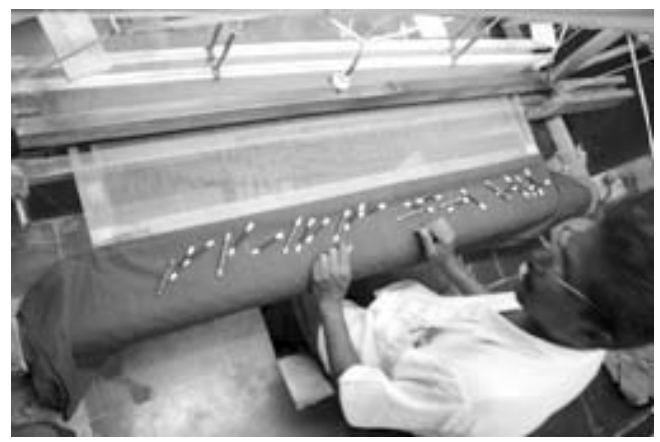

of the loom to the other. Next, he uses a beating movement to pack the weft thread tightly into place, using the beater, a frame that is attached to the top of the warp that can move back and forth. The motion is referred to as beating; both throwing and beating motions together create the "crackle-thud, crackle-thud" rhythm of the plain weaving loom that can be heard throughout any weaving village. The width of the loom constrains the width of the saree, usually a meter wide, while the warp length can go from three to five sarees length. The saree is divided usually into five meters of plainer cloth worn bunched around the waist, and half a meter of intensely patterned end-piece, referred to as "pallu," which ends up draped over the shoulder. There are borders on either side of the width of the saree; the borders and patterns may be generated with a sophisticated programming device, called "dobby," that controls the up-and-down movements of the shafts. The dobby's principle of operation is similar to the punch cards used by Jacquard in loom programming (1801) and by Hollerith in computer programming (1890) — except that the dobby uses wooden pins, where the punch cards have holes. J amdani is a technique of weaving discontinuous supplementary weft motifs usually in heavier threads than those in the warp and weft, using small spindles, onto the fabric while it is being woven (see Figs 6.4 and 6.5). Contemporary Jamdani in and around Uppada combines this technique with computer-aided design to produce large floral patterns that repeat all over the saree [Figs 6.6 and 6.7].

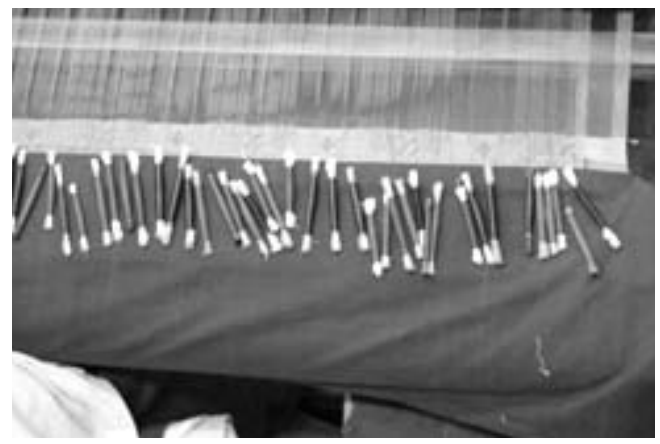

[Figs 6.4 and 6.5 Arranging the shuttles for weaving] 


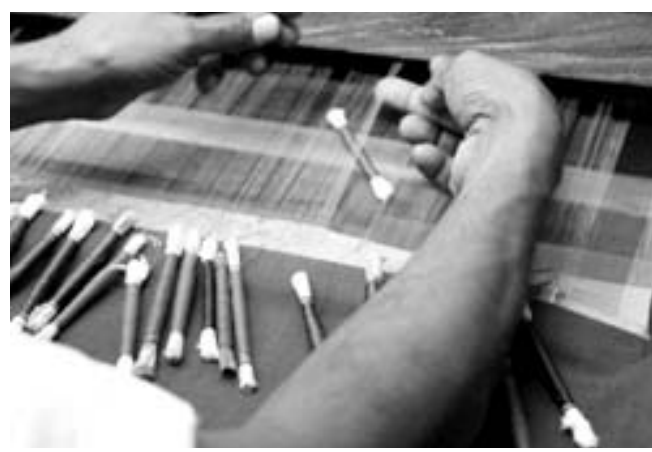

[Fig. 6.6 Lifting the yarn to insert shuttle]

Wherever it was produced in the past, Jamdani was a product associated with luxury and beauty, a connoisseur's collector item; worn as a saree, it had the potential to stand up to any sartorial competition and win. This was due to the laborious and intricate work of extra weft ornamentation on the loom using small spindles with multicolored threads. It brought to mind an economy of plenty and prosperity, where weavers would be rewarded for working at a slower pace, a time when markets would value such labor and pay for it, generously. However, this was a crisis when rising yarn prices were driving weaver wages down. It seemed logical that weavers would have to increase hours at the loom, or increase productivity of the loom to make up the loss in wage. Indeed this is what the state was suggesting that weavers do, with the policy recommendation ${ }^{211}$ toward mechanizing the loom. However, the solution that weavers came up with in Uppada was counter to this idea. If yarn prices ${ }^{212}$ were up, then they would use less yarn, not more, they decided. They would increase the amount of work they put into the warp, learn more intricate skills, and attempt to carve out a share of the market

211 http://www.indianexpress.com/news/govt-may-include-mechanisedprocesses-under-handlooms/1121115/A nil Sasi : New Delhi, M on M ay 27, 2013

212 Over the last 10 years, the shift to J amdani technique has coincided with a slow shift from cotton to silk yarn overall in the industry, as the differential in price between cotton and silk decreased, but for the purpose of this chapter, I study the shift as shift of technique, rather than material.

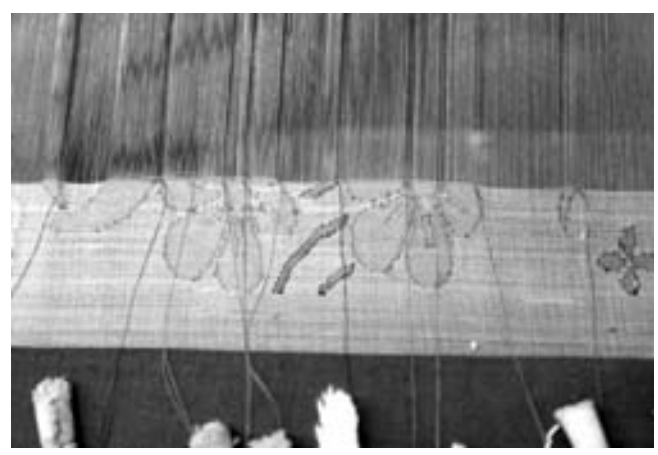

[Fig. 6.7 Producing floral motifs]

for luxury products. In essence, they would use old technologies that slowed down, rather than new ones that speeded up production. This was technological change that went backward rather than forward on the productivity and efficiency scale, but forward rather than backward on the scale toward beauty and excellence.

Venkatagiri was a center once known for J amdani weaving in Andhra Pradesh, where $J$ amdani had not in fact survived. Trying to find out why, I met Nakka Venkataramana, ${ }^{213}$ a successful master-weaver, in a large house on the Weavers' Street in Venkatagiri. A n elderly man with luxurious graying moustaches, he leisurely counted out the day's profits, stacking wads of notes into the floor level desk where he sat before answering my query about J amdani practice in Venkatagiri.

"Weavers now don't want to weave the J amdani designs, nor are we master-weavers willing to invest in the pure gold zari that the traditional saree demands. So, yes, the Venkatagiri saree with the Jamdani butis [motifs] is dead; but the Venkatagiri weaver is alive, weaving other things [that the market values]. And it is better to make what the market was willing to pay for without haggling, and then we can insist on our terms.

$\mathrm{He}$ is categorical that the Venkatagiri saree is a thing of the past. That said, it is a past that he

213 Field notes, Interview N akka Venkataramana, Venkatagiri 
is willing to own up to and is proud of. He was a Jamdani weaver himself for many years, he acknowledges, demonstrating the effect of slow Jamdani work on the skin of his forearm. There is a dark discolored part of the skin acquired from the constant friction of laying it on the warp, as the other hand picked out the motifs.

"I was a J amdani weaver, J amdani weaving was the forte of only the most clever and talented weavers. My father sent me out to my uncle, who was the only J amdani weaver in the village, to learn. Well, when you want your child to learn something difficult, say in mathematics, don't you find him a tutor? It's the same with this weaving you call Jamdani. You have to learn complex calculations in order to create beautiful patterns and you need a teacher. That is another myth about weavers; that intergenerational means father to son; it is uncles, cousins, the extended intergenerational family business that we manage. Anyway, the few new weavers who are weaving J amdani these days are not worth being called that; "telivi ekkuvai J amdani nesthunnaaru' [doing Jamdani because they have become oversmart] Well, they use all kinds of tricks to make the job easy, that is not what Jamdani is about"

J amdani as an older technique had died out and what was coming back was not entirely the same form, though coming back it was, even in Venkatagiri. Sure enough, as I ventured to ask during my travels to other villages, reluctantly weavers revealed, yes, there were five Jamdani looms in Muramunda village, the same in Vellasavaram, ten or twelve in Angara, more than hundred in Peddapuram, someone had heard of looms being set up in Siripuram off Ponduru, the list went on. In Uppada, which was being touted as the traditional J amdani center with unbroken practice there were more than 3000 looms, and in the villages around upto 10,000 . A nd none of these had been weaving J amdani for more than 20 years.

The initial effort of the reintroduction of the J amdani technique as practiced today on the looms of Uppada is credited to a master-weaver designer
Ghansyam Sarode. ${ }^{214}$ It was an effort at revival of the traditional J amdani technique, rather than of the traditional U ppada saree. Sarode started his career in B ombay studying to be a Chartered A ccountant. In order to supplement his income, he decided to cater to the demand in the urban middle class for the diminishing supply of traditional Paithani sarees from the village of Paithan in M aharashtra. He first set up looms in his village of Narayanpet, later, as demand for other rare type of sarees increased, he traveled to Venkatagiri in search of the J amdani saree. The Weavers Co-operative in Venkatagiri "did not co-operate, that is" he says in his inimitable style, so he traveled to U ppada and set up the first loom, in the mid-1980s, with the help of a local weaver introduced by "a relative." Soon, there was a demand for more and more intricate work from the elite cultural customers who saw this as revival of the traditional technique of J amdani. Slowly other weavers in U ppada took it up, though for a long time the technique was kept secret and contained to the village of Uppada. However, as interest in the saree increased, other designers from Hyderabad went to Uppada and started ordering sarees directly from weavers rather than through Sarode. This gave the saree visibility in newer and more fashionable and trendy markets. A nd soon the saree with the J amdani technique came to be known as the "U ppada ${ }^{215}$ J amdani' saree after the village.

Interestingly, the village has been accorded the Geographical Indicator [GI] mark, an accreditation giving "Uppada" the status of a product with a reputation that can be attributed to its place of origin or the area where it is manufactured. The GI makes illegal the selling of the product made from any other place under the trademarked name of U ppada and protects its identity and uniqueness. The Uppada Jamdani sari, the Hindu reports, ${ }^{216}$

"was once woven exclusively for the royal houses

214 Interview Ghanshyam Sarode Master-weaver, Entrepreneur, Hyderabad

215 The association of "U ppada" as a saree of some repute al ready exists in its cultural market, but it was a very different saree to the saree now being touted as the U ppada J amdani

216 http://www.thehindu.com/todays-paper/tp-national/tp-tamilnadu/ U ppada-J amdani-saris-get-gi-tag/article249034.ece 
of Pitapuram, Venkatagiri, and Bobbili". In response to this Sarode says "I got the GI accreditation for them myself," with a twinkle in his eye, the irony of the situation not lost on him. After all before his advent there had been no "authentic" J amdani Uppada saree in the memory of Uppada weavers; he had single handedly reinvented it, drawing from cultural memory in the market place. Uppada Jamdani was now an invented tradition, through implying continuity to "a suitable historical past" (Hobsbawm 1983, 1).

Barely surviving 25 years ago, the traditional J amdani technique had been innovated on to become the Uppada Jamdani. The work of entrepreneurial master-weavers in constructing an identity for the product through mobilizing cultural memory of urban women customers gave it value in the market. More weavers took up Jamdani weaving; this, along with market success, I suggest, had taken the Uppada J amdani from experimental niche to full blown innovation status; giving economic value through diffusion to new markets and producers (Garcia and Calantone 2002).

As examples of innovation, Schumpeter mentions "new products, new methods of production, new sources of supply, exploitation of new markets and new ways to organize business" (Fagerberg 2004, 18). Innovation is seen here clearly as a close conjunction of invention and diffusion. Scholars (Hagedoorn 1996, Fagerberg, Mowery, and Nelson 2006) have built upon the Schumpeterian ideal of the entrepreneur who forces the adoption of new combinations. The Uppada "Jamdani" was, as I shall evidence in the following sections simultaneously revival of an older technique that led to product innovation, invented traditional product that became market innovation, and technological innovation that could be constructed as production or process innovation.

In the next three sections, I follow the Uppada J amdani to three new places: each a site of innovation: Jamdani as product innovation, where the site of innovation is in creating new product, Jamdani as market and user innovation, where the site of innovation is in exploiting new markets, and Jamdani as process or production innovation, where the innovation is in the processes of production. I discuss J amdani as an innovative weaver's creative impulse to harness opportunity in the market using his deep craft; in order to solve the problem of increase in yarn price that constrained returns from the market for his current skill. These seem promising starting points to explore the idea of innovation in craft livelihoods. In each case, I point to the technological change and social learning that makes the innovation possible. ${ }^{217}$

\subsection{Jamdani AS PRODUCT INNOVATION: COMBINING SKILLS WITHIN THE KinSHiP NETWORK}

How did weavers learn to innovate new product in the face of rising yarn prices that were depressing wage for weaving? Once market opportunity was sighted, how did the elaborate set of techniques of J amdani spread to weavers in

217 Photos accompany the text to make a point that I felt was better explained visually. Most of these photos were taken with an iphone, as aide de memoirs as I traveled for my fieldwork, and are part of my field notes. The pictures of the J amdani process on the other hand are more systematic and were taken in the design studio by Yashoda, a young designer working on a project for sampling new products for Dastkar Andhra in their Design studio. neighboring and even further off villages of East Godavari? It was a laborious and time consuming set of techniques; how were weavers able to acquire this knowledge?

Following the trail to Mandapeta, another new center of J amdani weaving, $\mathrm{I}^{218}$ met with the master-weaver-traders who were the backbone

218 As the field work was taken up as participant observer over two years, I was accompanied by various members and guests of the Dastkar Andhra team. In particular for the work on this chapter, I was accompanied at different times by Latha Tummuru and Tonny A'Campo. 
of the networks of handloom production and consumption. Outside of the co-operatives, master weavers are the entrepreneurs who power the trade of handloom. They invest in yarn, in the weaver, in the finished stock, and decide on product based on market information. Theirs is the risk on capital; but the loose arrangement between them and the rest of the ensemble means that losses are passed on to weavers when times are bad, fairly quickly. The master weaver making profits signifies sure employment for the weavers he contracts with, the master weaver with losses means that weavers lose work or at least are paid less. Like in the case of any industry, there are exploitative master-weavers and benevolent ones. Where the weavers are organized as labor unions, the anti-masterweaver rhetoric is stronger. Where the relationships are more feudal, exploitation of the poor weaver by master-weavers is rampant. However, somewhere in between on examination emerges a picture of the social practices of master-weavers in innovating for the market.

Mandapeta in the district of East Godavari is not a weaving village known for any particular product or specific technique. Notwithstanding that, the conversation of a group of weavers meeting at the master weaver and yarn trader Penta Rao's ${ }^{219}$ house, about changes in weavers' lives in the past century portrays the community as vibrant and prosperous. The middle-aged yarn trader is clearly the head of the household and a respectable pillar of the community. The atmosphere is relaxed, the weavers engage in a discussion on a recent policy change for the handloom sector. The decision to charge a value added tax on handloom, and the ensuing strike of the weavers in response, results in much headshaking at the short sightedness of policy makers in general. A query about what varieties of sarees were traditionally woven and traded elicits a story about the yarn trader's grandfather's time. Colored yarn, usually black yarn was bought in far away Madurai, in Tamil Nadu, woven in Mandapeta and sold in the local markets.

219 Interviews in Mandapeta village [Penta Rao, Rambabu, Boodida Srinavasa] January 23rd, 2012
In general, weavers had to be temperamentally suited to long periods of still alertness, as they sat at their looms. This went hand in hand with certain voluntary religious practices, for example to "wear" the lingam; the symbol of Shiva. Such weavers then lived very austere lives according to strictly prescribed routines, including eating food cooked “only by their own hands." Penta Rao's grandfather was one such weaver. Typically marketing and trading involved long periods of travelling, a trip on foot to the Dwarapudi market for instance could take four to six days. In order to perform these functions of trading, Penta Rao's father in turn decided not to take up the rite. Explaining why that lifestyle had lost its charm, Penta Rao said, "Young people call it super stition; but the truth is that current lifestyles don't allow for such rigor. Rather than take it up and break the vows, it is better to respect it and accept that it is beyond us to follow it, now." 220

This view of weavers as meditative souls is rather in contrast to the picture of poverty and deprivation that policy makers paint as the lot of impoverished weavers. Responding to the fairly rampant alcoholism in the lower income groups of weavers, the young weaver Boodida Srinivasa refers to it as a "bad habit" acquired recently, rather than a traditional social evil that needed modern reform.

"It is the effect of media and politics; media makes it aspirational and elections make it accessible. It starts off as a bribe, every [political] candidate worth his salt will invite thirty people to a 'party', everyday till the el ection date; and when the election is over, the party is over.... but meanwhile this poor fellow is addicted, and ruins himself. 0 ur forefathers lived with self-respect; when the king offered them lands, they refused-said that they would rather weave-But what is the recognition for the weaver, he is nothing today, and he goes after the herd, to political 'parties, and refuses to experiment on what he weaves ${ }^{221 "}$

Weavers of Mandapeta were known to be versatile; they could weave practically anything,

220 Interview, Penta Rao, January 23rd 2012

221 Interview, Boodida Srinivasa, January 23rd 2012 
on request. They knew their growth depended on meeting the constant demands for "something new" that the customer clamors for. Pattimarpu, [extra weft weaving] dobby weaving, jacquard weaving, plain weaving, cotton counts that could range across 40, 60 to 100-whatever the demanding Chirala market wanted, it could be made here. In recent times, that included the Uppada Jamdani, too. This was the identity of Mandapeta weavers; that they were tractable and responsive to the market. It was the flexibility of the wage that allowed this; master weavers were not attached to a particular wage hierarchy, for instance they realized that change itself was worth paying for. A change from weaving silk to weaving cotton would generally be considered taboo for a silk weaver, since it would warrant a downgrade in wage, as well as in professional status. However, master-weavers in Mandapeta gave weavers who made this shift both respect and the equivalent wage of weaving silk when weaving cotton yarn. The continued demand from the market ensured the weaver got his or her due. It became clear that rather than any social recognition, or validation of capability, master-weavers manipulated conditions of wage in the market to induce weavers to change. "D esign will change, not the product [ the product is al ready ten years old]. This saree had first a small border, plain body cotton buta, then they increased the size of the border, then we put on checks, then gold zari. Sometimes people ask for different things [.... ] $\mathrm{He}$ and I [the yarn trader and the master-weaver] would want to change the style, we took off the temple from the Angara co-operative saree, and put in the buta. It depends on your strength to hold, and to go around and find new market. Anything will sell, if the quality is good. You just have to pay attention to market." 222

The master-weaver depended on members of his household for executing the back end of the business: yarn and cash moves back and forth between yarn trader, sizer, warper, dyer, and weaver; and stock and inventory are consigned to and fro between weaver, master weaver, and the market. He understood that he was as strong as his ensemble of production; choosing the right weaver is the key, he says, if you want to innovate. "Because in the morning the warp behaves in one way, when the sun is beating down, it is another type, and if it rains then it behaves another way. He has to keep the tension on the pogu [weaving yarn]. He needs to know these techniques. ${ }^{223 "}$ So, something new, an innovative product that would "go" in the market, hinged on the skill of the weaver, the enterprise of the masterweaver, and their relationship and chemistry. This becomes obvious when the master-weaver talks of the need for a "still" [skilled] weaver ["manchi panitanam unnavaadu" ] who is willing to experiment.

Jonna Suribabu and his wife Ramalakshmi are a weaver couple in the village of Angara who have recently shifted successfully to Jamdani weaving. When they speak, it is in tandem, reproducing their weaving action of passing the shuttle from one hand to the other; one sentence of the husband followed by one by the wife in the conversation. The two young daughters sit in the background, around a low table strewn with books, finishing their school homework. In the foreground is the loom, in the room that is in a kind of verandah, an inside outside airy room with lots of light. They are weavers who have always been willing to dance to the tune of the market. When the demand for J amdani first emerged, they decided they wanted to try their hand at it. They had already seen it being woven in Uppada, where the technique was a wellkept secret. The master-weaver from Uppada sent them a "designer"; someone who knew how to "set up" the loom, and teach them how to begin. However, once they started, he recanted on the wage. Rambabu came to their rescue, he was a late entrant into J amdani, [by then it was already one year on the local market] but he grabbed the opportunity that the experimental weaver couple presented to enter into this market. 
Ramalakshmi had taken well to Jamdani weaving. While the technique itself was more timeconsuming, there is less continuous "beating," making it less strenuous. The slow pace had another advantage; more time was spent on the loom doing skilled work and less on "baita pani" [ancillary work]. Of course, the couple had to be on good terms, if work was to go on smoothly. If one was upset, then he or she would go away for an hour, to cool down, till ready to come back to the loom — not that different from living together." Figuring out a new technique takes patience, and a peaceful mind and the support of the master-weaver. [oorpu, opika]lt is important not to share the secret once you have figured it out. If someone comes in [into the room with the loom, to visit], we cover the loom, so that they can't get the technique tricks" 224__[ suluvu.]

When they first set up the loom, Rambabu had visited the loom every two hours, to discuss how it was going to help facilitate progress. Even then, the first saree was "spoiled," and the cost had to be shared between the weaver couple and the master-weaver Rambabu. After two sarees, they were skilled enough to start making it for the market. The first experimental saree is a beautiful gray saree with elaborate sky blue and rose pink motifs; not an idea of aesthetic associated with a poor weaver's wife. However, it was mutually agreed between the master-weaver and Suribabu that Ramalakshmi was the rightful owner of that experiment: the saree would be in her wardrobe.

The master-weaver's entrepreneurial insight and facilitating of technological change in the sociotechnical ensemble of handloom are explicated in this experiment. There is no single innovator or innovating firm. The creative entrepreneurial response is collective (Hagedoorn 1996, 893) across the ensemble. Both master-weaver and weaver couple are connected through social practices and networks in order to produce innovative knowledge (Brown and Duguid 2002). The master-weaver is the entrepreneur who acts out of market insight, while the weaver who invests visibly in the skill component of weaving J amdani too is experimenting tacitly with a

224 Interview weaver Jonna Suribabu, January 28th, 2012 new way of weaving which needs a meditative state of engagement, "oorpu." Therefore, both skill and insight; learned and unlearned activities (Ruttan 1959) are engaged in order to innovate a new product.

Yet, success in the market, in the best Schumpeterian tradition is a necessary entrepreneurial condition in innovation. The market is an economic phenomenon but also embedded in the social, through its materiality-money, commodities, calculative devices, and its functions - exchange, capital management, entrepreneurship, and its institutionsfirms, factories, industry, and so on. The study of entrepreneurship in innovation literature extends its function from individuals to innovating firms, from industrial districts to networks of innovators, from Regional and National Systems of Innovation to global networks of innovation (Fagerberg 2004). The innovative firm is not a faceless entity, it is built by "an able man who works hard [...] and collects around him subordinates [...] and as his business increases, they rise with him (Marshall 1961, 315). The essence of the innovative firm is "the organizational integration of a skill base that can engage in collective and cumulative learning" (Lazonick 2005, 34). When this transition in operationalized, the social and the collective functions of innovation can be formalized and termed as "innovative organization" or "innovative firm." In handloom, typically it is the master-weaver that plays the role of entrepreneur. Not all master-weavers evolve organizationally into firms; this is dependent on their ability to access formal institutions of banking and retail.

To make the case for J amdani as successful innovation, having innovated on the product, it must grow in the market. Who were the users of this new J amdani product? How was value created for an older technology, which must surely be more expensive for the customer? We see how the weaver learned Jamdani as "new" technology, and produced an innovative product, but how was the customer drawn into the ensemble? Were new markets accessed, and if so, how? To answer these questions, I bring back the analytical unit of the sociotechnical ensemble to widen the frame of enquiry for examining innovation practices across the Jamdani ensemble. 


\subsection{JAMDANI AS MARKET INNOVATION: AUNTIES, LADIES, AND MOBILE PHONES}

"Will you be traveling again to Mandapeta?" My grandmother asks as I leave for Peddapuram during the summer of 2012. "If so, ask if they know the mansion that Charla Venkata Shastry built." She is the niece of that man; a Zamindar [Land owner] from her village in the district of West Godavari, who frittered away all his money to build the said mansion for the woman he admired, a Devadasi dancer from Peddapuram. My grandmother had her love of beautiful things from him, she always said. However, his fate is not an uncommon one. East Godavari was known for its devadasis [women artists who served temples and/or courts] traditional holders of the knowledge of dance and music. Their extra-domestic non-normative sexual lives, devotional lives, their art, none of these anymore exist as markers of their devadasi identity. Reviled as prostitutes during the British rule and subject to reform in the 20th century, they were stripped of their wealth and position, and had sunk into poverty and obscurity, taking the rich knowledge of the arts along with them (Soneji 2004). Peddapuram continues to be known for the flesh trade, but alongside is a thriving handloom weaving community; evidencing again the close relation between the arts and artisans.

Peddapuram, unlike a lot of villages in East Godavari has not yet abandoned its old lanes and tile roofed houses for concrete. The dyehouse ${ }^{225}$ we visited is in one such house. The floor is crimson "redoxide" mineral mixed into cement. In the courtyard beyond are the woodstoves where the dyeing takes place. "The 'ladies' from Hyderabad are here" our entrance is announced. The young dye-house owner who receives us is soft spoken, and hospitable as we settle down to wait our turn to be served. His tone, as he confers with the dyer on quantities to be dyed that day is not authoritative. Not many words are spoken, but the relationship is visibly one of ease, and the dyer gets to work willingly. Another young man is waiting for his attention; he is a weaver

225 Dyehouse Visit Peddapuram with Latha Tummuru 2011 collecting a warp dyed to order. There is cordiality evident in the conversation: the weaver collecting the warp acknowledges that it is the right color, and expresses reservations about the quality of the yarn. There is no explosive argument about who would bear the cost of the spoiled yarn. Both acknowledge the difficulty in weaving yarn that is knotted up; the weaver is reassured about the quality of the new warp, and he pays out the money owed for dyeing the warp and they part in harmony.

This investment of a weaver in his own raw material, without the aegis of a master-weaver, is unusual. Generally, weavers are contracted to master-weavers or are members of producer cooperatives that provide them with yarn and pay them wage. While weavers invest in loom accessories like reeds or jacquard attachments, they generally do not have the capital to invest in raw material or finished stock. This young weaver though, seemed able to afford the investment in the silk warp. "Out of my own profits driving an auto rickshaw" he said, as he did not weave anymore "fulltime," but chauffeured clients for his livelihood. From this he was able to afford the capital investment on the loom. His wife was educated; worked in a school as a teacher. In the evenings, they would weave for three or four hours together and make one J amdani saree every month. The loom was not anymore in the front of the house; this was now transformed into a "modern" room, with a television and a raised table for schoolwork for children. Instead the loom was now in the backyard, out of sight of casual visitors, in the private area of the house.

The absence of the master-weaver meant not only that they invested in their own raw material but also that they had to market the product themselves. This too was not anymore a problem, he said. The weaver had the phone numbers of 30 weavers like himself, who each had numbers of another 30 weavers. When his saree was ready, he would call weavers in his network and collect 20 to 30 more sarees and head out to the city of Hyderabad on the night bus. Once there, he would call customers 
using his mobile phone; "Ladies" on his list of clients, who would be willing to invite him to their home and peruse/browse the merchandise. If they found the sarees to their taste, they would instantly pay cash. Of the 30 sarees, he would typically sell around five, at a 100 percent profit. He would then meet the "Aunties" a different category of clients, again in their home usually chaperoned by an older member of the family or a domestic servant. These "Aunties" would have their own network of women interested in "luxury custom made" sarees. Off these sarees, he would make less of a profit. The "Aunty" would pay only 20 percent more than the cost price, but would take at least five sarees. Before leaving the sarees with her, he would call and check with the weavers back at home; and decide if he would leave the sarees behind. If not, he would carry them back to Peddapuram, to become part of the consignment of the next weaver travelling to the next city.

The mobile phone had connected and created networks of weavers and networks of customers. There were no retail costs; instead there was a relationship, a new one, of an "Aunty" who would mediate between her social network and the weavers. These fairly affluent women lived dotted across the suburbs and satellite towns around the large cities. Generally, they were part of kinship networks or immigrant communities from the same districts that were also home to the weavers. The women still recalled from memory or from family stories the exclusivity of Jamdani sarees; and experienced the personal attention of weavers as familiar and socially acceptable. They could exercise aesthetic choice, and be taken seriously by the weaver producers. Most important the price could be negotiated to suit the purse of the buyer, if not this time, then the next. In the market, the Ladies and Aunties became cultural experts who appropriated consumer goods to perform identity (Du Gay 1997, 104). They could guarantee the authenticity of the invented tradition Uppada J amdani, recalling it from their own roots, as it were. Buying and selling a Jamdani saree in this kind of environment was substantially different from buying something in the mall or flea market. It was a distinctively personalized shopping experience; a club where aesthetic as much as buying power was recognized as the entry point.

The association of traditional technique to high-end luxury and culture was kept up through the cultural practices of higher up doyennes of craft and handloom. Ghansyam Sarode strategically plays on the association to the icons of craft and handloom of yester year; "Since 2003 Mrs Gandhi using the white $\mathrm{K}$ hadi sarees with interlock border with intricate Jamdani buties [motifs]." Here, the Mrs. Gandhi he refers to is the head of the Indian National Congress Party, and the white K hadi saree referred to is the iconic saree worn by women in the freedom struggle. A broad enough identity had been constructed in the customer base for the Uppada Jamdani, allowing for a multitude of product improvisations and incremental innovations to flood the market; and all through the personalized interactions between weavers and their new found "traditional" customers.

The mobile phone was undoubtedly an innovative technological addition to the ensemble; but the practices of both the Jamdani weaver and the face-to-face marketing between weaver and customer recalled traditional cultural practices. Till recently in village communities, weavers and women customers had had long standing transactional relationships. Clothes had important ritual meaning, and weavers were invited to the homes of their women customers so that they could produce to order the clothing needs of the household, very often using the yarn spun in that very household. With the breaking down of these economic relationships, these forums of interaction had broken down; socially, it was not anymore respectable for women of higher social class and caste and men of lower social status and caste to meet. By entering the ensemble, the mobile telephone remade these older ensembles, and newly "shaped the way financial counterparts addressed one another, and the way trade interactions are 
enacted." (Muniesa 2008, 293) Indeed, on a mobile phone, traditional caste and class hierarchies too were reshaped, creating social counterparts who were addressed with the more egalitarian label of "Aunties" and "Ladies."

Using the mobile phone weavers created new market infrastructure; they also succeeded in shifting market access away from the large retail agencies with their own interests. Through the use of the mobile phone, they created a new forum for product feedback from lead users directly to producers (Oudshoorn and Pinch 2008), as well as allowing better price negotiation. On the production side, weavers built on the flexible time and work that the loom at home provides, to earn substantial incomes for both men and women, while working more inflexible day jobs. ${ }^{226}$

This was an important innovation in the market for the livelihood of handloom. It built on the original innovation of J amdani as new product. The flexibility of the Jamdani loom coupled with the ability of skilled weavers to customize new products to order enabled the weavers to create a feedback loop that ensured market success. It allowed for effective and efficient turnaround of capital since capital was not locked up as inventory_-"waiting undadu" ["there is no delay"]. No sooner were sarees being made, then they could be sold, the mobile phone helped weavers reach and sustain new markets. Finally, the mobile phone was a technological adoption by the handloom industry, which made the promise of economic progress through new technologies true even for handloom.

It also explained the ease of entry that I had gained as a researcher to the Jamdani production and customer ensemble. I was the archetypical "aunty" personified. I came from a cultural background that recognized the saree was broadly from the geographical area that it were now being made, I had reached a stage and phase in life where I would be expected to wear an expensive saree to mark any social attendance. I would be willing to pay for the privilege of customizing it to my

226 Interview Srinivas, Dyehouse Peddapuram January 29th, 2012 preference and personal idea of beauty: in short the market embodied. This also signified a shift in site of innovation: from the single point of the innovative Jamdani saree, to the multiple innovations in the sociotechnical ensemble of J amdani, which now showed itself to be able to leverage the traditional kinship network to include new technologies and new counterparts.

Local firms combine knowledge in order to innovate; Charles Sabel, Michael Piore, and Jonathan Zeitlin have studied the importance of the business district as a site for innovation. Their research suggests that a physical location defined by geography can be an alternative to mass production and the corporate as a model of organizing for innovation. (Piore and Charles 1984, Sabel and Zeitlin 1985) Collaborative networks have long been part of such industrial districts, as well as in craft-based industries and in fields with diverse participants (Powell and Grodal 2005 , 59) as innovation requires that complex knowledge be transferred. This is best done through tight knit networks (Hansen 1999), where trust plays an important role (Uzzi 1997, 72).

However, networks that determine innovation can equally constrain it, too much embedding within one "organizational community" may constrain the processes of innovation through inhibiting learning radically new knowledge from external sources (Lam 2005, 128). Indeed, as an antidote, heterogeneity in the collaborators allows for wider stock of knowledge as base for innovation. In this view, innovation occurs at the boundaries between mind-sets, not within the provincial territory of one knowledge and skill base (Leonard-Barton 1995, 62). The sociotechnical ensemble of handloom in order not be constrained by its geography and mindset, when it innovates, must seek access to environments where creative abrasion, the synthesis that is developed from multiple points of view is likely to occur (Powell and Grodal 2005, 59). From the time of Megasthanes, more than 2000 years ago, who encountered J amdani through traveling from Greece to India by land and sea to the "Aunty" in Hyderabad communicating using the mobile phone, innovation has spatial reach-location 
matters for face-to-face interaction (Brown and Duguid, 143). It is through such system building interactions that handloom weavers grow markets for their products.

However, the question of technological innovation endogenous to handloom is yet to be explored. The mobile phone technology is not unique to handloom, it was an innovation produced in the communication industry, which was being used in the textile industry. I argue that handloom is a sociotechnical ensemble of weavers, spinners, dyers, warpers, sizers, and so on, and of people and their technologies working together in production and consumption. The mobile phone was an innovative addition to this sociotechnical ensemble. On the other hand, was it possible to look beyond adoption of new technologies exogenous to the sector, to technological innovation endogenous to the sector? This quest takes us to Vellasavaram, another village in East Godavari, to the J amdani designer and computer programmer Balaji and to a possible site of J amdani as production or process innovation.

\subsection{Jamdani AS PROCESS InNOVATION IN THE SOCIOTECHNICAL ENSEMble: THE DIGITAL LOOM}

In the weavers co-operative in the village of Angara, a few miles from Vellasavaram, which is our next site of innovation, the secretary of the weavers co-operative proudly showed off a silk J amdani saree woven by a weaver of their village. Again, it was referred to as the "Uppada" saree. The saree was woven in "peacock blue," the colloquial term for a shade of turquoise where the deep blue warp is shot with a bright green weft. The beautiful motif that dominated the saree was the "Paisley," a traditional motif that has been part of the design repertoire of the Indian subcontinent for the last 1000 years. The Paisley motif, originally from Persia is named after the weaving centre in Scotland of the same name. It is shaped like a twisted tear drop and referred to as "Kairi" [raw mango] in Hindi; the curve-shape,

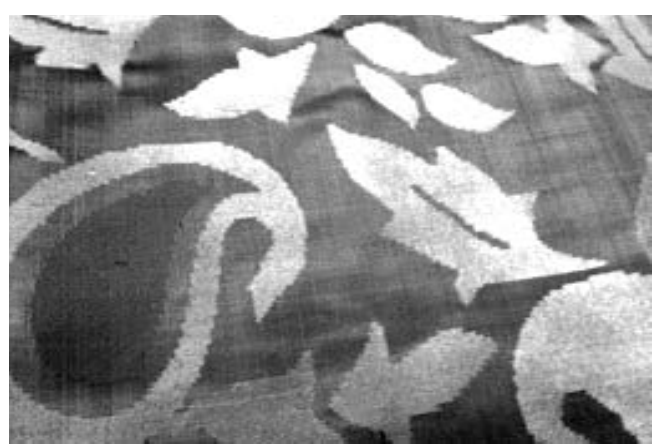

[Fig 6.8 Jamdani on silk from Banaras c. 1880 (V\&A Museum)] reminiscent of the elongated raw mango. Here, it was seen in the style generally described as "allover," [referring to a pattern that was a connected repeat woven all over the saree] - to differentiate it from the less labor-intensive style where the paisley was seen as "buta" or extra weft pattern dropped onto the saree in disconnected but evenly spaced intervals.

However, visually the paisley on this saree showed an inconsistency, closer examination revealed that the curvature of the motif was rather more jerky than one expected when the Jamdani technique was employed. It did not seem to be the inexperience of the weaver; subsequent sarees we were shown, all carried the same jerkiness.

Described in digital terms, the curve of the motif appeared as if it had been drawn on a low-

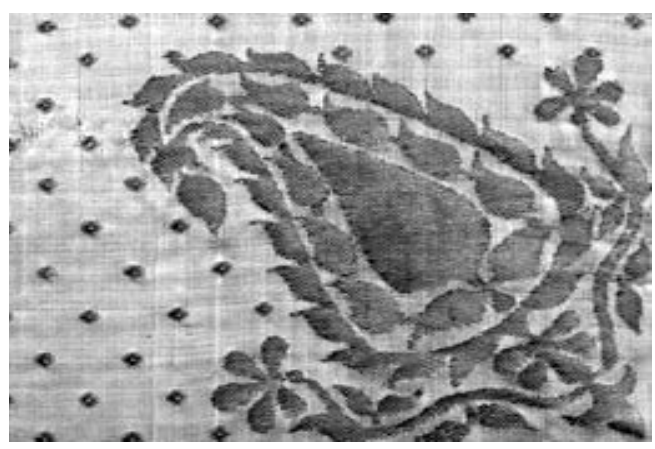

[Fig. 6.9 Jamdani on silk from East Godavari c 2011 (Weaver Vellasavaram)] 
resolution scale, with the pixelation on the curve in relief when seen at close quarters. This was a startling contradiction. One did not associate a low-resolution computer screen image with a motif on an exquisite hand-woven saree [Figs 6.8 and 6.9]. But indeed the secretary confirmed that it was a computer design, designed by a "young and dynamic" computer programmer who lived in the village of Vellasavaram. My first instinct, as would have been of most handloom and craft connoisseurs was one of disappointment and disapproval. This was not authentic design, I instantly [and as it proved later, wrongly] judged. It was an external technology being imposed on hapless Jamdani weavers in the spirit of modernization, and could only result in turning weavers into mindless units that produce less quality products; the worst fears of handloom aficionados realized.

Craft activists generally perceive "computerization" much like mechanization: as a depression of craft products' unique handmade value. In addition, it is implicitly assumed that once the labor component of hand production is taken over by the machine and the design component by the computer, there is nothing left of economic value to recommend craft modes of production. It ended up leaving only the labor of production to the weaver. Also, in this case, the pixelation pointed to an awkward application of computer design technology; presumably a result of outdated software that was inflexible with regard to the sophisticated differentiation that the weaver was capable of. Did the insensitivity of the computer programmer lead to the blind imposing of the pixelation of the low-resolution design onto the loom, I wondered.

When one walks into any weaving village it is to the accompanying humming of the winding wheels and clacking of the looms that emanates from each house as if from a giant organism. People are friendly and willing to help, as in Vellasavaram, and the home of the computer programmer was easily found. A smiley young man in his twenties dressed in trousers and shirt, Balaji introduced himself as the computer designer who had designed the sarees woven in Angara. The room was a study

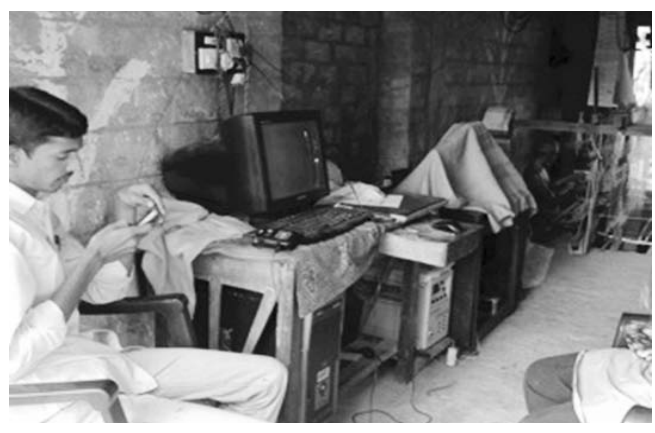

[Fig. 6.10 Balaji's house with loom in the background and computer in the foreground]

in technological time travel; at the far end was an older man, Balaji's father seated at the pit loom, further up was the jacquard punching machine, then a desktop computer with "Shadhana Creations" on the screen, and closest to the entrance sat the young designer with his cell phone [Fig 6.10].

Balaji demonstrated in detail how he used the software program to design motifs for the sarees. The original design was "art" he said; indicating that it was drawn by hand. The software converted the patterns into a scaled graph. For example, the paisley, the "chakram" [wheel], the "hamsa" [swan], were well known and available on the software's repertoire, but sometimes one had to draw new motifs and they could be done easily using the mouse. This explained another disconcerting element in the design; the paisley though pixelated was finely proportioned, the leaf accompanying it [photograph on 181], on the other hand was smooth-edged but less proportionate. Since it was drawn with the mouse directly using the software program, the designer did not draw the curves so fine that they pixelated on the screen. The jerky pixilated curve that I had observed on the paisley on the saree was also prominent on the screen. On the leaf, drawn by the mouse, it was not. Both elements were attractive enough, but they did not "match."

The pixelation itself was puzzling; since Jamdani was a technique that allowed insertion of extra weft threads into the warp end by end, why did the computer designer not design a motif 
with the right resolution? For a while the young designer Balaji did not understand my question, I demonstrated the problem by zooming in and out on the computer screen, and pointed to how the curves smoothed out when the motif was smaller, and explained that the smoother [not smaller] version was what I wanted woven on the saree. It was a frustrating conversation for both of us. ${ }^{227}$

B: I'm telling you! It has to be done on the loom by the weaver, not me!

A: No, but what you design on the computer screen is what the weaver can make on the loom, it is here that the change has to be made!

B: I understand what you are saying, but you are wrong. You are not paying attention to what I am saying!

It was later watching him as he designed at his computer, for his master-weaver clients, that the cause for his frustration at my lack of understanding became apparent. "A mango with two leaves" said the master-weaver, and Balaji pulled out a folder with mango motifs from the stored memory of the computer. "Not more than 100 turns and 3 bends" the master-weaver further specified; and Balaji immediately reduced the resolution [Figs 6.11 and 6.12]. The master-weaver was defining the labor that would make up each motif, this translated to resolution on the loom. Balaji's job was to design a motif that was aesthetic at that resolution. So rather than size of motif, it was the labor in weaving it that decided resolution of the motif. The master weaver and weaver were in control of the decision, rather than Balaji, and therefore, the decision to change was not made on the screen but had to be "done on the loom."

Once the resolution was fixed, the weaver carried it onto the loom. Depending on how labor intensive the weaver's choice was, each pixel in a graph would represent one end and one pick on the $\mathrm{x}-\mathrm{y}$ axis, or be bunched into two or three or even four ends and picks in the same pixel.
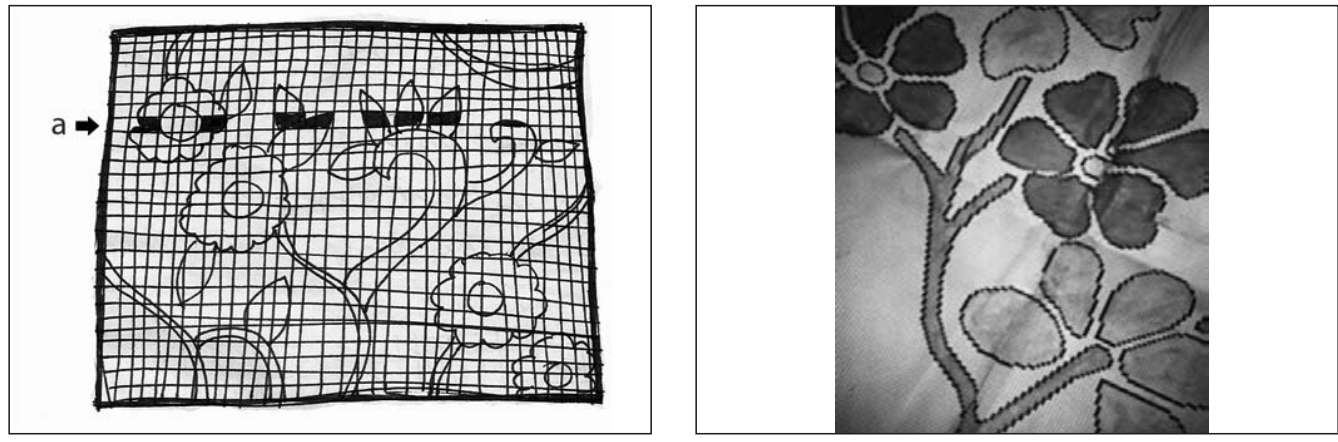

[Figs 6.11 and 6.12 "a" points to the line in this pattern with the maximum number of spindles that would have to "bend." In this case 8 spindles would have to be inserted into the weft to make the pattern.]
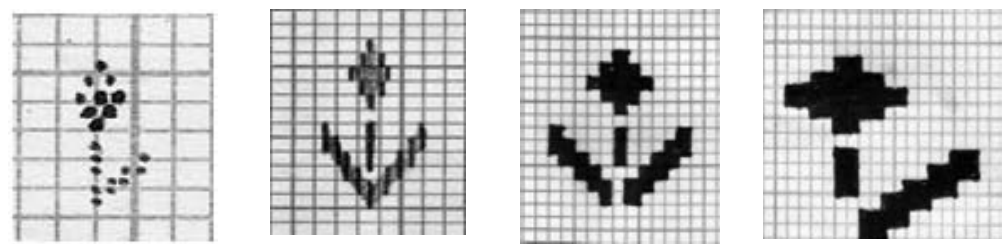

[Fig. 6.13 Graph 1 above shows a single end flower] [Fig. 6.14 Graph 2 shows a flower woven with two ends bunched together with three picks][Fig. 6.15Graph 3 shows a flower woven with three ends bunched together with three picks][Fig. 6.16Graph 4 shows a flower woven with six ends bunched together with three picks-One can notice how the pattern turns into a lower resolution version of itself with the decision to reduce labour]

227 Interview Balaji in Vellasavaram March 12th, 2012 


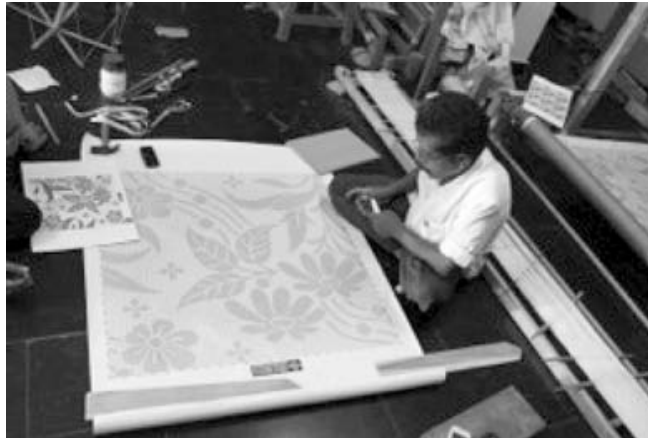

[Fig. 6.17 Making a printout of the pattern to be repeated for setting the loom]

In the instance of the pixelated paisley, the weaver worked on blocks of 4-by-4 ends and picks. Rather than lifting every thread to insert the extra weft bobbin, four threads were grouped together and lifted - thus, the pixelation on the woven motif, rather than the smooth curve [Figs 6.136.16]. This reduced labor and time of weaving and brought the cost down to the price available in the market. In the interaction between computer programmer and master weaver, this was the information that was also affecting the decision on pattern. Clearly, it was not the loom that was in the service of the computer, but contrary to all expectations, it was the computer programmer in service to the master weaver. Once recognized, this reversal of roles became apparent across all

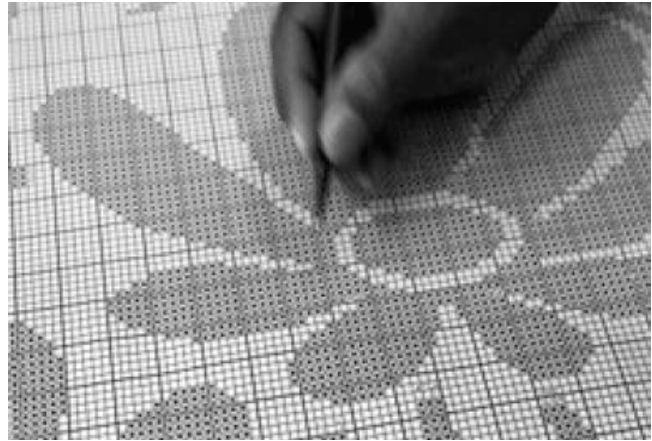

[Fig. 6.18 Smoothing out the pattern for ease of weaving on the graph]

the different stages where the computer acted in the sociotechnical ensemble.

How did this happen? Visually the computer digitized on the $\mathrm{x}-\mathrm{y}$ axis much as the loom did on the warp and weft. So at every stage, designing the motifs, planning the layout on the five and half meter length for repeats of the design, for setting up the loom so that the right threads from the warp would be tied up, using a graphical representation, to printing out the design onto graph paper, so that the weaver did not need to "keep it in his mind" but could visually follow the design rather like a cross stitch pattern, for all these functions the computer played a calculative role [Fig 6.17 and 6.18]. As a consequence, the labor could be decided prior to weaving, the price estimated, and the visualization of the layout could be simulated.
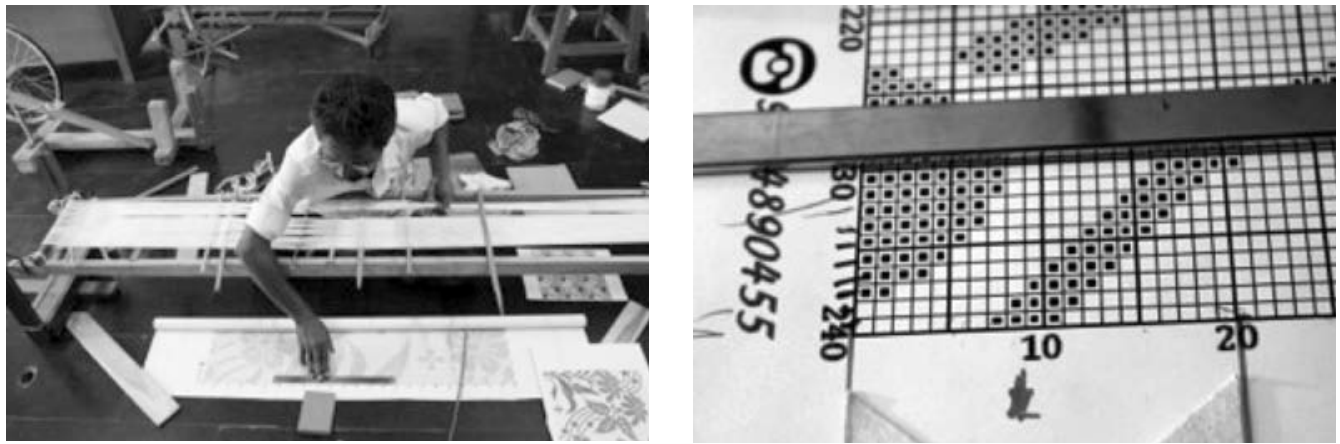

[Figs 6.19 and 6.20 Using the Graph to tie the repeat pattern into the jalari] 

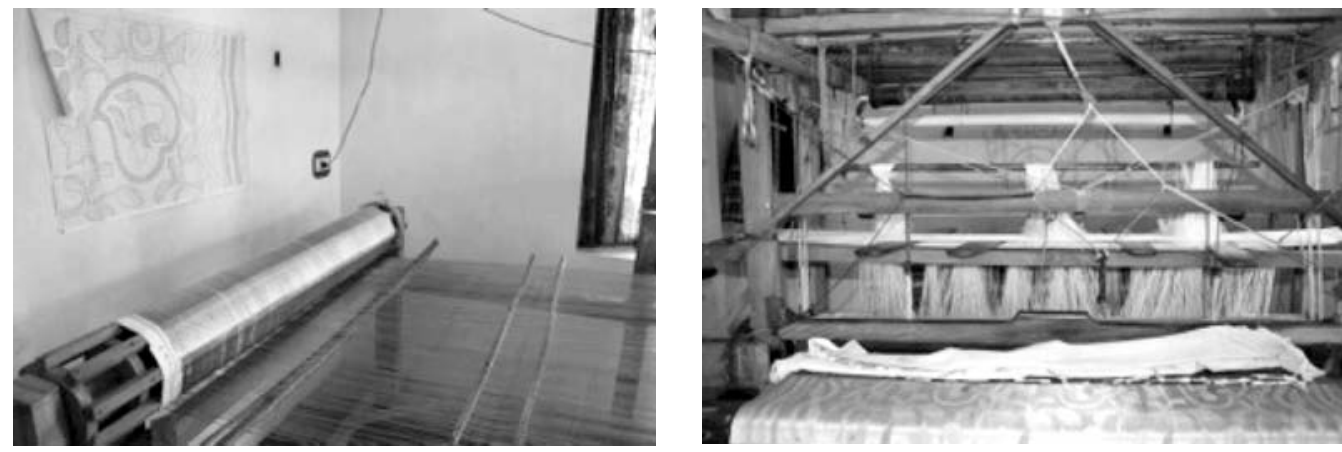

[Figs 6.21 and 6.22 Two views of the loom. The gold warp is wound on one side, and the graph is pasted above. The second view is from the perspective of where the weaver sits, the graph is visible at eye-level on the other side, for ease of weaving]

Furthermore, the weaving action worked on binary logic; at any point of time a thread could be lifted up or pressed down, with the shuttle passing in between in sequence to complete the weaving. To pick out a pattern, certain threads of the warp would be lifted and smaller shuttles carrying extra weft threads would pass between them, in an embroidering motion. The weft shuttle fixed the pattern in place. This required a "setting" of the loom using a jalari, [loom device that picks up warp ends according to the design repeats]. A graphic printout of the design to be repeated was taken out using the same count of blocks per inch as threads per inch to be woven. Threads to be lifted were marked in black, and to be pressed down left blank. The weaver setting the jalari setting performed the action of "remembering" and lifting the warp threads following the graph pattern [Figs 6.19 and 6.20]. While this was handcrafted, on the loom, the action could be simulated using the digital output of the computer software in a graph form. While the jalari had to be tied by hand, on the loom, the action could be coded in binary, (thread up black spot, thread down blank spot) using the output of the computer software in a graph form. Using this insight, any new design could be converted to a digital graph and printed out, and the time taken for setting up the loom came down by more than half [Figs 6.21 and 6.22].

\begin{tabular}{|l|l|l|}
\hline \multicolumn{1}{|c|}{ Function } & \multicolumn{1}{c|}{ Jamdani } & \multicolumn{1}{c|}{ Computer jamdani } \\
\hline Making the design & Master-Weaver & $\begin{array}{l}\text { Master weaver and Computer } \\
\text { programmer } \rightarrow\end{array}$ \\
\hline Making the graph for the design & Master-Weaver & Computer programmer $\rightarrow$ \\
\hline Making the set-up on the loom & Master-weaver by calculations & $\begin{array}{l}\text { Masterweaver by using } \\
\text { computer printout } \rightarrow\end{array}$ \\
\hline $\begin{array}{l}\text { Visualisation, Layout, Wages, } \\
\text { price }\end{array}$ & On the loom after weaving & On computer before weaving $\rightarrow$ \\
\hline Weaving & Weaver & Weaver $\leftarrow$ \\
\hline Changing to next design & Weaver & Weaver and Programmer $\rightarrow$ \\
\hline
\end{tabular}

Table 6.1 Comparison of functions in the Jamdani and computer Jamdani ensembles. The red arrows indicate speeding up and the green arrow indicates slowing down. 
For each of the functions in the Table 6.1 above, the computer was introduced as a tool to speed up the digital computing of the function. This reduced risk of errors in real-time on the loom. The loom had moved to a slower technique, but the computer had speeded up the "calculative" digital functions. These calculative functions had been "framed" in turn by the capabilities of the loom (Callon 1998, 15). As a result, the interaction of the slow and fast technologies was constantly mediated in order to reach an optimum match with regard to labor and value in the market.

Indeed today the computer is ubiquitous. Its presence in craft seems contradictory in a linear understanding of the time line of technologies. However, if we see them as two technologies that work on similar principles of computing, their coexistence does not seem so surprising. The digital loom in fact facilitated the advent of computers into the ensemble. It is already a well known historical detail that the cards that Charles Babbage planned to use to store programs in his analytical machine were inspired by the cards of the jacquard loom, an important predecessor to the development of computer programming (Randell 1994). When working together with the loom and the computer, for the handloom weaver, the computer was interestingly, not a radical technology; it demonstrated to the weaver the programmability of the loom as in the case of the master weaver who decreed his motif was worth " 3 bends and 100 turns" in order to tailor labor to price. Then, as Ensmenger (Ensmenger 2012) suggests, it makes sense to look at the "rich possibilities suggested by the inclusive term "computing" [that] have been limited by the narrow specificity implied by the word "computer," and equally, to talk not "in terms of 'computerization' but rather of 'digitisation"” (Ensmenger 2012, 767). Digital, thus, comes to mean an underlying structure of data, and it is in this core structure that we see how the loom and the computer overlap.

Handloom weavers across East Godavari had adapted to technological change in the environment and assimilated the computer into their ensemble of production, but if the loom itself remained static, was this really innovation? Was I, to take a cultural example, complimenting the newly widowed woman who had been forced to shave her head, on her radical new hairstyle? In my enthusiasm to find innovation, was I recasting what was a circumstance of misfortune into a considered and innovative choice? Was handloom doomed to dredge up old practices and techniques and serve them up as innovations, when the reality was that these "backward" technological changes were not choices made, but choices forced on weavers in their struggle to survive?

Would it not indeed be better if the weaver could mechanize the loom and improve productivity, rather than take up more laborious work on the primitive loom? To answer this, I had to better understand the weaver's understanding of the nature of choice. Why did the weaver innovate "backward" as it were, rather than forward? While on the one hand introducing the computer into the handloom ensemble seemed radical, was it indeed so, if in effect it allowed the loom to stay static?

I had seen weavers chose not productivity over beauty, nor tradition over technology, nor market over identity, but consistently a balance between the two. In the case of the digital Jamdani, the computer and loom did not just coexist in the ensemble as standards of oppositional paradigms; they worked together. In order to do that, they had to be made to interact and shape each other's functions to reach a balance in the service of the user. One produced intricate painstaking motifs to the taste of the user, one pixelated them to tailor the price to the buyer's purse. One technology slowed down productivity of the network, the other balanced it by speeding up the calculative functions, and so on. Where in just co-existing in an ensemble their purposes might have become oppositional to each other, in interacting and shaping each other, they worked together for a common purpose. The digital character worked as a common code between loom and computer. Since both the weaver 
and the computer programmer knew each other's technologies and shaped this interaction actively, this made the bridge between the loom and the computer usable.

What might drive weavers to swim against the prevalent tide of technology modernization, and remain bound to the handloom? Gangadhar, master craftsman in the Dastkar Andhra Design Studio explaining why weavers might make choices that seemed tradition bound, said: "I had the same question, when I went to visit a Gadwal weaver who makes the most elaborate patterns with his hands using the most basic loom. Why didn't he upgrade his loom with newly available accessories? The man told me, "Here everything I need is at hand. I don't have to get up and bother myself over this activity and that. Once I am weaving, I don't know time passing, it is a flow. And when I get up from the loom in the evening, I feel as alert as I did when I woke up in the morning." 228

Mechanizing was not always a better choicesome things were, in the master trainer's opinion, better done using human skill. Explaining what it was the weaver of J amdani could not delegate to the computer, the mastercraftsman Gangadhar made a distinction between understanding J amdani and weaving Jamdani. "This is like learning to swim, you have to get in the water! The skill is in the rhythm of the body and focus of the mind.... It is hard work when the weaver labours over the motif, thread by thread. But what he is building is patience/attentiveness [opika]. After that comes the role of skill. Even as he learns to pick out the J amdani motif on the loom, what he is evaluating is his own skill in maintaining a perfectly even warp to weft ratio. The design is made for a certain width and length, which has to be maintained through perfect denting and beating. If the weaver beats to 0 hard, the threads are compressed, and the motif is foreshortened, if he beats to o loosely, it is el ongated. $\mathrm{His}$ body needs to have the right rhythm in it, like an in built drum, except this is not the rhythm of

228 Interview with Master Jamdani weaver, G. Gangadhar, Hyderabad, April 27th, 2013 time wielding a stick, but the rhythm of movement in wielding the loom. Only if he has that, can he begin to aspire to weave J amdani."

Sorensen links technological innovation to embodied knowledge-“Locally available knowledge — both explicit and tacit—embodied in living persons is known to be critical to innovation." (Sorensen and Levold 1992, 21) The interaction between the weaver and his loom and shuttles, the interaction between the programmer and his computer and mouse both could be understood as tacit, embodied knowledge. One skill was not necessarily better than the other, but could be seen as the choice that each innovator deployed based on their expertise. It was not chance that Balaji innovated for the loom using the computer, this innovative computer programmer was the son of a weaver and understood both sets of skills and their graphic commonality. The interactive nature of balancing choices makes the endeavor a collective one, an exercise in practical social construction of technology based on effective social practices.

The need for complex social organization for technological innovation is predicated on how technological systems problem-solve, as against science. Constant (Constant 1984) characterizes innovation in technology as having three features; decomposability of technological problems into subproblems, interface constraints, and interactions between specialist communities, sometimes outside the network. This decomposition requires complex social organization; subproblems are distributed according to disciplines or expertise. Interactions between these communities have to be disciplined, and integrated into a whole to represent a solution to the original problem. (Sorensen and Levold 1992). Actors in the network may define their problems differently, based on their interest, (Callon 1980) but a dominant problem definition has to be negotiated between the actors (Vergragt 1988). In handloom, the complex social organization and robust social practices are a given, but since expertise is "tacit and embodied" (Polanyi 1962) rather than explicit and propositional, the expertise is not so visible. To outside viewers, such as policy makers, the 
expertise and interactions that produce the digital Jamdani are as invisible as the resulting innovation is. However, closer to the weaver, the innovation becomes visible; particularly as the problem that the innovation sets out to solve is explicated.

At a basic level the turn to J amdani solved the problem of increasing capital costs of yarn and the resulting decreasing returns on labor. Through adopting Jamdani, weavers constructed value for weaving labor, value in the market that could absorb the rising capital costs as yarn prices increased. The focus of the weaver shifted from viewing the problem as crisis, to turning it into opportunity and allowed for innovating in the market for luxury products. In making the most of this opportunity, the solution of the weaver is to find balance between productivity and an intuitive goal of visual appeal or beauty, in this case they shift to J amdani.

The technological move "backwards" can then be seen from two perspectives. As an innovative and entrepreneurial move forward, one that uses cultural knowledge of both producers and users to create a new product, a new market and a new quality of product. Initially innovation is driven by those master weavers who are intimate with the recipient or consumer process, resulting in product innovation, later when needs are well defined, innovation locus shifts to those with technological insights, resulting in process innovation (Utterback and Abernathy 1975, 646). This innovation of process successfully combines old and new technologies in the network. It can simultaneously be seen, in answer to the question about the widow and her shorn hair - as a political move. In choosing to move back in time toward the more traditionally identified product, weavers chose to address the loss of self-respect that they feel modernity has served them. There is another opportunity here for the researcher to mirror to weavers that they do not have to be a "herd" following the rest of the world into productivity and efficiency; they have other alternatives up their sleeve. Resisting the label of labor, they can demand recognition of their skill and their innovative capability-recognition through calling on collective cultural memory and creating a valued identity in the customer's mind. This is what turns J amdani from being a solution in a crisis, to opportunity in the existing market, and finally to a vision and direction for innovation in the handloom industry.

\subsection{Cultures of INNOVATION IN HANDLOOM: THE NEED FOR CONTINUITY IN Cultural Production And MARKeT}

The handloom ensemble does innovate, as we have seen, why then is it not seen as innovative? What makes this innovation invisible to policy makers, to society at large, to the weavers themselves? The state sees handloom as "backward" technology, drawing on the discourse of industrial modernization. Within this discourse, handloom can progress only through mechanizing. For society at large, the discourse of tradition as regressive plays an important role in keeping innovation invisible. Weavers themselves recast their products as traditional, while innovating. It is only when we explicitly look for innovation that we are able to demonstrate it, as imperceptible and invisible collective change in a technological culture that values tradition and continuity. However, when we use current concepts of innovation in order to describe creative change and growth in handloom, are we using a rhetorical trick of recasting handloom as innovation, as weavers would recast innovation as tradition? Are we as analysts playing theoretical catch-up with the newest concept on the block?

Working in what evolved into the "Development Sector" for 20 years between 1991-2011 entailed a great deal of sitting on old newspapers in obscure railway stations, waiting companiably for co-travelers and trains, drinking coffee of varying quality - bilge water to milky sugar syrup to dark grounds. It seemed only fit that most of my regular meetings where both my Dutch 
supervisors were present, would take place in the cafés of the train station in Utrecht; the location of the actual coffee drinking shifting as the station refurbished itself around us. It was February 2014, in a meeting where the innovation chapter was being discussed, that Prof. Louk Box pointed to the fourth empty chair at our table, and wondered aloud "What would I say to my esteemed Indian social scientist colleague, who if sitting on this fourth chair, reading this chapter, would congratulate me on turning you into an excellent Dutch scholar, but....would ask what happened to the Indian?" I recognized the researcher's trap that I was being warned about: understanding that is limited by the analytical concept that I was using. My analysis had made the particularity of the culture of innovation in handloom disappear.

I had had a similar moment of disorientation when discussing innovation with the senior musician Smt. Vedavalli, some months before, at her home in Chennai. Karnatik classical music is a tradition of music from the South of India, which has in the last century produced reflexive musicians who have developed a vocabulary for raising questions regarding its evolution as tradition into contemporary practice. Smt. Vedavalli is an acknowledged traditionalist at the same time had been fiercely independent in the creative aspect of her music. I was meeting her at a serendipitous moment when she had just innovated on a piece of traditional music, yet had seemed to retract and announced it as an older traditional design of her teacher that she was presenting. I related to her what weavers did, innovated their product, and recast it as tradition, and suggested that her innovation too was of that style. Rather than being complimented on being seen as innovative, she rejected it strongly - "Why would I need such an immodest term to describe my singing - everything that I have is through the grace of my teachers and the blessings of the Divine." Though shocked by her response, at that time, I had brushed it aside as being sentimental. However, it provided strong evidence of the gap in my understanding pointed out in the Utrecht coffee meeting, the need to define a concept of innovation that was particular to this context. To this end, I interviewed reflexive musicians, Sangeetha Siva Kumar, T. M. Krishna, Sumitra Vasudev, and Sushruti Santanam in order to understand a new concept of innovation that would be useful in contexts where tradition is innovated to maintain tradition.

Indeed the existing concept of innovation disrupted the idea of technological progress as being inevitably that of mechanizing, which would lead to the extinction of the hand operated loom. However, it was not enough to conceptualize adequately innovation within craft, where the term innovation itself was seen as pejorative. At this point, I made an unconventional shift. Innovative Karnatik classical musicians rather than innovative weavers became the source for studying the culture of innovation in tradition. One clear conceptual move that facilitated this shift was to study music too as craft, ${ }^{229}$ with a tradition of innovation - this helped bridge the core difference between music and handloom as art and economic activity, respectively.

Amartya Sen investigated how an Indian identity matters in firing innovation action and in identifying the influence of values and cultural identities on economic behavior "over and above the general discipline that is provided by economic feasibility and commercial viability" (Sen 2005, 335). He finds it useful to recollect at that point Rabindranath Tagore's remarkable claim, made in a letter to CF Andrews in 1921 that the idea of India itself militates "against the intense consciousness of the separateness of one's own people from others" (Sen 2005, 339). In describing innovation in handloom as innovating tradition, we can describe a new concept of innovation, one that invokes a particular rule/structure/framework through its practice - as Indian craft that has a long tradition of innovation, and examine if it indeed can stand up to the integrative claim that Rabindranath Tagore makes of the Indian Identity.

229 For another discussion on music craftsmanship see (Roy 1998b) 


\subsubsection{INNOVATION THAT PERMITS CHANGE TO MAINTAIN TRADITION: VALUING CONTINUITY}

An important step in describing innovation in the handloom ensemble is the paradox of permitting change to maintain tradition in the art, craft, and aesthetics of handloom; that is, we have to pay attention to how innovation as a concept both maintains continuity as well as propels change. Handloom activist and scholar Niranjana raised the question of innovation in tradition, when first encountering the concept in 2006, "I'm not very certain how innovation is seen as a concept, but it must be as a series of incremental changes to an existing body of knowledge, which allows us to explore new angles. But doesn't innovation also serve to found new traditions (whether in music or philosophy, or technological innovation)-where innovation is driven mainly by the limitations inherent within the existing body? Are there tensions between the innovation and the tradition that we are missing? 230"

How did handloom innovators of the past manage a process that innovates and sustains tradition at the same time? Tirthankar Roy's scholarly work based on a series of craft studies between 1900 and 1920 points to the notion of continuity in handloom innovation among J amdani master artisans in colonial India. These "masters" adapted to technological changes in the world around them and innovated in craftsmanship through their agency as individual skill leaders. However, innovations could not be arbitrary changes: "Skill leaders were the collective's answer to the question of who had the right to decide technological change or continuity" (Roy 2007, 365)-delicately titrating both to leverage their skill as well as market recognition.

Another way to understand innovation in tradition-bound technologies is offered by Pinch and Bijsterveld (Pinch and Bijsterveld 2004), who put forward the auditory dimension as an extension of Science and Technology Studies' focus on material [and embodied] practices. Employing analyses from

230 Seemanthini Niranjana, personal email, 12/3/06
STS in the study of Sound, Pinch and Bijsterveld say "thinking of musical instruments as technological artefacts with unique user communities [musicians] brings sound studies within the domain of technology studies" (Pinch and Bijsterveld 2004, 638). Musical instruments are not only technological artefacts, in fact "studying the evolution of musical instruments can tell us much about music as a form of culture. Musical instruments are used within highly developed and circumscribed social and cultural environments.[...] What is often at stake in such cultural transformations is the very demarcation between noise, sound, and music (and indeed silence)." By extending the study of technology into music, they move from the domain of science to art; from technology to music, from knowledge to culture.

Studying instrument makers in the world of western classical music, Bijsterveld and Schulp (Bijsterveld and Schulp 2004) describe how innovations in instruments come about in this conservative and stable world. "How do today's instrument makers innovate and sell in a traditionbound field?" More important for this chapter, they ask, "How could insights in such strategies be valid for fields of technology-development in which tradition and craft have a similar significance?" Their paper draws attention to how successful innovators rephrase or repackage tradition in a new waythey recast tradition so as to innovate and sustain tradition at the "very same time." (Bijsterveld and Schulp 2004, 649) Like the instrument makers whom they study, handloom weavers too change the design of the new Uppada Jamdani saree to bring it closer to tradition, and rely on rhetoric such that tradition appeared closer to innovation.

Taking this metaphor of recasting tradition from Sound Studies back into the craft paradigm, there are other comparisons we can make. As in sound, so in handloom craft innovators have to contend with "history." Such histories "encompass orchestral culture, including its visual icons and 
'frozen' ideals of sound, the patents of times past, the longstanding master-apprenticeship model of teaching, the individual histories of time consuming practice leading to tacit knowledge; and the engaging character of the musical instruments, partly constituted by their wear and tear." (Bijsterveld and Schulp 2004, 669) In the case of Jamdani, history encompasses the sociotechnical ensemble of production and consumption, including its visual icons and museumized relics, and the identity and social status of its historical patrons. Indeed exactly as in the case of music, Jamdani had a smiliar longstanding model of teaching and the consuming practice leading to tacit knowledge and the engaging character of the technology. The computer programmer as innovator in the handloom ensemble strives to use a modern technology to sustain a traditional world through "creative marginality" (Dogan and Pahre 1990), the impulse of which is not to destroy but to sustain the old.
Radical innovations are antithetical in large technological systems, violating the conservatism that is inherent in these as they grow and gain momentum (Hughes 1987 (2012)). The handloom ensemble seeks stability in a shifting market. Here also, radical innovations that generate discontinuity between the old and the new would add pressure to already vulnerable livelihoods and thus increase risk. So, primarily, weavers aim at incrementally innovating for continuity that sustains their deep craft on the loom. The value that their market attaches to continuity-handloom's association with Gandhi and the freedom struggle, with the finesse and beauty of the Banarasi brocade, the Kanchipuram silk, or the Ponduru cotton, with India's past when its industry produced the best textiles in the world - allows for a sizable margin for sustaining such innovation. Cultural memory is invoked and refashioned for a new generation of users, rather than stressing newness and change; thus, Jamdani weavers innovate to maintain tradition.

\subsubsection{TRANSGRESSING THE DILEMMA BETWEEN REGRESSIVE AND PROGRESSIVE: INNOVATING TRADITION}

If continuity were so important to cultural markets, why then would weavers experiment with radical innovations such as introducing computers into J amdani weaving? Such innovations become necessary when risks to livelihoods are already high, due to instability in the market as with the increased yarn prices. Then the continuum of technological trajectories that exist during more stable times sharply divides into two extremes, both of which would result in the loss of handloom livelihoods. One trajectory is toward mechanization, with its implicit connotation of progress; the other is to museumization, as preservation of a regressive past-for the consumption by the progressive cultural elite. In the first case, handloom technology is forced into a predetermined path to modernity toward its extinction; in the second, handloom is frozen in time as fossilized technology. At this point, tradition becomes a boundary that constrains handloom and even threatens its survival. Therefore, the next step in conceptualizing innovation in handloom comes from understanding handloom innovators' need for disrupting existing trajectories that constrain sociotechnical change in handloom. These innovators then encounter a new dilemma: how to maintain continuity for the loom while transgressing the boundaries drawn by tradition. This they achieve through shifting the boundary of what constitutes tradition. They innovate tradition itself.

When the master weaver Sarode transplants the traditional technique of Jamdani to newer locations and recasts tradition with little regard for historicity or geography, when programmer Balaji uses computer software to redesign centuries old motifs in low resolution, when a young weaver Suribabu learning Jamdani uses a graph paper to 
repeat a pattern rather than engage his memory as the older Venkatagiri weavers did, there is a sense of deflation of the authentic. Even when one explains it away as a survival tactic, it is an outrageous stretching of a classical metaphor that brings forth a nervous giggle in its irreverence for the sacred. It is immediately perceived as transgression of tradition.

All innovations are about change, some are acts of boundary shifting (Pinch and Trocco 2002), which can be experienced as transgressive. The transgressive act I describe is then a trespassing of the boundary between the traditional and the modern as defined by cultural arbiters of tradition from within handloom. When does it become necessary to transgress this internalist boundary of tradition? I introduce the notion of transgression in order to create space for dissenting to the regressiveprogressive bind. The standard analyst's assumption in the regressive-progressive dualism is one of discontinuity, mirroring the incommensurable fracture between what is traditional and what is modern. Traditional handloom weaving is perceived as regressive technology, and in need of becoming progressive. Yet handloom technology if it is to be progressive, can only be mechanized; the loom cannot be hand-operated and still be considered modern. On the other hand, its regressive identity will result in handloom being museumized. How does the weaver resist this dilemma? Acts of transgression become necessary to escape the bind that this dilemma creates for technologies embedded in history and culture. This is what weavers do in the case of computer Jamdani. Innovatively combining J amdani weaving with computer design is a clear transgression of the "traditional" identity of J amdani.

What happens next, to the computer Jamdani innovation? Weavers carefully mediate innovation, otherwise they can lose the niche of cultural customers; these customers only respect the old. At the same time, the new innovated product is in danger of losing its novelty value to the new customers over time to newer innovations - the novelty market segment is fickle, looking for the next new thing, the market for tradition is more stable. The Jamdani weaver initially transgresses the boundaries of geography, authenticity, and purity in order to innovate. As he gains sanction from a new market, Jamdani achieves success among an emergent cultural group who are looking for a new product to express their identity: the weaver is now recognized as being innovative. It is at this point that the weaver performs an inversion. If continuity has to be maintained, for both the producer and user of the artefact, then the innovator cannot transgress beyond the boundaries of the art as defined by its history. Also, he does not want to risk being cast out as a transgressor of tradition. Instead, the weaver recants from the position of innovator: he prevails on the cultural memory of key opinion makers, the Aunties and Ladies, and recasts Jamdani as tradition. In doing so, J amdani gives up its claim to innovation, but gains continuity in cultural production and in the market.

At the same time, the weaver has succeeded in innovating Jamdani with the computer, and making it acceptable within the handloom tradition. The explanation, thus, follows three steps: first innovators transgress the boundaries of tradition; second, through gaining acceptance for their innovations in the market and then recasting it as tradition, they succeed in shifting the boundary of tradition; third, this shifting of the boundary between tradition and modernity resolves the weaver's dual transgression of both domains and his innovation is sanctioned. Therefore, tradition is innovated. 


\subsubsection{TRANSCENDING THE GAP BETWEEN TRADITION AND MODERNITY: EFFACING INNOVATION}

The notion of continuity in innovation in traditional crafts finds an echo as we have seen in the thriving art of South India, Karnatik classical music. Here too innovation is linked to skill and the tension between the "authentic old" and the "creative new"; and innovation as a word is perceived as immodest, rather it has to "feel right." "In an art, where continuity is important, change is arrived upon which 'it feels right'. Innovation [on the other hand] has explicit ownership and the radical is all about [individual] ownership: 'I changed it, I innovated, I created' . It is immodest." ${ }^{231}$ This echoes the sense of "arriving" through repetition, which scholars Emily Gomart and Antoine Hennion (Gomart and Hennion 1999) refer to with respect to musicians and their instruments.

As much as innovation has positive value in the field of technology, it has a negative one in the minds of practitioners of Indian arts and craft where being traditional has positive connotations. Here, rather than being desirable the demand for innovation is experienced as an immodest attempt to change and dilute what is authentic. To stand for tradition is to invoke and value the masters of the past, to claim innovation would be ascribed as presumption in the face of that greatness; after all how does one innovate on a classic?

In support of this perspective, musician Sangeetha Sivakumar upturns the view of tradition as a constraining set of rules that inhibits innovation: "the more rules the better, within which I can challenge my creativity." ${ }^{232}$ Rules are boundaries within which she can focus on aesthetic evolution, a pleasurable rather than constraining experience. How can we capture this culture of innovation, in which the core value is not newness but rather tradition? In the previous subsection I sketched how the weaver escapes the double bind of regression/

231 Interview and Telephone conversation Sushruti Santanam quoting her mother, Classical Musician Vedavalli

232 Interview, Sangeetha Siva Kumar $7^{\text {th }}$ December 2012 museumization - progression/mechanization; can we also find a way out for the analyst-researcher? Can we find a vocabulary that makes sense of the innovative character of handloom development and at the same time is recognized by weavers?

Such vocabulary is elusive for two reasons. First, weavers who innovate for their livelihood do not theorize it, but practice it on a routine everyday basis "idi maaku maamoole" (this is normal for us) ${ }^{233}$. Second, from conversing with creative Indian musicians (who closely follow the trajectory of the handloom weavers when they innovate in the classical form of Karnatik music, recasting it as tradition), it became apparent that the language of innovation with its focus on the innovating self is perceived as being immodest as a claim, and populist and market driven as an action. For the musicians both connotations are pejorative. Instead, the creative response - the impulse to create-as well as the creative moment are both part of a spiritual journey that is sublime. ${ }^{234}$ The creative response is received as "grace," from God, ${ }^{235}$ as well as the "blessing" of generations of teachers who handed the gift down across time. This cultural reading of innovation foregrounds the value of continuity; not just for the loom and in the market, but for retaining craft knowledge over time. Knowledge is held in trust, to be handed to the next generation of practitioners, much as it was handed down by masters from the previous generations.

Not just in Indian culture, even in the place where it originated as a concept, innovation did not always have a positive value. Writers in early 19 th century Britain and France essentially represent innovation as pejorative, the innovator was a person who departed from social norms, a deviant

233 Weavers' meeting in KICS, Krishna Rao, Weaver, ponduru 8/1/2015

234 Faith in god is perceived as deeply personal, and was not always expressed in the interviews with musicians. Some musicians [particularly TM Krishna] are perturbed about the over-religiosity perceived in their music, and express reservations regarding audiences' ability to appreciate music in itself as art. Yet, all acknowledge that creativity is a sublime experience.

235 Discussion Sushruti, Vedavalli, Karnatik Classical Musicians, $7^{\text {th }}$ December 2012 
(Godin 2015, loc 276). Yet despite the denials, people innovated constantly. Innovation-which included heretical thought and deviant actionwas part of the movement in the mid-19th century that was concerned with the quest for freedom (Godin 2015, loc 381). We see that even in such a contemporary [modern] culture, which values risk taking and individualism, innovation cannot be assimilated unless its meaning is shared. Others besides the innovator himself have to be able to find the thread of continuity in the novelty he imposes. Schumpeter's choice of terminology in which innovations and new combinations are used as synonyms already points to the perspective that "almost all innovations reflect already existing knowledge" (Lundvall 1992, 9) and that innovation is ubiquitous. Novelty must then be perceivable as a regular event. Indeed even when the social ideal may value change and innovation for their own sakes, "underlying the novelty is a deeper recognition of its familiar aspect" (Marris 1975loc 2415).

One way to resolve the tension between sublime tradition and modern innovation can be through focusing on the "creative response" of Schumpeterian innovation (Schumpeter 1947, 150). While they reject the claims of innovation as immodest, Indian classical musicians accept the vocabulary of creativity in its place. In order to explain creative ability, they separate practice, "saadhana," and the creative expression of it, "manodharma." Practice that builds craft, "saadhana," has clearly defined steps: first skill is built through repetition, then rules are learned through imitation and emulation, then fluency is acquired through variation, and finally-while learning to face the uncertainty of performing creative ability is tested. ${ }^{236}$ The creative response or "Manodharma" on the other hand is not clearly defined, except that it comes after long years of acquiring skill-it is a leap of faith, accompanied by an experience of the sublime divine. It is an unconscious moment that needs the guiding hand of

236 Interviews with musicians Sangeetha Sivakumar, TM Krishna, Sumithra Vasudev, S. Vedavalli, December 7th, 2012 the engaged teacher and is received as "blessing," by the student.

In science too, it is believed that many creative advances are a result of a leap of insight accompanied by the "aha" experience (Weisberg and Reeves 2013, Akin and Akin 1996, Bassok and Novick 2012). Therefore, studying insight in the lab provides understanding of creative thinking in the world (Weisberg and Reeves 2013, 12374, Ohlsson 1992). Like in music, practice that builds craft is important: scientists need 10 years of building skill before producing their important publications (Simonton 1996)(Weisberg and Reeves 2013, loc 13377). Social processes that led to scientific discoveries included learning heuristics from senior scientists, much as students imitated their musician teachers (Dunbar 1995). Fluency and flexibility of thought are a prerequisite for creative thinking both for scientists and musicians (Guildford 1950). In both cases, fluency implied sufficient mastery of the heuristics while being flexible in the face of uncertainty. In science, problem solving is seen as the site of testing for unconscious processes of creative ability. The uncertainty of reaching an impasse in problem solving, when the mind is "blank" comes before an insight that is the "act of breaking out" of the impasse, leading to an unconscious leap of insight, which scientists call the "aha" moment, (Ohlsson 1992, 4) and musicians express as a leap of faith leading to a moment of "grace." While in science, the focus on reason centers the individual innovator and in Indian music the focus on the "divine bliss of creativity" centers faith, I want to argue that the creative process that leads to innovation is identical in modern western science and traditional Indian music.

Sennett explored the same intimate connection between hand and head in his book "The Craftsman" (Sennett 2008). He theorizes that all skills - even the most abstract—begin as bodily practices, and that technical understanding develops through powers of imagination. The capacity to sustain repetition is important and it expands with skill. He focuses on imitation and 
on learning as copying. The eureka moment, he asserts, is embedded in routine; he contrasts this view to the criticism of modern education that fears repetitive learning as being mind-numbing. Skill opens up in this way because "the rhythm of solving and opening up occurs again and again" (Sennett $2008,38)$. Yet, rather than giving up in competition with the machine, he suggests that the assertion of our own individuality is key and to be achieved through modesty and an awareness of our own inadequacies. Exploring a concrete account of how intuitive leaps happen, even within the limitless horizon of the sublime that defies syllogisms, he settles like the weaver-dyer on the tool as the route to take the imaginative leaps toward an "unknown reality latent with possibility" (Sennett 2008, 213). Though he does not refer to creativity, we see the same steps as in music or science - that sheer movement repetition becomes a pleasure in itself, rules that establish the rhythms of repetition have to be learnt, but simple imitation does not sustain satisfaction, skill has to evolve. In describing the intuitive leap as a form of reasoning that defies syllogisms, Sennett suggests that intuition can be crafted. The clubfooted Hephaestus, proud of his work, if not of himself, is the ideal to strive for (Sennett 2008). All three examples-Karnatik music, science, and craft-bring to the fore the quality of effacement of the innovator, explaining how innovation is itself effaced in handloom.

\subsection{A CONSTRUCTIVIST VieW OF HANDLOOM INNOVATION: TACIT IN EXPERTISE AND TACIT BY DESIGN}

To summarize, Jamdani is a 2000 year old tradition, and at the very same moment an innovation driven by and in turn driving the market. J amdani has materiality; the sociotechnical ensemble is made of old things like the loom and warping drum but also of new things like the computer and the mobile phone. High on tacit knowledge, it is dependent on face-to-face interaction for knowledge transfer to succeed, so spatiality and geography matter. As an idea of innovation, it travels through time, constantly acquiring new meaning, like in the case of $\mathrm{G}$ adwal then and J amdani now.

I have attempted to conceptualize innovation in J amdani within innovation theory: J amdani as a product innovation, market innovation, user-driven innovation, and as process innovation, through focusing on the innovative weaver. Innovation typologies abound in literature; the product and process as sites of innovation are well recognized, Schumpeter onward. Weavers skill themselves, learn Jamdani weaving and create innovative products as a response to the crises such as the yarn price rise. Users are key for weavers to innovate in the market, in this case through the assimilation of the mobile phone into the sociotechnical ensemble, which creates new customer groups for Jamdani. Using the computer as a graphical device across weaving functions is a process innovation; it speeds up the calculative functions so that the weaver on the loom may take up intricate J amdani weaving.

I define innovation in handloom as a recombination of old and new knowledge in the sociotechnical ensemble of handloom. Rather than viewing it as an adaptive response to the environment (suggesting a rather linear problemsolving logic), Jamdani is a creative response, an unlikely opportunity seized in a moment of crisis by skill leaders designated as such by the collective. Not all creative responses need to be born of crises; under stable conditions innovation in Jamdani could have been measured and incremental.

I categorize Jamdani as a full-blown innovation by handloom weavers on the premise that if it walks like a duck, quacks like a duck, it must be a duck. Jamdani as innovation does not completely fit the duck allegory though, when it 
recasts itself as tradition in order to gain continuity in the cultural market, and thus shed its pejorative aspect. The definition for innovation in handloom that till now seemed firmly within innovation literature categories suddenly falls through our grasp. Something is indeed missing.

At this point, rather than constraining creative change in Jamdani into the categories of existing innovation concepts, I want to ask what an analysis of innovation in Jamdani weaving adds to our understanding of sociotechnical change in handloom weaving. It is here that I make a case for a constructivist [and in this context socio-cultural] interpretation of Schumpeterian innovation, arguing for a specific innovation culture that characterizes technologies that innovate for continuity. In doing so, I explicate how different actors construct a tacit dimension to innovation.

Innovation in handloom is predicated on the engagement of weavers with the "hand" loom, where their deep craft has been built. This craft is imbued with a high level of somatic tacit knowledge, embodied expertise. Such somatic expertise is by definition tacit; innovations in this sphere tend to also be tacit.

Innovation becomes tacit because weavers innovate for continuity both for the loom and in the market; innovation maintains tradition. Weavers refer to this kind of innovation as normal and routine ['idi maaku maamoole']. Radical innovations that create discontinuity between the old technologies and the new in the ensemble add pressure to already vulnerable livelihoods and are not the norm. Weaver innovators strive for continuity for tradition in the market, with the result of not being recognized as progressive technologists and innovators. It is authenticity that is important. Therefore, even when weavers innovate, they do not focus on change, but make visible the familiar aspects that aspire to be closer to the authentic old.

This does not mean that innovation in such a culture is always incremental. Innovation within the boundaries of tradition can be compared to
Kuhn's normal science, with one paradigm and a dedication to solving puzzles. What follows next, when innovators transgress the boundaries of tradition is similar to revolutionary science, which is full of anomalies and unexpected outcomes (Kuhn 1962). Innovators in handloom do transgress the boundaries of tradition and innovate radically, as in the case of the computer J amdani. However, when innovators have transgressed the boundary of tradition, even if it is successful, they retract the innovation and cast it as tradition. If the innovation succeeds in the market, it does so because the boundary of what constitutes tradition has been shifted; as a result, tradition has been successfully innovated. Such innovations are designed to be tacit, so that overall stability in the cultural market for craft production is conserved over the long term.

Another reason for innovation in handloom being tacit or invisible is that even where they innovate, actors efface their innovation in a culture that does not value the immodest "I" of the innovator. Innovation of tradition has a pejorative association, in a culture that translates the unconscious leaps of insight and creativity that innovators experience, as divine grace. In the case that there is no spiritual motivation, yet, a label of immodesty is attached to the explication of innovation, though creativity of the actor is finely evaluated and valued. Effacement of the self, rather than hubris is seen as a prerequisite to being open to receiving creative insights. Even when the creative act fits the criteria for being conceptualized as such by researchers, innovative actors actively disown the label.

Why then do we need to label innovation in handloom? There is a sense of disquiet in conceptualizing innovation in the context of handloom; the attempt seems to undermine the nature of change it displays of valuing continuity and tradition. It is here I turn back to the original crisis of the policy maker in handloom that I started with - the problem of handloom being outdated because it does not innovate - and the supposed solution of increased productivity through 
mechanization. This pervading atmosphere of technological determinism that dictates the handoperated loom must give way to mechanization predisposes policy makers to overlook creative changes that actually take place in handloom.

Innovation in handloom, like in any technological culture is socially constructed as being so. This analysis suggests that innovation in handloom is ever-present, but is not recognized as such because the society within which it innovates does not expect it to innovate, or understand how it innovates. To acknowledge the validity of innovation in handloom technology demands from the policy maker cognitive justice (Visvanathan 2006). Then he would recognize innovation as it exists within handloom and not as a modernist concept that constrains the development of handloom, or has to be imposed on it. This understanding would dislodge the perception of the weaver as an old-fashioned cultural icon and recognize him as an innovative technologist-a citizen in a society that continues to sustain and value him, but now with more self-awareness about why it chooses to do so. 


\section{TOWARDS A THEORY OF INNOVATION FOR HANDLOOM WEAVING IN INDIA}

It began with the quest for indigo, the opening of the trade routes between India and the West in 1498, as "an emporium of colour was shipped to Europe [...] and big chunks of empire were acquired through red cloth, and blue and white beads," as "colour bequeathed colour" (Taussig 2008 , 3). Indigo was the pride of the master dyers of India (Gittinger 1982), and in the century after indigo was first synthesized in 1880, handloom weavers experienced the crisis of confidence and the consequent decline in their livelihoods, which were relinquished to industrialization (Bagchi 1976). Indigo was again the reason that farmers of Champaran in Bihar rose in revolt against the feudal system and the colonial masters (Guha 1974). The battle to regain independence for India first began with indigo in 1916, when a youngish man named Gandhi chronicled the travails of the indigo farmers, beginning of a civil resistance movement that he called satyagraha(insistence on truth), which was to win India her freedom (Gandhi 1948).

In a little booklet Gandhi wrote in 1908 called Hind Swaraj, he described what freedom for India would look like, including the role that science and technology could play in the lives of the ordinary people of India. For a people whose sense of self was being fragmented by a warped alien mirror, the confidence with which he constructed a new reality contiguous with the lines of the old brought coherence, both in thought and action.
Thus, Indians allowed themselves the possibility of change that would lead to better outcomes - a new reality that did not erode their sense of self.

In November of 2008, a hundred years after that little booklet was written, a small group of academics and activists from across India ${ }^{237}$ engaged in a collective act of remembrance. Over a turbulent period of five days of the "writeshop" titled "Science, Ethics, and Politics of Research and Technology: An Indian Manifesto," we attempted to remember and rewrite Hind Swaraj for the current time, as science policy for $21^{\text {st }}$ century Indian people. Rural energy activist Sreekumar, a student of Amulya Reddy, the scientist and follower of Gandhi who had famously demanded that Indian science and technology should,"devote itself to the generation of an alternative pattern of [.... technologies of relevance to the rural poor," (Sreekumar and Sant 2006) was one of this group. Struggling with the impossibility of laying out a manifesto that could stand up to the legacy we had set for it, he said, ruefully, "the person who can tell the story of energy in India is yet to be born." Indeed this felt true for every one of us engaged with our particular story - in energy, water, land, livelihoods, handloom weaving, displaced people, communal violence - the list seemed endless.

237 "Science, Ethics, and Politics of Research and Technology: An Indian Manifesto" 'writeshop' in Ahmedabad, 21-25 November 2008. Wiebe Bijker was also present in this group and, along with others in the group, authored the final report ([KICS] 2011). 
Paradoxically, I recognize that it is this acceptance of the impossibility of the task of writing the story of handloom that made the attempt possible. I started with one question in the beginning of this thesis: "What is the relevance of craft knowledge in contemporary society?" I will attempt now to answer this question in three parts: first, its importance as contemporary livelihood practice, sustaining livelihoods of millions of vulnerable handloom weavers; second, as a robust practice of solid knowledge building, theorizing that craft as embodied knowledge is indispensable to the creative act of innovation; and, finally, combining these insights from craft to create an ethos to sustain development.

\subsection{PraCtiCING SUSTAINABILITY IN THE HANDLOOM ENSEMBLE: YAMA-NIYAMA ${ }^{238}$}

In general, it is understood that handloom weaving was prevalent all over the Indian subcontinent in the past and buckled under the arrival of the industrialized mills during the early twentieth century. Under the pressure to their livelihoods, it is assumed that handloom weavers slowly dissipated into other occupations outside of traditional categories - outside caste, outside caste occupation, outside village - with the hope of transformation into secular modern urban lives and sustainable livelihoods. Policy makers endorse the view of the inherent unsustainability of handloom weaving as livelihood and the inevitability of the extinction of craft and handloom, except as esoteric art, while India develops and modernizes.

The reality is more complex, as we have seen. This secular, modern, urban transformation is rarely fully achieved. Many vulnerable weavers who leave the village in search of better livelihoods are doomed to shuttle back and forth till they slide into urban poverty (Breman 1996). Neither is the transformation inevitable: weavers use the same to and fro mobility to stay in weaving and work towards sustainability as a collective (Mamidipudi, Syamasundari, and Bijker 2012). The threat of leaving life, livelihood, and village that weavers themselves use, indeed as they historically used it (Parthasarathi 2001), to hold the state and society accountable to their reduced circumstances usually achieves the opposite effect with today's modern policy makers. These policy makers do not have a memory of this practice; so do not respond to it as a warning about impending crises, or a call for validation. Instead, to them, it only adds to the evidence against handloom's trajectory to a promising future-further diminishing investments to the sector and creating a vicious cycle of deprivation. Meanwhile, the deterministic trajectory that frames traditional technologies as inevitably heading towards mechanization distracts from the real competition that traditional handloom weaving as well as modern industrialized mills both face from power looms. The decentralized, unregulated growth of the power loom sector has taken over most of mill textile production, imitating handloom product and infringing on rights that the state has provided for the handloom industry on the one hand, while undercutting their markets on the other. The power loom lobby advocates for the repeal of the state's protection to handloom, even as it survives on copying handloom products, blind to the reality of its dependence on the innovating capacities of the handloom weavers that in many instances feed its growth.

The monolithic notion of unsustainability of weaver livelihoods in current policy understanding is only partly true, but it is constructed as being fully so within discourses of modernization, industrialization, and development. If, however, we frame the actions and discourses in social, cultural, moral, and now environmental terms, it is clear that weaver livelihoods are sustainable. In fact, the poverty line splits the weaver population almost exactly in the middle, with half over the 
line and a little less than the other half below it. ${ }^{239}$ Within this complex and contested terrain, weavers weave trajectories for themselves that range across the continuum of sustainability to unsustainability. These varied trajectories offer us opportunities to understand how different cultures craft alternative sustainable futures, countering dominant imaginations of development and success that are proving unsustainable for the planet.

In order to evaluate livelihood sustainability in handloom weaving, I assess sustainability on what it means to the people whose sustainability is being measured, rather than absolute financial terms or proxy indicators of wellbeing, which could still miss essential qualities of what needs to be measured (Wilk 1999). Weavers use a simple internal scale, or gittubaatu, the lack of which signals unsustainability for weavers. At its most basic, gittubaatu refers to a fair balance between personal income and expenditure. When balance is achieved, livelihood is presumed to be sustainable. A reasonable expenditure is generally agreed upon: food, shelter, clothing, education for the children, some gold for the woman of the house, and capacity to take care of old parents. These were minimum obligations of the householder couple. Further, social obligations in the community - an annual surplus in good years for religious festivals or the odd pilgrimage, a daughter's wedding, a grandson's naming ceremony - and, over time, a nest egg for their own old age or as insurance against a health crisis completed the moderate list of necessities of most weaving households. Since livelihood circumstances were not always stable - there are always good times and bad times in livelihood lifecycles - it was hoped that the good times and bad times would balance out in the long term.

In addition, weavers sought some modicum of respect from society and acceptance for their way of life and livelihoods as a way of being socially sustainable, feeling the loss of self-respect acutely when, for example, wage labor from unskilled

239 http://economictimes.indiatimes.com/opinion/view-point/censusweaves-rich-handloom-data/articleshow/7440632.cms work outstripped income from skilled weaving. A common refrain of weavers, "idi naluguri tho koodina pani" (work that requires four people to work together), highlights the interdependence of weavers within their ensembles of production and the relational work that is necessary to engage with others in it. This collaborative work is compared unfavorably by weavers to the modern individuated workplace where, "everyone does their work and earns their money, unlike here [in weaving] where the remuneration is for the whole extended family." ${ }^{240}$ Yet, weavers acknowledge that there are benefits in the quality of the community that they build, particularly in the symmetric relationship between man and wife weaving together: "a weaver's marriage is made of gold." ${ }^{241}$ Even when children of weavers move on to more contemporary professions in the city, it is the same kinship networks that are leveraged and that sustain them during this shift.

An important analytical step at this point is the broadening of the unit of analysis from the weaver to the socio-technical ensemble. As a result, un/sustainability becomes the characteristic of the ensemble, not just of the individual weaver. We study the loom, the weaver, and the dyeing technology as being embedded in an ensemble, constituted as a collection of heterogeneous elements of technologies, practices, formal institutions, informal institutions, and social groups (Bijker 1995). This is not to take away the agency of the resilient weaver, who makes choices towards better outcomes based on his or her environment, but to make an analytical shift from weaver to sociotechnical ensemble in order to better understand the livelihood trajectories that form the continuum from vulnerability to sustainability.

We start with the premise that we can learn from the resilient practices of sustainable weavers how to support livelihoods of other vulnerable handloom weavers (see Section 3.5), differentiating between environments and conditions where

240 Interview with Krishna Rao, $16^{\text {th }}$ November 2011

241 Interview with weaver participant, Daram meeting, October 2011 
livelihoods of handloom weavers are sustainable and those where they become unsustainable. From studying the interaction between vulnerability and sustainability in handloom livelihoods where vulnerability does not lead only to unsustainability, I arrive at a first, simple, even self-evident, point. Weavers embedded in robust socio-technical ensembles with heterogeneous social groups, engaged in symmetric social, as well as technical, relations with each other, coherently acting to understand and alleviate vulnerability in handloom livelihoods, are more likely to be sustainable than those embedded in socio-technical ensembles that do not have these characteristics.

The heterogeneous groups whose presence makes for robust ensembles include those from state, market, producer,and civil society. This heterogeneous collectivity can facilitate symmetry between players with differing bargaining powers: while it is well known that forming collectives with members who share the same vulnerability (for example, cooperatives of farmers or weavers) helps in improving bargaining power, being part of collectives where there is heterogeneity in the social groups mediates power differentials in other ways. Management paradigms of adaptive management recognize that "diversity of stakeholders with different types of knowledge and from different institutional settings is a critical factor in maintaining and enhancing resilience of a sociotechnical system" (Keulartz and Schermer 2014, 286). For example, the presence in the handloom ensemble of NGOs (alongside market, state, and producer organizations) that have egalitarian practices can make for more equitable outcomes for weavers.

In heterogeneous ensembles, interaction is important. Social groups engage in argumentative interaction (Hajer 1995, 54) over their differing frames of understanding handloom weavers' vulnerabilities, and this very argumentation and seeming lack of consensus leads to plurality in interventions for alleviating vulnerabilities of weavers. Heterogeneous groups make discourse alliances (Hajer 1995) that cohere through overlaps in story lines and that intervene to afford more promising futures for weavers. They depend on their discourses around handloom. When interaction breaks down, ensembles become more vulnerable.

For example the preferred technological intervention of industry, market, and state is that of mechanization, which is framed as a solution to the problem of handloom weavers, but which, in fact, threatens their existence. Mechanization is the outcome of a discourse coalition where industry groups that frame handloom as unproductive technology and market groups that frame handloom weavers as expensive labor align with the progress and modernization agendas of the state towards traditional technologies. Mechanization as a solution is resisted by a coalition of and an alignment between the social marketing approaches of enterprising NGOs and the service agenda of cooperatives that, through collective action, negotiate with powerful market players to try to gain equity for weavers and social sustainability within the ensemble.

Further, we see that different social groups - not just the weaver-in the ensemble catalyze socio-technical change needed for survival. Different social groups act to adapt new technologies and new opportunities in the environment around their shared technological frame that values craft skill. The technological frame-in this case, the value of craft skill - is a way to understand the shared meanings of a technology held by social groups that structure interactions and choices in the ensemble (Bijker 1995). Contrary to the idea that weavers are tradition bound and change averse, social groups in the ensemble negotiate a balance between adapting mechanized technologies to operate with craft technologies and optimizing craft technologies to compete with economies of scale. This balance is achieved through transforming mechanized technologies back into the constituent elements of skill and labor, retaining the skill component while mechanizing the labor intensive component, or, in some cases, outsourcing it to workers who are further down the skill-labor continuum. We can understand how obtaining this 
balance might require that technological frames, as well as technologies, be adapted.

Actors in the handloom ensemble who acquire interactional expertise (Collins and Evans 2007, 35) experience inclusion within multiple technological frames and are able to facilitate the acquisition of technologies from one frame to the other, even if, as in the case of power loom and handloom, they are perceived as being antagonistic. Here the analytical concept of the technological frame is again useful to explain how interactional experts make choices in adapting new technologies. Interactional expertise is relational; when it is reciprocal across two different kinds of expertise, it can contribute to symmetry in the exchange of knowledge-in this case, so that the values of mechanized technologies do not deterministically overtake craft interests. Actors from one technological frame acquire interactional expertise-ability to speak the socio-technical language of specialists - in other technological frames. This gives them inclusion (Bijker 1995, 143) and a level of involvement in multiple technological frames which facilitates this symmetric exchange.

From weaver to socio-technical ensemble to technological culture-we widen further the scope of the analysis of socio-technical change of the present to include both history and possible futures. The handloom ensemble has a temporal dimension: it has accumulated over time a large repertoire of technologies, social organizations, and products within it - in practice, as well as in memory traces, in samples, in museums, in mythologies, and in ritual associations. Actors in the ensemble also show themselves to be symmetric in adapting technologies both backwards and forwards in the timeline of technological progress. Indigo dyeing is remembered and redeemed anew through an act of collective remembrance; reactive dye technology is adapted and stabilized as craft skill.

The acquisition of new social and cultural groups into the ensemble requires actors, such as designers, to engage in combinatory acts of building value for craft in the socio-technical ensemble through mediating technological as well as aesthetic cultures. The actor categories of financial, social, and cultural interventions in design then are reconstructed as design of new material (products), new socio-technical ensembles, and even new and better futures. From designers, craftspeople learn to service social groups that have different aesthetic preferences from their own. This requires craftspeople, too, to turn into cultural mediators. Becoming a cultural mediator in turn increases the chances for social change that craftspeople desire as, through this process, they acquire cultural capital themselves. Their cultural capital is evidenced materially by the accumulated aesthetic repertoires that have evolved along with contemporary societal ideas of beauty over time.

This combination of an acquisitive (of new technologies, social groups, and cultures) and accumulative (of technologies, design repertoires, and memory traces) style can be seen to drive sociotechnical change in the handloom ensemble. New technologies from the environment are adapted in order to be acquired by the handloom ensemble. The old technologies in the ensemble are adapted to changes in the environment in order to conserve them in the ensemble - negotiating difficulties that arise when technology that is made for one time and place is transferred to another time and place through adaptation (Hughes 1987 (2012), 60). This concept of technological style, which stresses that system builders have creative latitude (Hughes 1987 (2012), 61), resonates with the Gandhian idea of flexibility of tradition to adapt parts of the idea without losing sight of the whole, as well as Ambedkar's call for cultures that are stagnant to be open to new knowledge and change.

Finally, collective work that is an attribute of the handloom ensemble is better understood in terms of the interwovenness of the practices of the self and the collective - the weaver and the ensemble or, metaphorically, the yarn and the cloth that fabricate sustainability. Rather than locating the value of selflessness in the collective endeavor - with the self-seeking individual placed in isolation-we may resolve this polarity using 
the principle of yama-niyama. ${ }^{242}$ Yama is social discipline and niyama, personal discipline. Actors in the ensemble individually practice the yamascollective social disciplines that rule the interaction of the individual with the world - while collectively binding themselves to the niyamas-the personal disciplines that each individual follows. In this understanding, the rules governing the self are not positioned in opposition to the rules of the collective, yet they are different. The discipline of the self is accepted collectively - all weavers individually accept the discipline of sustainability as living within your means (the principle of gittubaatu) and the disciplines of the collective are maintained by the individuals in it, as when market standards are individually maintained.

The yama-niyama principle helps us understand the distinction between the goals of the self and the collective without positioning them in opposition to each other. Rather than the ideal of one universal solution that wins or one social group's technological frame being the right one, collective sustainability is woven into the practices of the ensemble, beat by individual beat of the hand-operated loom.
In the following section, I propose to work towards a theory of innovation for handloom weaving. I build substantively on the constructivist understanding of Schumpeterian innovation that I developed in Chapter 6. At the center of this theory is a vocabulary for traversing the terrain from embodied skill to expertise and from creativity to innovation. While this may appear to shift my focus back from the socio-technical ensemble to the individual innovating weaver, I again invoke the principle of yama-niyama, which relates individual discipline to the collective and vice versa to explain this shift. Acquiring somatic expertise is expressed as improvement through iteration or honing oneself (meruguparachadam). Here it is the mind and body interaction in acquiring expertise that is the focus, foregrounding the craftsperson who innovates. If one understands this in terms of the principle of personal discipline (niyama), then we understand how each individual craftsperson in the ensemble might acquire the capability to innovate. In constructivist terms, the individual craftsperson who is acquiring expertise could belong to any one of the social groups in the craft ensemble. Thus, the theory of innovation potentially holds for any craftsperson present in the ensemble.

\subsection{TOWARDS A THEORY OF INNOVATION: $S_{\text {AADHANA-MANODHARMA }}$}

Ever a science of statistics and probability in India, mathematics was used equally to foretell eclipses and prognosticate futures. Bhaskara, a $12^{\text {th }}$ century mathematician who lived in Vijayapura (modern-day Bijapur), not too far from the weavers of our stories, writes addressing his mischievous daughter Lilavati, whose fortune he had calculated using his knowledge of the stars. In order to escape the prediction of widowhood that the stars foretold, the perfect moment when Lilavati should marry would have to coincide with the moment that a little cup of water with a hole in its base, kept safely in his room, would empty. The curious little girl, it is said, having been forbidden to touch the little gadget, was unable to stop herself, and she dropped a pearl from her nose-ring into it, upsetting his calculations for a future filled with love and children, and instead dooming her to becoming a widow. In despair, Bhaskara promised that he would immortalize her through his poetry, written as a mathematical treatise. Below is one of the poems in the Sanskrit treatise titled Lilavati a worked-out example equivalent to what would today be calculus.

242 Social disciplines or yama, (for example non-violence, truth, restraint of the senses) and personal disciplines or niyama (such as training the senses, self study that lead to discriminatory knowledge which is universally valid "viveka jati desha kala samaya anavichchinnah sarva bhaumah mahavratam." Translated, this reads, "Knowledge whose validity is not limited by species, place, time, context.") Yoga sutras 2.30-2.34 
The square root of half the number of a swarm of bees is gone to a shrub of jasmine; and so are eight-ninths of the whole swarm:

A female is buzzing to one remaining male that is humming within a lotus in which he is confined, Having allured to it by its fragrance at night.

Say, lovely woman [Lilavati], the number of bees. $^{243}$

If one were to take a global view, as Anil Menon, contemporary author and computer scientist, does of Bhaskara's time-1114 A.D - it was "when Angkor Wat was still an idea searching for its stone, but its future builder, King Suryavarman II, was already a year old. Genghis Khan was just fifty odd years away. The West hadn't rediscovered Euclid and Aristotle yet, but Abelard of Bath and his students were in Syria, poring over the Arabic texts that would eventually ignite the Western Renaissance. The Muslims had gained a foothold in Gujarat, and in the 13th through 15 th centuries, they were to reinvigorate the subcontinent. And way north of Vijayapura, about 400 miles from Delhi, the last of the magnificent Khajuraho temples were being built." 244 Bhaskara's "Lilavati" was written almost a thousand years ago, yet we marvel along with Menon that though Angkor Wat and Khajuraho are ruin and memory today, lotuses and bees entangled in ponds, eyes, and mathematics remain.

From writing mathematics in poetical cadence to describing handloom weaving in a language of innovation does not seem too far a stretching of the imagination. However, first, I explore some ways of thinking about theorizing embodied practice. Here I refer to handloom scholar and activist Seemanthini Niranjana, who responded in 2006 to a comparison of music and weaving theory thus:

243 Translated from Sanskrit in 1817 by Henry Thomas Colebrooke, mathematician and scholar of Sanskrit language

$244 \mathrm{http} / /$ anilmenon.com/blog/say-lovely-woman-the-number-of-beesbhaskaras-lilavati/
There seem to be parallels here [between traditional music and handloom weaving], to think of how musical traditions emerged-we might label it classical, or something else. But if we see how schools of music (or traditions of thought in philosophy) got consolidated - there is the repetition of a pattern of notes (or ideas) in a certain way that probably then becomes distinctive - it becomes the rule - the "theory?" Every time you sing, you don't practice the theory, but invoke the rule/structure/framework, and breathe life into it? ${ }^{245}$

What could then constitute theory for innovation in handloom weaving in the absence of text, Niranjana asks, "If weavers know the rules by doing, rather than by text, what does that do to the rules and what freedom does it allow [in] practice?"246 In a later email, she answers the question herself:

The weaver as technologist is somebody who in the very practice of weaving, brings to life a "theory of weaving" (a knowledge based on which the handloom [ensemble] is built), and specific techniques (which are more region specific). So $\mathrm{s} / \mathrm{he}$ carries within them that conceptual and technological knowledge (only it isn't spoken of like that). Unlike some other knowledges (say broad principles in physics, or whatever), is it that weaving theory exists only inpractice? And that is why the weaver is the technologist [holding such theory] working with a received framework of knowledge, but also always carrying within them thepotential for alteration, change, innovation? ${ }^{247}$

This insight leads to an innovative way of understanding weaving theory other than as propositional text-theory as conceptual frameworks of bodily memory learnt over time as habituated craft, "because what's taken for granted

245 Personal email Seemanthini Niranjana, Dastkar Andhra $12^{\text {th }}$ March 2006

246 Personal email, Seemanthini Niranjana, Dastkar Andhra, $27^{\text {th }}$ May 2006

247 Personal email, Seemanthini Niranjana, Dastkar Andhra 12 $12^{\text {th }}$ July 2006 
is what counts" (Arthur 2002, 8). Thus when innovating, weavers do not use the intermediate stage of converting their intention into a text, or a plan, or a drawing, but rather they invoke somatic knowledge gained through previous trials to turn out the innovation that is being reached for. Watching a master craftsman working out a pattern directly onto the fabric on the loom is like watching a computer printer at work; the pattern seems like a series of stops and starts, $0 \mathrm{~s}$ and $1 \mathrm{~s}$ in the punch card. The design held in the mind's eye is unerringly translated into its constituent serial actions by the practiced hand, till the weaver reaches the end of the task, and the pattern emerges fully formed. It is the same with indigo dyers who when given strict instructions by the master to turn the yarn in the vats fifty times, regulate their breath, and allow their body to remember the count rather than count aloud, instead focusing on the quality of the color.

Scholars think of science and its theories as existing within a realm of ideas; written texts become the carriers of science and theory across time and space (Smith 2015). Texts serve the purpose of "proof" or validation, and develop abstract thought by fostering an internal monologue (Smith 2010); texts are perceived to be opposite of hands-on experience yet practice can always override and rewrite them (Smith 2012). In this concept of knowledge, theory is knowledge that is stabilized as text in between practice iterations that are constantly in the process of change. In the absence of such text, rather than presuming that handloom does not have theory, we can imagine that theory in handloom is always in the process of becoming embodied in the practice of craftspeople: between iterations, between places and across time.

Explicit in Niranjana's reading of theory for handloom weaving is the idea that in handloom, rules are known by doing. The standard understanding that the practical implementation of any task entails the mechanical application of a set of operating principles regardless of context or prior experience must be set aside for understanding the nature of craft skill. In trying to elicit methodology, one must not fall into the trap of supposing that "such principles are engraved in the minds of practitioners in the form of words, diagrams, charts, or formulae [. ..] - propositional knowledge that is simply waiting to be revealed and written down" (Ingold 2001, 29). Instead, standards, recipes and vocabularies perform the function of mobilizing knowledge in the handloom STE. Yet such knowledge very quickly becomes tacit once stabilized.

In weaver parlance, knowledge of underlying principles (parignaanam) bridges the distance between the changing practice of craft and the unchanging rules that bind its identity to tradition. To use an example from Indian grammar, Pathanjali, a noted scholar of Sanskrit from 150 BCE, wrote the Mahabhashya commentary on the Ashtadhyaayi, which is a treatise on grammar authored by Panini around $400 \mathrm{BCE}$. Introducing it to his students, Pathanjali explains that the language of the scriptures (vedas) is fixed and unchanging, and the language in practice (loukikam ${ }^{248}$ ) is ever changing according to the whims of the world. Yet if these domains are not to become incommensurable, there is a need to understand how they interact. This is the role that grammar plays. It explains underlying structures of use in both domains. While knowing one domain gives a scholar the understanding of difference, it is by knowing grammar as the underlying structure of both domains that a scholar can understand sameness. Also, it is only with grammar that one can meet the challenge of combinatory change of making new words for new use; here Pathanjali uses the example of naming a newborn child.

Translated to our case, only when weavers have an understanding of underlying principles can they make changes in standards, vocabularies, or recipes. It is the knowledge of the same underlying principles that allows them to innovate in their

248 From the Paspasha Anhika (1st day/chapter) of Patanjali's Mahabhashya, detailing the primary and secondary uses of studying grammar. Of particular interest is one of the uses, referred to as "0oha" - the capability to appropriately adapt a word from one context to another. 
practice, relating it to the received framework of knowledge. Thus, knowledge of underlying principles (parignaanam) becomes an integrative and interactive concept to connect propositional knowledge and practice in the handloom ensemble, and it explains how weavers are technologists, "carrying within them the potential for alteration, change, and innovation." 249 If one accepts that the inflexible boundaries between related yet often antagonistically positioned domains (such as tradition/modernity, science/art, theory/practice, individual/collective, mind/body) need softening, then we see that this understanding of interaction, coming from craft, has the potential to catalyze such processes.

In the next sections, I use these insights to work towards a theory of innovation within handloom technological culture. I outline four different sets of concepts that overlap between craft vocabularies and STS. I describe the first step as the acquisition of craft expertise, of embodied or somatic knowledge that engages the body and also the mind; it is technical as well as social. Iteration leading to reflection plays a constituent part in acquiring expertise, and stresses the circularity between intent and crafting. The second step is the journey to the creative leap of innovationhere, I compare creativity in classical Indian music to research on creativity in science. With this comparison, I seek to generate an integrative vocabulary that communicates across both traditional and modern cultures of craft. The third step explores the interactive and relational aspect of innovation when describing socio-technical change - the creative innovator's encounter with the unfamiliar that sparks something "new." It is here that the concept of innovation in traditional handloom culture adds to contemporary innovation concepts. Innovation acts as the bridge between what is known already by the craftsperson within the boundaries of tradition, and what is new and yet to be discovered by him outside those boundaries. Finally, in the fourth step, I explore from these understandings what theorizing innovation implies for handloom weavers' futures.

\subsubsection{ACQUisition OF EXPERTISE: MeruguparaCHADAM ${ }^{250}$}

With regard to the acquisition of (embodied) expertise, weavers themselves give importance first to workmanship (panitanam), acquiring knowledge and application of technical rules (saanketika parignaanam) and then to acquiring dexterity (nerpu $)^{251}$ along with excellence in workmanship (manchi panitanam). In the next stage, the skills to be achieved are of problem-solving and labor-saving "tricks"(melakuvalu, suluvulu); then the vocabulary of embodied skill shifts to that of artistry (kala). At the most advanced level of acquiring expertise, the weavers refer to the understanding of underlying

249 Personal email, Seemanthini Niranjana, Dastkar Andhra, 12 $2^{\text {th }}$ July 2006

250 Honing oneself, improving one's skills

251 While many translations are possible of these words, I interpret nerpu, or dexterity, as being in the domain of the (weaver's) skilldexterity in weaving, in dyeing, and so on. principles, or parignaanam, ${ }^{252}$ that connect practice to received heuristics. When referring to the acquisition of parignaanam, weavers are pointing to cerebral activity in acquiring craft expertise. Weavers who possess parignaanam are higher up in the hierarchy of learning-it is knowledge that bridges the distance between stabilized rules and ever-changing practice. However, skill and dexterity (panitanam, nerpu) are squarely in the domain of all weavers, and through the fine differentiations and specializations that weavers draw upon, skill and dexterity define their core specialty and their capability to participate in socio-technical change. A constituent part of moving from the first level to

252 The vocabulary of the weaver that I could elicit regarding acquiring the highest stages of specialist expertise differentiates between three key words:vignaanam or science; gnaanam or wisdom and parignaanam, which I interpret as the understanding of underlying principles. 
the final one in acquiring expertise is reflection on practice (aalochana) and iteratively honing oneself (meruguparachadam).

In the table below I summarize the Dreyfusian (Dreyfus, Dreyfus, and Athanasiou 1986, 16) five- stage model of acquisition of expertise for the internalization of physical skills, or for skill to become embodied, as well as a five stage model in the weaver-dyers' vocabulary of acquiring expertise in dyeing, another expertise in the Handloom STE.

\begin{tabular}{|c|c|c|c|c|}
\hline Stage & \multicolumn{2}{|c|}{ Stages of acquiring expertise } & \multicolumn{2}{|c|}{ H andloom weaver stages of acquiring [new] expertise } \\
\hline & \multicolumn{2}{|c|}{ Learning to drive a bicycle } & \multicolumn{2}{|r|}{ Change in weaving practice } \\
\hline 1 & Novice & Follows rules jerkily & $\begin{array}{l}\text { Panitanam, } \\
\text { parikaram }\end{array}$ & $\begin{array}{l}\text { Learning workmanship, understanding the } \\
\text { new tool }\end{array}$ \\
\hline 2 & $\begin{array}{l}\text { Advanced } \\
\text { beginner }\end{array}$ & $\begin{array}{l}\text { Heuristics are mastered, } \\
\text { responds to un-explicated } \\
\text { features }\end{array}$ & $\begin{array}{l}\text { Sanketika } \\
\text { parignaanam }\end{array}$ & $\begin{array}{l}\text { Learning technical rules and their } \\
\text { application }\end{array}$ \\
\hline 3 & Competence & $\begin{array}{l}\text { Expertise is intuitive rather } \\
\text { than calculative }\end{array}$ & $\begin{array}{l}\text { Nerpu, manchi } \\
\text { panitanam }\end{array}$ & $\begin{array}{l}\text { Mastering dexterity that combines } \\
\text { heuristics and skill seamlessly; excellence } \\
\text { in workmanship }\end{array}$ \\
\hline 4 & Proficiency & $\begin{array}{l}\text { Recognizes problem situations } \\
\text { holistically }\end{array}$ & $\begin{array}{l}\text { M elakuvalu, } \\
\text { Suluvulu } \\
\text { Alavaatu }\end{array}$ & $\begin{array}{l}\text { Adding the awakening of subtle and tacit } \\
\text { techniques to existing habituated intuitive } \\
\text { practice and received framework of } \\
\text { knowledge; tricks for problem-solving }\end{array}$ \\
\hline \multirow[t]{2}{*}{5} & Expertise & $\begin{array}{l}\text { Skills practiced by individuals } \\
\text { are internalized in order to be } \\
\text { efficient }\end{array}$ & $\begin{array}{l}\text { Kala, } \\
\text { shareeramlo } \\
\text { Feed ayipovadam }\end{array}$ & $\begin{array}{l}\text { Artistry, as if programmed (fed) into a } \\
\text { body }\end{array}$ \\
\hline & Iteration & $\begin{array}{l}\text { Involvement over time } \\
\text { Dreyfus (Dreyfus 2004, 180) } \\
\text { refers to the recognition of } \\
\text { the role of experience and } \\
\text { time spent engaged on a task, } \\
\text { relating it to the different kinds } \\
\text { of engagement in the brain, at } \\
\text { the different levels of acquiring } \\
\text { expertise. }\end{array}$ & $\begin{array}{l}\text { Merugu } \\
\text { parachadam } \\
\text { Aalochana, } \\
\text { Parignaanam, }\end{array}$ & $\begin{array}{l}\text { Honing of skills over time through } \\
\text { reflection resulting in abstract } \\
\text { understanding acquired through application } \\
\text { of underlying principles }\end{array}$ \\
\hline
\end{tabular}

Table 7.1: Dreyfus's five-stage model of acquisition of expertise compared with weavers' vocabulary

This is how weaver-dyers describe change in the technological process and product (vastu, rakham). This first process of change has two components: acquiring workmanship (panitanam) and acquiring knowledge of the tool (parikaram). Acquisition of technical knowledge (sanketika parignaanam), as embodied in their practice, results in dexterity (nerpu). Change in practice is directed broadly by three main considerations: whether there is reduction in physical labor (shrama), an opportunity for "awakening" of intricate and tacit techniques (melakuvalu) while learning how to do something new, which can only be learnt face to face from an expert, and third, the overlap with existing habituated norms (alavaatu), or what Nirjanjana earlier referred to as a "received framework of knowledge." These considerations place individual learning within the community of experts of 
practice, bringing social practices of learning back into the individual's acquisition of expertise.

The accolade given to weavers in recognition of their having achieved artistry is that they become known as artists, or kalakarulu, that have acquired artistry, or kala, an attribute of weavers that has to be bestowed as such by their community of practitioners. I include as a final step the stage of reflection (aalochana) that leads to the abstract understanding of underlying principles (parignaanam) and their application. Reflection in practice and abstract understanding of underlying principles are seen as mental activities that lead to (technological) change. The entire process of acquiring expertise is thus one of honing oneself (merugu parachadam) over iterations.

The same craft object is made and remade; each time it is different, as the weaver hones himself or herself, adding more and more elements of skill, till the artisan is confronted with a problem: a change in input that challenges him or her to master a new material, a change in demand that requires him or her to innovate a new product, and so on. Finally the artisan will reflect on how to use his or her expertise to find a solution outside of the existing knowledge. Usually it is the skill leaders who will define the problem and who solve it for the collective.
Just as the steps in this table shift gears seamlessly between individual, embodied, somatic knowledge (such as learning to control the steering wheel) and collective tacit knowledge (such as understanding traffic norms), the addition of problem-solving to this table closes the mind and body distance (as thinking and doing) in both the expertise of driving as well as weaving. Instead, reflection, "which is a constitutive aspect of all levels of practice," (Portisch 2010, 2367) and internalizing of underlying principles (though it comes at the end of the weaver's skill acquisition cycle) refer to the iterative nature of acquiring expertise, where reflection on past practice plays an important part in shaping future practice.

In both the case of Drefusian expertise and in the vocabulary of the weaver, we see that acquiring expertise requires not just embodied skill but being socialized into the relevant group practices - an engagement and involvement with the task as well as with peers. In true Wittgensteinian sense, the craftsperson concurs that the meaning of a concept can be understood through its use, rather than through a dictionary definition. Since the self - the combined mind and body — is the tool for acquiring expertise, self-improvement or honing one's skills (meruguparachadam) becomes a critical process in theorizing socio-technical change.

\subsubsection{MaPping CREATIVITY IN INNOVATION: MaNODHARMA}

At this stage, I move from the concrete steps of acquiring expertise, to the second set of concepts I engage: creative leaps of innovation. Collins (Collins 2007) suggests that propositional knowledge has a somatic limit. In other words, human embodiment places limits on the use of propositional knowledge in learning. Here, I attribute the limit of the use of propositional knowledge in craft innovation-evidenced in its tacit nature - to the somatic nature of craft expertise that accords primacy to immersion in practice in order to acquire it. Looking for a vocabulary, then, which resonates with the culture of innovation of handloom, I draw parallels between handloom weaving and Karnatik music, another long tradition that exists side by side with the craft tradition of India. An important reminder here is that I study Karnatik music, too, as craft with a tradition of innovation. Further, taking into account the pejorative connotations the word "innovation" has in traditional crafts (see Section 6.7), it is "creativity" as a condition of innovation that I bring to the fore. I explore an integrative approach that looks simultaneously at creativity in science in order to transcend the tradition/modern dialectic. 
Detailed below are the equivalent practices of music (from musician's narratives) and science (from scholarly research on creativity in science) that come before creativity, yet are described as important steps to acquiring the capacity to be creative as well as the moment of creative expression itself. As we can see below, there are striking parallels between traditional Karnatik music and modern science.

\begin{tabular}{|c|c|}
\hline Karnatik Music & Science \\
\hline Saadhana (to practice) & Practices that come before innovation \\
\hline Repetitive practice & $\begin{array}{l}10 \text { years of practice in creative development (Hayes } 1989 \text {, } \\
\text { Simonton 1996) }\end{array}$ \\
\hline Learning rules through imitation & The importance of heuristics (Dunbar 1995) \\
\hline Becoming fluent through variation & Learn fluency and flexibility (Guildford 1950) \\
\hline Performance: Tests practice, and creates uncertainty & $\begin{array}{l}\text { Testing for creative ability: Problem-solving (Weisberg and } \\
\text { Reeves 2013) }\end{array}$ \\
\hline Manodharma & Creative expression \\
\hline The moment of creativity: Requires leaps of faith & $\begin{array}{l}\text { The eureka moment of creativity: Leap of insight (Akin and } \\
\text { Akin 1996, Ohlsson 2011) }\end{array}$ \\
\hline Needs guidance of the guru & $\begin{array}{l}\text { Requires supervision by a teacher (Ericsson, Roring and } \\
\text { Nandagopal 2007) }\end{array}$ \\
\hline Experienced as the absence of self & $\begin{array}{l}\text { Experienced as an unconscious creative process } \\
\text { (Csikszentmihalyi 1996) }\end{array}$ \\
\hline
\end{tabular}

Table 7.2: Comparison of practices that come before and with creativity in Karnatik music, and Science

Craft is learnt through repetition, over and over, till the basics are mastered, whether musical scales, or multiplication tables, or learning to produce original academic work. Once scales are mastered, the rules of how to sing have to be learnt through imitating the teacher. Where one is learning from a teacher that one is emulating, imitation is seen as a legitimate activity. It is only when one tries to pass off the style as one's own that the activity of imitation becomes illegitimate. Imitation requires the use of vision: to see (or hear) for oneself, rather than to be told (in verbal or written instructions). When imitating a master's actions, vision gains "simultaneity of practice" that language cannot capture (Marchand 2010, S112). In the laboratory, too, rules are learnt by being socialized into themwe know that heuristics are learned by association. It is in this socialization that the collective nature of creative practice - belonging to a community of practitioners-becomes most important. Up to this point, there is not much of a variance between this model of learning craft and the Dreyfusian table of acquiring embodied expertise.

The next step is to become fluent through variation. This is a first step towards creativity, when students learn the boundaries of the ruleswhat is admissible and what is not. In science, this is seen as learning flexibility: to experiment without feeling overly constrained by the boundaries. After this stage comes the test: when the student is ready to take a leap of faith in an uncertain situation under the guidance of the teacher. Practice coalesces into a moment of insight, and is experienced as an absence of self in an unconscious process of creativity - whether in music or science - and the leap to creativity is made.

The presence of the teacher (guru) in this process can be explained metaphorically as the hand on the seat of the bicycle when one is learning to cycle. In the beginning, it is a strong hand, 
preventing falling and directing balance. Eventually the student outruns the guru, and the task of the teacher and the student's journey to learning is complete. In the words of TM Krishna, musician and teacher, "Think of creativity as a room. The student is not yet in that room. He is imitating me, wants to sing exactly like me. Then suddenly, he does something new. He doesn't know it, but I do, because I didn't do that. He is suddenly in the room of creativity, but doesn't recognize it. He walks in and walks back out without realizing he has been there. At that point, I stop him, and say 'Hey! That is yours! Go back in!'”253 At the same time, since effacement of the self, or modesty rather than hubris, is seen as a pre-requisite to being open to receiving creative insights, the teacher is the beacon that stops the learner from cutting himself on the sharp rocks of the creative ego while he learns to express his creativity. The teacher's role is to help the innovating student balance between what is sanctioned as creative self-expression (judged as such by the teacher and then the collective) and the immodest breaking of rules that lead to transgression.

It is important to understand that skillbuilding practices that lead to creativity are not linear, though generally each builds on top of the last. For example, it is not enough to watch and imitate. Skill needs time to mature: skill is an outcome not a pre-requisite (Venkatesan 2010). Deleuze and Guattari describe it as a matter not of iteration but of itineration (Deleuze and Guattari 2004) along the "taskscape." It is a process of continual correctionthat is why no two strokes or a repetitive task are identical. This is rhythm that is not just repetition, but with differences within repetition (Lefebvre 2004, 90): "Iteration is metronomic, itineration is rhythmic" ${ }^{254}$ (Ingold 2009, 98).

253 Interview of musician and teacher, TM Krishna, Chennai, $7^{\text {th }}$ December, 2012

254 Here Tim Ingold makes a distinction between the handsaw and the mechanical rotary cutter, the hand of the carpenter, and the pendulum. Implicit in this difference is that the machine is mechanical and the hand is always creative. I do not use it in this way, since weavers themselves refer to a certain type of mechanical repetitive work that they do as drudgery, different from skill building repetitive work.
We could conjecture from this model that the practices of acquiring craft that lead to creativity are not so different in traditional and modern crafts. Disciplined, rule-bound rigor, and leaps of creative insight are not antagonistic; in fact both are complementary to each other in the process of creativity. Yet musicians focus on the sublime moment of faith, and scientists stress on rigor and the rational discipline of the scientific method. In truth, both scientist and musician submit to the rigor and experience the moment of creativity as unconscious and not as rational logical outcome. Shyamasundari, handloom activist and scholar, referring to a conversation with Gangadhar, the master trainer in Jamdani, writes in Telugu, "a gifted J amdani weaver talking of his craft does not so much bring to mind an artist, as a mathematician describing an abstract and exact science." ${ }^{255}$

From her study of European artisans in the early modern period, historian of material culture Pamela Smith elaborates almost exactly the same steps. She adds that scholarly observers from early modern Europe attributed their bafflement in describing techniques that were learnt by observation and imitation to the non-theoretical character of manual work, rather than to their own lack of ability to articulate artisanal processes. They assumed that, "their own verbal ingenuity outstripped the material ingenuity of the artisan" (Smith 2004, 82). Here too is the comparison of art and science-artisanal epistemology and alchemical theory as a vernacular science of matter. The artisan, who sought knowledge of materials in order to produce, engaged in an imitation of nature that involved repetition through "constant trial and retrial" (Smith 2004, 98). A deep knowledge of how to manipulate nature - as in Jan van Eyck's knowledge of pigments, oils and their refractive qualities-illustrates the cognitive processes of imitation that leads to knowledge. And finally, Smith refers, too, to the split-second intuitive decisions of experience, in the words of a modern Japanese sword smith "remember, our work is not

255 Translated from a Telugu note on Jamdani Shyamasundari, Oct 2013 
done by measuring and talking, . . . it is these acts of intuition that produce a sword" (Smith 2004, 99).

So how does this integrative understanding of the creative process of art and science, past and present, help us with respect to creativity in handloom weaving? Performing before an audience which expects creativity from the musician, or problem-solving in a laboratory when the problem challenges the boundaries of what the scientist already knows and takes them into the unknown, these can be mapped against problems in production, marketing, or even organization that the weaver may encounter. It is at this point that a creative solution is required-whether by innovating product, innovating technology, or innovating the socio-technical ensemble. Each requires a different expertise - the first is aesthetic, the second is sociotechnical, and the third is a combinatory activity that may have to bring both these as well as other expertises into play in order that something "new" is created. In addition, the new creative activity has to accrue value in the collective; this is a social process- as is all innovation.

\subsubsection{INNOVATING TRADITION IN HANDLOOM WEAVING: A TRADITION OF INNOVATION 256}

At last we come to the final third step, an innovation vocabulary that is particular to handloom. The socio-technical ensemble within which the innovation has to accrue value is not one in which the innovation is valued as such, but one which values the old and the traditional. So how does one innovate tradition?

Weavers refer to socio-technical change in broadly three terms:normal and familiar change (maarpu), improvement through iterations (meruguparachadam - literally to polish to a fine shine), and change that is new (kothadanam), which is usually outside their existing knowledge. When weavers refer to maarpu, they refer to a change in routine that is still routine, part of a normal interactional dynamic - between customer and weaver in order to change a pattern, between retailer and weaver to change a color palette, between sizer and weaver to change the yarn count, and so on. Meruguparachadam, or improvement, is a constant endeavor; it is the honing of the weaver's craft, the result of the iterative engagement between the craftsperson and his or her craft. This leads to innovation that is creative within the boundaries of the "old," change that yet maintains tradition.

N ewness (kothadanam), on the other hand, is an encounter or engagement with something that

256 This phrase emerged in conversation with Gita M anaktala, editor at the MIT Press is not within the purview of normal practice, but outside it. Kothadanam may take the form of a new product, a new process, or a new person that stimulates a change in the way one thinks. This is the final step in making the working of the mind visible in embodied craft expertise. Extending the metaphor of modesty to this recognition of the new, the encounter of the unfamiliar other can instead be read as the acceptance of the limits of one's own knowledge. It is the encounter with one's own ignorance. ${ }^{257}$ What does this encounter with difference, or with one's own ignorance, do to stimulate innovation? Musician TM Krishna suggests that the deeper one's own craft is, the more profound the effect of this encounter with ignorance is on one's craft. ${ }^{258}$ This implies that the final step of innovation is not just the management of change and the uncertainty it brings, but innovation is a way of imagining new outcomes in one's own practice. It is recognition of the potential for new ness that the future can bring. Such outcomes can combine a new imagination of the future, be crafted in the present, and yet contain knowledge of the past.

In the handloom socio-technical ensemble, an important step in socio-technical change is the

$257 \mathrm{http} / / / w w w . n y t i m e s . c o m / 2015 / 08 / 24 / o p i n i o n /$ the-case-for-teachingignorance. html? action $=c$ lick $\&$ content $C$ ollection $=0$ pinion $\&$ module $=\mathrm{M}$ ostPopularF $B \&$ version $=F$ ul $\&$ region $=M$ arginalia $\& s r c=m e \& p g t$ ype $=$ article\&_ $r=0$

258 Interview with TM K rishna, $7^{\text {th }}$ December 2012 
encounter of the ensemble with the unfamiliar other, the outside, which has to be adapted to, mediated, or combined with as innovation. It is this encounter and interaction at the margins that is described in STS and related fields as "creative marginality": that it is individuals at the margins or intersections of disciplines and traditions who are often most likely to innovate (Dogan and Pahre 1990). The translation that this entails, according to Latour, is a strange "mixture of audacity and traditionalism" that innovates by linking together (Latour 1988, 267). As a result, the socio-technical ensemble itself is innovated. All three kinds of socio-technical change that weavers describe-normal change, iterative change that leads to improvement, and the change to something new-can require creative ingenuity from craftspeople, who respond to the challenges posed to them based on the innovative capacities they carry.

\subsubsection{THEORIZING HANDLOOM AS INNOVATIVE SOCIO-TECHNOLOGY: WHAT DO WEAVERS GAIN?}

"Passed on from one generation to another, taught by elders who expected unquestioning obedience from their students, mastered through rote and repetition of gradually more difficult tasks, artisanship offered no space for individual ownership of knowledge, let alone incentive to explore the underlying principles that informed daily work. Embodied, traditional craft skills appeared, in other words, as the anti-thesis of the modern" (McGowan 2009, 63).

The above quote is the analysis of the status of craftspeople's knowledge in the late nineteenth century that led to them being treated as objects of development rather than as agents. Ignoring several centuries of attempts to appropriate Indian skills and designs - particularly in textile weaving, printing, dyeing to raise the quality of European industries (Berg 2004)-observers in the Great Exhibition of the East India company in 1851 in London claimed that Indian technologies offered no contribution to global knowledge. Observers declared that craftspeople were "so limited in application that they can scarcely be considered as bringing into play any principle of comparison or competition." They were proof of the stasis of Indian (technological) culture (Tallis 1852, 163). This view led to the distinction between "genuine knowledge," the ability to understand the meaning of something through one's own reasoning processes, having made knowledge one's own, and "second hand knowledge" that came from being stuffed with others' ideas. This distinction of good knowledge and failed knowledge was mapped onto the distinction between autonomy and heteronomy between an active subject and a passive one. Craft skills failed to make the grade of "genuine knowledge" on all levels (McGowan 2009, 63).

So, what do we gain for craftspeople that currently are categorized as "unskilled" and "uneducated" by the state and in formal educational evaluations when we analyze indigenous handloom knowledge as sustainable and innovative sociotechnology? It is in answering this question that we see the utility of the STS concepts with their tradition of opening the black box of scientific knowledge. The imperative to break down categories comes from a political urge within STS to loosen inbuilt hierarchies that would in fact stand in the way of robust science and technology. This political agenda within STS scholarship paves the way for a normative shift in the hierarchy of knowledge, which in turn can be employed to explicate the importance of craft in knowledge building. Then, in answering the question of craft's relevance to society, by labeling it as robust knowledge-building practice and key to innovation, I can address some of the underlying insidious assumptions in society and policy that cut at weavers' sense of identity and dignity in their profession. 
With reference to the previous sections, the explicit claim I make is that the weaving body is intelligent; acquiring embodied expertise requires that the mind is engaged. This counters the assumption that all repetitive embodied activity is mere manual labor that can be replaced by a machine and that isolates cerebral activity as the true domain of human endeavor. Instead, I propose that we recognize the skill-building stages of craft knowledge - repetition, imitation, variationas indispensable to all creative innovation. This proposal counters policy makers' understanding of craft that privileges and rewards weaver innovators without realizing that they emerge from a community base of expert practitioners: if innovation is to be encouraged, then efficient machines cannot replace practice. Innovators don't appear in isolation; there is a pyramid of expertise with innovators who lead the collective at the apex, resting on a large base of expert craft practitioners who engage in emulating and imitating their leaders, while those even younger in skill are engaged in the repetitive activities of acquiring expertise.

We can dismiss oppressing constructs of the traditional caste system that place those engaged in manual work lower in the social hierarchy to those engaging their mind in knowledge building. We see that the core assumptions behind both the positions of modernity and tradition are the same: they do not recognize and value the embodied nature of knowledge that weavers carry, and instead frameweaving as manual and menial labor. In this framing of the weaving body, being born in the weaver caste implies a handloom weaving trap that weavers today cannot break out of, by moving out of handloom weaving, or by moving out of the village or even by abandoning life itself in despair. Yet, when we widen the unit of analysis to the entire handloom ensemble, the ensemble disrupts the oppositional associations of traditional caste as being inside handloom weaving and modern occupations and lives as being outside. A new social identity of belonging in the ensemble can be created-one which connects all the different groups and castes in the ensemble. Then, innovation within the traditions of caste can be as accepting of the constraints and rules as it choses in order to maintain identity as well as continuity for the weaver. At the same time innovation at the margins - of tradition, of the rules, of the ensemble itself - can work to shift boundaries and meet goals of social change and development.

In addition, in this analysis, embodiment is always also about embodying the mind, binding it to the body of the weaver. In embodying the mind, we embody knowledge. The distinction between the "theoretical knowledge of scholars and scientists which draws knowledge into a system, and practical craft knowledge seen as a collection of recipes, rules, and standards to be followed more or less mindlessly" - the distance between those who work with their minds and those who work with their hands - then blurs to a continuum (Smith 2004, 7).

This analysis explicates the innovating capability of the weaver, rather than consigning the body that weaves to the futureless loom. At the same time, it engages us in an act of boundary shifting; both of traditional knowledge-building practices in science, and traditional social organization in Indian society. It demands recognition that it is not enough if the weaver innovates; society's conception of the role of embodied craft in knowledge building and innovation also needs to renovate. It is from this creative shift that both weavers and society will achieve gain. 


\subsection{Creating an ethos of Sustainable Development: $S_{\text {Atyam }}$ Sivam SUNDARAM 259}

From theorizing practices of sustainability and innovation in craft, I explore, finally, a unifying metaphor of craft as truth (knowledge), equity, and beauty. I seek within this metaphor help in creating an ethos of sustainable development, an allegory to remind us how to live within our means.

\subsubsection{COMBINING KNOWLEDGE, EQUITY AND BEAUTY}

Knowledge, according to Wittgenstein, is taken to be the property of a social group and constitutes a form of life (Wittgenstein 1958). It calls for immersion to be developed, and consists of individuals who follow a rule in the same way in similar conditions, who share a common paradigm (Ribeiro 2013, 28). I use this understanding to make patent the embodied nature of knowledge. Then we can begin again to associate knowledge with the people who know it. Knowledge is not just propositional; it is material, historical, collective, socio-technical and embodied.

When we recognize that indigo dyeing is the smell, taste, and memory of a people, we recognize that the chemical formula of indigo is only one part of indigo knowledge. When indigo is disembedded from its context, in a situation where power hierarchies are able to frame the chemistry as knowledge and the embodied expertise as culture, it is mobilized in parts that do not make up the whole. It is an unfair appropriation of another person's knowledge; it is not equitable. For the consumer, it becomes a product that is sustainable only in parts - either for one's purse, or for the producer or the planet. Indigo in this form does not satisfy the quest for the color of the sacred, nor satisfy the need for the particular that has no precedent-it does not have the unique particularity that craft brings to color. No indigo-dyed Chandrakali saree can or need be completely identical to another. Instead, when we recognize that knowledge is embodied, it awakens us to the engagement of our senses as well as our sensibilities, allowing us to make sustainable choices that satisfy the quest for the equitable, the beautiful, and the particular, rather than consuming in dissatisfactory parts.

Craft is the means through which Indian society materializes its notions of beauty. When aesthetics is combined with craft production, it gives rise to beautiful products, the consumption of which can promote satiety rather than hunger. When craft production is combined with drudgery-reducing technology, rather than mechanizing production, it makes the marketplace more sustainable. At the same time it speeds up the drudgery-inducing component of labor and makes craft affordable, thus sustaining producers. Craft production mediates the dialectic of design as pure aesthetic intent in the service of the market and technology as multiplying mindlessly in order to increase productivity. It seamlessly combines in itself both the value of art as sublime and satisfyingand the value of knowledge as utilitarian in its avatar of providing livelihoods. When we are able to link both sustainable productivity and beautiful products through combining socio-technical and aesthetic cultures of craft, production becomes equitable and consumption becomes satisfying. Thus, we are able to attribute purpose as well as politics to craft.

Perhaps this is why resistance to the harmful and potential dehumanizing effect of industrialization is expressed through the vocabularies of craft that combine aesthetics and socialism, both in the 19th century Arts and Crafts movement in the West (Livesey 2004) and in the 20th century craft-supporting civil

259 The Indian philosophy about the indivisible quest for that (divinity) which embodies Truth, Goodness and Beauty, which I paraphrase in this context as Knowledge, Equity and Aesthetics 
society organizations in the South. Vulnerable craft livelihoods become a site where societal notions of equity and inclusion become visible. Thus, demanding that the Indian policy makers recognize the validity of handloom knowledge is to urge them to perform a creative and political act of democracy - through accepting the right to cognitive justice (Visvanathan 2006), the right of craftspeople to their way of knowing the world.

Contemporary craft modes of production anywhere in the world can become potential sites for combining knowledge, equity, and beauty for sustainable development. Craft predicates innovating for continuity and being thrifty with resource, as one might in a household. Craft sustains its members rather than expands unsustainably into the world; it is understands that the new is immanent in the old ${ }^{60}$. In effect, craft knowledge foregrounds both the unlimited capability of the human senses to evolve aesthetically towards beauty and the limits of the human body that constrain unlimited productivity. In all these aspects, by combining knowledge, equity, and beauty, craft impels us towards an ethos of sustainable development.

\subsubsection{CRAfting SUStainable DEVELOPMENT: LIVING WITHIN OUR MEANS}

I end here with bringing back reflexivity, symmetry, and interaction-now, not as heuristics, but as underlying values from STS-for sustainable development. Reflexivity is the value of examining one's own practice; in order to make explicit what might otherwise stay tacit. Reflexivity both helps one maintain the boundary between dualities and provides reasons for transgressing them. The second value is symmetry-balancing knowledge with power-which in turn brings equity. The final value is interaction-connecting what we have disconnected: the mind and body, theory and practice, village and city, production and market, means and ends, past and the future, the old and the new, change and stability.

New innovations are being crafted in the futuristic, developed world in order to transition to more modest consumption of resources. Eric Hobsbawm in The Age of Extremes, his study of the modern age in Europe, says "the most dramatic and far-reaching social change of the second half of this century (the 20th), and the one which cuts us off for ever from the world of the past, is the death of the peasantry. For since the Neolithic era most human beings had lived off the land and its livestock or harvested the sea as fishers" (Hobsbawm 1994, 289). Ruskin Bond, Morris, Coomaraswamy, and Gandhi seem to suggest that the most important product of industrialism isn't progress but the destruction of civilization, that is, the destruction of the very possibility of social formation in which both justice and beauty prevail (Brantlinger 1996). Yet in a globalizing world a cautious optimism may not be misplaced. The slower pace of development in the traditional societies of the globalizing world means that the world of the past still lives on in the large part of the developing world's population that still lives off the land, the sea, and in forests. Craft production in this world continues to be associated with agricultural and rural populations as the longest tradition of innovation.

We see one technological culture that values technological change over continuity and another that values continuity over technological change. One culture predicates a restless concept of innovation that straddles the uncertainty of technological risks and the promise of positive change it brings (Nowotny 2006b, 13). This concept predicates a culture that creates obsolescence in its wake as it progresses. In the other culture, the ethos of sustainable production seems to be over-endowed with the value for continuity and protection of tradition. This concept diminishes that culture's confidence to direct change and is vulnerable to becoming regressive. Our research shows us that change and continuity, innovation and

260 Discussion Sushruti, Vedavalli -Musicians, 24th December 2013 
stabilization processes exist in any technological culture; it is the positive value that one places on change and the other on continuity that positions them as oppositional. Instead, taking the similarities in the two technological cultures rather than their differences into account, I propose a way of bridging the two. It may be possible to combine innovation and sustainability across both cultures, bringing together the potential of the old as well as sustenance for the new in a new concept of "creative sustenance."

If the readings of sustainability and innovation can work in tandem, rather than mechanizing the weaver to suit the unsustainable consumer or muzzling the consumer to suit the modest innovator, a new trajectory can be mutually and respectfully constructed. Thus, if we take globalization to be a two-way street, the utopian dream of justice and beauty may still prevail through the interaction of the two worlds. Craft becomes the thread of continuity, an interactive and ongoing normal practice of peoples of both worlds who innovate in socio-technical ensembles. This results in development that is an outcome of living within our collective financial, social, and environmental means. Such development is equitable, sustainable, and within reach. Every culture already knows this, if only it chooses to remember. 


\section{APPENDICES}

\section{GLOSSARY}

\begin{tabular}{|c|c|}
\hline $\begin{array}{l}\text { Vernacular terms } \\
\text { [Telugu, H indi/ } \\
\text { Dakhni, Sanskrit] }\end{array}$ & M eaning \\
\hline Aaku Pacha & Leaf Green \\
\hline Aalochana & Reflecting on practice \\
\hline Abhinaya & Story Telling through dance/Mime \\
\hline Adimai & Labour bonded to landlords \\
\hline Alarippu & $\begin{array}{l}\text { Traditionally the first dance piece that Bharatanatyam dancers learn and } \\
\text { perform in this type of classical dance recital. }\end{array}$ \\
\hline Alavaatu & Existing habituated practice \\
\hline Ammaayi & Daughter \\
\hline $\begin{array}{l}\text { Anaganagaa Oka } \\
\text { Nethagadu }\end{array}$ & Once upon a time, a weaver... \\
\hline Astadhyaayi & The Eight Chapters \\
\hline Atharva Veda & $\begin{array}{l}\text { A sacred text of Hinduism and one of the four Vedas, often called the "fourth } \\
\text { Veda". }\end{array}$ \\
\hline Avasaralu & Needs \\
\hline Avasaram & Need \\
\hline Avatars & Incarnations \\
\hline Ayurveda & Traditional Indian herbal medicine \\
\hline Baita Pani & Ancillary Work \\
\hline Bhakti & Devotion \\
\hline Biyyam Veesa & Little metal pot to measure rice \\
\hline Brahmanical Caste & The highest, or priestly and scholarly class among the Hindus. \\
\hline Buta & Almond shaped motif \\
\hline Butis & Motifs \\
\hline Chaakali & Washerman \\
\hline Chaduvukovadam & Book learning \\
\hline Chakram & Wheel \\
\hline Chandrakali & Literally flower of the moon. A type of saree \\
\hline
\end{tabular}




\begin{tabular}{|c|c|}
\hline Chaya Veru & Root of a red dye bearing plant in Andhra Pradesh, Indian Madder \\
\hline Chenetha & Woven by hand \\
\hline Chevalikudi & Twigs of red dye bearing plant in South India, Another kind of Indian Madder \\
\hline Chittashuddhi & A combination of focus and a sense of responsibility \\
\hline Coolie & Labourer \\
\hline Dakhni & Language of the Deccan Plateau, similar to Urdu \\
\hline Dalits & $\begin{array}{l}\text { Refers to one's caste rather than class; it applies to members of those menial } \\
\text { castes which have borne the stigma of OuntouchabilityÓ because of the } \\
\text { extreme 'impurity and pollution' connected with their traditional occupations. } \\
\text { It is the term that they adopt as a name for themselves over harijans, schedule } \\
\text { castes and untouchables. }\end{array}$ \\
\hline Damayanti & The name of the colour named after a beautiful queen \\
\hline Danima & Pomegranate \\
\hline Devangula & $\begin{array}{l}\text { A community from South India that traditionally followed the occupation of } \\
\text { weaving. }\end{array}$ \\
\hline Dhobi & Washerman \\
\hline Dhurrie & A heavy cotton rug \\
\hline Fakirs & Religious ascetics who live solely on alms \\
\hline Gharaana & $\begin{array}{l}\text { The word gharaana comes from the Urdu/Hindi word 'ghar', which means } \\
\text { 'family' or 'house'. It typically refers to the place where a particular musical } \\
\text { ideology originated, its iconic teachers [gurus] and is associated with a } \\
\text { particular style and genealogy of performance. }\end{array}$ \\
\hline Gittubaatu & Fair balance between income and expenditure \\
\hline Gittubaatu Ledu & Inadequacy of income \\
\hline Gnaanam & Wisdom \\
\hline Gorre Penda & Sheep dung \\
\hline Goudas & Agricultural caste of Andhra Pradesh \\
\hline Guru & Teacher \\
\hline Hamsa & Swan \\
\hline Idi Maaku Maamoole & This is normal for us \\
\hline $\begin{array}{l}\text { Idi Naluguri Tho } \\
\text { Koodina Pani }\end{array}$ & This is work that needs collective effort \\
\hline Jala & Extra weft setting \\
\hline Jalari & Loom device that picks up warp ends according to the design repeats \\
\hline Jathiswaram & An abstract dance where the drums set the beat. \\
\hline Jati & Local word for category or 'sub caste' \\
\hline
\end{tabular}




\begin{tabular}{|c|c|}
\hline Kairi & Raw Mango \\
\hline $\begin{array}{l}\text { Kaise Karte Hain } \\
\text { Dekhthe Hain }\end{array}$ & How to do, we'll figure out \\
\hline Kala & $\begin{array}{l}\text { Artistry that is a combination of technical, aesthetic and creative aspects of } \\
\text { production that are imagined as the artisan's forte }\end{array}$ \\
\hline Kapulu & $\begin{array}{l}\text { A social grouping of the Telaga and Balija subcastes found primarily in } \\
\text { the southern Indian state of Andhra Pradesh. Kapus speak Telugu and are } \\
\text { primarily an agrarian community, forming a heterogeneous peasant caste. }\end{array}$ \\
\hline Karakkai & Myrobalam \\
\hline Karkhanas & Small production units/Factories \\
\hline $\begin{array}{l}\text { Karnatic or Karnatik } \\
\text { Classical Music }\end{array}$ & A tradition of music from the South of India \\
\hline Karuvu & $\begin{array}{l}\text { Referring to conditions of drought when not just weaving but most } \\
\text { occupations in the village didn't meet basic needs }\end{array}$ \\
\hline Kasimi & Fermented black liquid dye \\
\hline Katha & $\begin{array}{l}\text { A unit of area in Bangladesh and India approximately equal to } 1 / 20 \text { of a bigha } \\
\text { (a traditional unit of land in several parts of India) }\end{array}$ \\
\hline Khaddar, Khadi & A hand spun handloomed plain-weave cotton fabric \\
\hline Khaddar Movement & $\begin{array}{l}\text { The Khadi/Khaddar movement, started by M.K. Gandhi promoted an } \\
\text { ideology, an idea that Indians could be self-reliant on cotton and be free from } \\
\text { the high priced goods and clothes which the British were selling to them. }\end{array}$ \\
\hline Kothadanam & Newness \\
\hline Kula Vritti. & Caste occupation/Hereditary vocation \\
\hline Kulam & Local word for 'caste' \\
\hline $\begin{array}{l}\text { Kunche Erukula } \\
\text { Community }\end{array}$ & $\begin{array}{l}\text { A community found largely in the Southern Indian states of Andhra Pradesh, } \\
\text { Tamilnadu and Karnataka. Yerukalas are indigenous people of South India. }\end{array}$ \\
\hline Kundalu & Earthen pots \\
\hline Kurtha & Tunic \\
\hline Lungi & Men's wear \\
\hline Maarpu & Change \\
\hline Madhya Taragati & Middle class \\
\hline $\begin{array}{l}\text { Madhya Taragati } \\
\text { Kutumbam }\end{array}$ & Middle class household \\
\hline Mallari & Musical composition played in the temple, used in Bharatanatyam dance \\
\hline Manchi Panitanam & Excellence in workmanship \\
\hline $\begin{array}{l}\text { Manchi Panitanam } \\
\text { Unnavaadu }\end{array}$ & One who is willing to experiment \\
\hline
\end{tabular}




\begin{tabular}{|c|c|}
\hline Manodharma & Creative expression \\
\hline Manu Shastra & $\begin{array}{l}\text { The most important and most studied ancient legal text of Hinduism } \\
\text { pertaining to religious and legal duty (dharma) }\end{array}$ \\
\hline Margam & Way \\
\hline Marwari Banias & $\begin{array}{l}\text { An occupational community of merchants, bankers, money-lenders, dealers in } \\
\text { grains or in spices, and in modern times numerous commercial enterprises. }\end{array}$ \\
\hline Melakuvalu & Tacit techniques \\
\hline Menthi & Fenugreek seeds \\
\hline Meruguparachadam & Literally to polish to a fine shine / honing one's skills \\
\hline Muhammadans & Muslims \\
\hline Myrobalam & Mordant, Terminalia Chebula \\
\hline Naamosikaram & Below the dignity of the weaver \\
\hline Naga red & Deep reddish brown \\
\hline Nalugo Taram & Fourth generation \\
\hline Neeli & Indigo; deep black blue \\
\hline Neeli Thutham & Copper sulphate \\
\hline Nerpu & Acquiring expertise, dexterity \\
\hline Netagani & Caste of Weaver, from Adilabad in Telengana \\
\hline Neyyi Veesa & Metal pot to measure clarified butter \\
\hline Nritta & Demonstration of rhythm through graceful body movements \\
\hline Oorpu & Meditative state of engagement \\
\hline Opika & Patience/attentiveness \\
\hline $\begin{array}{l}\text { Pachchi Gaddi Thinna } \\
\text { Gorre Penda }\end{array}$ & $\begin{array}{l}\text { Dung of the sheep that had grazed on moist fresh grass from the first } \\
\text { monsoon }\end{array}$ \\
\hline Padam & Musical composition, used in Bharatanatyam dance \\
\hline Padmasali & $\begin{array}{l}\text { A Telugu-speaking Hindu artisan caste predominantly residing in the Indian } \\
\text { states of Andhra Pradesh, Telangana, Karnataka, Tamil Nadu and Kerala }\end{array}$ \\
\hline Pallu & Patterned end-piece of a saree \\
\hline Panitanam & Workmanship \\
\hline Parignaanam & Acquisition of knowledge of underlying principles \\
\hline Parikaram & Change in tool \\
\hline Pasupu & $\begin{array}{l}\text { Tumeric- Curcuma longa or curcuma tinctoria, yields yellow \& orange hues; } \\
\text { root is used }\end{array}$ \\
\hline Pattimarpu & Extra weft weaving \\
\hline
\end{tabular}




\begin{tabular}{|c|c|}
\hline Pattis & Straps, three to four inches wide \\
\hline Pattusali & $\begin{array}{l}\text { A caste of the Telugu-speaking [] weavers caste.[1] They are found largely in } \\
\text { the South Indian states of Andhra Pradesh, Karnataka and Tamil Nadu. The } \\
\text { members of this subcaste specialise in weaving silk cloth, known as Pattu in } \\
\text { Tamil, hence the name Pattusali. }\end{array}$ \\
\hline Peer & Saint of Islamic lineage \\
\hline Pettelu & $\begin{array}{l}\text { Hank yarn is sold in } 4.54 \mathrm{kgs} \text { packages - this is referred to as bundle \& in } \\
\text { Telugu as petta, plural pettelu }\end{array}$ \\
\hline Pogu & Weaving yarn \\
\hline Purogathi & Livelihood \\
\hline Raasko Nee Phd Lo & Write it in your Ph.D \\
\hline Rajakulu & A minority Indian caste \\
\hline Rakham & Type \\
\hline Rang & Colour \\
\hline Rangaari & Dyers \\
\hline Rangrez & Dyers, Colour maker, Muslim dyer community \\
\hline Ratanjot & Alkanna tinctoria \\
\hline Reddy & $\begin{array}{l}\text { A caste that originated in India, predominantly settled in Andhra Pradesh \& } \\
\text { Telangana. }\end{array}$ \\
\hline Rekhtan & To pour \\
\hline Resham Rangulu & Silk colours \\
\hline Saadhana & Disciplined and dedicated practice or learning, especially in religion or music \\
\hline Saankethikam & Technology \\
\hline Sanketika & Technological \\
\hline $\begin{array}{l}\text { Sanketika } \\
\text { Parignaanam }\end{array}$ & Technological principles \\
\hline Sanyasi & Ascetic \\
\hline Sari, Saree & A woman's garment that consists of a drape of varying length and breadth \\
\hline Sarvodaya & Enlightenment for all \\
\hline Satyagraha & Insistence on truth \\
\hline Satyam & The truth \\
\hline Saudu Matti & Alkaline river mud \\
\hline
\end{tabular}




\begin{tabular}{|c|c|}
\hline Settibalijas & $\begin{array}{l}\text { A group of the Balija and are also known as Chettibalija, Ediga, Settiga, } \\
\text { Settikula or Indra. Many live in the East and West Godavari districts of } \\
\text { Andhra Pradesh and they tend to be employed in poorly paid low-status } \\
\text { occupations, such as agricultural labour and the manufacture and petty } \\
\text { trading of bangles. }\end{array}$ \\
\hline Seva & Service \\
\hline Seva Bhavana & The attitude of service \\
\hline Shabdam & Musical composition used in Bharatanatyam dance \\
\hline $\begin{array}{l}\text { Shareeramlo Feed } \\
\text { Ayipovadam }\end{array}$ & Programmed into a body \\
\hline Shivam & The good, the divine \\
\hline Shrama & Labour \\
\hline Suluvu & Technique trick \\
\hline Suluvulu & Technique tricks \\
\hline Sundaram & The beauty \\
\hline Sunnam & Lime \\
\hline Swadeshi Movement & $\begin{array}{l}\text { The Swadeshi movement, part of the Indian independence movement and the } \\
\text { developing Indian nationalism, was an economic strategy aimed at removing } \\
\text { the British Empire from power and improving economic conditions in India } \\
\text { by following the principles of swadeshi (self-sufficiency) }\end{array}$ \\
\hline Swadesi & Home country product \\
\hline Swaraj & Self governance \\
\hline Tagirasa & Cassia tora seeds \\
\hline $\begin{array}{l}\text { Telivi Ekkuvai } \\
\text { Jamdani Nesthunnaru }\end{array}$ & Doing Jamdani because they have become oversmart \\
\hline Thaadu & Thread \\
\hline Tillana & $\begin{array}{l}\text { A rhythmic piece in Karnatik music that is generally performed at the end of } \\
\text { a concert and widely used in dance performances }\end{array}$ \\
\hline Tinkathia Law & $\begin{array}{l}\text { A law imposed on indigo planters of Champaran to grow indigo on } 3 / 20 \text { of } \\
\text { their land and to sell produce to British planters at rates fixed by them. }\end{array}$ \\
\hline Tirrigin Orlu & Wanderers \\
\hline Udyamalu & Revolutions \\
\hline Utna Baithna & Getting up and sitting down together \\
\hline Valasa Vellipovadam & Migration to city \\
\hline Varnam & In this context, a composition of music that is used in dance. \\
\hline Vastu & Thing \\
\hline
\end{tabular}




\begin{tabular}{|l|l|}
\hline Veesa & A measure of weight (1400 grams) \\
\hline Veesa Billa & Iron weighing measure of one veesa \\
\hline Veesa Chambu & Metal pot to measure one veesa \\
\hline Velagapandu & Wood apple \\
\hline Vidhanam & Technique \\
\hline Vidya & Education \\
\hline Vignaanam & Science \\
\hline Virasaiva & An independent religion worshipping Lord Shiva \\
\hline Vis & A measure of weight (1400 grams) \\
\hline Vivaha Patu & Wedding silk \\
\hline Vritti & Vocation \\
\hline Waiting Undadu & There is no delay \\
\hline Yama-Niyama & $\begin{array}{l}\text { Yama: codes of restraint, self regulation as social disciplines, Niyama: } \\
\text { observances, practices, self training, personal disciplines }\end{array}$ \\
\hline Zari & A type of gold thread used decoratively on Indian clothing \\
\hline
\end{tabular}

\begin{tabular}{|c|c|}
\hline Textile terms & \\
\hline $\begin{array}{l}\text { 2-nitrobenzaldehyde } \\
\text { with acetone }\end{array}$ & $\begin{array}{l}\text { Organic aromatic compound containing a nitro group ortho to formyl; this } \\
\text { was once produced as an intermediate in the synthesis of Indigo }\end{array}$ \\
\hline $40 ' \mathrm{~S}, 60$ 'S , 80's count & see "COUNT" \\
\hline Acacia Katechu & $\begin{array}{l}\text { Acacia Catechu, commonly referred to catechu or katha; an extract of } \\
\text { heartwood \& pods of Acaia catechu; natural colorant \& yields light brown to } \\
\text { blackish brown depending on the mordant used }\end{array}$ \\
\hline Acid dyes & $\begin{array}{l}\text { Class of dyes which have direct affinity towards protein fibers, they are } \\
\text { mostly sulphonic acid salts, but some contain carboxyl groups. So called } \\
\text { because original members of this class were applied in a bath containing } \\
\text { mineral or organic acids }\end{array}$ \\
\hline Ahmednagar loom & $\begin{array}{l}\text { Innovated loom named after Mr Churchill of the American Mission at } \\
\text { Ahmednagar in the early 1900's (1905) where the weft insertion was } \\
\text { effected by a mechanism worked from the slay which comes into operation in } \\
\text { the process of beating up; in } 1906 \text { he developed a loom with an improved take } \\
\text { up motion driven by foot power that left the weavers hands free to change the } \\
\text { shuttle without stopping the weaving shuttle - this, he claimed made it twice } \\
\text { as fast as the fly shuttle loom }\end{array}$ \\
\hline Al & Al morinda; see Al morinda \\
\hline Al morinda & $\begin{array}{l}\text { Natural colorant; dyes extracted from the roots of Morinda Citrifolia, Morinda } \\
\text { Tinctorium; yields red to maroon, reddish brown; commonly used in Orissa }\end{array}$ \\
\hline
\end{tabular}




\begin{tabular}{|c|c|}
\hline Alizarine & $\begin{array}{l}\text { Organic compound used since } 1869 \text { as a red dye; historically derived from the } \\
\text { madder root; since } 1869 \text { it became the first natural pigment to be duplicated } \\
\text { synthetically. }\end{array}$ \\
\hline Alkali & $\begin{array}{l}\text { Basic, ionic salt of an alkali metal; a solution of a soluble base with a } \mathrm{pH} \\
\text { greater than } 7\end{array}$ \\
\hline Alum & $\begin{array}{l}\text { Hydrated sulfate pottasium; has acidic } \mathrm{pH} \& \text { used as mordant \& post dyeing } \\
\text { fixing agent when dyeing \& printing cotton with natural dyes }\end{array}$ \\
\hline Annatto & $\begin{array}{l}\text { Seeds of the Bixa orellana tree; natural colorant from seeds; yields organge } \\
\text { to yellow orange hues; commonly used as food colorant; used in dyeing silk } \\
\& \text { cotton textiles }\end{array}$ \\
\hline $\mathrm{APCO}$ & $\begin{array}{l}\text { Andhra Pradesh State Handloom Weavers Cooperative Society ; apex body of } \\
\text { the Primary Handloom Weaver's Cooperative Societies }\end{array}$ \\
\hline $\begin{array}{l}\text { Apex cooperative } \\
\text { societies }\end{array}$ & $\begin{array}{l}\text { State level apex body, APCO, set up in 1976, to undertake marketing of } \\
\text { production carried out by village level cooperatives }\end{array}$ \\
\hline Ayurveda & $\begin{array}{l}\text { System of medicine native to the Indian subcontinent; literal meaning" } \\
\text { science of life"- Ayur:Life; Veda " Science }\end{array}$ \\
\hline Azo dyes & $\begin{array}{l}\text { Class of synthetic organic dyes that contain nitrogen as the group -N=N- } \\
\text { as part of their molecular structures; Direct dyes, acid dyes, a few of the } \\
\text { anthraquinone vat dyes \& disperse dyes are some of the well known azo dyes. } \\
\text { Depending on other chemical feature, these dyes fall into several categories } \\
\text { defined by the fibers for which they have affinity or by the methods by which } \\
\text { they are applied. }\end{array}$ \\
\hline Bale & $\begin{array}{l}\text { Large bundle of raw or finished material packed \& bound with cord or wire; } \\
\text { in Andhra region } 20 \text { bundles of } 4.54 \mathrm{kgs} / \text { bundle of hank yarn is referred to } \\
\text { as a bale }\end{array}$ \\
\hline Banarasi brocade & $\begin{array}{l}\text { Richly decorated shuttle woven saris handwoven in Varanasi, often } \\
\text { made using colored silks with or without gold and silver threads. It is a } \\
\text { supplemtary weft technique ; that is the ornamental brocading is produced by } \\
\text { a supplementary non structural weft in addition to the standard weft yarn }\end{array}$ \\
\hline Basic dyes & $\begin{array}{l}\text { Also known as cationic dyes; class of synthetic dyes that act as bases \& when } \\
\text { made soluble in water form a colored catioinc salt, which can react with the } \\
\text { anionic sites on the substrate's surface. }\end{array}$ \\
\hline Beams & $\begin{array}{l}\text { Warp beams; roller located on the back of the loom on which the warp ends } \\
\text { are wound in preparation for weaving \& drawn from as the weaving proceeds }\end{array}$ \\
\hline Beater & Loom part; pushes the weft yarn securely in place during weaving process \\
\hline Beating & $\begin{array}{l}\text { Also referred to as Beat -up mechanism; beats or pushes the newly inserted } \\
\text { length of weft yarn (pick) into the already woven fabric at a point known as } \\
\text { "fell of the cloth". The three important mechanisms for producing fabric on } \\
\text { the loom are Shedding, Picking \& Beat -up mechanism }\end{array}$ \\
\hline Banarasi sari & $\begin{array}{l}\text { Fine silk saris made in Varanasi known for their gold and silver brocade or } \\
\text { zari, fine silk and decorated with intricate designs }\end{array}$ \\
\hline
\end{tabular}




\begin{tabular}{|c|c|}
\hline Binary logic & $\begin{array}{l}\text { Works on } 1 \mathrm{~s} \text { and } 0 \mathrm{~s} \text {; in weaving strands of warp \& weft are can be } \\
\text { represented in an on /off binary method }\end{array}$ \\
\hline Bixa orellana & Anatto; see Anatto \\
\hline Black vat & $\begin{array}{l}\text { Vat containing black dye resulting from fermentation of rusted iron with } \\
\text { jaggery this black dye is used in traditional dyeing and printing }\end{array}$ \\
\hline Bleach & $\begin{array}{l}\text { Treatment for removal of natural colouring matter of the substrate using either } \\
\text { chemicals or natural materials }\end{array}$ \\
\hline Bobbin winding & $\begin{array}{l}\text { Transfering yarn from coiled hank form to linear form; winding onto bobbins } \\
\text { that facilitate weft insertion during weaving }\end{array}$ \\
\hline Bobbins & Spindle or cylinder on which yarn is wound \\
\hline Bundle & Standardised hank yarn package weighing 4.54 kilograms \\
\hline Cabinet dyeing & Mechanized hank yarn dyeing machines \\
\hline Candies & $\begin{array}{l}\text { Cotton measure; traditional south asian unit of mass, roughly equivalent to } \\
227 \text { kilograms }\end{array}$ \\
\hline Carding & $\begin{array}{l}\text { Pre spinning process; mechanical process that disentangles, cleans } \\
\& \text { intermixes fibers to produce a continuous web or sliver suitable for } \\
\text { subsequent processes of spinning }\end{array}$ \\
\hline Cassia Tora & seeds of Cassia Tora plant is used to help fermentation of the Indigo vat \\
\hline Caustic & Common term for Caustic soda; Sodium hydroxide \\
\hline Caustic soda & Sodium hydroxide, also known as Lye \\
\hline Charkhas & $\begin{array}{l}\text { Spinning wheel; also adapted for winding warp \& weft hank yarn onto } \\
\text { bobbins }\end{array}$ \\
\hline Chaya veru & $\begin{array}{l}\text { Indian madder ; Hedyotis umbellate L., oldenlandiaumbellate -L, "veru" - } \\
\text { root; root of the Chaya plant }\end{array}$ \\
\hline Cheese dyeing & $\begin{array}{l}\text { Equipment to dye yarn; similiar to cabinet dyeing; yarn is wound from either } \\
\text { hank or cone to a 'cheese' package } \& \text { then dyed; more sophisticated than } \\
\text { cone dyeing \& hank dyeing machines }\end{array}$ \\
\hline $\begin{array}{l}\text { Circular warping } \\
\text { drum }\end{array}$ & see "Warping Drum" \\
\hline Colour fastness & $\begin{array}{l}\text { Resistance of the substrate's colour to fading or bleeding to various types of } \\
\text { influences e.g. water, light, rubbing, washing, pesperiation, etc to which they } \\
\text { are normally exposed in various manufacturing processes \& in daily use }\end{array}$ \\
\hline Colour fixing & $\begin{array}{l}\text { Applying a substance, generally organic, to fix the dyes onto the substrate to } \\
\text { improve its fastness to wet treatments }\end{array}$ \\
\hline Cone dyeing & $\begin{array}{l}\text { Equipment to dye yarn; similiar to cabinet dyeing; yarn is wound from either } \\
\text { hank or cones onto a cone package \& then dyed; more sophisticated than } \\
\text { hank dyeing machines }\end{array}$ \\
\hline
\end{tabular}




\begin{tabular}{|c|c|}
\hline Cone yarn & $\begin{array}{l}\text { Refers to yarn wound on cones post spinning (as opposed to yarn converted to } \\
\text { hank form): stiff cardboard or plastic cones used; a typical hole runs through } \\
\text { the inside center of the yarn cone, which then is fitted over the machine. } \\
\text { Unlike hank yarn, this is already in linear form }\end{array}$ \\
\hline $\begin{array}{l}\text { Continuous } \\
\text { fermentation Vat }\end{array}$ & $\begin{array}{l}\text { A vat that produces colour as it ferments, breaking down the materials in } \\
\text { the vat as it does so. The vat can then be used for dyeing, after which the } \\
\text { materials have to be replenished in such a way that they do not interfere with } \\
\text { the balance needed for fermentation. This evaluation of what material needs } \\
\text { to be added is done by smell. }\end{array}$ \\
\hline Copper sulphate & $\begin{array}{l}\text { Also referred to as cupric sulphate and blue vitrol, it is used as a mordant } \\
\text { when using natural dyes for dyeing textiles }\end{array}$ \\
\hline Cotton spinning & Process of producing yarn from cotton fibres \\
\hline Count & $\begin{array}{l}\text { Numerical system for measuring yarn size indicating relationship of length } \\
\text { to weight; number indicates length, thickness of yarn and composition of ply } \\
{[1,2]}\end{array}$ \\
\hline Craftmark & $\begin{array}{l}\text { Initiative of All India Artisans \& Craftworkers Welfare Association (AIACA), } \\
\text { an Indian NGO to denote genuine Indian handicrafts, develop sector wide } \\
\text { minimum standards and norms for product labelling as handicrafts \& } \\
\text { increase consumer awareness of distinct handicraft traditions. As part of } \\
\text { this initiative, AIACA licenses the Craftmark logo for use by craft based } \\
\text { business, cooperatives and NGOs for use on product tickets \& labels }\end{array}$ \\
\hline Cream of tartar & $\begin{array}{l}\text { Pottasium bitartrate; pottasium acid salt of tartaric acid; used along with alum } \\
\text { when dyeing wool for improving color consistency }\end{array}$ \\
\hline Curcuma longa & tumeric; used in dyeing textiles; is a fugitive dye \\
\hline Curing & $\begin{array}{l}\text { Process where appropriate conditions are created to effect a chemical } \\
\text { reaction; in natural dyes, substrate is dried \& put away overnight or even as } \\
\text { long as a week in between processes esp. after tannin \& mordant application }\end{array}$ \\
\hline Dent & Space between two reed wires \\
\hline Denting & $\begin{array}{l}\text { Drawing warp threads through the dent as required; this determines fabric } \\
\text { width \& ends / inch }\end{array}$ \\
\hline Dhurrie & Heavy cotton rug \\
\hline Di-azo dyes & $\begin{array}{l}\text { Azoic dyes; contain insoluble azo group }(-\mathrm{N}=\mathrm{N}) \text {; produced by reaction of } 2 \\
\text { components of coupling compund (napthol \& the Dia azo compound either } \\
\text { base or salt); popularly known as Napthol dyes }\end{array}$ \\
\hline Direct dyes & $\begin{array}{l}\text { Chemical dye group of coloured water soluble compounds that have an } \\
\text { affinity for cellulosic fiber \& good substantivity, without the necessity of a } \\
\text { pre mordanting treatment }\end{array}$ \\
\hline Disperse dyes & $\begin{array}{l}\text { Organic colorants free fom ionizing groups, have low water solubility \& are } \\
\text { used for dyeing hydrophobic fibers like polyester, nylon, acrylic \& other } \\
\text { synthetic fibers }\end{array}$ \\
\hline
\end{tabular}




\begin{tabular}{|c|c|}
\hline Dobby & $\begin{array}{l}\text { Loom device that selectively raises \& depresses heald shafts containing warp } \\
\text { threads as per design requirement thus making more complex patterns than } \\
\text { plain weaving; an extra weft technique used for weanong patterns, mostly } \\
\text { borders }\end{array}$ \\
\hline $\begin{array}{l}\text { Dobby attachment on } \\
\text { loom }\end{array}$ & $\begin{array}{l}\text { Punched narrow strips of wood arranged as per design, } \mathrm{i} / \mathrm{o} \text { jacquard cards } \\
\text { which controls the harness \& movement of heald shafts, allowing weaving of } \\
\text { predetermined small patterns }\end{array}$ \\
\hline Dye & $\begin{array}{l}\text { Staining or colouring substance either natural or chemical capable of } \\
\text { giving color to a substrate; dyes are soluble in water or made soluble during } \\
\text { application \& have affinity for one or more textile fibres under precise } \\
\text { conditions of temperature and presence of specific auxiliaries }\end{array}$ \\
\hline Dyeing & Processof imparting colour or stain \\
\hline Dyers & Persons whose are specialized in dyeing of textiles or other materials \\
\hline End & A single thread of warp \\
\hline European fly shuttle & $\begin{array}{l}\text { A variation of the shuttle that is thrown using the foot pedals, rather than by } \\
\text { hand }\end{array}$ \\
\hline Extra weft weaving & $\begin{array}{l}\text { To create designs / motifs by floating extra wefts over ground weave, without } \\
\text { disturbing basic structure of the weave. Wefts are inseted along the same } \\
\text { pasasge as the main weft \& then worked backwords and forwards to create } \\
\text { the design. also called Supplementary weft technique }\end{array}$ \\
\hline Fast color bases & $\begin{array}{l}\text { Any of the several bases used as such or in the form of fast color salts in } \\
\text { producing azoic dyes }\end{array}$ \\
\hline Ferrous sulphate & $\begin{array}{l}\text { Iron sulphate FeSO4; a pale white to blue green crystalline compound } \\
\text { occuring in nature; used as a morant mostly for fixing wool colors }\end{array}$ \\
\hline Fixing & $\begin{array}{l}\text { To fix the dyes onto the substrate for good fabric performance during } \\
\text { subsequent washing }\end{array}$ \\
\hline \multicolumn{2}{|l|}{ Fly shuttle sley } \\
\hline Fly shuttle & $\begin{array}{l}\text { also known as flying shuttle ; patented by John Kay in } 1733 \text {, this dramatically } \\
\text { increased speed of weaving; earlier shuttle carrying weft yarn would be } \\
\text { passed slowly from one hand to the other. Kay placed shuttle boxes at each } \\
\text { side of the loom connected by a long board, known as Shuttle race, By means } \\
\text { of cords attached to a picking peg, a single weaver, using one hand could } \\
\text { cause the shuttle to be knocked back \& forth across the oom from one shuttle } \\
\text { box to the other; by means of two strings attached to the opposite ens of the } \\
\text { shuttle race, and both held by a peg in the weavers hand, he, with a slight \& } \\
\text { sudden pluck was able to get the shuttle to propel to the other side }\end{array}$ \\
\hline Gadwal saree & $\begin{array}{l}\text { Handwoven saris from the Gadwal region of Andhra; typically cotton body } \\
\text { with silk border \& pallu woven on a three shuttle loom, where the border } \\
\text { yarns are interlocked and the silk pallu warp threads is attached onto the } \\
\text { cotton body yarn \& then woven }\end{array}$ \\
\hline
\end{tabular}




\begin{tabular}{|c|c|}
\hline German indigo & Industrial Indigo dye synthesized first in Germany \\
\hline GI & $\begin{array}{l}\text { Geographical Indication (GI) is a name or sign used on certain products } \\
\text { which corresponds to a specific geographic location or origin;use of GI may } \\
\text { act as a certification that the product possesses certain qualities, is made } \\
\text { according to traditional methods or enjoys a certain reputation, due to its } \\
\text { geographical origin }\end{array}$ \\
\hline Hand weaving & $\begin{array}{l}\text { Weaving done on the loom by hand, without electricity; weaver moves the } \\
\text { treadles with his feet as well as throws the shuttle by hand }\end{array}$ \\
\hline Handicraft & $\begin{array}{l}\text { Skilled activity in which something is made in a traditional way with the } \\
\text { hands rather than being produced by machines in a factory, or an object made } \\
\text { by such an activity }\end{array}$ \\
\hline Handloom & A loom that is not driven by electricity, but by the human body \\
\hline $\begin{array}{l}\text { Handloom co- } \\
\text { operatives }\end{array}$ & $\begin{array}{l}\text { autonomous association of handloom weavers united voluntarily to meet } \\
\text { their economic needs through a jointly ownd and democratically controlled } \\
\text { enterprise; Primary handloom cooperative societies are village based } \\
\text { institutions and in Andhra link up to the apex body APCO for marketing } \\
\text { support; known commonly as PHWCS - Primary Handloom Weavers } \\
\text { Cooperative Society }\end{array}$ \\
\hline $\begin{array}{l}\text { Hank washing } \\
\text { machines }\end{array}$ & Special machines fabricated to wash hank yarn \\
\hline Hank & $\begin{array}{l}\text { A specific length of yarn according to fiber type wound as a loop or a skein; } \\
840 \text { yards for cotton }\end{array}$ \\
\hline Hattersley & $\begin{array}{l}\text { Specially developed loom in } 1921 \text { for home use for easier \& faster weaving } \\
\text { with all the loom motions are connected via crankshaft \& gear wheels, } \\
\text { manually operated using foot pedals or treadles. }\end{array}$ \\
\hline Heddles & $\begin{array}{l}\text { Single or set of frames of vertical wires or cords on a loom, each wire having } \\
\text { an eye through which a warp thread can be passed. Also known as Heald, this } \\
\text { enables the yarn to be raised or lowered during weaving to create a shed for } \\
\text { passage of weft yarn }\end{array}$ \\
\hline Hoisery & Reference in this context is to knitwear \\
\hline Hydro extractors & Mechanized equipment that removes excess water using centrifugal force \\
\hline Hydro-sulphite & $\begin{array}{l}\text { Sodium Hydrosulphite, used as a reducing agent for the reducion of vat dyes. } \\
\text { The purpose of reduction is to form leuco components which are soluble in } \\
\text { water which then will have a great affinity for the textile substrate }\end{array}$ \\
\hline Hydrolysis & The chemical breakdown of a compound due to reaction with water \\
\hline Hydrose & $\begin{array}{l}\text { Sodium Hydrosulphite (sodium dithionite) is used to reduce a water insoluble } \\
\text { dye to a water soluble dye. It also eliminates excess dye, residual oxide, } \\
\text { thereby improving overall color quality }\end{array}$ \\
\hline Indigo & Dye extract of Plant Indigofera Tinctoria \\
\hline
\end{tabular}




\begin{tabular}{|c|c|}
\hline Indigofera tinctoria & $\begin{array}{l}\text { plant species from the bean family; one of the original sources of indigo dye; } \\
\text { dye is obtained from the processing of the plant leaves }\end{array}$ \\
\hline Indoxyl & $\begin{array}{l}\text { Indoxyl is a nitrogenous substance with a chemical formula } \mathrm{C} 8 \mathrm{H} 7 \mathrm{NO} \text {; it is } \\
\text { obtained from Indican; Indigo dye radical precursor to Leuco indigo in the } \\
\text { Indigo fermentation vat; Indigo dye is a product of the reaction of indoxyl by } \\
\text { a mild oxidizing agent such as atmospheric oxygen }\end{array}$ \\
\hline Integrated mills & $\begin{array}{l}\text { Textile mills having complete vertical operations from spinning, weaving of } \\
\text { fabric, and dyeing facilities }\end{array}$ \\
\hline I ron acetate & Metal complex with formula $\mathrm{Fe}(\mathrm{C} 2 \mathrm{H} 3 \mathrm{O} 2)$ \\
\hline $\begin{array}{l}\text { Jacquard punching } \\
\text { machine }\end{array}$ & $\begin{array}{l}\text { Machine used to punch cards that can be attached to the hand loom, which } \\
\text { control the weaving patterns in fabric }\end{array}$ \\
\hline Jacquard weaving & $\begin{array}{l}\text { Weaving on looms fitted with cards that move the harnesses as per complex } \\
\text { design requirement, thus facilitating control over individual warp threads } \\
\text { rather than groups of warp threads, creating more complex patterns than the } \\
\text { dobby looms }\end{array}$ \\
\hline Jaggery & Unrefined brown sugar \\
\hline Jala & $\begin{array}{l}\text { Extra weft setting that lifts the warp yarns in as per design requirements to } \\
\text { facilitate insertion of extra weft threads }\end{array}$ \\
\hline Jalari & $\begin{array}{l}\text { Vertical harness that picks up warp ends according to the design repeats; } \\
\text { design is tied to the jala }\end{array}$ \\
\hline Jamdani & $\begin{array}{l}\text { An extra weft weaving technique to weave complex \& elaborate all over } \\
\text { motifs }\end{array}$ \\
\hline $\begin{array}{l}\text { Jesop's Japanese } \\
\text { loom }\end{array}$ & Early 1900 s innovations in loom technologies \\
\hline Kalamkari & $\begin{array}{l}\text { Traditional hand painting \& block printed craft practised in different pockets } \\
\text { in India; Literal translation: Kalam- pen, kari - craftsmanship; }\end{array}$ \\
\hline Kanchipuram silk & $\begin{array}{l}\text { Pure mulberry silk saris handwoven with traditional motifs, using zari in } \\
\text { Kanchipuram town using three shuttles }\end{array}$ \\
\hline Kasimi & $\begin{array}{l}\text { Black dye made from fermented solution of rusted iron \& jaggery; used for } \\
\text { dyeing / printing textiles }\end{array}$ \\
\hline Katha & $\begin{array}{l}\text { Catechu; an extract of accia trees used as food additives, astringent, tannin \& } \\
\text { dye; also see 'Acacia Katechu' }\end{array}$ \\
\hline Khaddar & Also known as Khadi, pl see 'Khadi' \\
\hline Khaddar movement & $\begin{array}{l}\text { Movement started by Gandhi in the } 1920 \text { s around the freedom movement } \\
\text { promoted an ideology, an idea that Indians could be self reliant with } \\
\text { indigenious production and be free from the high priced goods \& clothes sold } \\
\text { by the British }\end{array}$ \\
\hline Khadi & Hand woven fabric using hand spun yarn \\
\hline
\end{tabular}




\begin{tabular}{|c|c|}
\hline Knitting & $\begin{array}{l}\text { Method by which yarn is manipulated using knitting needles to create } \\
\text { knitwear }\end{array}$ \\
\hline Lathe & $\begin{array}{l}\text { Machine tool for holding \& turning metal, wood or other material against a } \\
\text { cutting tool }\end{array}$ \\
\hline Lay & $\begin{array}{l}\text { Also known as Sley; used for pushing the last pick of weft to the fell of the } \\
\text { cloth by means of the beat up motion. The sley moves faster when moving } \\
\text { towards the fell of the cloth \& slower when moving backwards. }\end{array}$ \\
\hline Leases & $\begin{array}{l}\text { Arrangements of warp yarns to maintain the same relative position. This is } \\
\text { done generally by criss crossing the warp yarns alternatively, keeping them in } \\
\text { position by lease rods }\end{array}$ \\
\hline Leuco indigo & Reduced indigo soluble in water \\
\hline Light fastness & Resistance of colours to fading, changing shade under the influence of light \\
\hline Lime water & Calcium oxide, $\mathrm{CaO}$ dissolved in water \\
\hline Loom & Equipment that faciliates interlacement of warp \& weft yarns \\
\hline Mill sector & $\begin{array}{l}\text { Organized sector in the textile industry comprising of spinning mills \& } \\
\text { composite mills; as opposed to the decentralized sector engaged mainly in } \\
\text { weaving }\end{array}$ \\
\hline Mill spun yarn & Yarn spun in mills using mechanized processes \\
\hline Mill yarn & See "mill spun yarn" \\
\hline Mordant & $\begin{array}{l}\text { Metallic salts which assists reaction to occur between dye and fabric and also } \\
\text { fix colour; 'bites' into the substarte \& helps bind color }\end{array}$ \\
\hline Mordanting & Process of coating substrate with mordants \\
\hline Motifs & Designs, patterns \\
\hline Mule & $\begin{array}{l}\text { Machine invented by Samuel Crompton that spins cotton into yarn and winds } \\
\text { yarn on spindles }\end{array}$ \\
\hline Muslin & $\begin{array}{l}\text { Fine plain weave cotton fabric; gets its name from Masulipatnam, an Indian } \\
\text { port. Early Indian muslin was handwoven of delicate fine handspun yarn }\end{array}$ \\
\hline Muslins & see "Muslin" \\
\hline Myrobalan & $\begin{array}{l}\text { Botanical name: Terminalia Chebula; high in tannins which make them good } \\
\text { mordants }\end{array}$ \\
\hline Naga red & Deep reddish brown colour \\
\hline Naphthols & $\begin{array}{l}\text { Insoluble azo dyes that are produced on the fiber by first adding napthol to the } \\
\text { fiber \& then combining it with a diazotised base to produce an insoluble dye } \\
\text { molecule within the fiber }\end{array}$ \\
\hline Natural dyes & Dyes extracted from natural materials - vegetable, mineral etc \\
\hline
\end{tabular}




\begin{tabular}{|c|c|}
\hline NHDC & $\begin{array}{l}\text { National Handloom Development Corporation, a Public sector undertaking } \\
\text { set up by the Indian Government in Feb } 1983 \text { to assist the speedy } \\
\text { development of handloom sector }\end{array}$ \\
\hline Optical brighteners & $\begin{array}{l}\text { Chemical compounds that absorb light in the ultra violet \& violet regions of } \\
\text { the electromagnetc spectrum \& re emit light in the blue region; this enhances } \\
\text { the appearance of color of fabrics causing a whitening effect making materials } \\
\text { loook less yellow by increasing overall amount of blue light reflected }\end{array}$ \\
\hline Organic pigments & $\begin{array}{l}\text { water insoluble colouring matter; applied onto textile materials, by adding } \\
\text { in polymer melt or solution or by applying on fiber surface with the help of } \\
\text { adhesives called binder; oganic pigments such as insoluble azo or polycyclic } \\
\text { keto compounds are mostly applied on textiles }\end{array}$ \\
\hline Paisley & $\begin{array}{l}\text { Design motif of Persian \& Indian origin resembling a twisted droplet, much } \\
\text { like an enlongated mango }\end{array}$ \\
\hline Paithani sarees & $\begin{array}{l}\text { Named after the Paithan town in India, these are handwoven saris made from } \\
\text { very fine silk, and characterised by borders of an oblique square design and a } \\
\text { pallu with a peacock design }\end{array}$ \\
\hline Pallu (sari) & $\begin{array}{l}\text { Loose end of the sari, hanging from the shoulder after worn; typically the } \\
\text { pallu is differentiated from the rest of the sari by distinct pattern }\end{array}$ \\
\hline Palm jaggery & $\begin{array}{l}\text { Extract from the palm tree sap; concentrated without the seperation of the } \\
\text { molaasses and crystals }\end{array}$ \\
\hline Pick & $\begin{array}{l}\text { A single crossing of the weft yarn carrying shuttle from one side of the loom } \\
\text { to other; End: A single thread of warp; Pick: a single weft yarn }\end{array}$ \\
\hline Pirn & Small bobbin used for weft yarn insertion \\
\hline Pixelation & $\begin{array}{l}\text { Display of a digitized image where the individual pixels are apparent to } \\
\text { the viewer. This can happen unintentionally when a low resoloution image } \\
\text { designed for an ordinary computer dispaly is projected on a large screen and } \\
\text { each pixel becomes seperately viewable }\end{array}$ \\
\hline Post loom washing & $\begin{array}{l}\text { Washing of fabrics post weaving to remove any residue that maybe present } \\
\text { from weaving as well as to relax the interwoven yarns from its streched stage }\end{array}$ \\
\hline Post loom & Processes carried on the fabric post weaving - washing, finsihing etc \\
\hline Post mordanting & $\begin{array}{l}\text { Application of mordants after dyeing to change color tones or perk up } \\
\text { uninteresting colours; also used to remove residual dyes on substrate surface } \\
\text { and help fix dye within the fibers }\end{array}$ \\
\hline Potassium dichromate & $\begin{array}{l}\text { Mineral mordant used for dyeing wool; it leaves wool soft unlilke other } \\
\text { mordants which tend to harden the wool }\end{array}$ \\
\hline Power loom sector & $\begin{array}{l}\text { Textile segment of powerlooms; this is a decentralized sector with a share of } \\
\text { nearly } 55 \% \text { of total cloth produced }\end{array}$ \\
\hline Powerloom & $\begin{array}{l}\text { Mechanized loom using electricity; one of the key developments in the } \\
\text { industrailzation of weaving during the early Industrial Revoloution; the 1st } \\
\text { powerloom was designed in } 1784 \text { by Edmund Cartwright and built in } 1785 \text {. }\end{array}$ \\
\hline
\end{tabular}




\begin{tabular}{|c|c|}
\hline Pre loom workers & $\begin{array}{l}\text { Workers engaged in pre loom processes of dyeing, warping, sizing, \& } \\
\text { winding of both warp \& weft yarns }\end{array}$ \\
\hline Pre treat & $\begin{array}{l}\text { Process of pretreatment of yarn before taking up for dyeing; series of } \\
\text { operations to clean impurities in yarn that occur naturally \& which are } \\
\text { added during spinning; activities include, desizing, scouring \& sometimes } \\
\text { bleaching of the yarn before taking up for dyeing }\end{array}$ \\
\hline Pre-loom & $\begin{array}{l}\text { processes that the yarn undergoes before weaving; these include dyeing, } \\
\text { warping, sizing \& winding }\end{array}$ \\
\hline Preparatory work & $\begin{array}{l}\text { Here referring to processes before weaving; dyeing, sizing, winding of warp } \\
\& \text { weft; in sector, refers to pre dyeing process of desizing, scouring \& } \\
\text { bleaching }\end{array}$ \\
\hline $\begin{array}{l}\text { Primary weaver co- } \\
\text { operatives }\end{array}$ & see 'handloom cooperatives' \\
\hline Processing & $\begin{array}{l}\text { Refers to all wet processes : ie desizing, scouring, bleaching, dyeing \& post } \\
\text { dyeing fixing, washing, etc }\end{array}$ \\
\hline Punica granatum & Botanical name for pomegrante ; natural colorant \\
\hline Quercus fenestrate & Botanical name for a species of Oak; used as natural colorant \\
\hline Ratanjot & $\begin{array}{l}\text { Hindi name for number of plants in the borage famiy traditionally used for } \\
\text { coloring textiles \& foods, medicines, etc. In India the species most commonly } \\
\text { used is Arnebia nobilis; the purple brown roots are covered in a papery bark } \\
\text { from which the dye is extracted ; depending on the mordants shades yeilded } \\
\text { range from pinkish (acidic) to greyish blue (alkaline) }\end{array}$ \\
\hline RCKS & $\begin{array}{l}\text { Rashtriya Chenetha Karmika Samkhya, an independent weaver movement } \\
\text { from Chirala, Andhra }\end{array}$ \\
\hline $\begin{array}{l}\text { Reactive dye } \\
\text { technology }\end{array}$ & Process of dyeing with reactive dyes \\
\hline Reactive dyes & $\begin{array}{l}\text { highly coloured organic substances, primarily used for dyeing textiles, that } \\
\text { attach themselves substrates by a chemical reaction that forms a covalent } \\
\text { bond between the dye molecule \& fiber molecule }\end{array}$ \\
\hline Reed & $\begin{array}{l}\text { Comb like frame consisting of regularly spaced wires; this is used also to } \\
\text { push the weft yarn firmly against the fabric after each insertion }\end{array}$ \\
\hline reed makers & Artisans who produce the reeds used on handlooms \\
\hline Roxb & Garcinia Dulcis; extract from bark of this tree is used to dye silk \\
\hline Rubbing fastness & $\begin{array}{l}\text { Degree of colour which may be transferred from the surface of a colored } \\
\text { fabric to another surface in the process of rubbing; resistance of fading of } \\
\text { dyed textiles when rubbed against aanother surface both when wet \& dry }\end{array}$ \\
\hline Rubia Cordifolia & Biological name for Madder; produces rust, pink, red \& maroon shades \\
\hline Rubia Sikkimensis & belonging to the Rubiaceae, this a herb that yields red dye \\
\hline Rubia tinctoria & Rubia tinctorium, commonly known as Madder; roots yield red dyes \\
\hline
\end{tabular}




\begin{tabular}{|c|c|}
\hline $\begin{array}{l}\text { Salvation Army } \\
\text { Triumph }\end{array}$ & Invented in the early 1900s by Captain Maxwell of the Salvation Army \\
\hline Sari, saree & $\begin{array}{l}\text { Unstitched outer garment consisting of a length of fabric elaborately draped } \\
\text { around the body with one end forming an ankle length skirt and the other end } \\
\text { draped across the bososm, over one shoulder \& sometimes over the head; } \\
\text { traditioanly worn by women from South Asia }\end{array}$ \\
\hline Saudu matti & Alkaline river mud \\
\hline Scouring & $\begin{array}{l}\text { Process of removal of all natural \& additive impurities such as wax, oils etc to } \\
\text { clean up textile substrate and make it ready for dyeing }\end{array}$ \\
\hline Scrap iron & Discarded metal suitable for reprocessing \\
\hline Serampore loom & $\begin{array}{l}\text { Loom with fly shuttle attached instead of the throw shuttle which increased } \\
\text { productivity; this invented in the early } 1900 \text { s by E.B. Havell }\end{array}$ \\
\hline Shafts - loom & $\begin{array}{l}\text { Also referred as harness; frame of the loom that holds the warp threads, these } \\
\text { shafts are moved up \& down by treadles to allow the weft to cross through } \\
\text { and create the desired pattern. The more number of shafts the more patterns } \\
\text { can be created. }\end{array}$ \\
\hline Shed & $\begin{array}{l}\text { Temporary seperation between upper \& lower warp yarn on the loom through } \\
\text { which the weft is inserted }\end{array}$ \\
\hline Shrinkage & $\begin{array}{l}\text { Process in which fabric becomes smaller than original measurements, usually } \\
\text { when washed. Yarn is stretched in pre loom process of warping \& sizing and } \\
\text { also on the loom during weaving; after weaving when washed for the } 1 \text { st } \\
\text { time, yarns will relax into its original length causing shrinakge across both } \\
\text { length \& width of fabrics }\end{array}$ \\
\hline Shuttles & $\begin{array}{l}\text { Yarn package carrier that is used to carry weft thread through the shed to } \\
\text { insert weft yarn during weaving. }\end{array}$ \\
\hline Size & $\begin{array}{l}\text { Starch in liquid form used to strengthen warp threads to prevent breakage or } \\
\text { damage of warp yarns during weaving due to abrasion }\end{array}$ \\
\hline Sizers & Persons undertaking activity of applying size to warps \\
\hline Sizing brush & $\begin{array}{l}\text { Special brush made from natural material like the palmyra fiber used to } \\
\text { spread starch evenly on the warp and ensure that each thread is coated }\end{array}$ \\
\hline Sizing shed & Shed where sizing activity is carried on \\
\hline Skeins & Lengths of yarn loosely coiled and knotted \\
\hline Sodium hydrosulphite & $\begin{array}{l}\text { Also known as Sodium dithionite; used as a reducing agent for the reducion } \\
\text { of vat dyes. The purpose of reduction is to form leuco components which are } \\
\text { soluble in water \& have a great affinity for the textile substrate }\end{array}$ \\
\hline Sodium hydroxide & $\begin{array}{l}\mathrm{NaOH} \text {, also known as lye \& caustic soda; used in textile industry in pre } \\
\text { dyeing process of scouring. It removes waxes \& oils from fiber to make fiber } \\
\text { more receptive to dyes. Also used for mercerizing }\end{array}$ \\
\hline Spinning & $\begin{array}{l}\text { Process of drawing out, twisting and winding of fibers into a continuous } \\
\text { thread or yarn }\end{array}$ \\
\hline
\end{tabular}




\begin{tabular}{|c|c|}
\hline Spinning jenny & $\begin{array}{l}\text { An early type of spinning frame with several spindles, invented by James } \\
\text { Hargreaves in } 1764\end{array}$ \\
\hline Staple & Fibre length of cotton \\
\hline Street sizing & $\begin{array}{l}\text { In most handloom clusters warps are stretched out in the streets \& sized, } \\
\text { hence sizing activity is referred to as Street sizing }\end{array}$ \\
\hline Sulfur dyes & $\begin{array}{l}\text { Synthetic organic substantive dyes for cellulsics; these dye contain sulfur as } \\
\text { an intergral of the chromophore as well in the polysulphide side chains }\end{array}$ \\
\hline Synthetic dyes & $\begin{array}{l}\text { Organic dye compounds originally derived from coal -tar derivatives ; } \\
\text { presently produced by synthesis from benzene \& its derivatives; they are } \\
\text { classified based upon their chemical compositions and method of application } \\
\text { in dyeing process }\end{array}$ \\
\hline Tannin & $\begin{array}{l}\text { Type of biomolecule found in vegetable \& natural matter which is an } \\
\text { astringent \& is used in tanning leather, when using natural dyes on textiles, } \\
\text { etc }\end{array}$ \\
\hline Tassles & $\begin{array}{l}\text { a tuft of loosely hanging threads or cords knotted at one end and attached for } \\
\text { decoration on clothing, curtains, etc }\end{array}$ \\
\hline Texture & Structure, appearance \& feel of fabric \\
\hline Tinkathia & Land measure \\
\hline Twist & $\begin{array}{l}\text { The twist of thread around its axis resulting from spinning, twisting, } \\
\text { throwing or plying- may be } \mathrm{S} \text { or } \mathrm{Z} \text { twist. }\end{array}$ \\
\hline Uppada jamdani & $\begin{array}{l}\text { Jamdhani saris made in Uppada, a town in East Godavari district in Andhra } \\
\text { state }\end{array}$ \\
\hline Vastu & $\begin{array}{l}\text { Also known as vastu shastra; a traditional Hindu system of architecture ; } \\
\text { literal translation "science of architecture" }\end{array}$ \\
\hline Vat & $\begin{array}{l}\text { A large container used for dyeing; also referes to the container used for } \\
\text { fermentation }\end{array}$ \\
\hline Vat dyes & $\begin{array}{l}\text { Dyes that contain at least } 2 \text { carbonyl groups }(\mathrm{C}=\mathrm{O}) \text { that enable these water } \\
\text { insluble dyes to be convertd by means of reduction under alkaline conditions } \\
\text { into water soluble 'leuco compounds' }\end{array}$ \\
\hline Vatting (instant) & $\begin{array}{l}\text { Reduction of insoluble vat dye with a reducing agent to make it water soluble, } \\
\text { usually sodium hydrosulphite in the presence of sodium hydroxide to form } \\
\text { sodium salt of leuco compound }\end{array}$ \\
\hline Veesa billa & Iron weighing measure of one veesa, ie 1400 grams \\
\hline Veesa chambu & Pot to measure out one veesa \\
\hline Veesa, vis & measure of weight, 1400 grams \\
\hline Warp & $\begin{array}{l}\text { Set of threads ordered \& attached to the loom which form the length of the } \\
\text { fabric and provides the base for the weft yarns }\end{array}$ \\
\hline
\end{tabular}




\begin{tabular}{|c|c|}
\hline Warp drum & $\begin{array}{l}\text { A hand driven circular drum which is used to wind yarn into linear lengths for } \\
\text { the warp }\end{array}$ \\
\hline Warper & Person under staking the process of warping \\
\hline Warping & $\begin{array}{l}\text { Process of creating the base yarn that runs along the length of the fabric; } \\
\text { parallel winding of large number of individual strands of warp yarn from } \\
\text { many winding packages (cone, drum) of a specified length. There are } 3 \text { types } \\
\text { of warping: sectional, beam \& ball warping; ball warping is commonly done } \\
\text { in the handloom weaving sector }\end{array}$ \\
\hline Warping drum & $\begin{array}{l}\text { Horizontal warping equipment for producing ball warps wherein full width } \\
\text { of warp ends is wound onto a circular drum; used mostly for warping long } \\
\text { lengths in handloom; warping equipment consists of a circular drum (width } \\
\text { as per warp length requirement) whereby all the requred ends of the warp } \\
\text { yarn is wound sequential next to each other until the full weaving width is } \\
\text { covered; when the required length is wound, it is taken off the circular drum } \\
\text { as a long rope which is then taken to the next process of either sizing or } \\
\text { tyeing (for tie dye fabrics); }\end{array}$ \\
\hline Washing & $\begin{array}{l}\text { Process of rinsing \& washing during a complete textile dyeing } \& \text { finishing } \\
\text { cycle both pre \& post dyeing \& during dyeing }\end{array}$ \\
\hline Water frame & $\begin{array}{l}\text { Water powered spinning frae developed by Richard Arkwright; patented in } \\
1769\end{array}$ \\
\hline $\begin{array}{l}\text { Weavers' service } \\
\text { centre }\end{array}$ & $\begin{array}{l}\text { Established in } 1956 \text { as a National level institution by the Indian Government } \\
\text { to promote and facilitate the continuous growth of handloom industry to } \\
\text { compete in the global market; specificallly dedicated to support Handloom } \\
\text { sector at large in upgrading skill, development / diversification of handloom } \\
\text { products, provide design inputs \& technical advice in weaving / dyeing / } \\
\text { printing to weavers and all concerned with Handloom sector }\end{array}$ \\
\hline Weaving & Process of interlacing of two sets of warp \& weft yarns \\
\hline Weft & $\begin{array}{l}\text { Transverse threads of fabric; those that are passed through the openings of the } \\
\text { warp }\end{array}$ \\
\hline Weft winding & $\begin{array}{l}\text { Winding of weft yarn onto small bobbins ; usually done with a hand operated } \\
\text { charaka }\end{array}$ \\
\hline Winding & $\begin{array}{l}\text { Process of transferring yarn from one type of package to another to facilitate } \\
\text { subsequent processing }\end{array}$ \\
\hline Woad & $\begin{array}{l}\text { Isatis tinctoria; commonly called dyer's woad; also name of the blue dye } \\
\text { produced from the leaves of this plant; this plant became the dominant blue } \\
\text { dy in Western Europe }\end{array}$ \\
\hline Woof & Weft yarn in weaving \\
\hline Yarn & Long continuous length of interlocked fibers \\
\hline Yarn count & See 'Count' \\
\hline
\end{tabular}




\section{LIST OF FIGURES}

\begin{tabular}{|c|c|c|}
\hline Figure & Page & Caption/Description \\
\hline Cover & 1 & $\begin{array}{l}\text { Representation of socio technical ensemble using Kondapally crafted figures } \\
\text {-Artist K. Ravi facilitated by Satish and Pradeep of KORA }\end{array}$ \\
\hline 2.1 & 32 & Mill spinning \\
\hline 2.2 & 32 & Hand spinning \\
\hline 2.3 & 33 & Dyeing of the yarn \\
\hline 2.4 & 33 & Drying of washed yarn \\
\hline 2.5 & 34 & Bobbin winding for the weft \\
\hline 2.6 & 34 & Warping drum \\
\hline 2.7 & 35 & Street sizing \\
\hline 2.8 & 35 & Attaching threads of the warp \\
\hline 2.9 & 36 & Weaving \\
\hline 2.10 & 36 & Designing \\
\hline 2.11 & 37 & Retailing \\
\hline 2.12 & 37 & $\begin{array}{l}\text { The social groups and technologies in the handloom ensemble } \\
\text { [with kondapally figs, and graphical representation] }\end{array}$ \\
\hline 3.1 & 76 & Social Groups \\
\hline 3.2 & 76 & Migration \\
\hline 3.3 & 76 & Mechanization \\
\hline 3.4 & 76 & Appropriate Technology \\
\hline 3.5 & 77 & Design Intervention \\
\hline 3.6 & 77 & Social enterprise \\
\hline 3.7 & 77 & NREGA \\
\hline 3.8 & 77 & CSR, Cluster Scheme \\
\hline
\end{tabular}




\begin{tabular}{|c|c|c|}
\hline 3.9 & 78 & Demonstrating how the entangled discourses emerge between the social groups \\
\hline 4.1 & 91 & $\begin{array}{l}\text { The dilemma of the task of consolidating design practice into an integrated } \\
\text { method }\end{array}$ \\
\hline 4.2 & 97 & Three conceptual frames \\
\hline 4.3 & 98 & Matching Approach, Design ideal and Craft group \\
\hline 4.4 & 99 & $\begin{array}{l}\text { Distributed technical and aesthetic expertise in the handloom sociotechnical } \\
\text { ensemble }\end{array}$ \\
\hline 4.5 & 101 & Mediating cultures \\
\hline 5.1 & 115 & $\begin{array}{l}\text { An impressionist sketch of the Indian textile Industry, with the size of the circles } \\
\text { broadly indicating number of people involved. }\end{array}$ \\
\hline $5.1 \mathrm{a}$ & 115 & The four main textile production systems \\
\hline $5.1 \mathrm{~b}$ & 115 & The enmeshed production systems \\
\hline $5.1 \mathrm{c}$ & 115 & The social groups that are relevant for understanding the sociotechnical ensemble \\
\hline $5.1 \mathrm{~d}$ & 115 & $\begin{array}{l}\text { The relevant social groups are joined by sharing the same technological of } \\
\text { handloom frame }\end{array}$ \\
\hline 5.2 & 126 & Inclusion of actor in the three frames of handloom, power loom and the CSO \\
\hline 5.6 & 150 & Chemical formula for the dyeing of Indigo \\
\hline 5.7 & 151 & Newton's prismatic light \\
\hline 5.8 & 156 & $\begin{array}{l}\text { The multiple handloom ensembles, with the diverse modes, unit sizes of } \\
\text { production and standardization points between multiple technological variants. }\end{array}$ \\
\hline 6.1 & 162 & Painting of Goddess Saraswati by Raja Ravi Varma [1848-1906] \\
\hline 6.2 & 162 & Jamdani on silk from Banaras c. 1880. [V\&A Museum] \\
\hline 6.3 & 166 & From the DA advocacy poster for government support for yarn prices \\
\hline 6.4 & 171 & Arranging the shuttles for weaving \\
\hline 6.5 & 171 & Arranging the shuttles for weaving \\
\hline 6.6 & 172 & Lifting the yarn to insert shuttle \\
\hline 6.7 & 172 & Producing floral motifs \\
\hline
\end{tabular}




\begin{tabular}{|c|c|c|}
\hline 6.8 & 181 & Jamdani on silk from Banaras c. 1880 (V\&A Museum) \\
\hline 6.9 & 181 & Jamdani on silk from East Godavari c 2011 (Weaver Vellasavaram) \\
\hline 6.10 & 182 & Balaji's house with loom in the background and computer in the foreground \\
\hline 6.11 & 183 & $\begin{array}{l}\text { 'a' points to the line in this pattern with the maximum number of spindles that } \\
\text { would have to 'bend'. In this case } 8 \text { spindles would have to be inserted into the } \\
\text { weft to make the pattern. }\end{array}$ \\
\hline 6.12 & 183 & With coloured threads indicated \\
\hline 6.13 & 183 & Graph 1 above shows a single end flower. \\
\hline 6.14 & 183 & Graph 2 shows a flower woven with two ends bunched together with three picks \\
\hline 6.15 & 183 & Graph 3 shows a flower woven with three ends bunched together with three picks. \\
\hline 6.16 & 183 & $\begin{array}{l}\text { Graph } 4 \text { shows a flower woven with six ends bunched together with three picks. } \\
\text { One can notice how the pattern turns into a lower resolution version of itself with } \\
\text { the decision to reduce labour. }\end{array}$ \\
\hline 6.17 & 184 & Making a printout of the pattern to be repeated for setting the loom \\
\hline 6.18 & 184 & Smoothing out the pattern for ease of weaving on the graph \\
\hline 6.19 & 184 & Using the Graph to tie the repeat pattern into the jalari \\
\hline 6.20 & 184 & Using the Graph to tie the repeat pattern into the jalari \\
\hline 6.21 & 185 & $\begin{array}{l}\text { Two views of the loom. The gold warp is wound on one side, and the graph is } \\
\text { pasted above }\end{array}$ \\
\hline 6.22 & 184 & $\begin{array}{l}\text { Two views of the loom. The second view is from the perspective of where the } \\
\text { weaver sits, the graph is visible at eye-level on the other side, for ease of weaving. }\end{array}$ \\
\hline
\end{tabular}




\section{LIST OF TABLES}

\begin{tabular}{|c|c|c|}
\hline Table & Page & Caption/Description \\
\hline 1.1 & 8 & List of chapters with their proposed socio-technical concept \\
\hline 2.1 & 30 & Units of analysis with associated research questions and key concepts. \\
\hline 2.2 & 38 & Production for the year 2011: Textile Commissioner Mumbai \\
\hline 2.3 & 38 & Table of handicrafts, including handloom weaving in India \\
\hline 3.1 & 73 & $\begin{array}{l}\text { Social groups of producers, their dominant discourses framing vulnerability of } \\
\text { weaver, and related desirable outcomes in the sociotechnical ensemble }\end{array}$ \\
\hline 3.2 & 73 & $\begin{array}{l}\text { Social groups of public sector, their dominant discourses framing vulnerability of } \\
\text { weaver, and related desirable outcomes in the sociotechnical ensemble }\end{array}$ \\
\hline 3.3 & 73 & $\begin{array}{l}\text { Social groups of Civil Society, their dominant discourses framing vulnerability of } \\
\text { weaver, and related desirable outcomes in the sociotechnical ensemble }\end{array}$ \\
\hline 3.4 & 73 & $\begin{array}{l}\text { Social groups of market, their dominant discourses framing vulnerability of } \\
\text { weaver, and related desirable outcomes in the sociotechnical ensemble }\end{array}$ \\
\hline 4.1 & 96 & Three complementary conceptual frames for interpreting design work in crafts \\
\hline 5.1 & 135 & Schedule of natural dyeing workshop \\
\hline 5.2 & 158 & $\begin{array}{l}\text { Table detailing dynamics of sociotechnical adaptation in the handloom ensemble, } \\
\text { at the level of the technological system, expert system, and system of knowledge } \\
\text { using three different instances of sociotechnical change in the technology of } \\
\text { dyeing. }\end{array}$ \\
\hline 6.1 & 185 & Comparison of functions in the Jamdani and computer Jamdani ensembles \\
\hline 7.1 & 208 & Dreyfus's five stage model acquisition of expertise compared with dyers' model \\
\hline 7.2 & 210 & $\begin{array}{l}\text { Comparison of practices that come before and with creativity in Karnatik music, } \\
\text { and Science }\end{array}$ \\
\hline
\end{tabular}




\section{LIST OF INTERVIEWS}

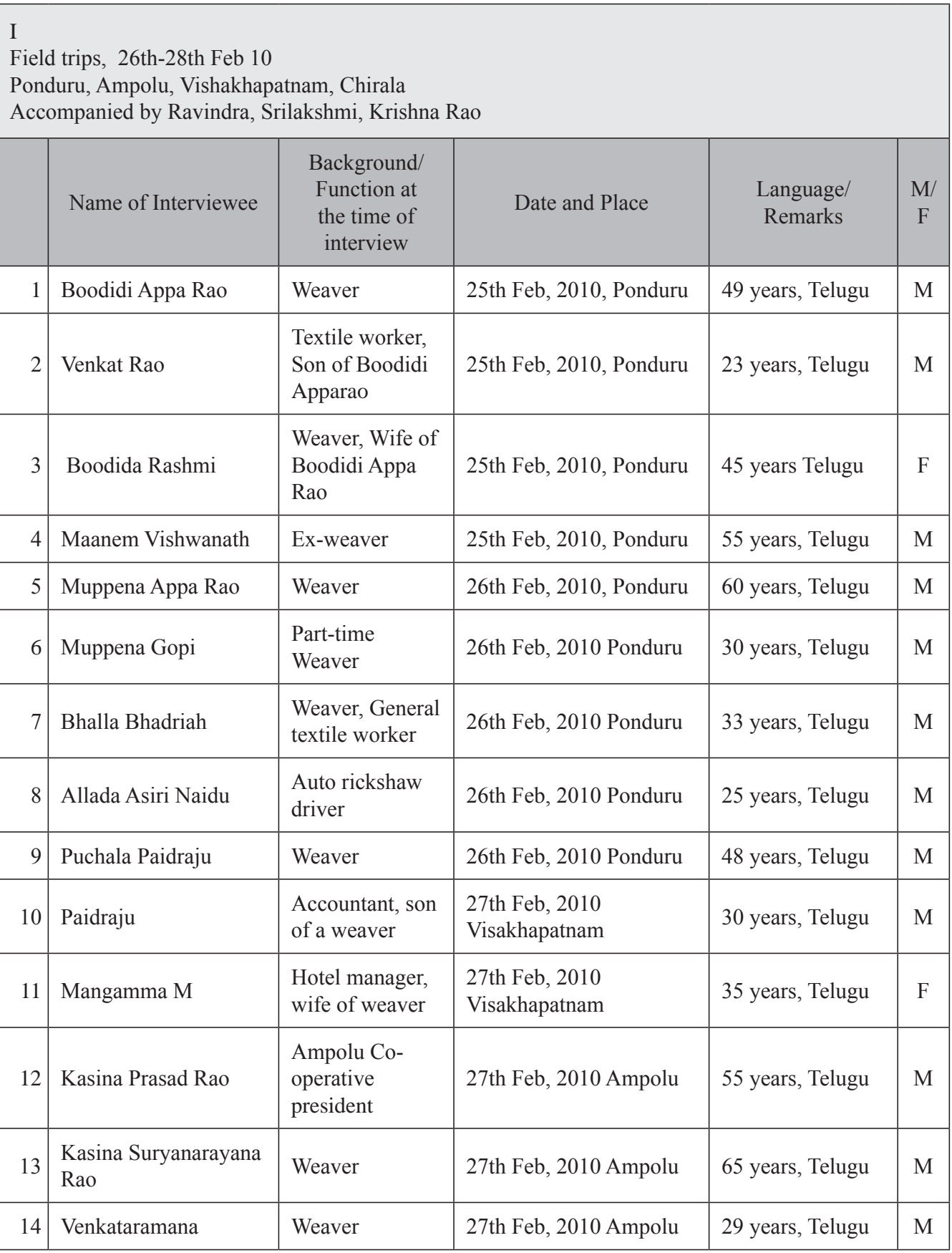




\begin{tabular}{|c|c|c|c|c|c|}
\hline 15 & Tutika Mohan Rao & $\begin{array}{l}\text { Weaver, } \\
\text { Accountant }\end{array}$ & $\begin{array}{l}\text { 27th Feb, } 2010 \\
\text { Vishakhapatnam }\end{array}$ & 20 years, Telugu & M \\
\hline 16 & Gadde Veeraraghavulu & Weaver & 28th Feb, 2010, Chirala & 50 years, Telugu & M \\
\hline 17 & Dunna Rambabu & Weaver & 28th Feb, 2010, Chirala & 40 years, Telugu & M \\
\hline 18 & Babu Rao & Weaver & 28th Feb, 2010, Chirala & 45 years, Telugu & M \\
\hline 19 & Gopichand & Weaver & 28th Feb, 2010, Chirala & 40 years, Telugu & M \\
\hline 20 & Krishna Rao & $\begin{array}{l}\text { Manager, } \\
\text { Ponduru } \\
\text { HLWCS }\end{array}$ & 25th Feb, 2010 Ponduru & 55 years, Telugu & M \\
\hline \multirow{2}{*}{\multicolumn{6}{|c|}{ II }} \\
\hline & & & & & \\
\hline \multicolumn{6}{|c|}{ Ponduru, Singupuram, Pulugurtha, Hasanbad, Mangalagiri, Vijayawada, Rajavolu, Chirala } \\
\hline \multicolumn{6}{|c|}{ Accompanied by Durgalakshmi Venkataswamy, Latha Tummuru } \\
\hline & Krishna Rao & $\begin{array}{l}\text { Manager, } \\
\text { Ponduru } \\
\text { handloom } \\
\text { weavers co- } \\
\text { operative } \\
\text { society [HWCS] }\end{array}$ & $\begin{array}{l}\text { 16th November, 2011, } \\
\text { Ponduru }\end{array}$ & 55 years, Telugu & M \\
\hline & Guru Naidu & $\begin{array}{l}\text { Dyer, Ponduru } \\
\text { HLWCS }\end{array}$ & $\begin{array}{l}\text { 16th November, 2011, } \\
\text { Ponduru }\end{array}$ & 55 years, Telugu & M \\
\hline & Punyavati & $\begin{array}{l}\text { Dyer, Ponduru } \\
\text { HLWCS }\end{array}$ & $\begin{array}{l}\text { 16th November, 2011, } \\
\text { Singupuram }\end{array}$ & 40 years, Telugu & $\mathrm{F}$ \\
\hline & Lakshmi & $\begin{array}{l}\text { Dyer, } \\
\text { Singupuram } \\
\text { HLWCS }\end{array}$ & $\begin{array}{l}\text { 16th November, 2011, } \\
\text { Singupuram }\end{array}$ & 40 years, Telugu & $\mathrm{F}$ \\
\hline & Appalasooramma & $\begin{array}{l}\text { Dyer, } \\
\text { Singupuram } \\
\text { HLWCS }\end{array}$ & $\begin{array}{l}\text { 16th November, 2011, } \\
\text { Singupuram }\end{array}$ & 65 years, Telugu & $\mathrm{F}$ \\
\hline & Vasantharam & $\begin{array}{l}\text { Dyer, } \\
\text { Singupuram } \\
\text { HLWCS }\end{array}$ & $\begin{array}{l}\text { 16th November, } 2011 \text {, } \\
\text { Singupuram }\end{array}$ & 40 years, Telugu & M \\
\hline & Veerabhadra & $\begin{array}{l}\text { Dyer, } \\
\text { Singupuram } \\
\text { HLWCS }\end{array}$ & $\begin{array}{l}\text { 16th November, } 2011 \text {, } \\
\text { Singupuram }\end{array}$ & 35 years, Telugu & M \\
\hline
\end{tabular}




\begin{tabular}{|c|c|c|c|c|}
\hline DVV Satyanarayana & $\begin{array}{l}\text { Manager, } \\
\text { Pulugurta } \\
\text { HLWCS } \\
\text { dyehouse }\end{array}$ & $\begin{array}{l}\text { 17th November, 2011, } \\
\text { Pulugurtha }\end{array}$ & 47 years, Telugu & M \\
\hline Virupaksham & $\begin{array}{l}\text { President, } \\
\text { Hassanbad } \\
\text { HLWCS } \\
\text { dyehouse }\end{array}$ & $\begin{array}{l}\text { 17th November, } 2011 \\
\text { Hassanbad }\end{array}$ & 60 years, Telugu & M \\
\hline Subbarao & $\begin{array}{l}\text { Dyer, } \\
\text { Mangalagiri } \\
\text { dyehouse, } \\
\text { previously } \\
\text { agricultural } \\
\text { labour }\end{array}$ & $\begin{array}{l}\text { 17th November, } 2011 \\
\text { Mangalagiri }\end{array}$ & 56 years, Telugu & M \\
\hline Narsimharao & $\begin{array}{l}\text { Dyer, Dastkar } \\
\text { Andhra } \\
\text { dyehouse }\end{array}$ & $\begin{array}{l}\text { 17th November, } 2011 \\
\text { Mangalagiri }\end{array}$ & 50 years, Telugu & M \\
\hline Srinivasa Rao & $\begin{array}{l}\text { Dyer, Propreiter, } \\
\text { Rex dyeing } \\
\text { house, } \\
\text { Mangalagiri }\end{array}$ & $\begin{array}{l}\text { 22nd November, 2011, } \\
\text { Mangalagiri }\end{array}$ & 42 years, Telugu & M \\
\hline NK Durgaprasad & $\begin{array}{l}\text { Dyer, Propreiter, } \\
\text { Annapurna } \\
\text { Dyehouse, } \\
\text { Vijayawada }\end{array}$ & 23rd November, 2011 & 55 years, Telugu & M \\
\hline Srirangam & $\begin{array}{l}\text { Dyer, Manager } \\
\text { dyehouse, } \\
\text { Rajavolu } \\
\text { HLWCS } \\
\text { dyehouse, } \\
\text { Rajavolu }\end{array}$ & 23rd November, 2011 & 40 years, Telugu & M \\
\hline Venkateswar Rao & $\begin{array}{l}\text { Dyer, Rajavolu } \\
\text { HLWCS } \\
\text { dyehouse, } \\
\text { Rajavolu }\end{array}$ & 23rd November, 2011 & 45 years, Telugu & M \\
\hline Balaji & $\begin{array}{l}\text { Owner, Balaji } \\
\text { dyehouse, } \\
\text { Chirala }\end{array}$ & 24th November, 2011 & 44 years, Telugu & M \\
\hline $\begin{array}{l}\text { Durgalakshmi } \\
\text { Venkataswamy }\end{array}$ & $\begin{array}{l}\text { NGO worker, } \\
\text { Textile } \\
\text { technologist, } \\
\text { Hyderabad }\end{array}$ & 24th November, 2011 & 50 years, English & $\mathrm{F}$ \\
\hline
\end{tabular}




\begin{tabular}{|c|c|c|c|c|c|}
\hline & Vanappa & Indigo Dyer & August 9, 2013 & 32 years, Telugu & M \\
\hline & Yellappa & Indigo Dyer & August 9, 2013 & 85 years, Telugu & M \\
\hline & Salim & Indigo Dyer & 11th September 2013 & 46 years, Hindi & M \\
\hline & Odellu & Indigo Dyer & 12th October, 2013 & 52 years, Telugu & M \\
\hline III & $\begin{array}{l}\text { Weavers meeting, } \\
\text { Daram }\end{array}$ & $\begin{array}{l}\text { Daram, } \\
\text { Hyderabad }\end{array}$ & 2nd October, 2011 & & \\
\hline IV & Dyers meeting, Daram & $\begin{array}{l}\text { Daram, } \\
\text { Hyderabad }\end{array}$ & 26th November, 2011 & & \\
\hline V & Sizers meeting, Daram & $\begin{array}{l}\text { Daram, } \\
\text { Hyderabad }\end{array}$ & 26th November, 2011 & & \\
\hline VI & $\begin{array}{l}\text { Senior Designers } \\
\text { meeting }\end{array}$ & $\begin{array}{l}\text { Dastkar Andhra } \\
\text { Design Studio, } \\
\text { Hyderabad }\end{array}$ & & & \\
\hline & $\begin{array}{l}\text { Latha Tummuru, Gopi } \\
\text { Krishna, Kamaii, } \\
\text { Jinnan, Tarun Deep } \\
\text { Giridhar, Saktivel } \\
\text { Vilvapathy, Sangita } \\
\text { sen, Aditi Shah Aman }\end{array}$ & & $\begin{array}{l}\text { 10th Jan } 2012, \\
\text { Hyderabad }\end{array}$ & & \\
\hline VII & $\begin{array}{l}\text { Junior Designers } \\
\text { meeting }\end{array}$ & $\begin{array}{l}\text { Dastkar Andhra } \\
\text { Design Studio, } \\
\text { Hyderabad }\end{array}$ & $\begin{array}{l}\text { 25th January 2012, } \\
\text { Hyderabad }\end{array}$ & & \\
\hline & $\begin{array}{l}\text { Geeta Patil, Aditi, } \\
\text { Satish, Sanjay garg, } \\
\text { Tarang, Sanjay } \\
\text { Chhipa, Roohi, } \\
\text { Samyukta, Aravind }\end{array}$ & & & & \\
\hline VIII & $\begin{array}{l}\text { Cultures of } \\
\text { Technology and } \\
\text { Design Seminar }\end{array}$ & $\begin{array}{l}\text { Dastkar Andhra, } \\
\text { Hyderabad }\end{array}$ & 22-24 March 2012 & & \\
\hline \multirow[t]{3}{*}{ IX } & Musician Interviews & & & & \\
\hline & R. Vedavalli & $\begin{array}{l}\text { Classical } \\
\text { musician }\end{array}$ & $\begin{array}{l}\text { 8th December 2012, } \\
\text { Chennai }\end{array}$ & Tamil, English & \\
\hline & Sangeetha Sivakumar & $\begin{array}{l}\text { Classical } \\
\text { musician }\end{array}$ & $\begin{array}{l}\text { 7th December 2012, } \\
\text { Chennai }\end{array}$ & English & \\
\hline
\end{tabular}




\begin{tabular}{|c|c|c|c|c|}
\hline & TM K rishna & $\begin{array}{l}\text { Classical } \\
\text { musician }\end{array}$ & $\begin{array}{l}\text { 7th December 2012, } \\
\text { Chennai }\end{array}$ & English \\
\hline & Sumithra Vasudev & $\begin{array}{l}\text { Classical } \\
\text { musician }\end{array}$ & $\begin{array}{l}\text { 8th December 2012, } \\
\text { Chennai }\end{array}$ & English \\
\hline & Sushruti Santanam & $\begin{array}{l}\text { Classical } \\
\text { musician }\end{array}$ & $\begin{array}{l}\text { 8th December 2012, } \\
\text { Chennai }\end{array}$ & English \\
\hline \multirow[t]{2}{*}{$x$} & $\begin{array}{l}\text { Presenting findings to } \\
\text { weavers }\end{array}$ & $\begin{array}{l}\text { Centre for world } \\
\text { Solidarity, } \\
\text { Hyderabad }\end{array}$ & 8th January 2015 & Telugu \\
\hline & $\begin{array}{l}\text { Mohan Rao, KJ } \\
\text { Ramarao, Tadaka } \\
\text { Yadagiri, Yasoda } \\
\text { Ramesh, Satish of } \\
\text { Kora, Uzra Bilgrami, } \\
\text { Suvarna A lladi, CV } \\
\text { Shastri, Joseph Satish, } \\
\text { Odellu, Krishna Rao }\end{array}$ & & & \\
\hline \multirow[t]{6}{*}{ XI } & $\begin{array}{l}\text { Focus group } \\
\text { discussion, Mandapeta }\end{array}$ & Mandapeta & 23rd January 2012 & \\
\hline & Batta Siva Pentarao & Mandapeta & 23rd January 2012 & 51 years, Telugu \\
\hline & Batta Vishwanatham & Mandapeta & 23rd January 2012 & 38 years, Telugu \\
\hline & Boodida Srinivasa & Mandapeta & 23rd January 2012 & 40 years, Telugu \\
\hline & $\begin{array}{l}\text { Matsa Ramakrishna } \\
\text { Parama Hamsa [Ram } \\
\text { babu] }\end{array}$ & Angara & 23rd January 2012 & 44 years, Telugu \\
\hline & Paranjyothi B & Mandapeta & 23rd January 2012 & 21 years, Telugu \\
\hline \multirow[t]{4}{*}{$X I 1$} & $\begin{array}{l}\text { M asterw eavers' visits } \\
\text { with L atha Tummuru }\end{array}$ & & & \\
\hline & Rambabu & $\begin{array}{l}\text { M asterw eaver, } \\
\text { A ngara }\end{array}$ & 28th January 2012 & 44 years, Telugu \\
\hline & Jonna Suribabu & Weaver, A ngara & 28th January 2012 & 33 years, Telugu \\
\hline & Ramalakshmi & Weaver, A ngara & 28th January 2012 & 31 years, Telugu \\
\hline
\end{tabular}




\begin{tabular}{|c|c|c|c|c|}
\hline & Srinivas & $\begin{array}{l}\text { Dyer, } \\
\text { Peddapuram } \\
\text { dyehouse }\end{array}$ & 29th J anuary 2012 & 40 years, Telugu \\
\hline & Ravi & $\begin{array}{l}\text { Weaver, } \\
\text { A uto driver, } \\
\text { Peddapuram } \\
\text { dyehouse }\end{array}$ & 29 $9^{\text {th }}$ January 2012 & 36 years, Telugu \\
\hline & Balaji & $\begin{array}{l}\text { Computer } \\
\text { programmer, } \\
\text { Vellasavaram }\end{array}$ & 27th J anuary 2012 & 28 years, Telugu \\
\hline & Balaji & $\begin{array}{l}\text { Computer } \\
\text { programmer, } \\
\text { Vellasavaram }\end{array}$ & 12th M arch, 2012 & Telugu \\
\hline & Gangadhar & $\begin{array}{l}\text { Jamdani } \\
\text { Weaver,A ngara }\end{array}$ & 27th A pril 2013 & 52 years, Telugu \\
\hline$X I I I$ & Visit & $\begin{array}{l}\text { Victoria and } \\
\text { A lbert M useum, } \\
\text { London }\end{array}$ & 11th J uly 2013 & \\
\hline \multirow[t]{6}{*}{ XIV } & Reports & & & \\
\hline & N atural Dyes of India & \multicolumn{2}{|c|}{$\begin{array}{l}\text { Publication of Patriotic and People Oriented } \\
\text { Science and Technology, and Dastkar } \\
\text { A ndhra }\end{array}$} & 1998 \\
\hline & $\begin{array}{l}\text { Natural Dyes } \\
\text { workshop report }\end{array}$ & \multicolumn{2}{|c|}{ Document of Dastkar A ndhra } & 1999 \\
\hline & DA A nnual reports & \multicolumn{2}{|c|}{ D ocuments of Dastkar A ndhra } & $1991-2005$ \\
\hline & DA Field notes & \multicolumn{2}{|c|}{ D ocuments of Dastkar A ndhra } & 1990-1998 \\
\hline & $\begin{array}{l}\text { M V Soumithri Field } \\
\text { notes }\end{array}$ & \multicolumn{2}{|c|}{ Research intern, Dastkar A ndhra Hyderabad } & $\begin{array}{l}\text { 29th A ugust, } \\
2012\end{array}$ \\
\hline
\end{tabular}




\section{ACRONYMS}

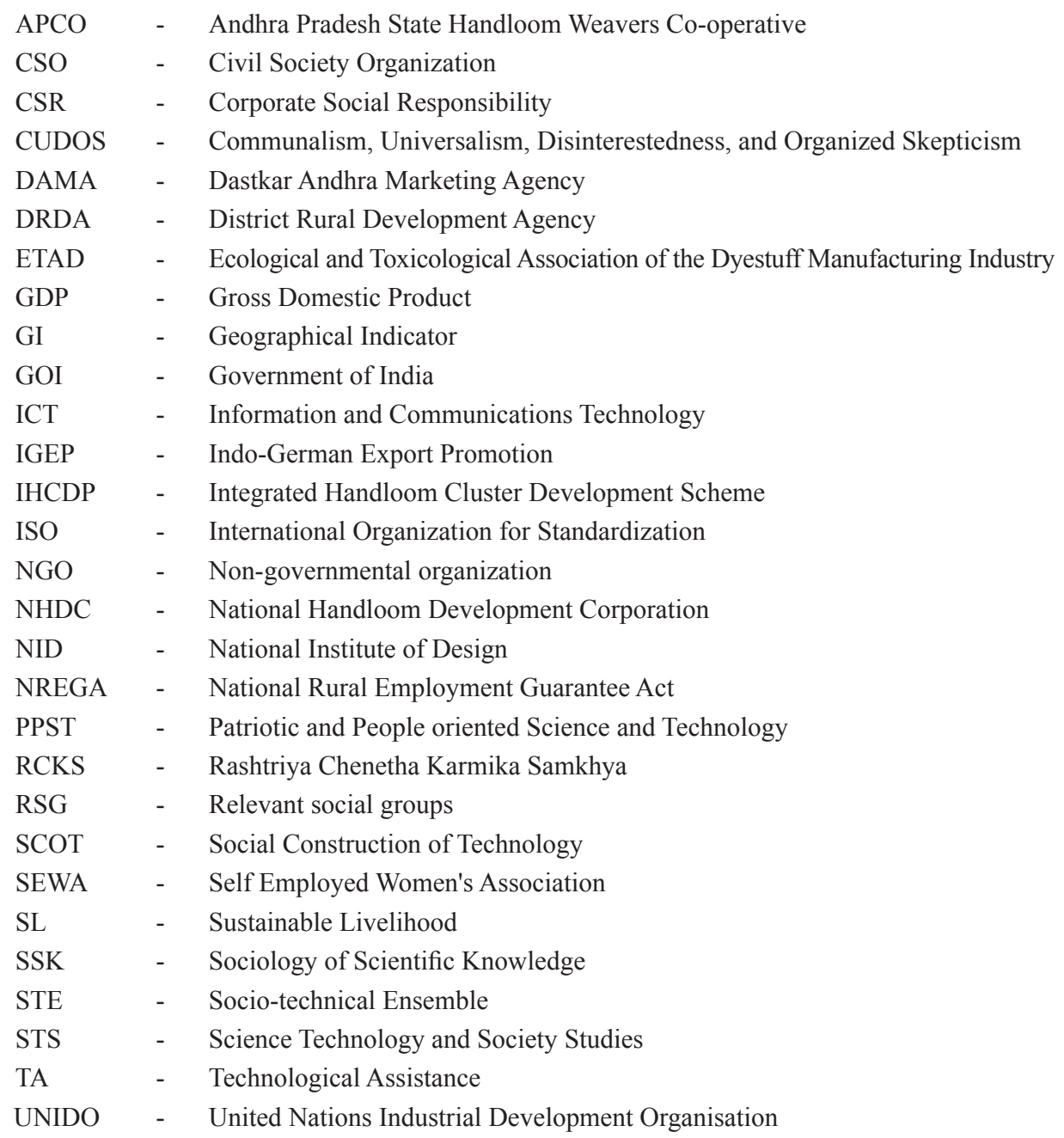




\section{ACKNOWLEDGEMENTS}

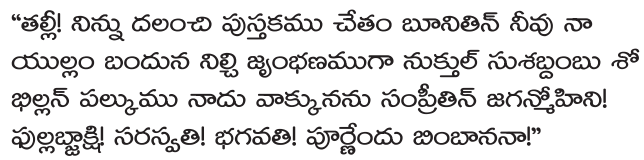

For me to write a book about handloom weaving is a dream come true, and it is with pleasure and heartfelt gratitude that I acknowledge my debt to the long list of teachers, co-travellers, colleagues, friends, and family who contributed to it.

This book was made possible mainly by the efforts of my two supervisors, Wiebe Bijker and Louk de la Rive Box. I have been incredibly fortunate to have their help and support, both as scholars engaged with STS and Development, and as teachers. For all the invisible work of supervision, now apparent in the added gray of their distinguished heads, there are not adequate words to express the gratitude I feel.

I thank Wiebe Bijker for the story of the bicycle as technology; the most important story that made all the constructivist stories about technology that came after possible, including the handloom one. Starting the $\mathrm{PhD}$ with the arrogance of a practitioner who thought that the $\mathrm{PhD}$ project was about writing what I already knew, I learnt from him to respect the knowledge of others. I learned to read, to reflect, to write; and in living up to the confidence he placed in me, I regained some of it in myself. For all these reasons and more, I will always be grateful to him.

I thank Louk Box for sharing his knowledge of the "Development" story, and encouraging me to tell the weavers' story. Many of the key passages in my thesis have been the direct result of his summarizing emails, sent as afterthoughts to joint meetings where I presented my findings. These showed such a particular understanding and clear articulation of what I was trying to argue, that they became guiding frameworks for the entire thesis. Because of him, I have found a way back to the community of craftspeople whose problems I had failed to solve as a development worker, but whose solutions I could celebrate, as a researcher. I would also like to thank his wife Barbara for her kind invitation to their home in Leiden, which made our research meetings possible.

I met Shiv Vishvanathan first when I presented initial experiments in natural dyeing in 1991, in a seminar in Chennai. He shocked me out of my complacence about teaching 'ignorant' weavers natural dyeing techniques from books, when he wondered aloud 'So is this your kitchen, or the weaver's laboratory?' His presence at critical moments in the $\mathrm{PhD}$ journey gave me the courage to draw and build on the idioms and epistemic systems that best allowed me to explicate the knowledge of handloom weavers, for which I am deeply grateful.

Karin Bijsterveld my first teacher of STS, whose module on research methods I attended during the CAST masters of 2011, taught me that empirical 
material and analysis must never be confused, but should be combined through writing. I learnt in her classroom that research wasn't about having the best idea, but about giving one's best to the idea. I am also thankful to the entire class of the CAST Masters of 2011 - Ranjit Singh, Bart Zwegers, Ana Teresa Pires, Aline Reichow, Rick Holsgens, Trust Saidi, Pankaj Sekhsaria, Jeremias Herberg, Charity Urama, Tuur Ghys, MeganCurtis and Brian Keller. I learned from their mistakes, as I hope they have learnt from mine. At the Faculty of Arts and Social Sciences (FASOS) at Maastricht University I had friendly encouragement from Anique Hommels, Bernike Pasveer, Sally Wyatt, Johanna Hoffkens, Alexandra Suppers, Sabine Cuiper and incredible kindness from the reception staff. I was forever forgetting my ID card, and losing my way, and their friendly faces and nods warmed me on many a cold winter day. I made friends here who I hope to keep for life; Ranjit Singh, co-student in CAST told me travel stories that inspired me to find my own follies funny, Koen Beumer politely reminded me to quit repeating myself, to my eternal gratitude. I owe a debt to many others, Pankaj Sekhsaria the journalist who insisted that some stories have to be told, Julia Quartz whose well argued story about vulnerable farmers inspired me to attempt my own, Ragna Zeiss, who is living her beautiful story, Aalok Khandekar who speaks softly, and cuts sharply- "what stories would the widows of Benaras tell about tradition?" I hope to be as good friend to them, as they have been to me.

I attended six summer schools and workshops of the WTMC between 2011 and 2013, lead by the inspiring co-ordinators Teun ZuiderentJerak and Willem Halffman. For her help in aiding my application each time as an external candidate, I will always remember Marjatta Kemppainen. Early mornings and late evenings with the other doctoral students in the nunnery turned workshop venue of Ravenstein had a magical timeless quality that form some of my best memories of working and learning in the Netherlands. My particular thanks to Teun for teaching me that 'intervention' was not a swear word, in STS, and Willem for always taking my question last. It taught me the perils of coming between hungry workshop participants and their lunch.

Uzramma has been one of the most important influences in my engagement with handloom weaving and craft. She has been and continues to be an inspiration for many young people working in this sector, working tirelessly to initiate people of different social and intellectual backgrounds into handloom and craft. Through her I became part of a community of people who with their ideas and work sought to make better lives for craftspeople, KV Chandramouli, Jagada Rajappa, Vinoo Kale, Ravindra Sharma, PB Srinivas, Ramakrishna, Kannan, Shambu Prasad, Madhulika Chaudhury and many others. For most of them this story will be familiar, and probably even self evident, and can only be evaluated for its shortcomings, because they were part of it, and saw its richness unfold. No narrative can compare with the reality of that experience. My childhood music teacher Parameshwara Bhat, whose one untranslatable sentence in Kannada could sum up this thesis 'bogali bogali raaga', Shanta Rameshwar Rao who let me teach Karnatic music and Science in her school, Rolf and Ronnie Lynton who first taught me to write a case, Sara Corse and Kenwyn Smith who taught me that not all thinking is rational; Shankar Datta who introduced me to Adam Smith, I owe them all thanks.

The dream of writing the story of handloom was a shared one, between four of us -Seemanthini Niranjana, Syamasundari Boddapati, Latha Tummuru, and myself; based on our work in Dastkar Andhra between 2002 and 2008. Seemanthini Niranjana, scholar, activist and writer was to have authored it. Instead, we lost her to cancer. This is not the book she would have written; yet in many ways, because I would not have written it if she were here, it is her book. For Syamasundari and Latha I have deep admiration for keeping the dream alive in the work, and continuing to support the lives and livelihoods of weavers in Andhra 
Pradesh and Telengana. I owe thanks to others in Dastkar Andhra; Ravindra for telling me his caste, Srilakshmi for not, Yasoda for warning me to never over pay an alcoholic weaver, even if he was an expert in Jamdani weaving, and Ramesh for his cheerful smile whenever I visited the Dastkar Andhra office. To my aunt and co-author, Radhika Gajjala, who encouraged my writing during the early years of work in Dastkar Andhra, I am deeply grateful. I thank the Trustees of Dastkar Andhra for taking my concerns regarding governance seriously, putting them to rest and allowing me to move on. Finally, I owe sincere thanks to three colleagues in the field of handloom who helped me tremendously with organizational support as well as in their individual capacities during the writing of this thesis; Durgalakshmi Venkataswamy, Poludas Nagendra Satish and Simrat Chaddha. Patta moved the printing along with his usual dose of humour. I thank Raghu and Lakshmi of Arthmedia solutions for the design layout. Sara Dovre Wudali helped with the final editing of the book, and got me thinking about the cover, I was running out of steam there, thank you!

Weavers Mohanrao of Chirala, Odellu of Chinnur, Krishna Rao and Maanem Vishwanath in Ponduru, computer programmer Balaji in Vellasavaram, Indigo dyer Salim in Hyderabad, master craftsmen Yellappa of Uruvakonda and Narsimhulu of Koyyalagudem, Jonnalagadda Niranjan the Kalamkari artist, and many others gave freely of their time as I presumed to write their story. To them and others who I have worked with over the last two decades, I am grateful for the trust they have placed in me.

For their engagement in building a conversation with handloom weavers in order to explicate craft knowledge and their participation in the workshop in Chennai titled Craft and Innovation, I thank scholars Prajit Basu, Suresh Bhagavatula, Francesca Bray, Lars Heide, Anique Hommels, Aarti Kawlra, Pamela Long, Karuna Miriam, Pamela Smith, Ineke Sluiter, Shaktivel Vilvapathy, Tadka Yadgiri; activists Jaya Jaitly, Gita
Ram, Bamini Narayanan; Priyadarshini Govind of Kalakshetra and other participants. For organizing an initial meeting of weavers, where I presented some of the findings in my thesis, I thank MV Shastri, Shambu Prasad and Joseph Satish of KICS. Sharan Appa Rao of the Yarn club let me have a trial run in defending my thesis over a series of three events where I presented to an informed audience the different chapters on livelihoods, design and innovation. I am grateful for the opportunity.

Conversations with many stalwarts engaged with supporting livelihoods of vulnerable communities helped to move this thesis along. Of them Laila Tyabji of Dastkar, Bablu Ganguly and Mary of the Timbaktu Collective, Jhumur Lahiri and Sunny Narang shared important insights that I am grateful for. In my journey to find a vocabulary for innovation rooted in the ethos of South Indian art and crafts, I was particularly helped by Srimati R. Vedavalli, senior musician and teacher. Sushruti Santhanam raised the question of tradition, when I was researching innovation, Sumithra Vasudev shared her insights on innovating tradition, and Sumathi Krishnan orchestrated their participation in the thesis, as well as in the Crafts and Innovation workshop. Musicians TM Krishna and Sangeetha Sivakumar contributed freely of their musical knowledge and pedagogical experience when I was attempting to theorize the idea of 'manodharma' as creative expression, even when it was clear that as reflexive practitioners they found this almost self evident. I thank them for their patience and generosity.

To Anna Joseph, friend and colleague from Vidyaranya, I offer my deepest apologies for the many evenings when I did not turn up when I said I would, and thank her for the coffee and comfort whenever I did. Ai Wyne Foo in Sheffield, Lekha Gopal and Sridhar Nori are dear friends that I share with my sisters, thank you for your patience with us. In Mumbai Leena and Aseem, in Chennai, little friend Anya -beloved daughter of Ajith and Ahalya, Sangeeta Patel -blouse maker extraordinaore, Pratibha Jain -Tarot card reader to the sceptic, 
Nalini Sriram -M ylapore mami, thank you for your many kindnesses. Friends in Hyderabad Vivek and Saroja, A jay and Neeta, M anek and Kerban, Vivek and Neily, Anoop and Jaz, Naren and Lakshmi, Shankar and Maya, Piyush and Seema, Suheim Sheikh, Shantaram, Praveena, Vaneeta, Chechi, thank you for staying my friends through missed calls, dinner events, weddings and funerals. In return, I will not insist that you read the thesis, but will be satisfied with a thorough going-through of the table of contents.

Rob Hagendijk I thank for his unstinting support and friendly encouragement particularly during the last leg of the thesis. M arian van Weert and Rob Witte, friends from ICCO -the Dutch NGO that funded more than a decade of development work in Dastkar A ndhra - supported my efforts to trace the roots of the B etter Cotton program within ICCO. Though I could not take the research further, I benefitted from attending stakeholder meetings, and from their advice in the early days of my PhD. Nelleke van der Vleuten who I met first in ICCO and her husband Chris Peeters were a warm fixture in every one of my visits to Netherlands. Chris's solemn question on extrapolating Hindu philosophy to the Dutch context, "Can the red cabbage I grow in my garden also be God?" challenged me as much as N elleke's keen questions about theorizing sustainable development. For their warmth and kindness, and the hospitality they offered a homesick stranger, I am deeply grateful.

Tonny à Campo, Liselotte Bijker, Sanne Bijker, Waldemar, B art Soeters and Gijs van Dorp were family in the Netherlands, during the six years I travelled to and from India. I will always be grateful to Tonny for the warm welcome I got from her whenever I landed on her doorstep in her beautiful home in Eijsden, in search of a quiet place to unstick my writing. To Else Bijker, friend, doctor and researcher in Malaria, I owe the most. She asked me an innocuously framed research question - 'do people think in pictures or words?' that opened the door to the world of social constructivism. For six years, her generous and openhearted welcome into her home in Nijmegen helped me overcome the natural difficulty and fears of setting out on a new path, in a new country. A lways at least three steps ahead of me, I'm grateful for every real and metaphorical train door she kept open for the extra five seconds, as I huffed and puffed to catch up. Dutch trains wait for no man or running woman in a saree.

To my extended family in Hyderabad, Bangalore, Chennai, US and UK, aunts, uncles, cousins, nieces and nephews who regularly made encouraging noises, I am deeply grateful. The peril of having a big family means that I cannot name them all, but I am extremely grateful for the support I received as I made an unconventional ly late detour into academia. Sanjay of A nandam and Company uncomplainingly co-ordinated visas, travel and foreign exchange; Subbaiah in Chennai, Mahesh, A zam, Satyanarayana, Santosh, Ravi, Pavani and $M$ allesh in Hyderabad kept the wheels of my home running. I cannot thank them all enough for their concern and care of me and my family.

To Vikram who became both mother and father to our children, to Suvarna and Jaidip who took over my responsibilities at home, and $\mathrm{K}$ rishna and Ravi who held my hand as I learned again to be a student, I owe more than the PhD, I owe my sanity. A parajitha, M edha and A mukta, Soumithri, Radha and A chyutha thank you for your love. A ppa and A mma, thank you, for everything. 


\section{REFERENCES}

[KICS], Knowledge in Civil Society. 2011. Knowledge Swaraj: An Indian Manifesto on Science and Technology. Hyderabad. Hyderabad: University of Hyderabad \& Knowledge in Civil Society Forum UoH-KICS.

Abdul, Noorbasha. 1996. "Handlooms in distress." Economic and Political Weekly 31 (23):1384-1386.

Aibar, Eduardo, and Wiebe E. Bijker. 1997. "Constructing a City: The Cerdà Plan for the Extension of Barcelona." Science, Technology \& Human Values 22 (1):3-30.

Akin, Ömer, and Cem Akin. 1996. "Frames of reference in architectural design: Analysing the hyper acclamation (Aha-!)." Design Studies 17 (4):341-361.

Anliker, R. 1979. "Ecotoxicology of dyestuffs - a joint effort by industry." E cotoxicology and environmental safety 3 (1):59-74.

Appadorai, Angadipuram. 1976. Documents on political thought in modern India. Vol. 2. London, New York: Oxford University Press.

Appadurai, Arjun, ed. 1988. The social life of things: Commodities in cultural perspective. New York: Cambridge University Press.

Appendini, Kirsten. 2001. "Land and livelihood: What do we know, and what are the issues?" In Land and sustainable livelihood in Latin America, edited by A Zoomers, 23-38. Amsterdam: Royal Tropical Institute/Vervuert Verlag.

Arasaratnam, Sinnappah. 1980. "Weavers, merchants and company: The handloom industry in southeastern India 1750-1790." The Indian Economic \& Social History Review 17 (3):257-281.
Arthur, W Brian. 2002. How growth builds upon growth in high-technology. Northern Ireland: Northern Ireland Economic Development Office.

Athreya, V.B., G. Boklin, G. Djurfeldt, and S. Lindberg. 1986. "Production Relations and Agrarian Change: Some Findings from a Case Study in Tamil Nadu." Social Scientist 14 (5):3-14.

Bagchi, Amiya Kumar. 1976. "De industrialization in India in the nineteenth century: Some theoretical implications." The J ournal of Development Studies 12 (2):135-164.

Baker, Christopher John. 1984. An Indian rural economy, 1880-1955: the Tamilnad countryside. Oxford: Clarendon Press

Balfour-Paul, Jenny. 1998. Indigo. London: British Museum Press.

Bandopadhyay, J, and Vandana Shiva. 1987. "The Chipko Movement against limestone quarrying in Doon Valley." Lokayan Bulletin 5 (3):19-25.

Banerjee, Madhulika. 2002. "Public policy and Ayurveda: Modernising a great tradition." Economic and Political weekly 37 (12):1136-1146.

Banerji, Debashish. 2002. "The Orientalism of EB Havell." Third Text 16 (1):41-56.

Basalla, George. 1988. The evolution of technology. Cambridge: Cambridge University Press.

Bassok, Miriam, and Laura R Novick. 2012. "Problem solving." In Oxford handbook of thinking and reasoning, edited by K. J. Holyoak and R. G. Morrison, 413-432. New York: Oxford University Press.

Baudrillard, Jean. 1975. The mirror of production. St. Louis: Telos Press. 
Bayly, Christopher Alan. 1983. Rulers, townsmen and bazaars: North Indian society in the age of British expansion, 1770-1870. Cambridge: Cambridge University Press

Bayly, Christopher Alan. 1986. "The Origins of Swadeshi (Home Industry): Cloth and Indian Society, 17001930." In The social life of things: Commodities in cultural perspective, edited by Arjun Appadurai, 285-322. Cambridge: Cambridge University Press.

Bebbington, Anthony. 1999. "Capitals and capabilities: A framework for analyzing peasant viability, rural livelihoods and poverty." World development 27 (12):2021-2044.

Berg, Maxine. 2004. "In pursuit of luxury: Global history and British consumer goods in the eighteenth century." Past and present 182 (February):85-142.

Bernshteĭn, Nikolaĭ Aleksandrovich. 1996. "On dexterity and its development." In Dexterity and its development, edited by Mark L Latash and Michael T Turvey, 3-244. New Jersey: Lawrence Erlbaum Associates.

Bhagavatula, Suresh. 2009. "Weaving Social Networks." Phd, Performance of small rural firms in India as an outcome of entrepreneurs' social and human capital, Vrije Universiteit

Bhattacharya, Subhas. 1977. "The Indigo Revolt of Bengal." Social Scientist 5 (12):13-23.

Bijker, Wiebe E. 1987 (2012). "The social construction of Bakelite: Toward a theory of invention." In The social construction of technological systems: New directions in the sociology and history of technology, edited by Wiebe E Bijker, Thomas P Hughes, Trevor Pinch and Deborah G Douglas, 155-182. Cambridge MA: MIT Press.

Bijker, Wiebe E. 2001. "Understanding Technological Culture through a Constructivist View of Science, Technology and Society." In Visions of STS: Counterpoints in science, technology and society studies, edited by S.H. Cutcliffe and C. Mitcham, 1933. New York: State University of New York Press.

Bijker, Wiebe E. 2010. "How is technology made?-That is the question!" Cambridge J ournal of Economics 34 (1):63-76.

Bijker, Wiebe E. 2012. "Do we live in water cultures? A methodological commentary." Social Studies of Science 42 (4):624-627.
Bijker, Wiebe E, Thomas P Hughes, Trevor Pinch, and Deborah G Douglas, eds. 1987 (2012). The social construction of technological systems: New directions in the sociology and history of technology. Cambridge MA: MIT press.

Bijker, Wiebe E. 1993. Dutch, Dikes and D emocracy. An Argument against democratic, authoritarian, and neutral technologies. Lyngby: Technical University of Denmark, Unit of Technology Assessment.

Bijker, Wiebe E. 1995. Of bicycles, bakelites, and bulbs : Toward a theory of sociotechnical change, Inside technology. Cambridge MA: MIT Press.

Bijker, Wiebe E., Anique Hommels, and Jessica Mesman. 2014. "Studying vulnerability in technological cultures." In Vulnerability in Technological Cultures: New Directions in Research and Governance, edited by Anique Hommels, Jessica Mesman and Wiebe E. Bijker, 1-26. Cambridge, Massachusetts: The MIT Press.

Bijsterveld, Karin, and Marten Schulp. 2004. "Breaking into a World of Perfection Innovation in Today's Classical Musical Instruments." Social studies of science 34 (5):649-674.

Birdwood, George Christopher Molesworth. 1880. The Industrial arts of India. London: Chapman and Hall.

Bjögvinsson, Erling, Pelle Ehn, and Per-Anders Hillgren. 2012. "Design Things and Design Thinking: Contemporary Participatory Design Challenges." Design Issues 28 (3):101-116.

Blaszczyk, Regina Lee. 2012. The color revolution. Cambridge MA: MIT Press.

Bloor, David. 1976. Knowledge and Social Imagery. London: Routledge \& Kegan Paul.

Bloor, David. 1983. Wittgenstein: A Social Theory of Knowledge. New York: Columbia University Press.

Botnick, Ken, and Ira Raja. 2011. "Subtle technology: The design innovation of Indian artisanship." D esign Issues 27 (4):43-55.

Bourdieu, Pierre. 2008. "The Forms of Capital." In Readings in economic sociology, edited by Nicole Woolsey Biggart, 280-291. Massachusetts, USA: Blackwell Publishers. Original edition, Handbook of theory and research for the sociology and education, 1986.

Bourdieu, Pierre. 1984. Distinction: A social critique of the judgement of taste. Translated by Richard Nice. Cambridge, MA: Harvard University Press. 
Bowker, Geoffrey C. 2005. Memory practices in the sciences. Cambridge MA: MIT Press.

Brantlinger, Patrick. 1996. "A postindustrial prelude to postcolonialism: John Ruskin, William Morris, and Gandhism." Critical Inquiry 22 (3):466-485.

Bray, Francesca. 2008. "Science, technique, technology: Passages between matter and knowledge in imperial Chinese agriculture." The British Journal for the History of Science 41 (03):319-344.

Breman, Jan. 1996. F ootloose labour: Working in India's informal economy. Cambridge MA: Cambridge University Press.

Breman, Jan. 2003. "At the bottom of the urban economy." Economic and Political Weekly, 38(39) 38 (39):41514158 .

Breman, Jan. 2005. "Work and Life in the Informal Economy." Economic and Political Weekly 40 (25):2500-2506.

Breman, Jan. 2009. "The great transformation in the setting of Asia." Public lecture to accept honorary doctorate (The Hague: International Institute of Social Studies).

Brennig, Joseph J. 1986. "Textile producers and production in late seventeenth century Coromandel." Indian economic \& Social history review 23 (4):333-355.

Brown, John Seely, and Paul Duguid. 2000. The social life of information. Boston: Harvard Business School Press.

Brown, John Seely, and Paul Duguid. 2002. "Local Knowledge Innovation in the Networked Age." M anagement Learning 33 (4):427-437.

Brown, Judith M, and Anthony Parel, eds. 2011. The Cambridge Companion to Gandhi. New York: Cambridge University Press.

Buchanan, DH. 1934. The Development of Capitalistic Enterprise in India. London: Frankess and Company.

Bühler, Georg. 1886. The laws of M anu. Vol. V. Oxford: Clarendon Press.

Callon, Michel. 1980. "Struggles and negotiations to define what is problematic and what is not." In The social process of scientific investigation. Sociology of the Sciences Yearbook Vol 4, edited by Knorr Karin, Roger Krohn and Richard Whitley, 197-219. Dordrecht: Kluwer Academic Publishers.
Callon, Michel. 1998. "Introduction: The embeddedness of economic markets in economics." In The Laws of the Market, edited by Michel Callon, 1-57. Oxford UK: Blackwell Publishers.

Ceglie, Giovanna, and Marco Dini. 1999. SME cluster and network development in developing countries: the experience of UNIDO. Geneva: UNIDO

Centellas, Kate M, Regina E Smardon, and Steven Fifield. 2013. "Calibrating Translational Cancer Research: Collaboration without Consensus in Interdisciplinary Laboratory Meetings." Science, Technology \& Human Values 39:311-355.

Cesarino, Letícia Maria Costa da Nóbrega. 2012. "Anthropology of development and the challenge of South-South cooperation." Vibrant: Virtual Brazilian Anthropology 9 (1):507-537.

Chambers, Robert, and Gordon Conway. 1992. Sustainable rural livelihoods: Practical concepts for the 21st century, IDS Discussion Paper 296. Brighton, UK: Institute of Development Studies

Chandavarkar, Rajnarayan. 1985. "Industrialization in India before 1947: Conventional approaches and alternative perspectives." Modern Asian Studies 19 (03):623-668.

Chandrasekhar, CP. 2001. "Handlooms: In Survival Mode." Seminar on „Growth and Prospects of the Handloom Industry $\square$, Centre for Economic and Social Studies, Hyderabad.

Chatterjee, Ashoke. 2005. "Design in India: The Experience of Transition." D esign Issues 21 (4):4-10.

Chatterton, Alfred. 1904. Agricultural and industrial problems in India. Madras: G A Natesan and Co.

Chatterton, Alfred. 1908. "Indian Trade Journal." April 9.

Chattopadhayay, Ms Kamaladevi. 1983. Indian Women's Battle for Freedom. New Delhi: Abhinav Publications.

Cherlet, Jan. 2014. "Epistemic and technological determinism in development aid." Science, Technology \& Human Values 39 (6):773-794.

Clark, Robin JH, Christopher J Cooksey, Marcus AM Daniels, and Robert Withnall. 1993. "Indigo, woad, and Tyrian Purple: Important vat dyes from antiquity to the present." Endeavour 17 (4):191-199.

Cobb, Betsey. 1975. "Kamaladevi Chattopadhyaya." Bulletin of Concerned Asian Scholars Volume 7 (1: January-March). 
Collier, Paul. 2007. The bottom billion: Why the poorest countries are failing and what can be done about it. New York: Oxford University Press.

Collins, H M. 1987 (2012). "Expert systems and the science of knowledge." In The social construction of technological systems: New directions in the sociology and history of technology, edited by Wiebe E Bijker, Thomas P Hughes, Trevor Pinch and Deborah G Douglas, 321-340. Cambridge MA: MIT Press. Original edition, 1987.

Collins, H M. 2004. "Interactional expertise as a third kind of knowledge." Phenomenology and the Cognitive Sciences 3 (2):125-143.

Collins, H M. 2007. "Bicycling on the moon: collective tacit knowledge and somatic-limit tacit knowledge." O rganization Studies 28 (2):257-262.

Collins, H M. 2010. Tacit and explicit knowledge. Chicago: University of Chicago Press.

Collins, H.M. 1974. "The TEA Set: Tacit Knowledge and Scientific Networks." Science Studies 4 (2):165-186.

Collins, H.M., and R. Evans. 2007. Rethinking expertise. Chicago: University of Chicago Press.

Constant, EdwardW, II. 1984. "Communities and Hierarchies: Structure in the Practice of Science and Technology." In The Nature of Technological Knowledge. Are Models of Scientific Change Relevant?, edited by Rachel Laudan, 27-46. Netherlands: Springer

Coomaraswamy, Ananda Kentish. 1909. The Indian Craftsman. London: Probsthain \& Company.

Correspondent, A Delhi. 1954. "The Future of Cotton Mills and Handlooms." Economic and Political Weekly 6 (42).

Cowan, R.S. 1976. "'The Industrial Revolution' in the Home." Technology and Culture 17 (1):1-23.

Cowan, Ruth Schwartz. 1983. More Work for Mother: The Ironies of Household Technology from the 0 pen $\mathrm{H}$ earth to the M icrowave. New York: Basic Books.

Cowan, Ruth Schwarz. 1987. "The Consumption Junction: A Proposal for Research Strategies in the Sociology of Technology." In The Social Construction of Technological Systems. New Directions in the Sociology and History of Technology, edited by Wiebe E. Bijker, Thomas P. Hughes and Trevor Pinch, 261-280. Cambridge MA: MIT Press.
Cozzens, Susan E, Sonia Gatchair, Kyung-Sup Kim, Gonzalo Ordóñez, and Anupit Supnithadnaporn. 2008. "Knowledge and development." In The $\mathrm{H}$ andbook of Science and Technology Studies, edited by Edward J. Hackett, Olga Amsterdamska, Michael Lynch and Judy Wajcman, 787-811. Cambridge MA: MIT Press.

Cuff, Dana. 1992. Architecture: The story of a Practice. Cambridge MA: Mit Press.

Das, Lalit Kumar. 2005. "Culture as the Designer." D esign Issues 21 (4):41-53.

Das, Sujit Kumar. 2001. The warp and woof: An enquiry into the handloom industry in West Bengal. Kolkata: KP Bagchi \& Co.

David, Brewster. 1855. M emoirs of the life, writings, and discoveries of Sir Isaac Newton. Edinburgh: Thomas Constable and Co.

De Haan, A. 1999. "Livelihoods and poverty: The role of migration-a critical review of the migration literature." J ournal of Development Studies 36 (2):1-47.

De Haan, A. 2011. "Title." ISS Working Papers, The Hague

De Neve, Geert. 2003. "Expectations and rewards of modernity: Commitment and mobility among rural migrants in Tirupur, Tamil Nadu." Contributions to Indian Sociology 37 (1-2):251.

De Neve, Geert. 2005. The everyday politics of labour: Working lives in India's informal economy. New Delhi: Social Science Press.

Deleuze, Gilles, and Felix Guattari. 2004. A thousand plateaus. London: Continuum.

Djurfeldt, G., V. Athreya, N. Jayakumar, S. Lindberg, A. Rajagopal, and R. Vidyasagar. 2008. "Agrarian change and social mobility in Tamil Nadu." E conomic and Political Weekly 43 (45):50-61.

Dobusch, Leonhard. 2007. "Schumpeter vs. path dependency: Innovation lessons from breaking through innovation barriers." Fifth International Critical Management Studies Conference, Berlin.

Dogan, Mattei, and Robert Pahre. 1990. Creative marginality: Innovation at the intersections of social sciences. Boulder: Westview Press

Dreyfus, Hubert, Stuart E Dreyfus, and Tom Athanasiou. 1986. Mind over machine: The Power of Human Intuition and Expertise in the Era of the Computer New York: Free Press. 
Dreyfus, Stuart E. 2004. "The Five-Stage Model of Adult Skill Acquisition." Bulletin of Science, Technology \& Society 24 (3):177-181. doi: $10.1177 / 0270467604264992$.

Du Gay, Paul. 1997. D oing cultural studies: The story of the Sony Walkman. London: Sage/Open University Press.

Dunbar, Kevin. 1995. "How scientists really reason: Scientific reasoning in real-world laboratories." In The nature of insight, edited by Janet E. Davidson and Robert J. Sternberg, 365-395. Cambridge MA: MIT Press.

Eapen, M. 1984. "And Now Legislation for Handloom Protection." Economic and Political Weekly 19 (14).

Egyedi, Tineke M. 1996. "Shaping Standardization: A study of standards processes and standards policies in the field of telematic services."Phd, Delft University of Technology.

Egyedi, Tineke M. 2003. "Consortium problem redefined: Negotiating democracy in the actor network on standardization." International J ournal of IT Standards and Standardization Research (IJ ITSR) 1 (2):22-38.

Elkington, J. 1998. Cannibals with forks. Gabriola Island: New Society Publishers.

Ensmenger, Nathan. 2012. "The Digital Construction of Technology: Rethinking the History of Computers in Society." Technology and Culture 53 (4):753-776.

Escobar, Arturo. 1995. Encountering development: The making and unmaking of development. New Jersey: Princeton University Press.

Escobar, Arturo. 2012. Encountering development: The making and unmaking of the Third World. 2nd Edition ed. Princeton: Princeton University Press.

Fagerberg, Jan. 2004. "Innovation: a guide to the literature." In O xford Handbook of Innovation, edited by J. Fagerberg, D.C. Mowery and R.R. Nelson, 1-27. Oxford: Oxford University Press.

Fagerberg, Jan, David C Mowery, and Richard R Nelson, eds. 2006. The Oxford handbook of innovation. Oxford: Oxford University Press.

Fawcett, CGH. 1908. "A Monograph on Dyes and Dyeing in the Bombay Presidency." In Art in industry through the ages : monograph series on Bombay Presidency., 83-125. New Delhi: Navrang. Original edition, 1896.

Feng, Patrick. 2003. "Studying standardization: A review of the literature." The 3rd IEEE Standardization and Innovation in Information Technology, Delft.
Ferguson,J.1990.Theanti-politicsmachine: 'development', depoliticization and bureaucratic power in Lesotho. New York: Cambridge University Press.

Foucault, Michel. 1991. "Politics and the study of discourse." In The Foucault Effect: Studies in Governmentality, edited by Graham Burchell, Colin Gordon and Peter Miller, 53-72. Chicago: University of Chicago Press.

Gajjala, Radhika, ed. 2013. Cyberculture and the Subaltern: Weavings of the Virtual and Real. Plymouth: Lexington Books.

Gandhi, Mahatma. 1948. Constructive Programme: Its Meaning and Place. Ahmedabad: Navajivan.

Garcia, Rosanna, and Roger Calantone. 2002. "A critical look at technological innovation typology and innovativeness terminology: a literature review." Journal of product innovation management 19 (2):110-132.

Garmezy, Norman. 1991. "Resilience and vulnerability to adverse developmental outcomes associated with poverty." American Behavioral Scientist 34:416-430.

Garud, Raghu, and Michael A Rappa. 1994. "A sociocognitive model of technology evolution: The case of cochlear implants." Organization Science 5 (3):344-362.

Gittinger, Mattiebelle. 1982. Master dyers to the world: Technique and trade in early Indian dyed cotton tex tiles. Washington DC: Textile Museum.

Glassie, Henry, and Firoz Mahmud. 2007. "Living Traditions in Weaving: Jamdani." In L iving Traditions, 351-360. Dhaka: Asiatic Society of Bangladesh.

Godin, Benoit. 2015. Innovation Contested: The Idea of Innovation 0 ver the Centuries. New York: Routledge.

GOI. 1915. Report of the Committee on Co-operation in India. Simla: Government Central Press.

GOI. 1942. Report of the Fact Finding Committee. Calcutta: Government of India.

GOI. 1954. Report of the Textile Enquiry commission. edited by Ministry of Commerce. New Delhi: Government of India.

GOI. 1955. Report of the Village and Small Industries Committee. edited by Planning Commission. New Delhi: Government of India.

GOI. 1964. Report of the Powerlooms Enquiry Committee. edited by Ministry of Industry. New Delhi: Government of India. 
GOI. 1974. Report of the High Powered Study Team on the Problems of Handloom Industry. edited by Ministry of Commerce. New Delhi: Government of India.

GOI. 1985. Report of the Expert Committee on Textiles. edited by Ministry of Textiles. New Delhi: Government of India.

GOI. 1988. Report on the Working and Living Conditions of Workers in the Powerloom Industry in India. edited by Ministry of Labour. New Delhi: Government of India.

GOI. 1990. 'The Textile Industry in 1990s: Restructuring with a Human Face'. Report of the Committee to Review the Programme of Implementation of Textile Policy of June 1985. edited by Ministry of Textiles. New Delhi: Government of India.

Gomart, Emilie, and Antoine Hennion. 1999. "A sociology of attachment: Music amateurs, drug users." The Sociological Review 47 (S1):220-247. doi: 10.1111/ j.1467-954X.1999.tb03490.x.

Gow, David D. 2008. Countering development: Indigenous modernity and the moral imagination. USA: Duke University Press.

Grant, Colesworthey. 1984. Rural Life in Bengal: Letters from an Artist in India to his Sisters in England. Calcutta: Subarnarekha.

Greenhalgh, Paul. 1997. "The history of craft." In The culture of craft, edited by P. Dormer, 20-53. Manchester: Manchester University Press.

Guha, Ashok. 1989a. "Consumption, efficiency and surplus labour." J ournal of D evelopment Economics 31 (1):1-12.

Guha, Ranajit. 1974. "Neel darpan: The image of a peasant revolt in a liberal mirror " The J ournal of Peasant Studies 2 (1):1-46.

Guha, Sumit. 1989b. "The handloom industry of Central India: 1825-1950." Indian E conomic \& Social History Review 26 (3):297-318.

Guha-Thakurta, Tapati. 1995. "Recovering the Nation's Art." In Texts of Power: Emerging Disciplines in Colonial Bengal, edited by Partha Chatterjee, 63-92. MN: University of Minnesota Press.

Guildford, J.P. 1950. "Creativity." American Psychologist (5):469-479.

Gupta, Akhil. 1995. "Blurred boundaries: the discourse of corruption, the culture of politics, and the imagined state." American ethnologist 22 (2):375-402.
Guru, Gopal. 2009. "Archaeology of Untouchability." Economic and Political Weekly 19 (37):49-56.

Hagedoorn, John. 1996. "Innovation and entrepreneurship: Schumpeter revisited." Industrial and Corporate Change 5 (3):883-896.

Hajer, Maarten A. 1995. The politics of environmental discourse: Ecological modernization and the policy process. Oxford: Clarendon Press.

Hall, S. 1996. "Who Needs' Identity'?" In Questions of cultural identity, edited by S. Hall and P. du Gay, 1-17. Thousand Oaks, CA: Sage.

Hansen, Morten T. 1999. "The search-transfer problem: The role of weak ties in sharing knowledge across organization subunits." Administrative science quarterly 44 (1):82-111.

Harding, Sandra. 1998. "Women, science, and society." Science 281 (5383):1599-1600.

Harding, Sandra. 2009. "Postcolonial and feminist philosophies of science and technology: Convergences and dissonances." Postcolonial Studies 12 (4):401-421.

Harding, Sandra, and Kathryn Norberg. 2005. "New feminist approaches to social science methodologies: An introduction." Signs 30 (4):2009-2015.

Harnetty, Peter. 1991. "De-industrialization revisited." M odern Asian Studies 25 (3):455-510.

Harvey, David. 2003. The new imperialism. Oxford: Oxford University Press.

Havell, Ernest Binfield. 1909. Reports Submitted by EB Havell During the Years 1885-1888 on the Art and Industries of Certain Districts of the Madras P residency, Selections from the records of the M adras Presidency; New (Reserve) Series. VI. Madras: Superintendent, Government Press.

Havell, Ernest Binfield. 1910. Essays on Indian art, industry \& education. Madras: GA Natesan and Co.

Hayes, John R. 1989. The complete problem solver. Mahvah, NJ: Erlbaum.

Haynes, Douglas E. 1986. "The dynamics of continuity in Indian domestic industry: Jari manufacture in Surat, 1900-47." Indian E conomic \& Social H istory Review 23 (2):127-149.

Haynes, Douglas E. 1996. The logic of the artisan firm in a capitalist economy: Handloom weavers and technological change in Western India, 1880-1947, Institutions and Economic Change in South Asia. New Delhi: Oxford University Press. 
Haynes, Douglas E. 2012. Small Town Capitalism in Western India: Artisans, M erchants and the Making of the Informal Economy, 1870-1960. Cambridge MA: Cambridge University Press.

Haynes, Douglas E, Abigail McGowan, Tirthankar Roy, and Haruka Yanagisawa, eds. 2010. Towards a history of consumption in South Asia. New Delhi: Oxford University Press

Haynes, Douglas E. 2001. "Artisan Cloth-Producers and the Emergence of Powerloom Manufacture in Western India 1920-1950." Past and Present 172:170-198.

Herzfeld, Michael. 2004. The body impolitic: Artisans and artifice in the global hierarchy of value. Chicago: University of Chicago Press.

Hessel, C, C Allegre, M Maisseu, F Charbit, and P Moulin. 2007. "Guidelines and legislation for dye house effluents." J ournal of environmental management 83 (2):171-180.

Hettne, B. 2008. "Current trends and future options in development studies." In The Companion to Development Studies, edited by Vandana Desai and Richard B Potter, 8-12. New York: Routledge.

Highmore, Ben, ed. 2009. The design culture reader. London: Routledge.

Hobsbawm, Eric J. 1983. "Introduction: Inventing Traditions." In The Invention of tradition, edited by Eric Hobsbawm and Terence Ranger, 1-14. Cambridge: Cambridge University Press.

Hobsbawm, Eric J. 1994. The age of extremes: a history of the world, 1914-1991. New York: Pantheon Books.

Hobsbawm, Eric J. 1999. Industry and empire: From 1750 to the present day. New York: The New Press.

Hoffenberg, Peter H. 2001. An empire on display: English, Indian, and Australian exhibitions from the Crystal Palace to the Great War. California: University of California Press.

Holmstrom, Mark. 1993. "Flexible Specialisation in India?" Economic and Political Weekly 28 (35):M82M86. doi: 10.2307/4400074.

Hommels, Anique. 2005. "Studying obduracy in the city: Toward a productive fusion between technology studies and urban studies." Science, technology \& human values 30 (3):323-351.

Hommels, Anique, Jessica Mesman, and Wiebe E. Bijker, eds. 2014. Vulnerability in Technological Cultures: New Directions in Research and Governance, Inside Technology. Cambridge, Massachusetts: The MIT Press.
Hopwood, Bill, Mary Mellor, and Geoff O'Brien. 2005. "Sustainable development: Mapping different approaches." Sustainable development 13 (1):38-52.

Hossain, Hameeda. 1979. "The alienation of weavers: impact of the conflict between the revenue and commercial interests of the East India Company, 1750-1800." Indian Economic \& Social History Review 16 (3):323-345.

Hughes, Thomas P. 1987 (2012). "The Evolution of Large Technological Systems." In The social construction of technological systems: New directions in the sociology and history of technology, edited by Wiebe E Bijker, Thomas P Hughes, Trevor Pinch and Deborah G Douglas, 45-76. Cambridge MA: MIT Press.

Hughes, Thomas P. 1983. Networks of Power. Electrification in Western Society, 1880-1930. Baltimore/London: The Johns Hopkins University Press.

India, Crafts Council of. 2011. Craft economics and impact study. Chennai, India: Crafts Council of India.

Ingold, Tim. 2001. "Beyond art and technology: The anthropology of skill." In Anthropological perspectives on technology, edited by Michael B. Schiffer, 17-31. Albuquerque: University of New Mexico Press.

Ingold, Tim. 2009. "The textility of making." Cambridge J ournal of Economics 34:94-102.

Jain, LC. 1985. "1985 Textile Policy: End of handloom industry." Economic and Political Weekly 20 (21):1121-1123.

Jain, LC. 1986. "A heritage to keep: The handicrafts industry, 1955-85." Economic and Political Weekly 21 (20):873-887.

Jasanoff, Sheila, ed. 2004. States of knowledge : the coproduction of science and social order, International library of sociology. New York: Routledge.

Jayakar, Pupul. 1989. The earth mother. New Delhi: Penguin Books.

Kasturi, Poonam Bir. 2005. "Designing Freedom." D esign Issues 21 (4):68-77.

Kawlra, Aarti. 2001. "The tradition in crafts." Indian Folklife 1 (4):6-7.

Keulartz, Jozef, and Maartje Schermer.2014. "APragmatist Approach to the Governance of Vulnerability." In Vulnerability in Technological Cultures: New Directions in Research and Governance, edited by Anique Hommels, Jessica Mesman and Wiebe E. Bijker, 286-304. Cambridge, MA: MIT Press. 
Kline, Stephen J, and Nathan Rosenberg. 1986. "An overview of innovation." In The positive sum strategy: Harnessing technology for economic growth, edited by Ralph Landau and Nathan Rosenberg, 275-306. Washington DC: National Academy Press.

Knorr-Cetina, K. 1999. Epistemic cultures : How the sciences make knowledge. Cambridge, Mass.: Harvard University Press.

Krais, Paul. 1927. "Standardisation of colour fastness." Society of Dyers and Colourists. J ournal 43:148-154.

Kramrisch, Stella. 1994. "Exploring India's Sacred Art. Selected Writings Of Stella Kramrisch " In, edited by Barbara Stoler Miller. Indian Edition Delhi: IGNCA and Motilal Banarsidass

Kuhn, Thomas. 1962. The Structure of Scientific Revolutions. Chicago: University of Chicago Press.

Kumar, Prakash. 2001. "Scientific experiments in British India: Scientists, indigo planters and the state, 18901930." Indian E conomic \& Social History Review 38 (3):249-270.

Kumar, S., A. Heath, and O. Heath. 2002. "Determinants of social mobility in India." Economic and Political Weekly 37 (29):2983-2987.

Kurien, CT. 1978. "Small Sector in New Industrial Policy." Economic and Political Weekly 13 (9):455-461.

Lam, Alice. 2005. "Organizational innovation." In The Oxford Handbook of Innovation, edited by Jan Fagerberg, David C. Mowery and Richard R. Nelson, 115-148. Oxford Oxford University Press.

Latour, Bruno. 1986. "Visualization and Cognition: Thinking With Eyes and Hands." Knowledge and Society: Studies in the Sociology of Culture Past and Present 6:1-40.

Latour, Bruno. 1987. Science in Action: How to Follow Scientists and Engineers Through Society. Milton Keynes Open University Press.

Latour, Bruno. 1988. The Pasteurization of France. Translated by Alan Sheridan and John Law. Cambridge, MA: Harvard University Press.

Latour, Bruno, and Steve Woolgar. 1987. Laboratory Life: The Social Construction of Scientific Facts. Princeton: Princeton University Press.

Law, John. 1987. "Technology and Heterogeneous Engineering: The Case of Portuguese Expansion." In The Social Construction of Technological Systems, edited by Wiebe E. Bijker, Thomas P. Hughes and Trevor Pinch, 111-134. Cambridge: MIT Press.
Lazonick, William. 2005. The innovative firm. New York: Oxford University Press.

Le Goff, Jacques. 1992. History and M emory. Translated by Steven Rendall and Elizabeth Claman. New York: Columbia University Press.

Leder, Helmut, Benno Belke, Andries Oeberst, and Dorothee Augustin. 2004. "A model of aesthetic appreciation and aesthetic judgments." British J ournal of Psychology 95 (4):489-508.

Lefebvre, Henri. 2004. Rhythmanalysis: Space, time and everyday life. London: Continuum.

Leonard-Barton, Dorothy. 1995. Wellsprings of knowledge: Building and sustaining the sources of innovation. Boston: Harvard Business Press.

Lewis, D., and D. Mosse, eds. 2006. Development brokers and translators: The ethnography of aid and agencies. Bloomfield CT: Kumarian Press.

Li, Tania Murray. 2005. "Beyond "the state" and failed schemes." American anthropologist 107 (3):383-394.

Liebl, Maureen, and Tirthankar Roy. 2004. "Handmade in India: Traditional craft skills in a changing world." In Poor People's K nowledge: Promoting Intellectual P roperty in D eveloping Countries, edited by Michael J Finger and Philip Schuler, 53-72. Washington DC: World Bank and Oxford University Press.

Linkenbach, Antje. 1994. "Ecological movements and the critique of development: Agents and interpreters." Thesis Eleven 39 (1):63-85.

Lipsey, Roger. 1977. Coomaraswamy. Volume 3 (H is Life and Work). Princeton: Princeton University Press.

Livesey, Ruth. 2004. "Morris, Carpenter, Wilde, and the Political Aesthetics of Labor." Victorian Literature and Culture 32 (02):601-616.

Loconto, Allison. 2014. "Sustaining an Enterprise, Enacting SustainabiliTea." Science, Technology \& Human Values 39 (6):819-843.

Long, N., and J.D. Van der Ploeg. 2008. "Demythologizing planned intervention: an actor perspective." Sociologia Ruralis 29 (34):226-249.

Lundvall, Bengt-Åke, ed. 1992. National systems of innovation: Toward a theory of innovation and interactive learning. London: Anthem Press.

MacKenzie, Donald A. 1998. Knowing machines: Essays on technical change. Cambridge MA: MIT Press.

MacKenzie, Donald, and Judy Wajcman, eds. 1985. The social shaping of technology. Buckingham, Philadelphia: Open University Press. 
Madan, Gurmukh Ram. 2007. Co-operative M ovement in India. New Delhi: Mittal Publications.

Maltz, Diana. 2006. British Aestheticism and the Urban Working Classes, 1870-1900: Beauty for the People. Basingstoke: Palgrave Macmillan.

Mamidipudi, A., B. Syamasundari, and W. Bijker. 2012. "Mobilising Discourses." Economic \& Political Weekly 47 (25):41-51.

Marchand, Trevor HJ. 2010. "Embodied cognition and communication: Studies with British fine woodworkers." J ournal of the Royal Anthropological Institute 16 (s1):S100-S120.

Markus, Hazel. 1978. "The effect of mere presence on social facilitation: An unobtrusive test." J ournal of Experimental Social P sychology 14 (4):389-397.

Marris, Peter. 1975. Loss and change. Garden City NY: Anchor Press/Doubleday.

Marshall, Alfred. 1961. Principles of Economics: 9th Variorum Edition. London: Macmillan for the Royal Economic Society.

Marx, K 1853-54 (1979). Collected Works. Vol. 12. Moscow: Progress Publishers. Original edition, 1979.

Mathur, Saloni. 2007. India by design: Colonial history and cultural display. Berkeley: University of California Press.

Mayer, Peter. 2010. Suicide and society in India. New York: Routledge.

McGowan, Abigail. 2009. Crafting the nation in colonial India. New York: Palgrave Macmillan.

Mebratu, Desta. 1998. "Sustainability and sustainable development: Historical and conceptual review." Environmental impact assessment review 18 (6):493-520.

Meera, NK. 2011. "Gandhian ideology, swadeshi and the working of the handloom industry in coastal Andhra region c. 1900-1950." Phd, Department of History, University of Hyderabad.

Merton, Robert. 1973. "Science and the Social Order." In The Sociology of Science. Theoretical and Empirical Investigations., edited by Robert Merton, 254-266. Chicago: University of Chicago Press.

Meyer-Thurow, Georg. 1982. "The industrialization of invention: a case study from the German chemical industry." Isis 73 (3):363-381.

Miller, Fiona, Henny Osbahr, Emily Boyd, Frank Thomalla, Sukaina Bharwani, Gina Ziervogel, Brian
Walker, Jörn Birkmann, Sander van der Leeuw, and Johan Rockström. 2010. "Resilience and vulnerability: Complementary or conflicting concepts." Ecology and Society 15 (3):11.

Mintzberg, Henry. 1987. "Crafting strategy." Harvard Business Review (July-August):66-75.

Miryam, DW Karuna. 2014. "Weaving histories: The handloom industry in South India." Phd, Department of History, University of Delhi.

Mishra, Girish. 1968. "Socio-Economic Background of Gandhi's Champaran Movement." Indian Economic \& Social History Review 5 (3):245-275.

Mody, Cyrus CM. 2004. "Small, but determined: Technological determinism in nanoscience." International Journal for Philosophy of Chemistry 10 (2):99-128.

Mohanty, Bijoy Chandra, KV Chandramouli, and HD Naik. 1987. Natural dyeing processes of India. Ahmedabad, India: Calico Museum of Textiles.

Mosse, David. 1994. "Idioms of subordination and styles of protest among Christian and Hindu Harijan castes in Tamil Nadu." Contributions to Indian sociology 28 (1):67-106.

Mosse, David. 2006. "Antisocial anthropology? Objectivity, objection, and the ethnography of public policy and professional communities*." J ournal of the Royal Anthropological Institute 12 (4):935-956.

Mosse, David. 2013. "The anthropology of international development." Annual Review of Anthropology 42:227-246.

Mukund, Kanakalatha, and B Syama Sundari. 2001. Traditional industry in the new market economy: The cotton handlooms of Andhra Pradesh. New Delhi: Sage Publications.

Mukund, Kanakalatha, and B Syamasundari. 1998. "Doomed to Fail? 'Handloom Weavers' Co-operatives in Andhra Pradesh." Economic and Political Weekly 23 (52):3323-3332.

Muniesa, Fabian. 2008. "Trading-room Telephones and the Identification of Counterparts." In Living in a material world, edited by T Pinch and R Swedberg, 191-213. Cambridge MA: The MIT Press.

Nadigera, GS. 2001. "Azo ban, eco-norms and testing." Indian J ournal of Fibre \& Textile Research 26:55-60.

Nair, T.S. 2001. "Institutionalising microfinance in India: An overview of strategic issues." Economic and Political Weekly 36 (4):399-404. 
Narasimhan, Sakuntala. 1999. Kamaladevi Chattopadhyay: The Romantic Rebel. New Delhi: Sterling Publishers.

Nauta, Wiebe. 2006. Ethnographic research in a nongovernmental organization: Revealing strategic translations through an embedded tale. Edited by David Lewis and David Mosse, Development brokers and translators: The ethnography of aid and agencies. West Hartford, CT: Kumarian Press.

Negus, Keith. 2002. "The work of cultural intermediaries and the enduring distance between production and consumption." Cultural Studies 16 (4):501-515.

Nickelsen, Niels Christian, and Thomas Binder. 2008. "Design and heterogeneous engineering: Toward an actor network perspective on design." Artifact 2 $(3-4): 164-175$

Ninan, Anup Sam. 2009. "Gandhi's technoscience: Sustainability and technology as themes of politics." Sustainable D evelopment 17 (3):183-196.

Niranjana, Seemanthini. 2004. "Thinking With Handlooms: Perspectives From Andhra Pradesh." Economic and Political Weekly 39 (06):553-563.

Niranjana, Seemanthini, B Syamasundari, Latha Tummuru, and Annapurna M. 2006. "MARKETING HANDLOOMS: AN INTRODUCTION." E conomic \& Political Weekly 41 (31).

Niranjana, Seemanthini, and Soumya Vinayan. 2001. Growth and Prospects of the Handloom Industry. New Delhi: Planning Commission, New Delhi: Government of India.

Nowotny, Helga, ed. 2006a. Cultures of Technology and the Quest for Innovation. New York: Berghahn Books.

Nowotny, Helga. 2006b. "Introduction: Cultures of Technology and the Quest for Innovation." In Cultures of Technology and the Quest for Innovation, edited by Helga Nowotny, 1-24. New York: Berghahn Books.

O'Laughlin, B. 2008. "Governing capital? Corporate social responsibility and the limits of regulation." D evelopment and Change 39 (6):945-957.

Ohlsson, Stellan. 1992. "Information-processing explanations of insight and related phenomena." In Advances in the psychology of thinking, edited by MT Keane and KJ Gilhooly, 1-44. New York: Harvester Wheatsheaf.

Oldmeadow, Harry. 2004. J ourneys East: 20th century
Western encounters with Eastern religious traditions. Bloomington IN: World Wisdom, Inc.

Oudshoorn, Nelly, and Trevor Pinch. 2003. How Users Matter: The Co-Construction of Users and Technology (Inside Technology). Cambridge MA: The MIT Press.

Oudshoorn, Nelly, and Trevor Pinch. 2008. "UserTechnology Relationships: Some Recent Developments." In The Handbook of Science and Technology Studies. 3rd Edition., edited by E.J. Hackett, O. Amsterdamska, M. Lynch and J. Wajcman, 541-65. Cambridge MA: MIT Press.

Parekh, Bhikhu C. 1989. Gandhi's political philosophy: A critical examination. London: Macmillan

Pargiter, F E. 1904. The M arkandeya Puranam. Calcutta: Asiatic Society of Bengal.

Parthasarathi, Prasannan. 2001. The Transition to a Colonial E conomy: Weavers, M erchants and K ings in South India, 1720-1800. Cambridge UK: Cambridge University Press.

Parthasarathi, Prasannan. 2009. "Historical issues of deindustrialization in nineteenth-century South India." In H ow India Clothed the World: The World of South Asian textiles, 1500-1850, edited by G Riello and T Roy, 415-35. Leiden: Brill.

Pestre, Dominique. 2008. "Challenges for the democratic management of technoscience: Governance, participation and the political today." Science as culture 17 (2):101-119.

Pfaffenberger, Bryan. 1992. "Social anthropology of technology." Annual review of Anthropology 21:491516.

Phillips, Peter L. 2004. C reating the Perfect D esign B rief: How to manage design for strategic advantage. New York: Allworth Press.

Pinch, Trevor, and Karin Bijsterveld. 2004. "Sound studies: New technologies and music." Social Studies of Science 34 (5):635-648.

Pinch, Trevor J, and Wiebe E Bijker. 1984. "The social construction of facts and artefacts: Or how the sociology of science and the sociology of technology might benefit each other." Social Studies of Science 14 (3):399-441.

Pinch, Trevor, and Richard Swedberg, eds. 2008. Living in a Material World: Economic Sociology Meets Science and Technology Studies. Cambridge MA: The MIT Press. 
Pinch, Trevor, and Frank Trocco. 2002. Analog Days. The Invention and Impact of the Moog Synthesizer Harvard, MA: Harvard University Press.

Piore, Michael J, and F Charles. 1984. The Second Industrial Divide: Possibilities for Prosperity. New York: Basic Books.

Polanyi, Karl. 1944. The great transformation: The political and economic origins of our time. Boston: Beacon Press.

Polanyi, Michael. 1962. "Tacit knowing: Its bearing on some problems of philosophy." Reviews of Modern Physics 34 (4):601-615.

Polanyi, Michael. 1966. The Tacit D imension. New York: Doubleday.

Porter, MichaelE. 2011. Competitiveadvantage of nations: Creating and sustaining superior performance. New York: The Free Press, Simon and Schuster.

Porter, Theodore. 1995. Trust in Numbers: The Pursuit of Objectivity in Science and Public Life. Princeton: Princeton University Press.

Portisch, Anna Odland. 2010. "The craft of skilful learning: Kazakh women's everyday craft practices in western Mongolia." Journal of the Royal Anthropological Institute 16 (s1):S62-S79.

Potukuchi, Swarnalatha. 2005. The world of the weaver in Northern Coromandel, c. 1750-c. 1850. Hyderabad: Orient Blackswan.

Powell, Walter W, and Stine Grodal, eds. 2005. Networks of innovators. Edited by J. Fagerberg, D. Mowery and R. Nelson, The 0 xford handbook of innovation. Oxford: Oxford University Press.

Prasad, C Shambu. 1999. "Suicide deaths and quality of Indian cotton: Perspectives from history of technology and Khadi Movement." Economic and political weekly 34 (5):12-21.

Prasad, C Shambu. 2014. "Creative Dissent: Linking Vulnerability and Knowledge in India." In Vulnerability in Technological Cultures: New Directions in Research and Governance, edited by Anique Hommels, Jessica Mesman and Wiebe E Bijker, 135-154. Cambridge, MA: MIT Press.

Proust, Marcel. 2000. In Search of L ost time, Vol VI: Time Regained. Translated by Andreas Mayor, Terence Kilmartin and revised by D J Enright. London: Vintage Original edition, 1927.

Quartz, Julia. 2014. "Agricultural Change in a South Indian Village: An Account of the Multiplicity of Vulnerable Livelihoods." In Vulnerability in Technological Cultures: New Directions in Research and $\mathrm{G}$ overnance, edited by Anique Hommels, Jessica Mesman and Wiebe E. Bijker, 33-50. Cambridge, MA: MIT Press.

Ramaswamy, Vijaya. 1985a. "The genesis and historical role of the Master Weavers in South Indian Textile Production." Journal of the Economic and Social $\mathrm{H}$ istory of the $\mathrm{O}$ rient// ournal del'histoireeconomique et sociale de l'O rient 28 (3):300-313.

Ramaswamy, Vijaya. 1985b. Textile weavers in M edieval South India New Delhi: Oxford University Press.

Ramaswamy, Vijaya. 2006. Textiles and Weavers in Medieval South India. 2nd edition ed. New Delhi: Oxford University Press. Original edition, 1985.

Randell, Brian. 1994. "The origins of computer programming." Annals of the History of Computing, IEEE 16 (4):6-14.

Ranga, N.G. . 1930. The Handloom Weaving Industry. Bombay.

Ravetz, Jerome \& Silvio Funtowicz. 1999. "Postnormal science - an insight now maturing." F utures 31:641-46.

Redclift, Michael. 2005. "Sustainable development (1987-2005): An oxymoron comes of age." Sustainable development 13 (4):212-227.

Ribeiro, Rodrigo. 2007. "Knowledge transfer." School of Social Sciences, Cardiff University.

Ribeiro, Rodrigo. 2013. "Tacit knowledge management." Phenomenology and the Cognitive Sciences 12 (2):337-366. doi: 10.1007/s11097-011-9251-x.

Riello, Giorgio, and Prasannan Parthasarathi. 2011. The spinning world: A global history of cotton textiles, 1200-1850. Oxford: Oxford University Press.

Rip, Arie, Pierre-Benoit Joly, and Michel Callon. 2010. "Reinventing innovation." In Governance and innovation, edited by MJ Arentsen, W Rossum and B Steenge. Cheltenhan: Edward Elgar Publishing.

Risatti, Howard. 2009. Theory of Craft: Function and Aesthetic Expression. USA: University of North Carolina Press.

Rodrigues, Valerian. 2011. "Reading texts and traditions: The Ambedkar-Gandhi debate." Economic and Political Weekly 46 (2):57-66.

Rottenburg, Richard. 2009. Far-fetched facts: A Parable of D evelopment Aid. Cambridge, MA: MIT Press. 
Roy, Tirthankar. 1988. "Size and structure of handloom weaving in the mid-thirties." Indian economic \& social history review 25 (1):1.

Roy, Tirthankar. 1993. Artisans and industrialization: Indian weaving in the twentieth century. New Delhi: Oxford University Press.

Roy, Tirthankar. 1998a. "Development or Distortion? 'Powerlooms' in India, 1950-1997." Economic and Political Weekly 33 (16):897-911.

Roy, Tirthankar. 1998b. "Music as artisan tradition." Contributions to Indian sociology 32 (1):21-42.

Roy, Tirthankar. 1999. Traditional industry in the economy of colonial India. Vol. 5. Cambridge: Cambridge University Press.

Roy, Tirthankar. 2000. The economic history of India 1857-1947. New Delhi: Oxford University Press.

Roy, Tirthankar. 2002. "Acceptance of innovations in early twentieth century Indian weaving." The Economic History Review 55 (3):507-532.

Roy, Tirthankar. 2007. "Out of tradition: Master artisans and economic change in colonial India." The J ournal of Asian Studies 66 (04):963-991.

Roy, Tirthankar. 2011. "Indigo and law in colonial India." The Economic History Review 64 (s1):60-75.

Russell, Glen Allan, and Gerd Kaupp. 1969. "Reactions of resonance stabilized carbanions. XXXI. Oxidation of carbanions. 4. Oxidation of indoxyl to indigo in basic solution." J ournal of the American Chemical Society 91 (14):3851-3859. doi: 10.1021/ja01042a028.

Russell, Stewart. 1986. "The Social Construction of Artefacts: A Response to Pinch and Bijker." Social Studies of Science 16 (2):331-346.

Ruttan, Vernon W. 1959. "Usher and Schumpeter on invention, innovation, and technological change." The quarterly journal of economics 73 (4):596-606.

Sabel, Charles, and Jonathan Zeitlin. 1985. "Historical alternatives to mass production: Politics, markets and technology in nineteenth-century industrialization." Past \& Present 108:133-176.

Sadanandam, Paidipala. 2008. Art and Culture of Marginalised Nomadic Tribes in Andhra Pradesh. New Delhi: Gyan Publishing House.

Sahai, R 1933. Report on the Survey of the Handloom Weaving and Dyeing Industries in the Nizam's Dominions. Hyderabad.

Saleebey, Dennis. 2008. "The strengths perspective:
Putting possibility and hope to work in our practice." In Comprehensive handbook of social work and social welfare, edited by Barbara. W. White. New Jersey, USA: John Wiley \& Sons.

Saravanamuthu, Kala. 2006. "Emancipatory accounting and sustainable development: A Gandhian-Vedic theorization of experimenting with truth." Sustainable D evelopment 14 (4):234-244.

Sarukkai, Sundar. 2007. "Dalit Experience and Theory." Economic and Political Weekly 17 (40):4043-4048.

Schaniel, William C. 1988. "New technology and culture change in traditional societies." J ournal of E conomic Issues 22 (2):493-498.

Schmitz, Hubert. 1995. "Collective efficiency: Growth path for smallscale industry." The journal of development studies 31 (4):529-566.

Schön, Donald A. 1979. "Generative Metaphor: A Perspective on Problem-Setting Social Policy." In M etaphor and Thought, edited by Andrew Ortony, 254-283. Cambridge: Cambridge University Press.

Schön, Donald A. 1983. The reflective practitioner: How practitioners think in action. London: Temple Smith.

Schumacher, Ernst Friedrich. 2011. Small is beautiful: A study of economics as if people mattered. London: Vintage Books. Original edition, 1973.

Schumpeter, Joseph A. 1942. Socialism, capitalism and democracy. New York: Harper and Brothers.

Schumpeter, Joseph A. 1947. "The creative response in economic history." The journal of economic history 7 (2):149-159.

Schumpeter, Joseph A. 1961. The theory of economic development: An inquiry into profits, capital, credit, interest, and the business cycle. New Brunswick, NJ: Transaction Books.

Sen, Amartya. 1981. Poverty and famines: An essay on entitlement and famines. Oxford: Clarendon Press.

Sen, Amartya. 2005. The argumentative Indian: Writings on Indian culture, history and identity. London: Penguin.

Sen, Amartya Kumar. 1999. Development as freedom. Oxford: Oxford University Press.

Sennett, Richard. 2008. The craftsman. New Haven: Yale University Press.

Shah, Esha. 2014. "Cultural Politics of Vulnerability: Historical-Ethnography of Dearth and Debt, and Farmers' Suicides in India." In Vulnerability in 
Technological Cultures: New Directions in Research and $\mathrm{G}$ overnance, edited by Anique Hommels, Jessica Mesman and Wiebe E. Bijker, 51-70. Cambridge MA: The MIT Press.

Shah, P.G. 1919. "Cottage Industries in India " The Bombay Co-operative quarterly 3 (3):133-134.

Simmel, Georg. 1950. "The stranger." In The Sociology of Georg Simmel, edited by Wolff K, 402-408. New York: The Free Press.

Simmel, Georg. 1957. "Fashion." American J ournal of Sociology 62 (6):541-558.

Simmons, Colin. 1985. "'De-industrialization', Industrialization and the Indian Economy, c. 18501947." M odern Asian Studies 19 (03):593-622.

Simonton, DK. 1996. "Achievement." In Encyclopedia of gerontology, edited by J.E. Birren, 20-29. San Diego, CA Academic Press.

Siraj-ul-Hassan, Syed. 1920. The Castes and Tribes of HEH the Nizam's Dominions. Bombay: The Times Press.

Sivasubramonian, Siva. 2000. The national income of India in the twentieth century. New Delhi: Oxford University Press.

Skeggs, Bev. 2004. Class, self, culture. London: Routledge.

Smith, Pamela H. 2004. The body of the artisan: Art and experience in the scientific revolution. Chicago: University of Chicago Press.

Smith, Pamela H. 2010. "Why write a book. From lived experience to the written word in early modern Europe." German Historical Institute Bulletin 47:25-50.

Smith, Pamela H. 2012. "In the workshop of history: Making, Writing, and Meaning." A Journal of Decorative Arts, Design History, and Material Culture 19 (1):4-31.

Smith, Pamela H. 2015. "The matter of ideas in the working of metals in early modern Europe." In The Matter of Art: Materials, Practices, Cultural Logics, C. 1250-1750, edited by Christy Anderson, Anne Dunlop and Pamela H Smith, 42-67. Manchester: Manchester University Press.

Smith, Veronica, and Kim Schonert-Reichl. 2013. "Contextual facilitators: Resilience, Coping and Sense of Coherence. ." In Life quality outcomes in children and young people with neurological and developmental conditions: concepts, evidence and practice, edited by Gabriel M Ronen and Peter L Rosenbaum. London: Mac Keith Press.

Soete, Luc, and A. Arundel, eds. 1993. An Integrated Approach to European Innovation and Technology Diffusion Policy: A Maastricht Memorandum. Brussels: Commission of the European Communities.

Soetsu, Yanagi. 1972. The unknown craftsman, A J apanese Insight into Beauty. Bernard Leach ed. Tokyo: Kodansha International.

Soneji, Davesh. 2004. "Living History, Performing Memory: Devadāsī Women in Telugu-Speaking South India." Dance Research J ournal 36 (2):30-49.

Sorensen, Knut H, and Nora Levold. 1992. "Tacit networks, heterogeneous engineers, and embodied technology." Science, Technology \& Human Values 17 (1):13-35.

Specker, Konrad. 1989. "Madras handlooms in the nineteenth century." Indian Economic \& Social History Review 26 (2):131-166.

Spicker, Paul. 2007. The idea of poverty. New Delhi: Policy Press, Rawat Publications.

Sreekumar, N, and Girish Sant. 2006. "Tribute: Amulya KN Reddy." Economic and Political Weekly 16 (22):2194-2196.

Srinivas, Nidhi. 2008. "Managerialism and NGO Advocacy: Handloom Weavers in India." In The new development management: critiquing the dual modernization, edited by Sadhvi Dar and Bill Cooke, 74-90. London: Zed Books.

Srinivasan, Sharada. 2012. "Carving a global icon: The Nataraja bronze and Commaraswamy's legacy." In Asian art and culture: A research volume in honour of Ananda Coomaraswamy, 245-256. Colombo: Department of Information, Government of Sri Lanka.

Srinivasulu, K. 1996. "The 1985 Textile Policy and Handloom Industry: Policy, Promises and Performance." Economic and Political Weekly 31 (49):3198-3206.

Srinivasulu, K. 1997. "High-Powered Committee, Low Voltage Report: Mira Seth Report on Handlooms." Economic and Political Weekly 32 (24):1381-1384.

Star, Susan Leigh. 1991. "The Sociology of the Invisible: The Primacy of Work in the Writings of Anselm Strauss." In Social Organization and Social Process: Essays in Honor of Anselm Strauss, edited by David R. Maines, 265-283. Hawthorne: Aldine de Gruyter. 
Star, Susan Leigh. 1995. Ecologies of knowledge: Work and politics in science and technology, SU NY series in science, technology, and society. Albany: State University of New York Press.

Staudenmaier, J. 1985. Technology's Storytellers: Reweaving the human fabric. Cambridge: MIT Press.

Steedman, Philip. 1991. "On the relations between seeing, interpreting and knowing." In Research and reflexivity, edited by F. Steier, 53-62. London: Sage.

Stirling, Andy. 2007. "Deliberate futures: precaution and progress in social choice of sustainable technology." Sustainable D evelopment 15 (5):286-295.

Subrahmanyam, Sanjay. 1990. "Rural industry and commercial agriculture in late seventeenthcentury south-eastern India." Past and Present 126 (February):76-114.

Subramanian, Lakshmi, ed. 1998. Power and the Weave: Weavers, Merchants and Rulers in Eighteenthcentury Surat.". Edited by Rudrangshu Mukherjee and Lakshmi Subramanian, Politics and Trade in the Indian O cean World: Essays in Honour of Flashin Das Gupta. Delhi.

Suchman, Lucy. 2002. "Located accountabilities in technology production." Scandinavian Journal of Information Systems 14 (2):91-106.

Suchman, Lucy, Jeanette Blomberg, Julian E Orr, and Randall Trigg. 1999. "Reconstructing technologies as social practice." American behavioral scientist 43 (3):392-408.

Swain, Ashok. 1997. "Democratic consolidation? Environmental movements in India." Asian Survey 37 (9):818-832.

Tallis, John. 1852. Tallis's History and Description of the Crystal Palace: And the Exhibition of the World's Industry in 1851. Vol. 2. London: London Printing \& Publishing Company.

Tarlo, Emma. 1996. Clothing matters: D ress and identity in India. Chicago: University of Chicago Press.

Taussig, Michael. 2006. "What Color Is the Sacred?" Critical Inquiry 33 (1):28-51.

Taussig, Michael. 2008. "Redeeming indigo." Theory, Culture \& Society 25 (3):1-15.

Taylor, James. 1851. Descriptive and historical account of the cotton manufacture of Dacca: London.

Telier, A, Thomas Binder, Giorgio De Michelis, Pelle Ehn, Giulio Jacucci, and Ina Wagner. 2011. Design things. Cambridge MA: The MIT Press.
Thomas, Angharad. 2006. "Design, poverty, and sustainable development." D esign Issues 22 (4):54-65.

Thomas, Sebastian. 2014. "Efficacy of Cluster Based Approach for the revival of Handloom Cooperative Societies in Kerala." PhD, Department of Applied Economics, Cochin University of Science and Technology.

Timmermans, Stefan, and Marc Berg. 1997. "Standardization in action: Achieving local universality through medical protocols." Social studies of science 27 (2):273-305.

Travasso, Maria Irene GMG, Paula Santos, Ana MF Campos, M Manuela M Raposo, and N Prasitpan. 2003. "Indigo revisited." Advances in Colour Science and Technology (5):95-99.

Travis, Anthony S., Willem J. Hornix, Robert Bud, and Peter Reed. 1992. "The British chemical industry and the indigo trade." British journal for the history of science 25 (1):113-25.

Traweek, Sharon. 1988. Beamtimes and lifetimes: The world of high energy physicists. Cambridge, Mass.: Harvard University Press.

Trigg, Andrew B. 2001. "Veblen, Bourdieu, and conspicuous consumption." Journal of Economic Issues 35 (1):99-115.

Tsing, Anna Lowenhaupt. 2005. Friction: An ethnography of global connection. Princeton: Princeton University Press.

Turnbull, David. 2012. "Travelling knowledge-narratives, assemblage and encounters." In Instruments, travel and science-itineraries of precision from the seventeenth to the twentieth century, edited by M.-N. Bourget, C. Licoppe and H.O. Sibum, 273-294. London: Routledge.

Tzeng, Cheng-Hua. 2009. "A review of contemporary innovation literature: A Schumpeterian perspective." Innovation: management, policy \& practice 11 (3):373-394.

Utterback, James M, and William J Abernathy. 1975. "A dynamic model of process and product innovation." O mega 3 (6):639-656.

Uzzi, Brian. 1997. "Social structure and competition in interfirm networks: The paradox of embeddedness." Administrative science quarterly 42 (1):35-67.

Van Lieshout, Marc, Tineke Mirjam Egyedi, and Wiebe Eco Bijker, eds. 2001. Social Learning Technologies: The introduction of multimedia in education. Aldershot U.K.: Ashgate. 
Venkatesan, Soumhya. 2009a. Craft matters: Artisans, development and the Indian nation. Hyderabad: Orient Blackswan.

Venkatesan, Soumhya. 2009b. "Rethinking agency: Persons and things in the heterotopia of 'traditional Indian craft'." J ournal of the Royal Anthropological Institute 15 (1):78-95.

Venkatesan, Soumhya. 2010. "Learning to weave; weaving to learn... what?" Journal of the Royal Anthropological Institute 16 (s1):S158-S175.

Verbeek, Peter Paul. 2006. "Materializing morality design ethics and technological mediation." Science, Technology \& Human Values 31 (3):361-380.

Vergragt, Philip J. 1988. "The social shaping of industrial innovations." Social Studies of Science 18 (3):483-513.

Vinayan, Soumya. 2006. "Liberalisation and Textile Industry: A Case Study of Interface between Handlooms and Powerlooms in Andhra Pradesh."Phd Thesis, University of Hyderabad.

Visvanathan, S. 2001. "Technology transfer." In International Encyclopedia of the Social \& Behavioral Sciences, edited by Smelser N.J and Baltes P.B., 15532-37. Oxford: Elsevier.

Visvanathan, Shiv. 1998. "A celebration of difference: Science and democracy in India." Science 280 (5360):42-43.

Visvanathan, Shiv. 2006. "Alternative science." Theory, culture $\&$ society 23 (2-3):164-169.

Viswanathan, Brinda. 2013. Enumeration of Crafts Persons in India. Chennai, India: Madras School of Economics.

Von Hippel, Eric. 1998. "Economics of product development by users: The impact of "sticky" local information." M anagement science 44 (5):629-644.

Von Tunzelmann, Nick, and Virginia Acha. 2005. "Innovation in 'low-tech'industries." In The Oxford handbook of innovation, edited by J Fagerberg, DC Mowery and RR Nelson, 407-432. Oxford: Oxford University Press.

Vyas, H Kumar. 1991. "The designer and the sociotechnology of small production." J ournal of Design History 4 (3):187-210.

Vyas, H Kumar. 2006. "Design History: An Alternative Approach." D esign Issues 22 (4):27-34.

Wallman, S. 1984. Eight London Households. London: Routledge.
Washbrook, David. 1990. "South Asia, the world system, and world capitalism." The J ournal of Asian Studies 49 (03):479-508.

Washbrook, David. 1993. "Land and labour in late eighteenth-century south India: The golden age of the Pariah?" In Dalit movements and the meanings of Labour in India, edited by Peter Robb, 68-86. Delhi: Oxford University Press.

Watson-Veran, H, and David Turnbull. 1994. "Science and other indigenous knowledge systems." In K nowledge: Critical Concepts, edited by Nico Stehr and Reiner Grundmann, 345-369. Oxford: Routledge.

Watt, George. 1889. A Dictionary of Economic Products of India 6vols. Vol. Vol 1-6. Calcutta India: Superintendant, Government Print Ofice.

Watt, George. 1904. Indian art at Delhi 1903: being the official catalogue of the Delhi Exhibition 1902-1903. London: John Murray.

WCED , Bruntland Commission). 1987. Our common future. London: Oxford University Press.

Weisberg, Robert W, and Lauretta M Reeves. 2013. Cognition: From M emory to C reativity. New Jersey: John Wiley \& Sons.

Wendt, Ian C. 2005a. "400 Years of Decline?: Understanding the Changing Structure of the South Indian Textile Industry." Global Economic History Network conference Padua Italy, November 18.

Wendt, Ian C. 2005b. "Writing the rich economic history of the South Asian textile industry: Spinners in early modern South India." Global Economic History Network Conference http://www. lse. ac. uk/collections/economicHistory/GEHN/ GEHNConference8 Papers. htm, Pune.

Westfall, Richard S. 1962. "The development of Newton's theory of color." Isis 53 (3):339-358.

Wilk, Richard. 1999. "Quality of Life and the Anthropological Perspective." F eminist E conomics 5 (2):91-93. doi: 10.1080/135457099337978.

Williams, R; Edge, D. 1996. "The social shaping of technology." Research Policy 25 (6):865-899.

Williams, Rosalind. 2006. "The Unintended Consequences of Innovation: Change and Community at MIT." In Cultures of Technology and the Q uest for Innovation, edited by Helga Nowotny, 39-51. New York: Berghahn Books. 
Wilson, Gordon. 2007. "Knowledge, innovation and reinventing technical assistance for development." Progress in D evelopment Studies 7 (3):183-199.

Windrum, Paul. 2000. Back from the brink: Microsoft and the strategic use of standards in the Browser Wars. In UNU-MERIT Research Memoranda. Maastricht: MERIT, Maastricht Economic Research Institute on Innovation and Technology.

Wisner, B., P Blaikie, Terry Cannon, and Ian Davis. 1994. At Risk: Natural Hazards, People's Vulnerability and Disasters. London: Routledge.

Wittgenstein, Ludwig. 1958. P hilosophical Investigations. Translated by G.E.M. Anscombe. 3rd ed. ed. New York: Macmillan Publishing.

Woodward, Ian, and Michael Emmison. 2001. "From aesthetic principles to collective sentiments: The logics of everyday judgements of taste." Poetics 29 (6):295-316.
Wyatt, Sally. 2008. "Technological determinism is dead; Long live technological determinism." In Handbook of science and technology studies, edited by $\mathrm{E}$ Hackett, O Amsterdamska, M Lynch and J Wajcman, 165-180. Cambridge MA: MIT Press.

Wynne, Brian. 1989. "Sheep farming after Chernobyl: a case study in communicating scientific information." Environment (March):10-15 \& 33-39.

Yanagisawa, Haruka. 1993. "The handloom industry and its market structure: The case of the Madras Presidency in the first half of the twentieth century." Indian E conomic \& Social History Review 30 (1):1-27.

Zuiderent, Teun. 2003. "Blurring the center." Scandinavian J ournal of Information Systems 14 (2):59-78.

Zuiderent-Jerak, Teun, and Casper Bruun Jensen. 2007. "Editorial introduction: Unpacking 'intervention'in science and technology studies." Science as Culture $16(3): 227-235$. 


\section{SUMMARY}

What is the relevance of craft today? This is the question that this dissertation seeks to answer through a detailed study of the case of handloom weavers in South India. More than 4.3 million craftspeople make a livelihood out of handloom weaving in India; about half of these live below the poverty line. It is generally accepted that the decreasing number of weavers in succeeding government censuses is evidence of unsustainability of handloom livelihoods, raising questions about its future. Why do weavers leave weaving? How can their hand-made products stand up to competition from mechanized production? How can an old technology of production be considered relevant in a modern industrialized world? Tradition is thought to be unchanging, and modernity constantly innovating - with the seemingly inevitable implication that tradition gives way to modernity. Can traditional handloom craft ever be relevant when it does not innovate?

Handloom weavers all over India have evidenced that under enabling circumstances they are sustainable and resilient through bad times and they can persist into good times. Yet, despite the unquestionable success of contemporary efforts in marketing handloom and craft, the association of unsustainability with handloom and craft livelihoods endures. This is because the narratives of technological progress, modernization and development characterize handloom as unproductive, pre-modern, and unsustainable manual labour and continue to influence public discourses around traditional crafts and hold power in Indian policy making.

Yet the paradox that a labor-intensive traditional craft like handloom has survived after two centuries of mechanization and governmentinduced industrialization in the market-economy of India has to be explained. In order to do so, I ask in this dissertation: First, how can we ameliorate unsustainability in the livelihoods of vulnerable craftspeople? Second, how can designers intervene to bring about social change in the lives of craftspeople? Third, how does handloom weaving technology survive, even after 200 hundred years of state-supported industrialization? Finally, how do handloom weavers sustain themselves in the changing market places?

To answer these questions, this dissertation provides an analysis of handloom weaving as sustainable and innovative socio-technology, using the concepts that scholarship in Science Technology and Society Studies [STS] has developed to unpack and reanalyze science and technology. I analyze the hand-operated loom as part of a socio-technical ensemble: handloom is a collection of heterogeneous elements of technologies [spinning, looms, warping drums, computers], practices [designing, sizing, computer programming], formal institutions [cooperatives, Civil Society Organizations (CSOs) and Non-Governmental Organizations (NGOs), government institutions], informal institutions 
[household, extended family, village community, caste] and social groups [weavers, dyers, designers, customers] that together constitute a sociotechnical ensemble. Sustainability I argue is the outcome of a responsibly innovating technological culture. This understanding displaces the idea that unsustainability is inherent to the vulnerable weaver or the loom. This is the main argument, towards which each succeeding chapter lays a building block.

The structure of the book is summarized in the following table, which also shows the conceptual shift in each of these chapters: from Unsustainability to Vulnerability, from Intervention to Mediation, from Technology transfer to Interactional expertise and from Innovation to Creativity. The aim of these conceptual shifts is to embed the project of the social analysis of handloom technology into the particular contexts of traditional Indian craftspeople and their vocabulary for technological change, while using STS scholarship. Shifting from a technological concept to a socio-technical concept foregrounds the social in the analysis of technology and the idea of handloom livelihoods as a socio-cultural idea, and not just an economic one.

\begin{tabular}{|c|c|c|c|}
\hline No & Chapter Title & Technological concept & $\begin{array}{l}\text { Proposed socio- } \\
\text { tedhnical concept }\end{array}$ \\
\hline 1 & Introduction & & \\
\hline 2 & Review of literature & & \\
\hline 3 & $\begin{array}{l}\text { Livelihood trajectories in Handloom } \\
\text { weaving }\end{array}$ & Unsustainability & Vulnerability \\
\hline 4 & Designing for social change & Intervention & Mediation \\
\hline 5 & $\begin{array}{l}\text { Handloom as adaptive socio- } \\
\text { technology }\end{array}$ & Technology transfer & Interactional expertise \\
\hline 6 & Cultures of Innovation in Handloom & Innovation & Creativity \\
\hline 7 & Conclusion & \multicolumn{2}{|c|}{$\begin{array}{l}\text { Practicing sustainability in the handloom STE } \\
\text { Theory of Innovation for Handloom weaving } \\
\text { An ethos of sustainable development }\end{array}$} \\
\hline
\end{tabular}

The literature review in chapter 2 is structured around narratives of what Breman calls "aborted transformations" (Breman 2009)-transformations to industrialization, to development, and to modernity. Scholars have taken three different approaches to the consequences of these aborted transformations. Counternarratives to the master narrative of handloom's inevitable demise as a mode of production, narratives of loss - descriptions of the losses that handloom communities bear as a result of these master narrative frames of viewing and (re) presenting handloom - and interrogations of policy understandings that ride on these deterministic frames. In the next section I demonstrate the considerable overlap between practices of theory building in STS and intervening in an NGO through explicating the heuristics of reflexivity, symmetry, and interaction that operate in both sites. STS scholarship on knowledge-building practices that does not operate on the assumption that labor and intelligence are mutually exclusive is reviewed briefly. In a further section there is a brief introduction to social construction of technology [SCOT] concepts that later chapters use.

Chapter 3 addresses the question: Under what conditions do livelihoods of handloom 
weavers become unsustainable, and when can they become sustainable? The notion of vulnerability is used for understanding both sustainability and unsustainability in handloom livelihoods. Employing this lens and not starting with the assumption of unsustainability, vulnerability is treated as a condition of openness that has the potential to lead to positive change and sustainability. The generative aspect of argumentation and dissent that characterizes debates around handloom vulnerability and leads to collective action is discussed. This helps to relate discourse analysis and collective action in order to explain how coherence is built in an argumentative culture: asserting argumentation can be generative rather than divisive.

Chapter 4 discusses designer interventions in supporting craft livelihoods. This chapter investigates how design can be the key to growth and a paradigm for development, using the market for craft and handloom. Design I define as a combinatory and entrepreneurial activity that spans aesthetic, economic, social, and cultural functions with the goal of increasing the value of the product. I propose that designers intending to mitigate vulnerability in livelihoods of craftspeople have to look beyond the economic into social and cultural outcomes of design interventions. The purpose of this chapter is to broaden understanding of design interventions in craft livelihoods through empirical examination of designer narratives as intervention in an economic frame, as interaction in a social frame, and as mediation in a cultural frame. Through the concept of $\mathrm{Kala}$ - artistry that is a combination of technical, aesthetic, and creative aspects of production that are imagined as the artisan's forte - I discuss how artisans themselves can take up the function of design in craft production. This chapter extends the STS concept of "cultures of technology" to "cultures of design" in order to understand the complex relationships between skills, tools, materials, markets, identities, aesthetics, and rituals in contemporary craft and handloom networks.
The question that Chapter 5 seeks to address is: How does handloom weaving technology succeed in persisting in the changing world, even as the loom itself looks unchanging? I relate how reactive dyeing, a technology from the mechanized sector, makes its way into the handloom ensemble as handloom weaver cooperatives adopt and adapt the technology for their contexts. In doing so, reactive dyeing itself is adapted as skill rather than as mechanized technology. But in the handloom ensemble, it is not only new and futuristic technologies that are added; in a counter-intuitive movement, we see that the ensemble can go back in time and add older forgotten technologies, such as natural dyeing, by recalling and reintroducing them into contemporary practices. This process creates multiple technological variants in the handloom ensemble, which are made operational through compatibility standards that allow them to couple with the other technologies in the ensemble. The only criterion is that the new or old technology has to work in the service of maintaining value for the loom and the deep craft attached to the loom.

I use the concepts of technological frame, interactional expertise, and memory practices to elucidate adaptive change, as well as its stabilization, in the handloom STE. This helps to understand how cultures of technology, which have persisted while adapting to meet market demands as well as societal aspirations and needs, acquire cultural meaning for every new generation of producers and users. This acquisition of cultural meaning adds to our understanding of change and stability, balancing productivity and sustainability.

In Chapter 6, I seek to address two related issues. The first is to deepen the theoretical understanding of innovation by exploring it in supposedly non-innovating traditional contexts. The second is to explore how this improved understanding of innovation in handloom can renovate the socio-cultural and technological imagination around the relevance of craft knowledge. I show how innovations are shaped by interactions between individuals across different 
weavers become unsustainable, and when can they become sustainable? The notion of vulnerability is used for understanding both sustainability and unsustainability in handloom livelihoods. Employing this lens and not starting with the assumption of unsustainability, vulnerability is treated as a condition of openness that has the potential to lead to positive change and sustainability. The generative aspect of argumentation and dissent that characterizes debates around handloom vulnerability and leads to collective action is discussed. This helps to relate discourse analysis and collective action in order to explain how coherence is built in an argumentative culture: asserting argumentation can be generative rather than divisive.

Chapter 4 discusses designer interventions in supporting craft livelihoods. This chapter investigates how design can be the key to growth and a paradigm for development, using the market for craft and handloom. Design I define as a combinatory and entrepreneurial activity that spans aesthetic, economic, social, and cultural functions with the goal of increasing the value of the product. I propose that designers intending to mitigate vulnerability in livelihoods of craftspeople have to look beyond the economic into social and cultural outcomes of design interventions. The purpose of this chapter is to broaden understanding of design interventions in craft livelihoods through empirical examination of designer narratives as intervention in an economic frame, as interaction in a social frame, and as mediation in a cultural frame. Through the concept of $\mathrm{Kala}$ - artistry that is a combination of technical, aesthetic, and creative aspects of production that are imagined as the artisan's forte - I discuss how artisans themselves can take up the function of design in craft production. This chapter extends the STS concept of "cultures of technology" to "cultures of design" in order to understand the complex relationships between skills, tools, materials, markets, identities, aesthetics, and rituals in contemporary craft and handloom networks.
The question that Chapter 5 seeks to address is: How does handloom weaving technology succeed in persisting in the changing world, even as the loom itself looks unchanging? I relate how reactive dyeing, a technology from the mechanized sector, makes its way into the handloom ensemble as handloom weaver cooperatives adopt and adapt the technology for their contexts. In doing so, reactive dyeing itself is adapted as skill rather than as mechanized technology. But in the handloom ensemble, it is not only new and futuristic technologies that are added; in a counter-intuitive movement, we see that the ensemble can go back in time and add older forgotten technologies, such as natural dyeing, by recalling and reintroducing them into contemporary practices. This process creates multiple technological variants in the handloom ensemble, which are made operational through compatibility standards that allow them to couple with the other technologies in the ensemble. The only criterion is that the new or old technology has to work in the service of maintaining value for the loom and the deep craft attached to the loom.

I use the concepts of technological frame, interactional expertise, and memory practices to elucidate adaptive change, as well as its stabilization, in the handloom STE. This helps to understand how cultures of technology, which have persisted while adapting to meet market demands as well as societal aspirations and needs, acquire cultural meaning for every new generation of producers and users. This acquisition of cultural meaning adds to our understanding of change and stability, balancing productivity and sustainability.

In Chapter 6, I seek to address two related issues. The first is to deepen the theoretical understanding of innovation by exploring it in supposedly non-innovating traditional contexts. The second is to explore how this improved understanding of innovation in handloom can renovate the socio-cultural and technological imagination around the relevance of craft knowledge. I show how innovations are shaped by interactions between individuals across different 
user groups and communities and I identify product, market, and process innovations in handloom. These innovations include the use of mobile phones to explore new markets and the use of computers to speed up calculative functions. These innovations allow weavers to engage in slower and more skilled work while keeping the product cost-effective.

In order to build a vocabulary of innovation in tradition, I borrow the language of the practitioners of South Indian classical music, a traditional genre known for its jazz-like-improvisation and creativity that is close to the vocabulary of innovating handloom weavers.

The concluding Chapter 7 has three sections: in the first section, I summarize sustainability in handloom weavers' livelihoods. In the second section, I attempt to explicate a vocabulary for innovation in handloom practice, moving towards a theory of innovation. In a final brief section, I point towards an ethos for sustainable development that we can learn from weavers, as living within one's means, combining knowledge, equity and beauty. Based on weavers' innovative sociotechnical practices, I highlight and foreground craft as an instance of embodied knowledge, which is indispensable to notions of democratic science, robust knowledge-building, and innovation. I conclude by arguing that craft embodies various forms of knowledge (material, historical, and collective) of often vulnerable communities, providing them forms of resilience against destabilizing paradigms (colonialist expansion, industrialization, and oppressive caste identities) and needs to be understood holistically (including the relation to ethical, spiritual and aesthetic values). 


\section{VALORIZATION ADDENDUM}

The term 'valorisation' has recently been adopted in The Netherlands to describe knowledge utilization or knowledge uptake. NWO-WOTRO, the Netherlands Organisation for Scientific Research explicitly encourages valorisation for all its research projects, and requires researchers to include an addendum on valorisation activities. The intention is to help researchers produce knowledge that is relevant to society, and make it available for and usable by societal actors who may find it valuable. In this section, I will attempt to lay out what the relevance of my research might be, to whom it may be relevant, and how I plan to communicate my findings to those who might be interested in using them.

Handloom weaving is the second most important livelihood in rural India after farming, employing over 4.3 million households. Intervening in handloom technologies and practices thus will directly affect the lives of millions of rural producers. Yet the linear perspective of technological innovation prophesies extinction for vulnerable craft producers such as handloom weavers -either through mechanisation or by museumization. Instead, my research project analyses handloom weaving as a socio-technology, making it possible to show how weaving communities are constantly innovating their technologies, designs, markets and social organization-often without calling it innovation. This demonstration of innovation in handloom contradicts the received image of handloom as a pre-modern and traditional manual labour that is unsustainable in current societies and that one therefore needs to get rid of. Instead, it offers possibilities for a re-invention of traditional crafts as sustainable technologies for our future.

For over fifteen years, before starting my research work in the University of Maastricht, I worked in an NGO in Andhra Pradesh in India, supporting craft livelihoods. As an engineer intervening in traditional technology, I played a key role in building successful social business models and producer friendly markets for vulnerable craftspeople in South India [www. dacottonhandlooms.in, www.dastkarandhra.org, http://nextbillion.net/social-capital-markets-09indian-social-enterprises/]. One generation of weavers in more than 35 co-operatives across Andhra Pradesh were supported by these efforts, as a result of which they were able to stabilise their lives and livelihoods. In spite of these efforts and many others like it, NGOs were not able to scale these experiments, and almost 2.5 million jobs were lost in the sector in the decade starting 2000, which saw unprecedented growth followed by a deep recession. This seemed to confirm policy understanding that craft production was unsustainable, and that handloom weavers could not innovate for the new markets. The conundrum that those of us working closely with craftspeople faced, was that while the problem of unsustainability of some weavers and despair of craftspeople was real, it was equally true 
that over half of them proved resilient to market changes and even thrived. Yet this resilience was not acknowledged or supported, nor did their innovative capability carry any credibility with policy makers.

I had three clear goals when I started my $\mathrm{PhD}$ project in 2010 in Maastricht University in the discipline of Science Technology and Society Studies. First, to reflect on over fifteen years of training and practice of ameliorating vulnerability of craftspeople; second to explicate the skills, knowledge and innovation of resilient craftspeople in a language that was recognisable to policy makers, society at large, and most importantly to the craftspeople themselves; and finally to explore vocabularies, spaces and conceptual frameworks where such conversations and exchanges could take place to the mutual benefit of all the stakeholders, particularly to vulnerable craftspeople. My research project therefore engaged with four questions from my larger engagement in working for vulnerable craftspeople. First, reflecting on my own practice, how could we ameliorate vulnerability in the livelihoods of traditional craftspeople? A related question was, how did designers [and other mediators] intervene to bring about social change in the lives of craftspeople? Next, I studied the innovative practices of weavers with whom I had closely worked as a social worker. I asked how handloom weaving technology survived and even thrived in markets, in seeming contrast to 200 hundred years of state-supported industrialisation. Using the tools and heuristics of my research training, I then expanded the research question to a more conceptual one about the relevance of 'craft' as embodied knowledge, whether in the scientific laboratory or in the traditional crafts. Not whether craft could survive without innovation, but whether there could be innovation without craft?

My answers add to the understanding of how to intervene to ameliorate vulnerability in craftspeople's livelihoods. Second, they offer insights regarding outcomes of such interventions, and how to direct such outcomes towards social and technological change that sustains both craftspeople and contemporary societies. Low-tech and high-tech technologies can become interoperable to sustain deep craft and knowledge of the material world that is critical to future sustainability of our energystressed planet. Through explicating the nature of innovation in handloom weaving, I offer insights to the craftspeople themselves, holding up to them an STS mirror - an analytical representation of their work and innovation culture - in order that they see themselves as experts, technologists, artists and innovators. An important insight here is regarding the acquisition and mobilising of embodied craft knowledge, which leads to innovation. Finally, the value of this research to knowledge building itself lies in understanding interaction. It reconnects what became disconnected: the mind and body, science and art, theory and practice, village and city, production and market, means and ends, past and the future, the old and the new, change and stability - thus putting craft back into the toolkit of contemporary knowledge building practices.

The theoretical framing of my research project was a direct result of my deep immersion in the field of craft, and my understanding of the underlying vulnerabilities as well as strengths of craftspeople. My close proximity to craftspeople meant that both actors from the field as well as academia were able to participate in the framing of the research and contributed to constructing its relevance. These actors included the weavers, artists, technologists, designers, NGO activists, as well as my supervisors and academic peers who engaged with my work and helped me to foreground one set of questions rather than others. These engagements were of many forms: interviews, presentations, seminars, concert halls, coffee shop encounters and research meetings, across India and The Netherlands. Such conversations forced me to pay to attention to that which is generally unspoken and not perceived to be in the public domain, for example, the culture of innovation in tradition that attributes the creative moment to divine grace, or to the blessings of the teacher; modesty is perceived as a necessary condition for creativity; and in this 
instance, it is faith that gives the artisan confidence to innovate.

I can now with reasonable confidence assert the usefulness of the research to three different groups, each pursuing a different goal. First, the different social groups - CSOs, designers, policy makers, marketing agencies in the craft ensembles - whose goal is to ameliorate vulnerability in the livelihoods of less fortunate craftspeople. Second, the weavers, artisans or craftspeople themselves, in order to advance their journey to sustainability in the contemporary world. Finally, the small and specialist group of scholars who are engaged in efforts to democratize knowledge itself. Being part of the life worlds of all three groups has made it possible for me to make conceptual connections that could be integrative of all three goals.

In summary, this research project offers a response to the assumption that traditional craft knowledge should be replaced by modern technological innovation, suggesting that what merits discussion is whether technological innovation can survive without craft knowledge. This resonates with historical accounts of innovation trajectories in the West, and within science. Given the low stature of embodied craft within discourses of knowledge, and the deficit of vocabulary to explicate tacit skills whether in the laboratory or village, there is a real danger that the contribution of embodied skills and iterative knowledge-building practices to innovation is missed. By making this contribution explicit, this research shows how political goals of democratization of knowledge can be achieved.

Yet if my research has to be made available to the different actors, in order to make a difference in the real world, it is my knowledge of their networks and vocabularies that I have to engage. Different activities are required to reach the different groups that I have detailed above. Since most of the handloom weavers are not English speaking, translation of key findings of the research into at least Telugu and into nonacademic accounts is important for reaching out to them. At various points in the research process, I have conducted and participated in workshops with craftspeople and their representatives, and presented the findings to them, using their questions and concerns to shape the direction of the research so as to be useful to them.

Publishing extracts from the dissertation to journals that explicitly target Indian policy makers and interventionists is another important activity I have taken up. I have already published a first co-authored article titled "Mobilizing discourses: Handloom as sustainable socio-technology" in the Economic and Political Weekly in 2012, one of India's leading academic journals for social sciences. A second article "Weaving trajectories of hope: from Vulnerability to Sustainability" based on the chapter on vulnerability in weaver livelihoods is due for publication in the Jindal Journal of Public Policy this month. I have contributed as co-author to a chapter titled "STS for Development", in the forthcoming Handbook of Science and Technology Studies, $4^{\text {th }}$ edition. In order to reach a wider academic audience, a fourth co-authored article "Innovation in Indian Handloom weaving" based on the chapter on innovation has been submitted and provisionally accepted by Technology and Culture, the journal of the Society for the History of Technology.

Venturing into new fields of practice - from engineer to social worker, from technologist to grass roots worker, from social work to social enterprise and market building, from NGO intervention to research — did imply that I was being socialized into different epistemic communities upholding those practices. In a general sense I began to understand that while these different communities of practice had clear areas where they would transact with each other, the boundaries between the areas were surprisingly obdurate to knowledge exchange. Yet, my research showed that each group has knowledge that is very important to the other's sustainability, even survival. Assuming that this obduracy did not arise from mal-intent, I began to think of bringing together the different social 
groups and stakeholders whose practices I had analyzed and understood as part of my research. This activity was absolutely necessary to the goal of my research project - to expand the idea of handloom as sustainable and innovative sociotechnology, and of craft as knowledge.

Thus, in January 2016, I co-organised a seminar on 'Craft and Innovation' in Chennai where stakeholders across the ensemble - NGO workers, artists, artisans and scholars from US and Europe and India - met to discuss the discourse of craft as knowledge. The approach of the seminar was to be comparative across fields of expertise. Sponsored by the Society of History of Technology, University of Maastricht and Kalakshetra (the famous Dance and Music Academy in Chennai), the initial note proposed to SHOT laid out the framework to the participants. "The first comparative perspective is across time: comparing early medieval craft and technics with current craft and technology. The second comparative perspective is cross-cultural: comparing artisans/craft practitioners in medieval and early modern Europe with Indian handloom weaving and with Indian Karnatik musicians. These comparisons were challenging and have to go beyond existing conceptual frameworks. To make this work, we will (1) engage in additional activities, beyond scholarly discussion; (2) invite a broad range of participants - from history of technology and STS scholarship, to engineers, artisans and craft practitioners, designers, and musicians; (3) use more time (i.e. five days) than in a regular scholarly workshop and thus create more space for joint reflection and interactions." The program included a dyeing workshop in the use of traditional practices in natural colours, a master-class in Karnatik music and an introduction to the handloom-weaving ensemble, through a field trip to Kanchipuram, a weaving village and temple town, two hours from Chennai, as an introduction to the context of craft and art in India. The main seminar on 'Craft and Innovation' had panels that stimulated conversations between craftspeople, academics and handloom experts across different locations. The experiment was productive, leading to many discussions that were at once relevant to livelihoods of vulnerable craftspeople as well as to the agenda of furthering scientific knowledge and agendas of innovation. Discussions are ongoing on how this network and its collaborative agendas can be supported in the future. In time, I hope these conversations will give lead to new concepts and possibilities for the future of traditional craft and craftspeople in India and elsewhere.

In parallel, I was able to contribute to a nascent network of scholars working on innovation across cultures, of both non-western and western cultures of technology. A series of panels is being co-organized by me along with Wiebe Bijker and Lars Heide in the 2016 meeting of the Society of History of Technology in Singapore where scholars including myself will explore ways to take up more work in this line. The Neubauer fellowship from the Chicago University (in May 2016) affords a next step in the journey: to work with committed scholars who are engaged with explicating the value of embodied knowledge and craft modes of production, particularly when such crafts show promise of being re-invented as sustainable technology for an energy stressed future. 


\section{CURRICULUM VitAE}

Annapurna Mamidipudi has a bachelor in engineering and is a graduate from the Netherlands Graduate School on Science, Technology and Modern Culture (WTMC). Her thesis titled "Towards a theory of innovation in handloom weaving in India" is grounded in her fifteen-year long experience in Dastkar Andhra. Dastkar Andhra, which she helped set up, is an NGO that supports livelihoods of vulnerable handloom weavers in rural India. Between 2004 and 2006, she was faculty in the Indian school of livelihood promotion BASIX, which developed teaching modules for livelihood promotion. Her publications include A. Mamidipudi et al. 2012. "Mobilising Discourses." Economic \& Political Weekly 47 (25: 41-51) and A. Mamidipudi, "Saris of Andhra Pradesh." in M. Singh. 2010. Saris of India, Development Commissioner Handlooms: 218-241. She has been offered the Neubauer research fellowship for 2016, University of Chicago, Department of History of Technology, for her work on theorizing innovation in handloom weaving. Annapurna Mamidipudi is currently a postdoc researcher in the Maastricht University Science, Technology \& Society program (MUSTS) on a project to study responsible innovation in biogas in India. 
